PROPERTIES OF ADSORBED HYDROGEN AND

METHANE FILMS ON NANOPOROUS SOLIDS

\author{
In Partial Fulfillment \\ of the Requirements for the Degree \\ Doctor of Philosophy
}

by

ANDREW KARL GILLESPIE

Dr. Peter Pfeifer, Dissertation Supervisor

MAY 2017 
The undersigned, appointed by the Dean of the Graduate School, have examined the dissertation entitled

\section{PROPERTIES OF ADSORBED HYDROGEN AND \\ METHANE FILMS ON NANOPOROUS SOLIDS}

Presented by Andrew Karl Gillespie,

A candidate for the degree of doctor of philosophy,

And hereby certify that, in their opinion, it is worthy of acceptance.

Professor Peter Pfeifer

Professor Carlos Wexler

Professor Gavin King

Professor Suchismita Guha

Professor Mark Lee

Professor Lucyna Firlej 


\section{DEDICATIONS}

To my parents, sister, and extended family for always encouraging me to live up to my full potential.

To my wife, Samantha, for her infinite support and love. Without her guidance and encouragement this journey would not be possible.

"Nature is our kindest friend and best critic in experimental science

if we only allow her intimations to fall unbiased on our minds."

"Whatever our opinions, they do not alter nor derange the laws of nature"

- Michael Faraday 


\section{ACKNOWLEDGEMENTS}

The research presented in this dissertation was funded in part by The U.S. Department of Energy, Office of Energy Efficiency and Renewable Energy award number DE-FG36-08GO18142 and The California Energy Commission contract number 500-08-022. I would like to express my gratitude to my committee members Dr. Mark Lee, Dr. Suchismita Guha, Dr. Gavin King, Dr. Lucyna Firlej, Dr. Carlos Wexler, and Dr. Peter Pfeifer for their overview and critical encouragement.

I would like to thank Dr. Matthew Beckner, Dr. Elmar Dohnke, and Dr. Tyler Rash for their contributions toward developing my abilities in scientific writing and improving my skills as an experimental physicist. Special thanks goes to David Stalla, Joseph Schaeperkoetter, and Ernest Knight, for all of your support in work, research, and personal life. Our conversations helped forge my path through these seemingly endless research projects. I would like to express my appreciation to all my academic and research colleagues including Matthew Prosniewski, Griffin Johnson, Nagaraju Chada, Sean Sweany, Kristen Blessing, Adam Smith, Mark Sweany, Fenfei Wang, Conrad Schulz, Florian Seydel, Amrit Bal, Alexander Müller, and Ezekiel Piskulich. Thank you to the members of the physics machine shop, especially to Roderic Schlotzhauer for creating custom parts to maintain the various sorption instruments in our laboratory. Special thanks go to Matthew Prosniewski and Samantha Gillespie for proofreading this dissertation. I would also like to thank Grant Knotts, Marat Musin, and all of my fellow graduate students, for their companionship over the years.

I owe a special note of gratitude to the following individuals: Dr. Dorina Kosztin of the University of Missouri and Dr. Jay Ansher of Illinois State University for their mentorship and for encouraging me to become a better science communicator. Dr. Fishman for his generous travel support over the years, which allowed me to present my research to a broader audience at the March Meetings of the American Physical Society. Dr. Brian Clarke and Dr. Qichang Su of Illinois State University for setting me on the path toward an academic career in science. Dr. Robert Duncan of Texas Tech University for reigniting my excitement and optimism toward the future of basic energy physics. 


\section{Table of Contents}

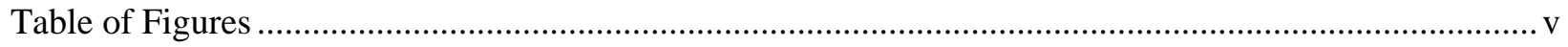

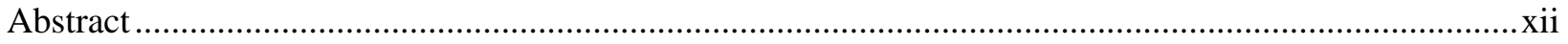

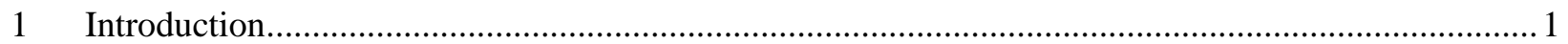

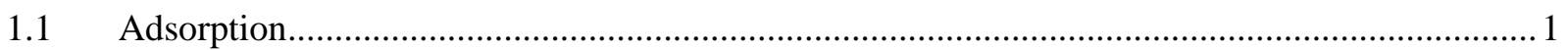

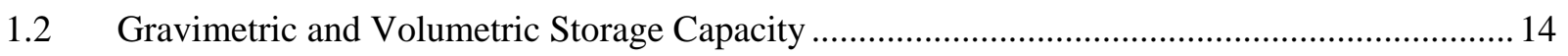

1.3 Absolute Adsorption and Differential Enthalpy .................................................................. 19

$1.4 \quad$ Alternate Methods to Obtain Parameters of the Absorbed Film ............................................... 27

1.5 Enthalpy, Binding Energy, and Frequency Determined from Henry's Law ............................. 32

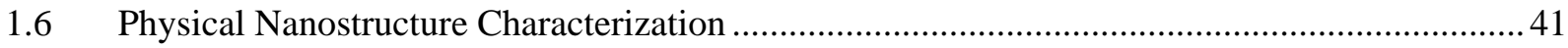

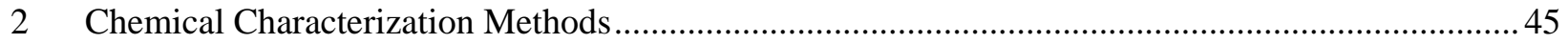

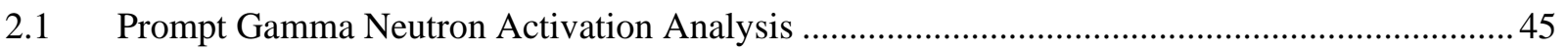

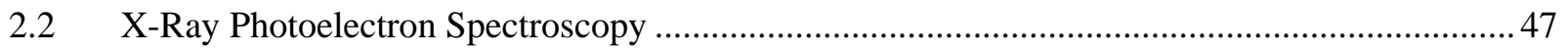

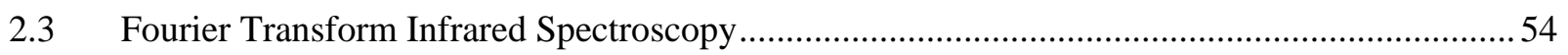

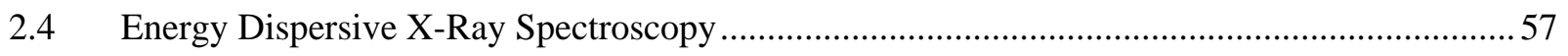

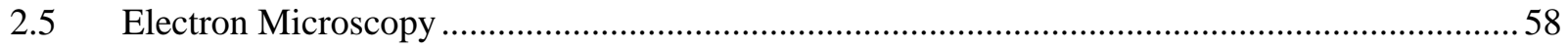

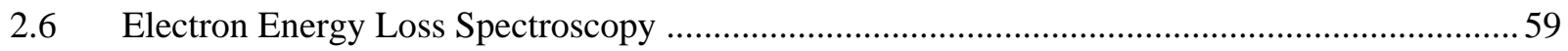

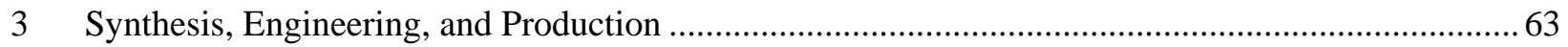

3.1 Nanoporous Carbon Powder Synthesis and Engineering......................................................... 63

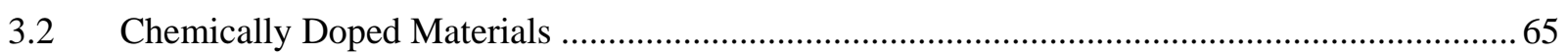

4 Material Performance for Hydrogen and Nitrogen Adsorption .................................................... 76

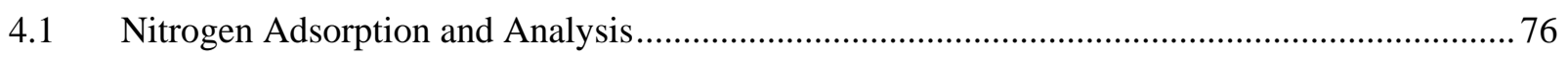

4.2 Gravimetric Excess, Gravimetric Storage, and Volumetric Storage ...................................... 98

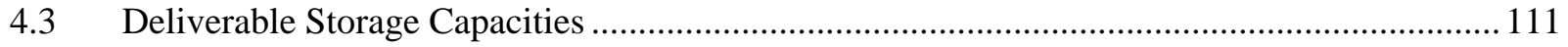

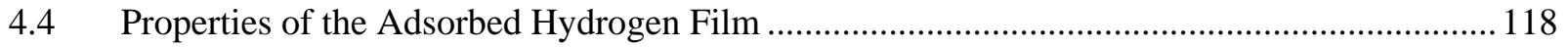

4.5 Absolute Adsorption and Coverage-Dependent Isosteric Heat.............................................. 127

4.6 Isosteric Heat from Henry's Law Analysis Near Zero-Coverage ............................................ 136

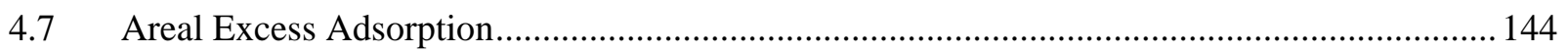

$5 \quad$ Parametric Case Studies for Improving Hydrogen Adsorption .................................................... 149

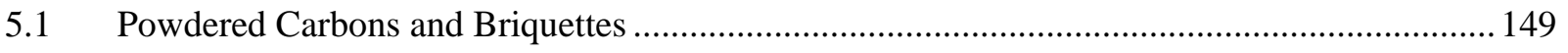

5.2 Powdered Carbons and KOH Activation Ratios ............................................................ 152

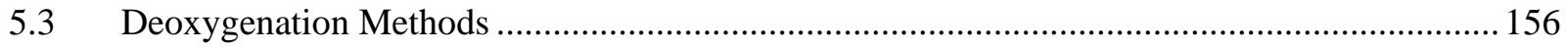




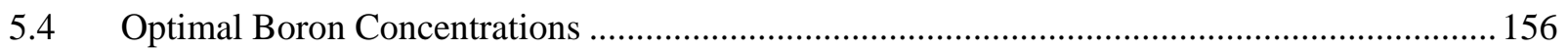

$5.5 \quad$ Structural Changes of Boron Doped Powders ....................................................................... 157

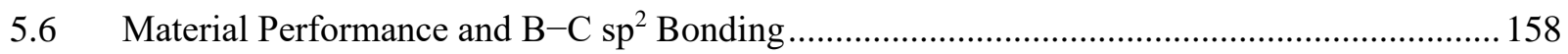

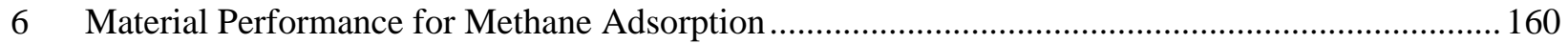

6.1 Properties of the Adsorbed Methane Film ............................................................................. 160

6.2 Isosteric Heat of Methane Adsorption as a Function of Temperature and Coverage ............... 162

7 Predicting Volumetric Storage Capacity from Surface Geometries .............................................. 166

7.1 Theoretical Framework for a Continuous Two-Fluid Model ................................................ 166

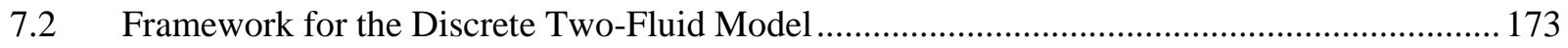

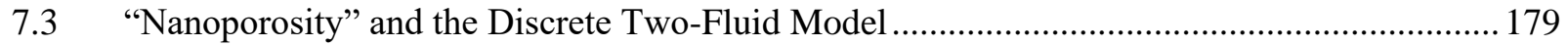

7.4 Discrete Two-Fluid Model: Comparisons with Experimental Storage Capacities .................. 181

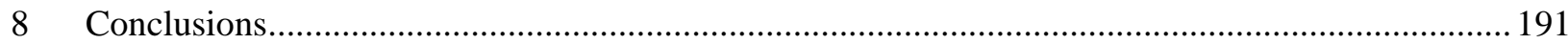

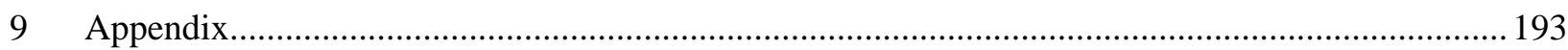

9.1 Redlich-Peterson and Modified Redlich-Peterson Models ................................................... 193

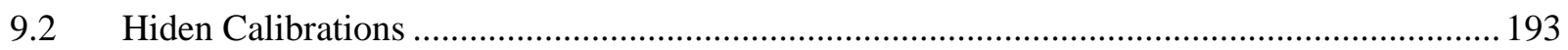

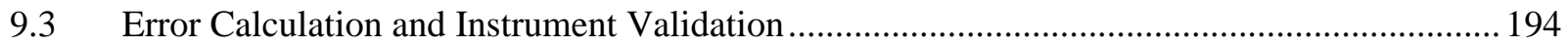

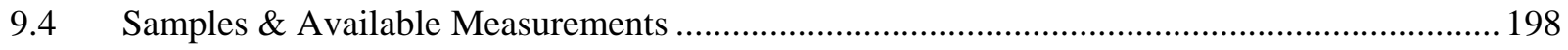

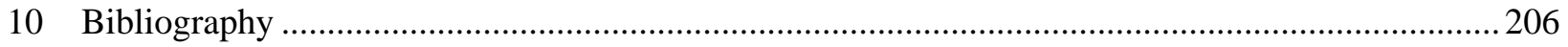

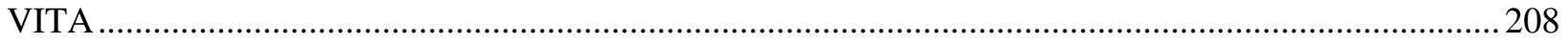




\section{Table of Figures}

FIGURE 1. AN ADSORPTION SCHEMATIC OF GAS DENSITIES VERSUS DISTANCE FROM ADSORBENT SURFACE. .................2

FIGURE 2. MANOMETRIC INSTRUMENT CONSISTING OF TWO KNOWN VOLUMES, SEPARATED BY A VALVE. ....................4

FIGURE 3. MANOMETRIC INSTRUMENT WITH THE REACTOR VOLUME SPLIT INTO THREE THERMAL REGIONS. ................6

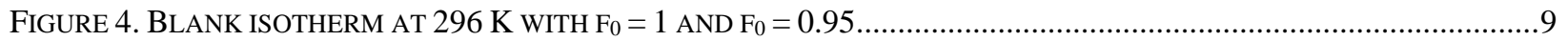

FIGURE 5. VOLUME FRACTION OF THE REACTOR VOLUME MAINTAINED IN THE 77 K COOLING BATH.........................10

FIGURE 6. BLANK ISOTHERM MEASURED AT 77 K USING THE VOLUME FRACTION FROM EQ(18)..............................11

FIGURE 7. DIFFERENCES IN GRAVIMETRIC EXCESS MEASUREMENTS WITH AND WITHOUT BLANK-SUBTRACTION FOR

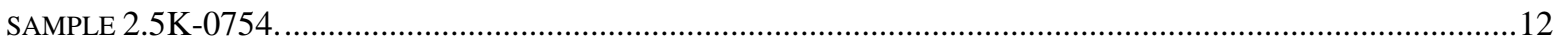

FIGURE 8. SKELETAL DENSITY MEASUREMENTS FOR TWO ADSORBENT SAMPLES USING HELIUM PYCNOMETRY...........13

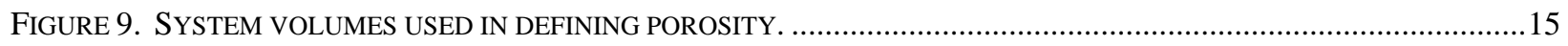

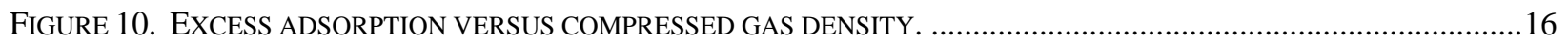

FIGURE 11. RELATIONS BETWEEN VOLUMETRIC AND GRAVIMETRIC STORAGE CAPACITIES......................................17

FIGURE 12. RELATIONSHIP BETWEEN GRAVIMETRIC EXCESS AND BET SPECIFIC SURFACE AREA.............................18

FIGURE 13. GRAVIMETRIC EXCESS AND GRAVIMETRIC STORAGE CAPACITY OF SAMPLE 3K-0285 AT 77 K................20

FigURE 14. STORAGE CAPACITY, VAN'T HOFF PLOT, AND CALCULATED ISOSTERIC HEAT FOR SAMPLE 3K-0285 .......21

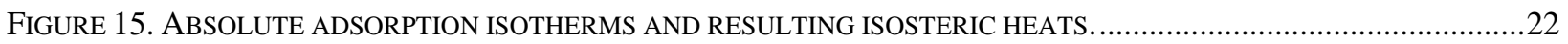

FIGURE 16. DEPICTION OF A SLAB-LIKE ADSORBED FILM. ….............................................................................24

FIGURE 17. GRAVIMETRIC AND ABSOLUTE ADSORPTION FOR SAMPLE 3K-0285 MEASURED AT 77 K .........................26

FIGURE 18. EXCESS ADSORPTION VERSUS GAS DENSITY ONO-KONDO MODEL FOR MONOLAYER ADSORPTION SCALING

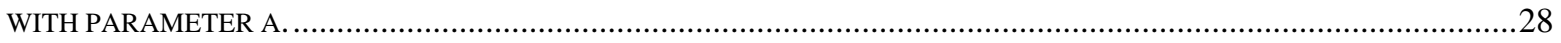

FIGURE 19. EXCESS ADSORPTION VERSUS GAS DENSITY ONO-KONDO MODEL ITERATING WITH PARAMETER B...........28

FIGURE 20. EXCESS ADSORPTION VERSUS GAS DENSITY ONO-KONDO MODEL ITERATING WITH PARAMETER C............29

FIGURE 21. EXCESS ADSORPTION VERSUS GAS DENSITY ONO-KONDO MODEL ITERATING WITH PARAMETER T. ...........30

FIGURE 22. EXCESS ADSORPTION VERSUS GAS DENSITY WITH LINEAR AND ONO-KONDO MODELS APPLIED TO THE HIGH

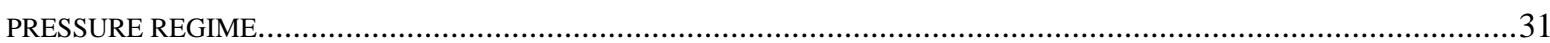

FIGURE 23. ABSOLUTE ADSORPTION VERSUS PRESSURE FOR TWO THEORETICAL LINEAR ISOTHERMS. .........................40

FIGURE 24. PORE SIZE DISTRIBUTION FOR H3PO4 CHAR AND KOH ACTIVATED CARBON ............................................44

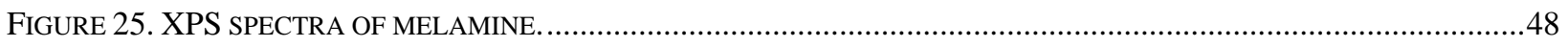

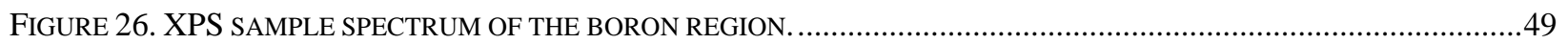

FIGURE 27. THE BORON, CARBON, AND OXYGEN XPS SPECTRA FOR SAMPLE 5K-0215 .........................................52

FIGURE 28. XPS SPECTRA OF BORON ON MULTIPLE DOPED CARBON MATERIAL. .......................................................54

FIGURE 29. FTIR TRANSMISSION SPECTRA FOR PRECURSOR AND BORON-DOPED CARBON MATERIALS. ........................56

FIGURE 30. CARTOON OF MECHANISMS UNDERLYING ENERGY DISPERSIVE X-RAY SPECTROSCOPY..............................58

FIGURE 31. EFTEM IMAGES AND BORON MAP FOR A DOPED PVDC-BASED SAMPLE. ..................................................59

FigURE 32. LEFT TO RIGHT: SEM IMAGES OF THE BORON DOPED CARBON PARTICLE EMBEDDED WITHIN THE KBR MATRIX, THE REGION OF INTEREST FOR STUDY BEING EXTRACTED BY DB-FIB, AND THE SUCCESSFUL TEM CROSSSECTION SUPPORTED WITHIN A KBR SUBSTRATE.

FiguRE 33. LEFT, MidDlE: BRIGHT-FIELD IMAGE OF CARBON SAMPLE LIFTED OUT AND SUSPENDED IN VACUUM VIA KBR POSTS AFTER THE MILLED KBR BODY HAS SUBLIMATED. THIS IS VIEWED FROM THE OPPOSITE SIDE OF THE SAMPLE AS SEEN IN THE PREVIOUS FIGURE. RIGHT: THICKNESS ANALYSIS OF SUSPENDED SAMPLE FROM EFTEM.ALL OF THE REGIONS WITHIN THIS PARTICULAR PARTICLE HAVE A MEAN FREE PATH UNDER ONE (BRIGHTER REFERS TO INCREASING THICKNESS)

. .61

FIGURE 34. EFTEM CHEMICAL MAP OF (LEFT TO RIGHT) CARBON, BORON, OXYGEN AND COMPOSITE MAP OF THE ASSIGNED MIXED COLORS IN RGB. THE SYSTEM IS MAINLY CARBON AS THE COMPOSITE STILL SHOWS MOSTLY RED 
WITH A MINOR PURPLE HUE. HOWEVER, THE BORON (GREEN) APPEARS TO LARGELY AGGREGATE AT PORE "POCKETS", A POSSIBLE CONSEQUENCE OF DOPING VIA DEPOSITION.

FIGURE 35. EELS SPECTRA SHOWING A MINOR BORON K-EDGE, CARBON K-EDGE, AND THE MAGNIFIED REGION OF A VERY MINOR OXYGEN EDGE INDICATING LOW OXYGEN CONTENT IN THIS PARTICLE. .....................................61

FIGURE 36. INTERCALATION OF METALLIC POTASSIUM INTO THE CARBON CHAR. .....................................................64

FIGURE 37. BORON-CARBON PHASE DIAGRAM OF SYNTHESIS TEMPERATURE VERSUS BORON WEIGHT PERCENT FOR

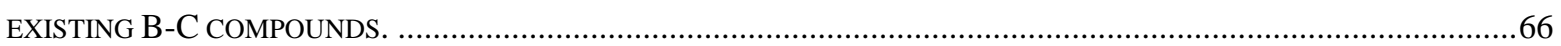

FIGURE 38. SURFACE-BOUND OXYGEN GROUPS IN GRAPHITIC/GRAPHENE-LIKE CARBON. ...........................................67

FIGURE 39. OXYGEN XPS SPECTRA AND PORE SIZE DISTRIBUTIONS OF HEAT TREATED, CARBON MATERIALS..............68

FIGURE 40. OXYGEN XPS SPECTRA AND PORE SIZE DISTRIBUTIONS OF MICROWAVE TREATED, CARBON MATERIALS. 68

FIGURE 41. OXYGEN XPS SPECTRA AND PORE SIZE DISTRIBUTIONS OF HYDRAZINE TREATED, CARBON MATERIALS...69

FIGURE 42. OXYGEN CONCENTRATION AS A FUNCTION OF SURFACE AREA FOR THREE DEOXYGENATION METHODS. ..70

Figure 43. PHASE DIAGRAM OF DECABORANE CONSTRUCTED FROM VARIOUS LITERATURE SOURCES ${ }^{[13,46-48] \ldots \ldots . . . . . .71}$

FIGURE 44. DECABORANE MOLECULE DECOMPOSING INTO DIBORANE AND ELEMENTAL BORON. ...............................72

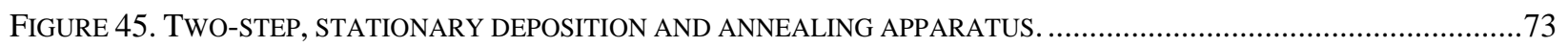

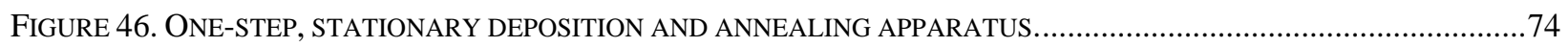

FIGURE 47. TWO-STEP, FLOW DEPOSITION AND ANNEALING APPARATUS. .................................................................

FIGURE 48. NITROGEN EXCESS ADSORPTION FOR A BROAD RANGE OF SORBENT SAMPLES. .......................................77

FIGURE 49. CUMULATIVE PORE VOLUMES OF A BROAD RANGE OF SORBENT SAMPLES. .............................................78

FIGURE 50. DIFFERENTIAL PORE VOLUMES OF A BROAD RANGE OF SORBENT SAMPLES..............................................79

FIGURE 51. NITROGEN EXCESS ADSORPTION FOR CHEMICALLY ACTIVATED, PRECURSOR SORBENT SAMPLES...............81

FIGURE 52. CUMULATIVE PORE VOLUMES FOR CHEMICALLY ACTIVATED, PRECURSOR SORBENT SAMPLES...................81

FIGURE 53. DIFFERENTIAL PORE VOLUMES FOR CHEMICALLY ACTIVATED, PRECURSOR SORBENT SAMPLES. .................82

FIGURE 54. NITROGEN EXCESS ADSORPTION FOR PRECURSOR MATERIALS OUTGASSED AT HIGH TEMPERATURES.........84

FIGURE 55. CUMULATIVE PORE VOLUMES FOR PRECURSOR MATERIALS OUTGASSED AT HIGH TEMPERATURES.............84

FIGURE 56. DIFFERENTIAL PORE VOLUMES FOR PRECURSOR MATERIALS OUTGASSED AT HIGH TEMPERATURES. ...........85

FIGURE 57. NITROGEN EXCESS ADSORPTION FOR BORON DOPED SAMPLES ORIGINATING FROM 2K AND 2.5K-TYPE

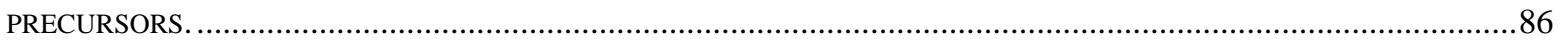

Figure 58. CUMULATIVE PORE VOlUMES FOR BORON DOPED SAMPLES ORIGINATING FROM 2K AND 2.5K-TYPE

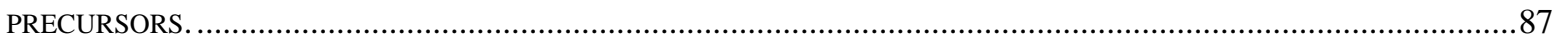

FIGURE 59. DIFFERENTIAL PORE VOLUMES FOR BORON DOPED SAMPLES ORIGINATING FROM $2 \mathrm{~K}$ AND 2.5K-TYPE

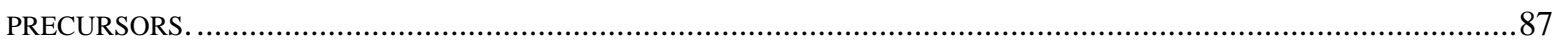

FIGURE 60. NITROGEN ADSORPTION FOR BORON DOPED SAMPLES ORIGINATING FROM 3K-TYPE PRECURSORS.............89

FIGURE 61. CUMULATIVE PORE VOLUMES FOR BORON DOPED SAMPLES ORIGINATING FROM 3K-TYPE PRECURSORS. ..89

FIGURE 62. DIFFERENTIAL PORE VOLUMES FOR BORON DOPED SAMPLES ORIGINATING FROM 3K-TYPE PRECURSORS.. 90

FIGURE 63. DIFFERENTIAL PORE VOLUMES FOR SELECT BORON DOPED 3K SAMPLES. .............................................91

FIGURE 64. NITROGEN ADSORPTION FOR BORON DOPED SAMPLES ORIGINATING FROM 4K-TYPE PRECURSORS............93

FIGURE 65. CUMULATIVE PORE VOLUMES FOR BORON DOPED SAMPLES ORIGINATING FROM 4K-TYPE PRECURSOR

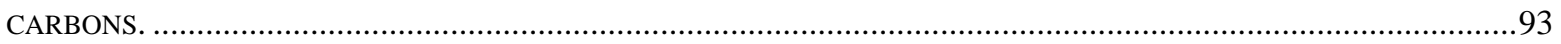

FIGURE 66. DIFFERENTIAL PORE FOR BORON DOPED SAMPLES ORIGINATING FROM 4K-TYPE PRECURSOR CARBONS....94

FIGURE 67. NITROGEN EXCESS ADSORPTION FOR BORON DOPED SAMPLES ORIGINATING FROM 5K-TYPE PRECURSOR

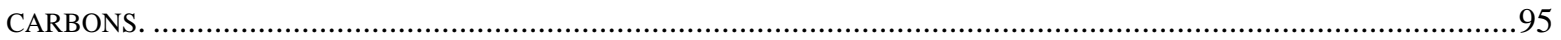

FIGURE 68. CUMULATIVE PORE VOLUMES FOR BORON DOPED SAMPLES ORIGINATING FROM 5K-TYPE PRECURSOR

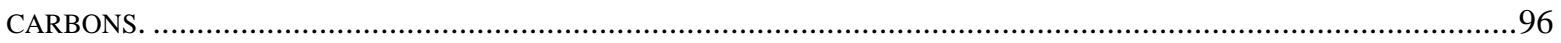

FIGURE 69. DIFFERENTIAL PORE FOR BORON DOPED SAMPLES ORIGINATING FROM 5K-TYPE PRECURSOR CARBONS....96 FIGURE 70. NITROGEN EXCESS ADSORPTION AND CUMULATIVE PORE SIZE DISTRIBUTION FOR MONOLITHIC SORBENT

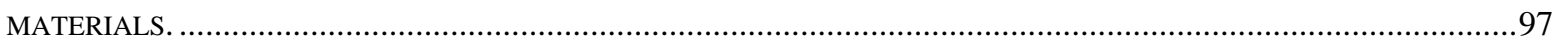

FIGURE 71. DIFFERENTIAL PORE SIZE DISTRIBUTION FOR MONOLITHIC SORBENT MATERIALS. ...................................98

FIGURE 72. GRAVIMETRIC EXCESS ADSORPTION ISOTHERMS FOR VARIOUS SAMPLES MEASURED AT 77 K...................99 
FIGURE 73. GRAVIMETRIC EXCESS ADSORPTION ISOTHERMS FOR ACTIVATED PRECURSORS MEASURED AT 77 K........100 FIGURE 74. GRAVIMETRIC EXCESS ADSORPTION ISOTHERMS FOR DEOXYGENATED PRECURSORS MEASURED AT $77 \mathrm{~K}$.

FIGURE 75. EXCESS ADSORPTION ISOTHERMS FOR 2.5K-TYPE BORON DOPED MATERIALS MEASURED AT 77 K...........101

FIGURE 76. EXCESS ADSORPTION ISOTHERMS FOR 3K-TYPE BORON DOPED MATERIALS MEASURED AT 77 K..............101

FIGURE 77. EXCESS ADSORPTION ISOTHERMS FOR 4K-TYPE BORON DOPED MATERIALS MEASURED AT 77 K..............102

FIGURE 78. EXCESS ADSORPTION ISOTHERMS FOR 5K-TYPE MATERIALS MEASURED AT 77 K.................................102

FIGURE 79. EXCESS ADSORPTION ISOTHERMS FOR MONOLITHIC SORBENT MATERIALS MEASURED AT 77 K................103

FIGURE 80. GRAVIMETRIC STORAGE CAPACITY ISOTHERMS FOR VARIOUS SAMPLES MEASURED AT 77 K...................104

FIGURE 81. GRAVIMETRIC STORAGE CAPACITY FOR ACTIVATED PRECURSOR SAMPLES MEASURED AT 77 K..............105

FIGURE 82. GRAVIMETRIC STORAGE CAPACITY FOR ACTIVATED PRECURSOR SAMPLES MEASURED AT 77 K..............106

FIGURE 83. GRAVIMETRIC STORAGE CAPACITY ISOTHERMS FOR BORON DOPED 2.5K AND 3K-TYPE SAMPLES MEASURED

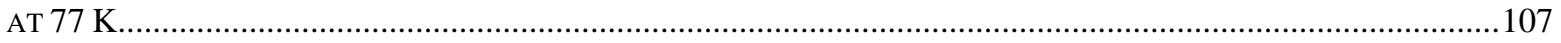

FIGURE 84. GRAVIMETRIC STORAGE CAPACITY ISOTHERMS FOR BORON DOPED 4K AND 5K-TYPE SAMPLES MEASURED

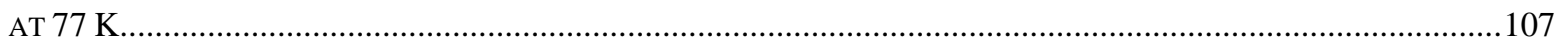

FIGURE 85. GRAVIMETRIC STORAGE CAPACITIES FOR MONOLITHIC SORBENT MATERIALS MEASURED AT 77 K...........108

FIGURE 86. VOLUMETRIC STORAGE CAPACITY ISOTHERMS FOR VARIOUS SAMPLES MEASURED AT 77 K.....................108

FIGURE 87. VOLUMETRIC STORAGE CAPACITY ISOTHERMS OF ACTIVATED PRECURSORS MEASURED AT 77 K.............109

FIGURE 88. VOLUMETRIC STORAGE CAPACITY ISOTHERMS OF DEOXYGENATED PRECURSORS MEASURED AT 77 K....110

FIGURE 89. VOLUMETRIC STORAGE CAPACITY ISOTHERMS OF 2.5K AND 3K-TYPE BORON DOPED MATERIALS MEASURED

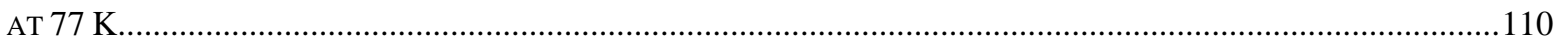

FIGURE 90. VOLUMETRIC STORAGE CAPACITY ISOTHERMS OF 4K AND 5K-TYPE BORON DOPED MATERIALS MEASURED

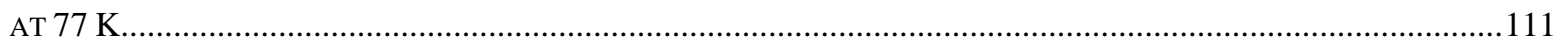

FIGURE 91. DELIVERABLE STORAGE CAPACITY OF 3K-0285 AND COMPRESSED HYDROGEN. ..................................112

Figure 92. DELIVERABLE GRAVIMETRIC STORAGE CAPACITIES FOR A BROAD RANGE OF SORBENT MATERIALS AT

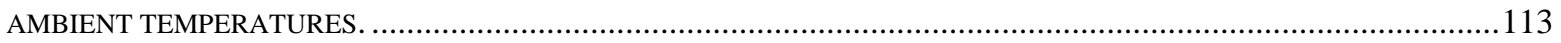

FiguRE 93. DELIVERABLE VOLUMETRIC STORAGE CAPACITIES FOR A BROAD RANGE OF SORBENT MATERIALS AT

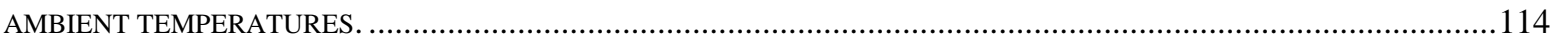

FiguRE 94. DELIVERABLE VOLUMETRIC STORAGE CAPACITIES FOR A BROAD RANGE OF SORBENT MATERIALS AT

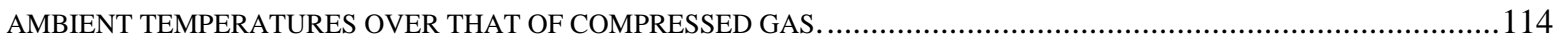

FiguRE 95. DELIVERABLE STORAGE CAPACITIES AT AMBIENT TEMPERATURES AS A FUNCTION OF ISOSTERIC HEAT OF

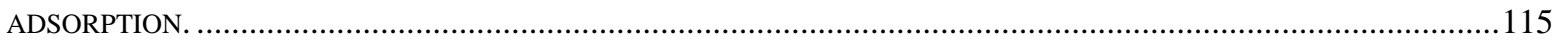

FiguRE 96. DELIVERABLE GRAVIMETRIC STORAGE CAPACITIES FOR A BROAD RANGE OF SORBENT MATERIALS AT

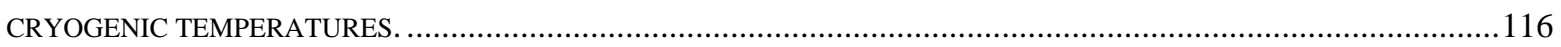

FiguRE 97. DELIVERABLE VOLUMETRIC STORAGE CAPACITIES FOR A BROAD RANGE OF SORBENT MATERIALS AT

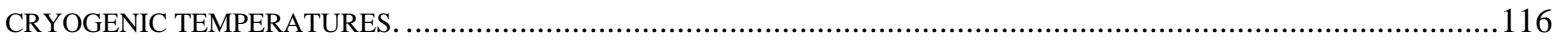

FiguRE 98. DELIVERABLE VOLUMETRIC STORAGE CAPACITIES FOR A BROAD RANGE OF SORBENT MATERIALS AT CRYOGENIC TEMPERATURES OVER THAT OF COMPRESSED GAS...................................................................117

FIGURE 99. HIGH DENSITY HYDROGEN ISOTHERMS FOR VARIOUS SAMPLES MEASURED AT 77 K. LEFT: EXPERIMENTAL RANGE OF HIGH DENSITY HYDROGEN ISOTHERMS. RIGHT: EXPERIMENTAL DATA INCLUDING AN ONO-KONDO FIT

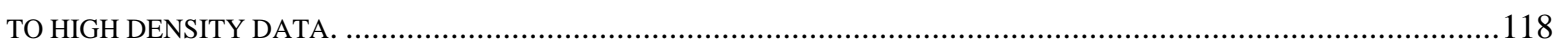

FiguRE 100. PROPERTIES OF THE ADSORBED FILM AT $77 \mathrm{~K}$ AS A FUNCTION OF SPECIFIC SURFACE AREA. LEFT: THE MAXIMUM CAPACITY OF THE ADSORBED FILM VERSUS SPECIFIC SURFACE AREA. RIGHT: THE ADSORBED FILM

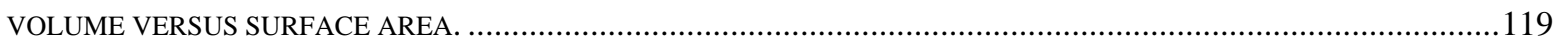

FIGURE 101. SATURATED DENSITY OF THE ADSORBED FILM AT $77 \mathrm{~K}$ AS A FUNCTION OF SPECIFIC SURFACE AREA. LEFT: THE SATURATED FILM DENSITY VERSUS SPECIFIC SURFACE AREA FOR ALL SAMPLES. RIGHT: THE RESULTING SATURATED FILM THICKNESS VERSUS SPECIFIC SURFACE AREA FOR ALL SAMPLES..........................................123

FigURE 102. MASS AND VOLUME OF THE SATURATED ADSORBED FILM AT $77 \mathrm{~K}$ AS A FUNCTION OF SPECIFIC SURFACE AREA.LEFT: THE MAXIMUM CAPACITY OF THE ADSORBED FILM VERSUS SPECIFIC SURFACE AREA. RIGHT: THE

vii 
ADSORBED FILM VOLUME VERSUS SURFACE AREA. THE ADSORBED FILM VOLUME INCREASES BY APPROXIMATELY $0.27 \mathrm{ML} / \mathrm{G}$ PER $1000 \mathrm{M}^{2} / \mathrm{G}$ OF SPECIFIC SURFACE AREA. 124

FIGURE 103. GRAVIMETRIC EXCESS ADSORPTION VERSUS BULK GAS DENSITY FOR SAMPLE 3K-0285 AT VARIOUS TEMPERATURES. LEFT: EXCESS ADSORPTION VERSUS GAS DENSITY. RIGHT: EXCESS ADSORPTION VERSUS GAS DENSITY WITH ONO-KONDO MODEL APPLIED TO EACH ISOTHERM EXTRAPOLATED TO THE HORIZONTAL AXIS. 125

FIGURE 104. PARAMETERS OF THE ADSORBED FILM FOR SAMPLE 3K-0285 AT VARIOUS TEMPERATURES. LEFT: SATURATED FILM VOLUME VERSUS TEMPERATURE. MIDDLE: MAXIMUM FILM CAPACITY VERSUS TEMPERATURE. RIGHT: SATURATED FILM DENSITY VERSUS TEMPERATURE. 125

FIGURE 105. GRAVIMETRIC EXCESS ADSORPTION VERSUS BULK GAS DENSITY FOR SAMPLE BR-0311 AT VARIOUS TEMPERATURES. LEFT: EXCESS ADSORPTION VERSUS GAS DENSITY. RIGHT: EXCESS ADSORPTION VERSUS GAS DENSITY WITH ONO-KONDO MODEL APPLIED TO EACH ISOTHERM EXTRAPOLATED TO THE HORIZONTAL AXIS. 126

FIGURE 106. PARAMETERS OF THE ADSORBED FILM FOR SAMPLE BR-0311 AT VARIOUS TEMPERATURES. LEFT: SATURATED FILM VOLUME VERSUS TEMPERATURE. MIDDLE: MAXIMUM FILM CAPACITY VERSUS TEMPERATURE. RIGHT: SATURATED FILM DENSITY VERSUS TEMPERATURE. ............................................................... 126

FIGURE 107. ABSOLUTE ADSORPTION ISOTHERMS FOR VARIOUS SAMPLES MEASURED AT 77 K.............................127

FIGURE 108. ABSOLUTE ADSORPTION ISOTHERMS AND RESULTING DIFFERENTIAL ENTHALPY OF ADSORPTION IN THE HIGH PRESSURE REGIME FOR SELECT SAMPLES. LEFT: ABSOLUTE ADSORPTION ISOTHERMS MEASURED BETWEEN 77 - 87 K. RIGHT: DIFFERENTIAL ENTHALPY OF ADSORPTION. 128

FIGURE 109. DIFFERENTIAL ENTHALPY OF ADSORPTION IN THE LOW COVERAGE LIMIT FOR VARIOUS SAMPLES. THE ClAUSIUS-CLAPEYRON RELATION WAS APPLIED TO THE 77 K AND 87 K ABSOLUTE ADSORPTION ISOTHERMS FOR EACH SAMPLE. 129

FIGURE 110. DIFFERENTIAL ENTHALPY OF ADSORPTION FOR ACTIVATED SORBENT MATERIALS. LEFT: ISOSTERIC HEATS RESULTING FROM APPLYING THE CLAUSIUS-CLAPEYRON RELATION TO HIGH PRESSURE ABSOLUTE ADSORPTION ISOTHERMS. RIGHT: ISOSTERIC HEATS RESULTING FROM APPLYING THE CLAUSIUS-CLAPEYRON RELATION TO LOW PRESSURE ABSOLUTE ADSORPTION ISOTHERMS. THE CLAUSIUS-CLAPEYRON RELATION WAS APPLIED TO ANY AVAILABLE ABSOLUTE ADSORPTION ISOTHERM DATA FOR SAMPLES BETWEEN 77-87 K. 129

FIGURE 111. DIFFERENTIAL ENTHALPY OF ADSORPTION FOR DEOXYGENATED SORBENT MATERIALS. LEFT: ISOSTERIC HEATS RESULTING FROM APPLYING THE ClAUSIUS-CLAPEYRON RELATION TO HIGH PRESSURE ABSOLUTE ADSORPTION ISOTHERMS. RIGHT: ISOSTERIC HEATS RESULTING FROM APPLYING THE CLAUSIUS-CLAPEYRON RELATION TO LOW PRESSURE ABSOLUTE ADSORPTION ISOTHERMS. THE CLAUSIUS-ClAPEYRON RELATION WAS APPLIED TO ANY AVAILABLE ABSOLUTE ADSORPTION ISOTHERM DATA FOR SAMPLES BETWEEN 77-87 K.........130

FIGURE 112. DIFFERENTIAL ENTHALPY OF ADSORPTION FOR 2.5K-TYPE BORON DOPED MATERIALS. LEFT: ISOSTERIC HEATS RESULTING FROM APPLYING THE CLAUSIUS-CLAPEYRON RELATION TO HIGH PRESSURE ABSOLUTE ADSORPTION ISOTHERMS. RIGHT: ISOSTERIC HEATS RESULTING FROM APPLYING THE CLAUSIUS-CLAPEYRON RELATION TO LOW PRESSURE ABSOLUTE ADSORPTION ISOTHERMS. THE CLAUSIUS-CLAPEYRON RELATION WAS APPLIED TO ANY AVAILABLE ABSOLUTE ADSORPTION ISOTHERM DATA FOR SAMPLES BETWEEN 77-87 K.........131

FIGURE 113. DIFFERENTIAL ENTHALPY OF ADSORPTION FOR 3K-TYPE BORON DOPED MATERIALS. LEFT: ISOSTERIC HEATS RESULTING FROM APPLYING THE CLAUSIUS-CLAPEYRON RELATION TO HIGH PRESSURE ABSOLUTE ADSORPTION ISOTHERMS. RIGHT: ISOSTERIC HEATS RESULTING FROM APPLYING THE CLAUSIUS-CLAPEYRON RELATION TO LOW PRESSURE ABSOLUTE ADSORPTION ISOTHERMS. THE CLAUSIUS-ClAPEYRON RELATION WAS APPLIED TO ANY AVAILABLE ABSOLUTE ADSORPTION ISOTHERM DATA FOR SAMPLES BETWEEN 77-87 K.........131

FIGURE 114. DIFFERENTIAL ENTHALPY OF ADSORPTION FOR 4K-TYPE BORON DOPED MATERIALS. LEFT: ISOSTERIC HEATS RESULTING FROM APPLYING THE CLAUSIUS-CLAPEYRON RELATION TO HIGH PRESSURE ABSOLUTE ADSORPTION ISOTHERMS. RIGHT: ISOSTERIC HEATS RESULTING FROM APPLYING THE CLAUSIUS-CLAPEYRON RELATION TO LOW PRESSURE ABSOLUTE ADSORPTION ISOTHERMS. THE CLAUSIUS-CLAPEYRON RELATION WAS APPLIED TO ANY AVAILABLE ABSOLUTE ADSORPTION ISOTHERM DATA FOR SAMPLES BETWEEN 77-87 K.........132

FIGURE 115. DIFFERENTIAL ENTHALPY OF ADSORPTION FOR 5K-0215 AND ITS PRECURSORS. LEFT: ISOSTERIC HEATS RESULTING FROM APPLYING THE CLAUSIUS-CLAPEYRON RELATION TO HIGH PRESSURE ABSOLUTE ADSORPTION ISOTHERMS. RIGHT: ISOSTERIC HEATS RESULTING FROM APPLYING THE CLAUSIUS-CLAPEYRON RELATION TO 
LOW PRESSURE ABSOLUTE ADSORPTION ISOTHERMS. THE CLAUSIUS-CLAPEYRON RELATION WAS APPLIED TO ANY AVAILABLE ABSOLUTE ADSORPTION ISOTHERM DATA FOR SAMPLES BETWEEN 77-87 K. 132

FIGURE 116. DIFFERENTIAL ENTHALPY OF ADSORPTION FOR MONOLITHIC SORBENT MATERIALS.ISOSTERIC HEATS WERE OBTAINED BY APPLYING THE CLAUSIUS-CLAPEYRON RELATION TO LOW PRESSURE ABSOLUTE ADSORPTION ISOTHERMS BETWEEN 77-87 K 133

FIGURE 117. HYDROGEN EXCESS AND ABSOLUTE ADSORPTION ISOTHERMS MEASURED BETWEEN 100 - 173 K FOR SAMPLE 3K-0285. LEFT: GRAVIMETRIC EXCESS ADSORPTION ISOTHERMS MEASURED BETWEEN 100 - 173 K. RIGHT: ABSOLUTE ADSORPTION ISOTHERMS MEASURED BETWEEN 100 - $173 \mathrm{~K}$. 134

FIGURE 118. RESULTING DIFFERENTIAL ENTHALPY OF ADSORPTION IN THE HIGH PRESSURE REGIME AS A FUNCTION OF COVERAGE AND TEMPERATURE FOR SAMPLE 3K-0285. 134

FIGURE 119. HYDROGEN EXCESS AND ABSOLUTE ADSORPTION ISOTHERMS MEASURED BETWEEN 100 - 173 K FOR SAMPLE BR-0311. LEFT: GRAVIMETRIC EXCESS ADSORPTION ISOTHERMS MEASURED BETWEEN 100 - 173 K. RIGHT: ABSOLUTE ADSORPTION ISOTHERMS MEASURED BETWEEN 100 - $173 \mathrm{~K}$. 135

FIGURE 120. RESULTING DIFFERENTIAL ENTHALPY OF ADSORPTION IN THE HIGH PRESSURE REGIME AS A FUNCTION OF

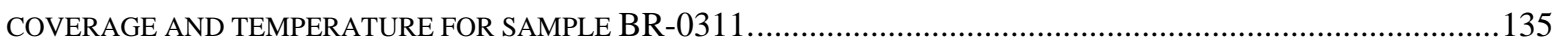

FIGURE 121. ABSOLUTE ADSORPTION IN THE LOW COVERAGE LIMIT AT 77 K AND 87 K......................................136

FIGURE 122. SLOPES OF THE LOW DENSITY EXCESS ADSORPTION ISOTHERMS AT 77 K VERSUS THE ISOSTERIC HEAT OF ADSORPTION. THE SLOPE OF THE $77 \mathrm{~K}$ EXCESS ADSORPTION ISOTHERM SHOULD BE DIRECTLY RELATED TO THE SPECIFIC SURFACE AREA AND THE ISOSTERIC HEAT. 140

FIGURE 123. LOW GAS DENSITY LINEAR REGIMES OF HYDROGEN EXCESS ADSORPTION AT 77 K AND 87 K. A LINEAR FIT WAS APPLIED TO ALL LOW PRESSURE ISOTHERMAL EXCESS MEASUREMENTS TO OBTAIN THE DIFFERENTIAL ENTHALPY OF ADSORPTION. 142

FIGURE 124. BAR GRAPH OF ISOSTERIC HEATS OF ADSORPTION FOR VARIOUS MATERIAL TYPES. A LINEAR FIT WAS APPLIED TO ALL LOW PRESSURE ISOTHERMAL EXCESS MEASUREMENTS .....................................................143

FIGURE 125. DIFFERENTIAL ENTHALPY OF ADSORPTION VERSUS THE SLOPE OF THE LOW PRESSURE ISOTHERMS AT 77 K

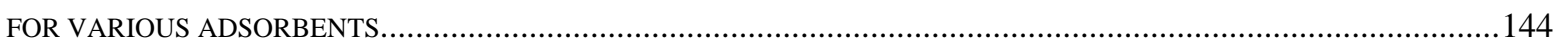

FIGURE 126. AREAL EXCESS ADSORPTION ISOTHERMS FOR VARIOUS SAMPLES MEASURED AT 77 K......................145

FIGURE 127. AREAL EXCESS ADSORPTION ISOTHERMS FOR ACTIVATED AND DEOXYGENATED SORBENT MATERIALS

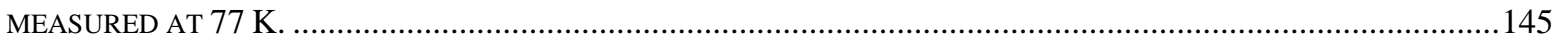

FIGURE 128. AREAL EXCESS ADSORPTION ISOTHERMS FOR 2.5K AND 3K-TYPE BORON DOPED MATERIALS MEASURED AT $77 \mathrm{~K}$ 146

FIGURE 129. AREAL EXCESS ADSORPTION ISOTHERMS FOR 4K AND 5K-TYPE BORON DOPED MATERIALS MEASURED AT $77 \mathrm{~K}$. 146

FIGURE 130. AREAL EXCESS ADSORPTION ISOTHERMS FOR MONOLITHIC SORBENT MATERIALS AND THEIR PRECURSOR

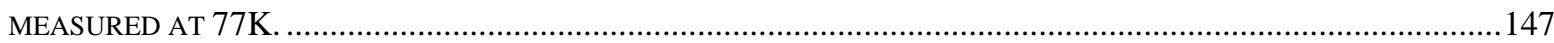

FIGURE 131. AREAL EXCESS ADSORPTION ISOTHERMS FOR SELECT PRECURSOR AND BORON DOPED SAMPLES..........148

FIGURE 132. LOW DENSITY LINEAR REGIME OF HYDROGEN EXCESS ADSORPTION ISOTHERMS AT 77 K AND 87 K......149

FIGURE 133. HIGH DENSITY LINEAR REGIMES OF HYDROGEN EXCESS ADSORPTION ISOTHERMS AT 77 K.................150

FIGURE 134. HIGH GAS DENSITY REGIMES OF HYDROGEN EXCESS ADSORPTION ISOTHERMS AT 77.35 K..................151

FIGURE 135. GRAVIMETRIC EXCESS ADSORPTION ISOTHERMS MEASURED AT 77 K AND 296 K FOR PRECURSOR CARBONS

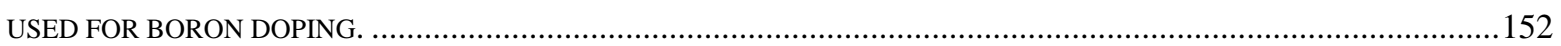

FIGURE 136. ABSOLUTE ADSORPTION AND ISOSTERIC HEATS FOR PRECURSOR CARBONS USED FOR BORON DOPING. . 153

FIGURE 137. ISOSTERIC HEAT OF ADSORPTION VERSUS KOH:C ACTIVATION RATIO. .............................................154

FIGURE 138. VOLUMETRC STORAGE CAPACITIES OF SAMPLE 3K-0285 COMPARED TO COMPRESSED HYDROGEN.......155

FIGURE 139. VOLUMETRIC STORAGE CAPACITY VERSUS ISOSTERIC HEAT OF ADSORPTION. ..................................155

FIGURE 140. PERFORMANCE OF VARIOUS ACTIVATED CARBON MATERIALS AFTER DEOXYGENATION.......................156

FIGURE 141. BINDING ENERGY VERSUS BORON CONCENTRATION FOR VARIOUS DOPED SAMPLES............................157

FIGURE 142. PORE SIZE INFORMATION FOR 4K SAMPLES DOPED WITH VARYING BORON CONCENTRATIONS. .............157 
Figure 143. Porosity, tOTAL PORE VOlume, AND SPECIFIC SURFACE AREAS AS A FUNCTION OF BORON

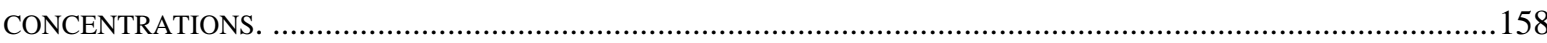

FIGURE 144. ISOSTERIC HEAT OF ADSORPTION NEAR ZERO COVERAGE AS A FUNCTION OF BORON CONTENTS FOR ALL

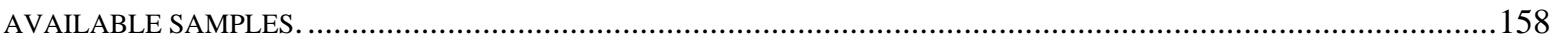

FIGURE 145. ISOSTERIC HEAT OF ADSORPTION NEAR ZERO COVERAGE AS A FUNCTION OF BORON CONTENTS FOR 4KTYPE DOPED MATERIALS. 159

FIGURE 146. METHANE GRAVIMETRIC EXCESS ADSORPTION VERSUS BULK GAS DENSITY FOR SAMPLE 3K-0285 AT VARIOUS TEMPERATURES. LEFT: EXCESS ADSORPTION VERSUS GAS DENSITY. RIGHT: EXCESS ADSORPTION VERSUS GAS DENSITY WITH ONO-KONDO MODEL APPLIED TO EACH ISOTHERM EXTRAPOLATED TO THE HORIZONTAL AXIS. 160

FIGURE 147. PARAMETERS OF THE ADSORBED METHANE FILM FOR SAMPLE 3K-0285 AT VARIOUS TEMPERATURES. LEFT: SATURATED FILM VOlUME VERSUS TEMPERATURE. MidDlE: MAXIMUM FILM CAPACITY VERSUS TEMPERATURE. RIGHT: SATURATED FILM DENSITY VERSUS TEMPERATURE. 160

FIGURE 148. METHANE GRAVIMETRIC EXCESS ADSORPTION VERSUS BULK GAS DENSITY FOR SAMPLE BR-0311 AT VARIOUS TEMPERATURES. LEFT: EXCESS ADSORPTION VERSUS GAS DENSITY. RIGHT: EXCESS ADSORPTION VERSUS GAS DENSITY WITH ONO-KONDO MODEL APPLIED TO EACH ISOTHERM EXTRAPOLATED TO THE HORIZONTAL AXIS. THE SATURATED FILM DENSITY REACHES $400 \pm 50$ G/L OVER THIS TEMPERATURE RANGE. INSUFFICIENT DATA EXISTS FOR THE 193 K MEASUREMENT. THEREFORE, NO ATTEMPT WAS MADE TO DETERMINE THE PARAMETERS OF THE ADSORBED FILM AT THIS TEMPERATURE.

FIGURE 149. PARAMETERS OF THE ADSORBED METHANE FILM FOR SAMPLE BR-0311 AT VARIOUS TEMPERATURES. LEFT: SATURATED FILM VOLUME VERSUS TEMPERATURE. MidDlE: MAXIMUM FILM CAPACITY VERSUS TEMPERATURE. RIGHT: SATURATED FILM DENSITY VERSUS TEMPERATURE. SATURATED FILM DENSITIES BETWEEN 350 - $450 \mathrm{G} / \mathrm{L}$ CORRESPOND TO FILM THICKNESSES BETWEEN $0.39-0.42$ NM. 161

FIGURE 150. METHANE EXCESS AND ABSOLUTE ADSORPTION ISOTHERMS MEASURED BETWEEN 173-296 K FOR SAMPLE 3K-0285. LEFT: GRAVIMETRIC EXCESS ADSORPTION ISOTHERMS MEASURED BETWEEN 173-296 K. RIGHT: ABSOLUTE ADSORPTION ISOTHERMS MEASURED BETWEEN 173-296 K. NO EXPERIMENTAL DATA EXISTS BELOW A COVERAGE OF $50 \mathrm{G} / \mathrm{KG}$. THEREFORE, ANY CALCULATED ISOSTERIC HEAT VALUES FOR COVERAGES BELOW THAT VALUE WILL ENTIRELY DEPEND ON THE CHOICE OF MODEL APPLIED TO THE ISOTHERMAL ADSORPTION DATA.. 162

FIGURE 151. RESULTING DIFFERENTIAL ENTHALPY OF ADSORPTION IN THE HIGH PRESSURE REGIME FOR SAMPLE 3K0285. LEFT: DIFFERENTIAL ENTHALPY OF ADSORPTION AS A FUNCTION OF COVERAGE AND TEMPERATURE. RIGHT: DIFFERENTIAL ENTHALPY OF ADSORPTION AS A FUNCTION OF THE GEOMETRIC MEAN PRESSURE AND TEMPERATURE. 163

FIGURE 152. EXCESS AND ABSOLUTE ADSORPTION MEASURED BETWEEN 193-296 K FOR SAMPLE BR-0311. LEFT: GRAVIMETRIC EXCESS ADSORPTION ISOTHERMS MEASURED BETWEEN 193-296 K. RIGHT: ABSOLUTE ADSORPTION ISOTHERMS MEASURED BETWEEN 223-296 K. INSUFFICIENT DATA EXISTS FOR THE ISOTHERMAL MEASUREMENT AT $193 \mathrm{~K}$. THEREFORE, NO ATTEMPT WAS MADE TO DETERMINE THE PARAMETERS OF THE ADSORBED FILM AT THAT TEMPERATURE. NO EXPERIMENTAL DATA EXISTS BELOW A COVERAGE OF 50 G/KG. THEREFORE, ANY CALCULATED ISOSTERIC HEAT VALUES FOR COVERAGES BELOW THAT VALUE WILL ENTIRELY DEPEND ON THE CHOICE OF MODEL APPLIED TO THE ISOTHERMAL ADSORPTION DATA. 164

FIGURE 153. RESULTING DIFFERENTIAL ENTHALPY OF ADSORPTION IN THE HIGH PRESSURE REGIME FOR SAMPLE BR-0311. LEFT: DIFFERENTIAL ENTHALPY OF ADSORPTION AS A FUNCTION OF COVERAGE AND TEMPERATURE. RIGHT: DIFFERENTIAL ENTHALPY OF ADSORPTION AS A FUNCTION OF THE GEOMETRIC MEAN PRESSURE AND TEMPERATURE. METHANE IS MORE MASSIVE THAN HYDROGEN AND ALSO HAS A HIGHER BINDING ENERGY TO THE SORBENT SURFACE. GRAVIMETRICALLY METHANE IS ADSORBED IN LARGE AMOUNTS, EVEN AT LOW PRESSURES. FOR THESE REASONS, IT IS OFTEN MORE PRACTICAL TO REPRESENT THE CALCULATED ISOSTERIC HEATS AS A FUNCTION OF THE GEOMETRIC MEAN PRESSURE. 164

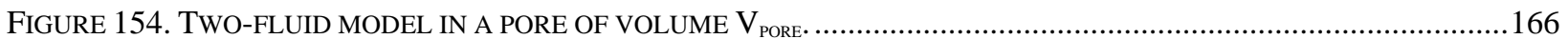

FIGURE 155. ASYMPTOTIC LINEAR RELATION FOR VOLUMETRIC STORAGE CAPACITY AS A FUNCTION OF GAS DENSITY AT HIGH PRESSURE. 172 
FiguRE 156. PREDICTED STORAGE CAPACITIES OF MSC-30 USING THE DISCRETE TWO-FLUID MODEL. ASSUMING THAT THE DENSITY OF THE ADSORBED FILM IS APPROXIMATELY $100 \pm 5 \mathrm{G} / \mathrm{L}$, THIS MODEL SUCCESSFULLY PREDICTS BOTH THE GRAVIMETRIC AND VOLUMETRIC STORAGE CAPACITIES OF SAMPLE MSC-30 AT 77 K AND IN HIGH PRESSURE REGIME. 172

FIGURE 157. ADSORBED FILM DENSITY OF HYDROGEN AS A FUNCTION OF PRESSURE AT 77 K ................................175

FIGURE 158. EXPERIMENTAL AND PREDICTED VOLUMETRIC STORAGE CAPACITIES AND EXCESS ADSORPTION OF

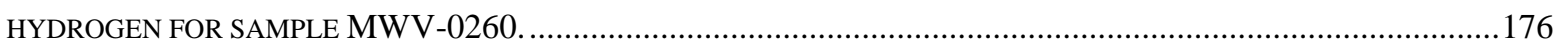

FIGURE 159. EXPERIMENTAL AND PREDICTED VOLUMETRIC STORAGE CAPACITIES AND EXCESS ADSORPTION OF

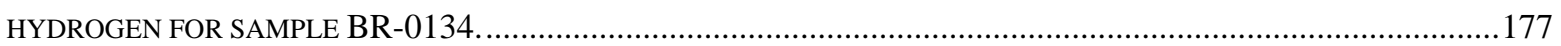

FIGURE 160. EXPERIMENTAL AND PREDICTED VOLUMETRIC STORAGE CAPACITIES AND EXCESS ADSORPTION OF

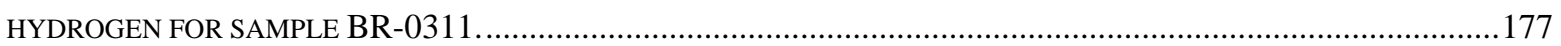

FIGURE 161. EXPERIMENTAL AND PREDICTED VOLUMETRIC STORAGE CAPACITIES AND EXCESS ADSORPTION OF

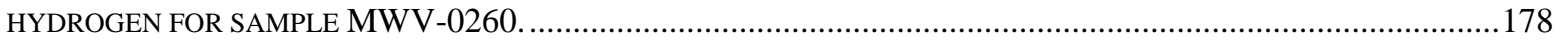

FIGURE 162. EXPERIMENTAL AND PREDICTED VOLUMETRIC STORAGE CAPACITIES AND EXCESS ADSORPTION OF

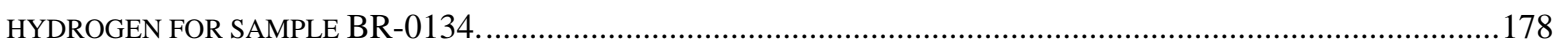

FIGURE 163. EXPERIMENTAL AND PREDICTED VOLUMETRIC STORAGE CAPACITIES AND EXCESS ADSORPTION OF

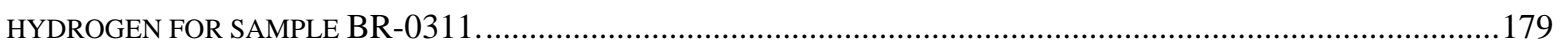

FIGURE 164. CUMULATIVE PORE VOLUME AND DIFFERENTIAL PORE VOLUME DATA OBTAINED FROM QSDFT ANALYSIS OF SUB-CRITICAL NITROGEN ISOTHERMS USING AN ASSUMPTION OF NEARLY SLIT-SHAPED PORES. ...................180

FigURE 165. VOLUMETRIC STORAGE CAPACITY AT P = 25 BAR AND T $=77$ K VERSUS $\Phi_{\text {NANO }}(0-13 \AA$ A $)$.........................182

FigURE 166. VOLUMETRIC STORAGE CAPACITY AT $\mathrm{P}=25$ BAR AND T $=77 \mathrm{~K}$ VERSUS $\Phi_{\text {NANO }}\left(30 \AA\right.$ A $\left.-\mathrm{V}_{\text {PoRE }}\right) \ldots \ldots \ldots \ldots \ldots . . . . . .182$

FIGURE 167. VOLUMETRIC STORAGE CAPACITY OF HYDROGEN AT $77 \mathrm{~K}$ VERSUS NANOPOROSITY..............................183

FIGURE 168. A SINGLE CRYSTAL OF CARBONACEOUS ADSORBENT MATERIAL WITH INCREASING $\Phi_{\text {NANO }}(0-13 \AA)$ AND

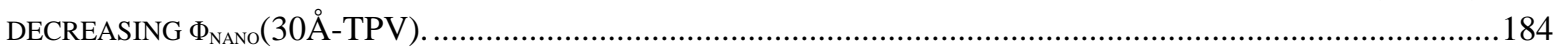

FIGURE 169. VOLUMETRIC STORAGE CAPACITY OF METHANE AT 296 K VERSUS NANOPOROSITY..............................186

FIGURE 170. EXPERIMENTAL AND PREDICTED METHANE GRAVIMETRIC EXCESS ADSORPTION VALUES FOR BR-0117, BR-

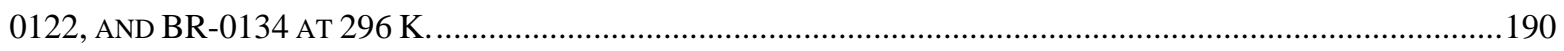

FIGURE 171. FRACTIONAL VOLUMES AT TEMPERATURES RANGING FROM 77-273 K. ................................................194

FIGURE 172. EXCESS ADSORPTION MEASUREMENTS FOR SAMPLES HS;0B-20 AND 4K-0245 MEASURED ON THE HTP-1,

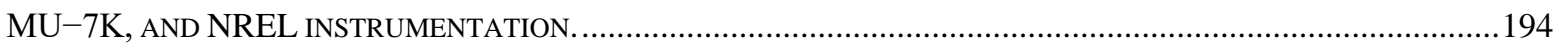

FIGURE 173. EXCESS ADSORPTION MEASUREMENTS AND CALCULATED ERROR FOR SAMPLE MSC-30.......................197 


\begin{abstract}
The environmental impacts and costs of fossil fuels necessitate the development of clean, renewable fuel sources for vehicular applications. Hydrogen based systems, with water as their byproduct, have zero carbon emissions, which mitigates the negative effects of using conventional fossil fuels. Further, hydrogen can be produced from renewable energy sources, such as renewable electrolysis and biohydrogen ${ }^{[1]}$. When produced from such methods, hydrogen is a renewable fuel. The main drawback of hydrogen as a fuel is its low energy density at ambient pressures and temperatures. Hydrogen has a mass energy density three times that of gasoline, but occupies more than 30 times the volume. Therefore, it is necessary to increase the volumetric energy density of hydrogen before it can be considered as a practical option ${ }^{[2]}$.
\end{abstract}

Conventional storage methods for hydrogen include compression and liquefaction. In order to yield a sufficient deliverable storage capacity, these methods require high pressures or cryogenic temperatures ${ }^{[3]}$. Compressed gas systems require tanks with massive walls which reduce spatial and mass efficiency and thus, vehicle performance. These systems are geometrically constrained due to their high pressure, making them difficult to integrate into the vehicle. Due to these constraints, conventional storage methods are insufficient at increasing the energy density of hydrogen to compete with that of fossil fuels ${ }^{[4]}$. To bridge this gap, it is necessary to develop a low-pressure, high-capacity storage technology in order to address the temperature, pressure, weight, and volume constraints present in the conventional storage methods. To achieve this, we investigate the storage capacity of nanoporous solids, which are capable of densifying a high volume of hydrogen on their surfaces through the process of adsorption.

Several factors affect the adsorptive capacity of these materials, such as specific surface area ${ }^{[5]}$, pore geometry, and the strength of the adsorption potential. The strength of the adsorption potential often cited as a figure of merit for the adsorptive capacity of new materials and is commonly estimated through the Clausius-Clapeyron relation between two adsorption isotherms. However, this method requires an assumption of the adsorbed film volume, which poses as the primary source of error ${ }^{[6]}$. From supercritical xii 
hydrogen isotherms from 77 - 473 Kelvin, we propose a method to measure the volumes, densities, and thicknesses of the adsorbed film. This method will lead to more accurate isosteric heat calculations, which is an important factor to consider when designing storage tanks.

Furthermore, we investigated the correlation between the isosteric heat of adsorption, surface chemistry, and pore size distribution with an adsorbed film. In most of the samples the saturated film density was approximately $100 \mathrm{~g} / \mathrm{L}$ across a large range of temperatures. The specific volumes of the adsorbed film scaled with specific surface area and binding energies. The saturated, adsorbed film density approaches $100 \mathrm{~g} / \mathrm{L}$ for all adsorbent types at $77 \mathrm{~K}$. The saturated, adsorbed film thickness was between $3.1-3.2 \AA$ for hydrogen on most sorbent materials. In the future, we intend to investigate changes in these parameters of the adsorbed film with increasing temperature as well as the affects that these changes may have on the estimated values of isosteric heat. Improved estimates of isosteric heats of adsorption will assist in optimizing the thermal properties of on-board storage tanks. 


\section{Introduction}

Though full fuel cycle analyses have demonstrated that hydrogen is an environmentally viable alternative, several critical technologies need to be developed in order to fully implement a sustainable hydrogen infrastructure ${ }^{[3]}$. There must be a substantial reduction in hydrogen production costs and fuel cell costs. It is also necessary to develop hydrogen storage systems capable of delivering a driving range of hundreds of kilometers without posing major detrimental effects to vehicle cost, safety, or cargo capacity. Hydrogen has a mass energy density three times that of gasoline, but occupies more than 30 times the volume $^{[6]}$. Therefore, it is necessary to increase the volumetric energy density of hydrogen before it can be considered a practical option.

To overcome the plethora of constraints present in conventional storage methods, it is necessary to develop a high-capacity storage technology. To overcome these storage challenges many researchers are investigating innovative materials, such as metal hydrides, chemical hydrides, cryogenic hydrogen, and adsorbents. Adsorbent types of interest include carbonaceous materials, metal organic frameworks (MOFs), Graphitic Carbon Nitrides (GCN), and PVDC-based materials. Though several materials have shown promise, none are currently able to fully meet the DOE's storage capacity requirements at ambient temperatures ${ }^{[7]}$.

\subsection{Adsorption}

Adsorption is the process by which an adsorbate gas increases in density when in the vicinity of a material interface due to Van der Waals interactions. Strong Van der Waals forces are capable of condensing $\mathrm{H}_{2}$ into a high density fluid at pressures and temperatures at which $\mathrm{H}_{2}$, in the absence of an adsorbing surface, would be a low density gas. Among several variables, this effect is largely due to the extent of the interfacial area, which is generated by increasing the network of channels in the pore volume of the adsorbent material. Though adsorption instruments vary greatly in type and technique, they all measure the same quantity: excess adsorption. Excess adsorption is defined as follows ${ }^{[8]}$. 
"Consider two systems of equal volume. The first system is that of free gas at a temperature

$T_{0}$, pressure $p_{0}$, and contains $N_{0}$ gas molecules. The second system contains an external potential $U(\vec{r})$ due to an adsorbing surface outside of the system and the gas has a temperature $T$, pressure $p$ far from the adsorbing surface, and contains $N$ gas molecules. If both systems have the same temperature and pressure (i.e. $T=T_{0}$ and $p=p_{0}$ ), then the excess adsorption is given by $N-N_{0}$ "

For high surface area adsorbent materials, excess adsorption is one of the only directly measureable quantities without theoretical assumptions ${ }^{[9]}$. Excess adsorption may be thought as the mass of the adsorbed film minus the mass of an equal volume of compressed gas.

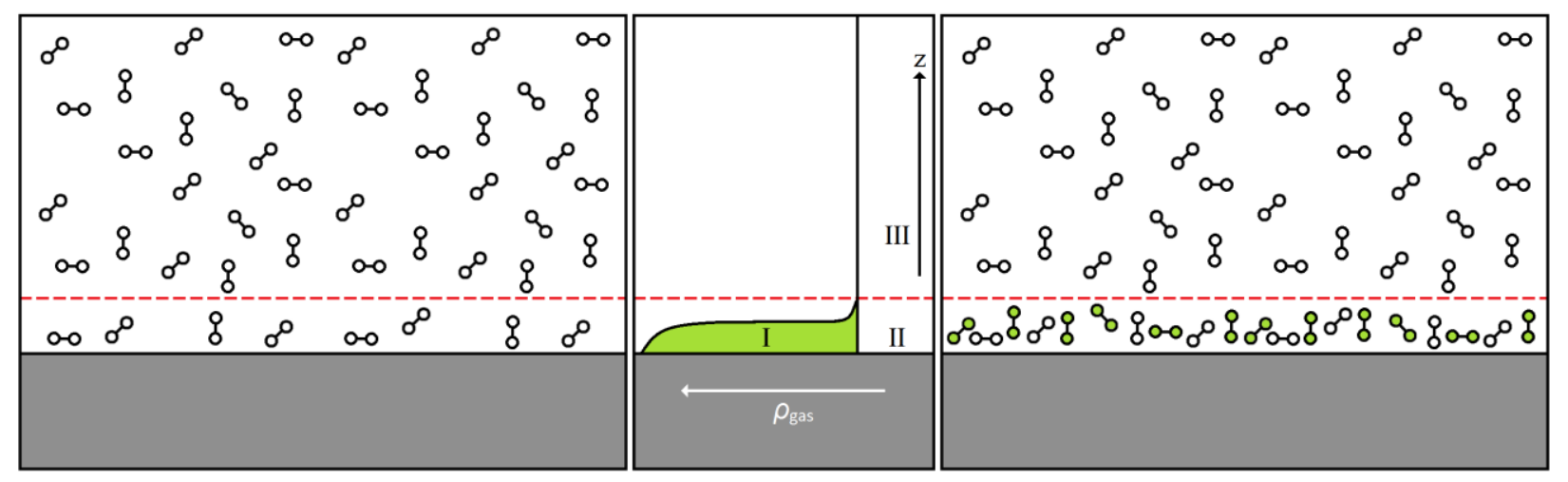

Figure 1. An adsorption schematic of gas densities versus distance from adsorbent surface. Left: Volume of compressed gas at a constant density in the absence of an adsorbing potential. Right: Compressed gas in the presence of an adsorbing potential. The gas densifies near the adsorbing surface. Colored molecules have been adsorbed in excess of those that would be present in the absence of an adsorbing potential. Thus, they are defined as the excess adsorption. Middle: Graphical representation of gas density vs. distance from the adsorbent surface. The three regions indicated show excess adsorption (I), absolute adsorption $(\mathrm{I}+\mathrm{II})$, and total storage capacity $(\mathrm{I}+\mathrm{II}+\mathrm{III})^{[10]}$.

Excess adsorption is the only quantity that may be directly measured directly. However, storage capacities and absolute adsorption are derived from the excess adsorption measurement using assumptions about the pore volume, adsorbed film thickness, or surface geometry. Therefore, the only way to improve the accuracy of absolute adsorption or storage capacity is to improve the accuracy of excess adsorption measurements. 
In our laboratory, we primarily use the volumetric method to determine excess adsorption. Hydrogen excess adsorption isotherms were measured using either a modified HTP-1 Volumetric Analyser manufactured by Hiden Isochema or a custom-built volumetric analyser manufactured in-house (MU-7K). The HTP-1 is a manometric instrument capable of measuring hydrogen isotherms at pressures ranging from 0.001 mbar to 1 bar using a set of two low-pressure Baratron capacitance manometers and from 1 bar to 200 bar using a 200 bar Baratron manometer. The system consists of a dosing volume and a reactor volume, separated by a pneumatic valve whose diaphragm displaces a volume when closed. The dosing and pneumatic valve volumes were contained within a temperature-controlled cabinet that was maintained at $30.0 \pm 0.1{ }^{\circ} \mathrm{C}$. The reactor volume was partially contained in this cabinet, partially exposed to the lab environment and partially submerged in a cooling bath. The sample temperature was controlled using either a cooling bath or a three stage tube furnace. Cooling baths were composed of ice water, liquid argon, or liquid nitrogen, allowing for measurement of isotherms at $77 \mathrm{~K}, 87 \mathrm{~K}, 273 \mathrm{~K}$, and $296 \mathrm{~K}$. The three stage tube furnace allowed for measurements up to $603 \mathrm{~K}$. Though the tube furnace is capable of maintaining temperatures over $1100 \mathrm{C}$, it is important to stay well below the autoignition temperature of the adsorbate gas ${ }^{[11]}$. The cabinet or dosing volume temperature was measured using two platinum resistance thermometers (PRTs) surrounding the dosing volume. The MU-7K is a manometric instrument capable of measuring hydrogen isotherms at pressures ranging from 1 bar to 200 bar. This system also consists of a dosing volume and a reactor volume, separated by a pneumatic valve whose diaphragm displaces a volume when closed. The dosing and pneumatic valve volumes were contained within a plexiglass cabinet that was maintained at $296 \mathrm{~K}$. The reactor volume was partially contained in this cabinet, partially exposed to the lab environment, and partially contained within a closed cycle refrigeration system. The sample temperature was controlled using the closed cycle refrigeration system.

Volumetric methods for determining excess adsorption have been used for almost 90 years. Most modern volumetric sorption instruments employ the Sieverts' method, monitoring changes in pressure and temperature in order to measure excess. Basic manometric instruments consist of two known volumes, 
referred to here as the dosing volume $V_{\mathrm{d}}$, and the reactor volume $V_{\mathrm{r}}$, separated by a valve. Let $V_{\text {sk }}$, represent the skeletal volume of the sample ${ }^{[12]}$.

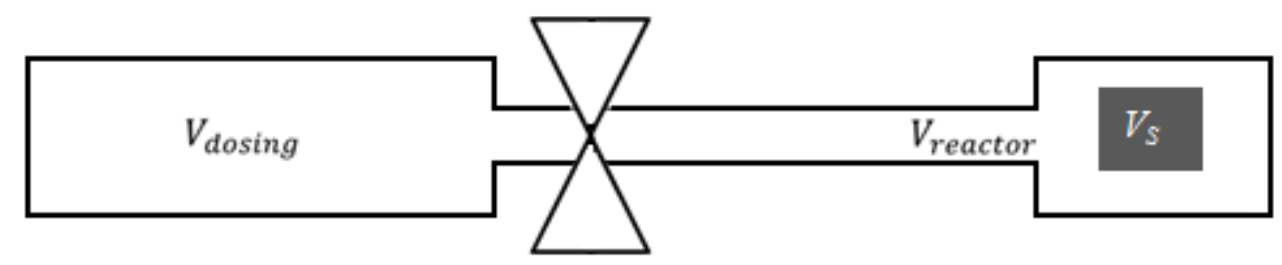

Figure 2. Manometric instrument consisting of two known volumes, separated by a valve.

If $V_{\mathrm{d}}, V_{\mathrm{r}}$, and $V_{\mathrm{sk}}$ are known, manometric instruments may use the conservation of particle number to perform sorption measurements. Beginning with an evacuated system, the dosing volume is pressurized with the adsorbate gas. The temperature and pressure are measured and the mass density $\rho_{1}$ is calculated using an appropriate equation of state. The mass of adsorbate gas contained in the system is now given by

$$
m_{\mathrm{g}}=\rho_{1} V_{\mathrm{d}}
$$

After an adequate equilibration time, the valve separating the dosing volume and reactor volume is opened allowing the adsorbate gas to enter $V_{\mathrm{r}}$. Again, equilibrium is reached and the gas density $\rho_{2}$ is calculated based on pressure and temperature measurements. In the presence of a non-adsorbing sample, the mass of the adsorbate gas may now be expressed as

$$
m_{\mathrm{g}}=\rho_{2}\left(V_{\mathrm{d}}+V_{\mathrm{r}}-V_{\mathrm{sk}}\right)
$$

In the presence of an adsorbing sample, the mass of adsorbate gas in the system may be expressed as

$$
m_{\mathrm{g}}=\rho_{2}\left(V_{\mathrm{d}}+V_{\mathrm{r}}-V_{\mathrm{sk}}\right)+\mathrm{V}_{\text {film }}\left(\rho_{\text {film }}-\rho_{2}\right)
$$

where $V_{\text {film }}$ is the volume occupied by the adsorbed film of adsorbate gas, $\rho_{\text {film }}$ is the density of gas in the adsorbed phase. The last term in this expression is the definition of excess adsorption. Thus, the mass of adsorbate gas contained in the system may be expressed as 


$$
m_{\mathrm{g}}=\rho_{2}\left(V_{\mathrm{d}}+V_{\mathrm{r}}-V_{\mathrm{sk}}\right)+\mathrm{m}_{\mathrm{exc}}
$$

Using the conservation of particle number and equating equations 1 and 4 yields

$$
m_{\mathrm{exc}}=V_{\mathrm{d}}\left(\rho_{1}-\rho_{2}\right)-\rho_{2}\left(V_{\mathrm{r}}-V_{\mathrm{sk}}\right)
$$

If two or more data points are to be measured, the valve is closed, which displaces a volume. This necessitates a third density $\rho_{3}$ to be determined. This third measurement is used to determine the amount of adsorbate gas that remains in each volume at the end of the measurement and is used to avoid double counting gas molecules. This dosing process is repeated for as many data points are desired. However, it is important to note that any uncertainties will compound with increasing successive measurements. The excess adsorption is calculated for any number of data points by determining the total amount of gas added to the system and subtracting from it the amount of gas that would be present in the system if there were no adsorption. The general expression for excess calculated for the $k^{\text {th }}$ data point will be given by

$$
m_{\mathrm{exc}}=\sum_{i=1}^{k}\left[\rho_{1 i} V_{\mathrm{d}}-\rho_{2 i}\left(V_{\mathrm{d}}+V_{\mathrm{r}}-V_{\mathrm{sk}}\right)+\rho_{2(i-1)}\left(V_{\mathrm{d}}+V_{\mathrm{r}}-V_{\mathrm{sk}}\right)-\rho_{3(i-1)} V_{\mathrm{d}}\right]
$$

where the first digit in the subscripts represents the step in the measurement and the second digit represents the measurement iteration. The gravimetric excess adsorption is obtained by normalizing the above expression by the sample mass.

One consequence of this expression is that every successive measurement in an isotherm is dependent upon all previous data points. Though this does result in an accumulation of uncertainties, the uncertainties do not simply add from data point to data point because all of the terms with $\rho_{2 \mathrm{i}}$ cancel from the previous data point. Additionally, since these are the only terms accounting for sample temperature, thermal fluctuations in the sample do not propagate errors to later calculated data points in the isotherm. To emphasize this point, I present a slightly more compact version of $\mathrm{Eq}(6)$ : 


$$
m_{\mathrm{exc}}=\left[\sum_{i=1}^{k} \rho_{1 i}-\rho_{3(i-1)}\right] V_{\mathrm{d}}-\left[\rho_{2 k}\left(V_{\mathrm{d}}+V_{\mathrm{r}}-V_{\mathrm{sk}}\right)\right]
$$

When the dosing volume is maintained at a different temperature than the sample, a volume fraction must be used in order to estimate the thermal gradient. Consider the case of using a liquid nitrogen cooling bath

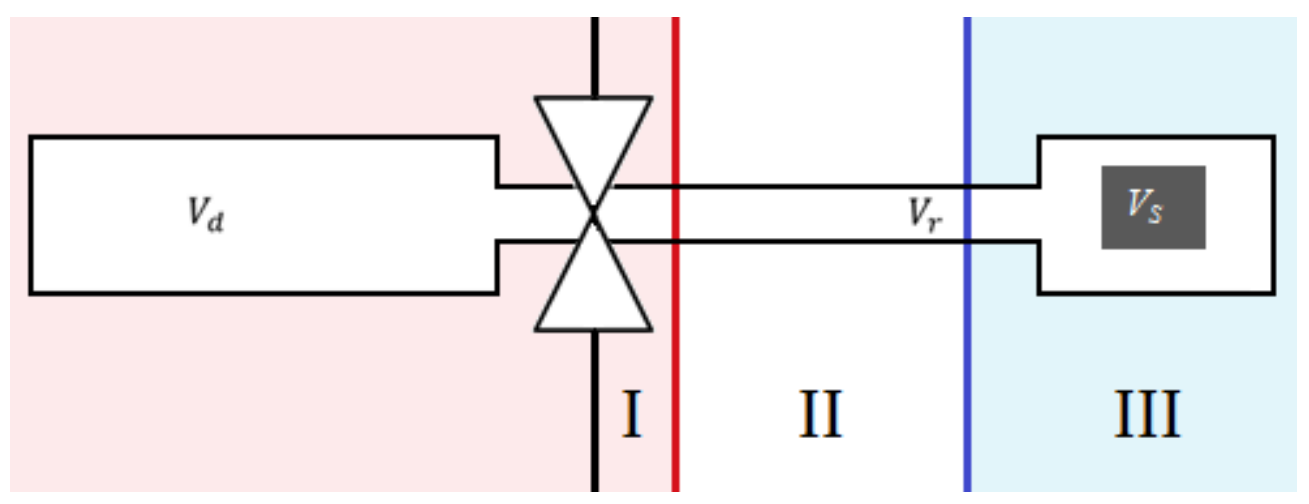

Figure 3. Manometric instrument with the reactor volume split into three thermal regions. The reactor volume is partially contained within a temperature-controlled manifold, partially exposed to the laboratory environment, and partially submerged in the liquid nitrogen cooling bath.

$$
V_{\mathrm{r}}=\mathrm{I}+\mathrm{II}+\mathrm{III}
$$

The reactor volume is the comprised of the sum of regions I, II, and III. Let $f_{0}$ represent the fraction of the reactor volume not contained in the manifold $\left(0 \leq f_{0} \leq 1\right)$. Let $f$ represent the fraction of the remaining reactor volume submerged in the cooling bath $(0 \leq f \leq 1)$. The three regions may be defined as the following:

$$
\begin{gathered}
\mathrm{I}=V_{\mathrm{r}}\left(1-f_{0}\right) \\
\mathrm{II}=V_{\mathrm{r}} f_{0}(1-f) \\
\mathrm{III}=V_{\mathrm{r}} f_{0} f
\end{gathered}
$$

Accounting for volume fractions in the excess equation requires the consideration of additional new gas densities for each thermal region. Substituting these newly defined thermal regions into Eq 7 for $V_{\mathrm{r}}$ yields 


$$
\begin{aligned}
m_{\mathrm{exc}}= & {\left[\sum_{i=1}^{k} \rho_{1 i}-\rho_{3(i-1)}\right] V_{\mathrm{d}} } \\
& \quad-\left[\rho_{2 k}\left(V_{\mathrm{d}}+V_{\mathrm{r}}\left(1-f_{0}\right)\right)+\rho_{2 k}^{\prime} V_{\mathrm{r}} f_{0}(1-f)+\rho_{2 k}^{\prime \prime}\left(V_{\mathrm{r}} f_{0} f-V_{\mathrm{sk}}\right)\right]
\end{aligned}
$$

where $\rho_{2 k}$ is still the mass density of the adsorbate gas after opening the valve, $\rho_{2 k}^{\prime}$ is the mass density of gas that is contained within region II and at the same temperature as the laboratory environment, and $\rho_{2 k}^{\prime \prime}$ is the mass density of gas that is contained within region III and maintained at the same temperature as the cooling bath. This is an expanded version of the excess equation for the $k^{\text {th }}$ data point. For the purpose of exhaustive validation of this equation, it is important to note two cases: 1 ) when the region III is maintained at the same temperature as region II such that $\rho_{2 k}^{\prime}=\rho_{2 k}^{\prime \prime}$ and 2) when all three regions are maintained at the same temperature such that $\rho_{2 k}=\rho_{2 k}^{\prime}=\rho_{2 k}^{\prime \prime}$. Considering the first case, $\rho_{2 k}^{\prime}=\rho_{2 k}^{\prime \prime}$, which necessitates that $f_{77 \mathrm{~K}}=0$ such that there is no fraction of the reactor volume maintained at the same temperature as the cooling bath. The excess equation becomes

$$
m_{\mathrm{exc}}=\left[\sum_{i=1}^{k} \rho_{1 i}-\rho_{3(i-1)}\right] V_{\mathrm{d}}-\left[\rho_{2 k}\left(V_{\mathrm{d}}+V_{\mathrm{r}}\left(1-f_{0}\right)\right)+\rho_{2 k}^{\prime}\left(V_{\mathrm{r}} f_{0}-V_{\mathrm{sk}}\right)\right]
$$

Considering the second case, $\rho_{2 k}=\rho_{2 k}^{\prime}$, which necessitates that $f_{0}=1$ such that the entire reactor volume is maintained at the same temperature as the dosing volume. The excess equation becomes

$$
m_{\mathrm{exc}}=\left[\sum_{i=1}^{k} \rho_{1 i}-\rho_{3(i-1)}\right] V_{\mathrm{d}}-\left[\rho_{2 k}\left(V_{\mathrm{d}}+V_{\mathrm{r}}-V_{\mathrm{sk}}\right)\right]
$$

which is equivalent to $\mathrm{Eq}(7)$. Therefore, if one can accurately determine $V_{\mathrm{d}}, V_{\mathrm{r}}, V_{\mathrm{sk}}, f_{0}$, and $f$ then one can accurately determine excess adsorption at a desired temperature. The complete details regarding volume calibrations, fractional volume determinations, and helium pycnometry 


\section{Volume Determinations \& Quality of Measurements}

The formulation of the above excess equations was based on the assumption that all volumes were known. The process used to calibrate the dosing volume, reactor volume, and fractional volumes is outlined below. First, the dosing volume, reactor volume, and $f_{0}$ need to be determined. Assuming that neither the dosing nor reactor volumes are known, three sets of measurements are required:

1. A minimum of 15 individual doses with no sample

2. A minimum of 15 individual doses with a non-adsorbing sample of known volume (silicon beads; $\rho_{\mathrm{Si}}=2.3290 \mathrm{~g} / \mathrm{cm}^{3}$ )

3. A full isothermal sorption measurement at room temperature in which the reactor volume contains no sample

For the fifteen individual data points with no sample, one may again use conservation of particle number to construct the equation

$$
\rho_{1 e} V_{\mathrm{d}}=\rho_{2 e}\left(V_{\mathrm{d}}+V_{\mathrm{r}}\left(1-f_{0}\right)\right)+\rho_{2 e}^{\prime} V_{\mathrm{r}} f_{0}
$$

where the additional subscript "e" has been added to indicate measurements taken with no sample. For the five individual data points with non-adsorbing sample of known volume, conservation of particle number gives

$$
\rho_{1 s} V_{\mathrm{d}}=\rho_{2 s}\left(V_{\mathrm{d}}+V_{\mathrm{r}}\left(1-f_{0}\right)\right)+\rho_{2 s}^{\prime}\left(V_{\mathrm{r}} f_{0}-V_{\mathrm{disp}}\right)
$$

where the additional subscript "s" denotes measurements taken with a non-adsorbing displacer and where $V_{\text {disp }}$ is the volume of the displacer. Solving the system of Eqs. (12) and (13) gives the dosing and reactor volumes in terms of gas densities and the displacer volume.

$$
V_{\mathrm{r}}=\frac{\rho_{2 s}^{\prime}\left(\rho_{2 e}-\rho_{i e}\right) V_{\mathrm{disp}}}{\rho_{2 e} \rho_{1 s}-\rho_{2 s} \rho_{1 e}+f_{0}\left(\rho_{2 e} \rho_{2 s}^{\prime}+\rho_{2 s} \rho_{1 e}-\rho_{2 s} \rho_{1 e}-\rho_{2 e} \rho_{1 s}+\rho_{2 e}^{\prime}\left(\rho_{1 s}-\rho_{2 s}\right)\right)}
$$




$$
V_{\mathrm{d}}=\frac{\rho_{2 s}^{\prime}\left(\rho_{2 e}\left(f_{0}-1\right)-f_{0} \rho_{2 e}^{\prime}\right) V_{\mathrm{disp}}}{\rho_{2 e} \rho_{1 s}-\rho_{2 s} \rho_{1 e}+f_{0}\left(\rho_{2 e} \rho_{2 s}^{\prime}+\rho_{2 s} \rho_{1 e}-\rho_{2 s} \rho_{1 e}-\rho_{2 e} \rho_{1 s}+\rho_{2 e}^{\prime}\left(\rho_{1 s}-\rho_{2 s}\right)\right)}
$$

We start with $f_{0}=1$, we may decrease $f_{0}$ until the room temperature blank isotherm is minimized.

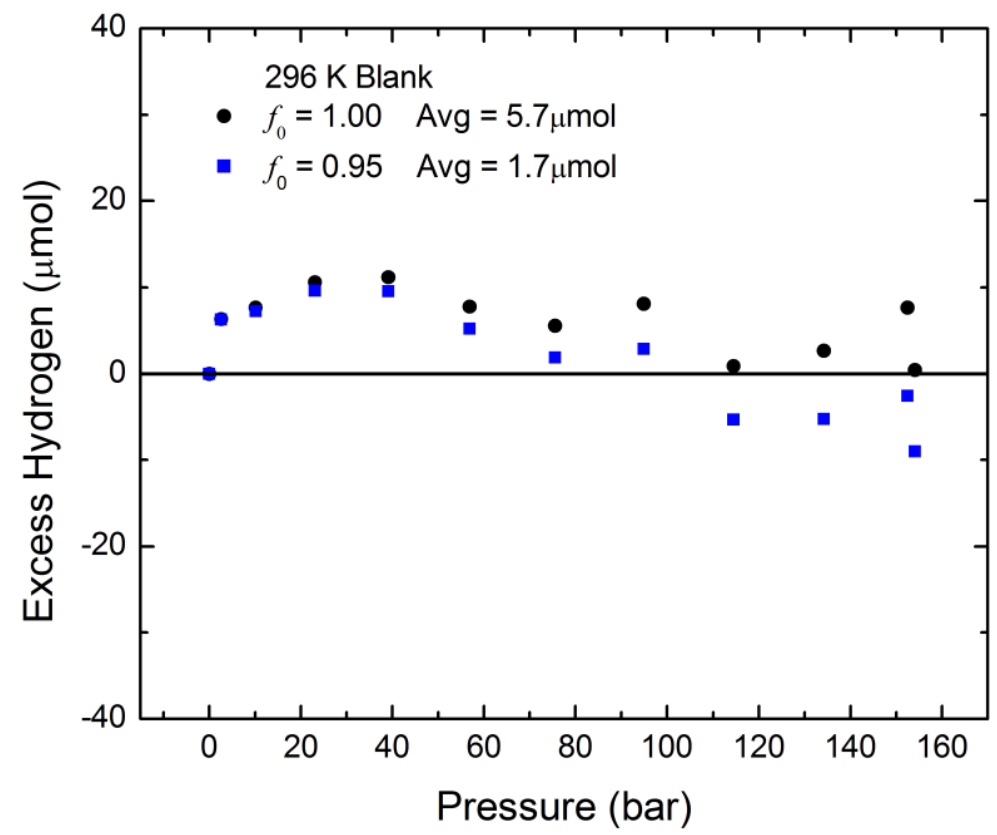

Figure 4. Blank isotherm at $296 \mathrm{~K}$ with $f_{0}=1$ and $f_{0}=0.95$. The fractional volume is decreased until the average departure from zero in the blank isotherm is minimized.

This volume fraction corresponds to $95 \%$ of the rector volume maintained at the same temperature as the laboratory environment and only $5 \%$ maintained at the same temperature as the dosing volume. This set of calibration measurements yielded a dosing volume of $V_{\mathrm{d}} \cong 5.08 \pm 0.02 \mathrm{~mL}$ and a reactor volume of $V_{\mathrm{r}} \cong 6.32 \pm 0.02 \mathrm{~mL}$. This blank has a maximum departure from zero excess of approximately $12 \mu \mathrm{mol}$, which is well below the tolerance of $100 \mu \mathrm{mol}$, proposed by the manufacturer ${ }^{[13]}$.

The above calibrations allow one to take isothermal measurements at the same temperature as the laboratory environment. In order to measure isotherms at alternate temperatures, additional volume fractions must be determined. The following procedure is used to determine the volume fraction for a setup using an isothermal bath. Cooling baths of liquid nitrogen or liquid argon evaporate as a function of time and, 
therefore, the thermal gradient also changes as a function of time. In order to determine the fractional volume one must use the following procedure:

1. Measure the pressure and temperature kinetics for a single data point for more than $100 \mathrm{~min}$.

2. Use the conservation of particle number to calculate the volume fraction as a function of time.

In general, the excess adsorption for the $k^{\text {th }}$ data point in a non-room temperature measure is given by Eq (9). For an empty sample cell $\left(m_{\mathrm{exc}}=0\right)$ the first data point $(k=1)$ may be expressed as

$$
m_{\mathrm{exc}}=\rho_{11} V_{\mathrm{d}}-\left[\rho_{21}\left(V_{\mathrm{d}}+V_{\mathrm{r}}\left(1-f_{0}\right)\right)+\rho_{21}^{\prime} V_{\mathrm{r}} f_{0}(1-f)+\rho_{21}^{\prime \prime} V_{\mathrm{r}} f_{0} f\right]
$$

For an empty sample cell $m_{\mathrm{exc}}=0$ and Eq. (16) can be solved for $f$.

$$
f(t)=\frac{\rho_{21}^{\prime} f_{0} V_{\mathrm{r}}-\rho_{11} V_{\mathrm{d}}+\rho_{21}\left(V_{\mathrm{d}}+V_{\mathrm{r}}-f_{0} V_{\mathrm{r}}\right)}{\left(\rho_{21}^{\prime}-\rho_{21}^{\prime \prime}\right) f_{0} V_{\mathrm{r}}}
$$

where the all mass densities are a function of time. The temperatures of the manifold, cooling bath, and laboratory environment are maintained and constant in time, but the pressure will vary due to the evaporation of the liquid cooling bath, which changes the fraction of submerged reactor volume.

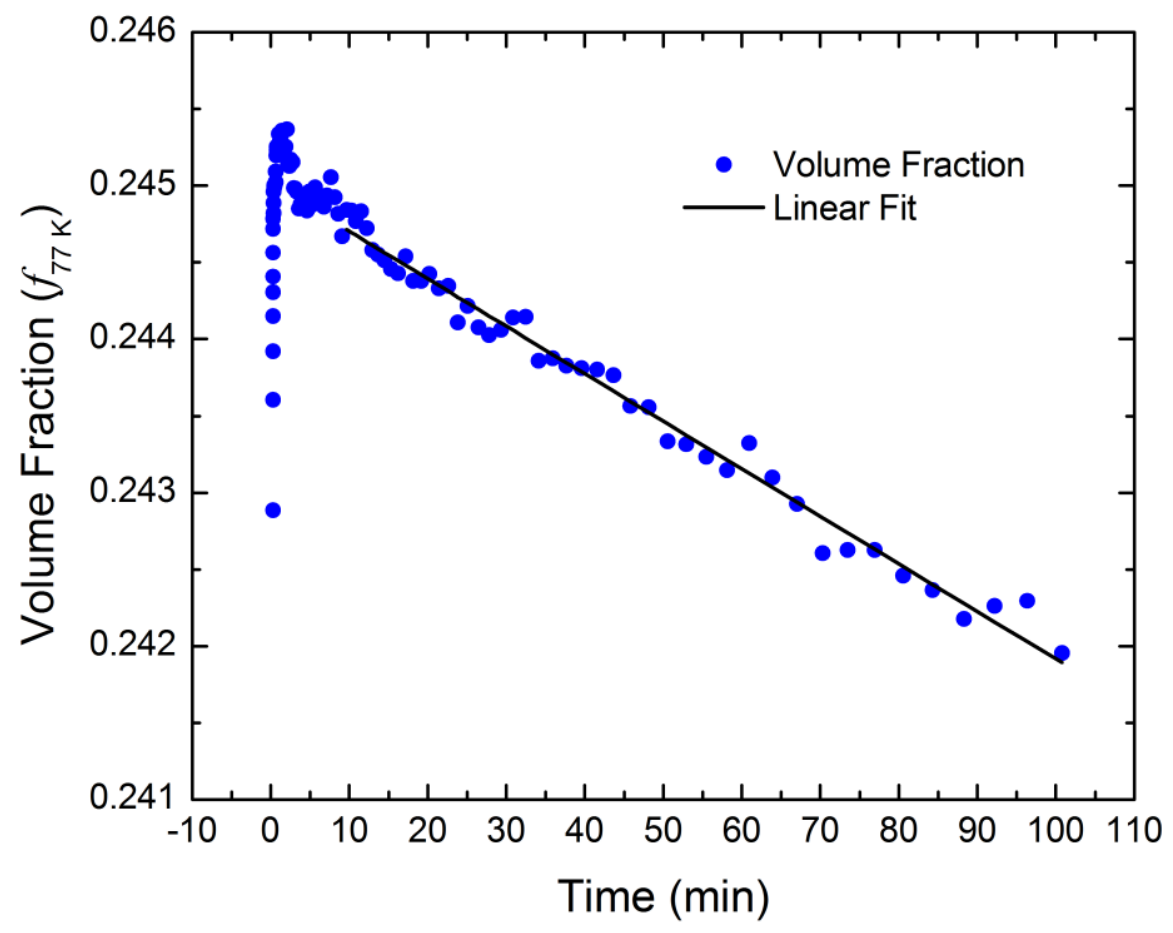

Figure 5. Volume fraction of the reactor volume maintained in the $77 \mathrm{~K}$ cooling bath. For a cooling bath of liquid nitrogen, approximately $24.5 \%$ of the reactor volume was maintained at $77 \mathrm{~K}$. 
The initial rise is due to the adsorbate gas equilibrating as it expands from the dosing volume and temperature into the reactor volume. Applying a linear fit to applicable fractional volume data yields the following relationship for $f(\mathrm{t})$

$$
f_{77 K}(t) \cong-3.1 * 10^{-5} t+0.245013
$$

where time is in minutes. By knowing the equilibration time allotted to each data point, one can use the corresponding fractional volume in Eq (9) to calculate excess adsorption. After all volumes and volume fractions have been determined, a blank isotherm should be measured to verify the quality of the calibration.

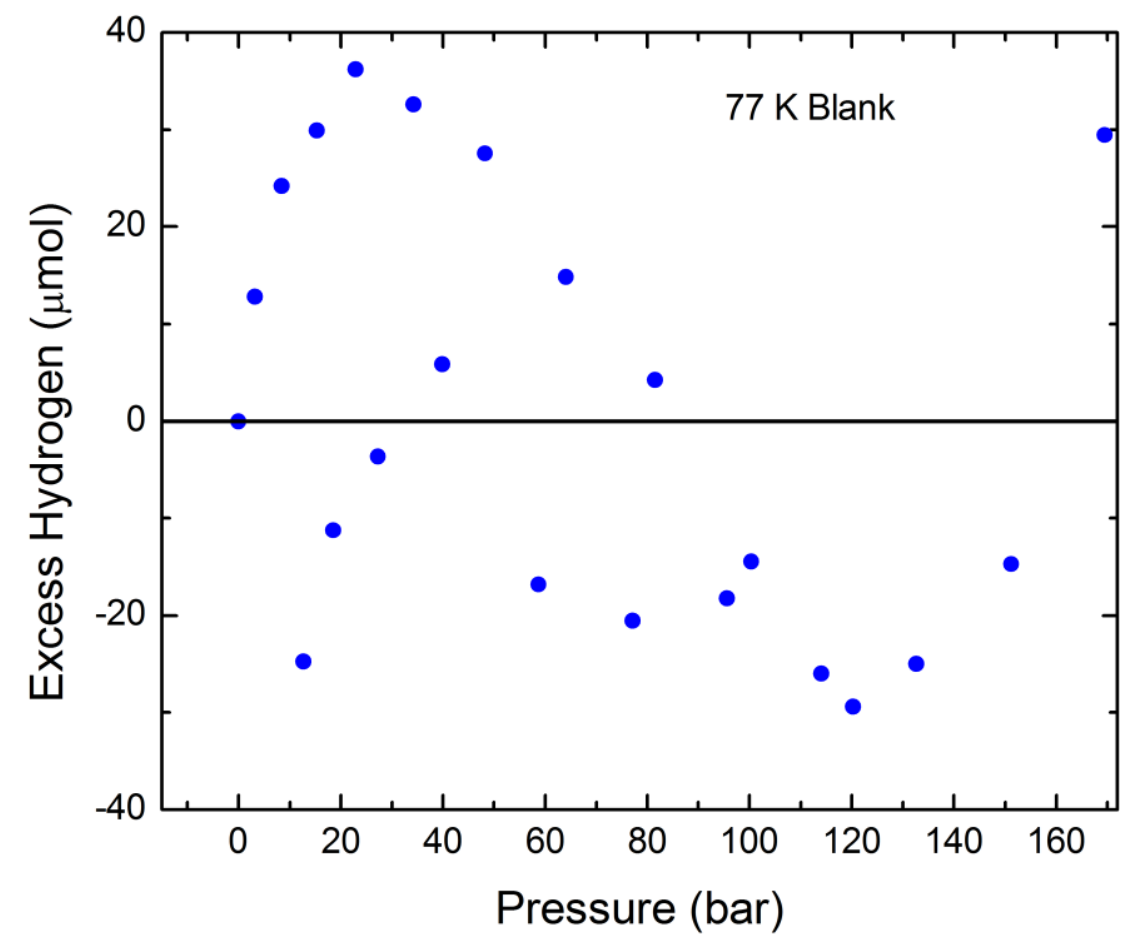

Figure 6. Blank isotherm measured at $77 \mathrm{~K}$ using the volume fraction from $\mathrm{Eq}(18)$.

The maximum departure from zero excess hydrogen is much larger at $77 \mathrm{~K}$ compared to the departure at $296 \mathrm{~K}$. However, it is still well within the suggested tolerance of $40 \mu \mathrm{mol}$ proposed by the manufacturer. It may serve as a figure of merit to display the difference between a gravimetric excess isotherm and the corresponding blank-subtracted isotherm for an arbitrary sample. 

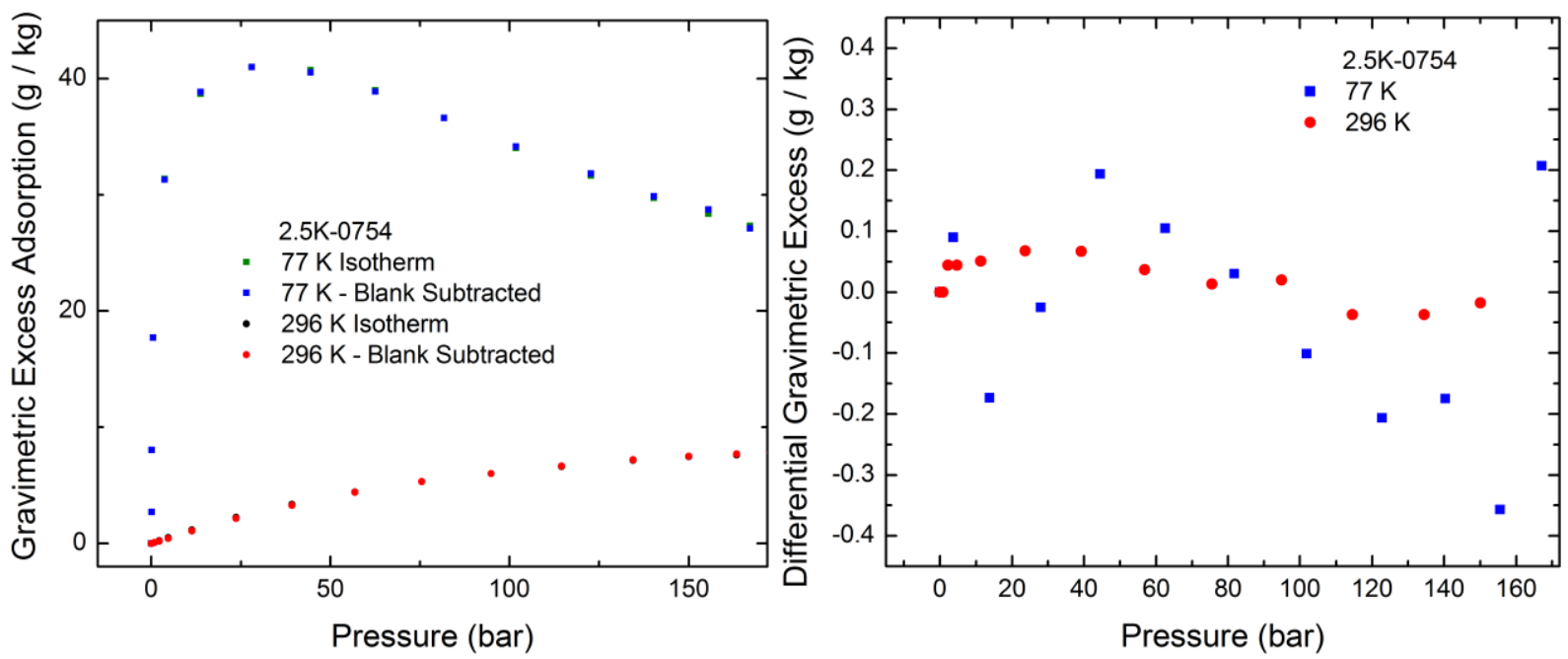

Figure 7. Differences in gravimetric excess measurements with and without blank-subtraction for sample 2.5K-0754. Left: Isotherms and corresponding blank subtracted isotherms at $296 \mathrm{~K}$ and $77 \mathrm{~K}$. Right: Differential gravimetric adsorption between isotherms and their corresponding blank subtracted isotherms at $296 \mathrm{~K}$ and $77 \mathrm{~K}$.

The gravimetric excess isotherm and corresponding blank-subtracted isotherms overlap one another. As long as the sample is adsorbs a large amount relative to the blank, subtracting the blank isotherm has little effect on the measured gravimetric excess. This holds true for all MU activated carbons.

\section{Pycnometry and Determining Sample Volume}

The last volume that remains unexplained from $\operatorname{Eq}(9)$ is the sample volume, $V_{\mathrm{s}}$. This may be determined by taking headspace measurements or by prior knowledge of the skeletal density. It is common practice to measure headspace by through helium pycnometry. However, these measurements are highly sensitive to uncertainties in dosing and reactor volumes. For this reason, helium pycnometry should be performed in a well-calibrated, voluminous reactor and on a large amount of the adsorbent sample.

The process used to determine headspace and sample volume is outlined below. Once the system is fully calibrated such that $V_{\mathrm{d}}, V_{\mathrm{r}}$, and $f_{0}$ are known, one can begin measuring the sample volume using a nonadsorbent gas, such as helium. Only one set of measurements is required:

1. A minimum of 15 individual data points using a non-adsorbing gas with a sample of unknown volume. 
One may again use conservation of particle number to construct the equation for sample volume

$$
\rho_{1 i} V_{\mathrm{d}}=\rho_{2 k}\left(V_{\mathrm{d}}+V_{\mathrm{r}}\left(1-f_{0}\right)\right)+\rho_{2 k}^{\prime}\left(V_{\mathrm{r}} f_{0}-V_{\mathrm{sk}}\right)
$$

Solving Eq(19) assuming zero excess yields

$$
V_{\mathrm{sk}}=V_{\mathrm{r}} f_{0}+\frac{1}{\rho_{2 k}^{\prime}}\left[\rho_{2 k}\left(V_{\mathrm{d}}+V_{\mathrm{r}}\left(1-f_{0}\right)\right)-\rho_{1 i} V_{\mathrm{d}}\right]
$$
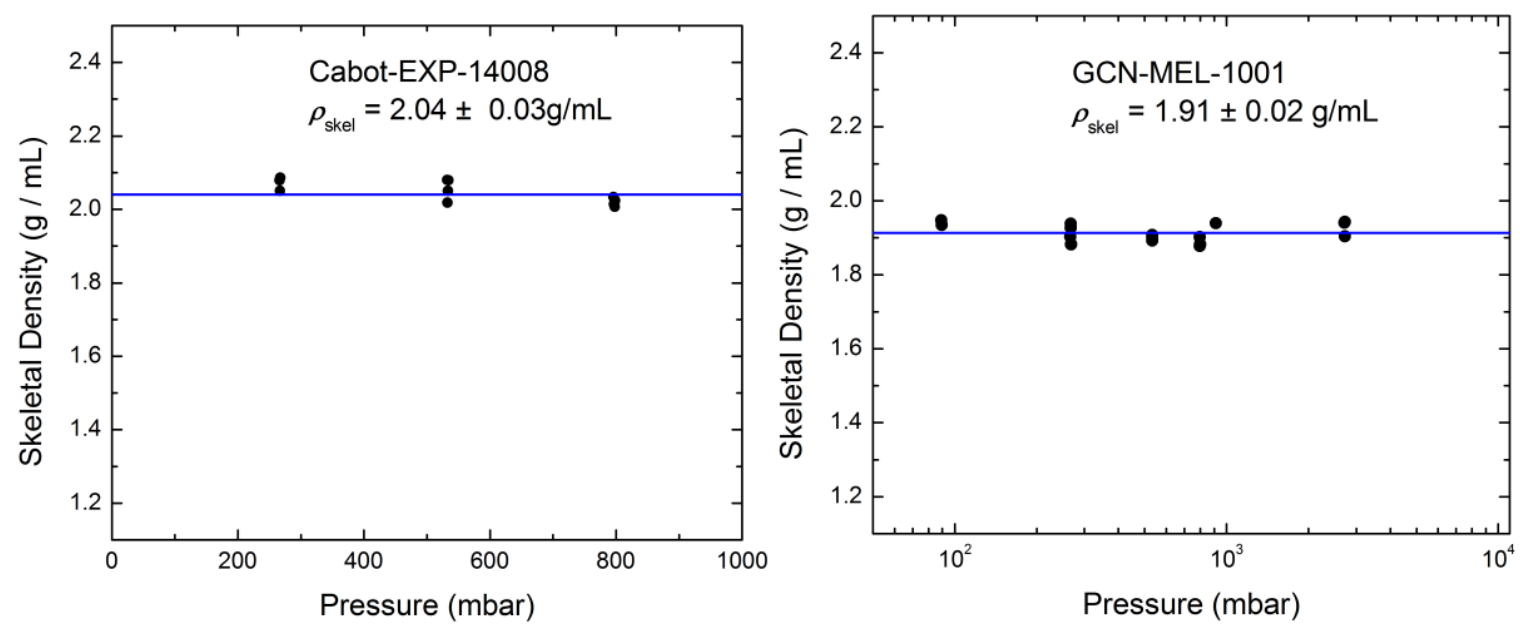

Figure 8. Skeletal density measurements for two adsorbent samples using helium pycnometry. Left: Skeletal density measurement of sample Cabot-EXP-14008. Right: Skeletal density measurement of sample GCN-MEL-1001 $\left(\rho_{\mathrm{sk}}=m_{\mathrm{sk}} / V_{\mathrm{sk}}\right)$.

This analysis was performed on $0.363 \mathrm{~g}$ of sample Cabot-EXP-14008 and $0.550 \mathrm{~g}$ of sample GCN-MEL-1001 in a dosing volume $V_{\mathrm{d}}=51.75 \pm 0.02 \mathrm{~mL}$ and a reactor volume $V_{\mathrm{r}}=6.32 \pm 0.02 \mathrm{~mL}$. The exhaustive nature of accurate helium pycnometry measurements, the typically small sample size of experimental adsorbent material, and the high throughput of adsorption measurements make it impractical to determine skeletal densities for all samples. For these reasons, we find it reasonable to determine the skeletal density of representative materials and apply it to all carbonaceous materials being screened. The majority of materials screened at MU are carbonaceous materials with skeletal densities of $\rho_{\mathrm{sk}}=2.04 \pm 0.04 \mathrm{~mL}$. Occasionally, alternate materials were screened, such as graphitic carbon nitride and various metal organic frameworks. 


\subsection{Gravimetric and Volumetric Storage Capacity}

Once gravimetric excess has been accurately determined, it can be used with porosity measurements to calculate other useful engineering metrics such as storage capacity. The gravimetric storage capacity, $G_{\text {st }}$, is defined as the total mass of adsorbate gas in the system per mass of sample and is calculated by

$$
G_{\mathrm{st}}=\frac{m_{\mathrm{st}}}{m_{\mathrm{s}}}=\frac{m_{\mathrm{exc}}}{m_{\mathrm{s}}}+\frac{\rho_{\mathrm{gas}}}{m_{\mathrm{s}}} V_{\mathrm{void}}
$$

where $m_{\text {exc }}$ is the excess adsorption, $\rho_{\text {gas }}$ is the compressed adsorbate density, and $V_{\text {void }}$ is the total void volume of the system and equivalent to the total volume available to the adsorbate gas. It is often convenient to define gravimetric storage capacity in terms of the porosity of the system. Porosity, $\phi$, is defined as the ratio of the void space to the volume of the entire system.

$$
\phi=\frac{V_{\text {void }}}{V_{\text {system }}}
$$

However, the definitions of these volumes depend on whether we are referring to envelope (crystalline) porosity or tank (bed) porosity. Crystalline porosity is defined as the amount of open pore volume normalized to the total system volume.

$$
\phi_{\text {envelope }}=\frac{V_{\text {pore }}}{V_{\text {system }}}=\frac{V_{\text {pore }}}{V_{\text {pore }}+V_{\text {sk }}},
$$

where $V_{\mathrm{sk}}$ and $V_{\text {pore }}$ are the skeletal volume and the open pore volume of the adsorbent material, respectively. It is important to note that crystalline porosity excludes gas stored between individual grains. 

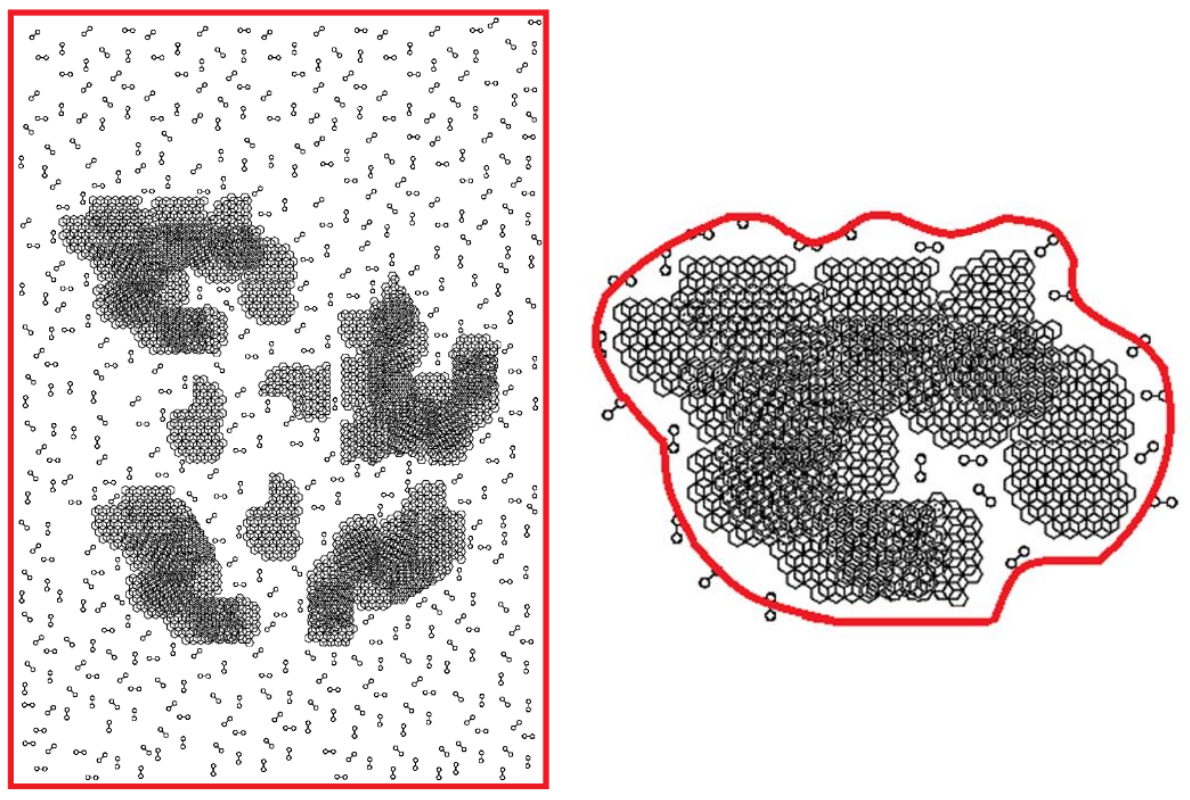

Figure 9. System volumes used in defining porosity. Left: System volume for a tank containing adsorbate gas and adsorbent material. The total volume of this system includes the skeletal volume of the material, the pore volume of the material, and the intergranular void space. Right: Volume of a single crystal of carbonaceous material. This system includes the skeletal volume of the material and the pore volume of the material

Tank porosity is defined as the amount of pore volume and intergranular space normalized to the system volume

$$
\phi_{\text {tank }}=\frac{V_{\text {void }}}{V_{\text {system }}}=\frac{V_{\text {pore }}+V_{\text {inter granular }}}{V_{\text {pore }}+V_{\text {sk }}+V_{\text {inter granular }}},
$$

where $V_{\text {inter granular }}$ is defined as the void space between the individual grains of adsorbent material ${ }^{[14]}$. The crystalline or envelope porosity will be referenced simply as "porosity" throughout the rest of this document and tank porosity will not be discussed unless mentioned specifically. The gravimetric storage capacity may be rewritten in terms of the porosity

$$
\frac{m_{\mathrm{st}}}{m_{\mathrm{s}}}=\frac{m_{\mathrm{exc}}}{m_{\mathrm{s}}}+\frac{\rho_{\mathrm{gas}}}{\rho_{\mathrm{sk}}}\left(\phi^{-1}-1\right)^{-1},
$$

where $\rho_{\mathrm{sk}}$ is the skeletal density of the adsorbent material. The volumetric storage capacity is defined as the total amount of adsorbate gas in the system normalized to the volume of the system. Since the total mass 
of gas stored in the system is the same as in the calculation for gravimetric storage capacity, one only needs to multiply by the density of the system to convert to volumetric storage capacity. Therefore, volumetric storage capacity can be calculated by ${ }^{[15]}$

$$
V_{\text {st }}=\frac{m_{\mathrm{st}}}{m_{\mathrm{s}}} \rho_{\text {system }}=\frac{m_{\mathrm{exc}}}{m_{\mathrm{s}}} \rho_{\mathrm{sk}}(1-\phi)+\rho_{\mathrm{gas}} \phi,
$$

In order to compare material performance, $m_{\mathrm{exc}}, m_{\mathrm{st}}$, and $V_{\mathrm{st}}$ are all either normalized to the sample mass or volume.

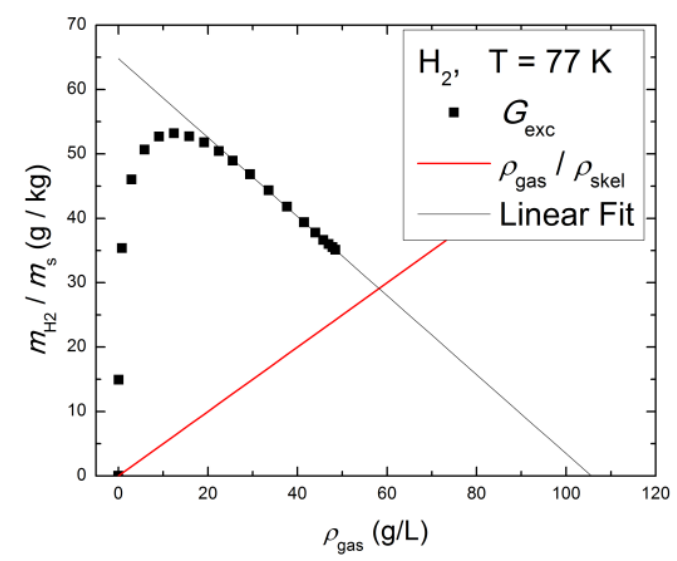

Figure 10. Excess adsorption versus compressed gas density.

Adsorption outperforms compression only when the volumetric storage capacity is greater than that of the compressed gas. Rearranging Eq (26) automatically requires this to occur if the gravimetric excess adsorption is greater than the ratio of the compressed gas density to the skeletal density of the adsorbent material.

$$
\frac{V_{\mathrm{st}}}{\rho_{\mathrm{gas}}}>1 \leftrightarrow \frac{m_{\mathrm{exc}}}{m_{\mathrm{s}}}>\frac{\rho_{\mathrm{gas}}}{\rho_{\mathrm{sk}}}
$$

Therefore, adsorption beats compression at low pressures when $\rho_{\text {film }}>\rho_{\text {gas }}$. Compression only performs better than adsorption at high pressures when it would be advantageous to replace the skeletal volume of the material with dense compressed gas. Interestingly, this condition is independent upon the porosity even though volumetric storage capacity is dependent upon porosity. Thus, all volumetric storage 
capacity curves for materials with identical excess adsorption, but different porosities must intersect at the same pressure. For hydrogen adsorption at $77 \mathrm{~K}$, this intersection pressure occurs above 300 bar.

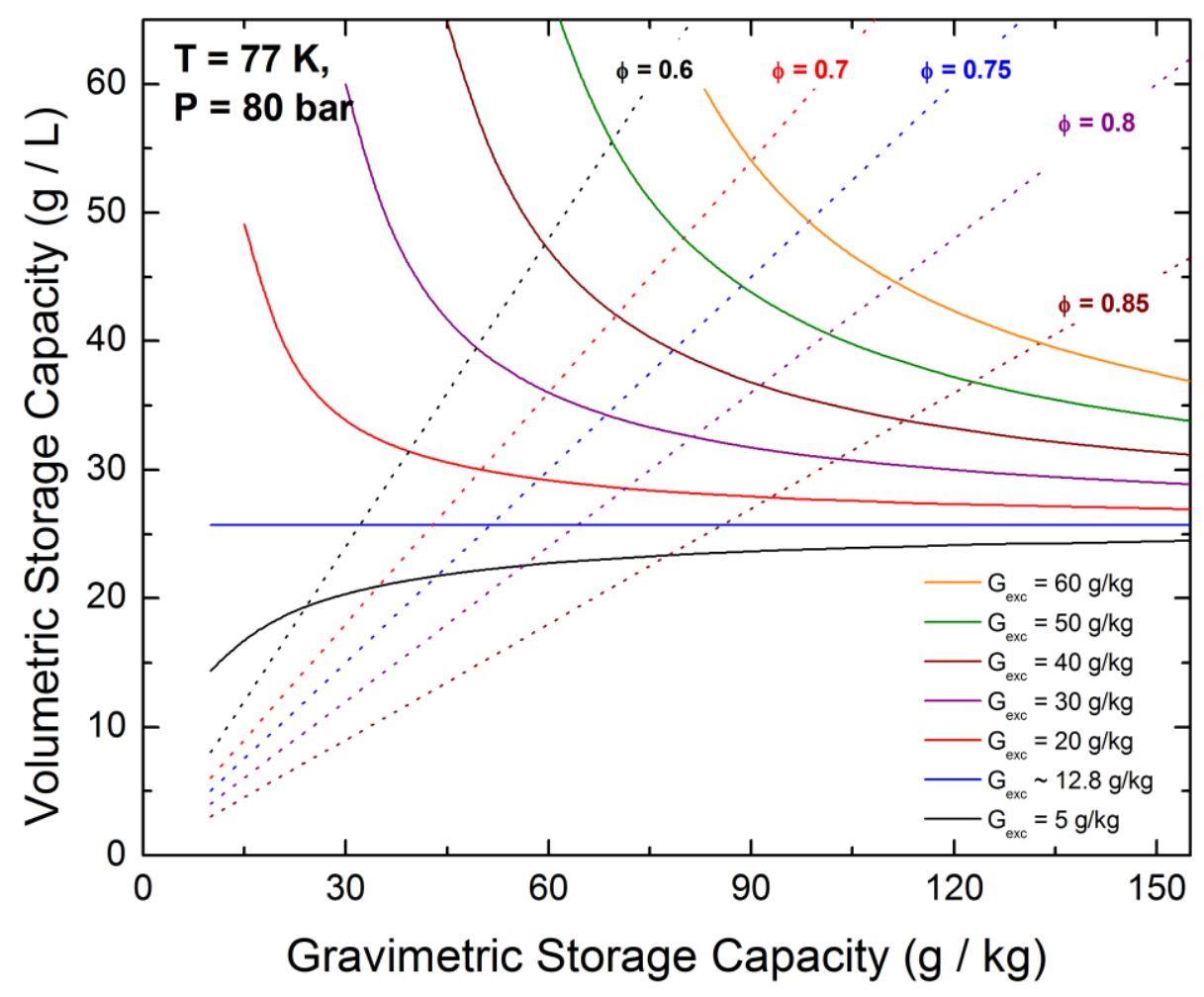

Figure 11. Relations between volumetric and gravimetric storage capacities. Volumetric and gravimetric storage capacity are related through several factors including porosity and excess adsorption. This plot was developed to represent the possible variance in storage capacities for activated carbon samples that have a typical skeletal density of $2.0 \mathrm{~g} / \mathrm{mL}$

Compressed gas has a volumetric storage capacity of approximately $25.7 \mathrm{~g} / \mathrm{L}$ at $77 \mathrm{~K}$ and 80 bar. Adsorbent samples occupy a volume, thus displacing compressed gas. Therefore, a sample with a skeletal density of $2.0 \mathrm{~g} / \mathrm{L}$ would need to have an excess adsorption exceeding $12.8 \mathrm{~g} / \mathrm{kg}$ at this temperature and pressure in order to outperform compressed gas. If this condition is met then the volumetric storage capacity will be higher when using the sorbent material compared to simply compressing the gas in the absence of the adsorbent material. For a fixed excess adsorption, the gravimetric storage capacity increases with porosity and volumetric storage decreases. This is because there is more void space within an individual adsorbent crystal that may be occupied by compressed gas in the non-adsorbed state. A sample with a porosity near 1.00 will have a volumetric storage capacity that approaches that of compressed gas. For a 
given porosity, the storage capacities may also vary from sample to sample due to higher specific surface area or binding energy. An increase in BET surface area or an increased isosteric heat should result in an increased excess adsorption.

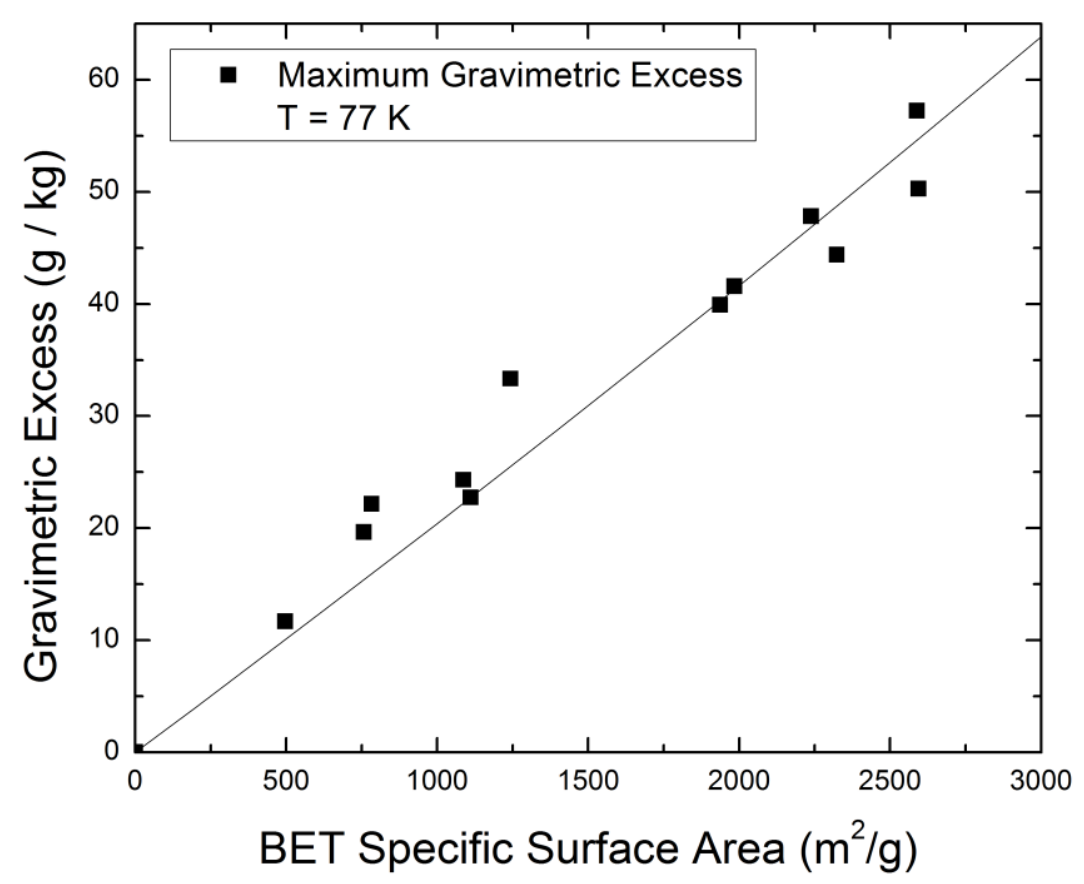

Figure 12. Relationship between gravimetric excess and BET specific surface area. This plot was developed using the maximum gravimetric excess adsorption at $77 \mathrm{~K}$.

It is well known that gravimetric excess tends to increase linearly with surface area. For most adsorbents, the maximum gravimetric excess at $77 \mathrm{~K}$ increases by $2 \mathrm{wt} \%$ per $1000 \mathrm{~m}^{2} / \mathrm{g}$ of BET specific surface area. If one can increase the surface area without changing the porosity, the volumetric and gravimetric storage capacities should also increase. Most methods of increasing the BET specific surface area also increase the porosity by expanding the pore volume of the sample. Therefore, an increase the gravimetric excess does not automatically generate increased volumetric and gravimetric storage capacities. Another method of generating increased storage capacities is to change the surface chemistry of the material such that it increases the strength of the adsorption potential. If one can accomplish chemical doping without significantly altering the pore structure, then the one should be able to tune the volumetric and gravimetric storage capacities without altering the BET specific surface area. 


\subsection{Absolute Adsorption and Differential Enthalpy}

Adsorption scientists often invest significant effort toward estimating the differential enthalpy of adsorption. This metric has often been used to screen the performance of adsorbent materials because a high enthalpy of adsorption indicates a high adsorbed film capacity. However, too high of an enthalpy will result in a lower deliverable storage capacity. It is therefore desirable to search for an adsorbent material with the optimal enthalpy of adsorption, which has been proposed to exist between $10-20 \mathrm{~kJ} / \mathrm{mol}^{[16,17]}$. The differential enthalpy of adsorption is commonly calculated by applying the Clausius Clapeyron relation to isothermal data collected at two different temperatures or by constructing a Van't Hoff plot from isothermal data collected at multiple temperatures. The Clausius-Clapeyron relation is given by

$$
\left|\Delta H_{\Theta}\right|=R \frac{T_{1} T_{2}}{T_{2}-T_{1}} \ln \left(\frac{P_{2}}{P_{1}}\right),
$$

where $\Delta H$ is the differential enthalpy of adsorption, the absolute value is the isosteric heat of adsorption, the indices correspond to conditions present in the isotherms taken at two or more temperatures. $T_{1}$ and $T_{2}$ are the temperatures at which the two adsorption measurements were taken and $P_{1}$ and $P_{2}$ are the pressures

at which a constant number of particles exists in the adsorbed phase ${ }^{[10]}$. Differential enthalpy of adsorption takes a negative value because adsorption is an exothermic process. The absolute value of the differential enthalpy is often referred to as the isosteric heat of adsorption. In order to calculate the isosteric heat, a constant number of molecules must be present in the relevant system. As the temperature is decreased, adsorbed molecules experience less thermal perturbation and the adsorbing potentials are more highly attractive. Therefore, a lower pressure is necessary in order for an equal number of molecules to be present in the adsorbed film. Though excess adsorption is the only experimental parameter that may be directly measured, it must be converted into absolute adsorption in order to analyze a system with a constant number of molecules. Absolute adsorption is different from gravimetric storage capacity because it only includes gas molecules that are in the adsorbed phase and does not include gas molecules that are in the bulk phase. The absolute adsorption is defined as the total mass of adsorbate gas in the adsorbed film per mass of sample and is calculated by 


$$
\frac{m_{\mathrm{abs}}}{m_{\mathrm{s}}}=\frac{m_{\mathrm{exc}}}{m_{\mathrm{s}}}+\frac{\rho_{\mathrm{gas}}}{m_{\mathrm{s}}} V_{\mathrm{film}}
$$

where $m_{\mathrm{exc}}$ is the absolute adsorption, $m_{\mathrm{exc}}$ is the excess adsorption, $\rho_{\text {gas }}$ is the compressed density, and $V_{\text {film }}$ is the specific film volume of the material. It is necessary to determine the volume that the adsorbed phase occupies. However, the task of experimentally determining the adsorbed film volume is not trivial. Hence, researchers commonly use the total pore volume as a rough estimate of the specific film volume which can be easily determined from a subcritical nitrogen isotherm. When employing this estimate, the absolute adsorption is equivalent to the gravimetric storage capacity.

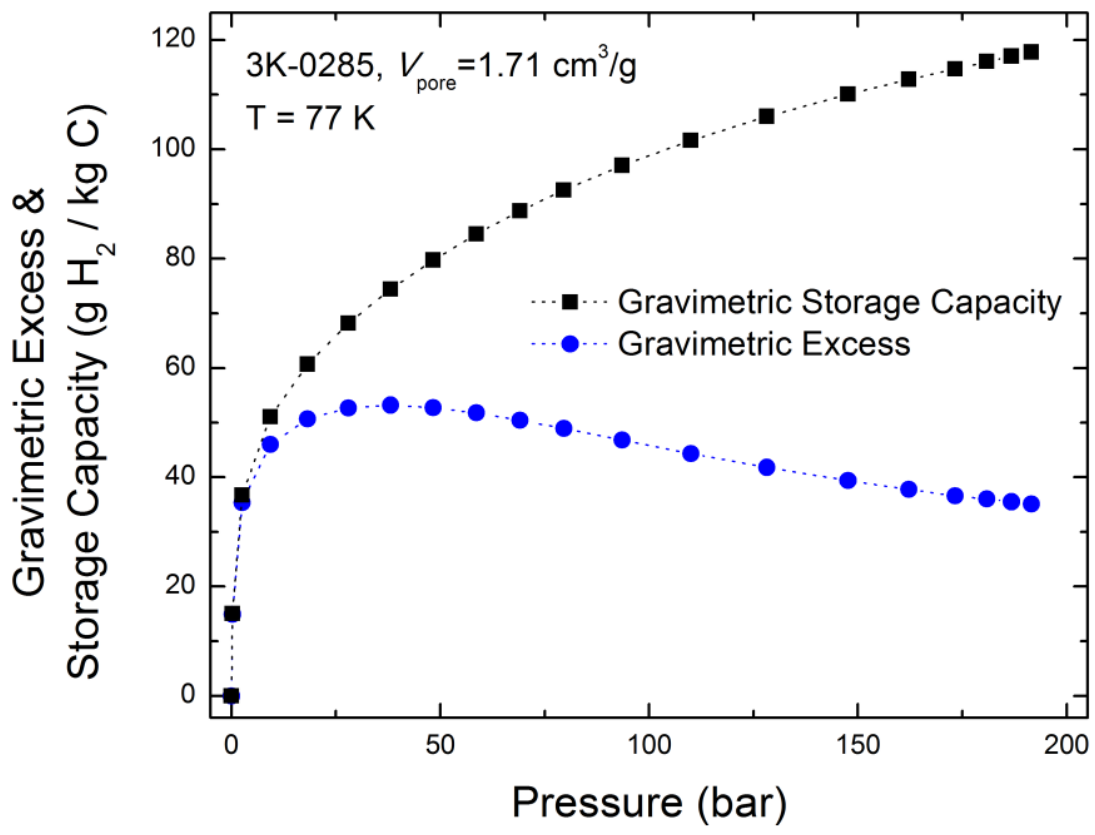

Figure 13. Gravimetric excess and gravimetric storage capacity of sample $3 \mathrm{~K}-0285$ at $77 \mathrm{~K}$. The total pore volume for sample $3 \mathrm{~K}-0285$ was determined to be $1.705 \mathrm{~cm}^{3} / \mathrm{g}$ from a subcritical nitrogen isotherm.

The effect of adding the compressed gas to the excess adsorption is greatest at low temperatures and high pressures where the gas density is greatest. Once excess adsorption is converted into absolute adsorption, the data can be fit with an appropriate model and interpolated to calculate differential enthalpy of adsorption. Different models will yield different interpolated values between experimental data and will thus give rise to slightly different isosteric heat values at low coverage. However, the quality of fit to the experimental data should be the primary consideration in choosing an appropriate model when calculating 
isosteric heats. For the purpose of this document, all absolute adsorption isotherms were interpolated using the Modified Redlich-Peterson Model due to its high quality of fit to experimental data (typical $\mathrm{R}^{2}$ values exceed 0.9999).
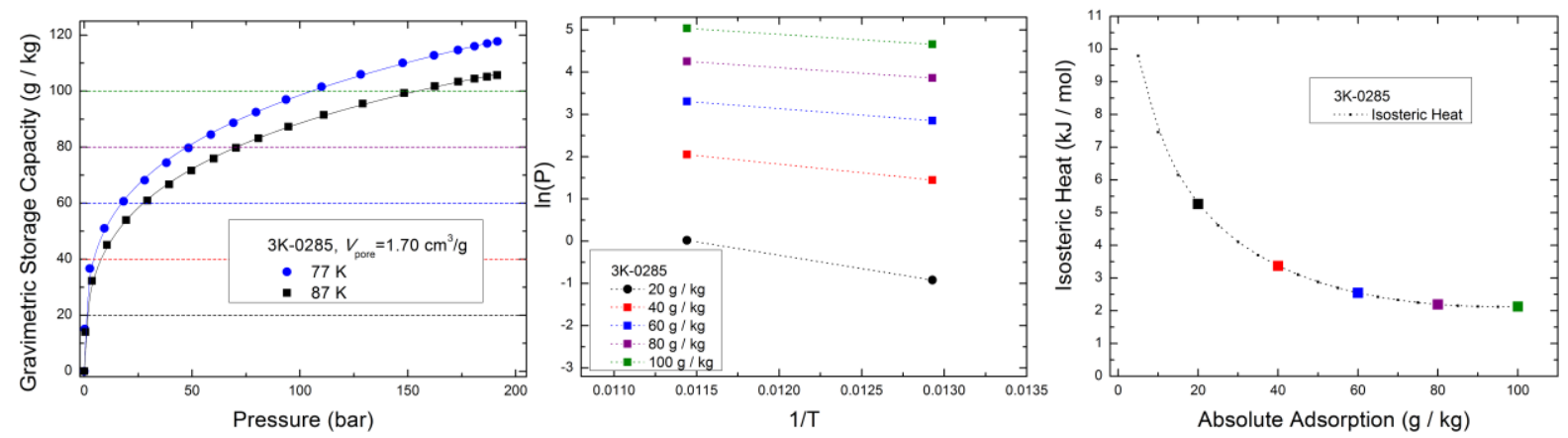

Figure 14. Storage capacity, Van't Hoff plot, and calculated isosteric heat for sample 3K-0285. Left: Interpolation of experimental data using the Modified Redlich-Peterson Model. Middle: Van't Hoff plot with lines indicating constant particle number. The derivative of the Van't Hoff plot are directly proportional to the isosteric heat. Right: Calculated isosteric heat of adsorption as a function of coverage.

As the name suggests, the Modified Redlich-Peterson Model is an altered version of the RedlichPeterson Model. The Redlich-Peterson Model is expressed as

$$
\frac{m_{\mathrm{abs}}(p, T)}{m_{\mathrm{s}}}=\frac{a p}{1+b p^{c}}
$$

where $\mathrm{a}, \mathrm{b}$, and $\mathrm{c}$ are empirical constants. This model obeys Henry's Law in the low pressure limit, but requires numeric approximation methods in order to interpolate between experimental data ${ }^{[18]}$. The Modified Redlich-Peterson Model is expressed as

$$
\frac{m_{\mathrm{abs}}(p, T)}{m_{\mathrm{s}}}=\frac{a(b p)^{1-c}}{1+(b p)^{1-c}}
$$

where $a, b$, and $c$ are empirical constants. This model does not satisfy Henry's Law. However, it offers advantages over the Redlich-Peterson model because it allows for pressure to be calculated analytically without employing numeric methods. Once the fitting parameters have been determined for all isothermal data, one may determine $P_{1}$ and $P_{2}$ analytically and apply Eq (28) to calculate the isosteric heat for any arbitrary absolute adsorption value. For this particular sample, the differential enthalpy of adsorption 
changes with coverage due to heterogeneities in the surface geometry. Most activated carbon samples are highly amorphous with overlapping Van der Waals interactions from pore walls in close proximity to one another. These high binding energy sites are filled at first at low pressures leaving lower binding energy sites to be filled at higher pressures.

This method of estimating isosteric heats is most sensitive to the choice of adsorbed film volume and the appropriateness of the model used to fit experimental data. Since materials research funding is often awarded based on claims of optimal isosteric heats, it is paramount to determine the volume of the adsorbed film for accurate estimations of the isosteric heat. First, let's pose a question: How significant is the choice of film volume in determining isosteric heat?
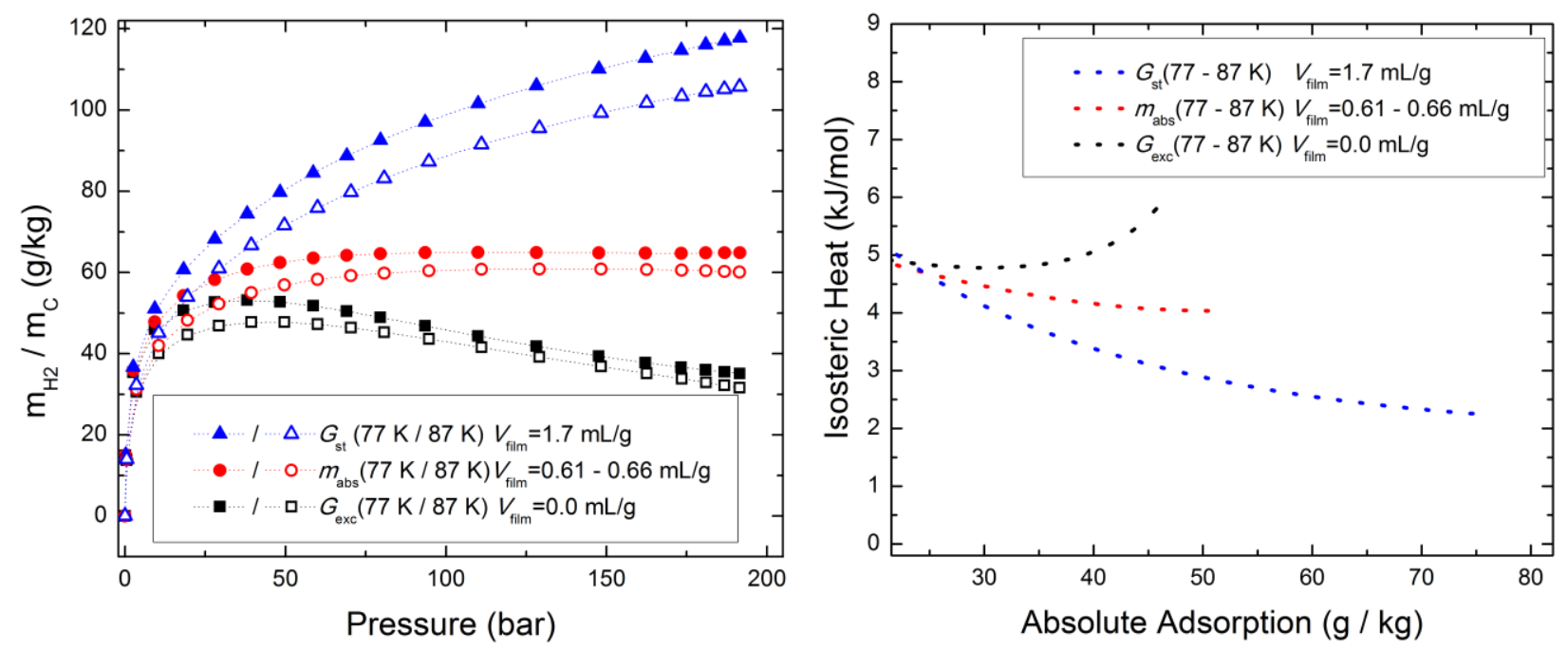

Figure 15. Absolute adsorption isotherms and resulting isosteric heats. Left: Absolute adsorption isotherms converted from excess adsorption using Eq (29) with varied adsorbed film volumes. Right: Calculated isosteric heats of adsorption resulting from the varied adsorbed film volumes.

The compressed gas density is relatively low at pressures less than 5 bar. Therefore, adding the compressed gas to the excess has little effect on the calculated absolute adsorption and resulting isosteric heats at low pressure. However, the compressed gas becomes significant at pressures exceeding 10 bar where the resulting isosteric heat of adsorption for hydrogen varies by $3 \mathrm{~kJ} / \mathrm{mol}$ depending on the chosen film volume. This difference can be as high as $5 \mathrm{~kJ} / \mathrm{mol}$ for methane. It is necessary that the isosteric heat of adsorption either remain constant or decrease with increasing pressure. Adsorbed molecules will be 
more probable to occupy the highest binding energy sites available. As the adsorbed layer continues to fill, lower energy sites will become occupied. Therefore, any rise in isosteric heat with increasing pressure is unphysical during monolayer adsorption. If one assumes too low of an adsorbed film volume, an unphysical rise will be observed in the calculated isosteric heat. If one assumes too high of an adsorbed film, the resulting isosteric heat will be too low at high coverages. Though one could use the two limits as upper and lower bounds for the heat of adsorption, the uncertainty between these two methods may be insufficient to yield an accurate estimate. This can cause major problems with thermal management if engineering storage tank properties based on such heat of adsorption calculations.

Since the operating pressures of an on-board storage tank will most certainly exceed 10 bar in order to meet energy density requirements, it is necessary to determine the isosteric heat of adsorption more accurately at high gas densities. In order to do so, we must establish a method of determining a more accurate adsorbed film volumes. It would be optimal if the adsorbed film volume could be calculated from directly measureable quantities. As previously stated, the only storage metric that can be directly measured without theoretical assumptions is the excess adsorption. It is often more useful to discuss an alternate version of Eq (5) which provides more insight into the physical properties of the adsorbed film. In terms of adsorbed film volume and gas density, the equation for Gibbs excess adsorption is given by

$$
m_{\mathrm{exc}}=\int_{V_{\mathrm{ads}}}\left(\rho_{\mathrm{ads}}-\rho_{\mathrm{gas}}\right) d V
$$

where $V_{\text {ads }}$, is the adsorbed film volume, $\rho_{\text {ads }}$ is the density of the adsorbed film, and $\rho_{\text {gas }}$ is the bulk gas density. Most cryogenic excess adsorption isotherms exhibit a linear regime at high pressures. This behavior arises when the monolayer reaches saturation and insignificant adsorption is observed in the higher layers with increasing bulk gas density. Once the adsorbed film reaches saturation, $V_{\text {ads }}$ and $\rho_{\text {ads }}$ become constant with increasing bulk gas density. 


$$
m_{\mathrm{film}, \mathrm{sat}}=\int_{V_{\mathrm{ads}}} \rho_{\mathrm{ads}} d V=\text { const. }
$$

Alternately,

$$
m_{\mathrm{exc}}=m_{\mathrm{film}, \mathrm{sat}}-\int_{V_{\mathrm{ads}}}\left(\rho_{\mathrm{gas}}\right) d V
$$

and

$$
\frac{\partial\left(\frac{m_{\mathrm{exc}}}{m_{\mathrm{s}}}\right)}{\partial\left(\rho_{\mathrm{gas}}\right)}=-V_{\mathrm{film}, \mathrm{sat}}
$$

Therefore, the equation becomes linear with increasing gas density with a negative slope. The magnitude of the slope is equal to the saturated, adsorbed film volume and the constant is equal to the monolayer capacity. In addition to yielding the saturated, adsorbed film volume, monolayer capacity, and film density, one may also determine an approximate film thickness of the saturated, adsorbed film.

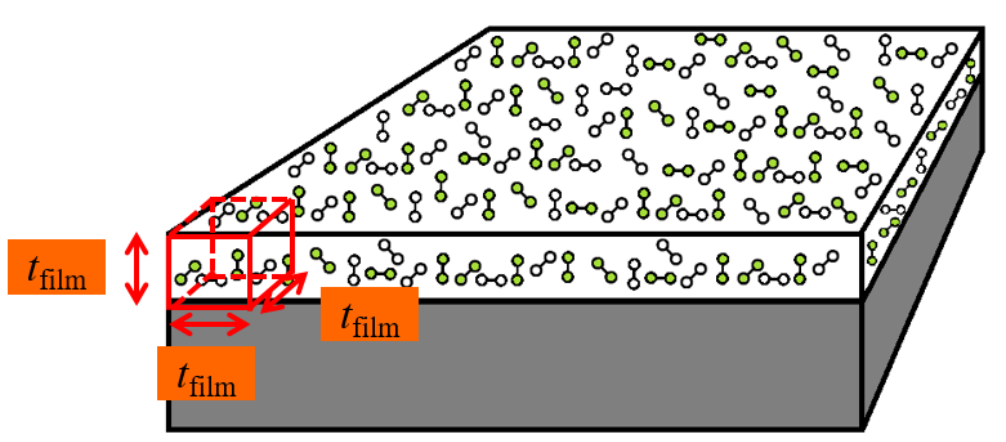

Figure 16. Depiction of a slab-like adsorbed film. In the high gas density limit, the adsorbed film saturates and maintains a constant volume. adsorption isotherms converted from excess adsorption using

Traditionally, the size of adsorbate molecules (footprint area and monolayer thickness) is determined from the bulk liquid density of adsorbate and the packing geometry of adsorbed molecules, treated as spheres, in monolayer. Here, the monolayer thickness, $t_{\text {film, }}$, has been determined from the saturated film density, $\rho_{\text {film,sat, }}$ without packing assumptions. 
Consider a slab of liquid with a footprint area $\sigma$ and a basal area $A$ and number density $N_{\text {liq. }}$ Decomposing the slab into layers equal to the monolayer thickness, $t_{\mathrm{o}}$, yields

$$
\begin{aligned}
& N_{\text {liq }}=\frac{\text { number of molecules in the slab }}{\text { volume of slab }} \\
& =\frac{\text { number of monolayers in the slab } * \text { number of molecules in a monolayer }}{\text { number of monolayers in the slab } * \text { volume of a monolayerslab }} \\
& =\frac{\text { number of molecules in a monolayer }}{\text { volume of a monolayer }} \\
& =\frac{\frac{A}{\sigma}}{A * t_{0}}=\frac{1}{\sigma * t_{0}}
\end{aligned}
$$

In the case of an isotropic molecule Eq 36 simplifies and the film thickness can be calculated.

$$
N_{\text {liq }}=\frac{1}{t_{0}^{3}}
$$

Therefore,

$$
t_{\text {film } \rho}=t_{0}=\left(\frac{\rho_{\text {sat. film }} * \mathrm{~N}_{\mathrm{A}}}{M}\right)^{-\frac{1}{3}}
$$

The validity of this decomposition of the slab into monolayers is dependent upon the film being fully saturated and the adsorbed $\mathrm{H}_{2}$ density staying constant throughout the slab. 


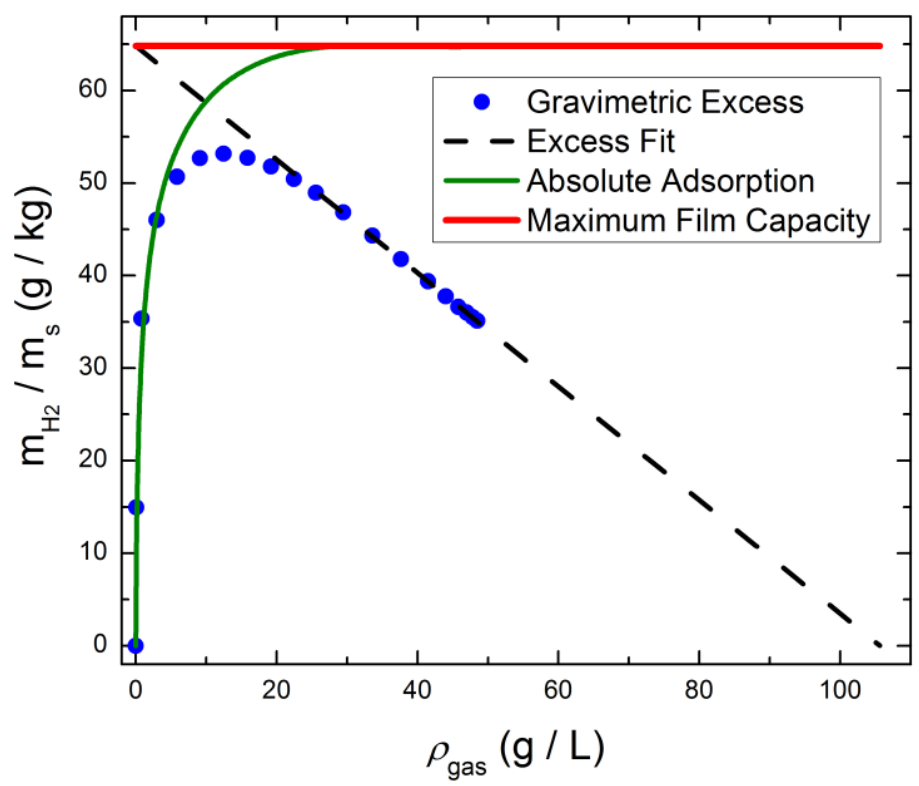

Figure 17. Gravimetric and absolute adsorption for sample $3 \mathrm{~K}-0285$ measured at $77 \mathrm{~K}$. A linear fit was applied to the high density linear regime. The slope and intercepts hold physical significance for the volume, density and capacity of the adsorbed film.

For this linear fit, the vertical intercept was $64.8 \mathrm{~g} / \mathrm{kg}$, corresponding to the maximum adsorbed film capacity at $77 \mathrm{~K}$. The slope is -0.614 , corresponding to $V_{\text {film,sat }}=0.614 \mathrm{~cm}^{3} / \mathrm{g}$. This is only $36 \%$ of the total pore volume $\left(V_{\text {pore }}=1.705 \mathrm{~cm}^{3} / \mathrm{g}\right)$ for this sample. When modelling the adsorbed film at pressures below the saturation pressure, it is important to remember that the chosen film volume must be sufficient to saturate at high pressures, but must not exceed the maximum film capacity. Observing from Fig 14, the adsorbed film volume determined here is sufficiently large to result in a saturated adsorbed film at high pressures in the $77 \mathrm{~K}$ isotherm. Therefore, $0.614 \mathrm{~cm} 3 / \mathrm{g}$ is the appropriate choice of a saturated film volume for this sample at $77 \mathrm{~K}$.

This only describes the volume of the film after saturation. So it may be necessary to model the adsorbed film volume at lower gas densities where the adsorbed layer is still building. Though this film volume may only be applicable to high pressures, it serves as a more reasonable estimate of the adsorbed film volume. To prove that this film volume is sufficient at all pressures, review the structure of Eq 28. If the bulk gas density becomes sufficiently low, its contribution to the calculated absolute adsorption becomes insignificant relative to the gravimetric excess. Therefore, any choice of adsorbed film volume 
$\left(0<V_{\text {film }}<V_{\text {pore }}\right)$ will yield an absolute adsorption that is approximately equal to the excess adsorption in the low pressure limit. Additionally, this will yield calculated values from Eq. 28 that converge upon the isoexcess solution in the low pressure limit, which can be seen graphically in Fig 15 .

\subsection{Alternate Methods to Obtain Parameters of the Absorbed Film}

The adsorbed film volume can easily be approximated by applying a simple linear fit to the high density regime of the excess adsorption isotherm. However, if no sufficient linear regime exists in the excess adsorption isotherm, then the linear model will be highly dependent upon the number of experimental data points used. Alternately to the linear model, one could obtain the parameters of the adsorbed film by applying a density-dependent adsorption model to the high gas density regimes of the excess adsorption isotherm. There are several models for how adsorption changes with pressure, temperature, binding energy, and surface areas. Some models more accurately describe physical phenomena in the low gas density regime whereas others better explain phenomena in the high gas density regimes. For example, the Langmuir, Redlich-Peterson, and Modified Redlich-Peterson models are continuously rising functions that accurately describe adsorption while the adsorbed film is increasing in mass prior to saturation. The Ono-Kondo Model, Dubinin-Astakhov, and several similar models do a decent job of describing adsorption at both high and low pressures. The Ono-Kondo model is expressed as

$$
\frac{m_{\mathrm{exc}}}{m_{\mathrm{s}}}=2 a \frac{\left(1-\frac{\rho}{b}\right)\left(1-e^{c / T}\right)}{\left(1+\left(\frac{b}{\rho}-1\right) e^{c / T}\right)}=2 a \frac{\left(1-\frac{\rho_{\mathrm{gas}}}{\rho_{\mathrm{film}, \mathrm{sat}}}\right)\left(1-e^{E_{\mathrm{b}} / R T}\right)}{\left(1+\left(\frac{\rho_{\mathrm{film}, \mathrm{sat}}}{\rho_{\mathrm{gas}}}-1\right) e^{E_{\mathrm{b}} / R T}\right)}
$$

Here, the gravimetric excess adsorption is given as a function of the gas density $\left(\rho_{\text {gas }}\right)$. Parameter $a$ is a scaling factor that is proportional to the adsorbed film volume $\left(V_{\text {film,sat }}\right), b$ is the saturated density of the adsorbed film $\left(\rho_{\text {film,sat }}\right), c$ is the binding energy of the gas-solid interaction $\left(E_{\mathrm{b}} / R\right)$, and $T$ is the temperature of the isotherm. 


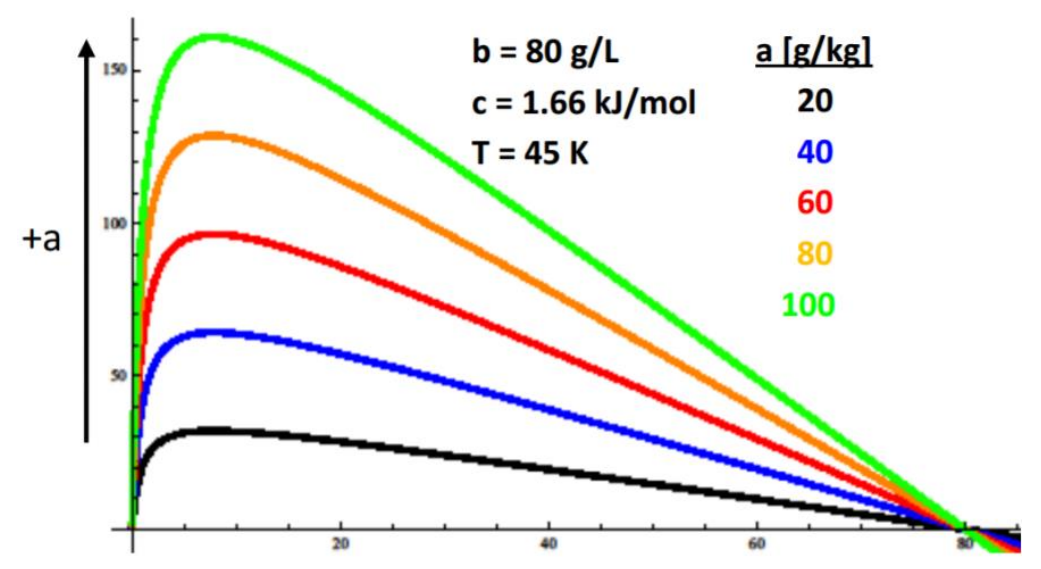

Figure 18. Excess adsorption versus gas density Ono-Kondo model for monolayer adsorption scaling with parameter $a$. The excess adsorption increases with increasing volume of the adsorbed film while holding parameters $b, c$, and $T$ constant at arbitrary values.

As can be expected, Fig 16 shows a simple increase in excess adsorption when increasing the scaling factor. This is most evident in the height of the peak. An increase in parameter $a$ while holding parameters $b, c$, and $T$ constant necessitates that the absolute value of the slope of the isotherm must increase in both the low gas density limit and the high gas density limit. However, the density at which the maximum excess adsorption occurs does not change.

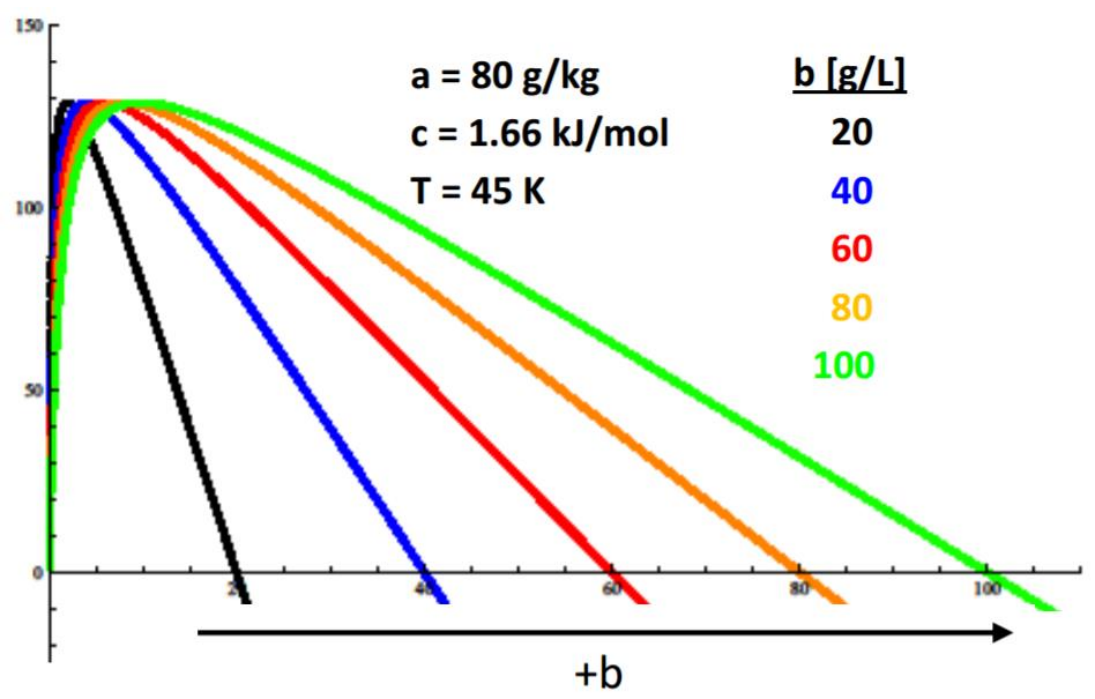

Figure 19. Excess adsorption versus gas density Ono-Kondo Model iterating with parameter b. The saturated film density increases with increasing parameter $\mathrm{b}$ while holding parameters $\mathrm{a}, \mathrm{b}$, and $\mathrm{T}$ constant at arbitrary values. 
The value of $b$ directly refers to the intersection with the horizontal axis. The height of the peak is unaffected. The maximum excess adsorption shifts to occur at slightly higher gas densities while increasing parameter b.

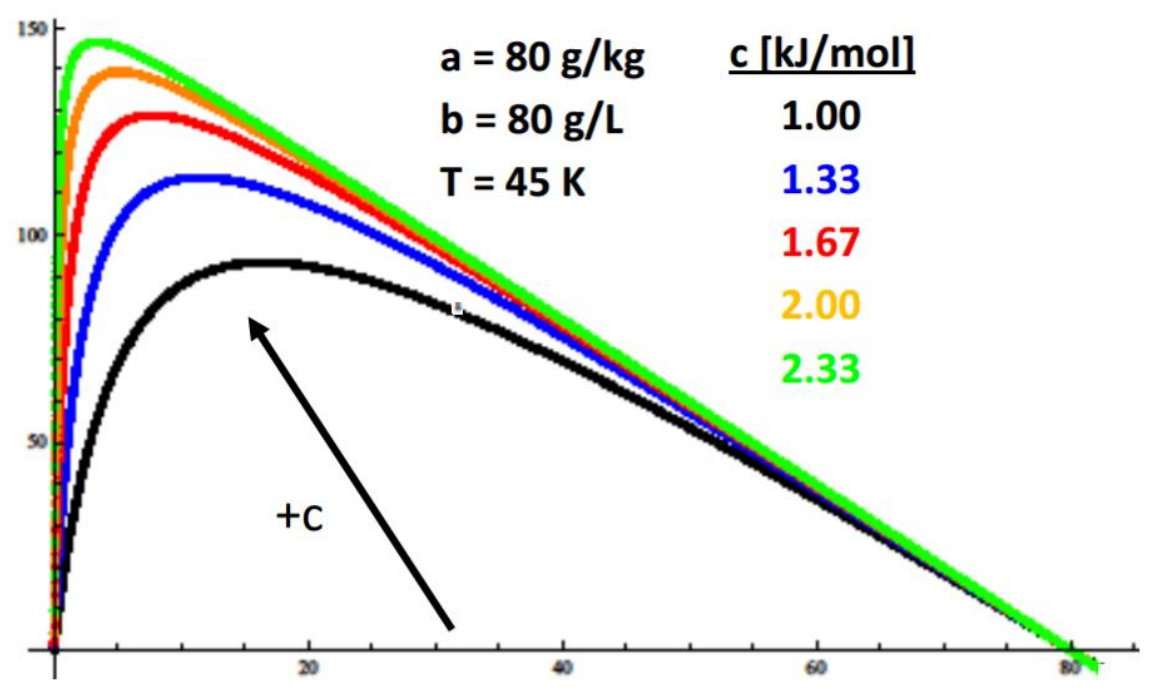

Figure 20. Excess adsorption versus gas density Ono-Kondo Model iterating with parameter c. The excess adsorption increases with increasing binding energy while holding parameters a, c, and $\mathrm{T}$ constant at arbitrary values.

As parameter c increases, the maximum excess adsorption shifts to occur at lower gas densities and higher excess adsorption values. Take the limit of the excess adsorption equation as parameter $\mathrm{c}$ approaches infinity

$$
\lim _{c \rightarrow \infty} \frac{m_{\mathrm{exc}}}{m_{\mathrm{s}}}=2 a\left(1-\frac{\rho}{b}\right)
$$

As parameter $\mathrm{c}$ is increased, the low pressure limits and high pressure limits of the excess adsorption both become more linear. For high binding energies, the model approaches a linear system, intersecting the vertical axis at $2 \mathrm{a}$ and the horizontal axis at $\mathrm{b}$. As parameter $\mathrm{c}$ approaches zero, the excess adsorption approaches zero at all densities. 


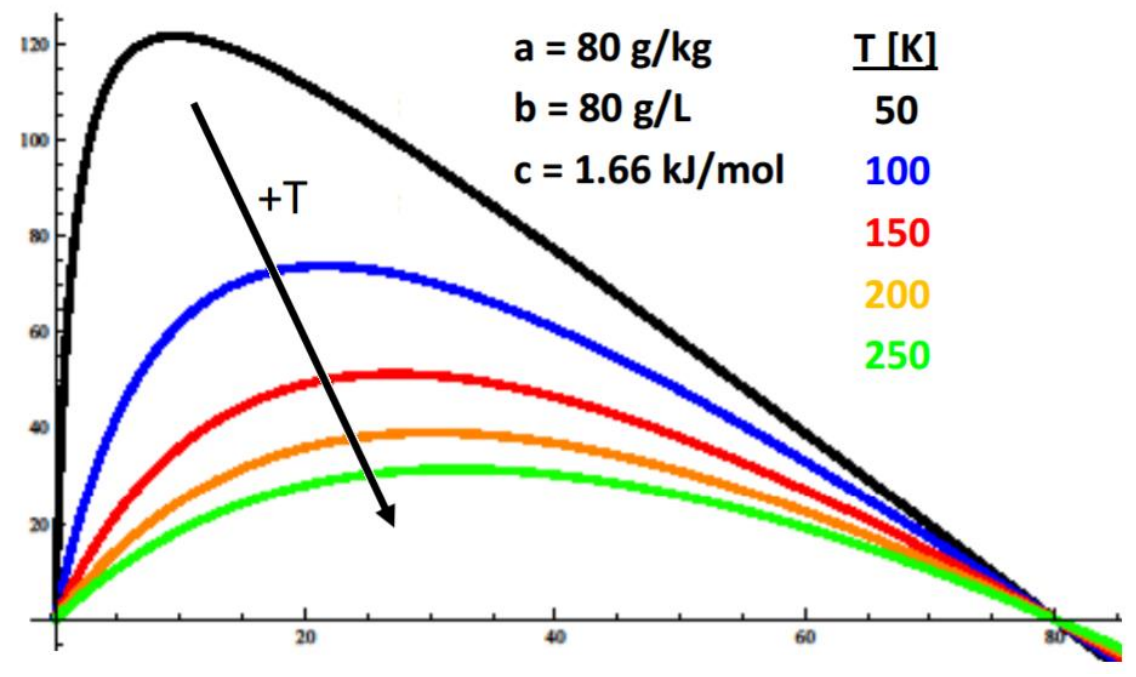

Figure 21. Excess adsorption versus gas density Ono-Kondo Model iterating with parameter T. The excess adsorption decreases with increasing temperature while holding parameters a, b, and c constant at arbitrary values.

The binding energy and isotherm temperature are inversely proportional through the quotient. Excess adsorption decreases with increasing temperature because there is more thermal perturbation.

Isotherms measured at low temperatures on samples with relatively high binding energies should exhibit excess adsorption curves having steep slopes in the low gas density limit as well as the high gas density limit. In both of these limits, the slope of the excess adsorption isotherm should scale with the adsorbed film volume. The derivative of the Ono-Kondo model is expressed as

$$
\frac{\partial\left(\frac{m_{\mathrm{exc}}}{m_{\mathrm{s}}}\right)}{\partial \rho}=-\frac{2 a\left(1-e^{\frac{c}{T}}\right)}{\left(1+\left(\frac{b}{\rho}-1\right) e^{\frac{c}{T}}\right)}\left[\frac{1}{b}-\frac{\left(1-\frac{\rho}{b}\right)\left(\frac{b e^{\frac{c}{T}}}{\rho^{2}}\right)}{\left(1+\left(\frac{b}{\rho}-1\right) e^{\frac{c}{T}}\right)}\right]
$$

In the high gas density limit, $\frac{b}{\rho} \sim 1$ and $\frac{\rho}{b} \sim 1$. Therefore, the derivative of the Ono-Kondo Model may be approximated as

$$
\frac{\partial\left(\frac{m_{\mathrm{exc}}}{m_{\mathrm{s}}}\right)}{\partial \rho}=-2 a\left(1-e^{\frac{c}{T}}\right)\left[\frac{1}{b}\right]
$$


in the high gas density limit. This is directly proportional to the scaling factor, a, and inversely proportional to $b$. This should make intuitive sense because the magnitude of the slope will be larger in the excess adsorption is larger. The excess adsorption is also directly proportional to the scaling factor. Additionally, larger saturated film densities results in lower magnitudes of the slope of the high density regime. This is depicted in Fig 18 above. According to the model-independent equation, the magnitude of the slope of the high pressure regime will be equal to the adsorbed film volume. Therefore, the Ono-Kondo Model may be used to estimate the volume of the saturated, adsorbed film ${ }^{[19]}$. This derivative can be used to set the upper limit for allowable volumes on the adsorbed film at a given temperature. This film volume may be used to convert excess adsorption into absolute adsorption for the purpose of calculating differential enthalpy of adsorption.

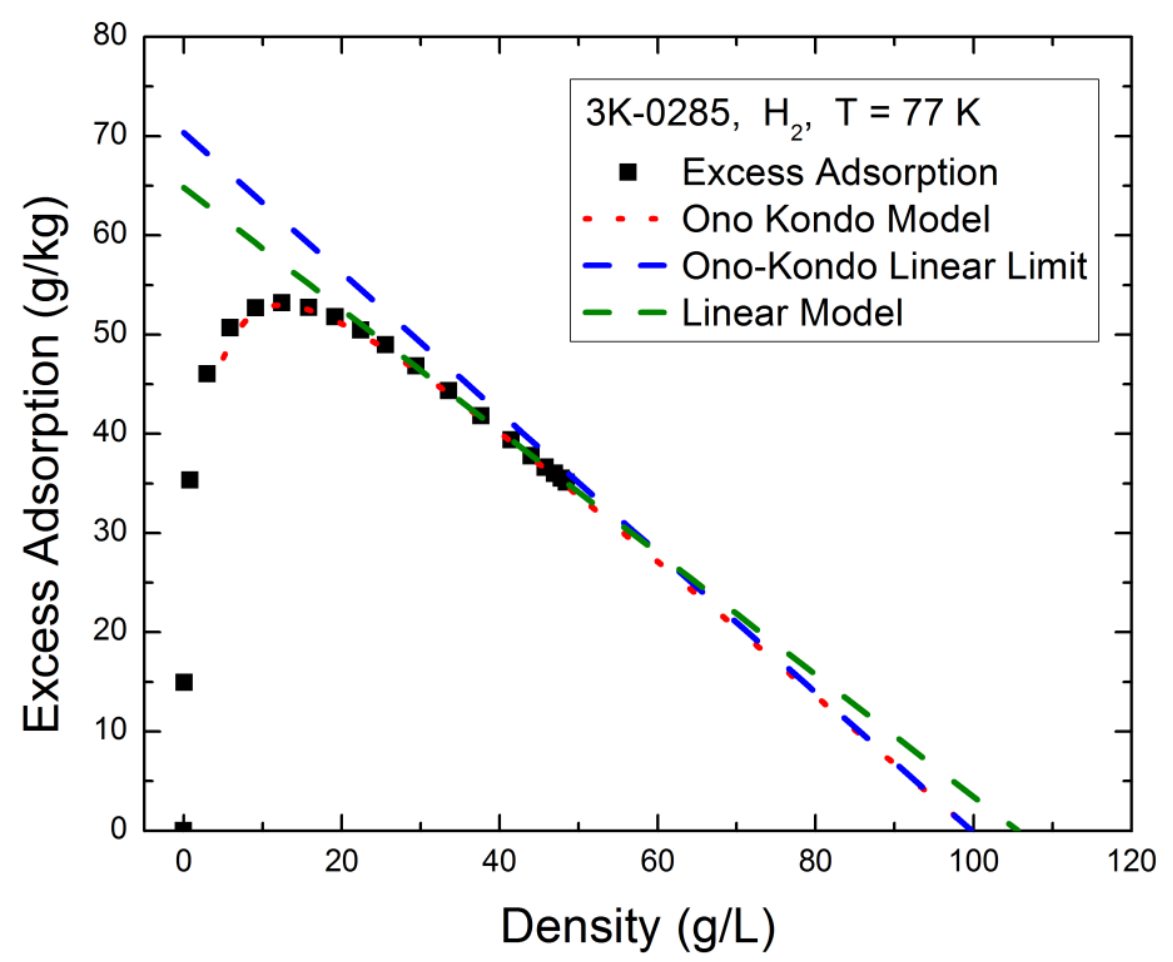

Figure 22. Excess adsorption versus gas density with linear and Ono-Kondo models applied to the high pressure regime. The high gas density limit of the Ono-Kondo equation yields slopes with a larger absolute value compared to those obtained by applying a linear model to experimental data. 
Table 1: Parameters obtained by applying both models:

\begin{tabular}{|l|r|r|r|}
\hline Parameter & Linear Model & \multicolumn{2}{|l|}{$\begin{array}{l}\text { Linear Limit of } \\
\text { Ono-Kondo Model }\end{array}$} \\
\hline Slope & -0.614 & -0.705 & 13.8 \\
\hline Vertical intercept & 64.8 & 70.4 & 8.3 \\
\hline$V_{\text {film }}[\mathrm{mL} / \mathrm{g}]$ & 0.614 & 0.705 & 13.8 \\
\hline$\rho_{\text {film }}[\mathrm{g} / \mathrm{L}]$ & 105.6 & 99.8 & 5.6 \\
\hline$m_{\text {film }}[\mathrm{g} / \mathrm{kg}]$ & 64.8 & 70.4 & 8.3 \\
\hline$t_{\text {film }}[\mathrm{nm}]$ & 0.316 & 0.323 & 2.2 \\
\hline
\end{tabular}

Applying a linear fit to experimental data will yield slopes with a smaller magnitude compared to those obtained from the high density limit of the Ono-Kondo Model. Parameters obtained from applying a simple linear fit will be heavily dependent upon the number of experimental data points used whereas the variance in parameters obtained from the Ono-Kondo Model is typically less than $2 \%$. The two models yielded similar densities, masses, and thicknesses of the saturated adsorbed film, but the film volumes obtained from the two models differed by approximately $14 \%$. The film volume obtained from the Ono-Kondo Model may be used as an upper limit for the adsorbed film volume when converting excess adsorption into absolute adsorption. The difference between the film volumes may be taken as the uncertainty.

\subsection{Enthalpy, Binding Energy, and Frequency Determined from Henry's Law}

One way to minimize the uncertainties in determining the enthalpy of adsorption is to analyze isotherms in the regime of low gas density. With sufficiently low gas densities, the absolute adsorption from Eq (29) is approximately equal to the excess adsorption. Any uncertainty in the adsorbed film volume becomes negligible because the gas density multiplied by the film volume approaches zero. According to Henry's Law, the adsorbed amount will be approximately linear in this regime. It states that at a constant 
temperature, the amount of a given gas that dissolves in a given type and volume of liquid is directly proportional to the partial pressure of that gas in equilibrium with that liquid.

Employing a linear model greatly reduces the uncertainties associated with the assumed film volume and the choice of model used to fit the experimental data. So it will be useful to analyze an adsorption model that agrees with Henry's Law. One such model is the Langmuir equation for monolayer adsorption. The Langmuir Model of adsorption may be easily derived by examining adsorption and desorption rates at equilibrium. The original derivation of the Langmuir equation is a kinetic one. The adsorbent surface is imagined as a flat, uniform, surface with equivalent and independent sites for localized adsorption. For a single layer of adsorbed material at a constant temperature, the rate of attachment, $d N^{\mathrm{a}} / d t$, should be proportional to a driving force multiplied by the surface area available to the gas and the concentration will depend solely upon the pressure. The driving force is proportional to the concentration of the adsorbate gas and the area is the amount of bare surface ${ }^{[10]}$. Therefore, the rate of adsorption is defined as

$$
\frac{d N^{\mathrm{a}}}{d t}=k_{1} p(1-\theta)
$$

where $\theta$ is the fraction of the surface covered, $p$ is the pressure and $k_{1}$ is the rate coefficient. From the kinetic theory of gasses, the desorption rate, $d N^{\mathrm{d}} / d t$, should be proportional to the amount of the surface that is covered and the energy of activation. Therefore, the desorption rate is defined as

$$
\frac{d N^{\mathrm{d}}}{d t}=k_{2} \theta e^{-\mathrm{E} / \mathrm{RT}}
$$

where $\theta$ is the fraction of the surface covered, $E$ is the activation energy expressed as a positive quantity, $R$ is the gas constant, $T$ is the average temperature of the system, and $k_{2}$ is the rate coefficient. In equilibrium the adsorption and desorption rate are equal such that

$$
k_{1} p(1-\theta)-k_{2} \theta e^{-\mathrm{E} / \mathrm{RT}}=0
$$


One may define a Langmuir coefficient in terms of the rate constants and the activation energy as

$$
\chi(T)=\frac{k_{1}}{k_{2}} e^{-\mathrm{E} / \mathrm{RT}}
$$

such that

$$
\chi(T) p(1-\theta)-\theta=0
$$

This allows for one to solve for $\theta$ and arrive at the equation for the Langmuir Model of adsorption.

$$
\theta(p, T)=\frac{\chi(T) p}{1+\chi(T) p}
$$

The Langmuir equation converges to a linear function obeying Henry's Law as $\mathrm{p} \rightarrow 0$ and approaches a value of $\theta=1$ at high pressures. This mathematical form may also be derived from a classical thermodynamic standpoint or through the application of principles of statistical mechanics ${ }^{[10]}$.

The Langmuir coefficient, $\chi(T)$, may be given in terms of the partition function of a single adsorbed molecule and the standard chemical potential ${ }^{[13]}$. Under a three dimensional harmonic oscillator approximation, the Langmuir coefficient depends upon temperature, binding energies, and vibrational frequencies of the adsorbed hydrogen molecules. These coefficients vary depending upon whether the adsorbed hydrogen is mobile or locally adsorbed. In localized adsorption, hydrogen molecules have three vibrational degrees of freedom, oscillating about the minimum of the adsorption potential. Under the conditions for mobile adsorption, the molecule has sufficient thermal energy to move about the plane parallel to the adsorbing surface, but will still have one vibrational degree of freedom. The Langmuir coefficients for mobile adsorption and local adsorption may be expressed as

$$
\chi(T)=\frac{\alpha(T) e^{\frac{E_{\mathrm{B}}}{N_{\mathrm{A}} k T}}}{\sinh \left(\frac{h v_{\mathrm{z}}}{2 k T}\right)} \sqrt{\frac{h^{2}}{8 \pi m(k T)^{3}}}
$$

and 


$$
\chi(T)=\frac{e^{\frac{E_{\mathrm{B}}}{N_{\mathrm{A}} k T}}}{\sinh \left(\frac{h v_{\mathrm{x}}}{2 k T}\right) \sinh \left(\frac{h v_{\mathrm{y}}}{2 k T}\right) \sinh \left(\frac{h v_{\mathrm{z}}}{2 k T}\right)} \sqrt{\frac{h^{6}}{(8 \pi m)^{3}(k T)^{5}}}
$$

respectively ${ }^{[13,15]}$. Harmonic oscillator type motion was assumed for all three dimensions. Here, we define binding energy, $E_{\mathrm{B}}$, as a positive quantity representing the depth of the minima of the adsorbing potential per mole of $\mathrm{H}_{2}$. The vibrational frequencies, $v_{\mathrm{x}}, v_{y}, v_{\mathrm{z}}$, are usually on the order of $10^{12} \mathrm{~s}^{-1}$. We have defined $m$ as the mass of the $\mathrm{H}_{2}$ molecule, $\alpha$ as the surface area per adsorption site, and $k$, $\mathrm{h}$, and $N_{\mathrm{A}}$ as the Boltzmann constant, Plank's constant, and Avagadro's constant, respectively. It is important to note that $\alpha$ is temperature-dependent because molecules can be densely packed at low temperatures, but occupy a larger area at higher temperatures due to thermal motion in the plane parallel to the adsorbing surface. Using these different models, we can estimate the binding energies from low pressure hydrogen isotherms using Henry’s Law analysis.

The absolute adsorption can be expressed as a function of coverage by the following:

$$
\frac{m_{\mathrm{ads}}(p, T)}{m_{\mathrm{s}}}=\frac{\theta(P, T) m \Sigma}{\alpha(T)}
$$

Using the low pressure limit of the Langmuir model, this becomes

$$
\frac{m_{\mathrm{ads}}(p, T)}{m_{\mathrm{s}}}=\frac{\chi(T) m \Sigma}{\alpha(T)} p
$$

Eq (52) shows that absolute adsorption is a linear function of pressure in the low pressure limit. The slope of the adsorption isotherm is called the Henry's Law coefficient, given by

$$
k_{\mathrm{H}}(T)=\frac{\chi(T) m \Sigma}{\alpha(T)}
$$

where $k_{H}$ has units of inverse pressure. At high temperatures, mobile adsorption is assumed. At cryogenic temperatures it is likely that there exist both mobile and locally adsorbed gas molecules. Treating the mobile case first, 


$$
\begin{gathered}
k_{\mathrm{H}}(T)=\frac{m \Sigma}{\alpha(T)} \frac{\alpha(T) e^{\frac{E_{\mathrm{B}}}{N_{\mathrm{A}} k T}}}{\sinh \left(\frac{h v_{\mathrm{z}}}{2 k T}\right)} \sqrt{\frac{h^{2}}{8 \pi m(k T)^{3}}} \\
k_{\mathrm{H}}(T)=\frac{m \sum e^{\frac{E_{\mathrm{B}}}{N_{\mathrm{A}} k T}}}{\sinh \left(\frac{h v_{\mathrm{z}}}{2 k T}\right)} \sqrt{\frac{h^{2}}{8 \pi m(k T)^{3}}}
\end{gathered}
$$

For sufficiently small $x, \sinh (x) \sim x$. This approximation is only important in that it allows one to separate the binding energy dependence on temperature from its dependence on $v_{z}$, as you will see in Eqs (57-59).

$$
k_{\mathrm{H}}(T)=\frac{2 m \sum e^{\frac{E_{\mathrm{B}}}{N_{\mathrm{A}} k T}}}{h v_{\mathrm{z}}} \sqrt{\frac{h^{2}}{8 \pi m k T}}
$$

One may measure adsorption isotherms at two temperatures to obtain $k\left(T_{1}\right)$ and $k\left(T_{2}\right)$. The ratio of the two constants yields the following

$$
\frac{k_{\mathrm{H}}\left(T_{1}\right)}{k_{\mathrm{H}}\left(T_{2}\right)}=\frac{\frac{2 m \sum e^{\frac{E_{\mathrm{B}}}{N_{\mathrm{A}} k T_{1}}}}{h v_{\mathrm{z}}} \sqrt{\frac{h^{2}}{8 \pi m k T_{1}}}}{\frac{2 m \sum e^{\frac{E_{\mathrm{B}}}{N_{\mathrm{A}} k T_{2}}}}{h v_{\mathrm{z}}} \sqrt{\frac{h^{2}}{8 \pi m k T_{2}}}}
$$

If the two isotherms are measured at temperatures sufficiently close to one another, it is safe to assume that $v_{\mathrm{z}}\left(T_{1}\right)=v_{\mathrm{z}}\left(T_{2}\right)$ such that

$$
\frac{k_{\mathrm{H}}\left(T_{1}\right)}{k_{\mathrm{H}}\left(T_{2}\right)}=\frac{e^{\frac{E_{\mathrm{B}}}{N_{\mathrm{A}} k T_{1}}} \sqrt{\frac{1}{T_{1}}}}{e^{\frac{E_{\mathrm{B}}}{N_{\mathrm{A}} k T_{2}}} \sqrt{\frac{1}{T_{2}}}}=e^{\frac{E_{\mathrm{B}}}{N_{\mathrm{A}} k}\left(\frac{T_{2}-T_{1}}{T_{1} T_{2}}\right)} \sqrt{\frac{T_{2}}{T_{1}}}
$$

which may now be solved for binding energy.

$$
E_{\mathrm{B}}=N_{\mathrm{A}} k\left(\frac{T_{1} T_{2}}{T_{2}-T_{1}}\right) \ln \left[\frac{k_{H}\left(T_{1}\right)}{k_{H}\left(T_{2}\right)} \sqrt{\frac{T_{1}}{T_{2}}}\right]
$$

This results bears a striking resemblance to the Clausius-Clapeyron relation for enthalpy of adsorption

$$
\Delta_{a d s} H(\theta)=N_{\mathrm{A}} k\left(\frac{T_{1} T_{2}}{T_{2}-T_{1}}\right) \ln \left[\frac{p_{2\left(T_{2}, \theta\right)}}{p_{1\left(T_{1}, \theta\right)}}\right]
$$


Now we will examine the case of localized adsorption. Recall that for localized adsorption,

$$
k_{\mathrm{H}}(T)=\frac{\chi(T) m \Sigma}{\alpha(T)}, \chi(T)=\frac{e^{\frac{E_{\mathrm{B}}}{N_{\mathrm{A}} k T}}}{\sinh \left(\frac{h v_{\mathrm{x}}}{2 k T}\right) \sinh \left(\frac{h v_{\mathrm{y}}}{2 k T}\right) \sinh \left(\frac{h v_{\mathrm{z}}}{2 k T}\right)} \sqrt{\frac{h^{6}}{(8 \pi m)^{3}(k T)^{5}}}
$$

Once again, $\sinh (x) \sim x$ for all sufficiently small $x$.

$$
k_{\mathrm{H}}(T)=\frac{8 m \sum e^{\frac{E_{\mathrm{B}}}{N_{\mathrm{A}} k T}}}{v_{\mathrm{x}} v_{\mathrm{y}} v_{\mathrm{z}}} \sqrt{\frac{k T}{(8 \pi m)^{3}}}
$$

if the two isotherms are measured at temperatures sufficiently close to one another, it is safe to assume that $v_{\mathrm{x}}\left(T_{1}\right)=v_{\mathrm{x}}\left(T_{2}\right), v_{\mathrm{y}}\left(T_{1}\right)=v_{\mathrm{y}}\left(T_{2}\right)$, and $v_{\mathrm{z}}\left(T_{1}\right)=v_{\mathrm{z}}\left(T_{2}\right)$ such that

$$
\frac{k_{\mathrm{H}}\left(T_{1}\right)}{k_{\mathrm{H}}\left(T_{2}\right)}=e^{\frac{E_{\mathrm{B}}}{N_{\mathrm{A}} k}\left(\frac{T_{2}-T_{1}}{T_{1} T_{2}}\right)} \sqrt{\frac{T_{1}}{T_{2}}}
$$

Solving for $E_{\mathrm{B}}$ yields

$$
E_{\mathrm{B}}=R\left(\frac{T_{1} T_{2}}{T_{2}-T_{1}}\right) \ln \left(\frac{k_{\mathrm{H}}\left(T_{1}\right)}{k_{\mathrm{H}}\left(T_{2}\right)} \sqrt{\frac{T_{2}}{T_{1}}}\right)=E_{\mathrm{B}}(\text { Mobile })+R\left(\frac{T_{1} T_{2}}{T_{2}-T_{1}}\right) \ln \left(\frac{T_{2}}{T_{1}}\right)
$$

When analyzing low pressure, linear isotherms at $77 \mathrm{~K}$ and $87 \mathrm{~K}, E_{\mathrm{B}}=E_{\mathrm{B}}($ Mobile $)+0.3416 \mathrm{~kJ} / \mathrm{mol}$. We need to place further scrutiny on this relation and examine whether or not the assumption that $x$ is sufficiently small such that $\sinh (x) \sim x$. 
Table 2: Deviations in $\mathrm{h} v_{\mathrm{i}} / 2 \mathrm{kT}$ for various vibrational frequencies and temperatures

\begin{tabular}{|l|r|r|r|r|}
\hline & $\mathrm{T}=77 \mathrm{~K}$ & $\mathrm{~T}=87 \mathrm{~K}$ & $\mathrm{~T}=273 \mathrm{~K}$ & $\mathrm{~T}=296 \mathrm{~K}$ \\
\hline $\mathrm{h} v_{\mathrm{i}} / 2 \mathrm{kT}$ & 0.031 & 0.028 & 0.009 & 0.008 \\
for $v_{\mathrm{x}}=v_{\mathrm{y}} \sim 10^{11} \mathrm{~s}^{-1}$ & & & & \\
\hline $\mathrm{h} v_{\mathrm{i}} / 2 \mathrm{kT}$ & 0.31 & 0.27 & 0.09 & 0.08 \\
for $v_{\mathrm{z}} \sim 10^{12} \mathrm{~s}^{-1}$ & 0.031 & 0.028 & 0.009 & 0.008 \\
\hline $\sinh \left(\mathrm{h} v_{\mathrm{x}} / 2 \mathrm{kT}\right)$ & 0.32 & 0.28 & 0.09 & 0.08 \\
\hline $\sinh \left(\mathrm{h} v_{\mathrm{z}} / 2 \mathrm{kT}\right)$ & 0.02 & 0.01 & 0.001 & 0.001 \\
\hline \% Difference $\left(v_{\mathrm{x}}\right)$ & 1.6 & 1.3 & 0.13 & 0.11 \\
\hline \% Difference $\left(v_{\mathrm{z}}\right)$ & & & & \\
\hline
\end{tabular}

The largest difference occurs in the approximation for $v_{z}$ at low temperatures. One could account for these differences by considering higher order terms of the expansion of $\sinh (\mathrm{x})$. Though, this should have a minimal impact on the calculated binding energies because the resulting binding energy equation takes the form $E_{\mathrm{B}}=\mathrm{C} * \ln (\mathrm{kT} / \mathrm{kT}+\delta)$, where $\delta$ is insignificant.

Once an approximate binding energy has been determined from the Henry's Law coefficients, one can use these parameters to solve for the vibrational frequencies. Assuming mobile adsorption,

$$
\chi(T)=\frac{\alpha(T) e^{\frac{E_{\mathrm{B}}}{N_{\mathrm{A}} k T}}}{\sinh \left(\frac{h v_{\mathrm{z}}}{2 k T}\right)} \sqrt{\frac{h^{2}}{8 \pi m(k T)^{3}}}
$$

Using various approximations stated earlier, the Henry's Law coefficients are defined as

$$
k_{\mathrm{H}}(T)=\frac{\chi(T) m \sum}{\alpha(T)}=\frac{m \sum}{\alpha(T)} \frac{\alpha(T) e^{\frac{E_{\mathrm{B}}}{N_{\mathrm{A}} k T}}}{\sinh \left(\frac{h v_{\mathrm{z}}}{2 k T}\right)} \sqrt{\frac{h^{2}}{8 \pi m(k T)^{3}}}=\frac{m \sum e^{\frac{E_{\mathrm{B}}}{N_{\mathrm{A}} k T}}}{\sinh \left(\frac{h v_{\mathrm{z}}}{2 k T}\right)} \sqrt{\frac{h^{2}}{8 \pi m(k T)^{3}}}
$$

Since an approximate binding energy has been determined based upon the slopes of the adsorption isotherms, one may also estimate the vibrational frequency through 


$$
\sinh \left(\frac{h v_{\mathrm{z}}}{2 k T}\right)=\frac{m \sum e^{\frac{E_{\mathrm{B}}}{N_{\mathrm{A}} k T}}}{k_{\mathrm{H}}(T)} \sqrt{\frac{h^{2}}{8 \pi m(k T)^{3}}}
$$

Therefore,

$$
v_{\mathrm{z}}=\frac{2 k T}{h} \sinh ^{-1}\left(\frac{m \sum e^{\frac{E_{\mathrm{B}}}{N_{\mathrm{A}} k T}}}{k_{\mathrm{H}}(T)} \sqrt{\frac{h^{2}}{8 \pi m(k T)^{3}}}\right)
$$

Which allows one to calculate the vibrational frequencies in the direction parallel to the adsorption interface.

\begin{tabular}{|c|c|c|c|c|c|c|}
\hline $\begin{array}{l}\text { Sample } \\
\text { Name }\end{array}$ & $\begin{array}{l}k_{\mathrm{H}}(77 \mathrm{~K}) \\
{\left[10^{-8} \mathrm{~Pa}^{-1}\right]}\end{array}$ & $\begin{array}{l}k_{\mathrm{H}}(87 \mathrm{~K}) \\
{\left[10^{-8} \mathrm{~Pa}^{-1}\right]}\end{array}$ & $\begin{array}{l}\sum_{\mathrm{BET}} \\
{\left[\mathrm{m}^{2} / \mathrm{g}\right]}\end{array}$ & $\begin{array}{l}\mathrm{E}_{\mathrm{B}} \\
{[\mathrm{kJ} / \mathrm{mol}]}\end{array}$ & $\begin{array}{l}v_{\mathrm{Z}}(77 \mathrm{~K}) \\
{[\mathrm{Hz}]}\end{array}$ & $\begin{array}{l}v_{\mathrm{Z}}(87 \mathrm{~K}) \\
{[\mathrm{Hz}]}\end{array}$ \\
\hline $4 \mathrm{~K}-0245$ & 467.7 & 119.8 & 2480 & 7.28 & $9.5 \mathrm{E}+12$ & $1.6 \mathrm{E}+13$ \\
\hline $4 \mathrm{~K}-0747$ & 421.6 & 119.1 & 2350 & 6.73 & $7.0 \mathrm{E}+12$ & $1.2 \mathrm{E}+13$ \\
\hline $4 \mathrm{~K}-0750$ & 511.7 & 118.2 & 2200 & 7.8 & $1.2 \mathrm{E}+13$ & $1.8 \mathrm{E}+13$ \\
\hline $5 \mathrm{~K}-0215$ & 638.5 & 114.6 & 1950 & 9.3 & $1.8 \mathrm{E}+13$ & $2.6 \mathrm{E}+13$ \\
\hline HKUST-1 & 198.8 & 59.5 & 2000 & 6.4 & $7.2 \mathrm{E}+12$ & $1.3 \mathrm{E}+13$ \\
\hline HS;0B-20 & 4451 & 773.4 & 900 & 9.45 & $9.9 \mathrm{E}+12$ & $1.8 \mathrm{E}+13$ \\
\hline
\end{tabular}

Table 3: Henry's Law coefficients, specific surface areas, binding energies, and vibrational frequencies

Thus, the vibrational frequency and the binding energy of the hydrogen to the adsorbent surface may be approximated by analyzing the low gas density regime of two excess adsorption isotherms and applying these model-dependent methods. Alternately, if an experimental isotherm is approximately linear in the low gas density regime then one may use Henry's Law analysis to determine differential enthalpies of adsorption by simply applying a linear model. 


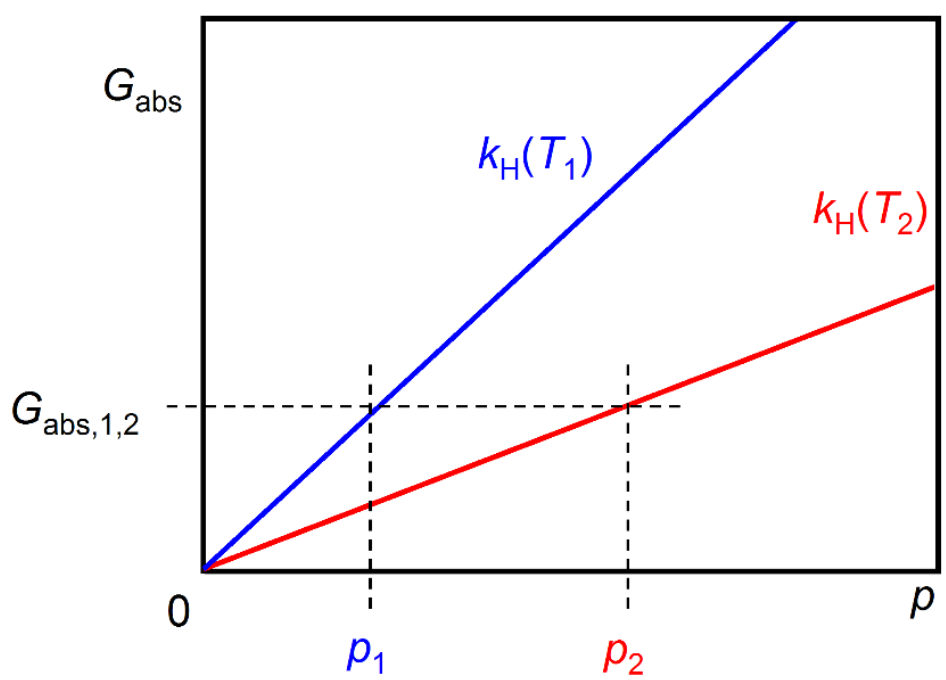

Figure 23. Absolute adsorption versus pressure for two theoretical linear isotherms. The ClausiusClapeyron relation may be applied to the two isotherms over an interval of constant coverage to determine differential enthalpy of adsorption.

Recall Eq (29), which defines the absolute adsorption as the total amount of gas in the adsorbed film. At these low pressures, where Henry's Law is valid, the excess adsorption is much larger than the bulk gas density. At such low pressures, the absolute adsorption is approximately equal to the excess adsorption, which mitigates any uncertainty in the volume of the adsorbed film.

If Henry's Law is observed then $G_{\mathrm{abs}}(p, T)=k_{\mathrm{H}}(T) p$. In order to apply the Clausius-Clapeyron relation, one must solve for the pressure at which both isotherms have an equal amount of gas involved in the absorbed film. If Henry's Law is observed then the Clausius-Clapeyron relation takes the following form:

$$
\Delta H_{\Theta}=R \frac{T_{1} T_{2}}{T_{2}-T_{1}} \ln \left(\frac{P_{2}}{P_{1}}\right)=R \frac{T_{1} T_{2}}{T_{2}-T_{1}} \ln \left(\frac{k_{H}\left(T_{1}\right)}{k_{H}\left(T_{2}\right)}\right)=\left(5.59 \frac{\mathrm{kJ}}{\mathrm{mol}}\right) * \ln \left(\frac{k_{H}\left(T_{1}\right)}{k_{H}\left(T_{2}\right)}\right)
$$

Interestingly, this result is quite similar to Eq (59), the binding energy solution assuming Langmuir-type mobile adsorption.

$$
\Delta H_{\Theta}=E_{\mathrm{B}}-\left(5.59 \frac{\mathrm{kJ}}{\mathrm{mol}}\right) * \ln \left[\sqrt{\frac{T_{1}}{T_{2}}}\right]=E_{\mathrm{B}}+0.341 \frac{\mathrm{kJ}}{\mathrm{mol}}
$$

This method of determining differential enthalpy of adsorption is less dependent upon the model and does not involve any assumptions about the volume of the adsorbed film. 


\subsection{Physical Nanostructure Characterization}

One of the primary and most important characteristics of an adsorbent material is its specific surface area. Specific surface area is often the first consideration when screening new materials with regards to gas storage and separation. Typically, subcritical nitrogen isotherms are measured and analyzed using the Brunauer-Emmett-Teller (BET) theory to determine the specific surface area. Though I will not describe it in its entirety here, the BET equation may be conveniently expressed as a linear equation

$$
\frac{p / p^{0}}{n\left(1-p / p^{0}\right)}=\frac{1}{n_{\mathrm{m}} C}+\frac{C-1}{n_{\mathrm{m}} C}\left(p / p^{0}\right)
$$

where $p$ is the pressure, $p^{0}$ is the coexistence pressure of the bulk liquid and gas (saturation pressure at the normal boiling point), $n$ is the number of molecules in the adsorbed film, $n_{\mathrm{m}}$ is the monolayer capacity, and $C$ is a relative interaction energy of the first monolayer ${ }^{[20]}$. Assuming that the BET theory is accurate, a plot of $\frac{p / p^{0}}{n\left(1-p / p^{0}\right)}$ versus $p / p^{0}$ should be a straight line with a slope of $m=(C-1) / n_{\mathrm{m}} C$ and an intercept $b=1 / n_{\mathrm{m}} C$. Solving these two simultaneous equations results in

$$
n_{\mathrm{m}}=\frac{1}{m+b}
$$

and

$$
C=\frac{m}{b}+1
$$

There are many models that may be employed to obtain the number of molecules in a single monolayer. Regardless of the model employed, one needs to form a monolayer of the adsorbate and count how many molecules there are in one layer and multiply it with the cross-sectional area of the probing molecule. The specific surface area (surface area per gram of material) is then expressed as

$$
\sum=\frac{n_{\mathrm{m}} * \alpha}{m_{\mathrm{solid}}}
$$

where $\alpha$ is the cross sectional area of a molecules of the adsorbate gas. Thus, if one knows the approximate cross-sectional area of the adsorbate gas, then one may determine the specific surface area. The cross- 
sectional area of a nitrogen molecule in a closed-packed monolayer is approximately $0.162-0.167 \mathrm{~nm}{ }^{[10,21]}$. The subcritical nitrogen isotherms for the materials discussed in this document were measured on an automated gas-adsorption instrument from Quantachrome (Autosorb-1), and the specific surface area determined at different pressure intervals. Due to the various ways in which the specific surface area depends on the pressure interval under analysis, Roquerol suggests three conditions that must be satisfied prior to analyzing nitrogen adsorption data for specific surface areas. To minimize the subjectivity in the assessment of the pressure interval, Rouquerol mentions three criteria which must be satisfied in order to obtain a reliable surface area measurement with BET theory ${ }^{[10]}$ :

1. The $C$ value must be positive because it is related to the heat of adsorption for attractive sorption potentials.

2. The pressure range is limited to the interval in which $n\left(1-\frac{P}{P_{0}}\right)$ continuously increases with $\frac{P}{P_{0}}$.

3. The calculated pressure from $\frac{1}{\sqrt{C}+1}=\left(\frac{P}{P_{0}}\right)_{N_{\text {mono }}}$ should not differ more than $10 \%$ from the corresponding pressure from the BET fit.

All Pressure intervals are compliant with criteria one and two. A pressure range (0.007-0.03 P/P0) is typically used for microporous materials, but there are uncertainties associated with the cross-sectional area, $\alpha$, used to obtain specific surface areas with BET. The $0.162-0.167 \mathrm{~nm}$ value originates from assuming that the packing of nitrogen in a monolayer is identical to the packing in its liquid state ${ }^{[22]}$. Extensive studies by McClellan and Harnsberger indicate the molecule's cross-sectional area is not a constant, especially for porous materials; the variation can be as much as $21 \%^{[23]}$. Therefore, the specific surface areas obtained from BET theory are only accurate to a similar degree. The cross-sectional area of the adsorbate molecule may also depend upon temperature. Ideally, the cross-sectional area should be treated as an experimental quantity and not as a universal constant. However, this leads to the problem of how to determine $\alpha$ easily.

In most cases nitrogen gas is used to obtain specific surface areas, but in most cases the material under investigation is designed to store a different adsorbate gas. In this case the surface seen by nitrogen can differ from the surface seen by hydrogen or methane. This is especially true for hydrogen because its 
size is significantly smaller than nitrogen and may access additional adsorption sites ${ }^{[24]}$. Ideally, the same "yardstick" should be used, meaning the specific surface area should be evaluated with the same molecule under investigation. However, due to availability, costs, and thermal management, this is not a practical suggestion.

The specific surface areas and pore size distributions for all materials in this document were determined from nitrogen sorption measurements under subcritical conditions. The measurements were performed using a Quantachrome Autosorb 1-C. The open pore volume for the activated carbons was determined at a relative pressure of $0.995 \mathrm{P} / \mathrm{P}_{0}$ by assuming that nitrogen has condensed to liquid densities within the pores. The specific pore volume includes only void volume within individual grains and does not include intergranular void space. Using the specific pore volume, the void fraction was calculated using

$$
\phi_{\text {envelope }}=\left(\left(1+\left(\rho_{\text {sk }} v_{\text {pore }}\right)^{-1}\right)^{-1}\right.
$$

where the skeletal density is measured by helium pycnometry. Cumulative pore volumes were determined by using quenched solid density functional theory (QSDFT) for slit shaped pores. This model is related to the popular non-local density functional theory (NLDFT). NLDFT has the drawback in that it assumes that the adsorbent has independent, perfectly spaced slit shaped pores and that the adsorbate forms well defined layers, which is an insufficient approximation for activated carbons. Nanoporous carbons are highly amorphous materials with great amounts of surface heterogeneity. Such heterogeneities will obstruct layering of the adsorbate causing false minima to appear in the NLDFT pore size distributions. QSDFT accounts for heterogeneities and surface roughness, which makes QSDFT ideal for modeling the pore structure of activated carbons and other materials having amorphous surface topographies. 


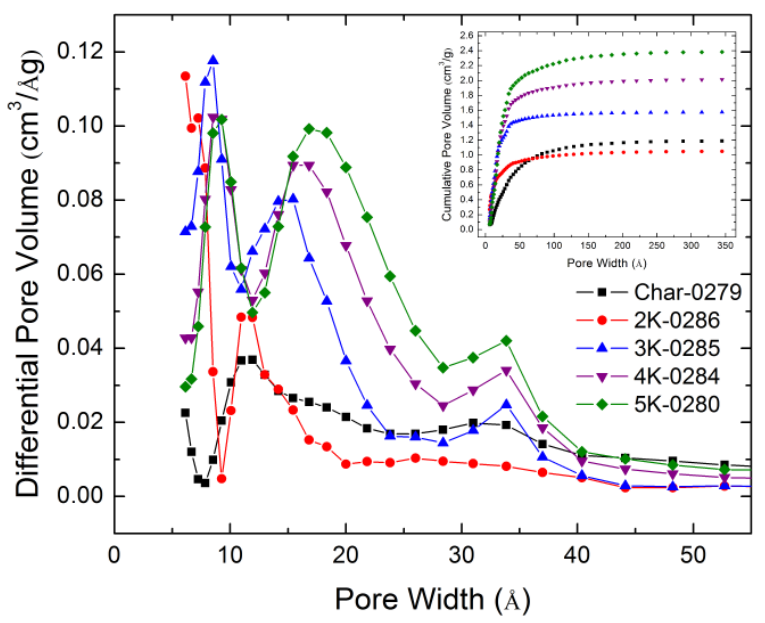

Figure 24. Pore size distribution for $\mathrm{H} 3 \mathrm{PO} 4$ char and $\mathrm{KOH}$ activated carbon. Inset: Cumulative pore volumes.

Prior to activation the $\mathrm{H}_{3} \mathrm{PO}_{4}$ char has a heterogeneous pore size distribution with its most prominent mode about $12 \AA$. After activation with $\mathrm{KOH}$, a bimodal pore size distribution is observed with both modes shifting to larger pore widths with increased ratios of $\mathrm{KOH}: \mathrm{C}$ used during activation. When an activation ratio greater than 2.5 is used, a third mode in the pore size distribution is created. The broadening of modes and the emergence of a third mode indicate that the pore structure becomes more randomized with increasing activation ratios. Additionally, the total pore volume is observed to increase with increasing activation ratios.

For physisorption, gas is adsorbed as a high density fluid by strong Van der Waals forces. GCMC simulations of hydrogen adsorbed in slit shaped pores support the conjecture that Van der Waals potentials overlap for pores with widths $>1 \mathrm{~nm}$, which we will call sub nanometer pores. The binding energy is enhanced by the overlapping potentials from opposing sides of the pore and subsequently, the adsorption density is increased. Therefore, an increase in isosteric heat of adsorption should be observed for samples having larger fraction of sub nanometer pores. This nanopore volume is maximized for carbon samples that have been activated with 2-3 $\mathrm{KOH}: \mathrm{C}$ mass ratio. 


\section{Chemical Characterization Methods}

Nuclear magnetic resonance spectroscopy (NMR) measurements are an obvious first choice to determine the bonding of non-magnetic samples. The activated carbons produced at the University of Missouri, as well as most commercially carbon materials, are produced from organic biowaste, such as corncob or sawdust. Even after charring, these activated carbons contain trace amounts of iron. In addition to the natural presence of iron, the charring and doping process typically involve a stainless steel pressure cell, which introduces additional magnetic impurities during high temperature annealing. Proton and carbon NMR proved to be ineffective because the carbon samples were not soluble in any known solvent and because they exhibited a paramagnetic behavior. Therefore, alternate methods must be employed to establish the presence of $\mathrm{sp}^{2} \mathrm{~B}-\mathrm{C}$ bonds. Boron doped samples were characterized using Prompt Gamma Neutron Activation Analysis (PGNAA), X-ray photoelectron spectroscopy (XPS), Fourier Transmission Infrared Spectroscopy (FTIR), X-ray diffraction (XRD), Energy-dispersive X-ray spectroscopy (EDXS), and transmission electron microscopy (TEM). PGNAA, XPS, and EDXS were used to establish the average boron content in the sample. XPS, FTIR, and XRD were used to gain information about the binding or carbon, oxygen, and boron.

\subsection{Prompt Gamma Neutron Activation Analysis}

Prompt Gamma Neutron Activation Analysis (PGNAA) is a nondestructive technique to determine elemental composition of a stable, target nuclide. The nuclei in the target sample undergo neutron capture in a flux of incident neutrons. When a neutron interacts with the target nucleus through a non-elastic collision, the compound nucleus forms in an excited state due to its binding energy with the incident neutron. The nucleus will emit one or more characteristic gamma rays in order to return to more stable configuration in a less excited state. This new configuration often yields a radioactive nucleus which also may decay by emission of delayed gamma rays ${ }^{[25]}$. The PGNAA technique takes place during irradiation using a beam of neutrons through a reactor beam port and is most applicable to elements with extremely high neutron capture cross-sections, such as Boron. 
The characteristic gamma rays emitted from the irradiated, unknown sample are compared them to those from a standard calibration sample in order to calculate concentrations of elements in the unknown sample. The energies of these gamma rays identify any elements involved in the neutron capture ${ }^{[26]}$. If the unknown sample and the calibration sample are both measured on the same detector, then one only needs to correct the difference in decay between the two. Decay corrections may be made for both samples using the half life of the measured isotope. The equation used to calculate the concentration of an element in the unknown sample relative to the calibration standard is expressed in terms of the activity.

$$
\frac{A_{\mathrm{s}}}{A_{\mathrm{cal}}}=\frac{m_{\mathrm{s}}\left(e^{-\lambda \mathrm{T}_{\mathrm{d}}}\right)_{\mathrm{s}}}{m_{\mathrm{cal}}\left(e^{-\lambda \mathrm{T}_{\mathrm{d}}}\right)_{\mathrm{cal}}}
$$

where $A$ is the activity of the sample (s) and calibration standard sample (cal), $m$ is the mass of the element, $\lambda$ is the decay constant for the isotope, and $T_{\mathrm{d}}$ is the decay time. This equation may be approximated when performing sufficiently short irradiation times. The irradiation, decay and counting times are normally fixed the same for all samples and their respective standards such that the time-dependent factors cancel. Thus the above equation simplifies into

$$
c_{\mathrm{s}}=c_{\mathrm{cal}} \frac{W_{\mathrm{cal}} A_{\mathrm{s}}}{W_{\mathrm{s}} A_{\mathrm{cal}}}
$$

where $c$ is the concentration of the element and $W$ is the weight of the sample and standard ${ }^{[27]}$. For the purpose of our experiments, PGNAA was used only to quantify concentrations of Boron in the activated carbon materials ranging from $0.1-30 \mathrm{wt} \%$. The calibration curve was developed over a broad range of boron concentrations. Using the calibration curves from the set of standard samples as a measure of the uncertainty, it was possible to reduce the statistical uncertainty to 3-5\% relative standard deviation (RSD) for samples with boron concentrations above $0.1 \mathrm{wt} \%$. For samples with trace concentrations $(10-100$ ppm), the uncertainty was between $20-25 \%$ RSD. This uncertainty may be reduced the uncertainty by either increasing count times for the low concentration samples or into concentration ranges and calibrating the system more carefully over a narrow concentration range ${ }^{[28]}$. 


\subsection{X-Ray Photoelectron Spectroscopy}

X-ray photoelectron spectroscopy (XPS) is a surface-sensitive technique based on the photoelectric effect. It is used to quantify elemental compositions and electronic states of the elements that exist inside materials. Planck showed that photons contain discrete, quantized energy levels that are dependent on their frequencies, $E_{p h o t o n}=h f$. The energy of inner shell electrons can be reliably described by first principles through

$$
E_{\text {electron }}=-13.6 \mathrm{eV} \frac{Z^{2}}{n^{2}}
$$

where $Z$ is the atomic number, $n$ is the principle quantum number. The photoelectric effect says that if a photon with sufficient energy is absorbed by an electron, the electron will be released with a kinetic energy expressed as

$$
K E_{\text {electron }}=E_{\text {photon }}-\phi
$$

where $\phi$ is the "work function" of the material. This colloquial "work function" is actually made up of the binding energy, $E_{\mathrm{B}}$, and the true work function, $\Phi$. This binding energy is defined as the energy needed to raise the electrons to the Fermi level, which is the highest possible energy of electrons at $0 \mathrm{~K}$. The 'true' work function, $\Phi$, is the energy required to raise the electrons to vacuum level.

In an XPS measurement, the sample is illuminated with a monochromatic beam. At the University of Missouri in Rolla, this is via a $150 \mathrm{~W}$ Al-Ka source. The monochromatic source allows for high resolution around $\Delta \mathrm{E} \approx 0.1 \mathrm{eV}$. The sample's electrons absorb the incident X-ray photons and are ejected from the sample. The detector measures the kinetic energy of the ejected electrons and reports the $E_{\mathrm{B}}$ through

$$
E_{\mathrm{B}}=E_{\text {photon }}-K E_{\text {electron }}-\Phi
$$

Experimentally, electrons give up a few $\mathrm{eV}$ as they absorbed by the detector, so $\Phi$ must be calibrated in the instruments, and $E_{\text {photon }}$ is set prior to the measurement. The various binding energies are well known and tabulated for each element and shell. Upon background subtraction, the species present 
will appear as sharp peaks at the characteristic energies. While most elements can be described by their $1 \mathrm{~s}$ features, higher orders help identify/quantize those who may be otherwise obscured by overlapping features.

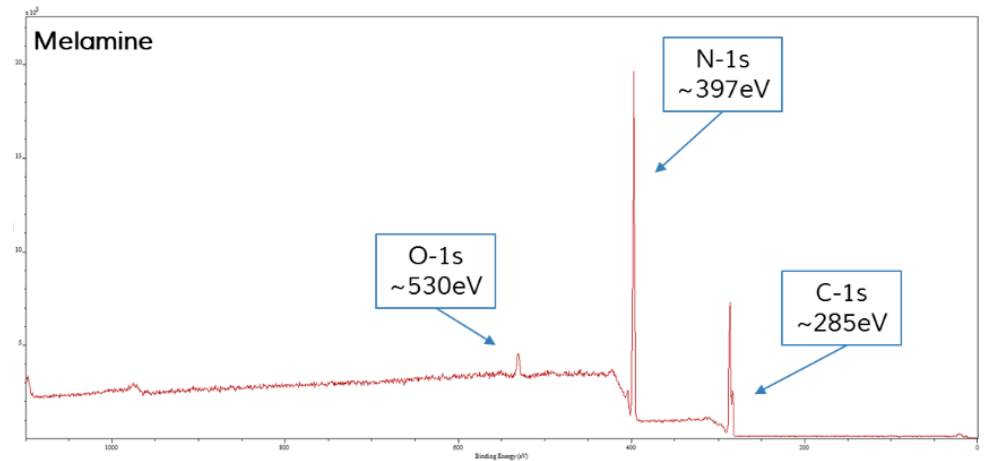

Figure 25. XPS spectra of melamine. Intensity (CPS) and binding energy (eV) are the $\mathrm{y}$ and $\mathrm{x}$ axes, respectively. As an industry standard, the binding energy is plotted high to low, as it is inversely related to the measured kinetic energy.

With all spectroscopic techniques, different elements will be more or less sensitive to specific phenomenon being measured. In XPS measurements, this manifests as a reduction in counts for less sensitive samples. To account for this, we introduce the relative sensitivity factor, RSF (sometimes referred to as the atomic sensitivity factor, ASF). This is a factor calibrated for each element for a given instrument ${ }^{[29]}$.

For example, suppose that one could create a sample composed entirely of solid CO. Ideally, one would observe distinct signals from $\mathrm{C}$ and $\mathrm{O}$ that have equal areas. However, these elements have very different RSF's: $\operatorname{RSF}(\mathrm{C})=0.25$ and $\operatorname{RSF}(\mathrm{O})=0.66$. Because of this sensitivity, the $\mathrm{C}$ peak would account for $27.5 \%$ of the full spectrum, and the $\mathrm{O} 72.5 \%$. One must account for these sensitivity differences by adjusting the integrated areas of the spectra. Using a measured spectrum, one may work backwards from the apparent peak areas to calculate the actual areas, and therefore, the concentrations. The atomic concentration of a given element in the measured sample may be expressed as 


$$
x_{\mathrm{k}}^{\text {atomic }}=\frac{\frac{A_{\mathrm{k}}^{\text {apparent }}}{R S F_{k}}}{\sum_{j=1}^{\text {all }} \frac{A_{\mathrm{j}}^{\text {apparent }}}{R S F_{\mathrm{j}}}}
$$

where $x_{\mathrm{k}}^{\text {atomic }}$ refers to the actual atomic concentration of element $k$ present in the sample, $A_{\mathrm{k}}^{\text {apparent }}$ is the 'apparent' area of that feature as measured in the spectrum. Dividing by the RSF of that sample gives the 'actual' area of the feature. However, this value is meaningless in itself. This process must be carried out for each feature in order to normalize by the total true area of all features present in the spectrum. This normalization of each feature by the total area yields the atomic concentration.

As a basic application, each feature in the spectrum can be fit using a single peak. For a first order approximation, this yields a decent estimate of the atomic concentration. However, upon close inspection, most peaks are generally not well-fit using only a single peak. Additionally, different binding environments yield minor shifts in $\mathrm{e}^{-}$binding energies. Employing the binding energy values from probable representative structures in the sample, one may can determine concentrations of various chemical species or phases present. When specifically applied to boron-doped activated carbon materials, this technique has been used by the University of Missouri to quantify the amounts of boron incorporated in the form of $\mathrm{sp}^{2}$ bonds ${ }^{[30]}$.

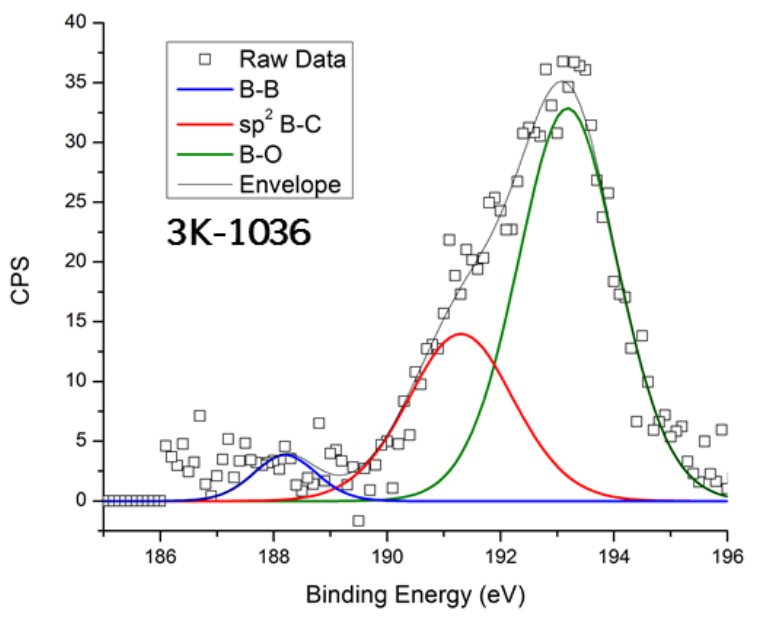

Figure 26. XPS sample spectrum of the boron region. Boron is found in the energy range of $E_{\mathrm{B}}=184-200 \mathrm{eV}$ for MU boron doped, activated carbon materials. As an analytical technique, XPS allows one to distinguish between $\mathrm{sp}^{2} \mathrm{~B}-\mathrm{C}$ bonds, and boron that has simply condensed on the surface in the form of B-B and B-O bonds. 
As discussed in the synthesis section, doped activated carbon materials may be oxygen-sensitive. These materials can accumulate adsorbed, and chemically bonded oxygen on their surfaces. This poses an additional layer of complications for XPS analyses. Air-contaminated samples will invariably suffer from the accumulation of adventitious carbon, a poorly-understood but ubiquitous layer of miscellaneous hydrocarbon contamination. The appearance of this feature is so omnipresent that it has become an industry standard to calibrate spectra/instrumentation to this feature (generally, $E_{\mathrm{B}} \approx 284.8 \mathrm{eV}$ ) for a given measurement. For non-organic samples, this feature can be ignored with minimal concern. However, organic samples suffer the consequence that the quantity of this contamination varies from measurement to measurement. In order to perform fine structure analysis on these decidedly carbon-containing structures, we need to be able to sufficiently account for these additional features.

\section{Establishing the Presence of $\mathrm{sp}^{2} \mathrm{~B}-\mathrm{C}$ Bonds}

The boron doping process was monitored by XPS in order to understand the environment of boron in the carbon matrix. The measured spectra can be notoriously hard to fit because of the deconvolutions process. Any number of quantizations can be achieved for a given set of peaks depending on the initial fitting conditions. Therefore, we have developed a method where XPS spectra are analyzed by quantitatively requiring consistency in multiple elemental spectra for a particular sample. If a compound of elements is observed in one high resolution elemental spectra, then that same compound must be observed in the complementary elemental spectra. For example, if we believe we observe the compound $\mathrm{BC}_{3}$ in the high resolution boron spectrum, then we require an equal amount of $\mathrm{BC}_{3}$ to show up in the high resolution carbon spectrum. Exact oxygen surface groups are difficult to classify in the spectra with complete certainty. For these reasons we have modeled all surface oxides to be of the form B-O or C-O.

Spectra are fit assuming an environment comprised of 6 unique bonds (resulting in 9 peaks across three elemental ranges: $\mathrm{C}-\mathrm{C}, \mathrm{B}-\mathrm{C}_{3}, \mathrm{~B}-\mathrm{B}, \mathrm{C}-\mathrm{O}, \mathrm{B}-\mathrm{O}$, and $\mathrm{C}-\mathrm{H}$. The comprehensive features for deconvolution are shown in Table 4. 
Table 4: Peak deconvolution assignments for our boron doped carbon systems, including initial fitting peak positions and FWHM's reported in the literature ${ }^{[31-33]}$ :

\begin{tabular}{|c|c|c|c|}
\hline Parameter & \multicolumn{3}{|l|}{ Description } \\
\hline$A_{y}^{z}$ & \multicolumn{3}{|c|}{ Raw area for each fitted peak of bond $z$ in the spectra of element $y$} \\
\hline$A_{y}$ & \multicolumn{3}{|c|}{$\begin{array}{l}\text { Raw area of the element } y \text { feature of the spectra, generated from the sum of the } \\
\text { individual components } A_{y}^{z}\end{array}$} \\
\hline$\sigma_{y}$ & \multicolumn{3}{|c|}{ Relative sensitivity factor (RSF) of element y. } \\
\hline$x_{y}^{Z}$ & \multicolumn{3}{|c|}{ Fraction of bond $z$ in the element $y$ feature. Calculated from $A_{y}^{z} / A_{y}$} \\
\hline$X_{y}$ & \multicolumn{3}{|c|}{$\begin{array}{l}\text { Fraction (concentration) of element } y \text { in the sample. Calculated from applying the } \\
\text { RSF corrections to the peak heights: }\left(A_{y} / \sigma_{y}\right) / \sum_{1}^{\infty}\left(A_{n} / \sigma_{n}\right)\end{array}$} \\
\hline Parameter & Description & \begin{tabular}{|l|}
$\begin{array}{l}\text { Peak Pos. } \\
(\mathrm{eV})\end{array}$ \\
\end{tabular} & $\begin{array}{l}\text { FWHM } \\
(\mathrm{eV})\end{array}$ \\
\hline$x_{B}^{B B}$ & Fraction of B1s spectrum with atoms in a BB bonding env. & 188.5 & 2.0 \\
\hline$x_{B}^{B C 3}$ & Fraction of $\mathrm{B} 1 \mathrm{~s}$ spectrum with atoms in a $\mathrm{BC}_{3}$ bonding env. & 191.0 & 2.5 \\
\hline$x_{B}^{B O}$ & Fraction of B1s spectrum with atoms in a BO bonding env. & 193.0 & 1.9 \\
\hline$x_{C}^{B C 3}$ & Fraction of $\mathrm{C} 1 \mathrm{~s}$ spectrum with atoms in a $\mathrm{BC}_{3}$ bonding env. & 283.5 & 1.0 \\
\hline$x_{C}^{C C}$ & Fraction of C1s spectrum with atoms in a CC bonding env. & 284.4 & 0.8 \\
\hline$x_{C}^{C H}$ & Fraction of C1s spectrum with atoms in a $\mathrm{CH}$ bonding env. & 285.0 & 1.5 \\
\hline$x_{C}^{C O}$ & Fraction of $\mathrm{C} 1 \mathrm{~s}$ spectrum with atoms in a $\mathrm{CO}$ bonding env. & 286.5 & 1.5 \\
\hline$x_{O}^{B O}$ & Fraction of O1s spectrum with atoms in a BO bonding env. & 531.8 & 1.8 \\
\hline$x_{O}^{C O}$ & Fraction of O1s spectrum with atoms in a CO bonding env. & 532.8 & 1.8 \\
\hline
\end{tabular}

The first three equations have been named the consistency equations. They require that the total concentration of each element be accounted for. For the concentration of a single element, the accounting takes place over all the different elemental spectra. The equations are:

$$
\begin{gathered}
x_{B}^{B O} X_{B}+x_{C}^{C O} X_{C}=X_{O} \\
3 x_{B}^{B C 3} X_{B}+x_{O}^{C O} X_{O}+x_{C}^{C} X_{C}+x_{C}^{C H} X_{C}=X_{C} \\
\frac{1}{3} x_{C}^{B C 3} X_{C}+x_{O}^{B O} X_{O}+x_{B}^{B B} X_{B}=X_{B}
\end{gathered}
$$

The second three equations have been named the reciprocal equations. They require that, for a compound composed of two elements, that compound must be observed in equal parts in the compound's two separate elemental spectra. The equations are:

$$
\begin{aligned}
\sigma_{C} x_{B}^{B C 3} A_{B} & =\sigma_{B} x_{C}^{B C 3} A_{C} \\
\sigma_{O} x_{B}^{B O} A_{B} & =\sigma_{B} x_{O}^{B O} A_{O} \\
\sigma_{C} x_{O}^{C O} A_{O} & =\sigma_{O} x_{C}^{C O} A_{C}
\end{aligned}
$$


Every value in these equations is either a constant or is a value determined from the spectral fit. The B, C, and O spectra are initially fit using the values reported in Table 4. The parameters from the initial fit are used in the above equations and adjusted until consistency is achieved. The degree of consistency dictates what subsequent changes are necessary while fitting the three spectra. If the left sides of Eq (82) and Eq (87) are notably higher than their right sides, then $x_{O}^{C O}$ is constrained to comprise a lower area; if Eq (84) displays the greatest inequality on its own, then $x_{B}^{B B}$ is adjusted accordingly. The process is iterated until the difference between the two sides of each equation is minimized; typically agreement can be achieved to within $1 \%$.
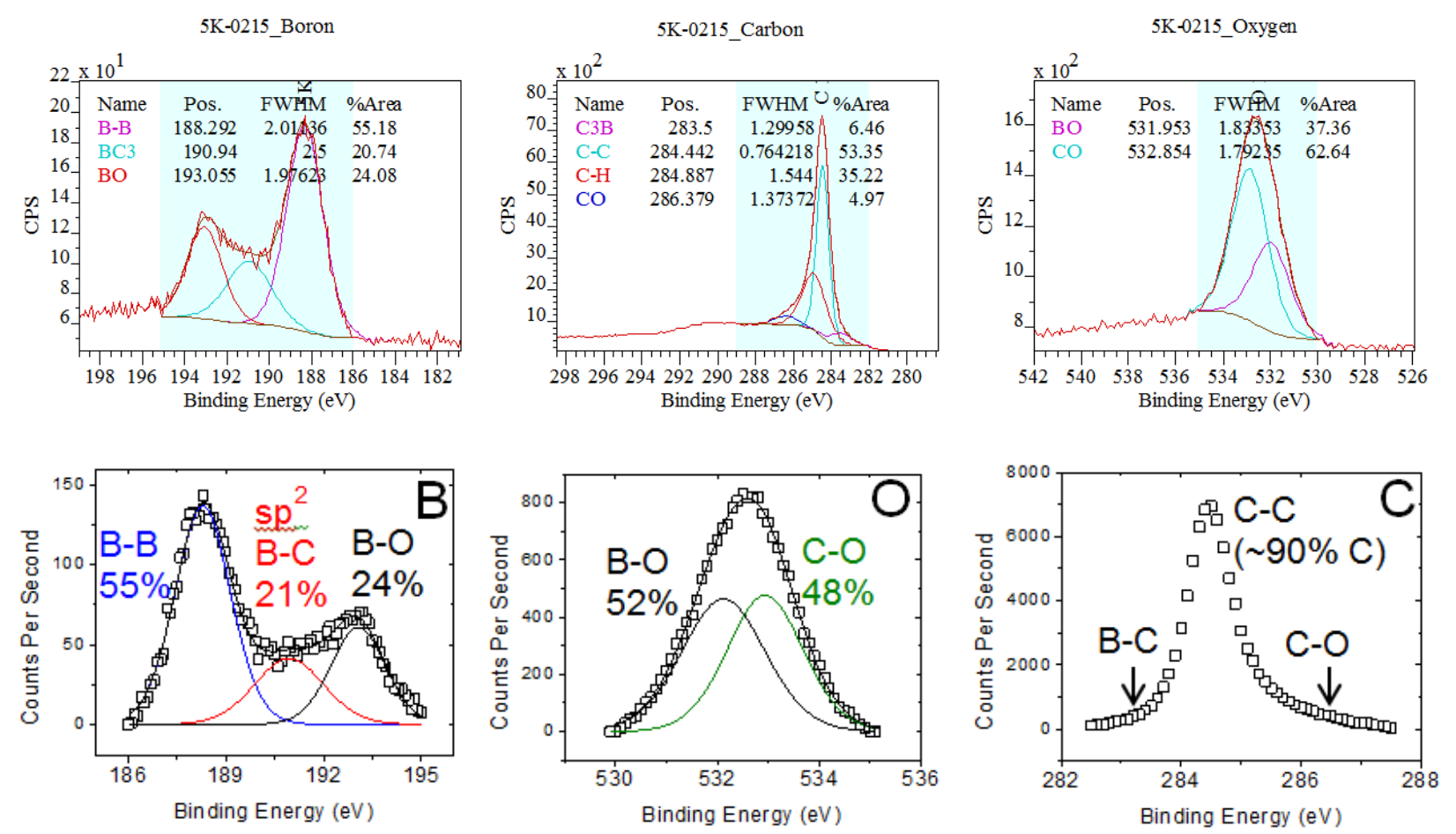

Figure 27. The boron, carbon, and oxygen XPS spectra for sample 5K-0215. 
Table 5: Boron contents as determined by XPS.

\begin{tabular}{|c|c|c|c|c|}
\hline Sample & $\begin{array}{l}\mathrm{B}_{\text {tot }} \\
(\mathrm{wt} \%)\end{array}$ & $\begin{array}{l}\mathrm{B}_{\mathrm{B}-\mathrm{C}} \\
(\mathrm{wt} \%)\end{array}$ & $\begin{array}{l}\mathrm{B}_{\mathrm{B}-\mathrm{C}} / \mathrm{B} \\
(\%)\end{array}$ & $\begin{array}{l}\mathrm{O} \\
(\mathrm{wt} \%)\end{array}$ \\
\hline \multicolumn{5}{|c|}{ Stationary Doping (Liquid-Phase Deposition) } \\
\hline $4 \mathrm{~K}-0240$ & 1.2 & 0.0 & 0.0 & 6.2 \\
\hline $4 \mathrm{~K}-0244$ & 1.7 & 0.0 & 0.0 & 7.8 \\
\hline $4 \mathrm{~K}-0245$ & 4.1 & 0.7 & 17.6 & 10.0 \\
\hline $4 \mathrm{~K}-0748$ & 5.2 & 1.0 & 18.6 & 7.9 \\
\hline $3 \mathrm{~K}-0205$ & 7.5 & 0.9 & 12.5 & 9.0 \\
\hline $3 \mathrm{~K}-0211$ & 7.6 & 0.6 & 8.5 & 10.9 \\
\hline $5 \mathrm{~K}-0215$ & 8.4 & 1.7 & 20.7 & 8.7 \\
\hline $3 \mathrm{~K}-0208$ & 14.6 & 1.7 & 11.7 & 9.7 \\
\hline \multicolumn{5}{|c|}{ Flow Doping (Vapor-Phase Deposition) } \\
\hline $3 \mathrm{~K}-0230$ & 2.2 & 0.1 & 3.1 & 5.7 \\
\hline $3 \mathrm{~K}-1035$ & 3.9 & 0.4 & 9.9 & 8.9 \\
\hline $3 \mathrm{~K} 0231$ & 6.1 & 0.8 & 13 & 11 \\
\hline $3 \mathrm{~K}-1036$ & 3.8 & 1.1 & 23 & 7.7 \\
\hline $3 \mathrm{~K}-0234$ & 4.8 & 0.6 & 13 & 8.5 \\
\hline $3 \mathrm{~K} 0235$ & 24 & 1.3 & 5.4 & 14 \\
\hline $3 \mathrm{~K}-1038$ & 19 & 1.4 & 7.5 & 12 \\
\hline
\end{tabular}

One interesting result from the 3 spectrum analysis is that $25 \%$ or less of the boron is making its way into the carbon. The majority of boron is staying as boron complexes; only some is forming oxides or incorporating into the carbon. 


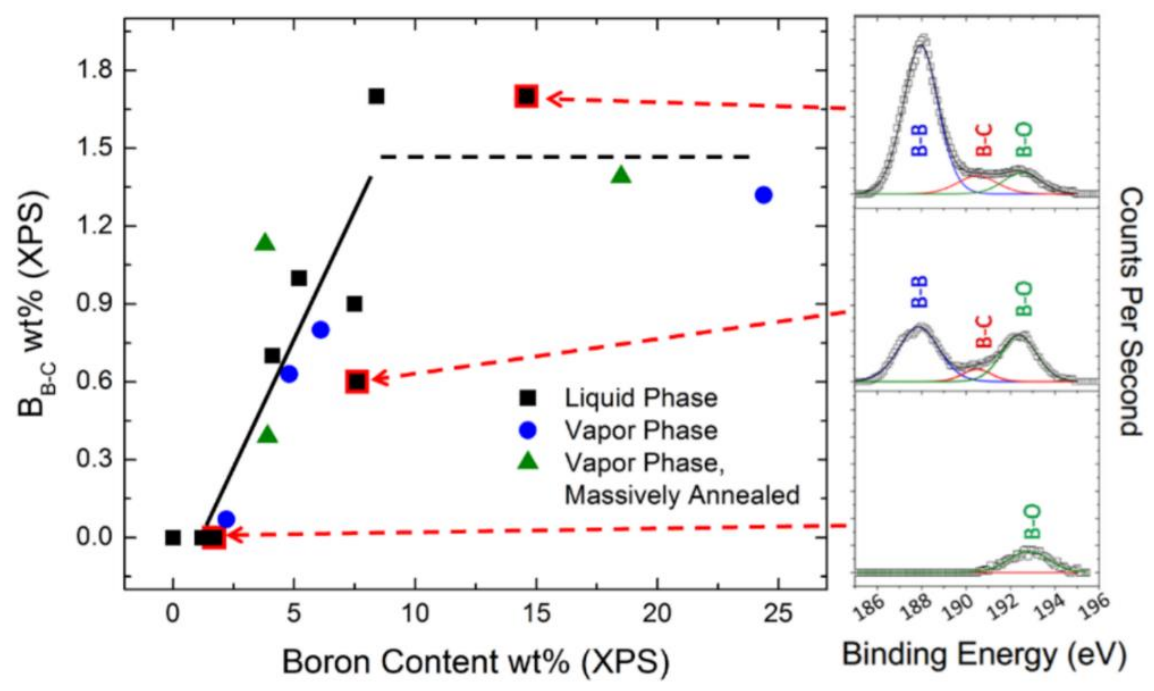

Figure 28. XPS spectra of boron on multiple doped carbon material.

Fig 28, Left: Concentration of $\mathrm{sp}^{2}$ bonded boron in different samples as a function of total boron concentration in the samples. XPS spectra for boron, carbon and oxygen were simultaneously fit to determine amounts of $\mathrm{sp}^{2}$ bonded boron in doped carbon samples. The amount of $\mathrm{sp}^{2}$ bonded boron increases with increasing total boron content. Fig 28, Bottom Right: Boron spectra for sample 4K-0244. This spectra is representative of all samples with boron contents $<2 \mathrm{wt} \%$. In this range, the decomposition of decaborane readily forms B-O bonds. No B-C bonds are observed. Fig 28, Middle Right: Boron spectra for sample $3 \mathrm{~K}-0211$. This spectrum is representative of samples with $2<\mathrm{B} w \mathrm{t} \%<7$. In this range, peak splitting is observed as the oxygen sites become saturated and B-B and B-C bonds emerge. Fig 28, Top Right: Boron spectra for sample 3K-0208. This spectrum is representative of samples with B wt $\%>7$. The B-B peak is most prominent in this spectrum due to the larger quantity of total boron in the sample. Further, the area under the B-C peak increased to be approximately equal to that under the B-O peak, indicating a larger amount of $\mathrm{sp}^{2}$ bonded boron in the sample. It is worthwhile to note that specific units are not included on the $y$-axes because of variations in x-ray intensity that occurred with different measurements.

\subsection{Fourier Transform Infrared Spectroscopy}

When exposed to infrared radiation, molecules selectively absorb light of specific wavelengths, which causes a change in their dipole moments. This selective absorption allows 
one to generate a molecular vibrational spectrum of a measured sample. Fourier Transform Infrared Spectroscopy (FTIR) employs this characteristic absorption of infrared radiation to determine the structures of molecules.

In FTIR spectroscopy, infrared radiation is passed through a sample. The transmitted radiation is directed to a detector and the resulting spectrum represents a molecular 'fingerprint' of the sample. During the selective absorption, the vibrational energy levels of sample molecules transfer from ground state to excited state. The frequency of the absorption peak is determined by this vibrational energy gap and the number of absorption peaks present in the spectrum is related to the number of vibrational degrees of freedom in the molecules. The intensity of absorption peaks is related to the change of dipole moment and the possibility of the transition of energy levels. Analyzing the infrared spectrum yields abundant structural information of a sample.

The instrument used at the University of Missouri is a Galaxy Series 5000 FTIR spectrometer (Mattson ATI) equipped with a Quantum Infrared Microscope (Mattson ATI). The microscope has a visible port that can be selected by mirrors. Using this function, the visible images are observed to accurately determine the sampling area during the infrared imaging. Infrared light is guided into the microscope by using an external mirror in the FTIR spectrometer. Every spectrum of each measured sample was generated by averaging 32 scans and the resolution was set to be $2 \mathrm{~cm}^{-1}$. Spectra were recorded over wavenumbers ranging between 4000 and $600 \mathrm{~cm}^{-1}$ according to the spectral response range of the cooled MCT detector. Measuring the FTIR spectra of powdered samples poses several experimental difficulties. Results from conventional FTIR exhibited spectral broadening of bands between $1000 \mathrm{~cm}-1$ and $1100 \mathrm{~cm}-1$ as well as band overlaps. This is due to the variation of microenvironment in the nanoporous carbon material. To mitigate the effects of spectral broadening, powdered samples were suspended in a potassium 
bromide $(\mathrm{KBr})$ pellet and were reduced to a low mass ratio of approximately ratio of 1:2000 in terms of sample mass : $\mathrm{KBr}$ mass. A pure $\mathrm{KBr}$ pellet and boron carbide were used as references samples during the microscopic FTIR experiments.

A keystone aperture was used to select the sampling area and limit the infrared beam. The aperture is permanently centered in both the infrared and visual beam paths to ensure the sample is accurately aligned. FTIR spectra were acquired with different aperture sizes, using the diagonal length to represent the size of the aperture ${ }^{[34]}$.
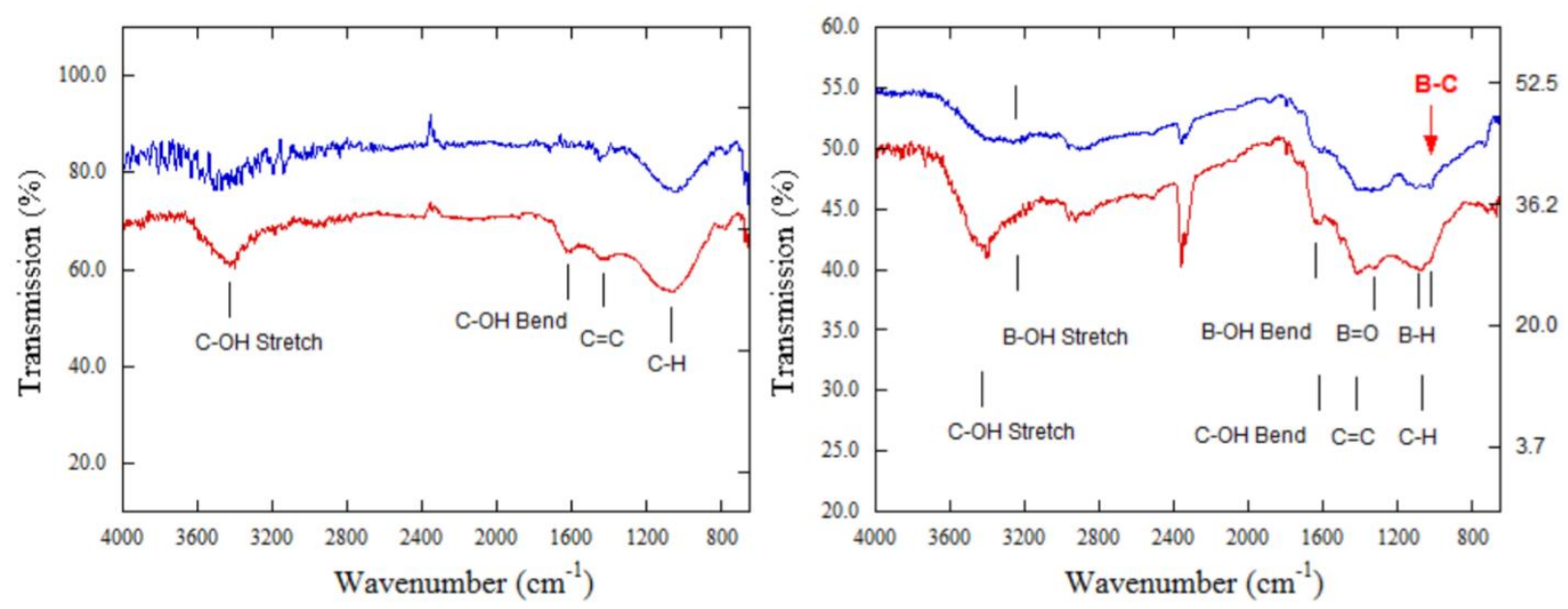

Figure 29. FTIR transmission spectra for precursor and boron-doped carbon materials.

Fig 29, Left: transmission spectra for 3K using the FTIR microscope with a larger aperture $(100 \mu \mathrm{m}-\mathrm{red})$ and small aperture $(20 \mu \mathrm{m}-$ blue $)$. The broadband around $1068 \mathrm{~cm}-1$ is due to the in-plane $\mathrm{C}-\mathrm{H}$ deformation bending modes in benzene. The micro-environment of porous carbon causes a broadening of $\mathrm{C}-\mathrm{H}$ related bands, but $\mathrm{B}-\mathrm{C}$ band is definitely absent in the spectra. Fig 29 , Right: transmission spectra for $3 \mathrm{~K}-\mathrm{H} 31$ (III,A) using the FTIR microscope with a larger aperture $(100 \mu \mathrm{m}-\mathrm{red})$ and small aperture $(20 \mu \mathrm{m}-$ blue $)$. In addition to carbon related peaks, this spectrum shows boron related bands. The narrow band associated with the B-C bond is clearer in the FTIR spectrum using the small aperture while intensities of $-\mathrm{OH}$ related bands decrease and shift. 
A controlled experiment showed that the B-C bond can be recognized in boron carbide sample in FT-IR microscopic spectrum with an aperture size of $20 \mu \mathrm{m}$. FT-IR microscopic spectra show no B-C bond in $3 \mathrm{~K}$ sample. FT-IR microscopic spectra clearly showed B-C bonds in the boron doped sample labeled 3K-H31 (III,A). This sample contained $10 \mathrm{wt} \%$ boron as measured by PGNAA.

\subsection{Energy Dispersive X-Ray Spectroscopy}

Energy dispersive $\mathrm{x}$-ray spectroscopy (EDS) is a chemical analysis technique that works in conjunction with scanning electron microscopy (SEM). Electron microscopes focus a beam of electrons on a sample. These electrons interact with the sample to produce a range of signals yielding information about the composition and surface topography. In SEM, electrons are knocked free from the sample. Those electrons are collected and their energies are generally indicative of Z-contrast. However, EDS makes use of a secondary effect in which an electron will move from a higher-n shell to fill the vacancy created by the ejected electron. As this is an exothermic process, it will release an X-ray photon with a well-defined, tabulated value.

While XPS is largely dependent on a single characteristic peak, EDS relies on the fact that there are several characteristic peaks, which help with identification and quantification because the energy and range are much smaller. The individual features are described using a 2-piece nomenclature $X Y$, where $X$ is the specific line representing the vacancy being filled (corresponding to $K, \mathrm{~L}, \mathrm{M} \ldots$ for an $\mathrm{e}^{-}$filling the $\mathrm{n}=1,2,3 \ldots$ shells) and $Y$ is the 'jump' $(\alpha, \beta, \gamma \ldots$ corresponding to a jump of $\Delta n=1,2,3)$.

EDS typically features an order of magnitude lower resolution $(\Delta \mathrm{E}=\sim 1 \mathrm{eV})$, but is a very simple and inexpensive technique. 

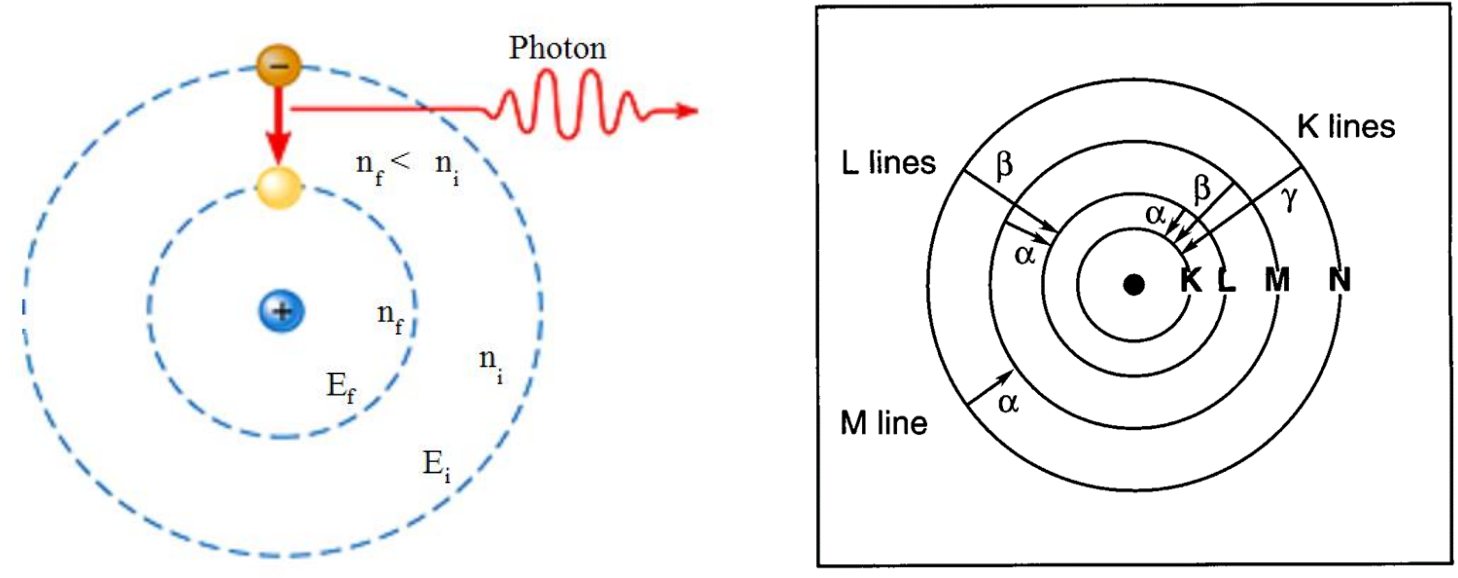

Figure 30. Cartoon of mechanisms underlying energy dispersive x-ray spectroscopy. Left: As an electron fills the vacancy left by a scattered inner shell electron, the exothermic process results in the release of a photon with an energy equivalent to the difference between the shells. In EDS, the energy of this photon is measured and compared against tabulated values for sample identification and quantification. Right: Photon energies for a single element can take by a number of different electron shifts.

\subsection{Electron Microscopy}

Exploring the distribution of deposited boron on a nanoporous carbon via TEM is made difficult by the amorphous structure of the material. In order to explore the nature of the doping mechanism, a PVDCbased precursor was boron doped under stationary conditions. PVDC thermally decomposes stoichiometrically into pure carbon and gaseous $\mathrm{HCl}^{[35,36]}$. The resulting carbon, named PVDC-0736, has a well-defined, ordered, graphite-like material, which is desirable for exploration via TEM. 


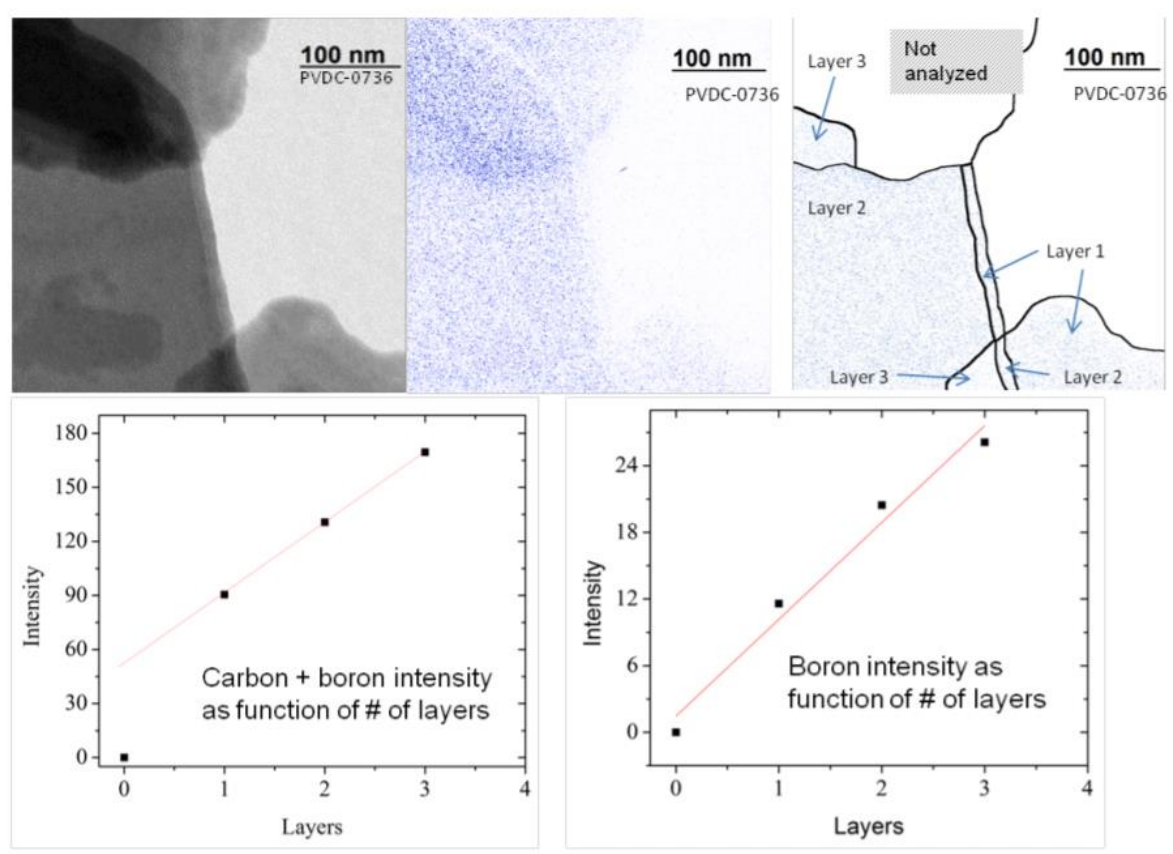

Figure 31. EFTEM images and boron map for a doped PVDC-based sample. Top-Left: EFTEM (carbon and boron) image of section comprised of less than three flat, parallel layers. Top-Center: EFTEM boron map of the same region, showing uniform boron content throughout carbon sections. Top-Right: Proposed model of the layout of structures based on the measured boron intensity and the assumption that boron is uniformly distributed. Bottom: Plots of intensity vs identified number of layers. Linear nature of the fits confirms that the boron is distributed uniformly over $>200 \mathrm{~nm}$ laterally and $\geq 3$ graphene layers vertically $[35,37,38]$.

\subsection{Electron Energy Loss Spectroscopy}

Determining the distribution of boron in real, discrete space has been a challenge, insurmountable by the standard techniques (i.e. FTIR, XPS, etc), due to the similar, low atomic weights of the organic (B/C/O/H) compounds comprising our systems. Transmission electron microscopy (TEM) electron energy loss spectroscopy (EELS) and energy filtered TEM (EFTEM) are spatial characterization techniques that are capable of overcoming these limitations. However, these are highly dependent on the thickness of the sample, as excessive thicknesses introduce multiple-scattering artifacts. As a rule, quality TEM-EELS and EFTEM require sample thicknesses less than one mean free path $(<200 \mathrm{~nm}$ at $300 \mathrm{kV}$ for carbon based materials). Scanning electron microscopy (SEM) has shown that our materials feature grain sizes on the microscale, necessitating some form of a thinning method. Standard microtoming isn't possible for powders. A common workaround is to embed them within an amorphous epoxy and microtome cross- 
sections of the appropriate thickness. However, this technique is not ideal for TEM analysis when encapsulating an amorphous material with similar high-carbon chemistries. Therefore, a novel technique must be developed. Boron-doped carbons are notoriously oxygen sensitive and thus may not be separated via centrifugation as in a common workaround. Previously, samples were prepared for FTIR via isolation within a pressed $\mathrm{KBr}$ "pill”. This technique was revisited as embedding an amorphous powder within a crystalline matrix also avoids many of the difficulties present when using an amorphous epoxy substrate. The pill was made using a 1:3000 mass ratio of 5K-0215 (PGAA: $8 \mathrm{wt} \%$ B) to $\mathrm{KBr}$; a very low ratio is required to successfully induce crystalline formation upon compaction. Dual beam focused ion beam (DBFIB) electron microscopy was then used to then select site specific thin samples for TEM.

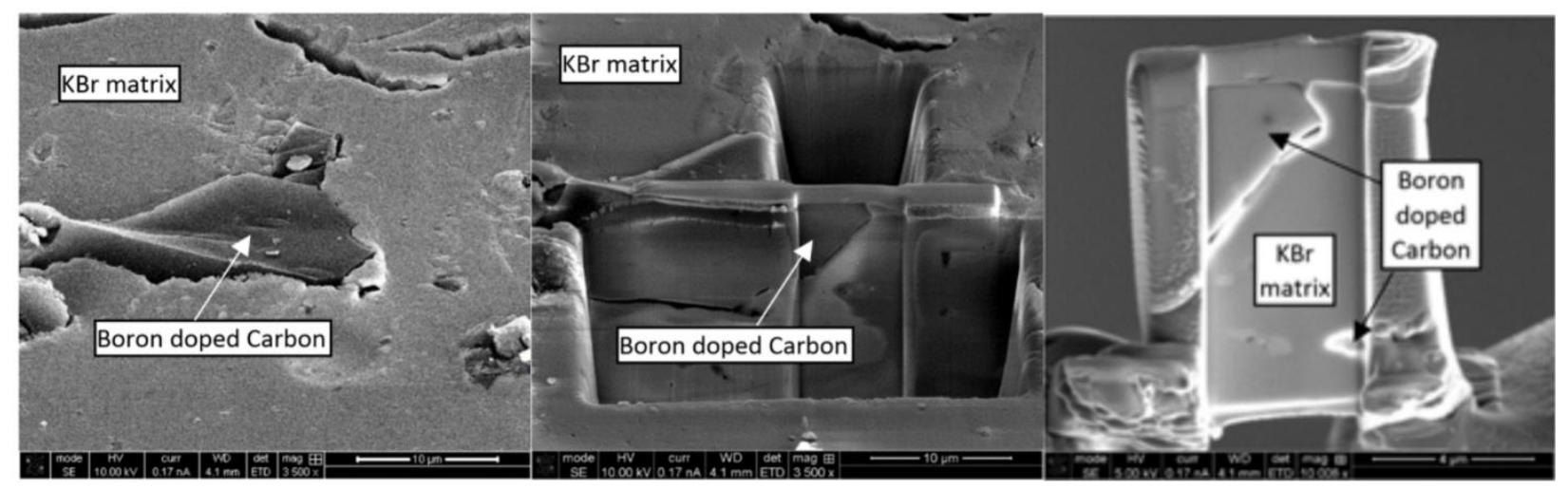

Figure 32. Left to Right: SEM images of the boron doped carbon particle embedded within the $\mathrm{KBr}$ matrix, the region of interest for study being extracted by DB-FIB, and the successful TEM cross-section supported within a $\mathrm{KBr}$ substrate.

$\mathrm{KBr}$ has been documented as being highly reactive. During transfer of the TEM sample from DBFIB to the TEM, the thinned regions of the $\mathrm{KBr}$ matrix sublimed leaving only carbon sections attached to a thicker $\mathrm{KBr}$ frame (>1 micron in thickness) which did not react, an ideal result for TEM analysis. Fig 2 (left) shows the bright-field image of the DB-FIB sample. 

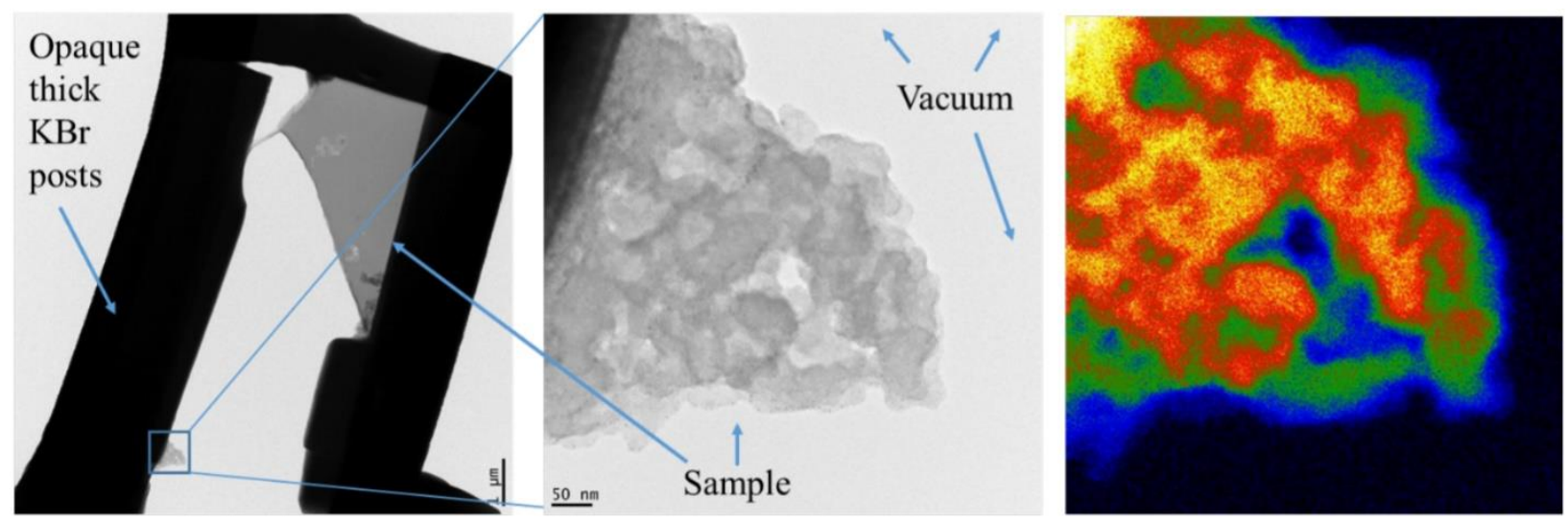

Figure 33. Left, Middle: Bright-field image of carbon sample lifted out and suspended in vacuum via $\mathrm{KBr}$ posts after the milled $\mathrm{KBr}$ body has sublimated. This is viewed from the opposite side of the sample as seen in the previous figure. Right: Thickness analysis of suspended sample from EFTEM.All of the regions within this particular particle have a mean free path under one (brighter refers to increasing thickness).

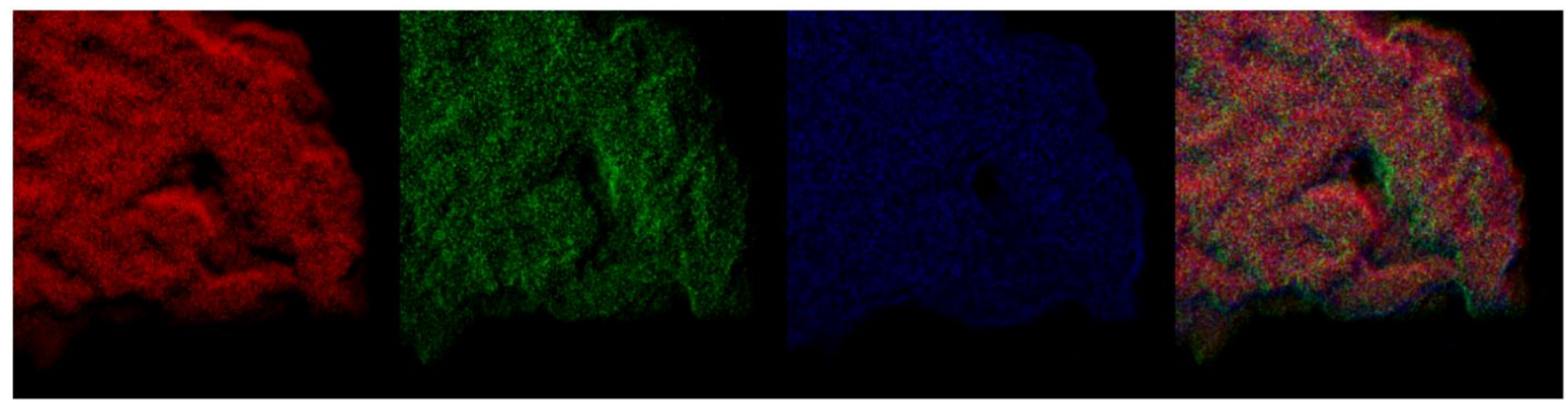

Figure 34. EFTEM chemical map of (left to right) carbon, boron, oxygen and composite map of the assigned mixed colors in RGB. The system is mainly carbon as the composite still shows mostly red with a minor purple hue. However, the boron (green) appears to largely aggregate at pore "pockets", a possible consequence of doping via deposition.

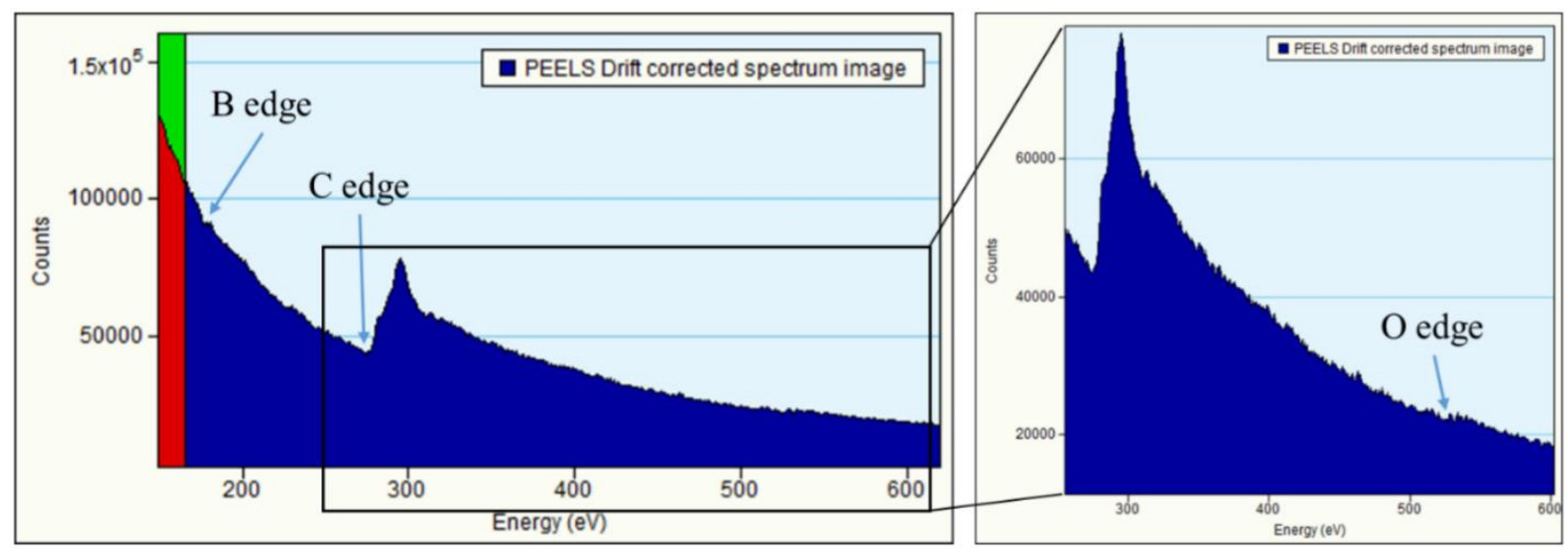

Figure 35. EELS spectra showing a minor boron K-edge, carbon K-edge, and the magnified region of a very minor oxygen edge indicating low oxygen content in this particle. 
Analysis of fine structure within the EELS edges can yield bonding and chemical environment information of the material system. However, the EELS capabilities accessible at the University of Missouri Electron Microscopy Core (EMC), where this work was performed, are chemical environment limited because the equipped gatan imaging filter features a prohibitively low energy resolution $(\sim 1 \mathrm{eV})$. 


\section{Synthesis, Engineering, and Production}

\subsection{Nanoporous Carbon Powder Synthesis and Engineering}

The adsorptive properties of nanoporous carbon can be modified by varying the initial synthesis parameters such as activation temperature, $\mathrm{KOH}: \mathrm{C}$ weight ratio, and flow rate of inert gas. Activated carbons may be produced from a range of natural or synthetic precursor materials, which have a slight impact on the surface area and adsorption capacity of the resultant material. In synthesizing most MU activated carbon materials, waste corncob was activated in a multi-step process. First, corncob was mixed with an $85 \%$ Phosphoric Acid $\left(\mathrm{H}_{3} \mathrm{P}_{4}\right)$ solution at a 1.5:1 mass ratio and allowed to soak for 12 hours at 40C. Then the temperature was raised to $480 \mathrm{C}$ at a rate of $.5 \mathrm{C} / \mathrm{min}$ where it was allowed to dwell for 2 hours in an argon atmosphere. After cooling, the carbon char was washed with distilled water until reaching an approximately neutral $\mathrm{pH}(\mathrm{pH}>6.5)$. Once fully washed, the char was mixed with a solution of $\mathrm{KOH}$ dissolved in a small amount of distilled water to achieve a slurry-like texture. This slurry consists of approximately $0.8 \mathrm{~mL} \mathrm{H} \mathrm{H}_{2} \mathrm{O} / \mathrm{g} \mathrm{KOH}$. Using too little water will result in insufficient or heterogeneous intercalation throughout the sample and using too much water will result in heating inconsistencies, dependent upon the activation apparatus used. The mixture was then heated to $700 \mathrm{C}$ at a rate of $5 \mathrm{C} / \mathrm{min}$ where it was allowed to dwell for two hours in an argon atmosphere 

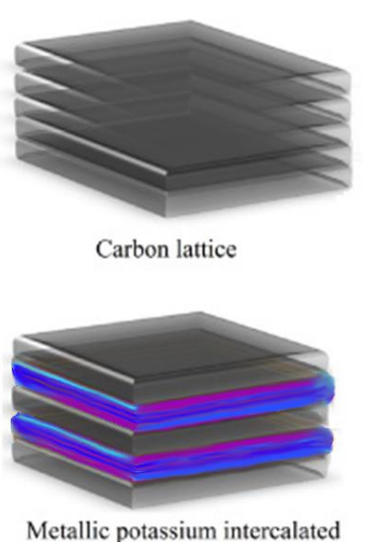

Metallic potassium intercalated

into the carbon lattice

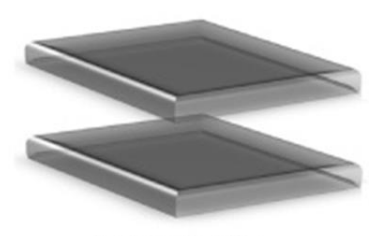

Activated carbon

Figure 36. Intercalation of metallic potassium into the carbon char. The potassium increases the surface area and expands the pore network.

Otowa et. al. described the activation process by the following reactions. Below $700 \mathrm{C}$, the main products are hydrogen, water, carbon monoxide, carbon dioxide, potassium oxide and carbonate. The dehydration of $\mathrm{KOH}$ to $\mathrm{K}_{2} \mathrm{O}$ (a) results in carbon consumption through the reaction of $\mathrm{CO}_{2}$, produced in reactions (b) and (c), with $\mathrm{K}_{2} \mathrm{O}$ to form $\mathrm{K}_{2} \mathrm{CO}_{3}{ }^{[39,40]}$ :

$$
\begin{aligned}
& 2 \mathrm{KOH} \rightarrow \mathrm{K}_{2} \mathrm{O}+\mathrm{H}_{2} \mathrm{O} \\
& \mathrm{C}+\mathrm{H}_{2} \mathrm{O} \rightarrow \mathrm{CO}+\mathrm{H}_{2} \\
& \mathrm{CO}+\mathrm{H}_{2} \mathrm{O} \rightarrow \mathrm{CO}_{2}+\mathrm{H}_{2} \\
& \mathrm{CO}_{2}+\mathrm{K}_{2} \mathrm{O} \rightarrow \mathrm{K}_{2} \mathrm{CO}_{3}:
\end{aligned}
$$

Above $700 \mathrm{C}$, however, an important activation mechanism occurs alongside the formation of metallic potassium. This mechanism, described in (e) and (f), is directly related to the formation of subnanometer pores:

$$
\begin{aligned}
& \mathrm{K}_{2} \mathrm{O}+\mathrm{H}_{2} \rightarrow 2 \mathrm{~K}+\mathrm{H}_{2} \mathrm{O} \\
& \mathrm{K}_{2} \mathrm{O}+\mathrm{C} \rightarrow 2 \mathrm{~K}+\mathrm{CO}:
\end{aligned}
$$


Activation above $700{ }^{\circ} \mathrm{C}$ allows for metallic potassium to penetrate between graphitic layers. The removal of potassium results in the expansion of the pore structure. The consumption of carbon by oxygen, the stretching of the lattice, and the removal of potassium result in the expansion of the pore network. This expansion corresponds to an increase in surface area and porosity. After cooling, the activated carbon is washed in distilled water until reaching a neutral $\mathrm{pH}$.

\subsection{Chemically Doped Materials}

The adsorptive capacity of any material is most affected by the extent of its specific surface area and the strength of its adsorption potential. It is possible for adsorption potentials to be modified by optimizing the pore size distribution. They may also be tuned by modifying the surface chemical composition. One potential pathway to achieving higher hydrogen binding energies in carbonaceous materials is by substituting a fraction of the carbon atoms in the carbon matrix with boron ${ }^{[41-43]}$. Functionalization through boron doping is predicted to create an electron deficiency via an empty $\mathrm{p}_{\mathrm{z}}$-orbital, yielding an increased depth of the gas-solid interaction potential. The proposed solubility limit to $\mathrm{sp}^{2} \mathrm{~B}-\mathrm{C}$ bonded boron substituted in carbon is 2.3 atm\%, though several compounds have been shown to exist with higher concentrations of $\mathrm{sp}^{2} \mathrm{~B}-\mathrm{C}{ }^{[44]}$. 


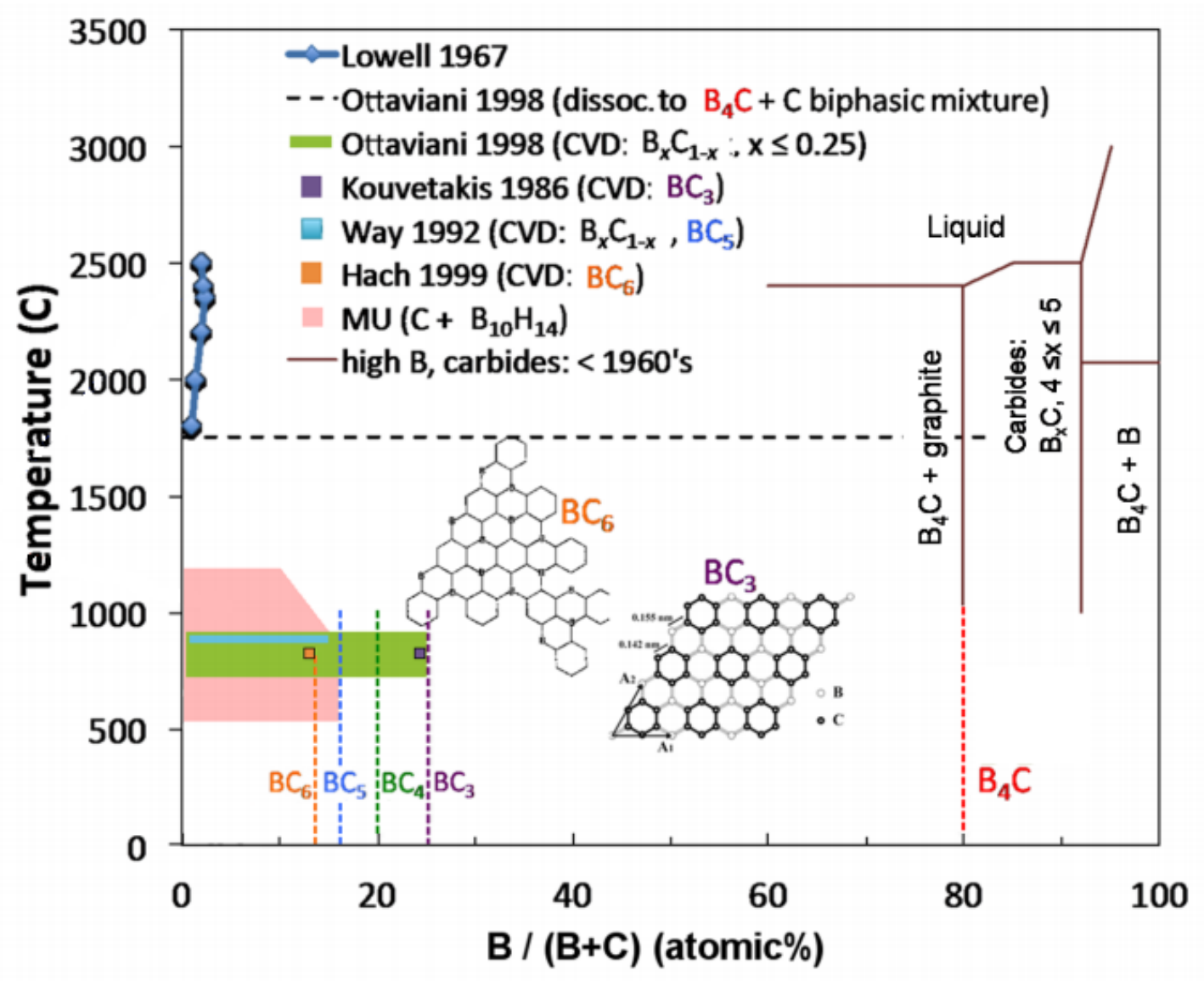

Figure 37. Boron-carbon phase diagram of synthesis temperature versus boron weight percent for existing B-C compounds. Vertical dashed lines show phases with fixed stoichiometric compositions. The targeted composition range of MU doped carbon materials is shown in pink. Despite predicting a $2.3 \mathrm{~B}$ wt $\%$ solubility limit, there are many known materials that have a higher concentration of $\mathrm{sp}^{2} \mathrm{~B}-\mathrm{C}$ bonds.

Adsorption potentials for boron-substituted graphene were computed from first principles and showed binding energies (potential well depths) of $12 \mathrm{~kJ} / \mathrm{molfor} 10 \mathrm{wt} \%$ boron. Grand Canonical Monte Carlo (GCMC) simulations in this potential predict gravimetric and volumetric storage capacities of $50 \mathrm{~g} / \mathrm{kg}$ and $32 \mathrm{~g} / \mathrm{L}$, respectively, at $298 \mathrm{~K}$ and 100 bar, which will deliver the 2010 DOE targets at room temperature. To generate systematic models of hydrogen storage on boron-substituted carbons as a function of boron concentration and distribution of boron at the surface and to be able to analyze experimental isotherms accordingly, we computed adsorption potentials for boron-substituted graphene from first principles and performed GCMC simulations of hydrogen adsorption in these potentials. Results are shown in the figures below. Boron substitution creates potential wells with potential well depths of $\sim 5,8,9$, and 
$12 \mathrm{~kJ} / \mathrm{mol}$ for $0,1,5$, and $10 \mathrm{wt} \%$ boron, respectively. So these simulations suggest that it is possible to raise the binding energy to hydrogen from $5 \mathrm{~kJ} / \mathrm{mol}$ up to $12 \mathrm{~kJ} / \mathrm{mol}$ by incorporating boron in the form of $\mathrm{sp}^{2} \mathrm{~B}-\mathrm{C}$ bonds.

This increase in binding energy should contribute toward improving gravimetric and volumetric storage capacities. However, boron atoms bonded to oxygen atoms are not expected to enhance binding of hydrogen. Typical surface-bound oxygen groups are shown in Fig 34. Therefore, a systematic effort was undertaken to remove oxygen from undoped carbon, prior to doping, while maintaining high surface areas of $\Sigma_{\mathrm{BET}} \approx 2,700 \mathrm{~m}^{2} / \mathrm{g}$.

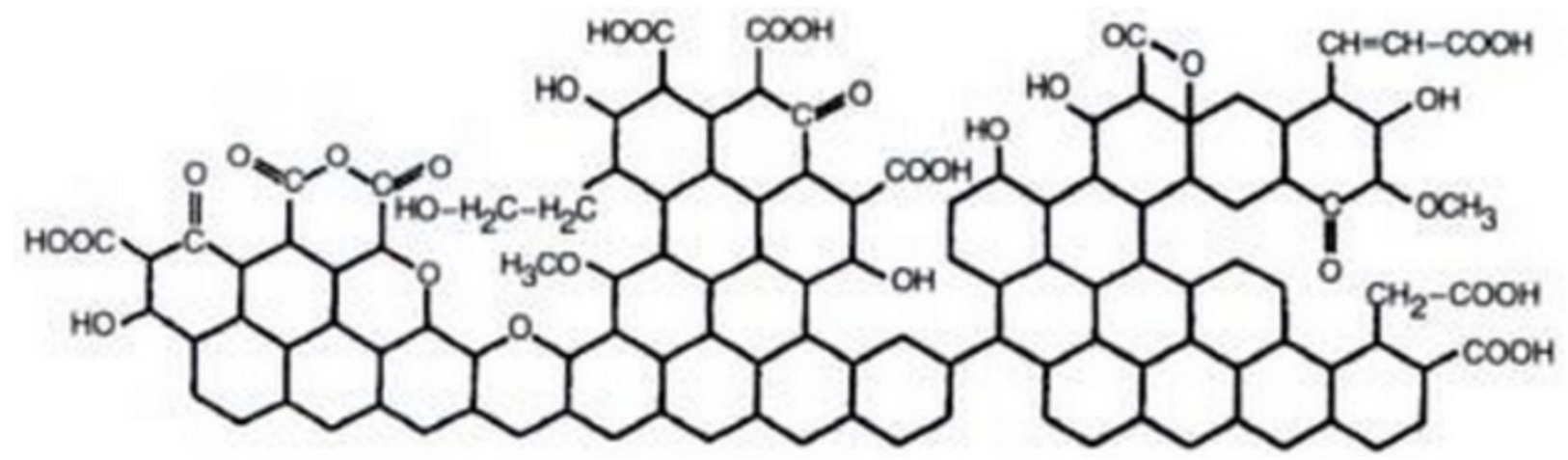

Figure 38. Surface-bound oxygen groups in graphitic/graphene-like carbon. These oxygen groups are representative of those contained within activated carbon materials synthesized at the University of Missouri.

\section{Deoxygenation of Precursor Carbon Materials}

Three different deoxygenation methods were used: (a) heat treatment up to $1,200{ }^{\circ} \mathrm{C}$; (b) microwave treatment; (c) treatment with hydrazine (reducing agent). Oxygen contents were monitored using XPS. Surface areas and pore-size distributions were monitored through BET analysis of nitrogen adsorption isotherms. Results are shown in Fig 39-41. Heat treatment and microwave treatment both gave a reduction of oxygen concentration from 8 to 1 atomic $\%$, accompanied by a drop in surface area from 2700 to $2300 \mathrm{~m}^{2} / \mathrm{g}$ or lower. 

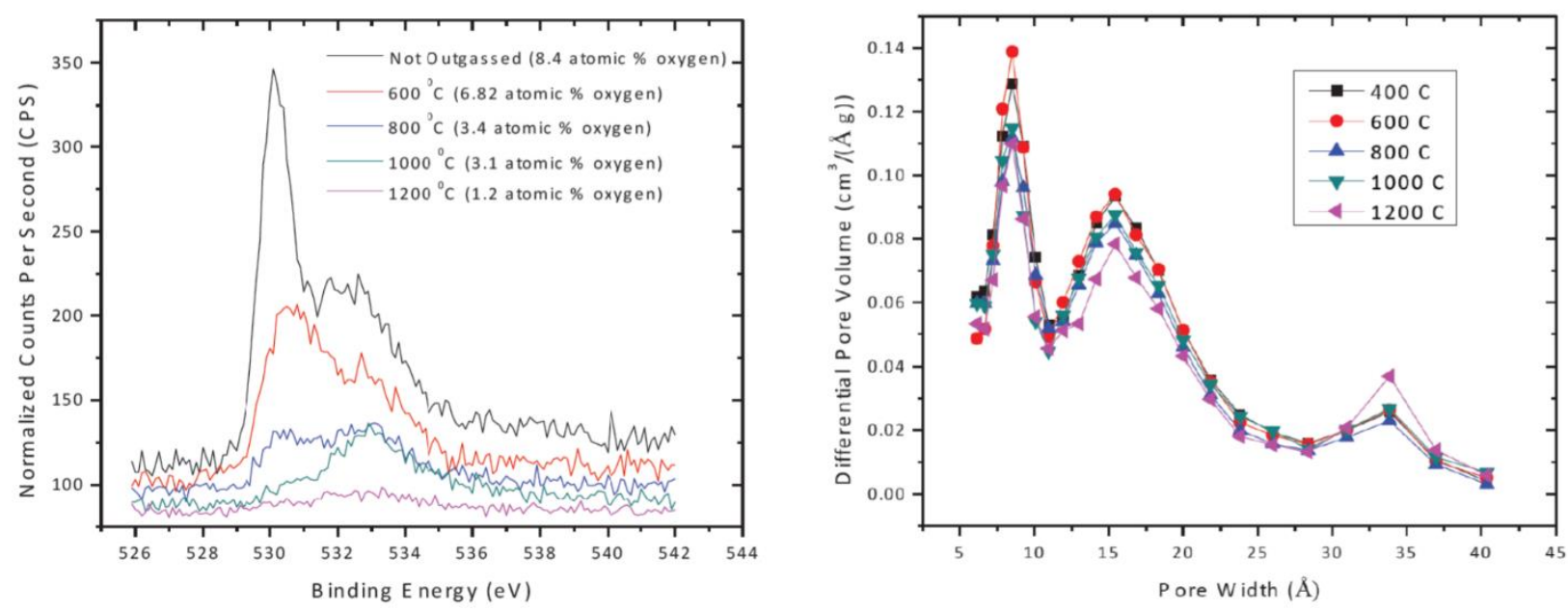

Figure 39. Oxygen XPS spectra and pore size distributions of heat treated, carbon materials. Activated precursor carbon materials were heat treated at $400,600,800,1000$, and $1200{ }^{\circ} \mathrm{C}$. The respective oxygen content was 8.4, 6.8, 3.4, 3.1, and 1.2 atomic\% (integrated, normalized intensity above background, 528$538 \mathrm{eV}$ ). The respective BET surface areas were 2700, 2700, 2500, 2500, and $2300 \mathrm{~m}^{2} / \mathrm{g}$.

The microwave treatments yielded results that varied considerably upon repeat experiments. These inconsistencies are most likely due to an inhomogeneous microwave field in the oven. Therefore, microwave treatments were determined to be unsuitable for "mass fabrication" of deoxygenated, precursor carbon materials. The comparison of the three methods, in terms of oxygen concentration and surface area, is shown in Fig 42. Hydrazine treatment gives the least loss of surface area (only $100 \mathrm{~m}^{2} / \mathrm{g}$ ) while reducing the oxygen concentration by $50 \%$. Heat treatment at $800-1000{ }^{\circ} \mathrm{C}$ gave comparable results
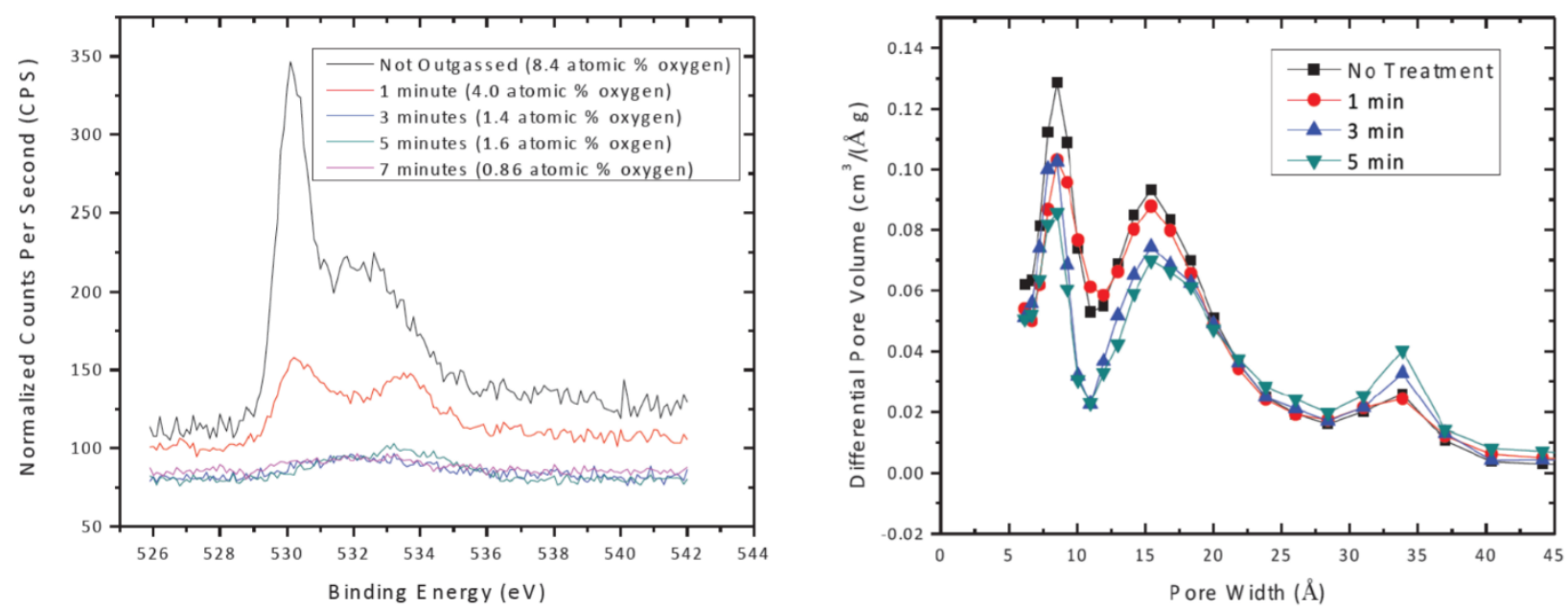

Figure 40. Oxygen XPS spectra and pore size distributions of microwave treated, carbon materials. 
Activated precursor carbon materials were deoxygenated through microwave treatment at varying durations of $0,1,3,5$, and 7 minutes. The resulting oxygen contents were $8.4,4.0,1.4,1.6$, and 0.9 atomic\%, respectively. Their respective BET surface areas were 2700, 2600, 2400, 2200, and $2000 \mathrm{~m}^{2} / \mathrm{g}$. Repeat experiments yielded surface areas that were lower by $100-300 \mathrm{~m}^{2} / \mathrm{g}$ for the same procedure.
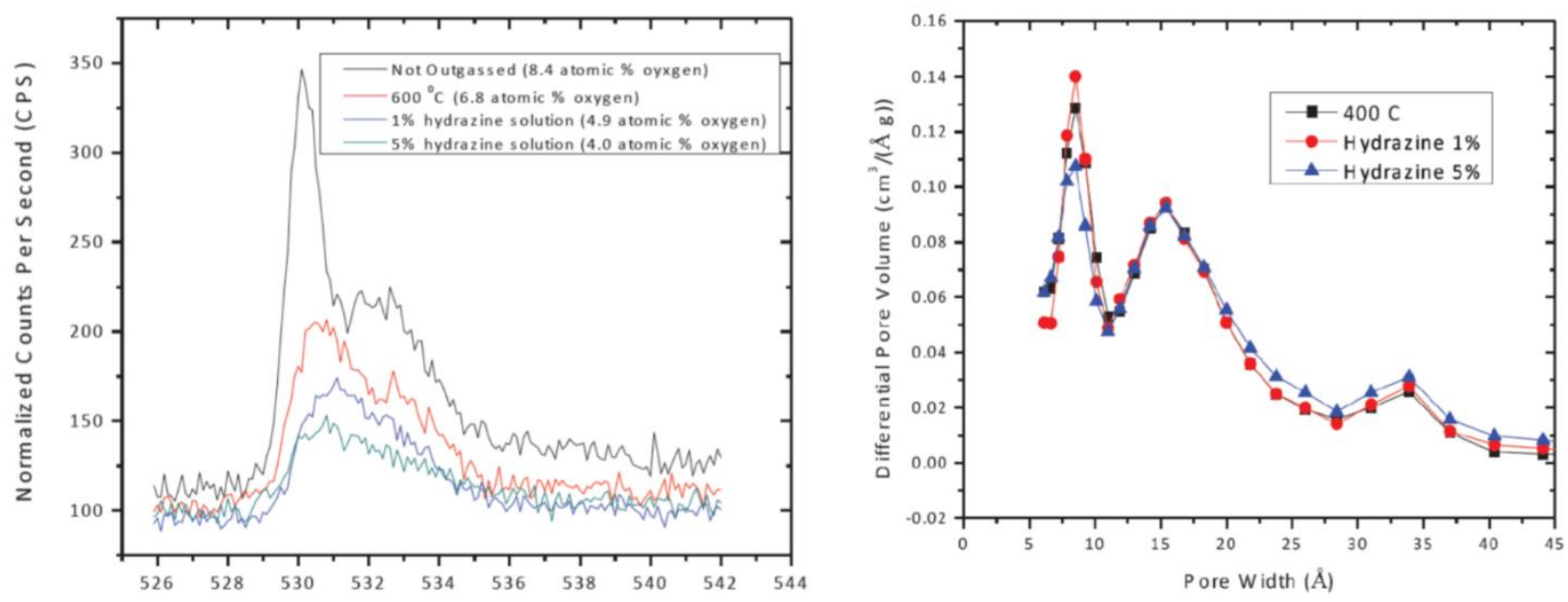

Figure 41. Oxygen XPS spectra and pore size distributions of hydrazine treated, carbon materials.

Activated precursor carbon materials were outgassed followed by hydrazine treated with $1 \%$ and $5 \%$ hydrazine solution. The respective oxygen contents were $8.4,6.8,4.9$, and 4.0 atomic $\%$. The respective BET surface areas were 2700, 2700, 2700, and $2600 \mathrm{~m}^{2} / \mathrm{g}$. 


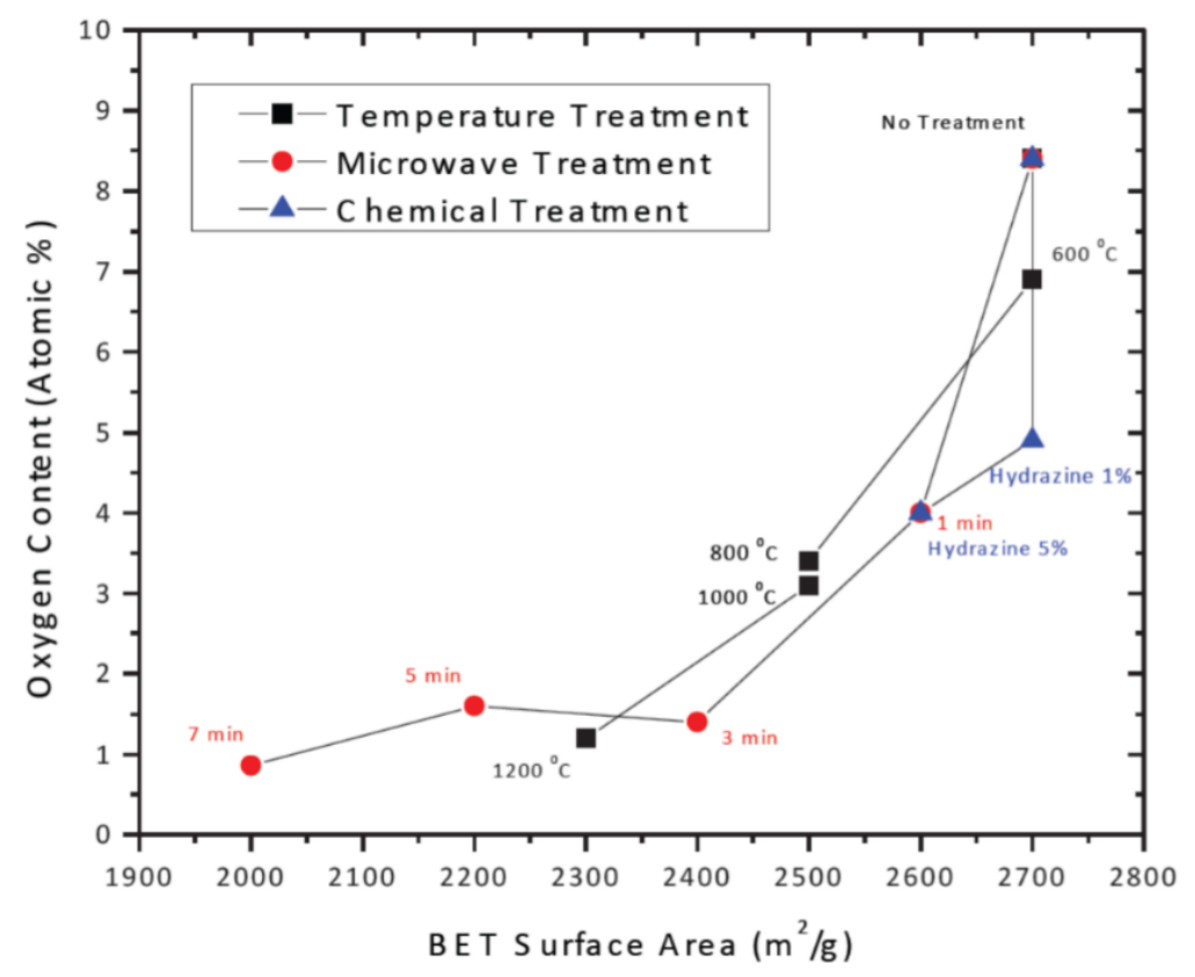

Figure 42. Oxygen concentration as a function of surface area for three deoxygenation methods.

The desirable reduction of oxygen concentration leads to the loss of surface area due to graphitization of the activated carbon. The loss of surface area also entails a decrease in surface defects that are normally serve as easy entry points for boron and high binding energy sites. In order to reduce surface-bound oxygen groups while maintaining high surface areas, a compromise must be made.

\section{Liquid and Gaseous Deposition of Decaborane}

Decaborane $\left(\mathrm{B}_{10} \mathrm{H}_{14}\right)$ was used as a dopant due to its high affinity to the surface of adsorbent carbon ${ }^{[45]}$. Additionally, $\mathrm{B}_{10} \mathrm{H}_{14}$ is extremely volatile and readily decomposes into Diborane $\left(\mathrm{B}_{2} \mathrm{H}_{6}\right)$ and elemental boron when annealed at high temperatures. If boron were successfully incorporated into the carbon matrix in the form of $\mathrm{sp}^{2} \mathrm{~B}-\mathrm{C}$ bonds, the doped samples would be very sensitive to oxygen due to the vacant $p_{z}$ orbital present after doping. Therefore, the deoxygenated samples were doped through the deposition of liquid and vapor phase $\mathrm{B}_{10} \mathrm{H}_{14}$ and high temperature annealing under oxygen-free conditions. In order to understand the conditions that are most conducive to homogeneous doping of boron on the carbon surface, it was necessary to construct a phase diagram for the doping material, $\mathrm{B}_{10} \mathrm{H}_{14}$. The phase 
diagram for $\mathrm{B}_{10} \mathrm{H}_{14}$, first presented by Beckner ${ }^{[13]}$, was constructed using various literature sources and is reproduced in Fig 43 for the purpose of discussing experimental design ${ }^{[13,30]}$.

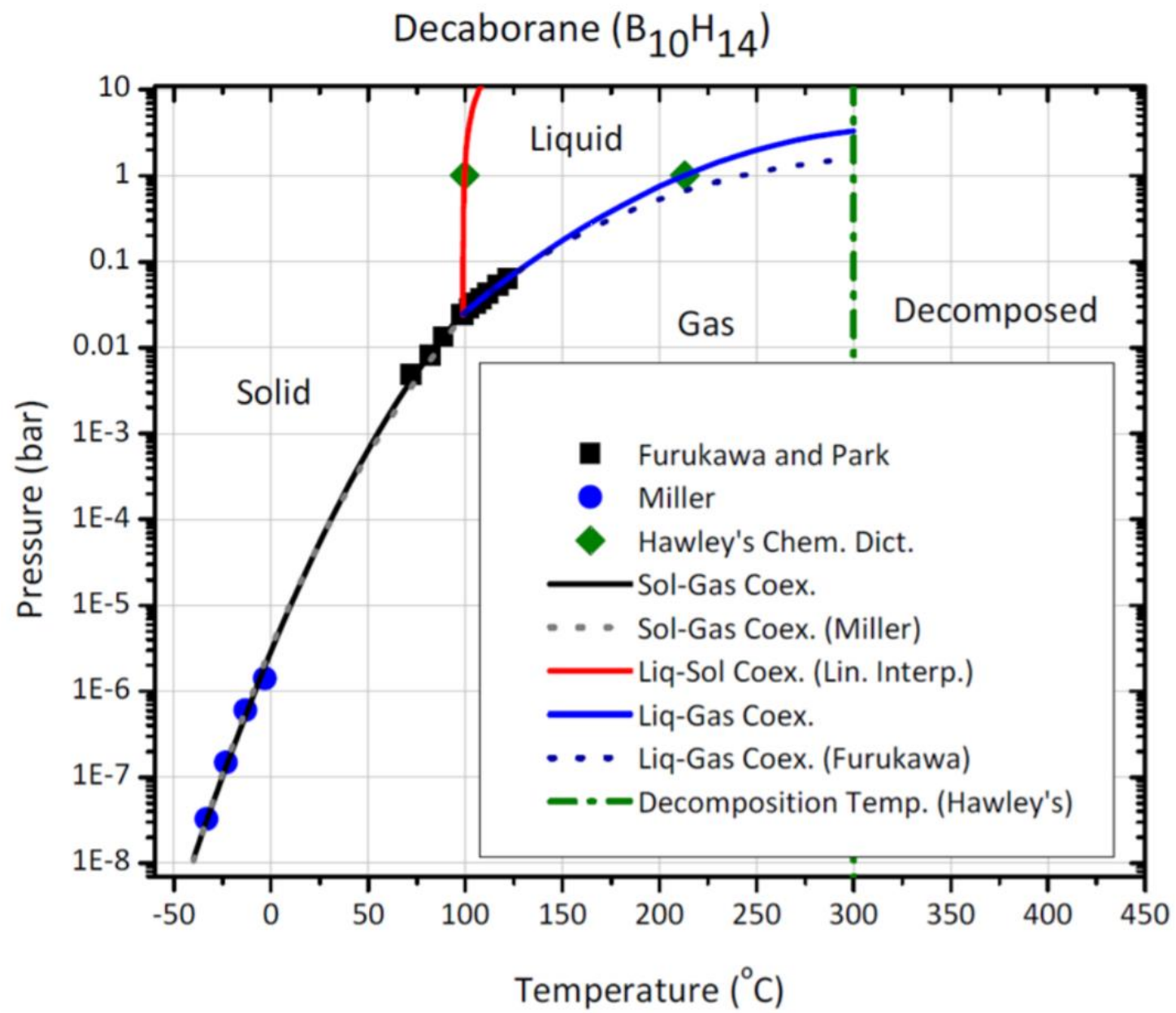

Figure 43. Phase diagram of Decaborane constructed from various literature sources ${ }^{[13,46-48]}$.

In order to ensure an even coating of during the doping process, all of the $\mathrm{B}_{10} \mathrm{H}_{14}$ must be in the gas phase before decomposition. This also assists to prevent blocking of pores by undesirable B-B and B-O groups ${ }^{[49,50]}$. A condition was developed to describe the vapor pressure of relating the vapor pressure of $\mathrm{B}_{10} \mathrm{H}_{14}$ as it relates to the mass ratio of $\mathrm{B}_{10} \mathrm{H}_{14}$ to carbon used during the doping process. In order for $\mathrm{B}_{10} \mathrm{H}_{14}$ to enter the gaseous phase, the following condition must be met

$$
p_{\text {vapor }}\left(T_{\mathrm{f}}\right)>\frac{\chi_{\mathrm{DB}}}{M_{\mathrm{DB}}} \frac{\rho_{\mathrm{sk}} \rho_{\text {bulk }}}{\left(\rho_{\mathrm{sk}}-\rho_{\text {bulk }}\right)} R T_{\mathrm{f}}+\frac{p_{\mathrm{i}} T_{\mathrm{f}}}{T_{\mathrm{i}}}
$$


where $p_{\text {vapor }}$ is the vapor pressure of $\mathrm{B}_{10} \mathrm{H}_{14}, \chi_{\mathrm{DB}}$ is the mass ratio of $\mathrm{B}_{10} \mathrm{H}_{14}$ to carbon, $M_{\mathrm{DB}}$ is the molar mass of $\mathrm{B}_{10} \mathrm{H}_{14}, \rho_{\text {bulk }}$ is the apparent density of the starting carbon material, $\rho_{\text {sk }}$ is the skeletal density of the carbon material, $p_{\mathrm{i}}$ and $T_{\mathrm{i}}$ are the initial pressures and temperatures at room temperature, and $T_{\mathrm{f}}$ is the final temperature during deposition. If this vapor pressure condition is satisfied, then all of the $\mathrm{B}_{10} \mathrm{H}_{14}$ will be in the gas phase for any temperature greater than $T_{\mathrm{f}}$.
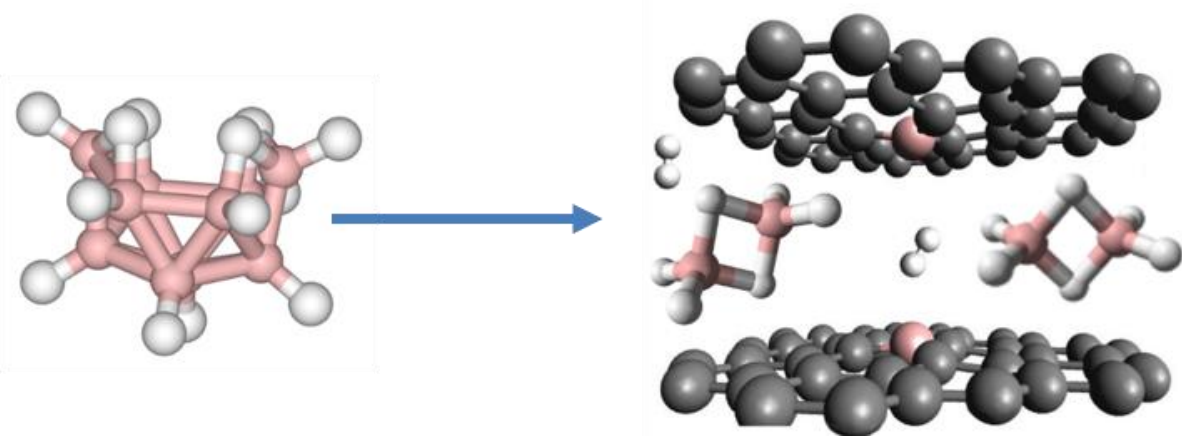

Figure 44. Decaborane molecule decomposing into diborane and elemental boron.

For all doping experiments, boron was deposited on carbonaceous samples under inert atmosphere of Argon. In an effort to create a homogeneous distribution of boron across the carbon surface, several attempts were made to deposit decaborane in the gas phase. During the early phases of synthesis, doping methods involved direct, manual mixing of the carbonaceous material with the $\mathrm{B}_{10} \mathrm{H}_{14}$ prior to high temperature annealing. However, this often resulted in pore clogging and surface area reductions due to the carbon being exposed to $\mathrm{B}_{10} \mathrm{H}_{14}$ in the liquid phase. Another method was developed involving a flow system in which a carrier gas was employed to pass $\mathrm{B}_{10} \mathrm{H}_{14}$ gas over the carbon surface. The decaborane and carbon mixtures were annealed at $600 \mathrm{C}, 800 \mathrm{C}$, $1000 \mathrm{C}$, or $1200 \mathrm{C}$. During annealing, $\mathrm{B}_{10} \mathrm{H}_{14}$ decomposes into lower boranes, such as diborane and elemental boron. If samples foster a high surface defect ratio, it is more likely that the elemental boron will incorporate into the carbon surface. 


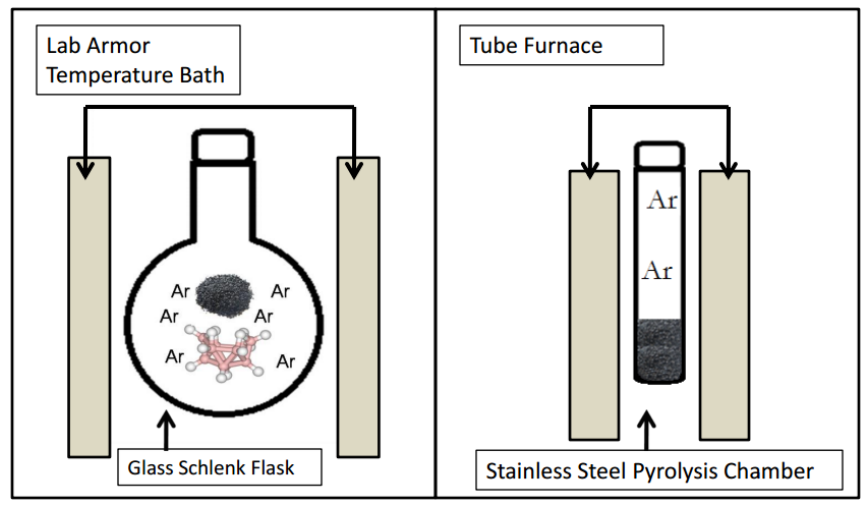

Figure 45. Two-step, stationary deposition and annealing apparatus. Left: carbon and decaborane mixture in a schlenk flask. Right: Decaborane deposited on the carbon surface inside a stainless steel annealing vessel.

In the two-step deposition and annealing method, a carbon-decaborane mixture was sealed in a Schlenk flask initially under Argon at atmospheric pressure and room temperature. The mixture was cooled to $-68^{\circ} \mathrm{C}$ using a dry ice and acetone bath to prevent sublimation of the $\mathrm{B}_{10} \mathrm{H}_{14}$. The mixture was outgassed at this temperature using a roughing pump to a pressure of approximately 20 mbar. This was performed as a precautionary step to ensure that any oxygen contamination was mitigated. The flask was sealed under vacuum and heated to $120{ }^{\circ} \mathrm{C}$ for 1 hour. This was performed in an effort to deposit gaseous $\mathrm{B}_{10} \mathrm{H}_{14}$ homogeneously over the carbon surface prior to annealing. The flask was then allowed to return to room temperature and the $\mathrm{B}_{10} \mathrm{H}_{14}$ solidified in the pores. The sample was transferred into either a stainless steel vessel or an alumina vessel under argon. The sample was heated in a tube furnace past the decomposition temperature of $\mathrm{B}_{10} \mathrm{H}_{14}$. Annealing was performed at $600{ }^{\circ} \mathrm{C}, 800{ }^{\circ} \mathrm{C}, 1000{ }^{\circ} \mathrm{C}$, or $1200{ }^{\circ} \mathrm{C}$. The annealing temperature was maintained for 12 hours and then cooled to room temperature. 


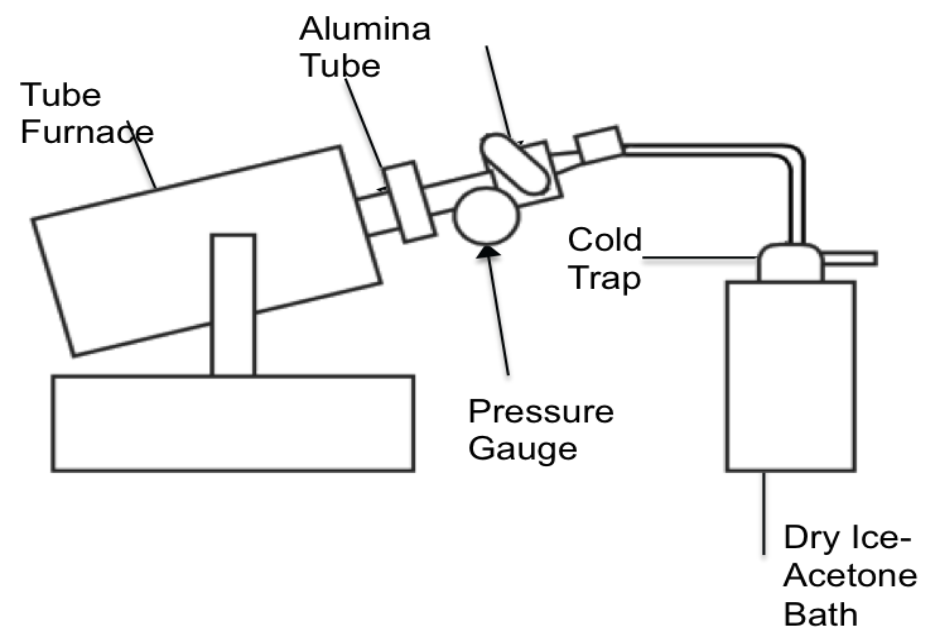

Figure 46. One-step, stationary deposition and annealing apparatus. The sample was contained in the alumina tube with a pressure relief valve.

In the one-step, stationary deposition and annealing method, a carbon-decaborane mixture was sealed in an alumina tube under Argon at atmospheric pressure and room temperature. The physical limitations of the alumina tube prevented outgassing at low temperatures prior to deposition. According to the manufacturer's recommendation, the alumina tube was heated to $120^{\circ} \mathrm{C}$ at a rate of $2{ }^{\circ} \mathrm{C} / \mathrm{min}$ and was allowed to dwell at that temperature for 1 hour in a tube furnace. This step was performed to deposit gaseous $\mathrm{B}_{10} \mathrm{H}_{14}$ homogeneously over the carbon surface prior to annealing. The alumina tube was heated at a rate of $2{ }^{\circ} \mathrm{C} / \mathrm{min}$ past the decomposition temperature of decaborane. Annealing was performed at $600{ }^{\circ} \mathrm{C}, 800{ }^{\circ} \mathrm{C}, 1000{ }^{\circ} \mathrm{C}$, or $1200{ }^{\circ} \mathrm{C}$. The annealing temperature was maintained for 12 hours and then cooled to room temperature at a rate of $2{ }^{\circ} \mathrm{C} / \mathrm{min}$.

Samples prepared using either stationary doping method were inevitably exposed liquid phase decaborane instead of undergoing gaseous deposition. To prevent this, a 2-step flow doping instrument was developed to deposit decaborane exclusively from the vapor phase (Fig 47). The deposition occurs within a single long, narrow quartz tube and is facilitated by a carrier gas of argon. The argon flow is controlled upstream by a supply pressure regulator and flow meter and the deposition cell pressure is controlled by a back-pressure regulator located downstream. 


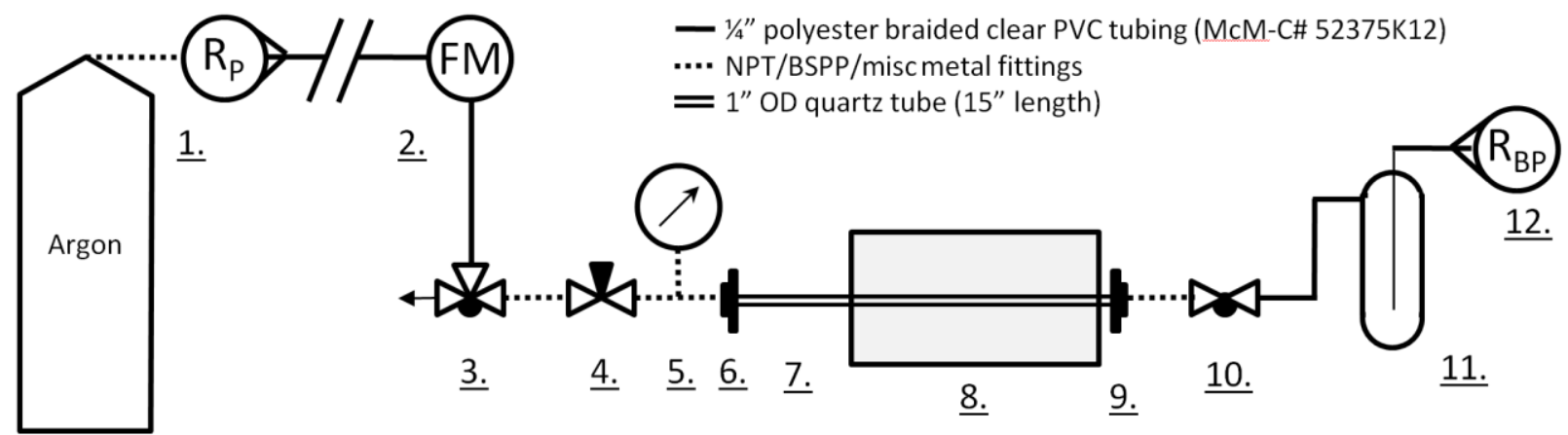

Figure 47. Two-step, flow deposition and annealing apparatus. The decaborane and activated carbon are kept in separate quartz boats under constant argon flow.

The decaborane powder is held in a quartz boat at position (7) controlled by a separate heating element from the quartz boat containing the carbon at (8). This allows for the carbon to be preheated prior to deposition to prevent condensation at a thermal gradient. The 2-step flow doping instrument features a heat bath that requires the sample to be removed and annealed for decomposition separately. This method was designed to guarantee that $\mathrm{B}_{10} \mathrm{H}_{14}$ was only in contact with the activated carbon in the gaseous phase because $\mathrm{B}_{10} \mathrm{H}_{14}$ in the liquid phase is literally kept in a separate vessel throughout the deposition and annealing processes. Under argon flow, the two quartz boats were heated to $120{ }^{\circ} \mathrm{C}$ at a rate of $2{ }^{\circ} \mathrm{C} / \mathrm{min}$ and was allowed to dwell at that temperature for 1 hour in a tube furnace. The alumina tube was heated at a rate of $2{ }^{\circ} \mathrm{C} /$ min past the decomposition temperature of decaborane. Annealing was performed at $600{ }^{\circ} \mathrm{C}, 800{ }^{\circ} \mathrm{C}$, $1000{ }^{\circ} \mathrm{C}$, or $1200{ }^{\circ} \mathrm{C}$. The annealing temperature was maintained for 12 hours and then cooled to room temperature at a rate of $2{ }^{\circ} \mathrm{C} / \mathrm{min}$. 


\section{Material Performance for Hydrogen and Nitrogen Adsorption}

\subsection{Nitrogen Adsorption and Analysis}

Excess adsorption isotherms were measured on each sample at $77 \mathrm{~K}$ and analyzed for specific surface areas, pore size distributions, and total open pore volumes. Assuming slit-shaped pores and interpretation of the cumulative pore volume allows one to determine the fraction of the total pore volume that is comprised of sub-nanometer pores. A higher fraction of sub-nanometer pores should translate into higher storage capacities due to overlapping Van der Waals potentials.

Broad Range of Activated and Synthetic Carbonaceous Sorbent Materials:

Table 6: Nitrogen Analyses for a broad range of sorbent materials

\begin{tabular}{|c|c|c|c|c|}
\hline Sample Name & $\begin{array}{l}\sum_{\mathrm{BET}} \\
\left(\mathrm{m}^{2} / \mathrm{g}\right)\end{array}$ & Porosity & $\begin{array}{c}\text { Total Pore Volume } \\
{[\mathrm{mL} / \mathrm{g}]}\end{array}$ & $\begin{array}{c}\text { Sub-nm Pore } \\
\text { Volume Fraction* } \\
{\left[V_{\text {sub-nm }} / V_{\text {total }}\right]}\end{array}$ \\
\hline $3 \mathrm{~K}-0285$ & 2589 & 0.773 & 1.71 & 0.316 \\
\hline MWV-0260 & 2638 & 0.755 & 1.54 & 0.380 \\
\hline BR-0311 & 2324 & 0.744 & 1.45 & 0.345 \\
\hline BR-0134 & 1985 & 0.697 & 1.15 & 0.371 \\
\hline $2.3 \mathrm{~K}-0810$ & 2595 & 0.766 & 1.47 & 0.402 \\
\hline A-149 & 3080 & 0.796 & 1.95 & 0.341 \\
\hline xGnP-750 & 758 & 0.755 & 1.54 & 0.082 \\
\hline $\mathrm{xGnP}-500$ & 497 & 0.736 & 1.27 & 0.052 \\
\hline Cabot EXP-14008 & 1087 & 0.535 & 0.58 & 0.327 \\
\hline Cabot EXP-14009 & 1243 & 0.579 & 0.69 & 0.319 \\
\hline PVDC-0400 & 783 & 0.489 & 0.48 & 0.258 \\
\hline HS;0B-20 & 936 & 0.464 & 0.43 & 0.348 \\
\hline
\end{tabular}

*The sub-nanometer pore volume describes the amount of pore volume contributed from pores of widths up to $1.3 \mathrm{~nm}$. The sub-nanometer pore volume fraction is normalized by the total pore volume. 
MWV, A-149, xGnP, and Cabot samples are commercially available materials. MWV is an activated carbon; A-149 and Cabot samples listed here are activated carbons that have been pressed into pellets; xGnP samples are carbon nanoplatelets with well-defined, homogeneous surface areas. Samples 3K-0285 and 2.3K-0810 are chemically activated carbon powders. PVDC-0400 and HS;0B-20 are synthetic carbon powder materials made from pyrolysis of polymeric Polyvinylidene Chloride (PVDC). Samples BR-0311 and BR-0134 are briquette carbon materials that were synthesized by MWV-like powder carbons with a binder under high pressures and temperatures.

Samples with lower porosities tend to have lower surface areas, which should translate into lower excess adsorption. However, samples with a high fraction of sub-nanometer pores should perform better with respect to volumetric storage capacity.

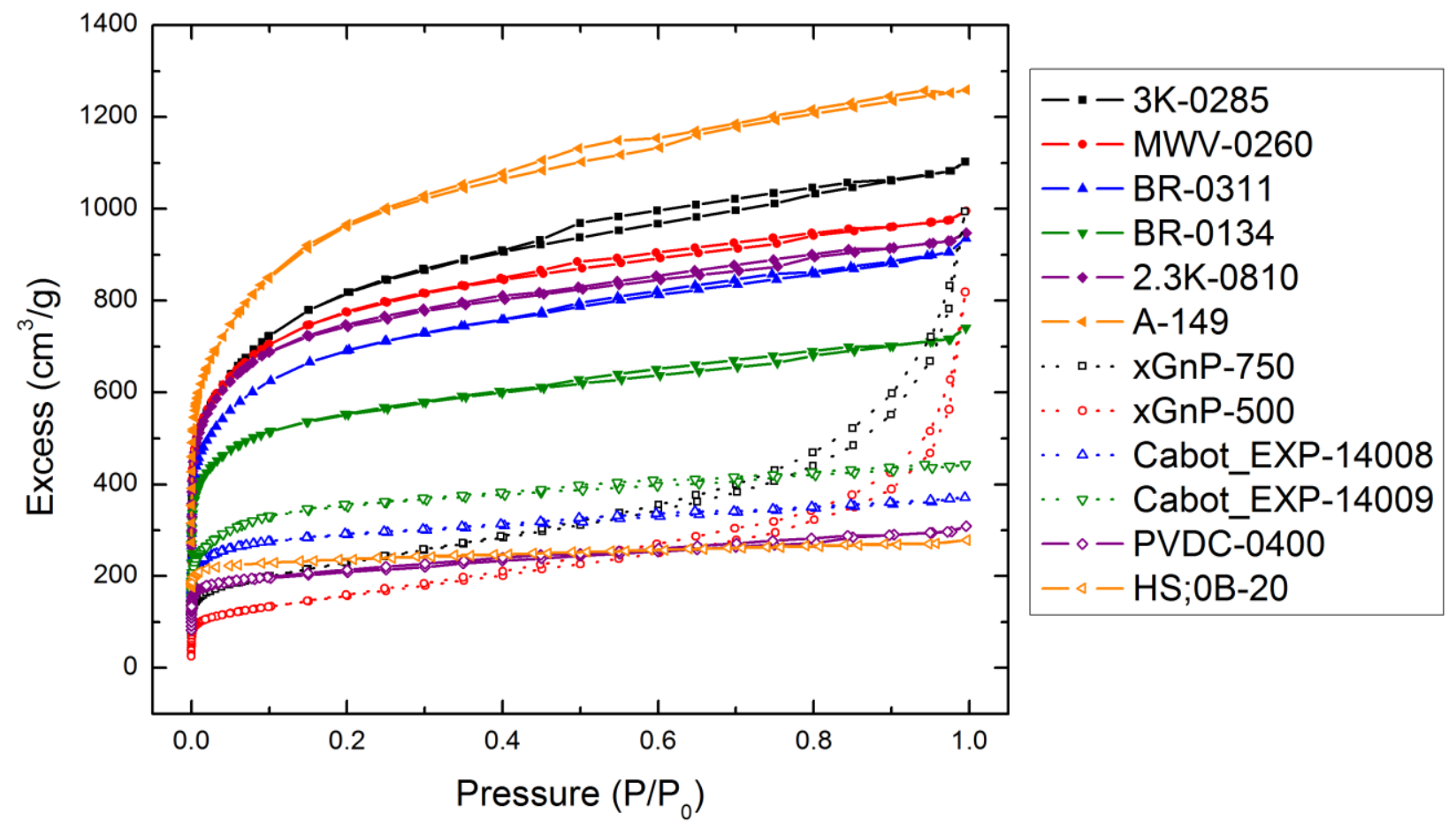

Figure 48. Nitrogen excess adsorption for a broad range of sorbent samples. 


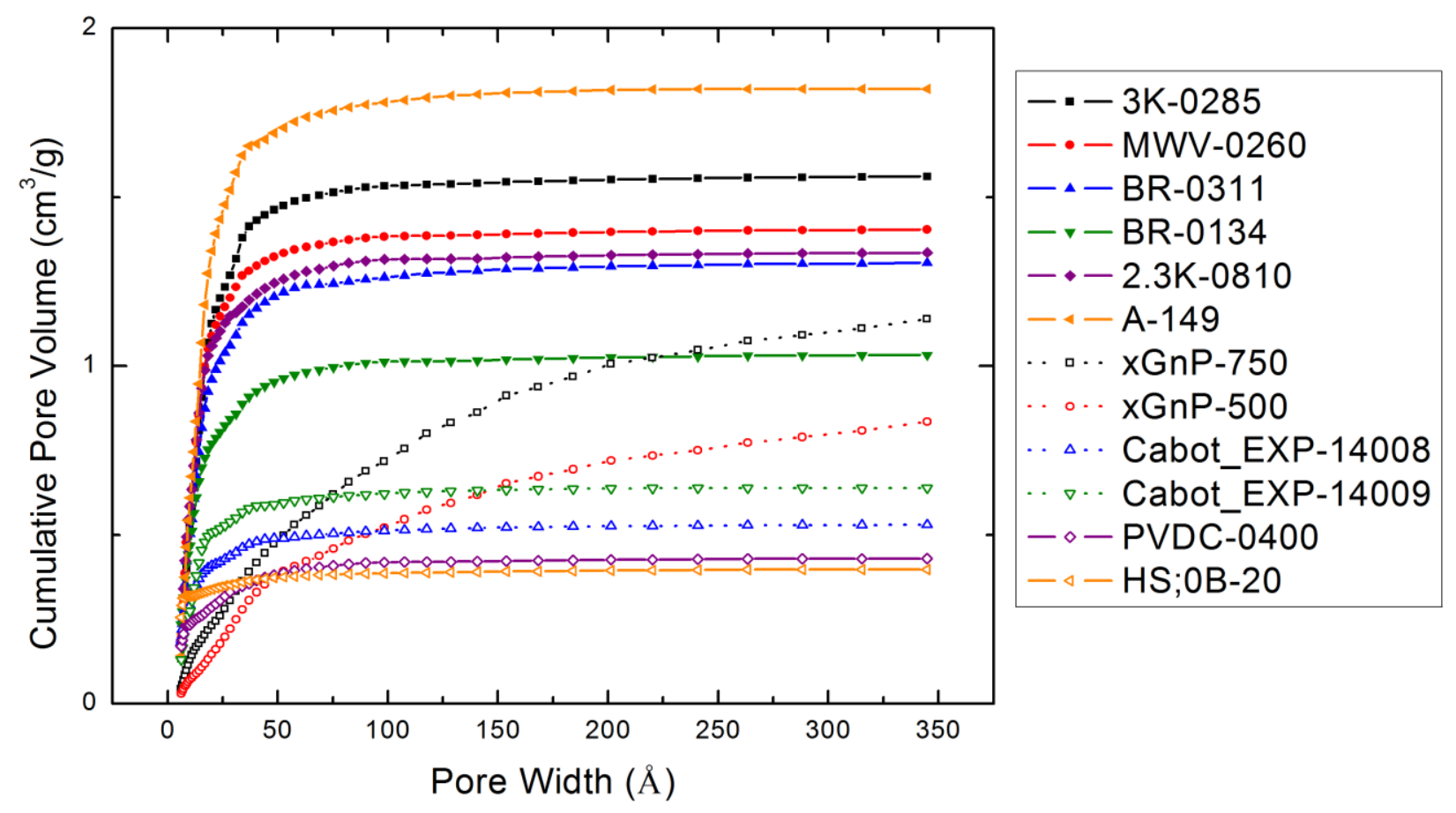

Figure 49. Cumulative pore volumes of a broad range of sorbent samples.

Many of the samples with high specific surface areas are composed almost entirely of pores less than $5 \mathrm{~nm}$ in width. From this selection of 12 random sorbent materials, only two contain a significant fraction of pore volume from pores with widths greater than $5 \mathrm{~nm}$. According to the manufacturer, $\mathrm{xGnP}-750$ and $\mathrm{xGnP}-500$ are graphitic nanoplatelets with well-defined, homogeneous, and relatively flat surfaces. This can be experimentally verified by electron microscope imaging. Based on this, one would expect that these two samples are entirely composed of pores with width $w<10 \mathrm{~nm}$. However, the plot of cumulative pore volume shows that these two samples exhibit an increase in cumulative pore volume for pore widths $w>10 \mathrm{~nm}$. This perceived inconsistency is most likely due to nitrogen condensing in the intergranular pore volume and results in artificially high porosities for these two samples. 

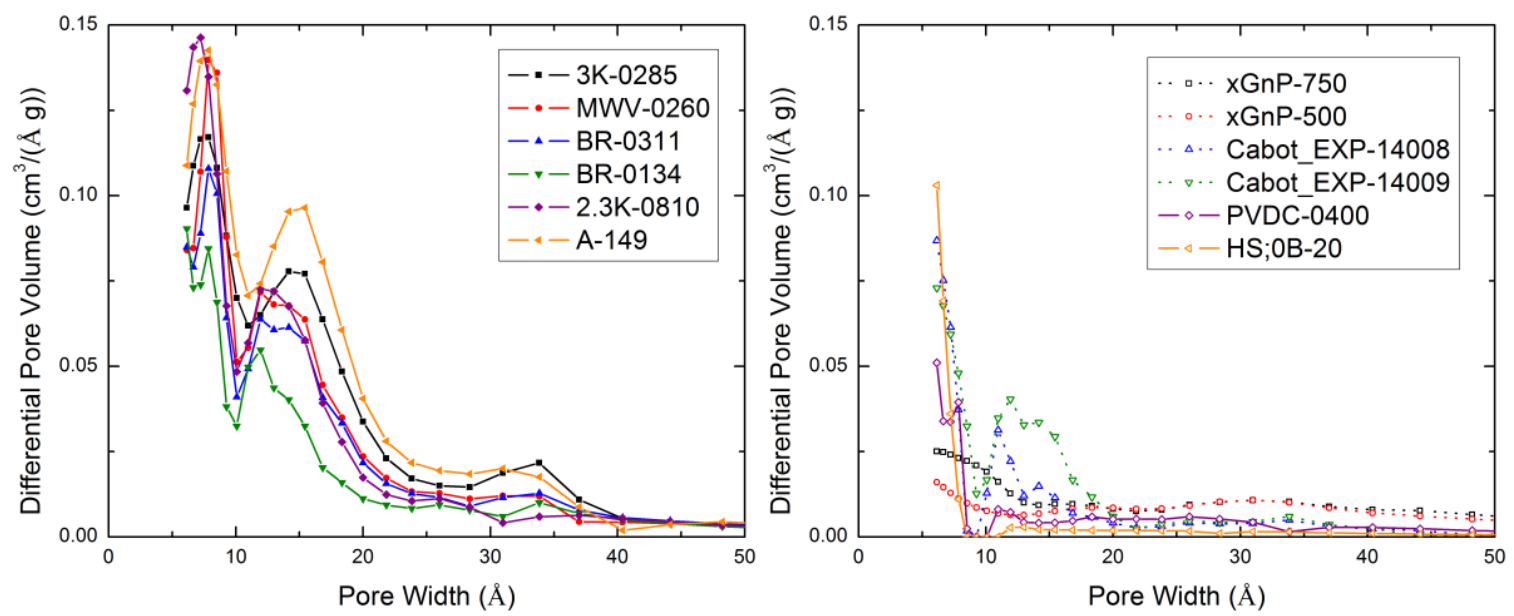

Figure 50. Differential pore volumes of a broad range of sorbent samples. Left: Differential pore volumes of chemically activated carbon materials. Right: Differential pore volumes of commercially available nanoplatelets and synthetic carbon sorbent materials.

The nanostructure of chemically activated sorbent materials may be optimized according to their application. The chemically activated materials present here have been tuned to exhibit a bimodal pore structure. Sub-nanometer pores facilitate high storage densities due to overlapping Van der Waals potentials. However, mesopores are also necessary to improve delivery rates from storage tanks ${ }^{[51]}$. Many of the synthetic carbon and nanoplatelet materials exhibit a monomodal pore size distribution ${ }^{[52,53]}$. 


\section{Chemically Activated, Carbonaceous Precursor Materials:}

Table 7: Nitrogen Analyses for precursor carbon sorbent materials.

\begin{tabular}{|c|c|c|c|c|}
\hline Sample Name & $\begin{array}{l}\sum_{\mathrm{BET}} \\
\left(\mathrm{m}^{2} / \mathrm{g}\right)\end{array}$ & Porosity & $\begin{array}{c}\text { Total Pore Volume } \\
\qquad[\mathrm{mL} / \mathrm{g}]\end{array}$ & $\begin{array}{c}\text { Sub-nm Pore } \\
\text { Volume Fraction* } \\
{\left[V_{\text {sub-nm }} / V_{\text {total }}\right]}\end{array}$ \\
\hline $1.85 \mathrm{~K}-0099$ & 2350 & 0.729 & 1.34 & 0.397 \\
\hline $2 \mathrm{~K}-0286$ & 1940 & 0.701 & 1.17 & 0.362 \\
\hline $2.3 \mathrm{~K}-0810$ & 2600 & 0.766 & 1.47 & 0.402 \\
\hline $2.5 \mathrm{~K}-0807$ & 2440 & 0.740 & 1.42 & 0.384 \\
\hline $3 \mathrm{~K}-0046$ & 2740 & 0.821 & 2.29 & 0.209 \\
\hline $3 \mathrm{~K}-0079$ & 2660 & 0.784 & 1.82 & 0.290 \\
\hline $3 \mathrm{~K}-0285$ & 2590 & 0.773 & 1.71 & 0.316 \\
\hline $4 \mathrm{~K}-0284$ & 2610 & 0.812 & 2.17 & 0.220 \\
\hline $4 \mathrm{~K}-0288$ & 2790 & 0.829 & 2.43 & 0.215 \\
\hline $5 \mathrm{~K}-0280$ & 2690 & 0.837 & 2.57 & 0.173 \\
\hline $6 \mathrm{~K}-0802$ & 2590 & 0.847 & 2.76 & 0.149 \\
\hline MSC-30 & 2760 & 0.806 & 2.08 & 0.238 \\
\hline MWV-0260 & 2638 & 0.755 & 1.54 & 0.380 \\
\hline
\end{tabular}

*The sub-nanometer pore volume describes the amount of pore volume contributed from pores of widths up to $1.3 \mathrm{~nm}$. The sub-nanometer pore volume fraction is normalized by the total pore volume.

Most samples synthesized at the University of Missouri were given a descriptive prefix followed by a four digit lot number. The descriptive prefixes of precursor carbons were often assigned according to the $\mathrm{KOH}: \mathrm{C}$ ratio used during their activation. For example $3 \mathrm{~K}-0285$ was activated with a 3:1 KOH:C ratio and 4K-0284 was activated with a 4:1 KOH:C ratio. Sample MSC-30 is well-performing industry standard by which most emerging materials are compared. MWV-0260 is a carbonaceous material manufactured by Meadwestvaco Corporation. 


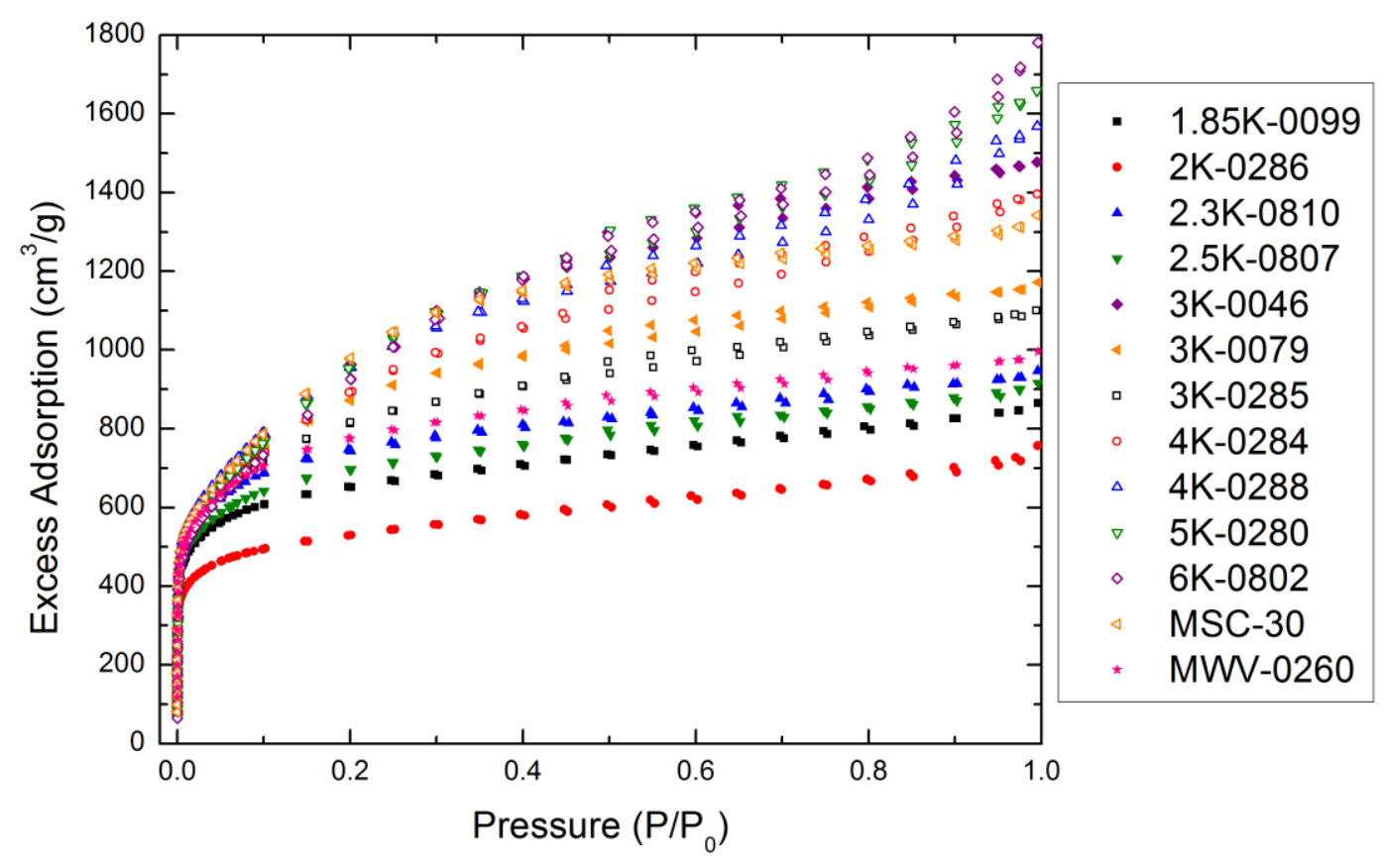

Figure 51. Nitrogen excess adsorption for chemically activated, precursor sorbent samples. In general, the nitrogen excess adsorption is directly correlated with the $\mathrm{KOH}: \mathrm{C}$ activation ratio. Nitrogen adsorbs in multilayers and liquefies in the pores to fill the entire pore volume near its liquefaction pressure. Therefore, higher $\mathrm{KOH}: \mathrm{C}$ ratios used during activation lead to increases in total pore volumes.

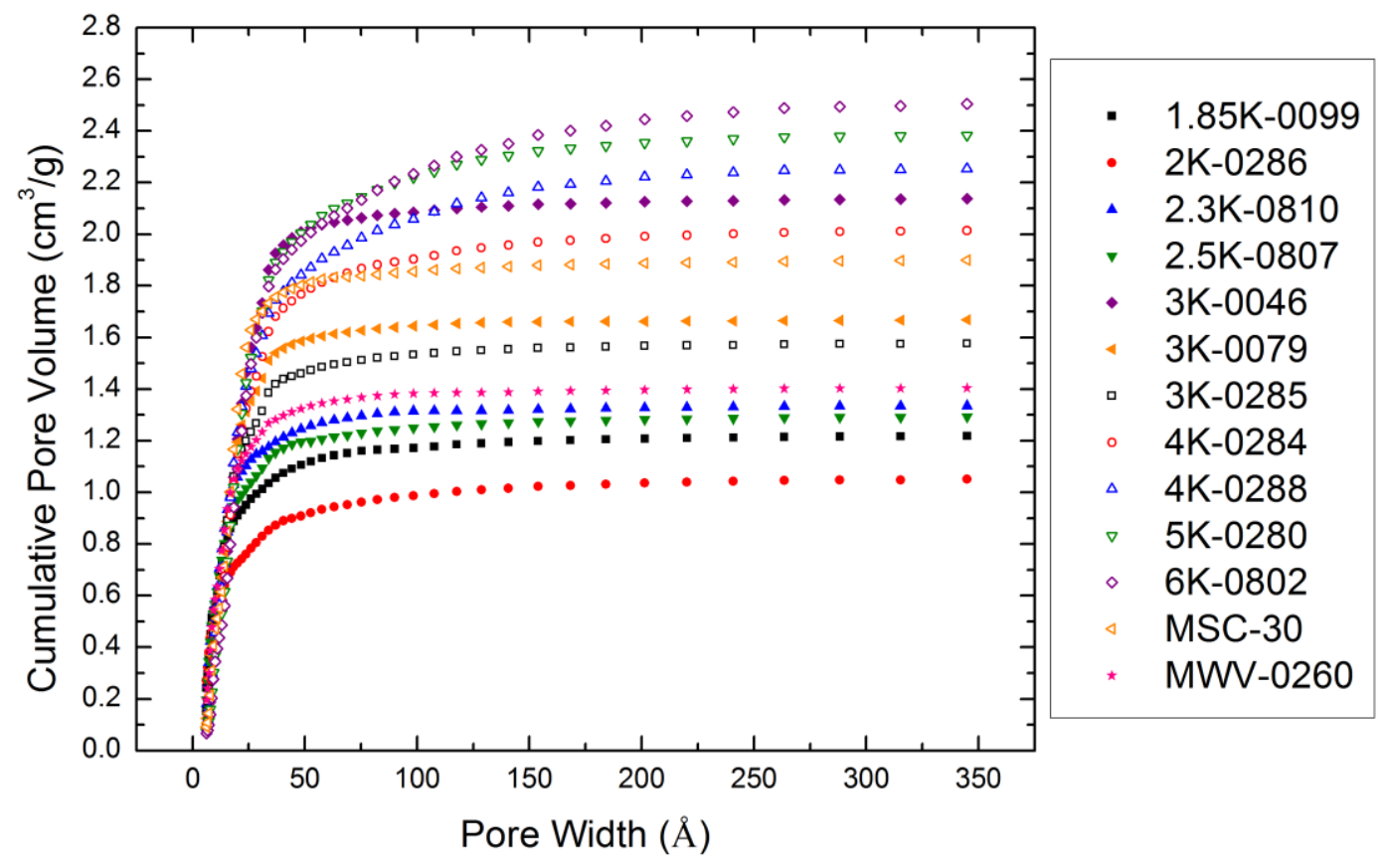

Figure 52. Cumulative pore volumes for chemically activated, precursor sorbent samples. 

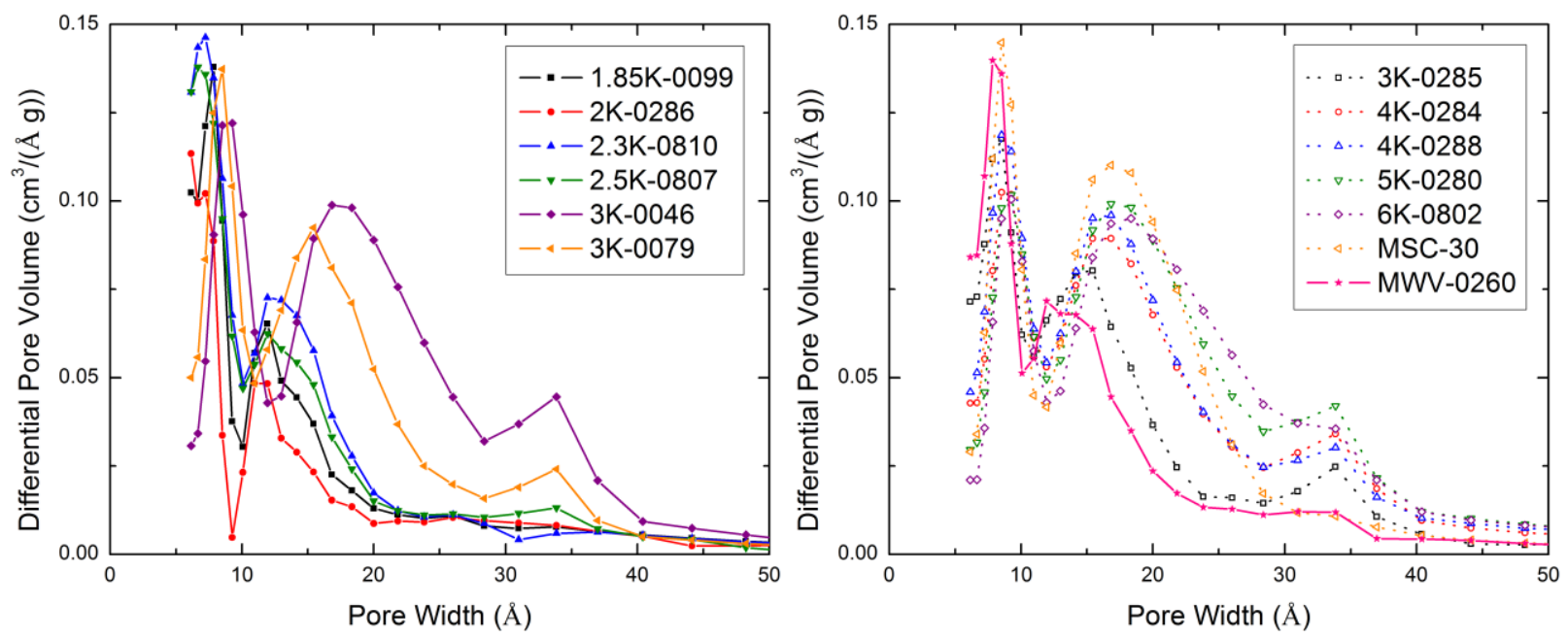

Figure 53. Differential pore volumes for chemically activated, precursor sorbent samples. Left: Differential pore volumes of chemically activated MU-synthesized materials. Right: Differential pore volumes of chemically activated MU-synthesized materials along with industry standard materials.

The distributions for chemically activated MU-sorbent materials show that as a higher $\mathrm{KOH}: \mathrm{C}$ ratio is used during synthesis, the second mode of pore widths becomes larger and broadens. The broadening of the second mode implies that higher $\mathrm{KOH}: \mathrm{C}$ ratios yield materials with more randomized pore widths and higher density of surface defects. MSC-30 and 3K-0079 have a similar pore size distributions, but MSC-30 has a slightly higher total pore volume and specific surface area. The first mode of the pore size distribution. Despite being synthesized from different biowaste materials, MWV-0260 and 2.3K-0810 also have very similar pore structures. MWV-0260 has a slightly larger pore volume due to its higher density of $1.5 \mathrm{~nm}$ pores. However, these two samples have nearly equivalent porosities and specific surface areas. Assuming that MWV-0260 and 2.3K-0810 exhibit a similar binding energy to hydrogen, they should perform similarly with respect to excess adsorption, gravimetric storage capacity, and volumetric storage capacity. These similarities are discussed in section 7.2.

\section{Carbonaceous Precursor Materials After High Temperature Outgassing:}

These precursor materials were outgassed at elevated temperatures in an attempt to deoxygenate the surfaces in preparation for boron doping. Sample $3 \mathrm{~K}-0079$ was outgassed at $800{ }^{\circ} \mathrm{C}$ and $1200^{\circ} \mathrm{C}$. The outgassed aliquots were named $3 \mathrm{~K}-0241-800 \mathrm{C}$ and $3 \mathrm{~K}-0218-1200 \mathrm{C}$ respectively. Sample $4 \mathrm{~K}-0284$ was 
outgassed at $800{ }^{\circ} \mathrm{C}$ and $1200{ }^{\circ} \mathrm{C}$. The outgassed aliquots were named $4 \mathrm{~K}-0239-800 \mathrm{C}$ and $4 \mathrm{~K}-0216-1200 \mathrm{C}$ respectively. Sample $5 \mathrm{~K}-0280$ was outgassed at $800{ }^{\circ} \mathrm{C}$ and $1200{ }^{\circ} \mathrm{C}$. The outgassed aliquots were named $5 \mathrm{~K}-0243-800 \mathrm{C}$ and $5 \mathrm{~K}-0214-1200 \mathrm{C}$ respectively. In addition to $\mathrm{KOH}$-activated carbon materials, a PVDC-based material was also prepared for boron doping under high temperature outgassing.

Table 8: Nitrogen Analyses for precursor carbon sorbent materials outgassed at high temperatures.

\begin{tabular}{|l|r|r|r|r|}
\hline \multicolumn{1}{|c|}{ Sample Name } & \multicolumn{1}{|c|}{$\begin{array}{c}\sum_{\text {BET }} \\
\left(\mathrm{m}^{2} / \mathrm{g}\right)\end{array}$} & \multicolumn{1}{|c|}{ Porosity } & $\begin{array}{r}\text { Total Pore Volume } \\
{[\mathrm{mL} / \mathrm{g}]}\end{array}$ & \multicolumn{2}{|c|}{$\begin{array}{c}\text { Sub-nm Pore } \\
\text { Volume Fraction* } \\
{\left[V_{\text {sub-nm }} / V_{\text {total }}\right]}\end{array}$} \\
\hline 2K-0228-800C & 1760 & 0.684 & 1.08 & 0.344 \\
\hline 3K-0218-1200C & 2140 & 0.740 & 1.42 & 0.317 \\
\hline 3K-0241-800C & 2550 & 0.771 & 295 \\
\hline 4K-0216-1200C & 2390 & 0.800 & 2.00 & 0.219 \\
\hline 4K-0239-800C & 2600 & 0.824 & 2.48 & 0.178 \\
\hline 5K-0214-1200C & 2560 & 0.832 & 2.39 & 0.190 \\
\hline 5K-0243-800C & 2600 & 0.827 & 0.69 & 0.203 \\
\hline PVDC-0735-800C & 849 & 0.580 & & 2.34 \\
\hline
\end{tabular}

*The sub-nanometer pore volume describes the amount of pore volume contributed from pores of widths up to $1.3 \mathrm{~nm}$. The sub-nanometer pore volume fraction is normalized by the total pore volume. 


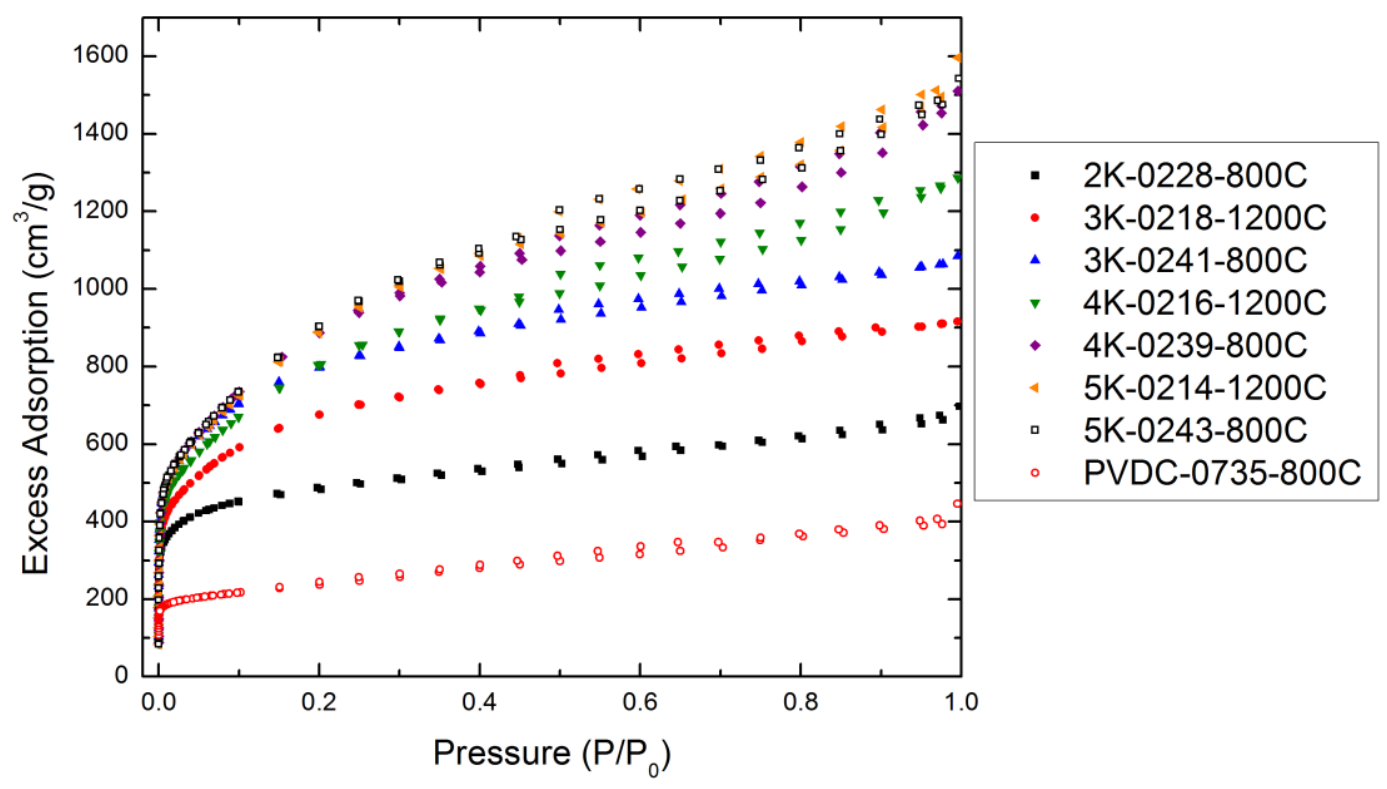

Figure 54. Nitrogen excess adsorption for precursor materials outgassed at high temperatures.

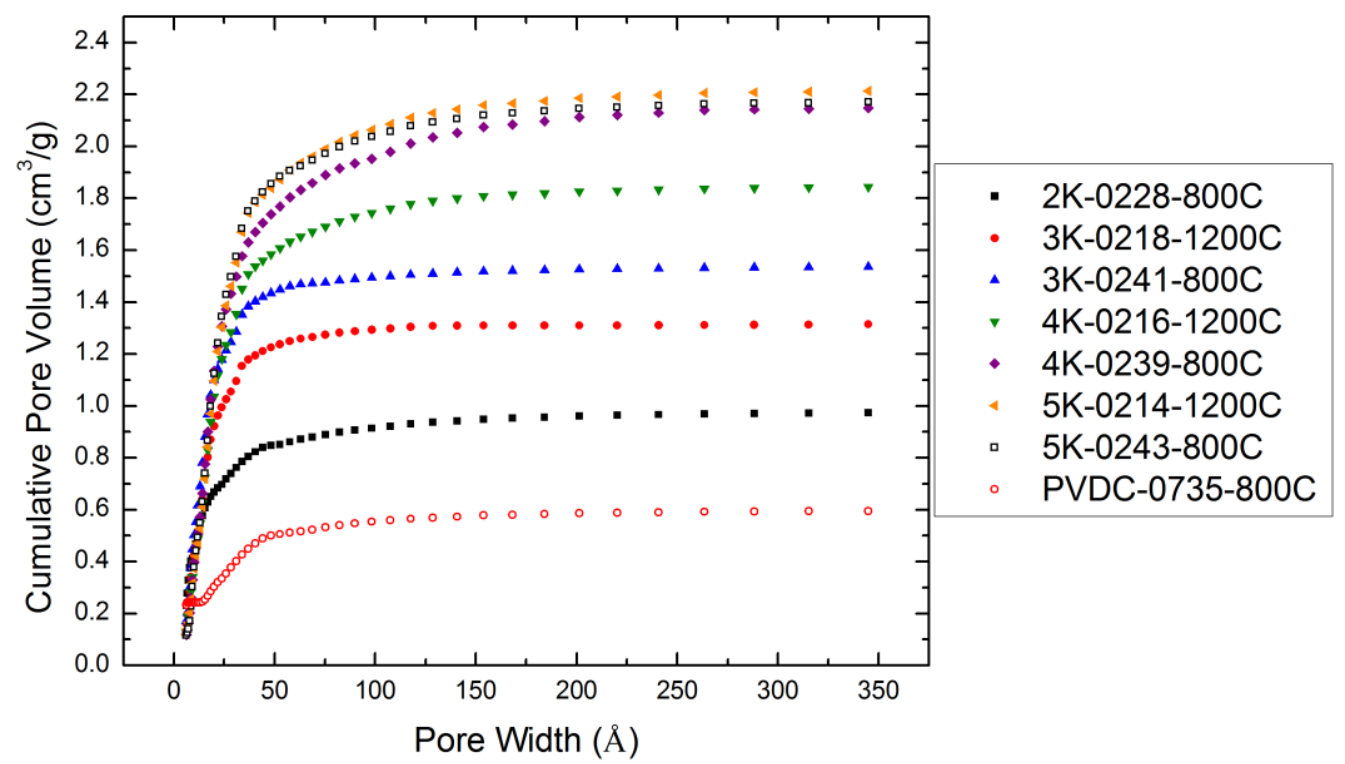

Figure 55. Cumulative pore volumes for precursor materials outgassed at high temperatures.

When comparing across activation ratios, one observes similar trends in that higher $\mathrm{KOH}: \mathrm{C}$ ratios yield higher total pore volumes. Outgassing at elevated temperatures tends to graphitize carbonaceous materials resulting in decreased pore volumes and specific surface areas. 5K-type materials show no appreciable changes in pore structure even when outgassed at $1200{ }^{\circ} \mathrm{C}$. 


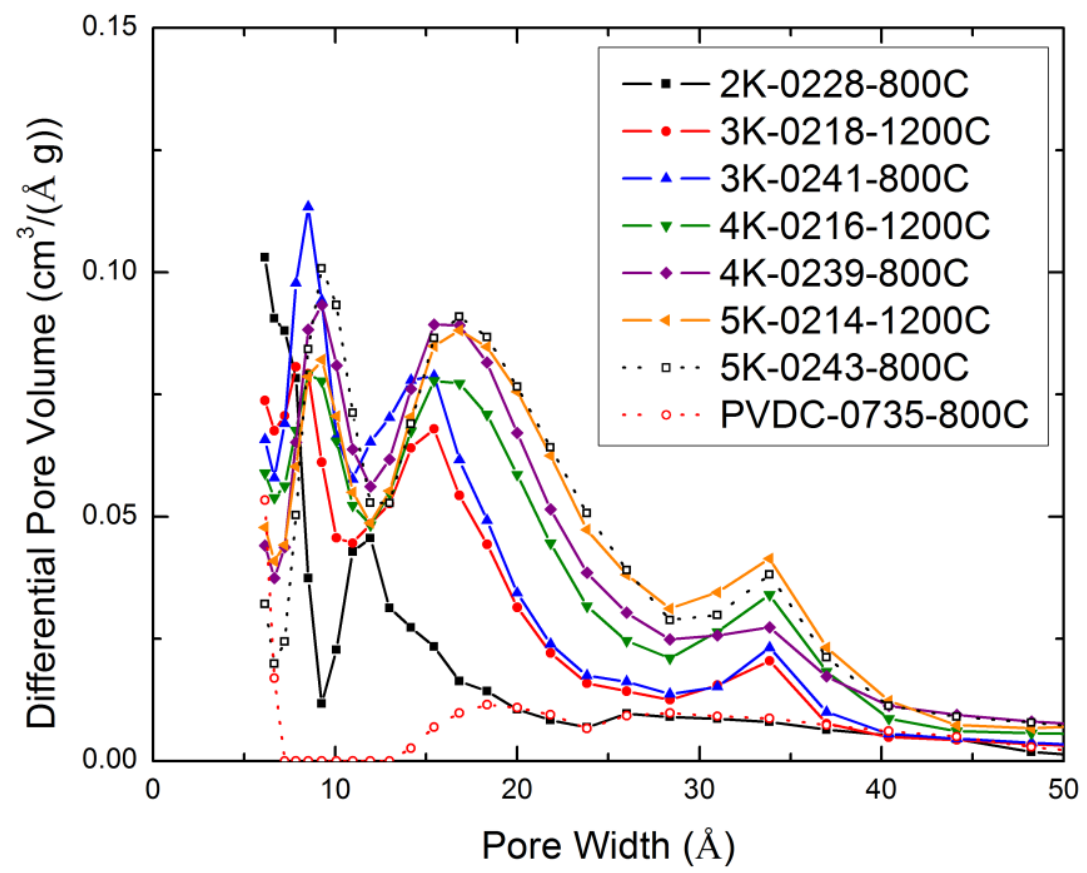

Figure 56. Differential pore volumes for precursor materials outgassed at high temperatures.

Most materials undergo partial graphitization when outgassed at temperatures exceeding $600{ }^{\circ} \mathrm{C}$. This may be observed by a reduction in the first mode of the pore size distribution and a slight reduction in the specific surface areas. For example, sample $4 \mathrm{~K}-0239$ was outgassed at $800{ }^{\circ} \mathrm{C}$ and $4 \mathrm{~K}-0216$ was outgassed at $1200{ }^{\circ} \mathrm{C}$. The surface areas of $4 \mathrm{~K}-0239$ and $4 \mathrm{~K}-0216$ were reduced to $2600 \mathrm{~m}^{2} / \mathrm{g}$ and $2390 \mathrm{~m}^{2} / \mathrm{g}$, respectively. A slight reduction in pore volumes is also observed with increased outgassing temperatures. 


\section{Boron-Doped Sorbent Materials (2K \& 2.5K-type):}

Table 9: Nitrogen Analyses for $2 \mathrm{~K}$ and 2.5K-type B-Doped Materials

\begin{tabular}{|l|r|r|r|r|}
\hline \multicolumn{1}{|c|}{ Sample Name } & $\begin{array}{c}\sum_{\text {BET }} \\
\left(\mathrm{m}^{2} / \mathrm{g}\right)\end{array}$ & Porosity & $\begin{array}{r}\text { Total Pore Volume } \\
{[\mathrm{mL} / \mathrm{g}]}\end{array}$ & $\begin{array}{c}\text { Sub-nm Pore } \\
\text { Volume Fraction* } \\
{\left[V_{\text {sub-nm }} / V_{\text {total }}\right]}\end{array}$ \\
\hline $2 \mathrm{~K}-0248(1.7 \mathrm{wt} \% \mathrm{~B})$ & 1670 & 0.657 & 0.96 & 0.359 \\
\hline $2.5 \mathrm{~K}-0754$ & 2460 & 0.733 & 1.37 & 0.397 \\
$(4.4 * * \mathrm{wt} \% \mathrm{~B})$ & & & & 0.332 \\
\hline $2.5 \mathrm{~K}-0755$ & 2030 & 0.717 & & 1.26 \\
$(5.6 * * \mathrm{wt} \% \mathrm{~B})$ & & & & \\
\hline
\end{tabular}

*The sub-nanometer pore volume describes the amount of pore volume contributed from pores of widths up to $1.3 \mathrm{~nm}$. The sub-nanometer pore volume fraction is normalized by the total pore volume.

**These boron weight percents were not measured by PGAA, but estimated base upon stoichiometry during synthesis.

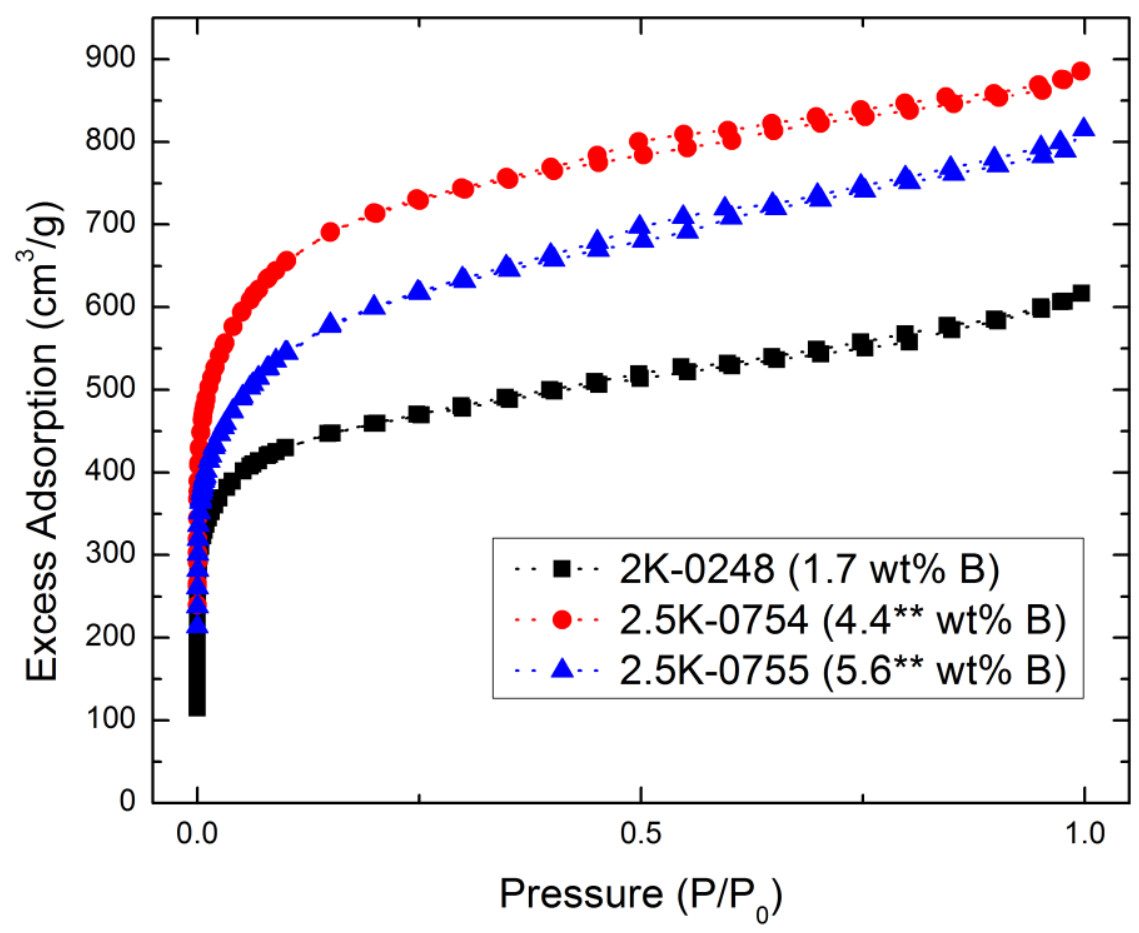

Figure 57. Nitrogen excess adsorption for boron doped samples originating from $2 \mathrm{~K}$ and $2.5 \mathrm{~K}$-type precursors. These materials were outgassed and annealed at $800{ }^{\circ} \mathrm{C}$. 


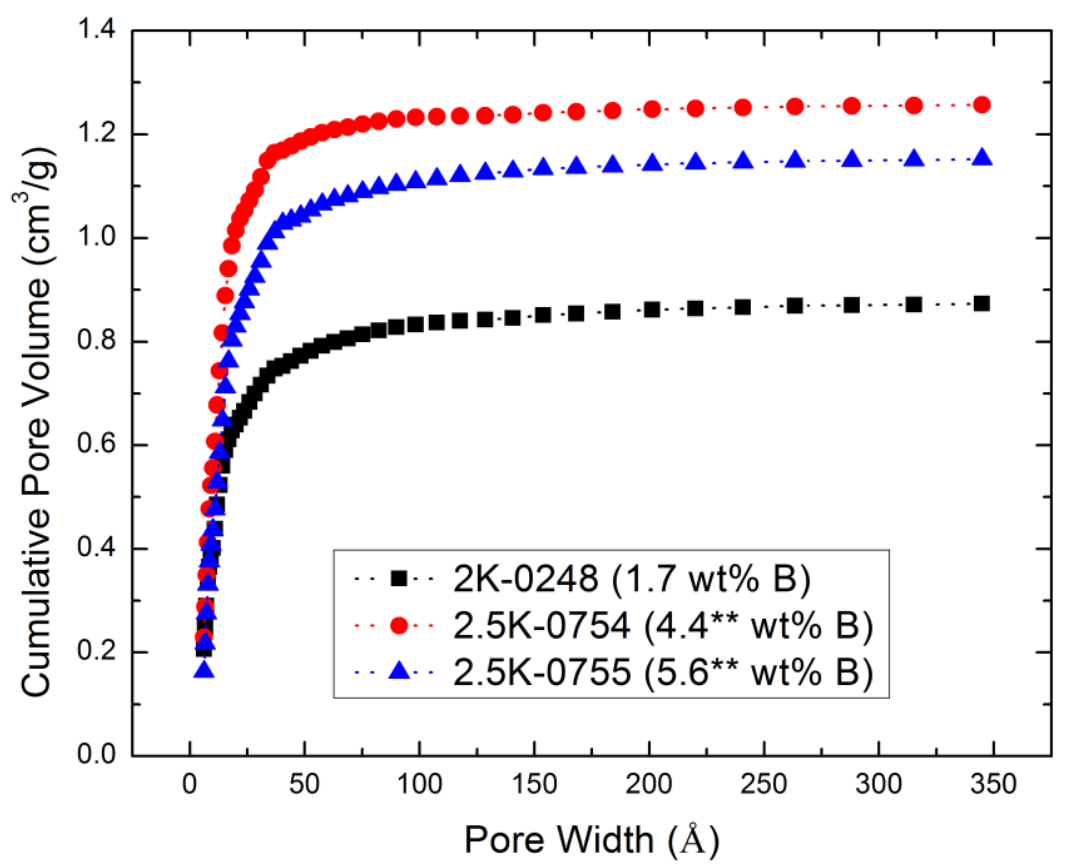

Figure 58. Cumulative pore volumes for boron doped samples originating from $2 \mathrm{~K}$ and $2.5 \mathrm{~K}$-type precursors. Samples that underwent $2 \mathrm{~K}$ activation during synthesis achieved an insufficient surface area. Samples that underwent $2.5 \mathrm{~K}$ activation or higher exhibited surface areas exceeding $2000 \mathrm{~m}^{2} / \mathrm{g}$ as well as large sub-nanometer volume fractions, which should be indicative of high storage capacities.

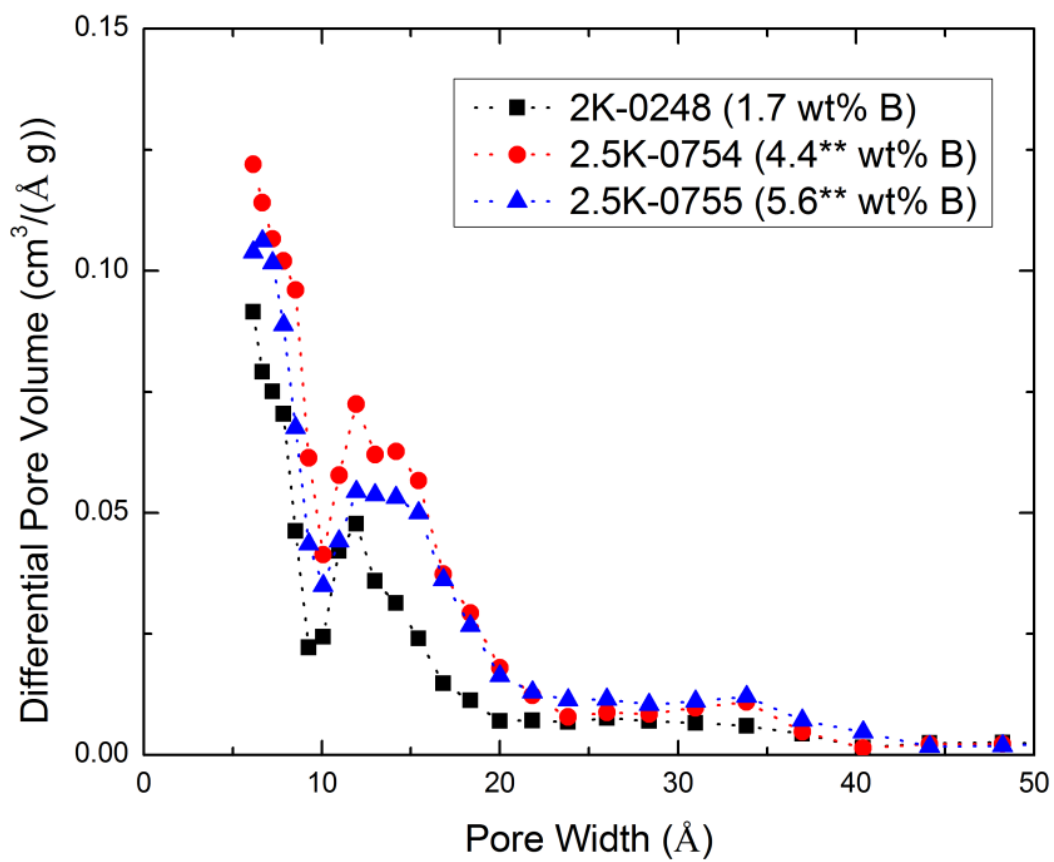

Figure 59. Differential pore volumes for boron doped samples originating from $2 \mathrm{~K}$ and $2.5 \mathrm{~K}$-type precursors. The pore size distributions of $2.5 \mathrm{~K}-0754$ and $2.5 \mathrm{~K}-0755$ show that differential volume of both modes is reduced compared to the precursor $2.5 \mathrm{~K}-0807$. Increased boron contents also appear to be correlated with decreasing pore volumes and sub-nanometer volume fraction. 


\section{Boron-Doped Sorbent Materials (3K-type):}

Table 10: Nitrogen Analyses for 3K-type B-Doped Materials

\begin{tabular}{|c|c|c|c|c|}
\hline Sample Name & $\begin{array}{l}\sum_{\mathrm{BET}} \\
\left(\mathrm{m}^{2} / \mathrm{g}\right)\end{array}$ & Porosity & $\begin{array}{c}\text { Total Pore Volume } \\
\qquad[\mathrm{mL} / \mathrm{g}]\end{array}$ & $\begin{array}{c}\text { Sub-nm Pore } \\
\text { Volume Fraction } \\
{\left[V_{\text {sub-nm }} / V_{\text {total }}\right]}\end{array}$ \\
\hline $3 \mathrm{~K}-0201(8.0 \mathrm{wt} \% \mathrm{~B})$ & 2030 & 0.742 & 1.44 & 0.260 \\
\hline $3 \mathrm{~K}-0203(0.3 \mathrm{wt} \% \mathrm{~B})$ & 2650 & 0.780 & 1.81 & 0.290 \\
\hline $3 \mathrm{~K}-0205$ (9.7 wt\% B) & 2260 & 0.779 & 1.76 & 0.245 \\
\hline $3 \mathrm{~K}-0208$ (13.7 wt\% B) & 1950 & 0.739 & 1.42 & 0.246 \\
\hline $3 \mathrm{~K}-0211(6.2 \mathrm{wt} \% \mathrm{~B})$ & 2180 & 0.749 & 1.49 & 0.275 \\
\hline $3 \mathrm{~K}-1035(4.1 *$ wt $\% \mathrm{~B})$ & 2180 & 0.775 & 1.72 & 0.231 \\
\hline $3 \mathrm{~K}-1036(4.3 * \mathrm{wt} \% \mathrm{~B})$ & 2250 & 0.836 & 2.55 & 0.152 \\
\hline $3 \mathrm{~K}-1037(4.7 *$ wt $\% \mathrm{~B})$ & 2660 & 0.814 & 2.19 & 0.217 \\
\hline $3 \mathrm{~K}-1038(20.5 * \mathrm{wt} \% \mathrm{~B})$ & 1690 & 0.709 & 1.22 & 0.241 \\
\hline $3 \mathrm{~K}-0219(8.7 \mathrm{wt} \% \mathrm{~B})$ & 1980 & 0.737 & 1.40 & 0.259 \\
\hline
\end{tabular}

The sub-nanometer pore volume describes the amount of pore volume contributed from pores of widths up to $1.3 \mathrm{~nm}$. The sub-nanometer pore volume fraction is normalized by the total pore volume.

*Indicates that boron contents were measured from XPS analysis of the B, C, and O energy regimes.

Samples 3K-0201, 3K-0203, 3K-0205, 3K-0208, and 3K-0211 were synthesized from a deoxygenated version of precursor material $3 \mathrm{~K}-0079-600 \mathrm{C}$ and annealed at $600{ }^{\circ} \mathrm{C}$. In addition to outgassing and annealing at $600{ }^{\circ} \mathrm{C}$, samples $3 \mathrm{~K}-1035,3 \mathrm{~K}-1036,3 \mathrm{~K}-1037$, and $3 \mathrm{~K}-1038$ were annealed a second time at $1200{ }^{\circ} \mathrm{C}$. Sample $3 \mathrm{~K}-0219$ was synthesized by outgassing $3 \mathrm{~K}-0079$ at $1200{ }^{\circ} \mathrm{C}$ and annealing at $1200{ }^{\circ} \mathrm{C}$ under Argon flow. 


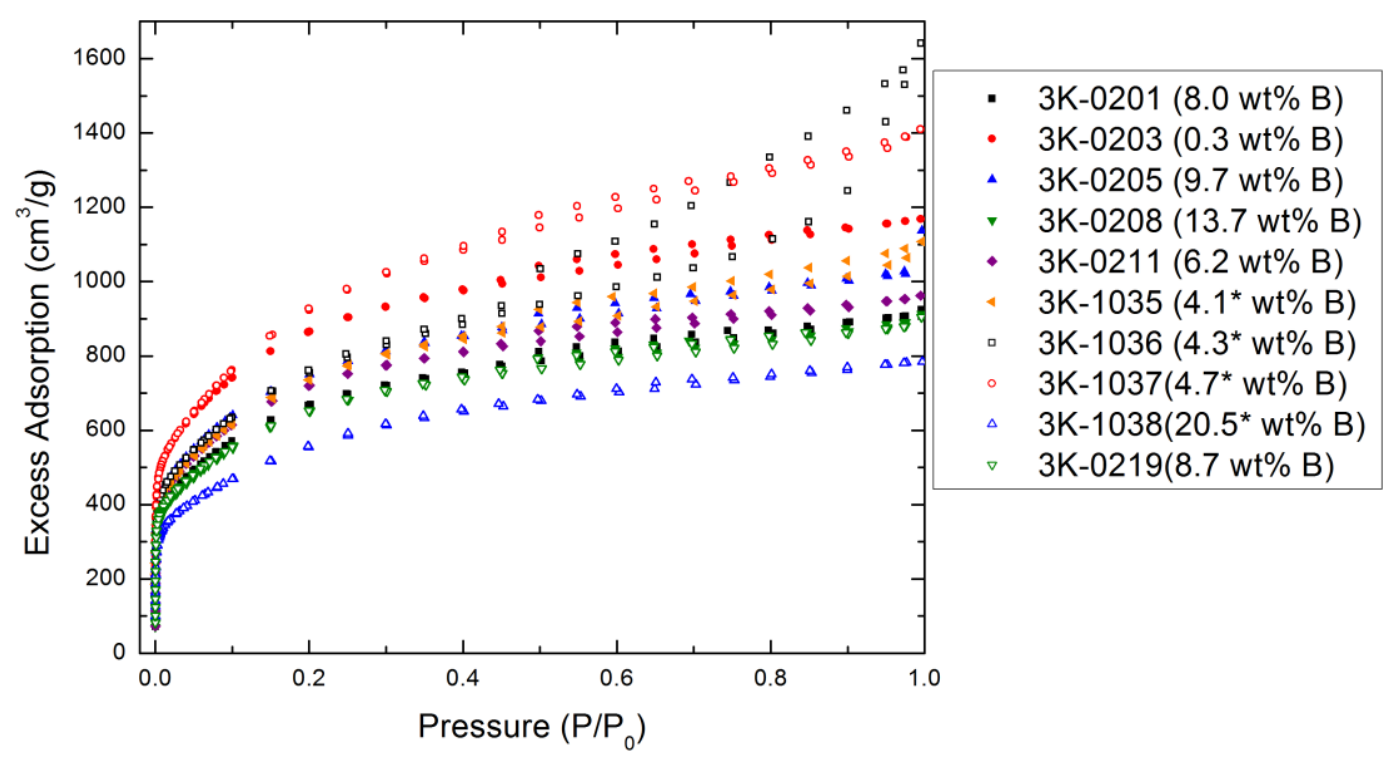

Figure 60. Nitrogen adsorption for boron doped samples originating from 3K-type precursors. These materials were outgassed and annealed at $800{ }^{\circ} \mathrm{C}$ or $1200{ }^{\circ} \mathrm{C}$.

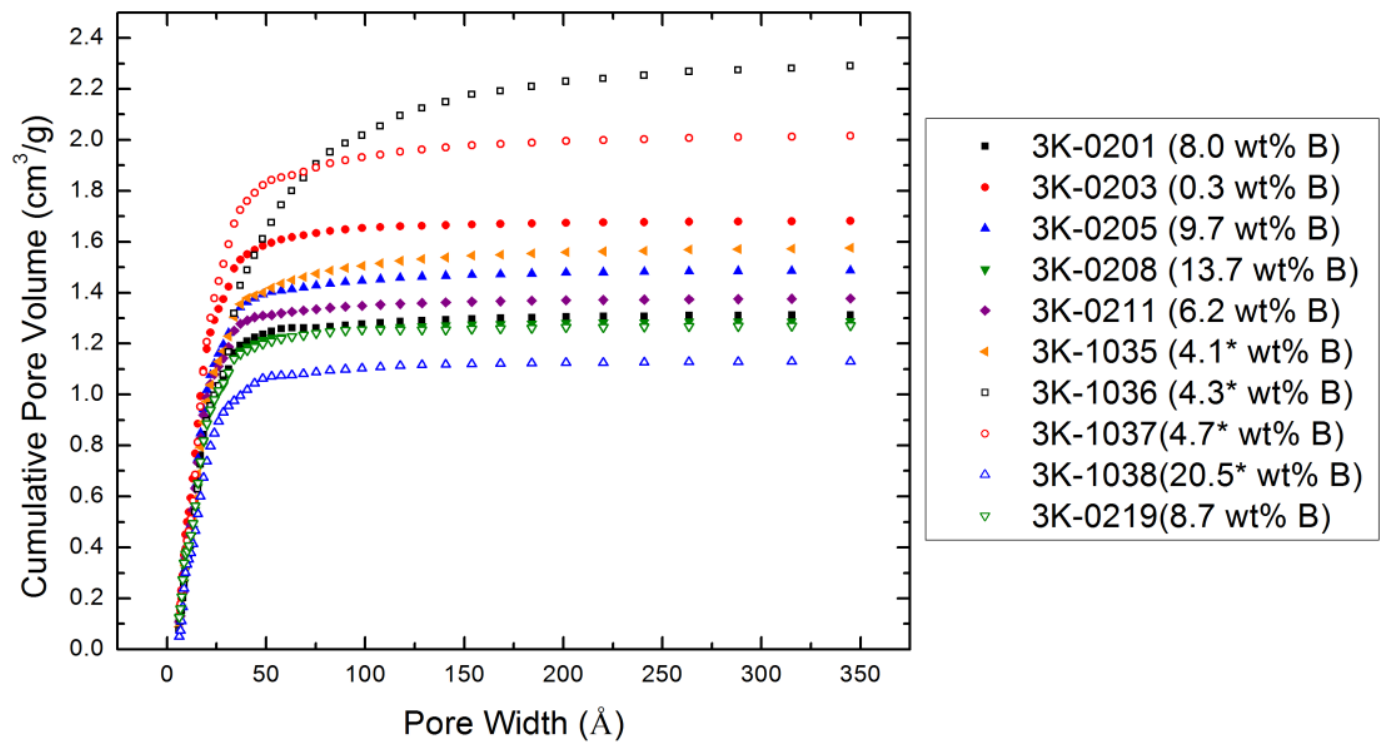

Figure 61. Cumulative pore volumes for boron doped samples originating from 3K-type precursors. 


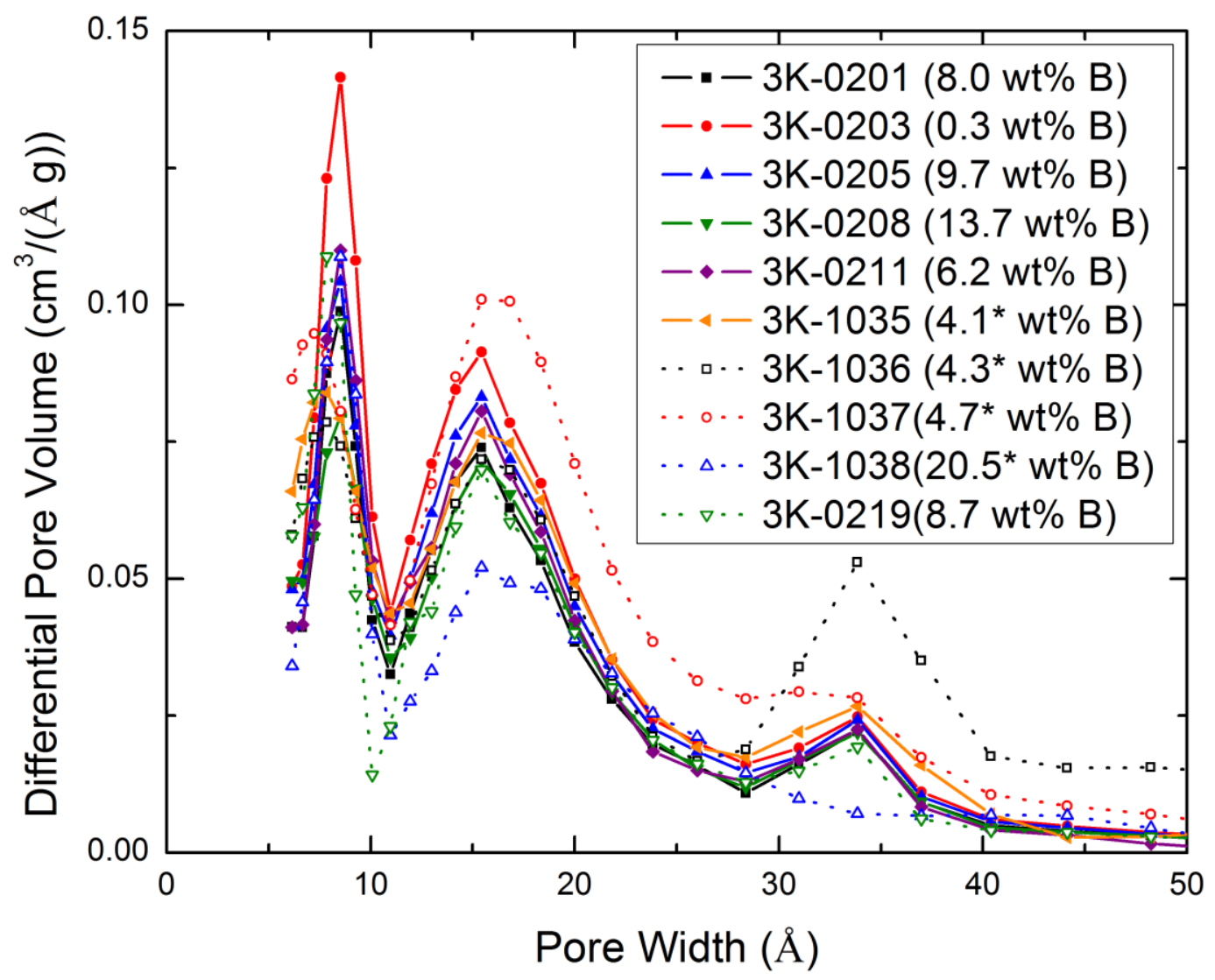

Figure 62. Differential pore volumes for boron doped samples originating from 3K-type precursors. All samples that were doped under stationary conditions experienced pore clogging in addition to graphitization. This results in lower specific surface area and porosities.

The pore size distribution of $3 \mathrm{~K}-0203$ is nearly identical to that of its precursor, $3 \mathrm{~K}-0079$. This is because it was doped with a very small amount of boron and underwent insignificant changes during the annealing process. Samples doped with high weight percentages of boron show a reduction of all pore sizes, especially in sub-nanometer pores 


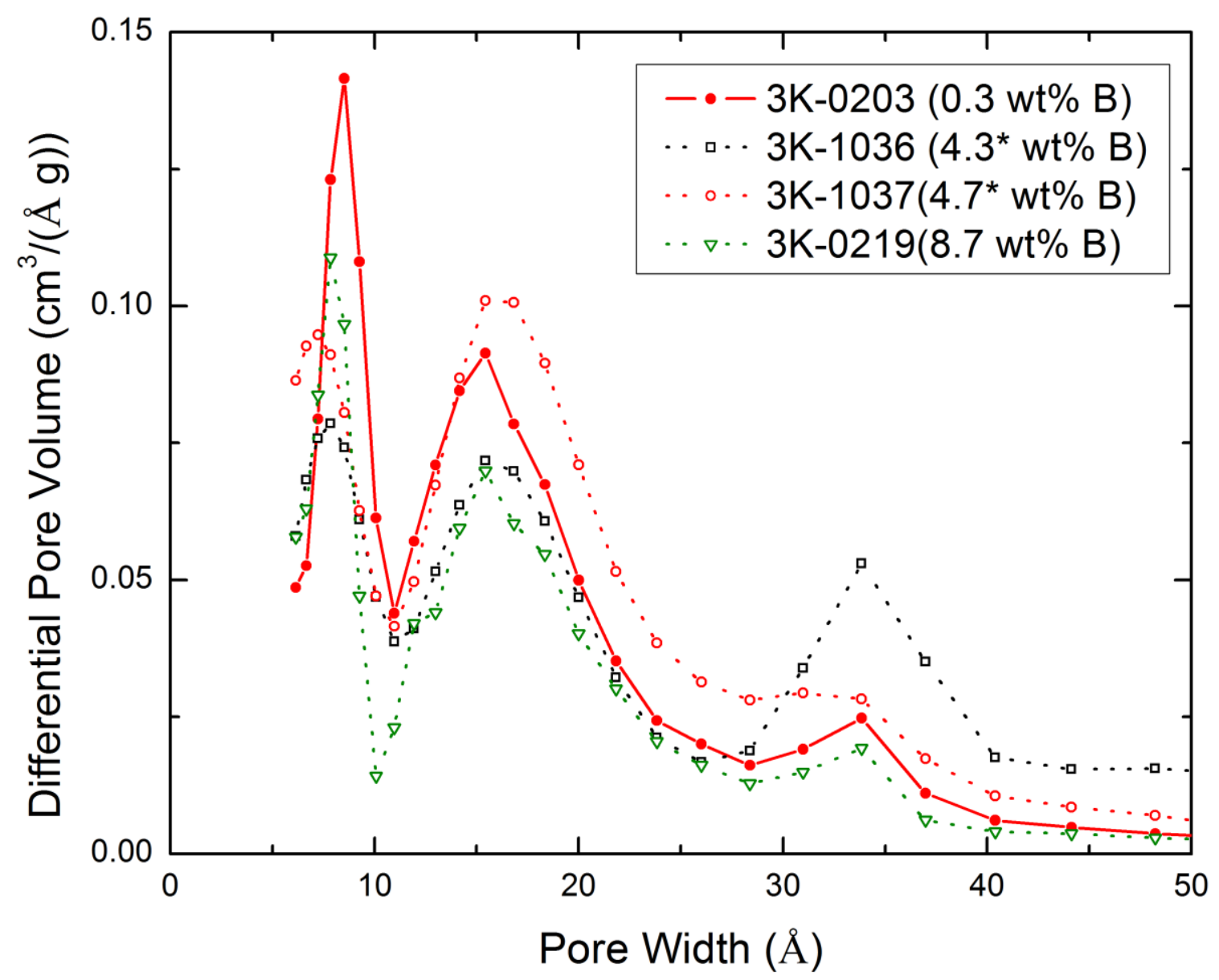

Figure 63. Differential pore volumes for select boron doped 3K samples.

Boron doping under stationary conditions tends to clog pores especially in the sub-nanometer regime. This can be seen when comparing $3 \mathrm{~K}-0203$ and $3 \mathrm{~K}-0219$. This is most likely due to the presence of undesirable $\mathrm{B}-\mathrm{O}$ and $\mathrm{B}-\mathrm{B}$ bonded aggregates on the surface after doping. Larger borane products are formed during the decomposition of decaborane, which adsorb to the surface with a high binding energy between $70-80 \mathrm{~kJ} / \mathrm{mol}{ }^{[54]}$. $3 \mathrm{~K}-0219$ was doped with a high weight percent of boron under stationary conditions and annealed at $1200{ }^{\circ} \mathrm{C}$. Samples $3 \mathrm{~K}-1036$ and $3 \mathrm{~K}-1037$ were prepared under similar conditions except these two samples were annealed under argon flow. Evidence of graphitization is present in all samples that experienced high temperature outgassing and annealing. However, samples that were annealed under argon flow exhibit less pore clogging in pores with widths between 1-5nm. During the second annealing stage, the larger decomposition products were desorbed and allowed to leave the 
annealing chamber by the carrier gas. This should result in a lower overall B:C weight percent, but should also remove much of the undesirable $\mathrm{B}-\mathrm{B}$ and $\mathrm{B}-\mathrm{O}$ compounds that would otherwise block adsorption sites.

\section{Boron-Doped Sorbent Materials (4K-type):}

Table 11: Nitrogen Analyses for 4K-type B-Doped Materials

\begin{tabular}{|c|c|c|c|c|}
\hline Sample Name & $\begin{array}{c}\sum_{\mathrm{BET}} \\
\left(\mathrm{m}^{2} / \mathrm{g}\right)\end{array}$ & Porosity & $\begin{array}{l}\text { Total Pore Volume } \\
\qquad[\mathrm{mL} / \mathrm{g}]\end{array}$ & $\begin{array}{c}\text { Sub-nm Pore } \\
\text { Volume Fraction } \\
{\left[V_{\text {sub-nm }} / V_{\text {total }}\right]}\end{array}$ \\
\hline $4 \mathrm{~K}-0240(1.5 \mathrm{wt} \% \mathrm{~B})$ & 2530 & 0.824 & 2.34 & 0.192 \\
\hline $4 \mathrm{~K}-0244(1.6 \mathrm{wt} \% \mathrm{~B})$ & 2460 & 0.817 & 2.23 & 0.196 \\
\hline $4 \mathrm{~K}-0245$ (3.9 wt\% B) & 2490 & 0.820 & 2.27 & 0.194 \\
\hline $4 \mathrm{~K}-0246$ (4.1 wt\% B) & 2370 & 0.810 & 2.13 & 0.196 \\
\hline $4 \mathrm{~K}-0747$ (3.6 wt\% B) & 2350 & 0.804 & 2.06 & 0.207 \\
\hline $4 \mathrm{~K}-0748(5.6 \mathrm{wt} \% \mathrm{~B})$ & 2390 & 0.805 & 2.07 & 0.213 \\
\hline $4 \mathrm{~K}-0749(5.9 \mathrm{wt} \% \mathrm{~B})$ & 2250 & 0.791 & 1.90 & 0.216 \\
\hline $4 \mathrm{~K}-0750(6.9 \mathrm{wt} \% \mathrm{~B})$ & 2190 & 0.788 & 1.86 & 0.213 \\
\hline $4 \mathrm{~K}-0751(5.9 \mathrm{wt} \% \mathrm{~B})$ & 2490 & 0.815 & 2.21 & 0.205 \\
\hline $4 \mathrm{~K}-0752(9.1 \mathrm{wt} \% \mathrm{~B})$ & 2060 & 0.779 & 1.76 & 0.209 \\
\hline
\end{tabular}

The sub-nanometer pore volume describes the amount of pore volume contributed from pores of widths up to $1.3 \mathrm{~nm}$. The sub-nanometer pore volume fraction is normalized by the total pore volume.

*Indicates that boron contents were measured from XPS analysis of the B, C, and O energy regimes. 

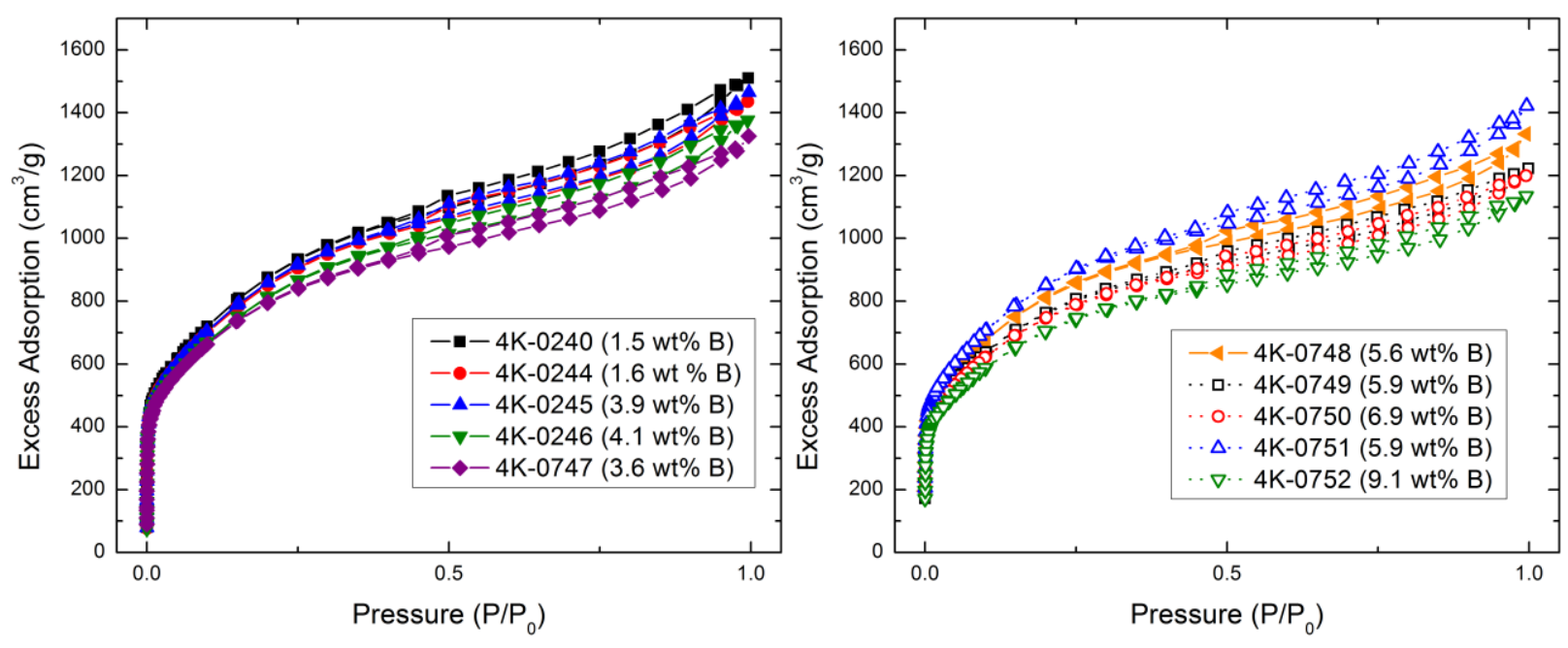

Figure 64. Nitrogen adsorption for boron doped samples originating from 4K-type precursors. Left: Nitrogen excess for samples doped with boron weight percent between 0-5\%. Right: Nitrogen excess for samples doped with boron weight percent between 5-10\%. Each of these materials were systematically outgassed and annealed at $800{ }^{\circ} \mathrm{C}$ under stationary doping conditions.

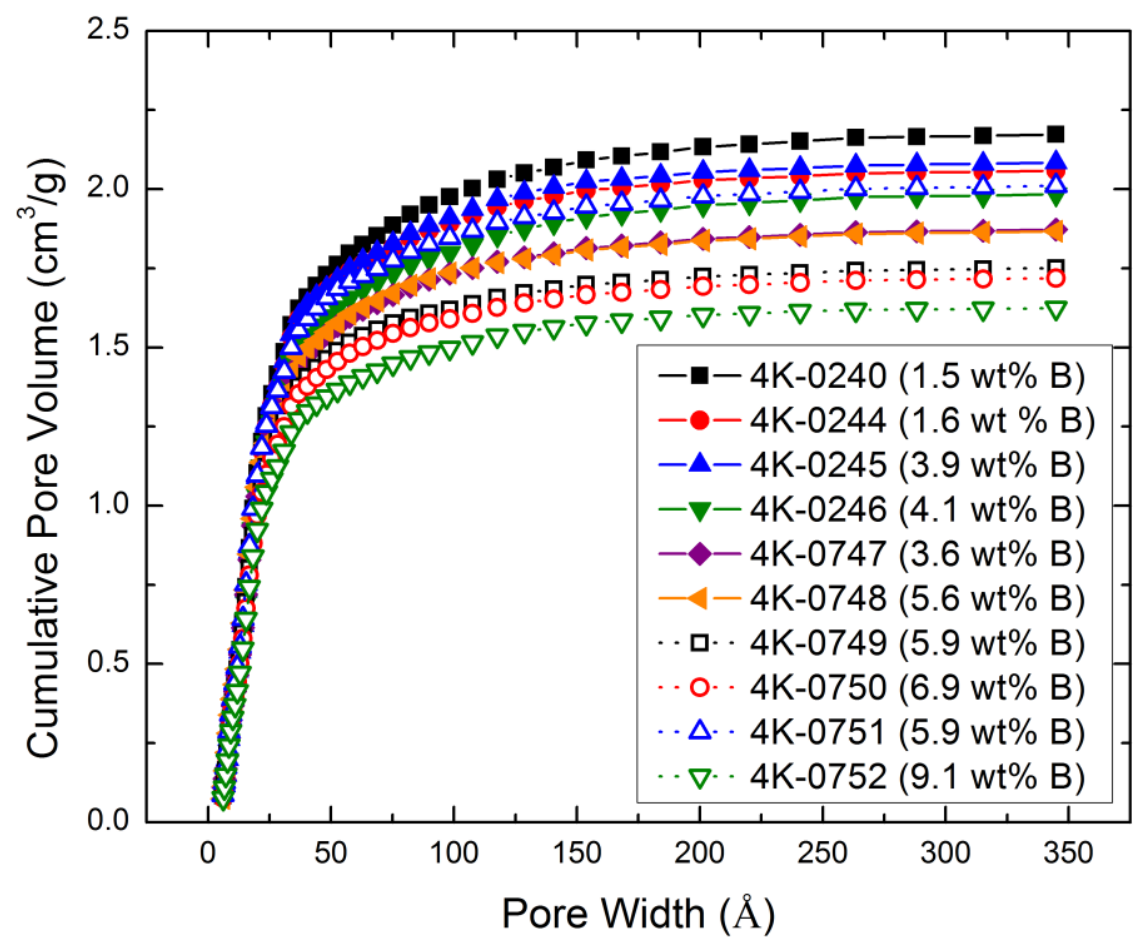

Figure 65. Cumulative pore volumes for boron doped samples originating from 4K-type precursor carbons. Pore volumes decrease with increasing boron weight percent for samples doped under stationary conditions. 

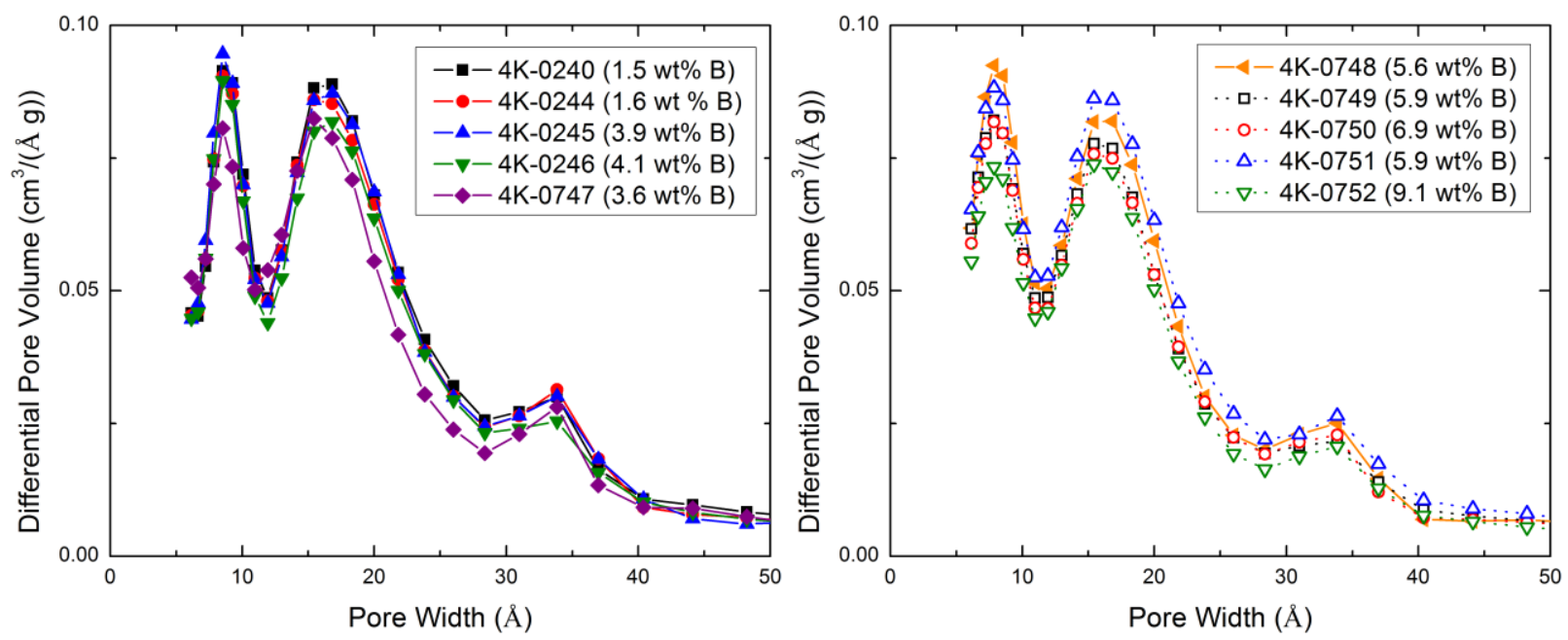

Figure 66. Differential pore for boron doped samples originating from 4K-type precursor carbons. Left: Differential pore size distributions for samples doped with boron weight percent between $0-5 \%$. Right: Differential pore size distributions for samples doped with boron weight percent between 5-10\%.

\section{Boron-Doped Sorbent Materials (5K-type):}

Table 12: Nitrogen Analyses for 5K-type B-Doped Materials and Their Deoxygenated Precursors

\begin{tabular}{|l|r|r|r|r|}
\hline \multicolumn{1}{|c|}{ Sample Name } & $\begin{array}{c}\sum_{\text {BET }} \\
\left(\mathrm{m}^{2} / \mathrm{g}\right)\end{array}$ & Porosity & $\begin{array}{r}\text { Total Pore Volume } \\
{[\mathrm{mL} / \mathrm{g}]}\end{array}$ & \multicolumn{2}{|c|}{$\begin{array}{c}\text { Sub-nm Pore } \\
\text { Volume Fraction } \\
{\left[V_{\text {sub-nm }} / V_{\text {total }}\right]}\end{array}$} \\
\hline $5 \mathrm{~K}-0214-1200 \mathrm{C}$ & 2560 & 0.832 & 2.48 & 0.178 \\
\hline $5 \mathrm{~K}-0215(8 \mathrm{wt} \% \mathrm{~B})$ & 1950 & 0.793 & 1.92 & 0.150 \\
\hline $5 \mathrm{~K}-0243-800 \mathrm{C}$ & 2600 & 0.827 & 2.39 & 0.181 \\
\hline $5 \mathrm{~K}-0742(3.9 \mathrm{wt} \% \mathrm{~B})$ & 2350 & 0.813 & 2.17 & \\
\hline
\end{tabular}

The sub-nanometer pore volume describes the amount of pore volume contributed from pores of widths up to $1.3 \mathrm{~nm}$. The sub-nanometer pore volume fraction is normalized by the total pore volume. 




Figure 67. Nitrogen excess adsorption for boron doped samples originating from 5K-type precursor carbons. $5 \mathrm{~K}-0214$ and $5 \mathrm{~K}-0215$ were both outgassed at $1200{ }^{\circ} \mathrm{C}$ and $5 \mathrm{~K}-0215$ was annealed under stationary conditions at $1200{ }^{\circ} \mathrm{C}$. Samples $5 \mathrm{~K}-0243$ and $5 \mathrm{~K}-0742$ were both outgassed at $800{ }^{\circ} \mathrm{C}$ and $5 \mathrm{~K}-0742$ was annealed under stationary conditions at $800{ }^{\circ} \mathrm{C}$.

In contrast to all other deoxygenated precursor materials in this study, $5 \mathrm{~K}$ samples were less affected by graphitization. Both deoxygenated samples (5K-0214 and 5K-243) experienced only minor changes to their pore structures compared to their precursor sample, $5 \mathrm{~K}-0280$, including a reduction in specific surface area on the order of $100 \mathrm{~m}^{2} / \mathrm{g}$. As expected, nitrogen excess decreased with increasing boron contents due to undesirable $\mathrm{B}-\mathrm{B}$ and $\mathrm{B}-\mathrm{O}$ aggregates blocking adsorption sites. 




Figure 68. Cumulative pore volumes for boron doped samples originating from 5K-type precursor carbons.

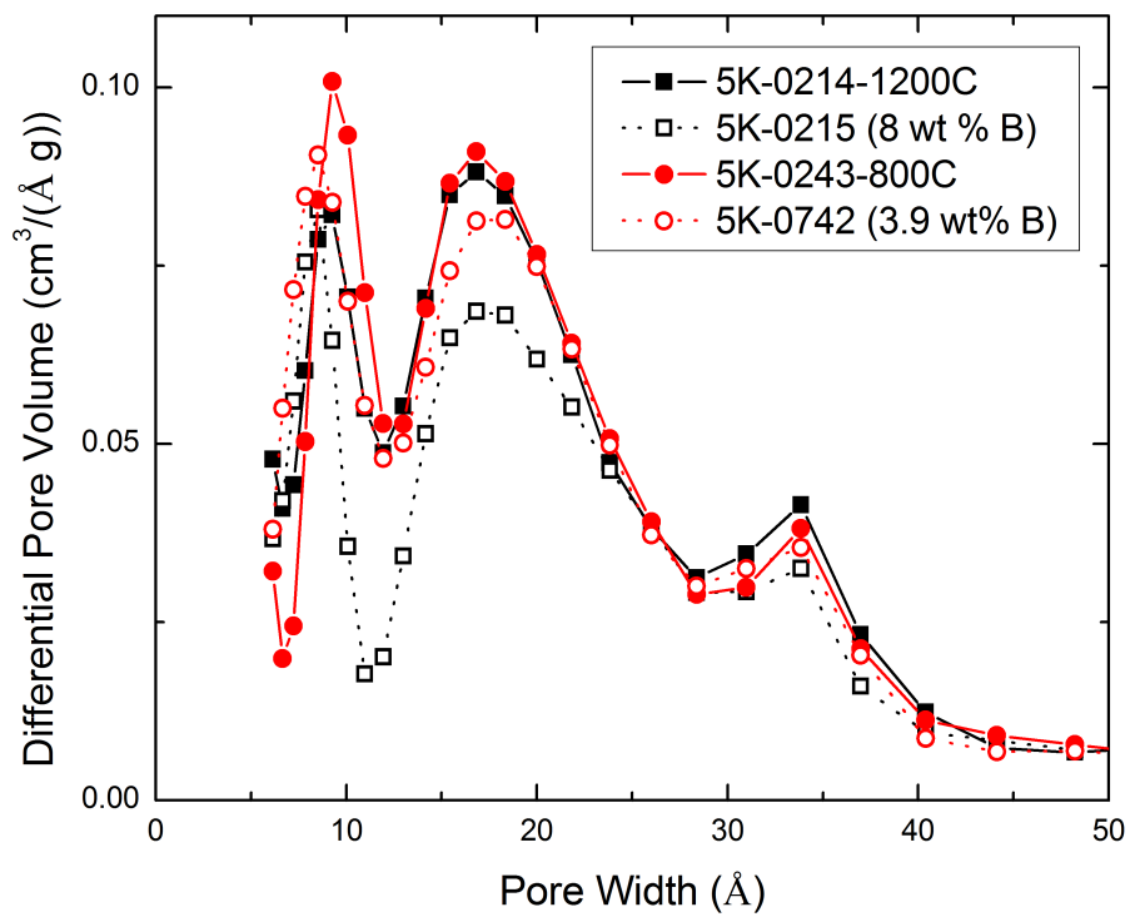

Figure 69. Differential pore for boron doped samples originating from 5K-type precursor carbons. The pore size distribution of sample 5K-0215 indicates that pore clogging occurred in pores of widths above $1 \mathrm{~nm}$, but it's primary mode of sub-nanometer pores remained nearly unchanged.

\section{Carbonaceous Monolithic Sorbent Materials:}


It is desirable to produce sorbent monoliths or briquettes in order to improve packing density and conformability of gas storage tanks. Carbon briquettes were produced by mixing MWV-0260 with a PVDC-based binder, partially thermally decomposing the binder while subjecting the mixture to compressive stress, and carbonizing the resultant green body under nitrogen flow.

Table 13: Nitrogen Analyses for Carbonaceous Monolithic Sorbent Materials

\begin{tabular}{|l|r|r|r|r|}
\hline \multicolumn{1}{|c|}{ Sample Name } & \multicolumn{1}{|c|}{$\begin{array}{c}\sum_{\text {BET }} \\
\left(\mathrm{m}^{2} / \mathrm{g}\right)\end{array}$} & Porosity & $\begin{array}{r}\text { Total Pore Volume } \\
{[\mathrm{mL} / \mathrm{g}]}\end{array}$ & \multicolumn{2}{|c|}{$\begin{array}{c}\text { Sub-nm Pore } \\
\text { Volume Fraction* } \\
{\left[V_{\text {sub-nm }} / V_{\text {total }}\right]}\end{array}$} \\
\hline MWV-0260 & 2640 & 0.755 & 1.54 & 0.380 \\
\hline BR-0122 & 1820 & 0.661 & 0.97 & 0.390 \\
\hline BR-0134 & 1990 & 0.697 & 1.15 & 0.345 \\
\hline BR-0311 & 2320 & 0.744 & 1.45 & \\
\hline
\end{tabular}
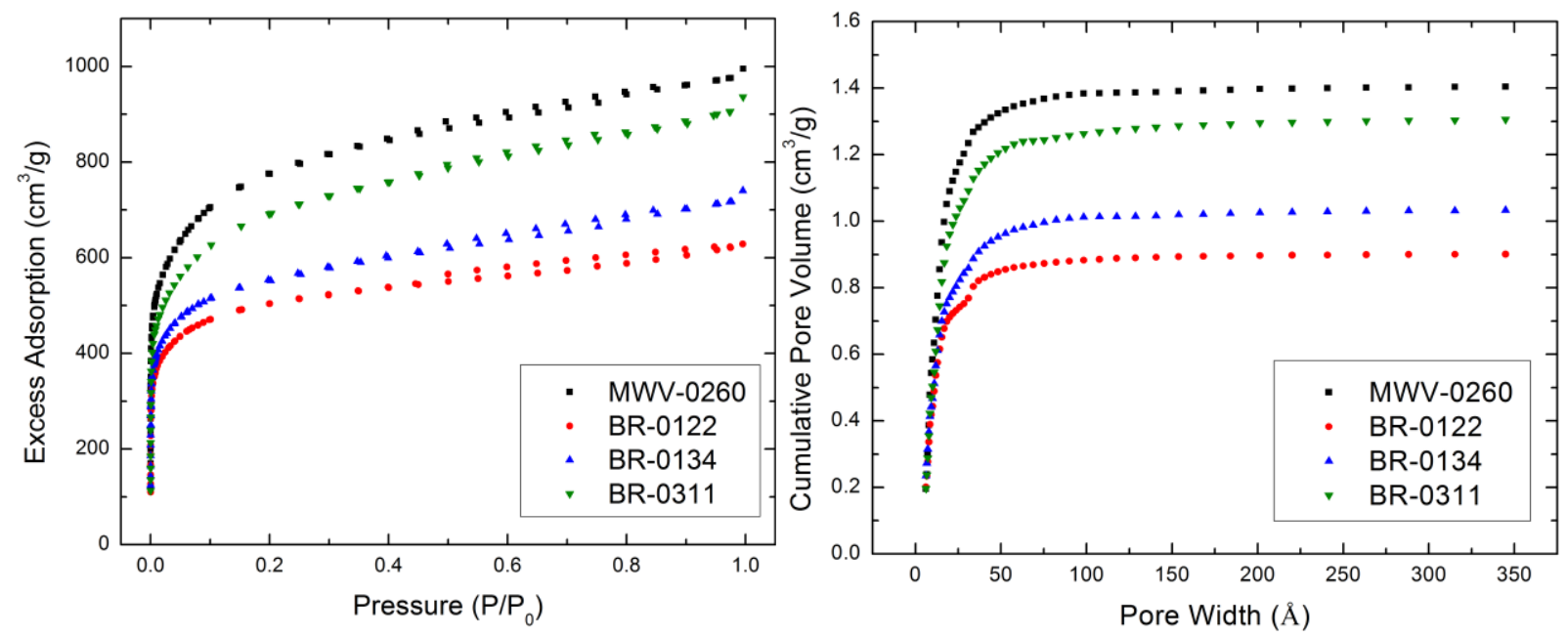

Figure 70. Nitrogen excess adsorption and cumulative pore size distribution for monolithic sorbent materials. 


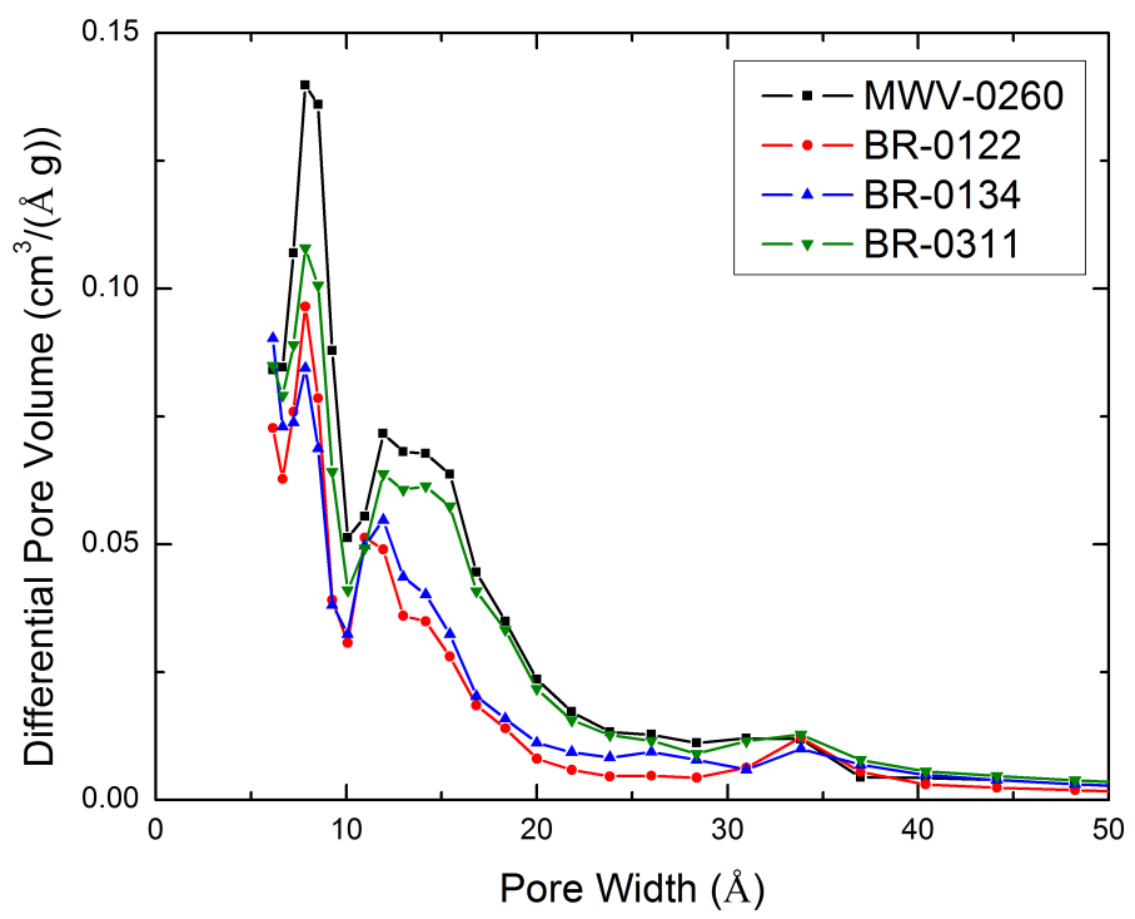

Figure 71. Differential pore size distribution for monolithic sorbent materials.

It was possible to produce a machinable, monolithic sorbent material, BR-0311, while only reducing the specific surface area by $300 \mathrm{~m}^{2} / \mathrm{g}$. With exception to a minor reduction in the sub-nanometer pore volume, the pore structure was largely maintained in producing BR-0311. The sub-nanometer pore volume fraction was greater than $34 \%$ for all briquettes in this study, which indicates that these samples should have relatively high binding energies and volumetric storage capacities due to overlapping Van der Waals potentials.

\subsection{Gravimetric Excess, Gravimetric Storage, and Volumetric Storage}

In order to gain some insight into the general correlations between storage capacities and pore size information, I will first compare a broad range of samples coming from a range of precursors and synthesis methods. This will give the reader some insight as to general trends that might exist across a wide range of samples. 


\section{Excess Adsorption for a Broad Range of Activated and Synthetic Carbonaceous Sorbent Materials:}
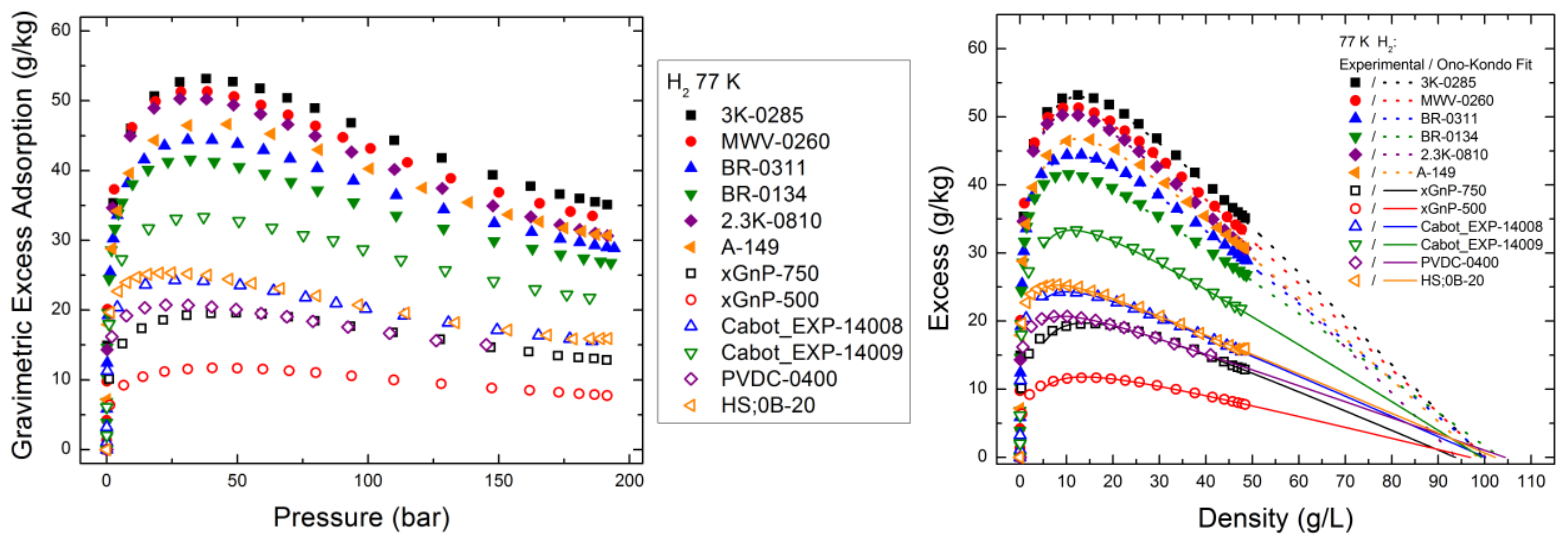

Figure 72. Gravimetric excess adsorption isotherms for various samples measured at $77 \mathrm{~K}$.

As described in the introduction, excess adsorption measurements will increase as the adsorbed film is building, but will decrease when the gas in the adsorbed film becomes less compressible than the bulk gas. With one exception, the maximum excess adsorption is observed to scale with surface area. Sample A-149 was measured to have a specific surface area over $3000 \mathrm{~m}^{2} / \mathrm{g}$, but has a maximum excess adsorption (at $\mathrm{T}=77 \mathrm{~K}$ ) comparable to typical activated carbon samples with lower surface areas.

Samples with lower porosities tend to have lower surface areas, which translates into lower excess adsorption. The peak positions of each isotherm occur at different bulk gas densities, which indicates varying binding energies according to the Ono-Kondo adsorption model. Specifically, the excess adsorption isotherm for HS;0B-20 has a peak position that occurs at much lower densities compared to that of MWV-0260. This should suggest that HS;0B-20 has a higher average binding energy to hydrogen compared to MWV-0260.

All excess adsorption isotherms tend to converge upon the same saturated film density of $\sim 100 \mathrm{~g} / \mathrm{L}$. This result comes from extrapolating using either the Ono-Kondo model or by fitting a straight line to high pressure data. For any given isotherm, both methods give the same result ( $\pm 10 \mathrm{~g} / \mathrm{L})$. 
Excess Adsorption for Chemically Activated, Carbonaceous Precursor Materials:
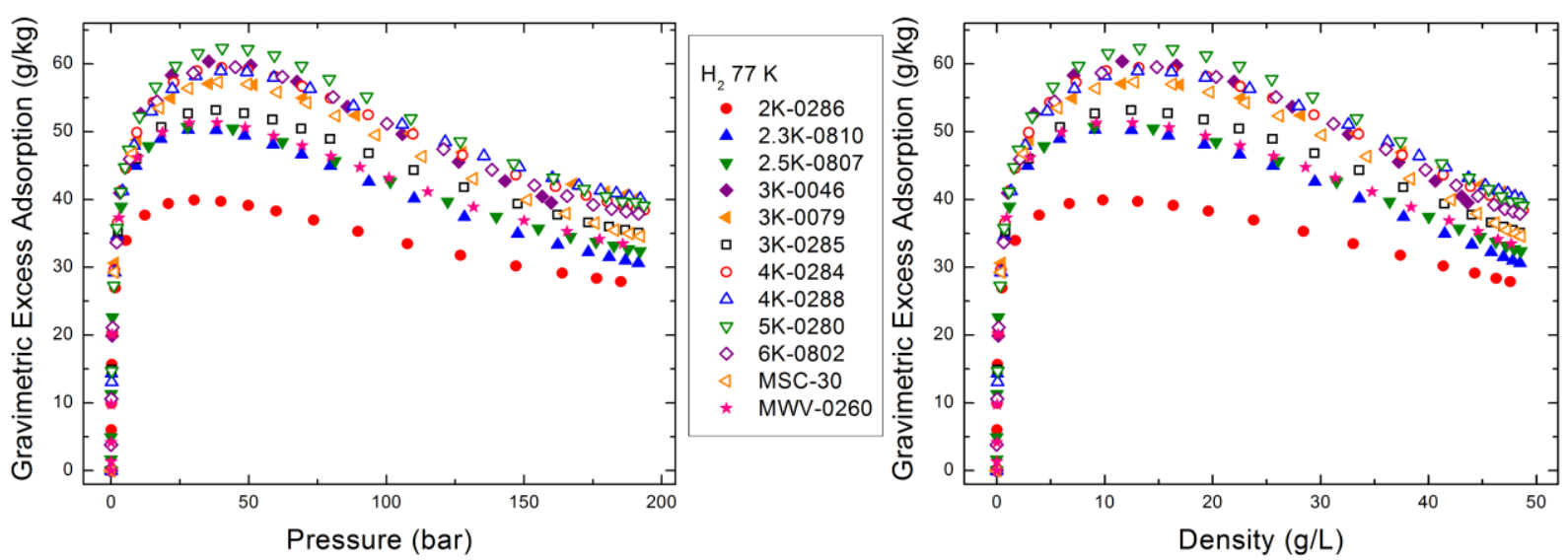

Figure 73. Gravimetric excess adsorption isotherms for activated precursors measured at $77 \mathrm{~K}$.

The maximum excess adsorption increases with increasing surface area. 2K-0286 has a surface area of $1940 \mathrm{~m}^{2} / \mathrm{g}$ and reaches a maximum hydrogen excess adsorption around $40 \mathrm{~g} / \mathrm{kg}$. $5 \mathrm{~K}-0280 \mathrm{has}$ a surface area of $2690 \mathrm{~m}^{2} / \mathrm{g}$ and reaches a maximum hydrogen excess adsorption over $60 \mathrm{~g} / \mathrm{kg}$. However, sample 2K-0286 reaches its maximum excess adsorption at a lower saturation pressure. According to the Ono-Kondo model of adsorption, this indicates that 2K-0286 will have a higher binding energy to hydrogen. This is also evidenced by the fact that sample $2 \mathrm{~K}-0286$ has a sub-nanometer volume fraction that is larger than that of $5 \mathrm{~K}-0280$ by a factor of 2 .

\section{Excess Adsorption for Carbonaceous Precursor Materials After High Temperature Outgassing:}
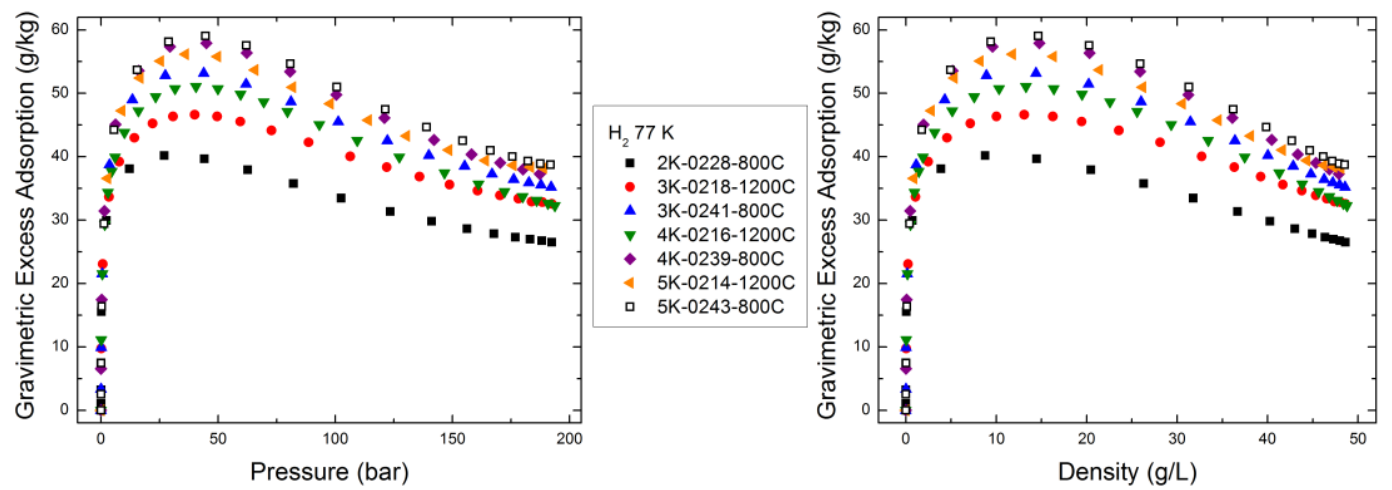

Figure 74. Gravimetric excess adsorption isotherms for deoxygenated precursors measured at $77 \mathrm{~K}$. 
The effects of graphitization may be observed for samples treated at high temperatures through the reduction in specific surface areas and, consequently, a reduction in excess adsorption. All samples treated at $800{ }^{\circ} \mathrm{C}$ have a higher excess adsorption compared to their cousin samples that were treated at $1200{ }^{\circ} \mathrm{C}$.

\section{Excess Adsorption for Boron-Doped Sorbent Materials:}
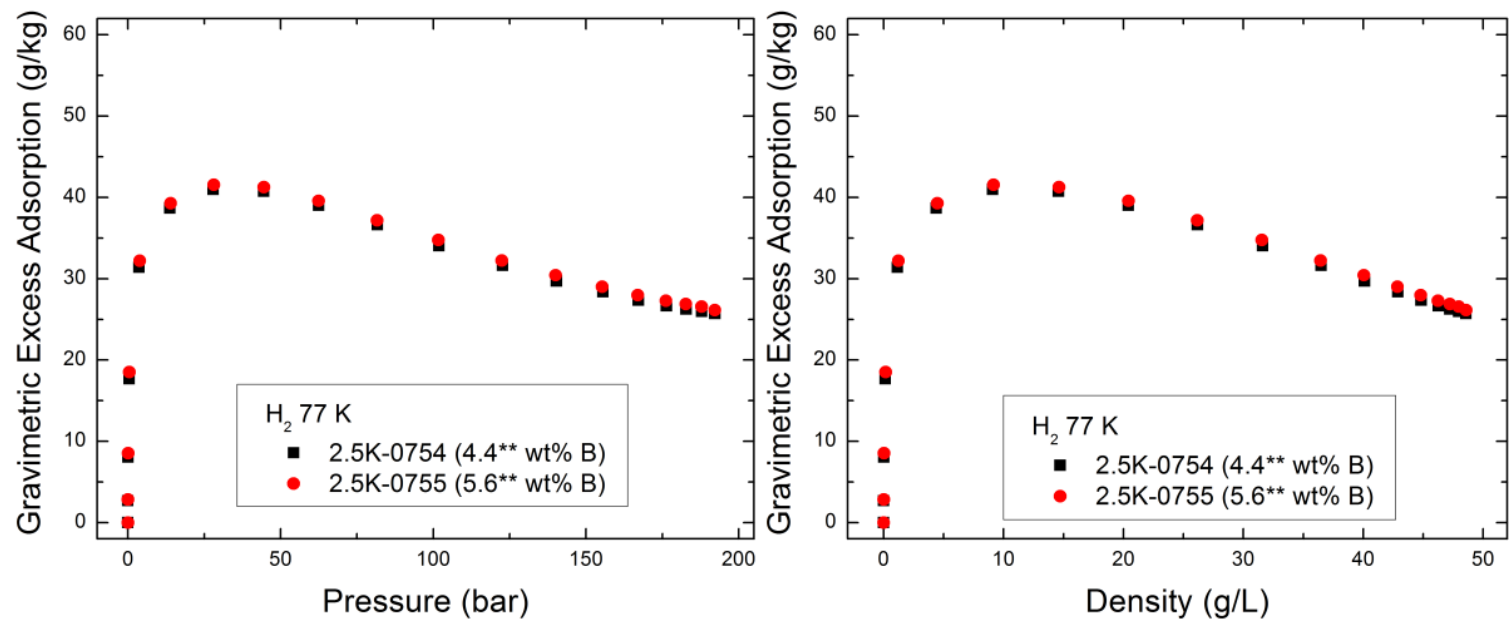

Figure 75. Excess adsorption isotherms for 2.5K-type boron doped materials measured at $77 \mathrm{~K}$.
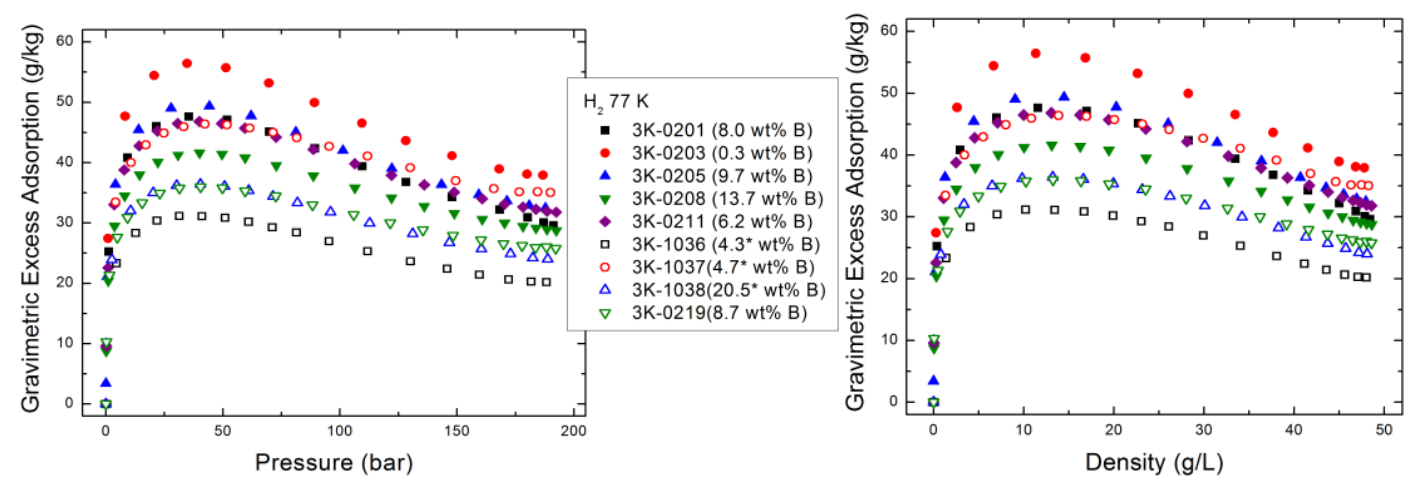

Figure 76. Excess adsorption isotherms for 3K-type boron doped materials measured at $77 \mathrm{~K}$. 

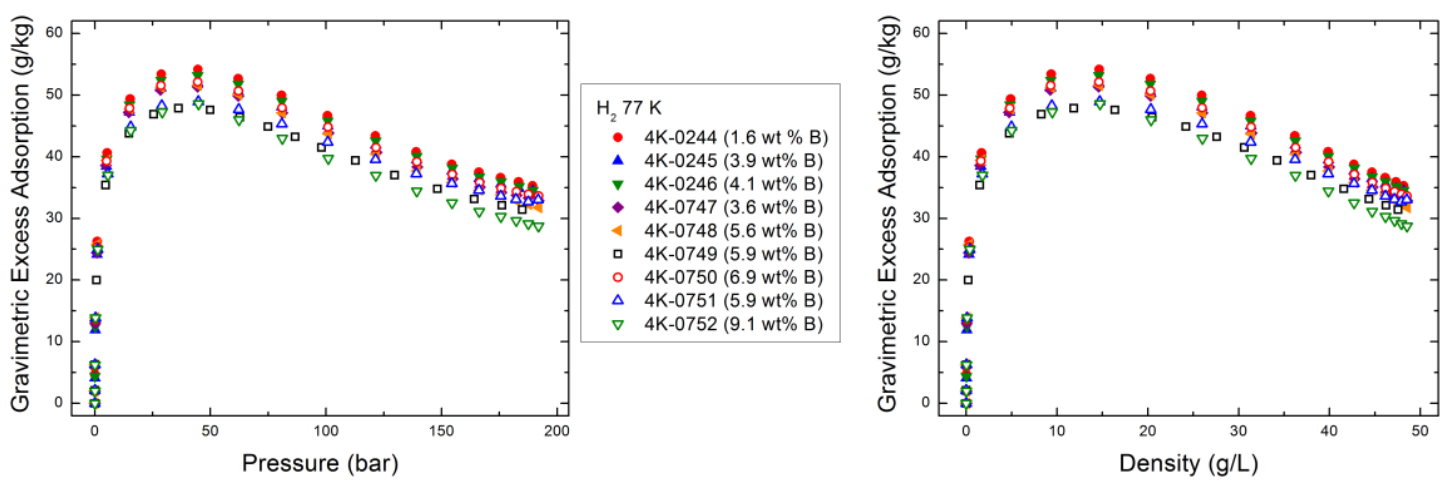

Figure 77. Excess adsorption isotherms for 4K-type boron doped materials measured at $77 \mathrm{~K}$.
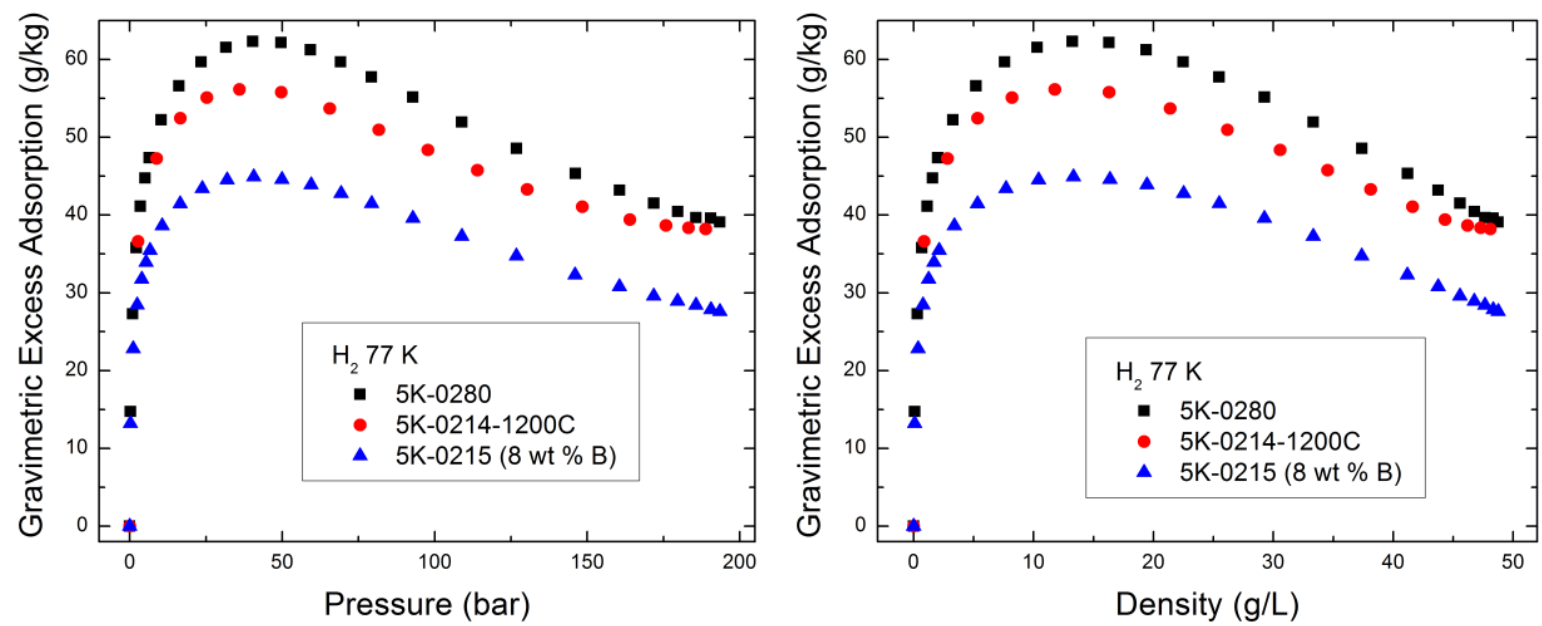

Figure 78. Excess adsorption isotherms for 5K-type materials measured at $77 \mathrm{~K}$. 
Excess Adsorption for Carbonaceous Monolithic Sorbent Materials:
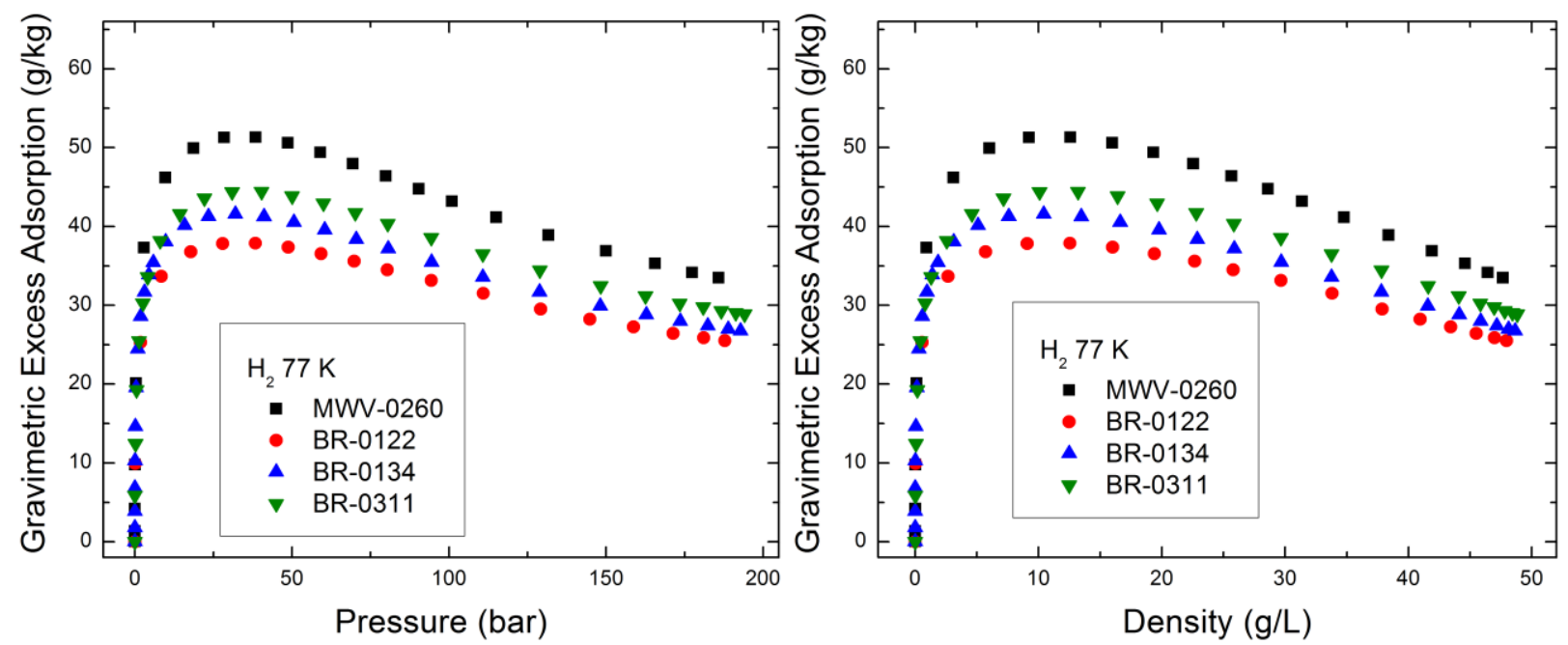

Figure 79. Excess adsorption isotherms for monolithic sorbent materials measured at $77 \mathrm{~K}$.

These excess adsorption values also increase as the adsorbed film is building and decrease when the gas in the adsorbed film becomes less compressible than the bulk gas. Sample 3K-1037 was measured to have a specific surface area of approximately $2700 \mathrm{~m}^{2} / \mathrm{g}$, but has a maximum excess adsorption (at $\mathrm{T}=77 \mathrm{~K}$ ) comparable to sample $3 \mathrm{~K}-0201$ with only $2000 \mathrm{~m}^{2} / \mathrm{g}$.

With a few exceptions, the peak positions of each excess adsorption isotherm occur at a similar bulk gas density of 10-15 g/L, which indicates similar binding energies according to the Ono-Kondo adsorption model. Adsorbed films tend to reach saturation at lower pressures for PVDC-based and Briquette samples. These samples reach a maximum excess adsorption at bulk gas densities as low as $5 \mathrm{~g} / \mathrm{L}$, which according to the Ono-Kondo adsorption model, indicates that these samples should have relatively high binding energies to hydrogen. 
Gravimetric Storage of a Broad Range of Activated and Synthetic Carbonaceous Sorbent Materials:

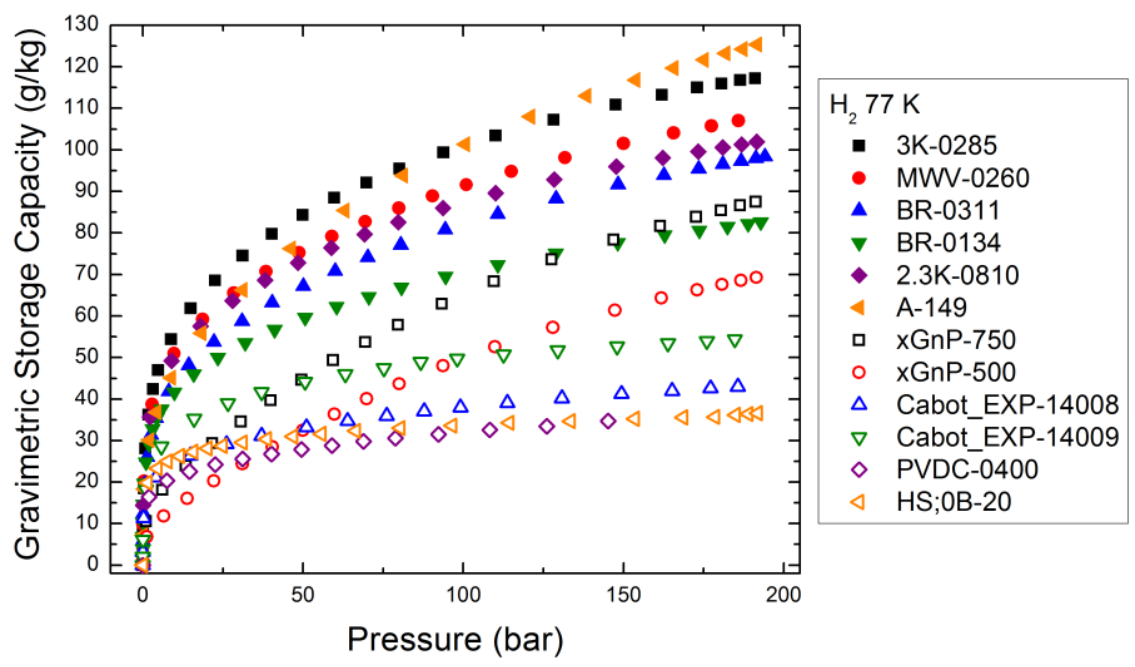

Figure 80. Gravimetric storage capacity isotherms for various samples measured at $77 \mathrm{~K}$.

These are envelope storage capacities, so it is important to remember that we're using this data to compare individual crystals of the adsorbent material. If these adsorbent types were packed into a tank there would be intergranular space occupied by the gas. In the case of an actual storage tank, we would need to consider the packing efficiency. The conclusions drawn here regarding the performance of individual crystals will be different from those of the same materials packed into a storage tank. The gravimetric storage capacity scales up with increasing porosity and excess adsorption. So naturally, samples with larger porosity values and surface areas will have a larger gravimetric storage capacity. 
Gravimetric Storage Capacity of Chemically Activated, Carbonaceous Precursor Materials:

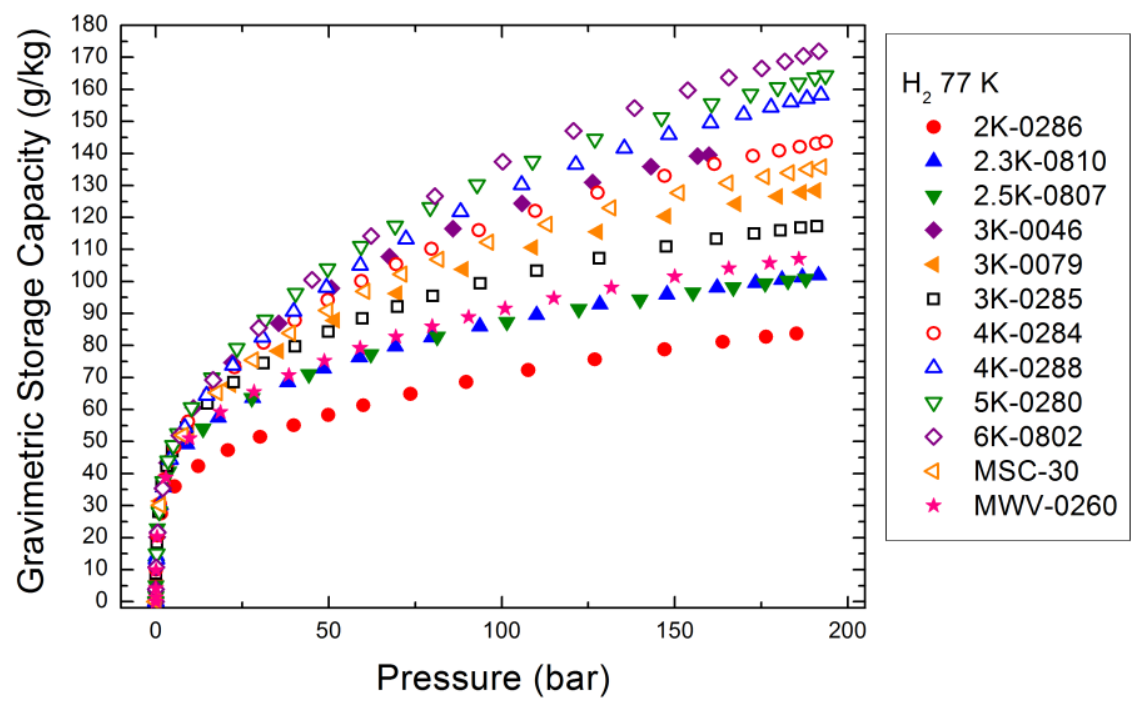

Figure 81. Gravimetric storage capacity for activated precursor samples measured at $77 \mathrm{~K}$.

Once again, samples with larger pore volumes will automatically have larger gravimetric storage capacities because they contain more bulk, compressed gas when normalized by mass. $5 \mathrm{~K}$ and $6 \mathrm{~K}$ precursor materials have porosities exceeding $84 \%$ and, consequently, have larger gravimetric storage capacities. 
Gravimetric Storage Capacity of Carbonaceous Precursor Materials After High Temperature Outgassing:

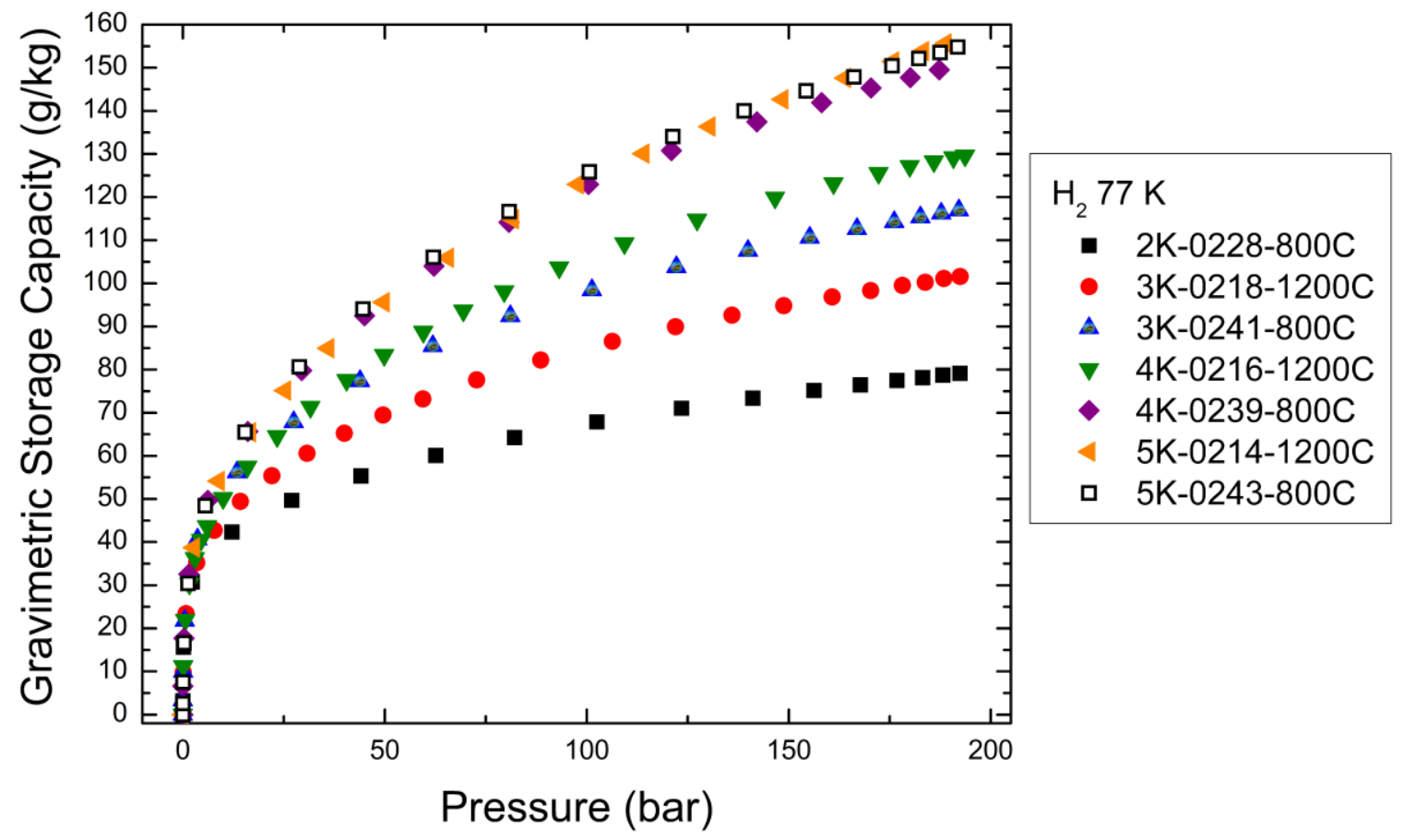

Figure 82. Gravimetric storage capacity for activated precursor samples measured at $77 \mathrm{~K}$.

After outgassing, precursor materials graphitize and as a result, tend to lose a fraction of their specific surface areas and porosities. For example, 5K-0280 had a gravimetric storage capacity of approximately $165 \mathrm{~g} / \mathrm{kg}$ at a pressure of $190 \mathrm{bar}$. Under the same conditions, 5K-0214 and 5K-0243 have gravimetric storage capacities of $155 \mathrm{~g} / \mathrm{kg}$. This reduced gravimetric storage capacity is almost entirely due to graphitization of the material during high temperature treatment. 


\section{Gravimetric Storage Capacity of Boron-Doped Sorbent Materials:}
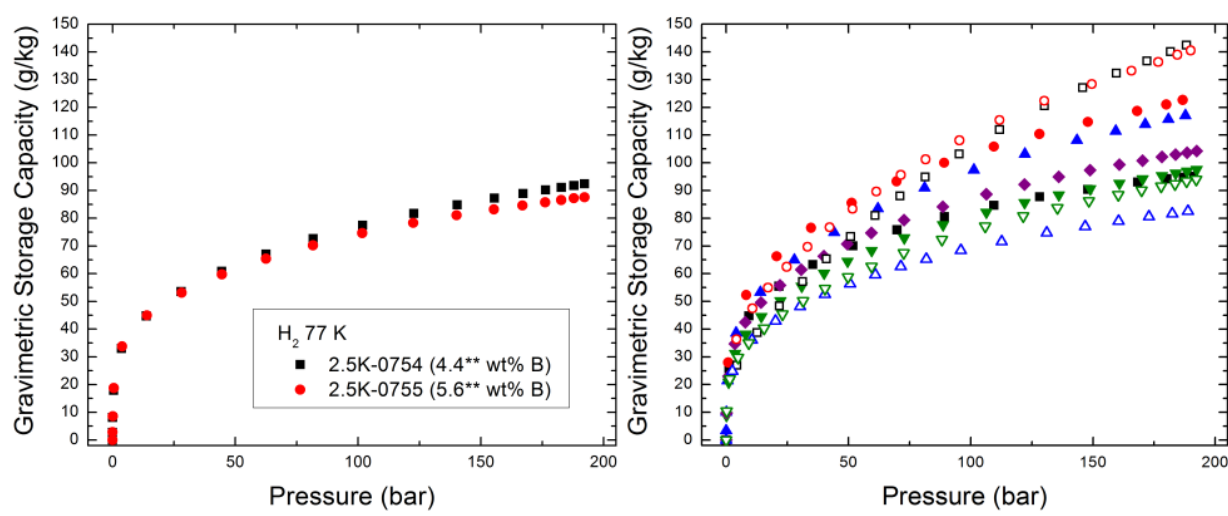

$\mathrm{H}_{2} 77 \mathrm{~K}$

- $3 \mathrm{~K}-0201(8.0 \mathrm{wt} \% \mathrm{~B})$

3K-0203 (0.3 wt\% B)

3K-0205 (9.7wt\% B)

v $3 \mathrm{~K}-0208(13.7 \mathrm{wt} \% \mathrm{~B})$

- $3 \mathrm{~K}-0211(6.2 \mathrm{wt} \% \mathrm{~B})$

$3 \mathrm{~K}-1036\left(4.3^{*} \mathrm{wt} \% \mathrm{~B}\right)$

$3 \mathrm{~K}-1037\left(4.7^{*} \mathrm{wt} \% \mathrm{~B}\right)$

$\Delta \quad 3 \mathrm{~K}-1038\left(20.5^{*} \mathrm{wt} \% \mathrm{~B}\right)$

Figure 83 . Gravimetric storage capacity isotherms for boron doped $2.5 \mathrm{~K}$ and $3 \mathrm{~K}$-type samples measured at $77 \mathrm{~K}$.

Samples with the largest porosities have the largest gravimetric storage capacities. Such samples have the largest fraction of their crystal volumes occupied by gas.
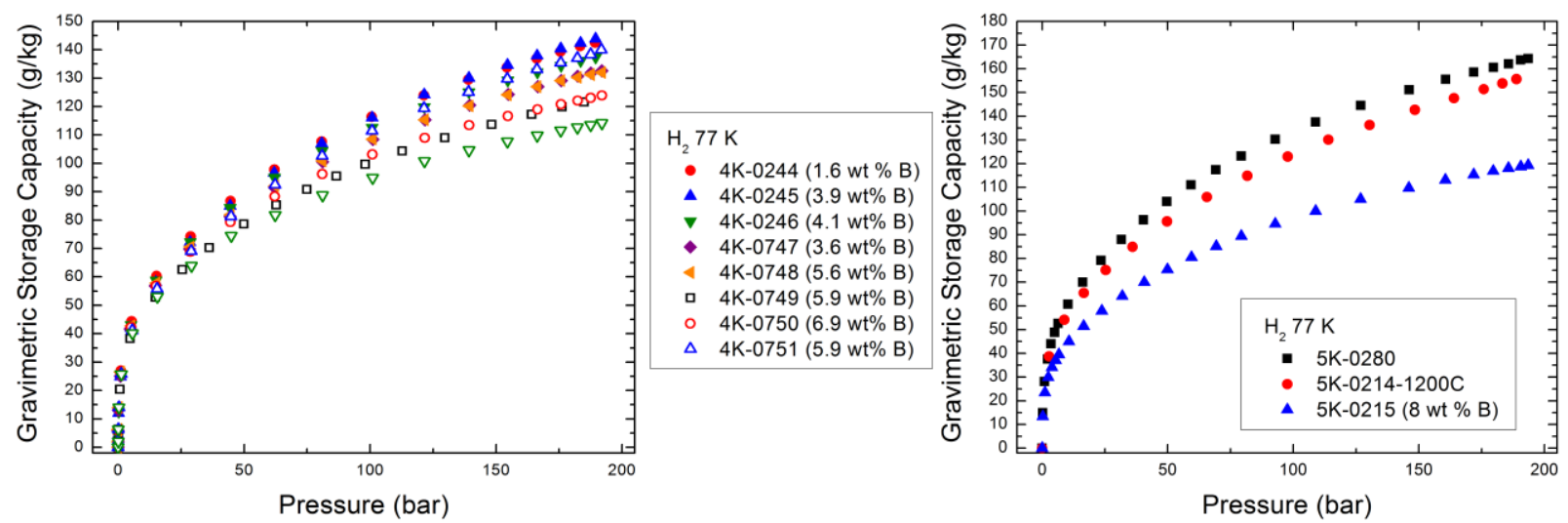

Figure 84. Gravimetric storage capacity isotherms for boron doped $4 \mathrm{~K}$ and $5 \mathrm{~K}$-type samples measured at $77 \mathrm{~K}$. 
Gravimetric Storage Capacity of Carbonaceous Monolithic Sorbent Materials:

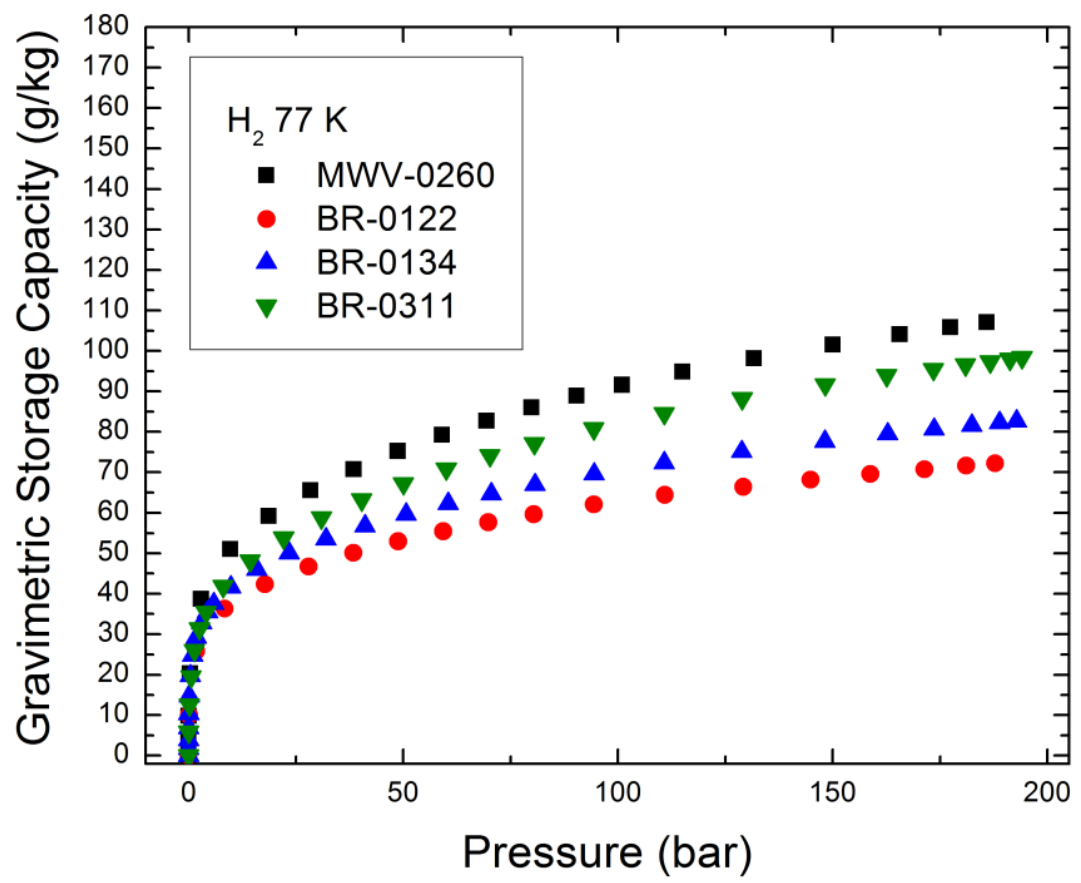

Figure 85. Gravimetric storage capacities for monolithic sorbent materials measured at $77 \mathrm{~K}$.

Sample BR-0311 experienced a minor reduction in pore volume, surface area, and porosity from its precursor material and exhibits only a minor decrease in performance when normalized to sample mass.

Volumetric Storage Capacities for a Broad Range of Activated and Synthetic Carbonaceous Sorbent Materials:
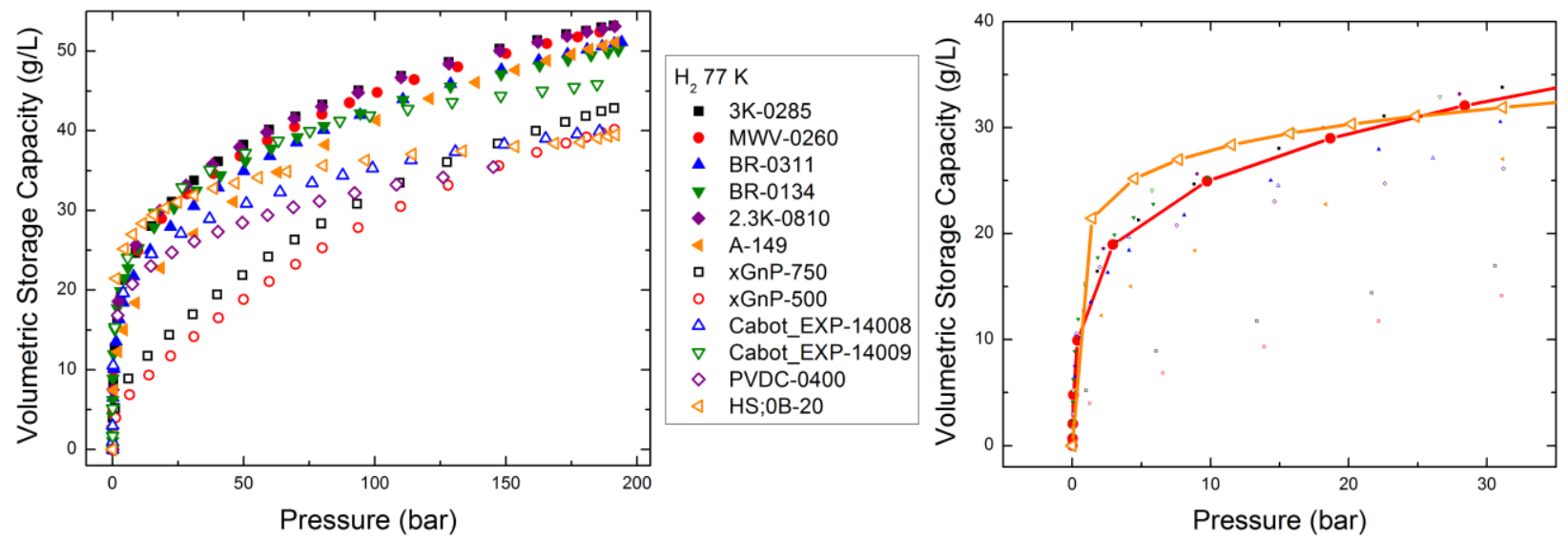

Figure 86. Volumetric storage capacity isotherms for various samples measured at $77 \mathrm{~K}$.

The volumetric storage capacity is heavily dependent upon the porosity. Samples with higher excess adsorption, but lower porosities have higher volumetric storage capacities. Samples that reach their 
maximum excess adsorption at relatively low gas densities, such as HS;0B-20, will exhibit volumetric storage capacities that increase more steeply with increasing pressure compared with typical activated carbons, such as MWV-0260.

\section{Volumetric Storage Capacities of Chemically Activated, Carbonaceous Precursor Materials:}
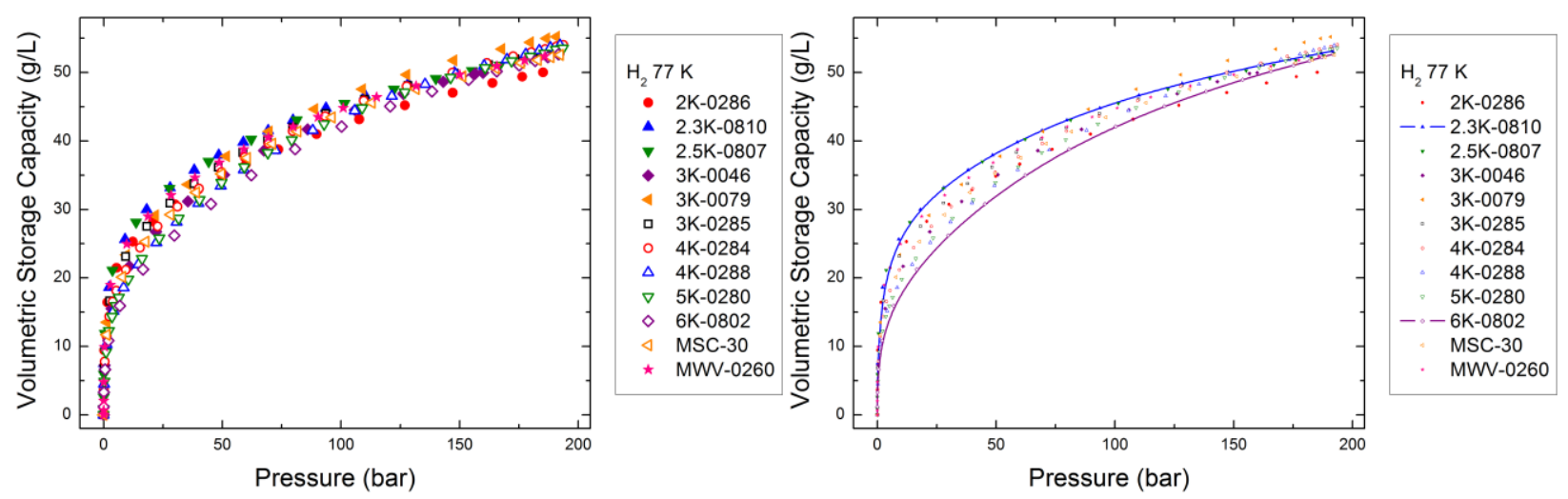

Figure 87 . Volumetric storage capacity isotherms of activated precursors measured at $77 \mathrm{~K}$.

The density of the adsorbed film reaches a maximum value at approximately 50 bar. As the pressure is increased past 50 bar, the bulk gas density converges upon the density of the saturated, adsorbed film. Therefore, all materials will perform similarly at sufficiently high pressures where the bulk gas is nearing the density of the adsorbed film. The performance of adsorbent materials at these extremely high pressures is not particularly interesting nor advantageous compared to compressed gas. However, the behavior of the volumetric storage capacity isotherm at lower pressures varies between samples due to structural and chemical differences in the materials. Materials with high binding energies to the adsorbate gas should exhibit higher volumetric storage capacities at pressures ranging between 0-50 bar. This may be specifically observed by comparing the isotherms of sample $2.3 \mathrm{~K}-0810$ and $6 \mathrm{~K}-0802$. At a pressure of $25 \mathrm{bar}$, the volumetric performances of these materials differ by as much as $10 \mathrm{~g} / \mathrm{L}$. Though all of these materials perform approximately the same at pressures above 150 bar, they exhibit stark differences is the low pressure regime due to differences in specific surface area, pore structure, and binding energy. 
Volumetric Storage Capacities of Carbonaceous Precursor Materials After High Temperature Outgassing:

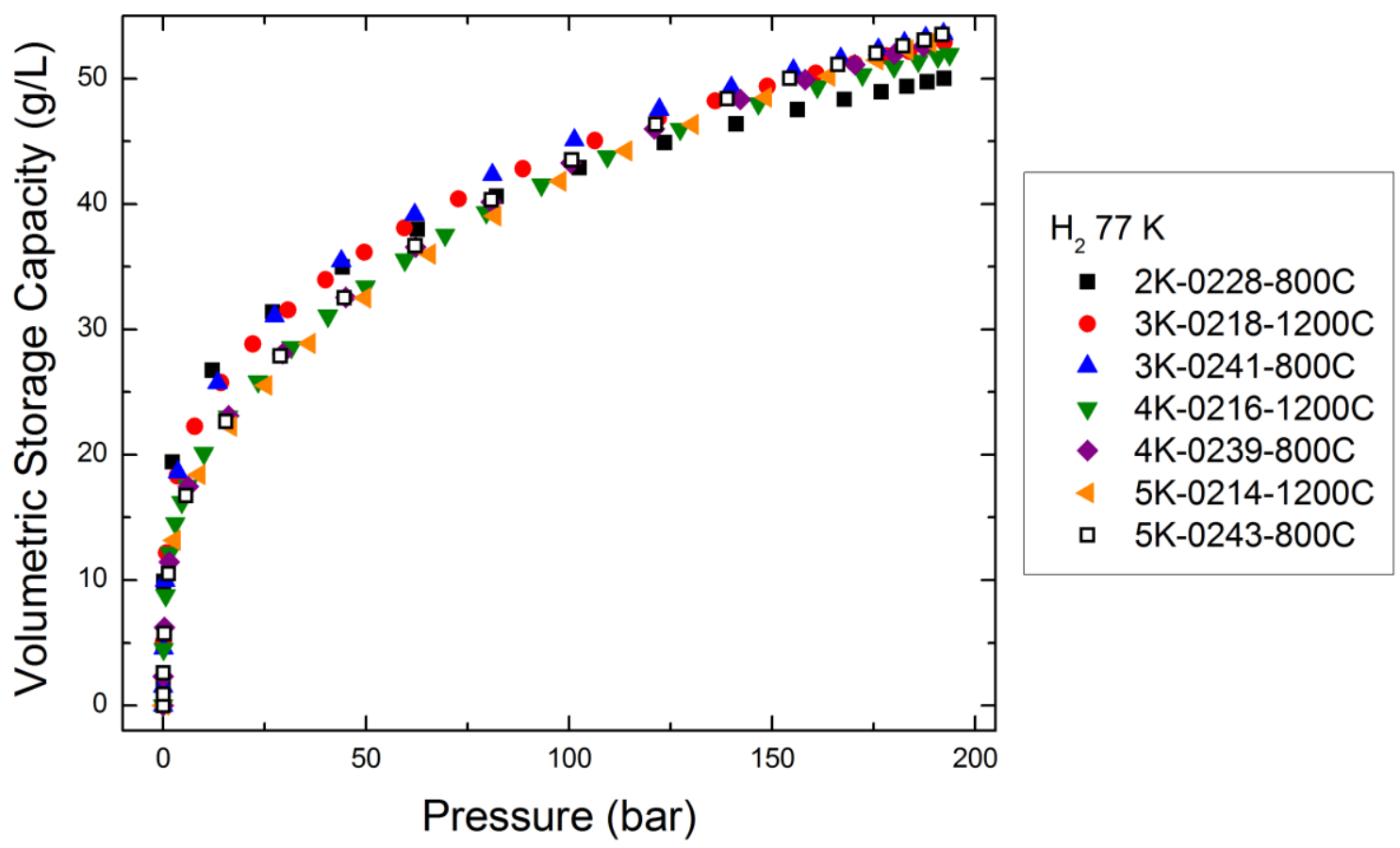

Figure 88. Volumetric storage capacity isotherms of deoxygenated precursors measured at $77 \mathrm{~K}$.

Once again, samples with large pore volumes, such as 5K-types, tend to perform worse in the low pressure regime. Samples with a higher sub-nanometer pore fraction, such as 3K-types, outperform the $4 \mathrm{~K}$ and $5 \mathrm{~K}$ types in the low pressure regime.

\section{Volumetric Storage Capacities of Boron-Doped Sorbent Materials:}
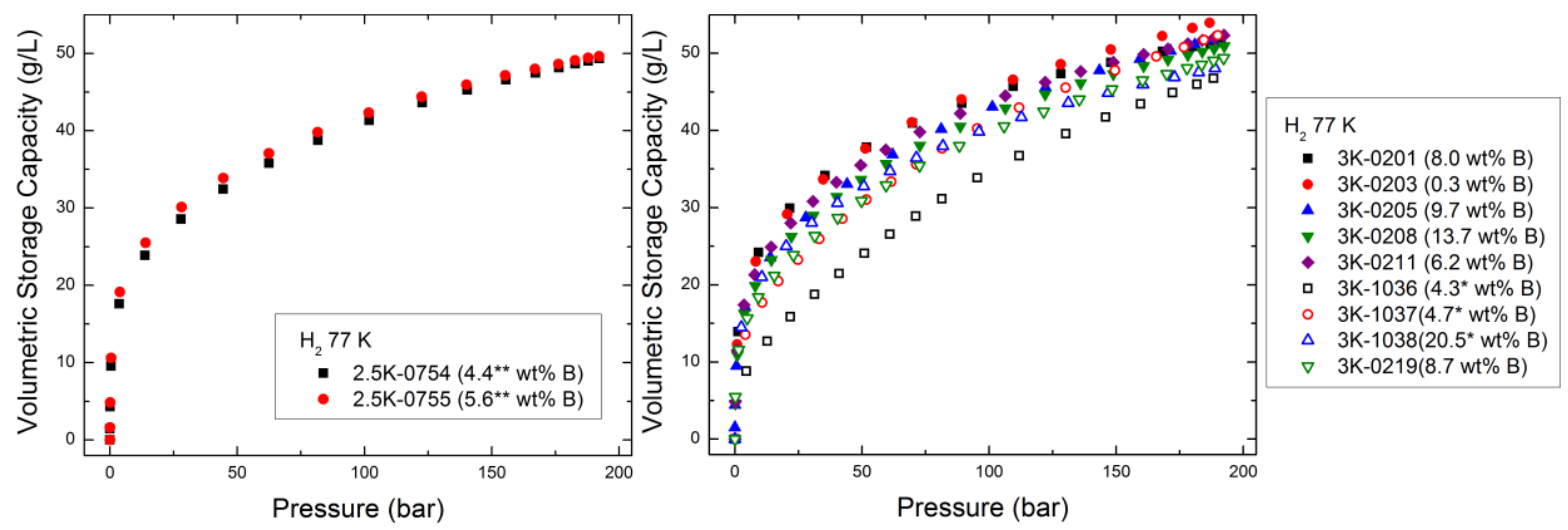

Figure 89 . Volumetric storage capacity isotherms of $2.5 \mathrm{~K}$ and $3 \mathrm{~K}$-type boron doped materials measured at $77 \mathrm{~K}$. 
Once again, samples with large pore volumes, such as 5K-types, tend to perform worse in the low pressure regime. Samples with a higher sub-nanometer pore fraction, such as $3 \mathrm{~K}$-types, outperform the $4 \mathrm{~K}$ and $5 \mathrm{~K}$ types in the low pressure regime.
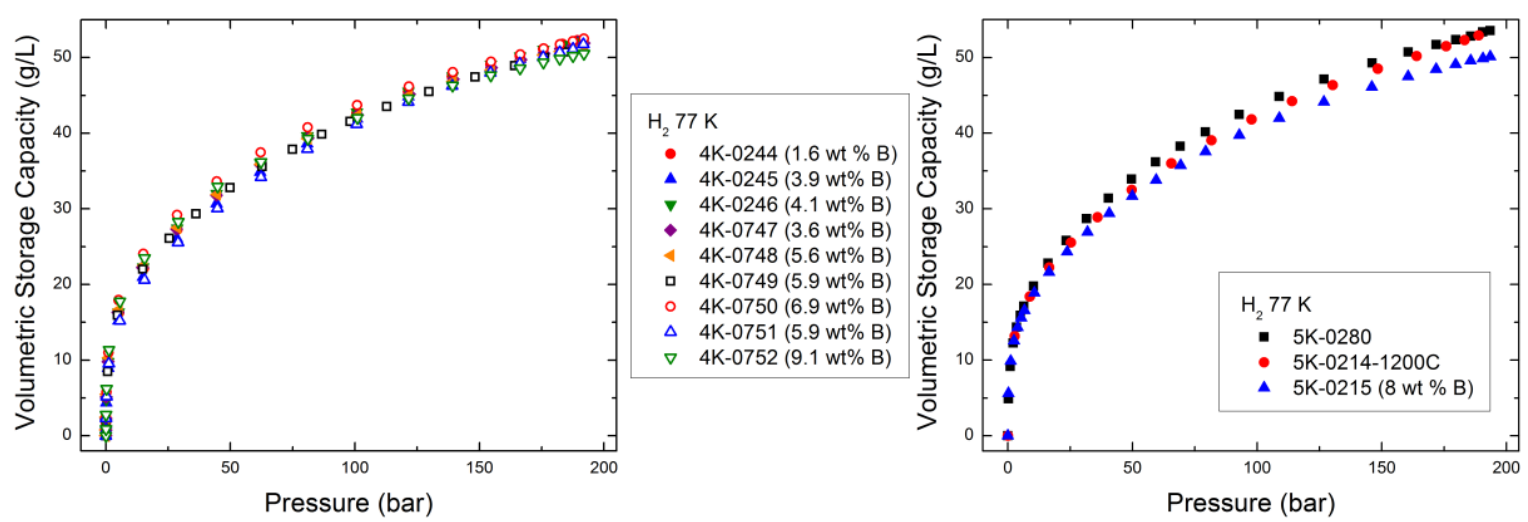

Figure 90. Volumetric storage capacity isotherms of $4 \mathrm{~K}$ and $5 \mathrm{~K}$-type boron doped materials measured at $77 \mathrm{~K}$.

The volumetric storage capacity is heavily dependent upon the porosity, but it can also vary with isosteric heat of adsorption. Larger interaction energies should allow the gas to be densified more readily at lower pressures. Though materials with similar porosities will reach similar volumetric storage capacities at high pressures, their performance will differ in the low pressure regime when the adsorbed film is still building. Sample 3K-0201 has a larger volumetric storage capacity at $77 \mathrm{~K}$ and 25 bar compared to that of 3K-1037. This indicates that 3K-0201 should have a higher isosteric heat of adsorption.

\subsection{Deliverable Storage Capacities}

One needs to consider the tradeoffs between porosity, surface area, and binding energy when screening adsorbent materials for use in an adsorbed gas storage tank. When naively examining the mathematical structure of the formulas for volumetric storage capacity, one might deduce that it is desirable to create an adsorbent material which has a low porosity, high surface area, and a high binding energy to maximize the deliverable volumetric storage capacity. Low porosities and high surface areas promote higher volumetric storage capacities. Materials with high binding energies form a fully saturated film at lower pressures than materials with lower binging energies. However, it's crucial to remember that the 
ultimate objective is to maximize the amount of usable gas that can be delivered out of the storage tank during discharge.

Even if the adsorbent material outperforms the bulk gas, it still might not be beneficial to include the material in a storage tank depending on the operating and delivery pressures of the tank. Let us define an important engineering quantity called the deliverable storage capacity. This quantity is defined as the difference between the storage capacity when the tank is filled to its maximum operating pressure and the storage capacity when the tank is at its lowest delivery pressure. The lowest delivery pressure has been assumed to be $\mathrm{P}=1$ bar in this study.

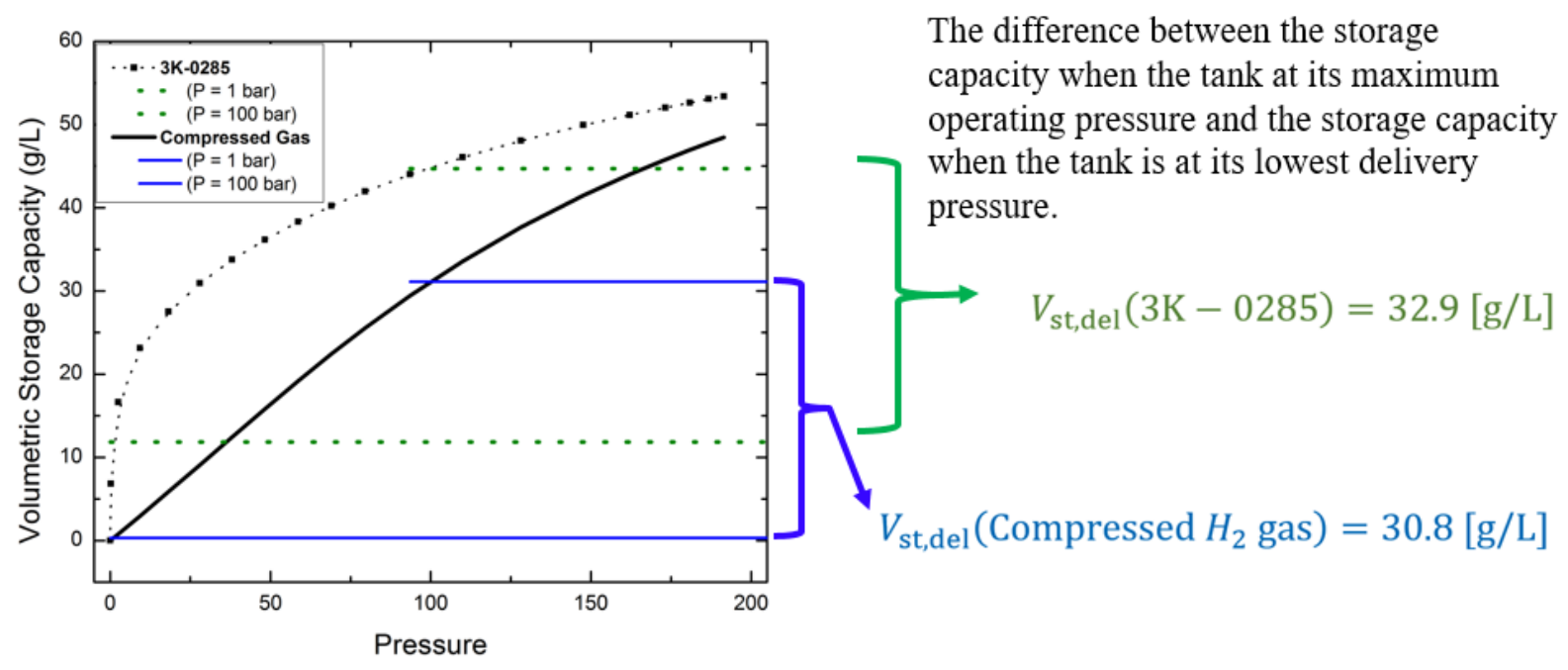

Figure 91. Deliverable storage capacity of 3K-0285 and compressed hydrogen. Extreme differences between deliverable storage capacities are observed depending on the maximum and minim operating pressures of the storage tank. The deliverable storage capacity presented here is the difference in performance between 100 bar and 1 bar. Between these pressures, sample 3K-0285 has a deliverable volumetric storage capacity of $32.9 \mathrm{~g} / \mathrm{L}$ compared to 30.8 from compressed hydrogen.

When screening materials based on deliverable storage capacity, it is necessary to clarify any biases that may be present in the analysis method. Choosing the lowest possible limit for a delivery pressure will automatically bias deliverable storage capacity results in favor of materials with high surface areas and high binding energies, such as Metal Organic Frameworks. This is because the adsorbed film saturates at lower pressures for materials with high surface areas and high binding energies. This will yield higher slopes in 
the volumetric storage capacity isothermal measurement. Choosing a high delivery pressure will bias deliverable storage capacity results in favor of low binding energy materials or compressed gas.

Including sorbent materials in storage tanks serves the most utility at low pressures (25-50 bar) because the difference in their performance compared to that of compressed gas is maximized in this pressure range. In this study, deliverable storage capacities were calculated based on a hypothetical storage tank with a maximum operating pressure of 25 bar and a delivery pressure of 1 bar. This comparison was performed for temperatures at both $77 \mathrm{~K}$ and $296 \mathrm{~K}$. The deliverable storage capacities of materials in Table 6 were compared to those of compressed gas over the same intervals of pressures and temperatures.
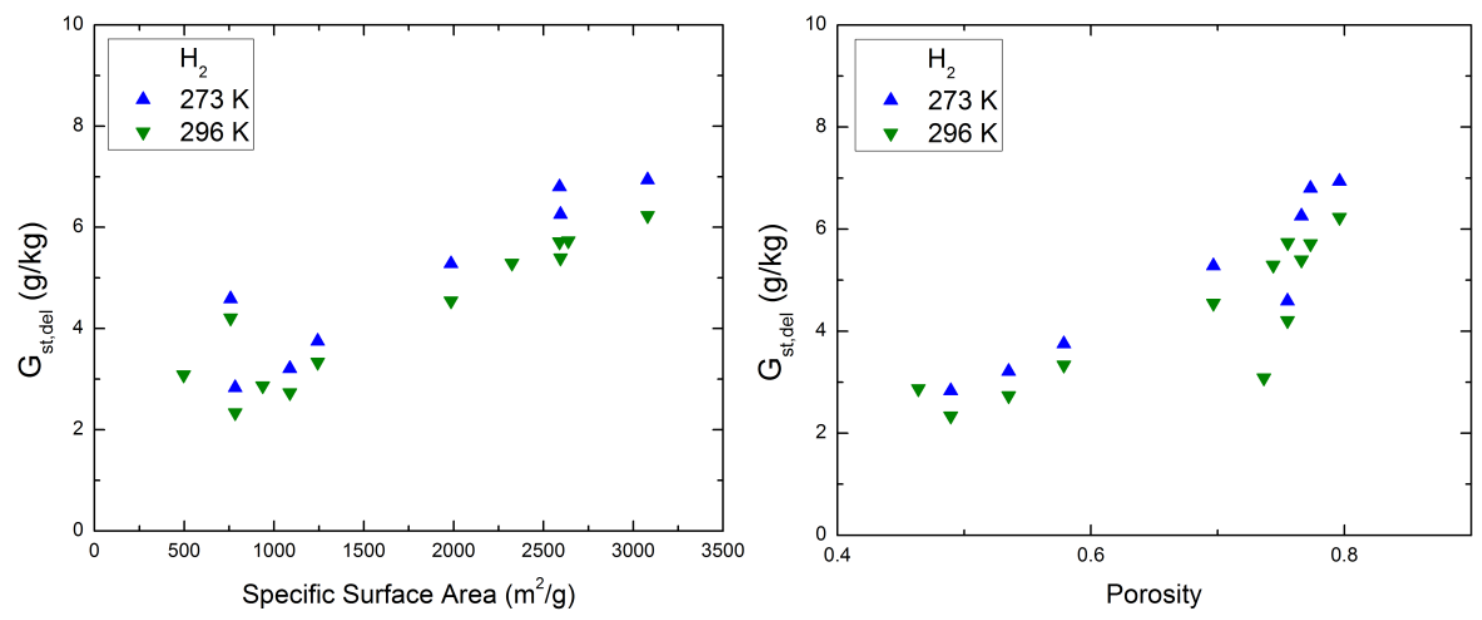

Figure 92. Deliverable gravimetric storage capacities for a broad range of sorbent materials at ambient temperatures. Left: Deliverable gravimetric storage capacity as a function of specific surface area. Right: Deliverable gravimetric storage capacity as a function of porosity.

Adsorbent materials with large pores with automatically have a larger deliverable storage capacity because there is a larger volume of bulk gas present in the tank. 

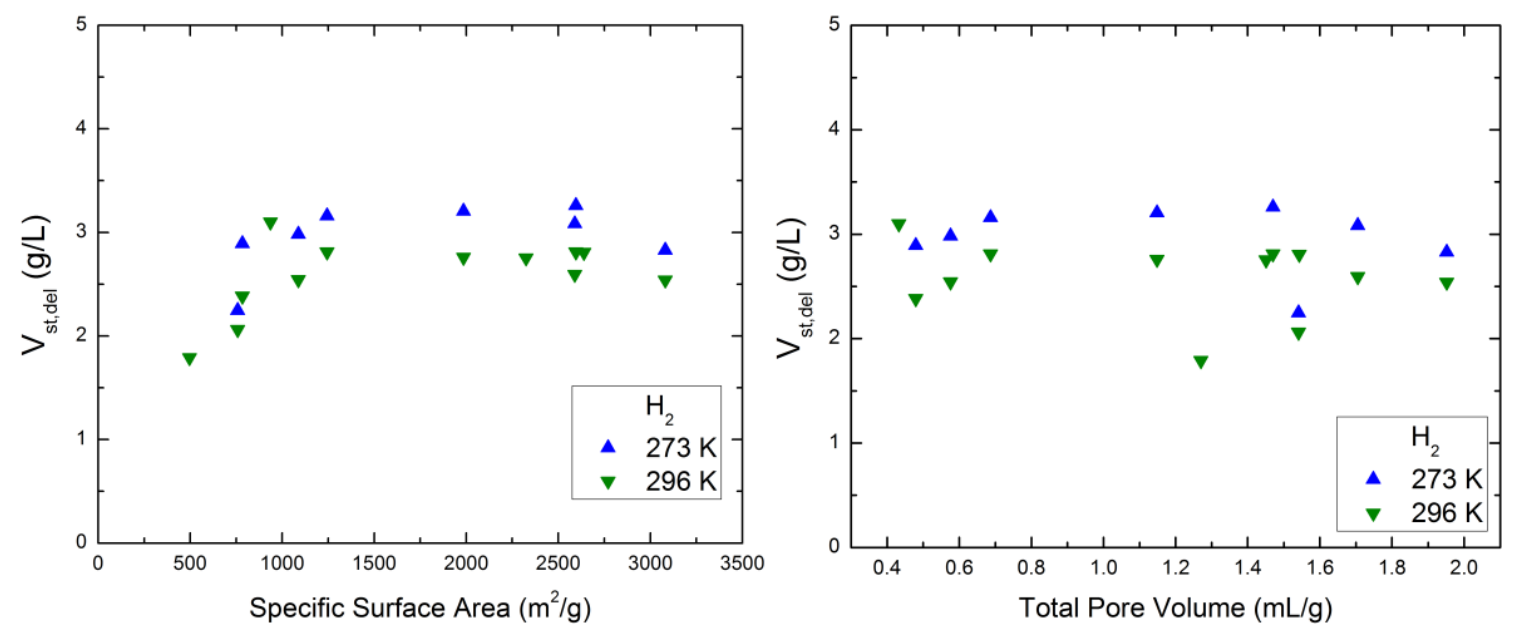

Figure 93. Deliverable volumetric storage capacities for a broad range of sorbent materials at ambient temperatures. Left: Deliverable volumetric storage capacity as a function of specific surface area. Right: Deliverable gravimetric storage capacity as a function of total pore volume.

Upon investigating the structure of the equations for volumetric storage capacity, one might naively expect that decreasing the total pore volume would result in a higher delivered volumetric storage capacity. However, no such correlation is observed.

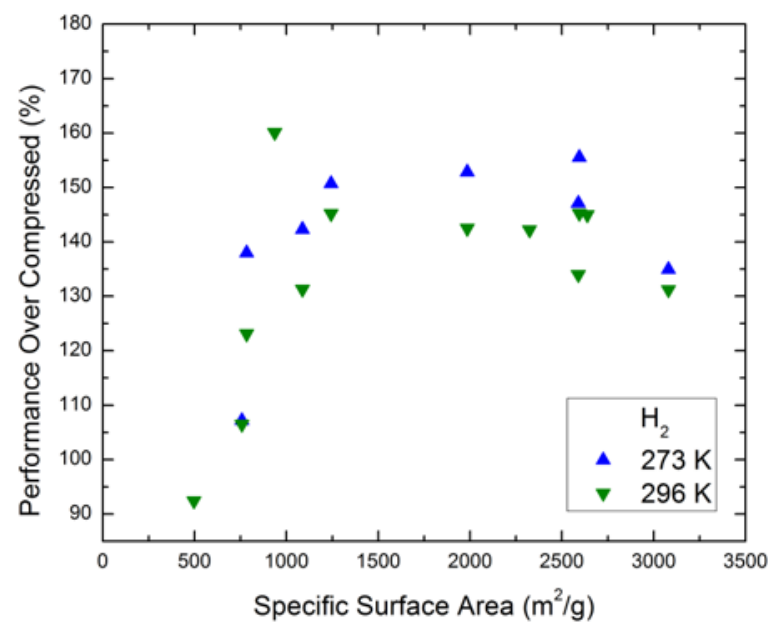

Figure 94. Deliverable volumetric storage capacities for a broad range of sorbent materials at ambient temperatures over that of compressed gas.

In terms of deliverable volumetric storage capacity, there appears to be benefit to creating sorbent materials with specific surface areas larger than $1000 \mathrm{~m}^{2} / \mathrm{g}$. However, increasing the specific surface area past this value does not yield a higher coefficients of performance over compressed gas. Creating samples with higher surface areas increases the number of sorption sites available to the adsorbate gas. This 114 
increases the rate at which gas is adsorbed with increasing pressures. Increasing this rate will increase the amount stored at the low pressure limit of a storage tank. This relation may actually yield lower deliverable storage capacities for samples with extremely high surface areas. In this study, samples with high specific surface areas performed 1.5-1.6 times better than the deliverable volumetric storage capacity of compressed gas at ambient temperatures.
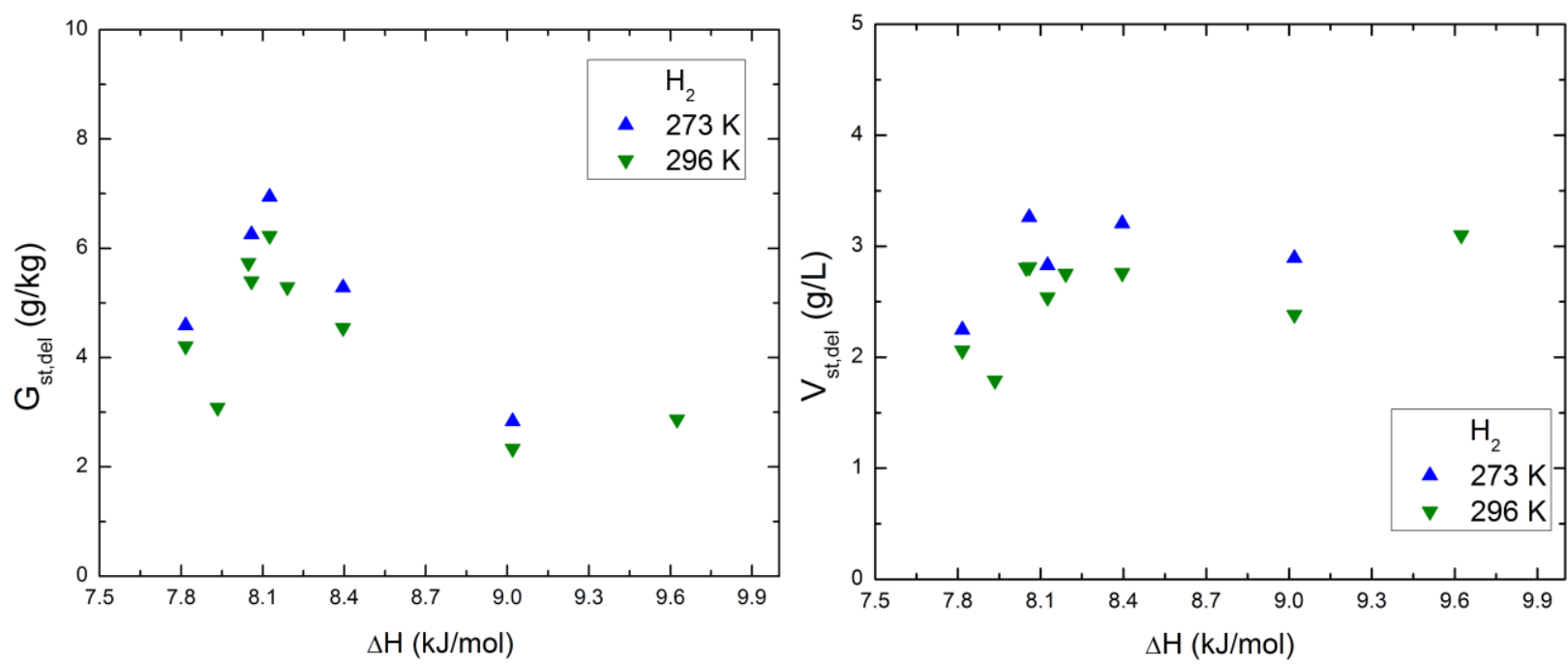

Figure 95. Deliverable storage capacities at ambient temperatures as a function of isosteric heat of adsorption. Left: Deliverable gravimetric storage capacity at ambient temperatures as a function of isosteric heat of adsorption. Right: Deliverable volumetric storage capacity at ambient temperatures as a function of isosteric heat of adsorption.

Increasing the isosteric heat between the adsorbent surface and adsorbate gas may increase the excess adsorption. However, increases in the isosteric heat of adsorption shows no correlation with deliverable storage capacity for this set of samples measured at ambient temperatures. 

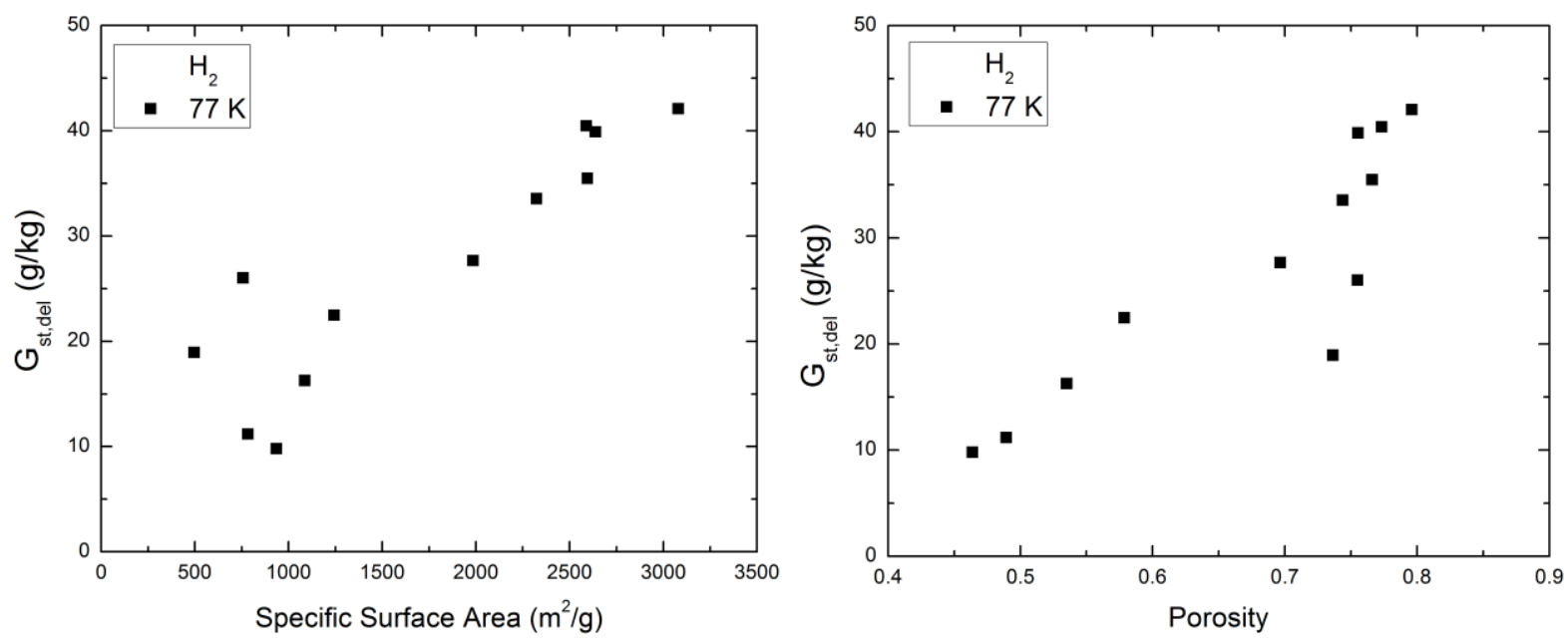

Figure 96. Deliverable gravimetric storage capacities for a broad range of sorbent materials at cryogenic temperatures. Left: Deliverable gravimetric storage capacity as a function of specific surface area. Right: Deliverable gravimetric storage capacity as a function of porosity.

Once again, deliverable gravimetric storage capacities tend to increase with increasing porosities and specific surface areas. Adsorbent materials with large pores with automatically have a larger deliverable gravimetric storage capacity because there is a larger volume of bulk gas present in the tank.
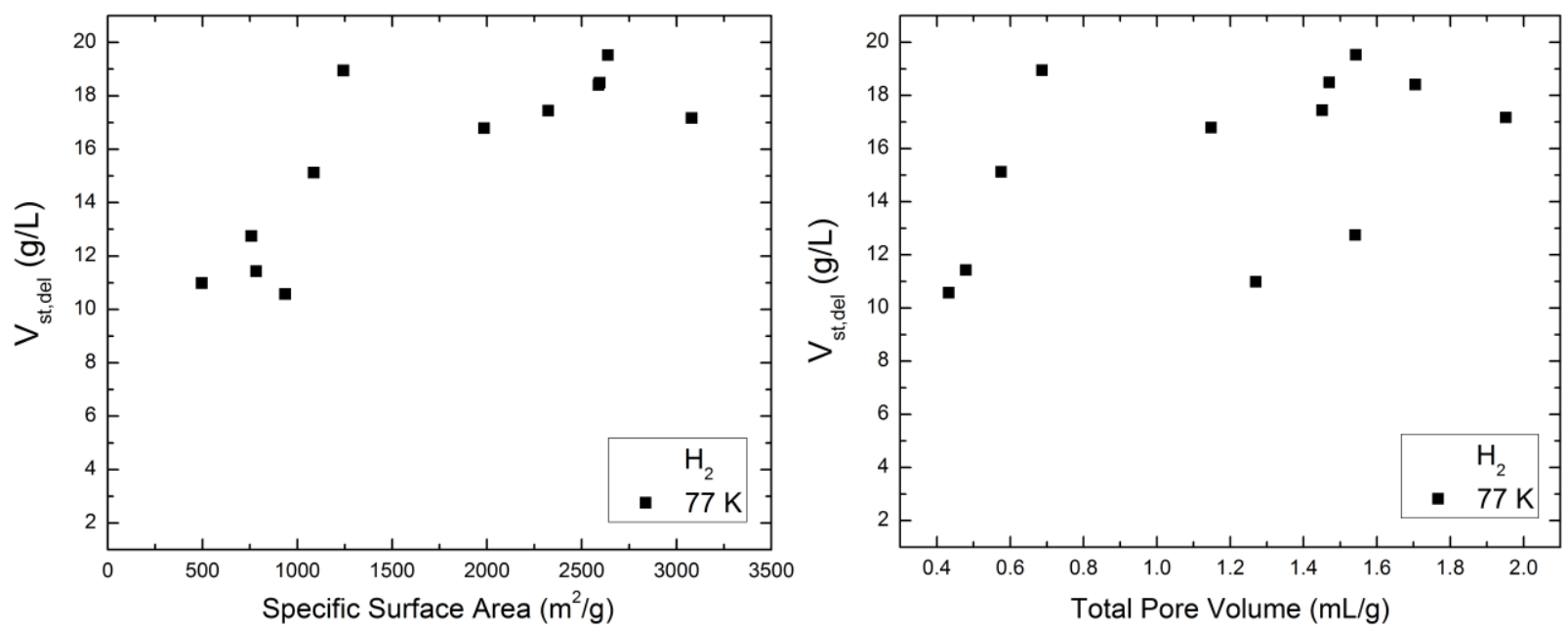

Figure 97. Deliverable volumetric storage capacities for a broad range of sorbent materials at cryogenic temperatures. Left: Deliverable volumetric storage capacity as a function of specific surface area. Right: Deliverable volumetric storage capacity as a function of total pore volume.

No correlation is observed between deliverable volumetric storage capacity and total pore volume. 


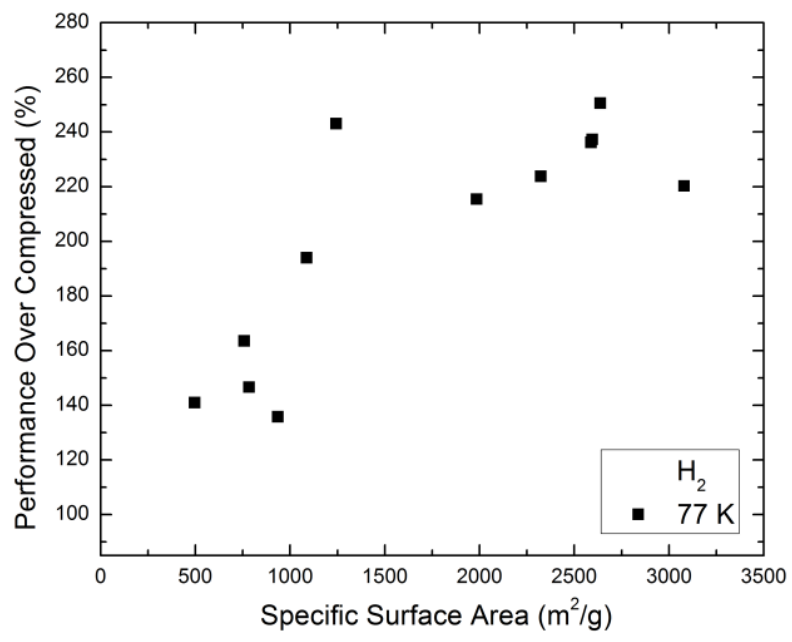

Figure 98. Deliverable volumetric storage capacities for a broad range of sorbent materials at cryogenic temperatures over that of compressed gas.

Improvements in deliverable volumetric storage capacity are observed for samples with specific surface areas up to $1500 \mathrm{~m}^{2} / \mathrm{g}$. However, little improvement is observed for samples with specific surface areas above that value. In this study, samples with high specific surface areas performed 2.2-2.6 times better than the deliverable volumetric storage capacity of compressed gas at cryogenic temperatures.

In summary, specifically designing materials with higher isosteric heats of adsorption, higher surface areas, and lower pore volumes is not necessarily the best method to achieve high deliverable storage capacities. Designing materials with surface areas in excess of $1500 \mathrm{~m}^{2} / \mathrm{g}$ is sufficient to achieve a deliverable volumetric storage capacity of hydrogen up to $260 \%$ of that of compressed gas. 


\subsection{Properties of the Adsorbed Hydrogen Film}

The high gas density regime of excess adsorption isotherms contains a wealth of information regarding the adsorbed film.
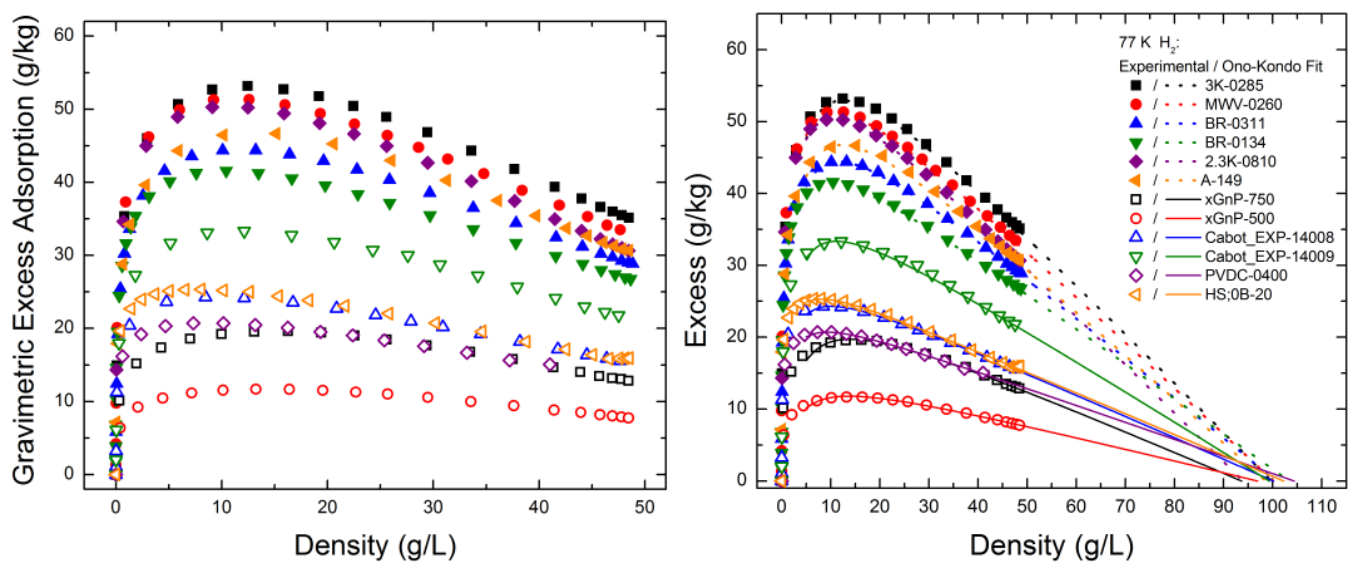

Figure 99. High density hydrogen isotherms for various samples measured at $77 \mathrm{~K}$. Left: Experimental range of high density hydrogen isotherms. Right: Experimental data including an Ono-Kondo fit to high density data.

Once the adsorbed film reaches saturation, the film is less compressible than the bulk gas and the isotherm exhibits linear behavior with increasing gas density. The linear behavior is related to the volume, density and capacity of the adsorbed film. 
Table 14: Parameters of the adsorbed film for a variety of samples

\begin{tabular}{|c|c|c|c|c|c|}
\hline Sample Name & $\begin{array}{c}\sum \mathrm{BET} \\
\left(\mathrm{m}^{2} / \mathrm{g}\right)\end{array}$ & $\begin{array}{c}V_{\text {film }} \\
(\mathrm{mL} / \mathrm{g})\end{array}$ & $\begin{array}{c}\rho_{\text {film (sat) }} \\
(\mathrm{g} / \mathrm{L})\end{array}$ & $\begin{array}{l}m_{\text {film sat }} \\
(\mathrm{g} / \mathrm{kg})\end{array}$ & $\begin{array}{c}t_{\text {film }} \\
(\mathrm{nm})\end{array}$ \\
\hline $3 \mathrm{~K}-0285$ & 2589 & 0.705 & 99.7 & 70.4 & 0.323 \\
\hline MWV-0260 & 2638 & 0.596 & 103.7 & 61.9 & 0.318 \\
\hline BR-0311 & 2324 & 0.513 & 104.9 & 53.8 & 0.317 \\
\hline BR-0134 & 1985 & 0.454 & 107.6 & 48.8 & 0.315 \\
\hline $2.3 \mathrm{~K}-0810$ & 2595 & 0.634 & 96.7 & 61.3 & 0.326 \\
\hline A-149 & 3080 & 0.570 & 101.9 & 58.0 & 0.320 \\
\hline xGnP-750 & 758 & 0.250 & 100.1 & 25.0 & 0.322 \\
\hline xGnP-500 & 497 & 0.142 & 103.7 & 14.7 & 0.318 \\
\hline Cabot EXP-14008 & 1087 & 0.277 & 103.7 & 28.8 & 0.318 \\
\hline Cabot EXP-14009 & 1243 & 0.415 & 99.8 & 41.4 & 0.323 \\
\hline PVDC-0400 & 783 & 0.219 & 109.2 & 23.9 & 0.313 \\
\hline $\mathrm{HS} ; 0 \mathrm{~B}-20$ & 936 & 0.267 & 107.8 & 28.7 & 0.314 \\
\hline
\end{tabular}
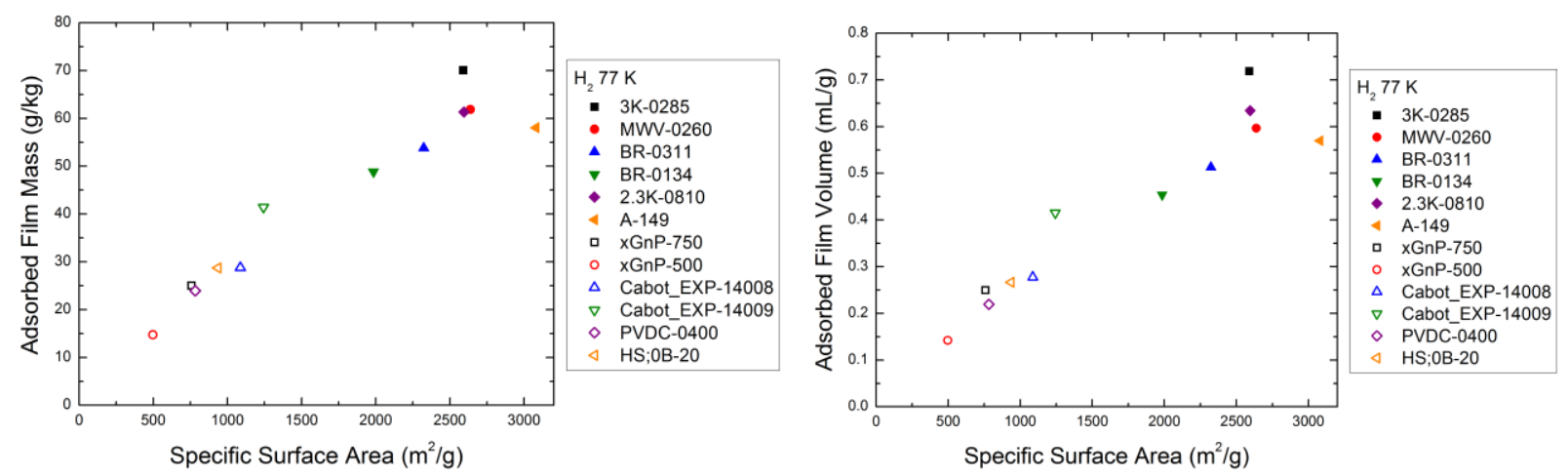

Figure 100. Properties of the adsorbed film at $77 \mathrm{~K}$ as a function of specific surface area. Left: the maximum capacity of the adsorbed film versus specific surface area. Right: The adsorbed film volume versus surface area.

The maximum excess adsorption increases with increasing surface area. The saturated adsorbed film density converges upon approximately equal values for all samples. If both of these statements are 
true, then it is necessary that the magnitudes of the slopes of the high density regime of the adsorption isotherm are directly proportional to both $V_{\text {film,sat }}$ and $m_{\text {film, max }}$.

The saturated adsorbed film density is approximately the same for all samples $(\sim 100 \mathrm{~g} / \mathrm{L})$. Consequently, so is the adsorbed film thickness $(\sim 0.31 \mathrm{~nm})$.

The fact that we can measure the $V_{\text {film,sat }}$ is especially important because most literature sources assume that $V_{\text {film,sat }} \sim V_{\text {pore, }}$ which overestimates the number of molecules involved in the adsorbed film and results in underestimation of the isosteric heat. As an example, the $V_{\text {pore }}$ of $3 \mathrm{~K}-0285$ was $1.71 \mathrm{~mL} / \mathrm{g}$ and its $V_{\text {film,sat }} \sim 0.72 \mathrm{~mL} / \mathrm{g}$. This means that the adsorbed film one occupies $\sim 42 \%$ of the total pore volume.

Table 15: Parameters of the adsorbed film for chemically activated precursor samples

\begin{tabular}{|c|c|c|c|c|c|}
\hline Sample Name & $\begin{array}{c}\sum \mathrm{BET} \\
\left(\mathrm{m}^{2} / \mathrm{g}\right)\end{array}$ & $\begin{array}{l}V_{\text {film,sat }} \\
(\mathrm{mL} / \mathrm{g})\end{array}$ & $\begin{array}{c}\rho_{\text {film,sat }} \\
(\mathrm{g} / \mathrm{L})\end{array}$ & $\begin{array}{l}m_{\text {film,sat }} \\
(\mathrm{g} / \mathrm{kg})\end{array}$ & $\begin{array}{l}t_{\text {film,sat }} \\
(\mathrm{nm})\end{array}$ \\
\hline $1.85 \mathrm{~K}-0099$ & 2350 & - & - & - & - \\
\hline $2 \mathrm{~K}-0286$ & 1940 & 0.424 & 114.3 & 48.4 & 0.308 \\
\hline $2.5 \mathrm{~K}-0807$ & 2440 & 0.636 & 100.4 & 63.9 & 0.322 \\
\hline $3 \mathrm{~K}-0046$ & 2740 & 0.977 & 86.1 & 84.1 & 0.339 \\
\hline $3 \mathrm{~K}-0079$ & 2660 & 0.691 & 108.2 & 74.8 & 0.314 \\
\hline $4 \mathrm{~K}-0284$ & 2610 & 0.843 & 95.8 & 80.8 & 0.327 \\
\hline $4 \mathrm{~K}-0288$ & 2790 & 0.782 & 101.4 & 79.3 & 0.321 \\
\hline $5 \mathrm{~K}-0280$ & 2690 & 0.972 & 90.5 & 88.0 & 0.333 \\
\hline $6 \mathrm{~K}-0802$ & 2590 & 0.926 & 90.6 & 83.9 & 0.333 \\
\hline MSC-30 & 2760 & 0.895 & 88.5 & 79.2 & 0.336 \\
\hline
\end{tabular}


Table 16: Parameters of the adsorbed film for deoxygenated precursor samples

\begin{tabular}{|l|r|r|r|r|r|}
\hline \multicolumn{1}{|c|}{ Sample Name } & \multicolumn{1}{c|}{$\begin{array}{c}\sum_{\text {BET }} \\
\left(\mathrm{m}^{2} / \mathrm{g}\right)\end{array}$} & $\begin{array}{c}V_{\text {film,sat }} \\
(\mathrm{mL} / \mathrm{g})\end{array}$ & \multicolumn{1}{c|}{$\begin{array}{c}\rho_{\text {film,sat }} \\
(\mathrm{g} / \mathrm{L})\end{array}$} & \multicolumn{1}{c|}{$\begin{array}{c}m_{\text {film,sat }} \\
(\mathrm{g} / \mathrm{kg})\end{array}$} & \multicolumn{1}{c|}{$\begin{array}{c}t_{\text {film,sat }} \\
(\mathrm{nm})\end{array}$} \\
\hline 2K-0228-800C & 1760 & 0.442 & 109.0 & 48.2 & 0.313 \\
\hline 3K-0218-1200C & 2140 & 0.546 & 109.5 & 59.8 & 0.313 \\
\hline 3K-0241-800C & 2550 & 0.651 & 103.4 & 67.3 & 0.319 \\
\hline 4K-0216-1200C & 2390 & 0.746 & 93.8 & 70.0 & 0.329 \\
\hline 4K-0239-800C & 2600 & 0.823 & 94.4 & 77.7 & 0.329 \\
\hline 5K-0214-1200C & 2560 & 0.698 & 103.2 & 72.0 & 0.319 \\
\hline 5K-0243-800C & 2600 & 0.802 & 97.6 & 78.3 & 0.325 \\
\hline PVDC-0735-800C & 850 & - & & - & - \\
\hline
\end{tabular}


Table 17: Parameters of the adsorbed film for boron doped materials

\begin{tabular}{|c|c|c|c|c|c|}
\hline Sample Name & $\begin{array}{c}\sum_{\text {BET }} \\
\left(\mathrm{m}^{2} / \mathrm{g}\right)\end{array}$ & $\begin{array}{l}V_{\text {film,,sat }} \\
(\mathrm{mL} / \mathrm{g})\end{array}$ & $\begin{array}{r}\rho_{\text {film,sat }} \\
(\mathrm{g} / \mathrm{L})\end{array}$ & $\begin{array}{r}m_{\text {film,sat }} \\
(\mathrm{g} / \mathrm{kg})\end{array}$ & $\begin{array}{r}t_{\text {film,sat }} \\
(\mathrm{nm})\end{array}$ \\
\hline $2.5 \mathrm{~K}-0754(4.4 * * \mathrm{wt} \% \mathrm{~B})$ & 2460 & 0.526 & 97.8 & 51.5 & 0.325 \\
\hline $2.5 \mathrm{~K}-0755(5.6 * * \mathrm{wt} \% \mathrm{~B})$ & 2030 & 0.527 & 99.0 & 52.1 & 0.323 \\
\hline $3 \mathrm{~K}-0201(8.0 \mathrm{wt} \% \mathrm{~B})$ & 2030 & 0.701 & 92.4 & 64.8 & 0.331 \\
\hline $3 \mathrm{~K}-0203(0.3 \mathrm{wt} \% \mathrm{~B})$ & 2650 & 0.722 & 100.8 & 72.7 & 0.321 \\
\hline $3 \mathrm{~K}-0205(9.7 \mathrm{wt} \% \mathrm{~B})$ & 2260 & 0.672 & 97.4 & 65.5 & 0.325 \\
\hline $3 \mathrm{~K}-0208(13.7 \mathrm{wt} \% \mathrm{~B})$ & 1950 & 0.519 & 105.5 & 54.7 & 0.317 \\
\hline $3 \mathrm{~K}-0211(6.2 \mathrm{wt} \% \mathrm{~B})$ & 2180 & 0.589 & 103.7 & 61.1 & 0.318 \\
\hline $3 \mathrm{~K}-1035(4.1 * \mathrm{wt} \% \mathrm{~B})$ & 2180 & - & - & - & - \\
\hline $3 \mathrm{~K}-1036(4.3 * \mathrm{wt} \% \mathrm{~B})$ & 2250 & 0.439 & 94.5 & 41.5 & 0.328 \\
\hline $3 \mathrm{~K}-1037(4.7 *$ wt $\%$ B $)$ & 2660 & 0.516 & 118.0 & 60.9 & 0.305 \\
\hline $3 \mathrm{~K}-1038\left(20.5^{*} \mathrm{wt} \% \mathrm{~B}\right)$ & 1690 & 0.494 & 98.0 & 48.4 & 0.324 \\
\hline $3 \mathrm{~K}-0219(8.7 \mathrm{wt} \% \mathrm{~B})$ & 1980 & 0.412 & 111.9 & 46.0 & 0.310 \\
\hline $4 \mathrm{~K}-0240(1.5 \mathrm{wt} \% \mathrm{~B})$ & 2530 & - & - & - & - \\
\hline $4 \mathrm{~K}-0244(1.6 \mathrm{wt} \% \mathrm{~B})$ & 2460 & 0.780 & 94.6 & 73.8 & 0.328 \\
\hline $4 \mathrm{~K}-0245(3.9 \mathrm{wt} \% \mathrm{~B})$ & 2490 & 0.730 & 96.5 & 70.5 & 0.326 \\
\hline $4 \mathrm{~K}-0246(4.1 \mathrm{wt} \% \mathrm{~B})$ & 2370 & 0.767 & 94.5 & 72.5 & 0.328 \\
\hline $4 \mathrm{~K}-0747(3.6 \mathrm{wt} \% \mathrm{~B})$ & 2350 & 0.736 & 94.3 & 69.4 & 0.329 \\
\hline $4 \mathrm{~K}-0748(5.6 \mathrm{wt} \% \mathrm{~B})$ & 2390 & 0.784 & 90.3 & 70.8 & 0.333 \\
\hline $4 \mathrm{~K}-0749(5.9 \mathrm{wt} \% \mathrm{~B})$ & 2250 & 0.689 & 94.2 & 65.0 & 0.329 \\
\hline $4 \mathrm{~K}-0750(6.9 \mathrm{wt} \% \mathrm{~B})$ & 2190 & 0.750 & 94.4 & 70.8 & 0.329 \\
\hline $4 \mathrm{~K}-0751(5.9 \mathrm{wt} \% \mathrm{~B})$ & 2490 & 0.670 & 98.5 & 66.0 & 0.324 \\
\hline $4 \mathrm{~K}-0752(9.1 \mathrm{wt} \% \mathrm{~B})$ & 2060 & 0.745 & 88.0 & 65.6 & 0.336 \\
\hline $5 \mathrm{~K}-0215(8 \mathrm{wt} \% \mathrm{~B})$ & 1950 & 0.665 & 91.3 & 60.8 & 0.332 \\
\hline
\end{tabular}


With the exception of sample $3 \mathrm{~K}-1037$, all excess adsorption isotherms tend to converge upon the same saturated film density of approximately $100 \mathrm{~g} / \mathrm{L}$. The saturated film density of sample $3 \mathrm{~K}-1037$ is an exception having a saturated film density of $118 \mathrm{~g} / \mathrm{L}$.

Table 18: Parameters of the adsorbed film for monolithic carbonaceous sorbent materials

\begin{tabular}{|l|r|r|r|r|r|}
\hline \multicolumn{1}{|c|}{ Sample Name } & $\begin{array}{c}\sum_{\text {BET }} \\
\left(\mathrm{m}^{2} / \mathrm{g}\right)\end{array}$ & $\begin{array}{c}V_{\text {film,sat }} \\
(\mathrm{mL} / \mathrm{g})\end{array}$ & $\begin{array}{c}\rho_{\text {film,sat }} \\
(\mathrm{g} / \mathrm{L})\end{array}$ & \multicolumn{1}{c|}{$\begin{array}{c}m_{\text {film,sat }} \\
(\mathrm{g} / \mathrm{kg})\end{array}$} & \multicolumn{1}{c|}{$\begin{array}{c}t_{\text {film,sat }} \\
(\mathrm{nm})\end{array}$} \\
\hline BR-0122 & 1820 & 0.448 & 105.8 & 47.4 & 0.316 \\
\hline BR-0134 & 1980 & 0.454 & 107.6 & 48.8 & 0.315 \\
\hline BR-0311 & 2320 & 0.513 & 104.9 & 53.8 & 0.317 \\
\hline
\end{tabular}

Even when comparing parameters of the adsorbed film across a broad range of sorbent types, similar trends hold constant. Since the maximum excess adsorption increases with increasing surface area, the film volume also increases with surface area. The saturated adsorbed film density converges upon approximately equal values for all samples. The saturated adsorbed film density is approximately the same for all samples ( 100 g/L). Consequently, the adsorbed film thickness is also approximately the same for all samples with a value of $t_{\text {film }} \approx 0.31 \mathrm{~nm}$.
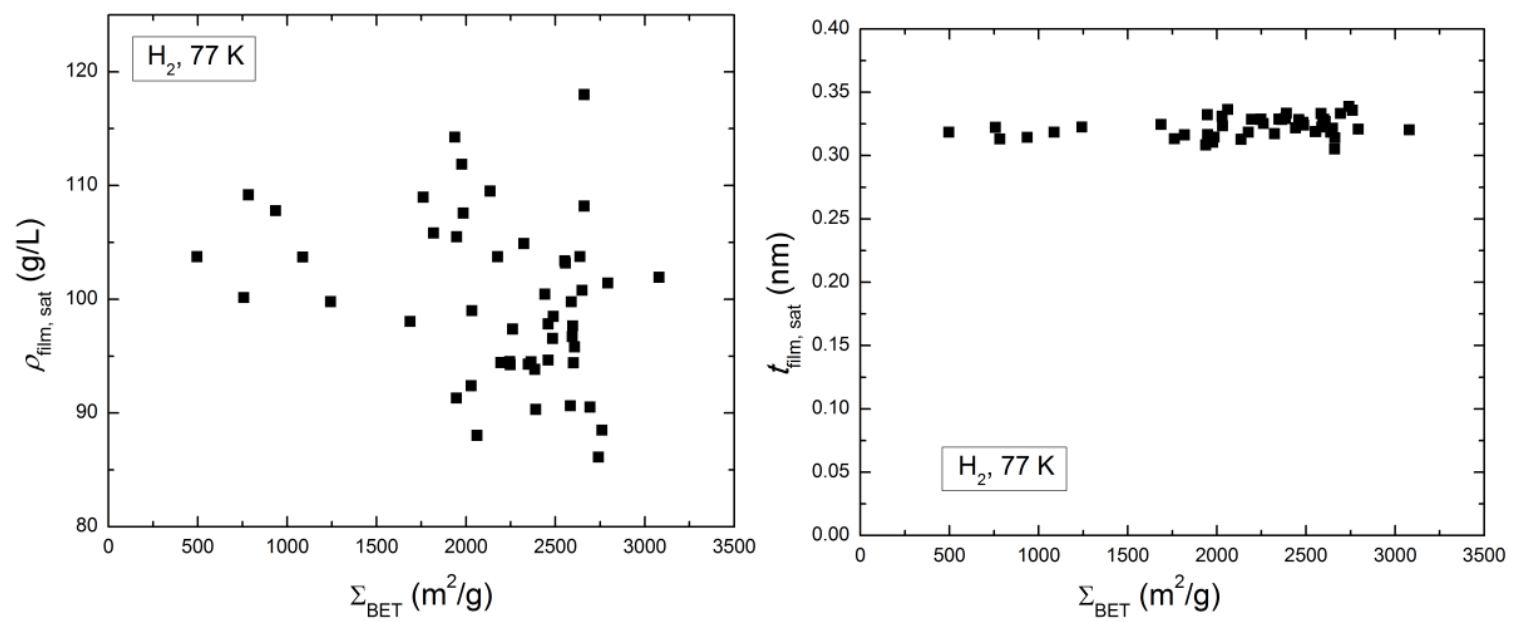

Figure 101. Saturated density of the adsorbed film at $77 \mathrm{~K}$ as a function of specific surface area. Left: the saturated film density versus specific surface area for all samples. Right: the resulting saturated film thickness versus specific surface area for all samples. 

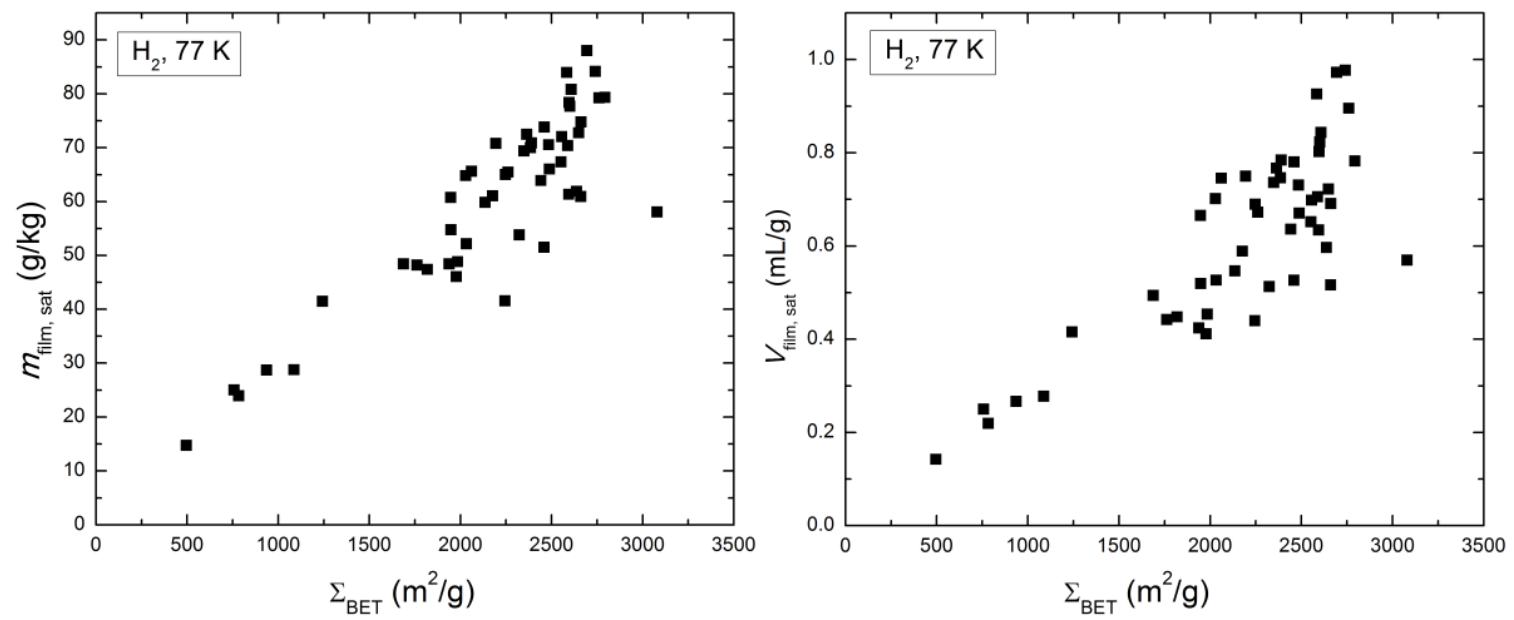

Figure 102. Mass and volume of the saturated adsorbed film at $77 \mathrm{~K}$ as a function of specific surface area.Left: the maximum capacity of the adsorbed film versus specific surface area. Right: The adsorbed film volume versus surface area. The adsorbed film volume increases by approximately $0.27 \mathrm{~mL} / \mathrm{g}$ per $1000 \mathrm{~m}^{2} / \mathrm{g}$ of specific surface area.

Regardless of surface areas, pore volumes, isosteric heats, adsorbed film volumes, and maximum film capacities, all samples converge on a saturated adsorbed film density of approximately $100 \mathrm{~g} / \mathrm{L}$. This is much higher than the liquid density of hydrogen at $20 \mathrm{~K}$ and 1 bar $(71 \mathrm{~g} / \mathrm{L})^{[53]}$.

\section{Temperature Dependence}

It is also interesting to consider how the parameters of the adsorbed film might vary with temperature. When considering an ideal gas, one expects the gas density to decrease with increasing temperature. However, the saturated adsorbed film acts quite differently with increasing temperature. 

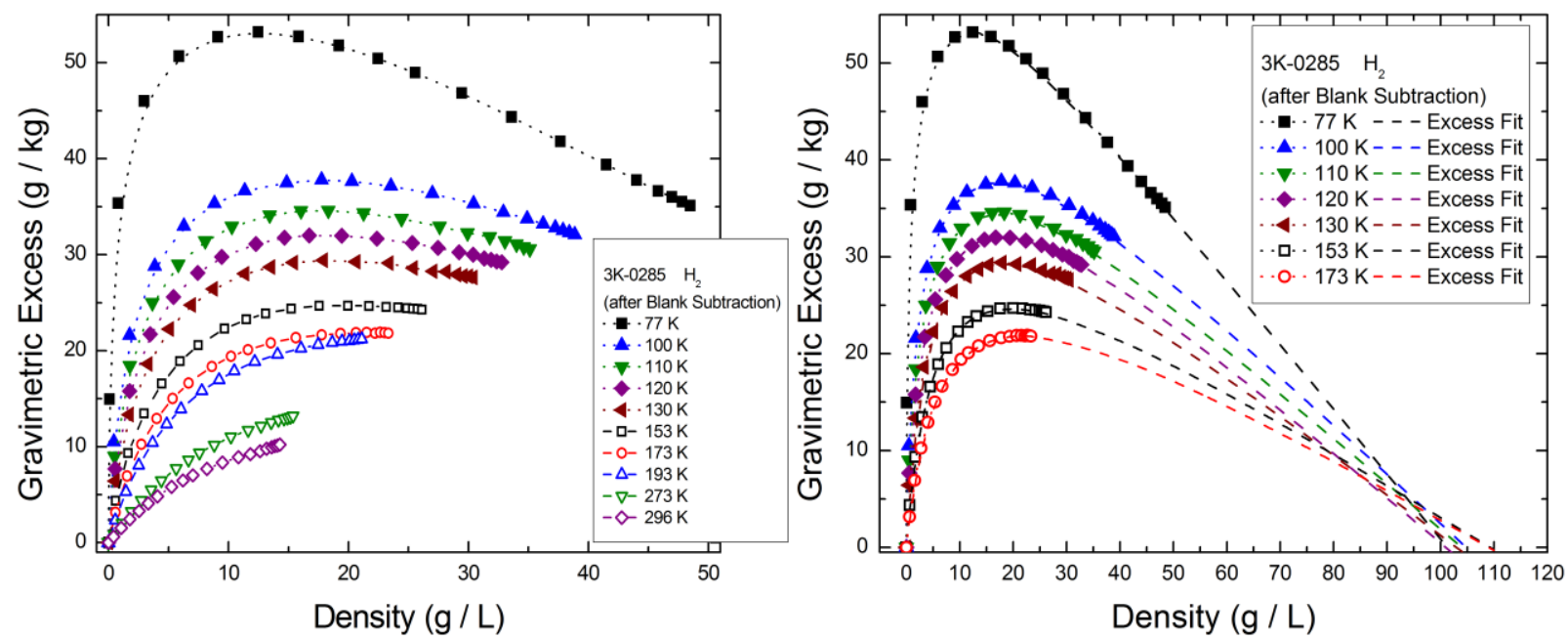

Figure 103. Gravimetric excess adsorption versus bulk gas density for sample $3 \mathrm{~K}-0285$ at various temperatures. Left: Excess adsorption versus gas density. Right: Excess adsorption versus gas density with Ono-Kondo model applied to each isotherm extrapolated to the horizontal axis.
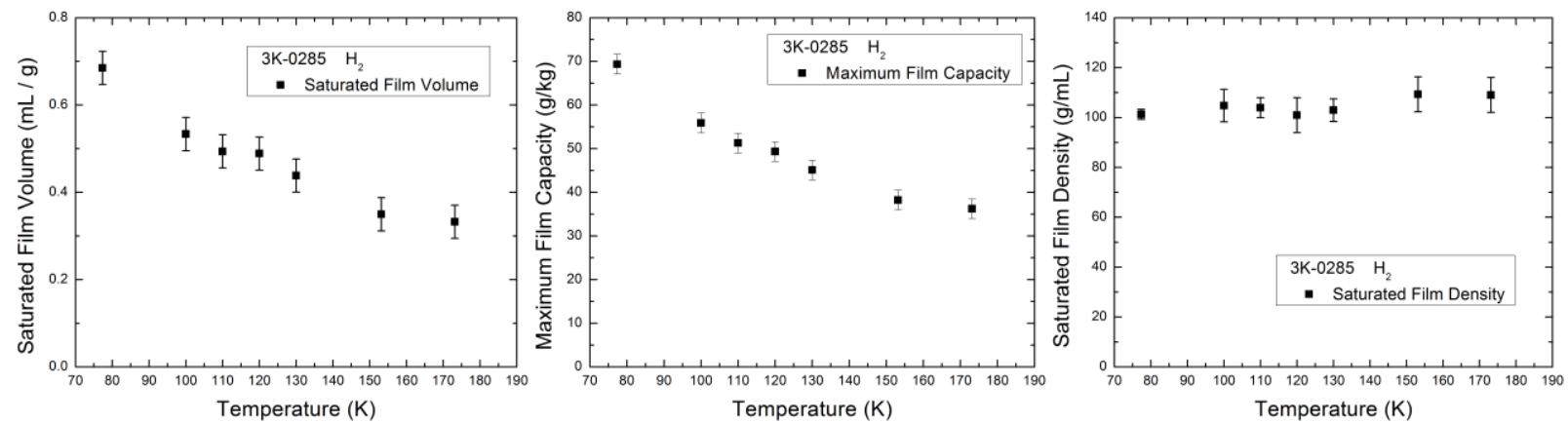

Figure 104. Parameters of the adsorbed film for sample 3K-0285 at various temperatures. Left: Saturated film volume versus temperature. Middle: Maximum film capacity versus temperature. Right: Saturated film density versus temperature.

The adsorbed film volume and maximum capacity both decrease with increasing temperature as predicted by the Ono-Kondo model. However, the saturated film density remains constant at all temperatures from $77-173 \mathrm{~K}$. 

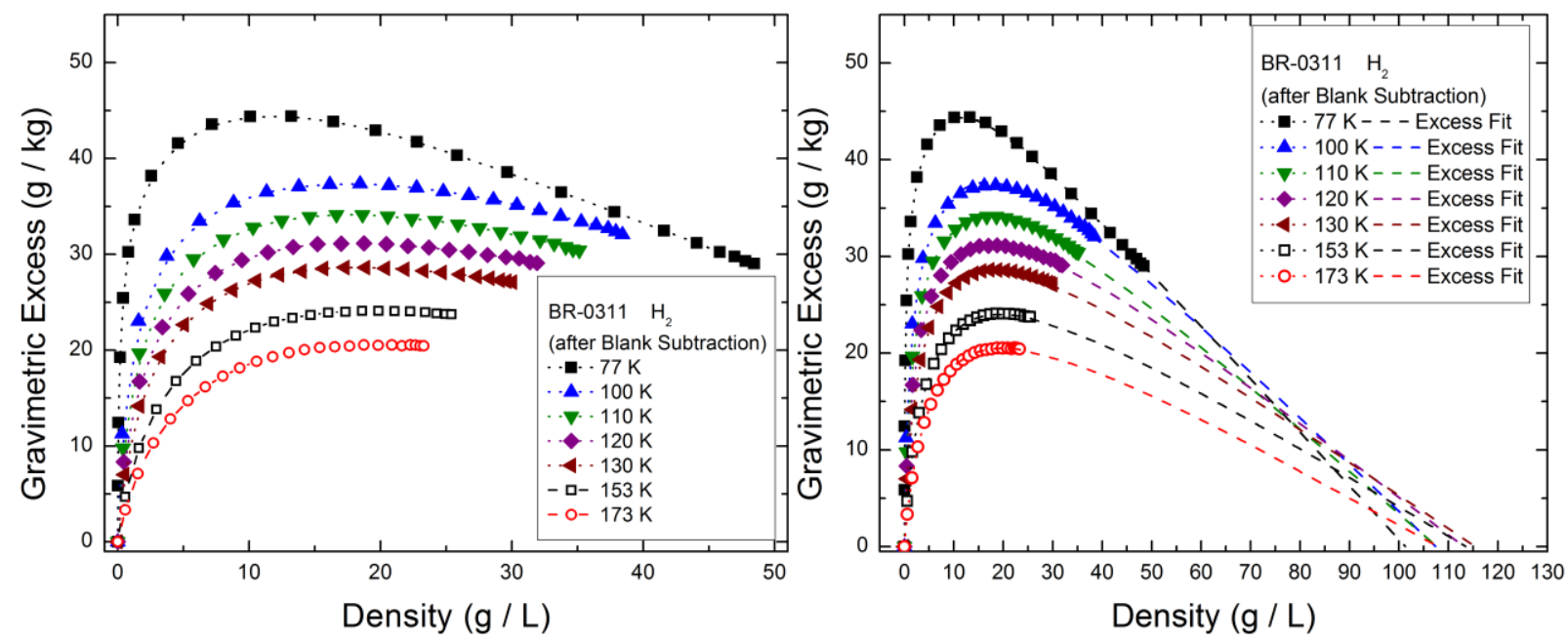

Figure 105. Gravimetric excess adsorption versus bulk gas density for sample BR-0311 at various temperatures. Left: Excess adsorption versus gas density. Right: Excess adsorption versus gas density with Ono-Kondo model applied to each isotherm extrapolated to the horizontal axis.
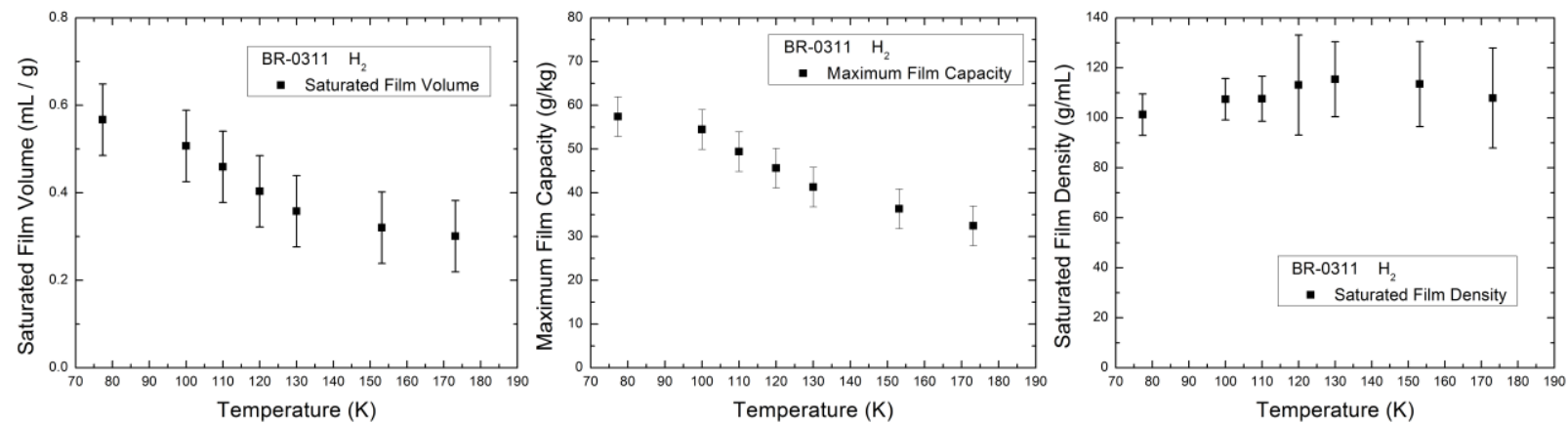

Figure 106. Parameters of the adsorbed film for sample BR-0311 at various temperatures. Left: Saturated film volume versus temperature. Middle: Maximum film capacity versus temperature. Right: Saturated film density versus temperature.

For sample BR-0311, the adsorbed film volume and maximum capacity also tend to decrease with increasing temperature as predicted by the Ono-Kondo model. However, the saturated film density remains constant at all temperatures from $77-173 \mathrm{~K}$. It would be incredibly interesting useful if the saturated film density were to remain constant with increasing temperature for all samples. If this is true, it would allow one to measure excess adsorption at $77 \mathrm{~K}$, determine the saturated film density, and use a simple model to approximate parameters of the adsorbed film at any other relevant temperature. 


\subsection{Absolute Adsorption and Coverage-Dependent Isosteric Heat}

Before obtaining differential enthalpy of adsorption results, one must determine the number of molecules involved in the adsorbed film as a function of pressure. After examining the high density regime of the excess adsorption isotherm, one may determine the volume of the adsorbed film. The absolute adsorption is calculated by adding the excess molecules to the number of molecules within the volume of the adsorbed film that would be at the bulk gas density in the absence of an adsorbing potential.

\section{Broad Range of Activated and Synthetic Carbonaceous Sorbent Materials:}

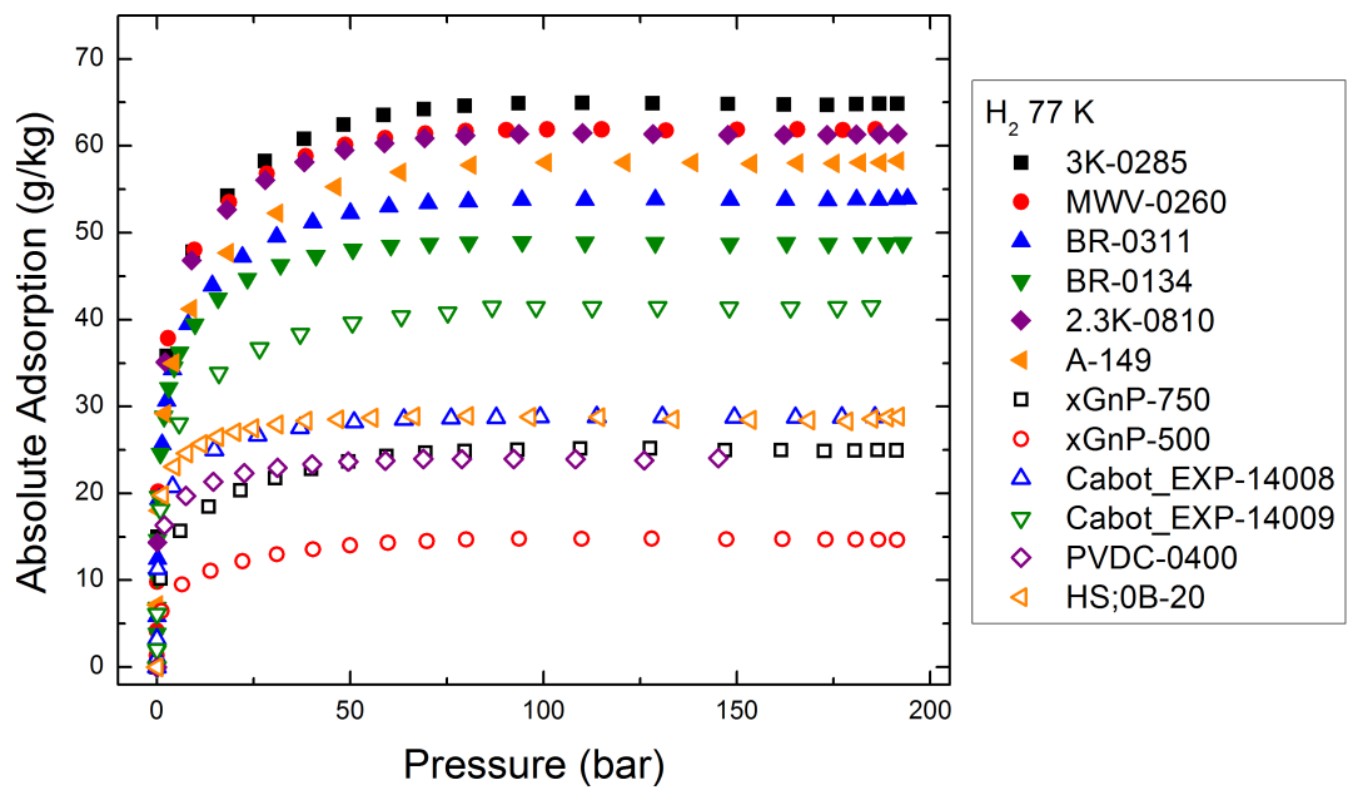

Figure 107. Absolute adsorption isotherms for various samples measured at $77 \mathrm{~K}$. The maximum absolute adsorption at $77 \mathrm{~K}$ scales with increasing specific surface areas and volumes of the adsorbed film. The absolute adsorption isotherms allow one to determine the number of molecules in the adsorbed film as a function of pressure. This allows one to apply the Clausius-Clapeyron relation to obtain differential enthalpies of adsorption. 

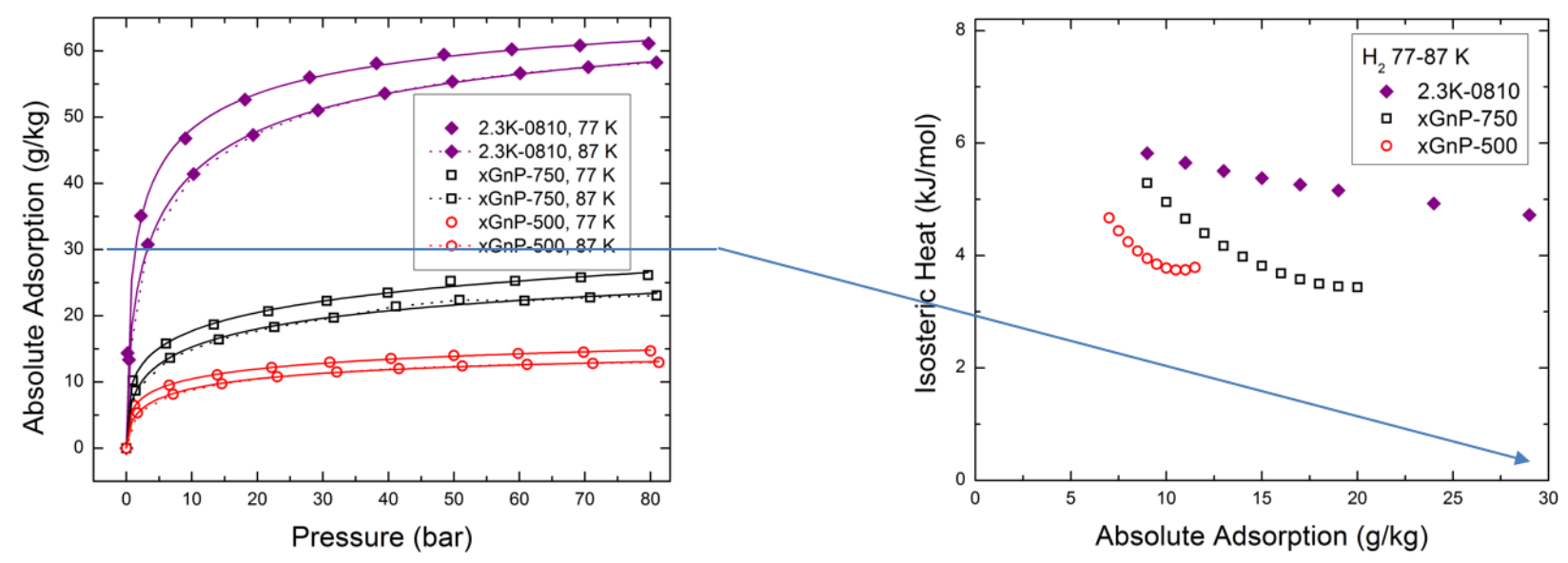

Figure 108. Absolute adsorption isotherms and resulting differential enthalpy of adsorption in the high pressure regime for select samples. Left: Absolute adsorption isotherms measured between $77-87 \mathrm{~K}$. Right: Differential enthalpy of adsorption.

A Modified Redlich-Peterson model was applied to absolute adsorption isotherms. This model allows one to directly solve for pressures at which a constant number of molecules are involved in the adsorbed film. The Clausius-Clapeyron relation was applied to this data to generate isosteric heats as a function of coverage.

The $\mathrm{xGnP}$ (nanoplatelet samples) have isosteric heats that quickly decrease with coverage indicating that the adsorbent surface is heterogeneous. High binding energy sites become filled at low pressures leaving only lower binding energy sites to be occupied as the adsorbed film becomes saturated. The $\mathrm{xGnP}-500$ and $\mathrm{xGnP}-750$ samples both have average isosteric heats around $4 \mathrm{~kJ} / \mathrm{mol}$ and reach saturation at much lower coverages compared to $2.3 \mathrm{~K}-0810$. One can observe this in the absolute adsorption plots on the left. Sample xGnP-500 only reaches an absolute adsorption coverage of approximately $20 \mathrm{~g} / \mathrm{kg}$ at $\mathrm{P}=80$ bar whereas sample $2.3 \mathrm{~K}-0810$ reaches an absolute adsorption of approximately $60 \mathrm{~g} / \mathrm{kg}$ at the same pressure. This is largely due to the differences in specific surface areas available to the hydrogen gas. Sample $2.3 \mathrm{~K}-0810$ has a surface area of around $2600 \mathrm{~m}^{2} / \mathrm{g}$ and the $\mathrm{xGnP}$ samples have surface areas between $500-750 \mathrm{~m}^{2} / \mathrm{g}$. 


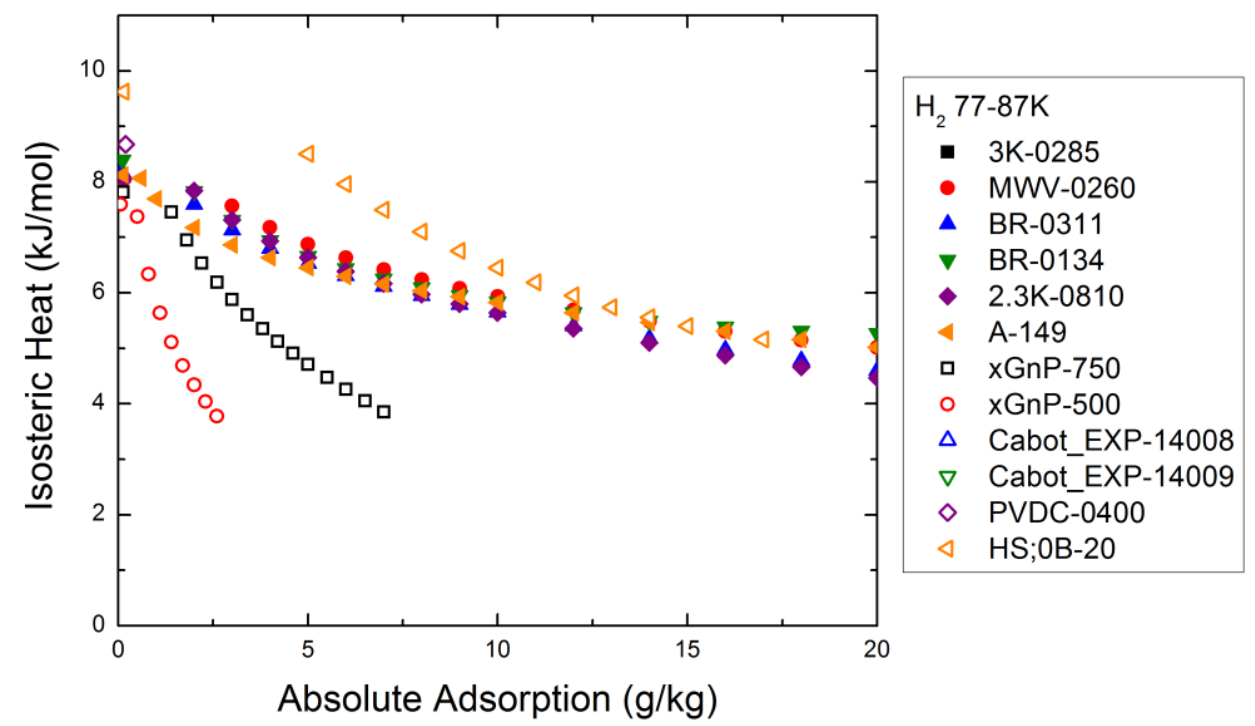

Figure 109. Differential enthalpy of adsorption in the low coverage limit for various samples. The ClausiusClapeyron relation was applied to the $77 \mathrm{~K}$ and $87 \mathrm{~K}$ absolute adsorption isotherms for each sample.

Samples with larger pore volumes and higher surface areas tend to have a more uniform adsorption potential. This is evidenced in the form of less variation in $\Delta \mathrm{H}$ as a function of coverage. Samples with porosities of $0.76-0.8$ all have large porosities and relatively homogenous isosteric heats as a function of coverage.

\section{Chemically Activated, Carbonaceous Precursor Materials:}
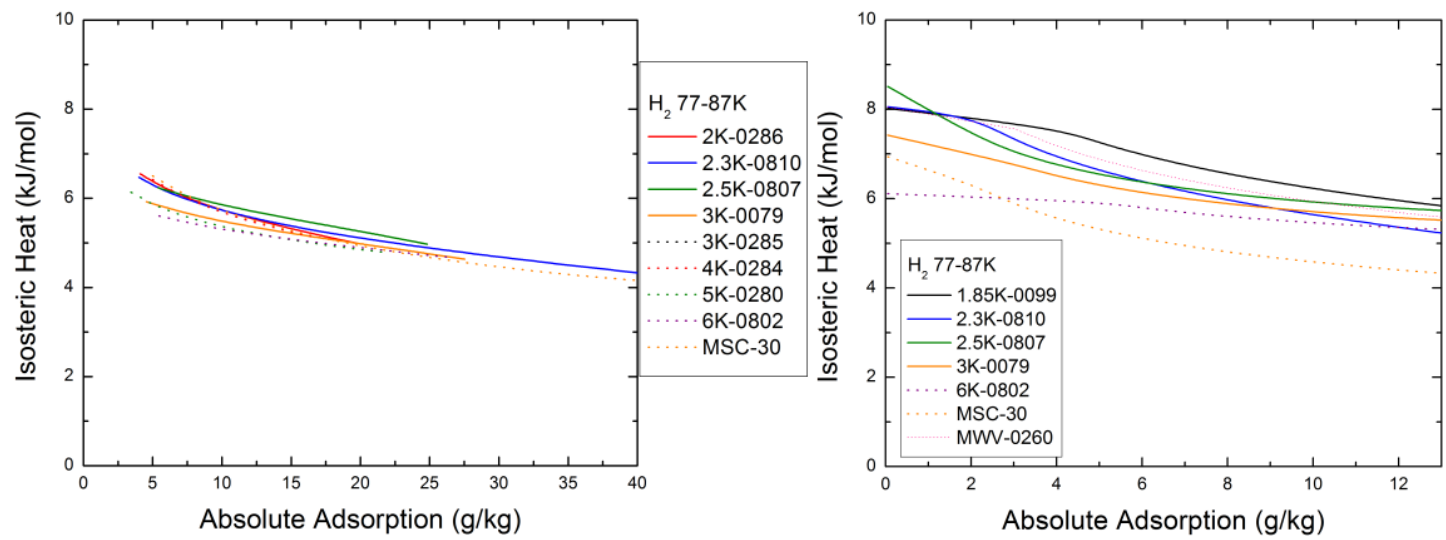

Figure 110. Differential enthalpy of adsorption for activated sorbent materials. Left: Isosteric heats resulting from applying the Clausius-Clapeyron relation to high pressure absolute adsorption isotherms. Right: Isosteric heats resulting from applying the Clausius-Clapeyron relation to low pressure absolute adsorption isotherms. The Clausius-Clapeyron relation was applied to any available absolute adsorption isotherm data for samples between 77-87 K. 
At coverages larger than $10 \mathrm{~g} / \mathrm{kg}$, these samples exhibit similar isosteric heats of adsorption between $4-5 \mathrm{~kJ} / \mathrm{mol}$ on average. Their isosteric heats deviate most at coverages less than $3 \mathrm{~g} / \mathrm{kg}$. The isosteric heat of adsorption for sample $6 \mathrm{~K}-0802$ is nearly constant in the range of $0-12 \mathrm{~g} / \mathrm{kg}$ coverage. This is indicative of its pore structure, which has a relatively large average pore width and high porosity. The isosteric heat of sample $2.5 \mathrm{~K}-0807$ approaches $9 \mathrm{~kJ} / \mathrm{mol}$ as the coverage approaches zero. This is due to the heterogeneous pore structure of this sample, which has a relatively high sub-nanometer volume fraction.

\section{Carbonaceous Precursor Materials After High Temperature Outgassing:}
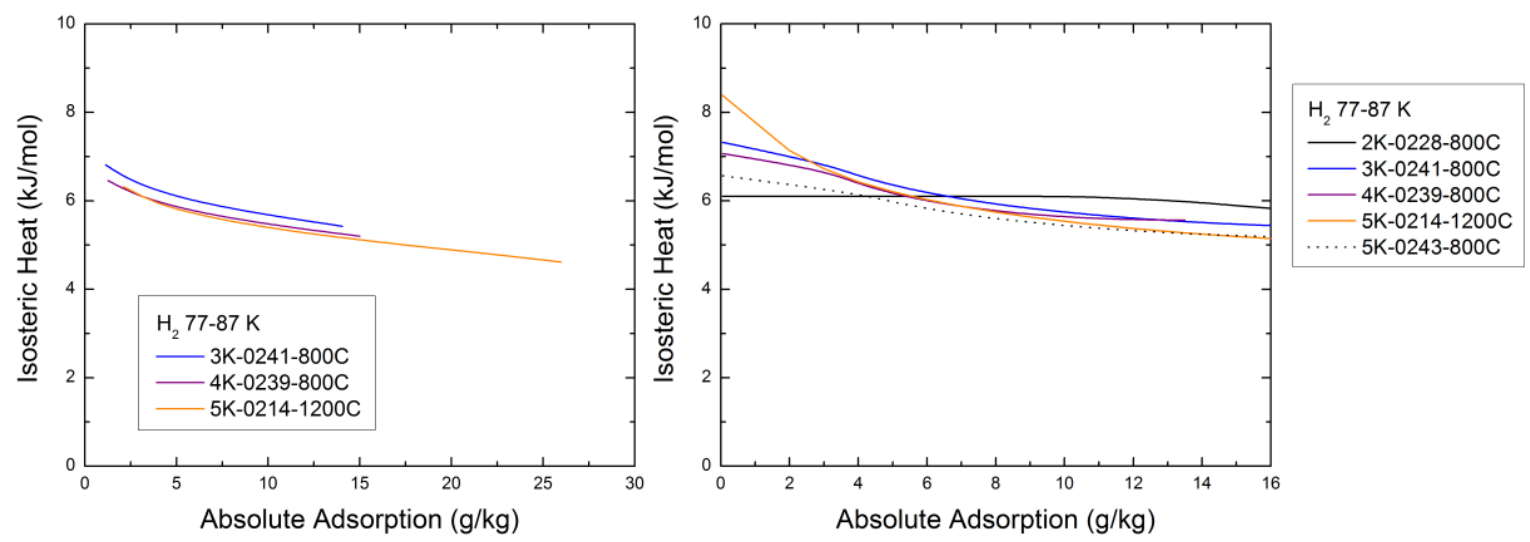

Figure 111. Differential enthalpy of adsorption for deoxygenated sorbent materials. Left: Isosteric heats resulting from applying the Clausius-Clapeyron relation to high pressure absolute adsorption isotherms. Right: Isosteric heats resulting from applying the Clausius-Clapeyron relation to low pressure absolute adsorption isotherms. The Clausius-Clapeyron relation was applied to any available absolute adsorption isotherm data for samples between 77-87 K. 


\section{Boron-Doped Sorbent Materials (2.5K-type):}
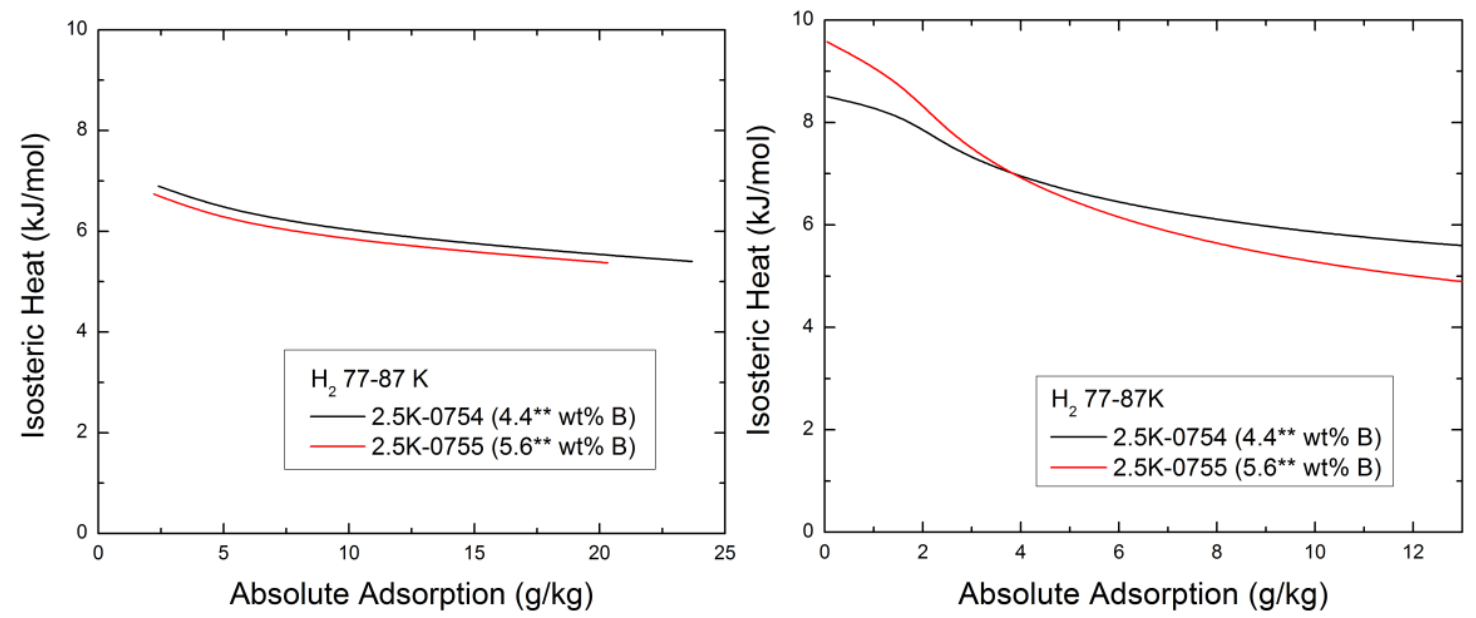

Figure 112. Differential enthalpy of adsorption for 2.5K-type boron doped materials. Left: Isosteric heats resulting from applying the Clausius-Clapeyron relation to high pressure absolute adsorption isotherms. Right: Isosteric heats resulting from applying the Clausius-Clapeyron relation to low pressure absolute adsorption isotherms. The Clausius-Clapeyron relation was applied to any available absolute adsorption isotherm data for samples between 77-87 K.

At high coverages, these two samples exhibit similar isosteric heats of adsorption. However, their isosteric heats deviate outside uncertainties at coverages and pressures approaching zero.

\section{Boron-Doped Sorbent Materials (3K-type):}
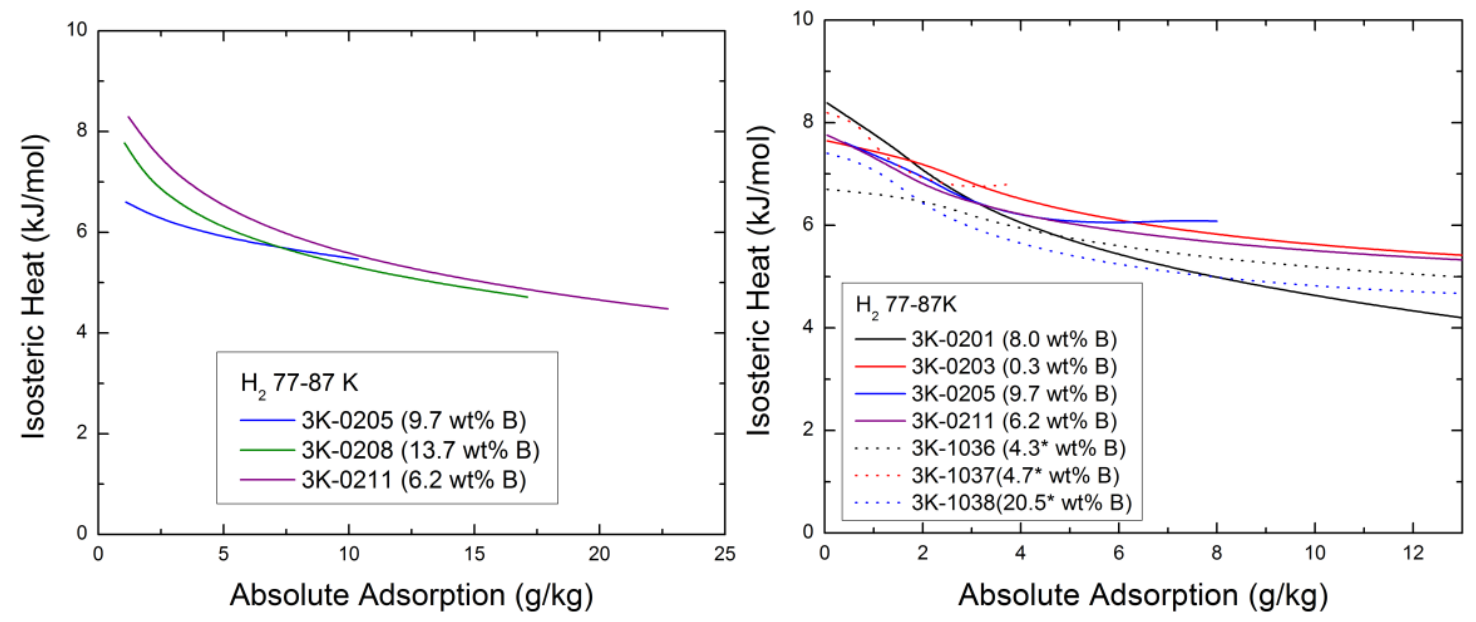

Figure 113. Differential enthalpy of adsorption for 3K-type boron doped materials. Left: Isosteric heats resulting from applying the Clausius-Clapeyron relation to high pressure absolute adsorption isotherms. Right: Isosteric heats resulting from applying the Clausius-Clapeyron relation to low pressure absolute adsorption isotherms. The Clausius-Clapeyron relation was applied to any available absolute adsorption isotherm data for samples between 77-87 K. 


\section{Boron-Doped Sorbent Materials (4K-type):}
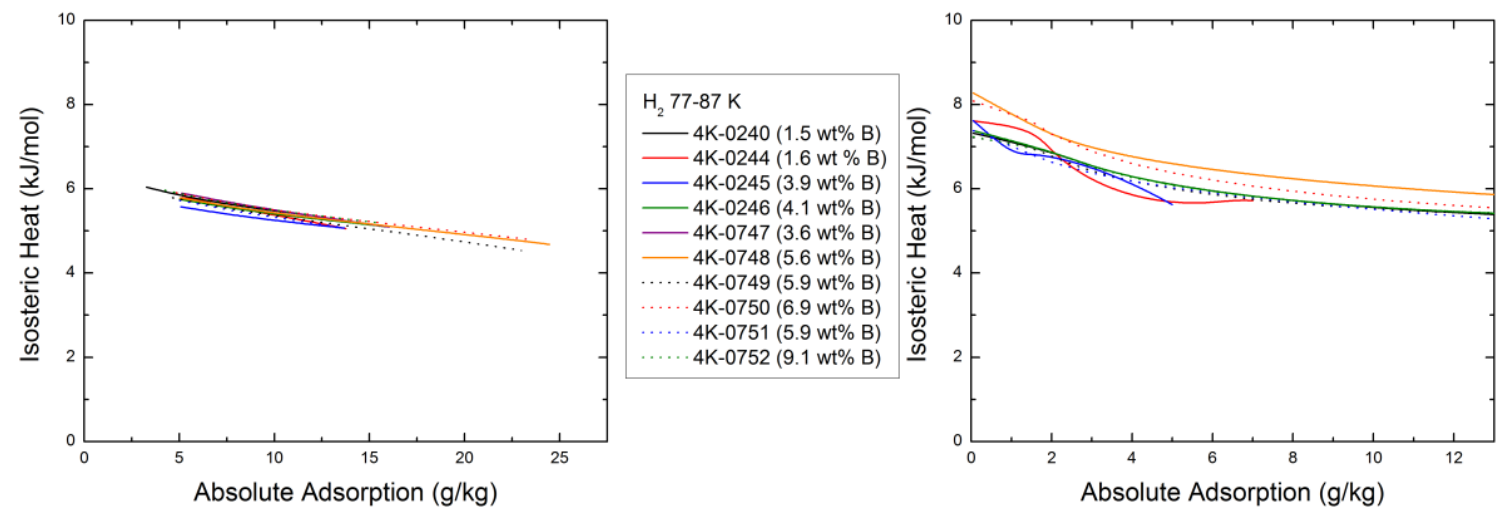

Figure 114. Differential enthalpy of adsorption for 4K-type boron doped materials. Left: Isosteric heats resulting from applying the Clausius-Clapeyron relation to high pressure absolute adsorption isotherms. Right: Isosteric heats resulting from applying the Clausius-Clapeyron relation to low pressure absolute adsorption isotherms. The Clausius-Clapeyron relation was applied to any available absolute adsorption isotherm data for samples between 77-87 K.

Boron-Doped Sorbent Materials (5K-type):
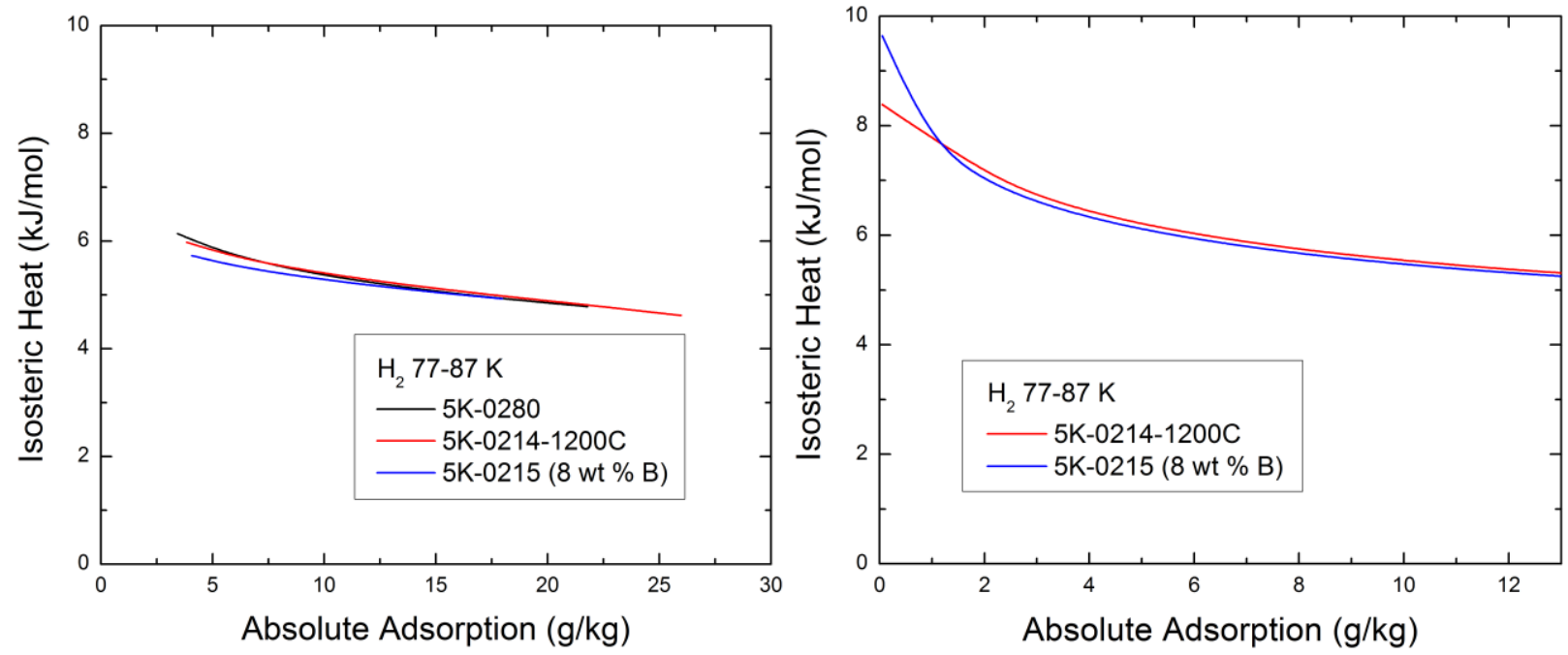

Figure 115. Differential enthalpy of adsorption for 5K-0215 and its precursors. Left: Isosteric heats resulting from applying the Clausius-Clapeyron relation to high pressure absolute adsorption isotherms. Right: Isosteric heats resulting from applying the Clausius-Clapeyron relation to low pressure absolute adsorption isotherms. The Clausius-Clapeyron relation was applied to any available absolute adsorption isotherm data for samples between 77-87 K.

At coverages larger than $10 \mathrm{~g} / \mathrm{kg}$, these samples exhibit similar isosteric heats of adsorption between 4-6 kJ/mol on average. Their isosteric heats deviate most at coverages less than $3 \mathrm{~g} / \mathrm{kg}$. The isosteric heat of adsorption for sample $5 \mathrm{~K}-0215$ has an isosteric heat approaching $10 \mathrm{~kJ} / \mathrm{mol}$ at low 
coverage, whereas its precursor material, $5 \mathrm{~K}-214$ only reaches an isosteric heat of approximately $8.5 \mathrm{~kJ} / \mathrm{mol}$. Unlike the other comparisons, these two samples have similar pore structures. Both samples underwent high temperature treatment at $1200{ }^{\circ} \mathrm{C}$ and have similarly small sub-nanometer volume fractions. Therefore, this difference in their isosteric heat values is probably not due to their pore structures. Instead, this difference is most likely due to the chemical nature of the $\mathrm{B}-\mathrm{C}, \mathrm{B}-\mathrm{B}$, and $\mathrm{B}-\mathrm{O}$ bonds that might be present on the surface of $5 \mathrm{~K}-0215^{[44]}$. According to XPS, sample $5 \mathrm{~K}-0215$ did exhibit the highest ratio of B-C sp ${ }^{2}$ bonds $(1.7 \mathrm{wt} \%)$.

\section{Carbonaceous Monolithic Sorbent Materials:}

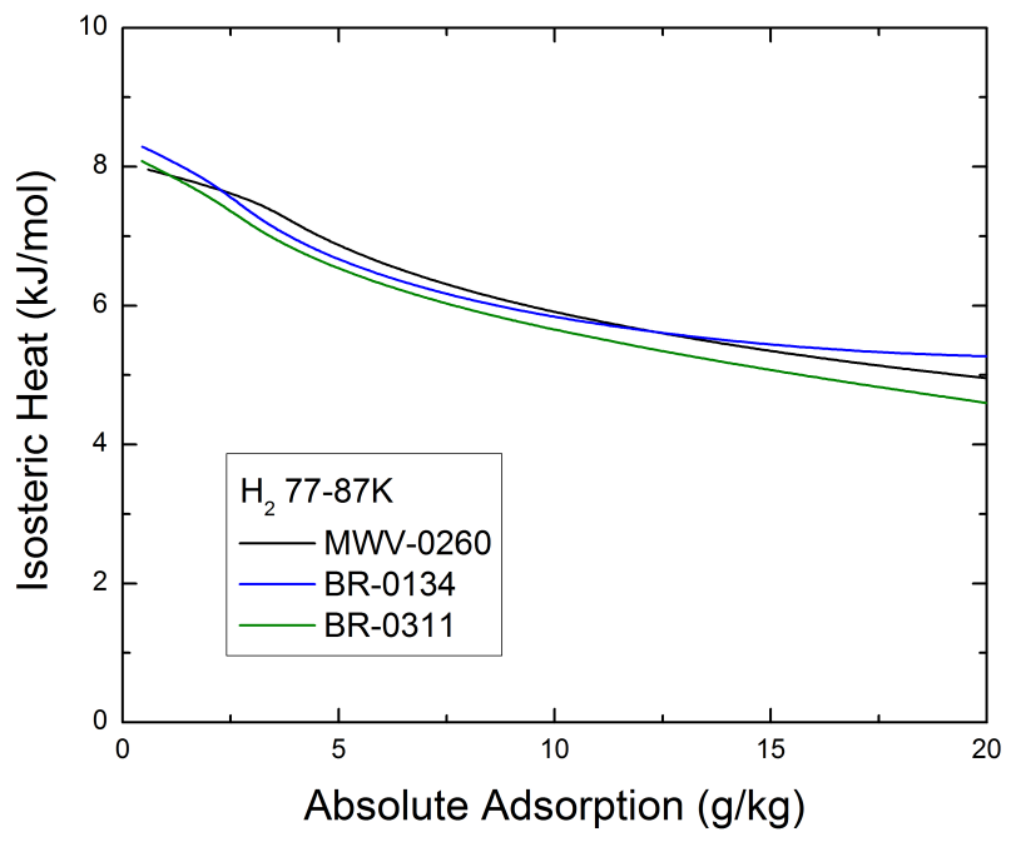

Figure 116. Differential enthalpy of adsorption for monolithic sorbent materials.Isosteric heats were obtained by applying the Clausius-Clapeyron relation to low pressure absolute adsorption isotherms between $77-87 \mathrm{~K}$.

Though the briquette materials differ in specific surface area, gravimetric excess adsorption, storage capacities, and sub-nanometer volume fraction, all exhibit similar isosteric heats of adsorption compared to their precursor material. 


\section{Temperature Dependence:}

Two samples were measured for excess adsorption over a temperature range of $77-173 \mathrm{~K}$. After determining the saturated adsorbed film volume, it was possible to convert excess adsorption into absolute adsorption isotherms and apply the Clausius-Clapeyron relation. This yielded isosteric heats of adsorption as a function of coverage as well as temperature.
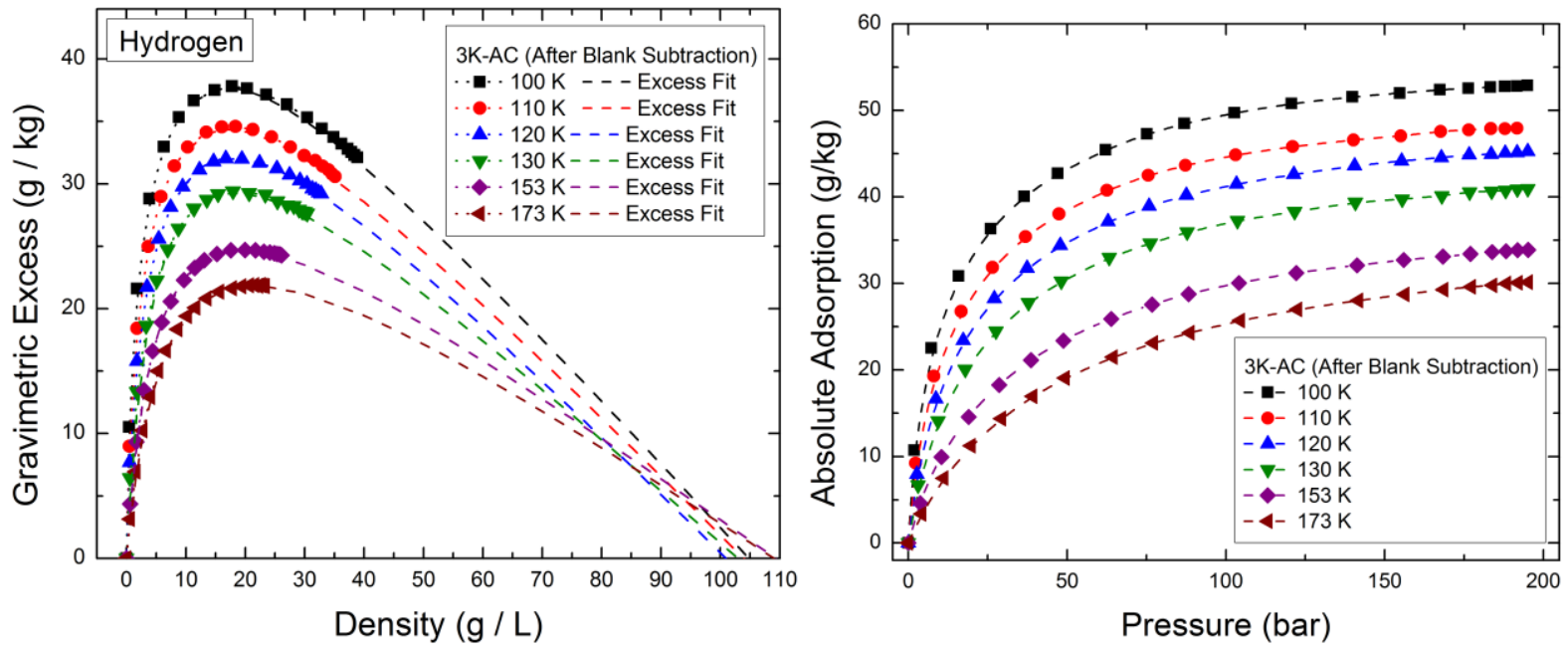

Figure 117. Hydrogen excess and absolute adsorption isotherms measured between $100-173 \mathrm{~K}$ for sample 3K-0285. Left: Gravimetric excess adsorption isotherms measured between $100-173 \mathrm{~K}$. Right: Absolute adsorption isotherms measured between $100-173 \mathrm{~K}$.

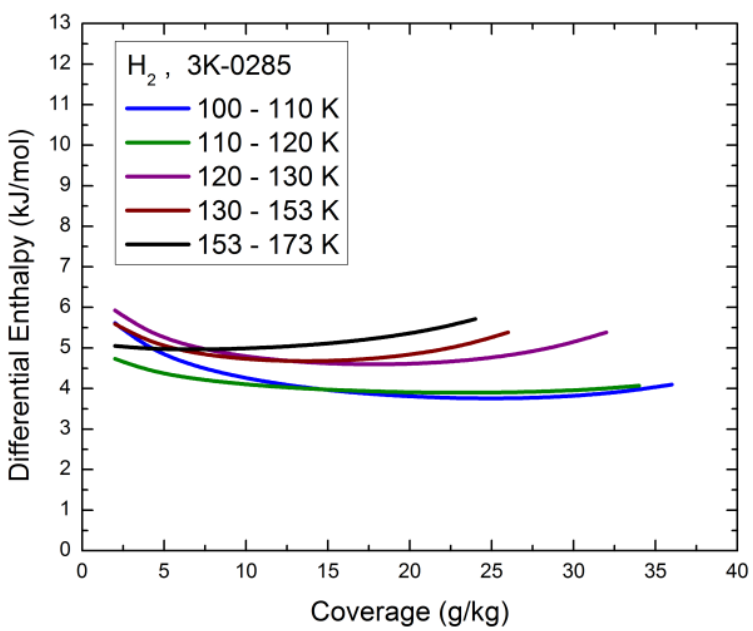

Figure 118. Resulting differential enthalpy of adsorption in the high pressure regime as a function of coverage and temperature for sample $3 \mathrm{~K}-0285$. 
All of these isosteric heats of adsorption have an unphysical rise in the high coverage regime. This is completely due to the choice of model used when interpolating between experimental absolute adsorption data. The Modified Redlich-Peterson Model tends to have greater residuals toward the extreme ends of the isotherm. This unphysical rise may also be due to the uncertainty in the adsorbed film volume. Unphysical rises in the isosteric heat with increasing coverage are indicative of an underestimated adsorbed film volume.
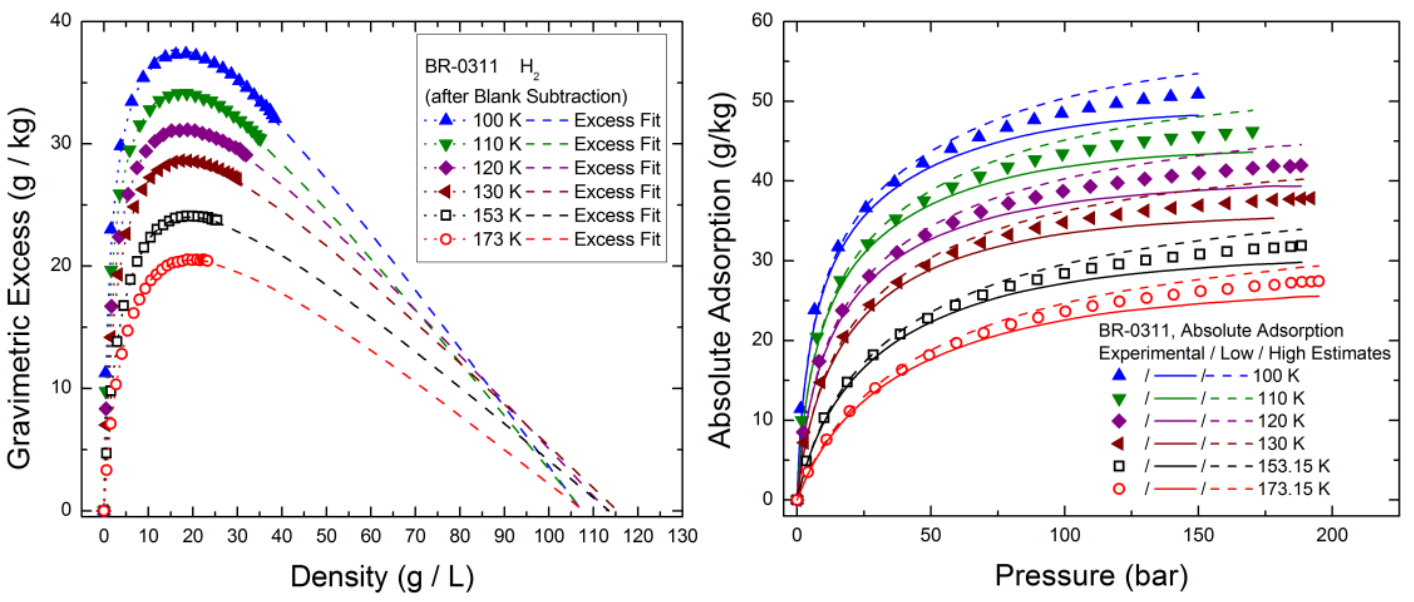

Figure 119. Hydrogen excess and absolute adsorption isotherms measured between $100-173 \mathrm{~K}$ for sample BR-0311. Left: Gravimetric excess adsorption isotherms measured between $100-173 \mathrm{~K}$. Right: Absolute adsorption isotherms measured between $100-173 \mathrm{~K}$.

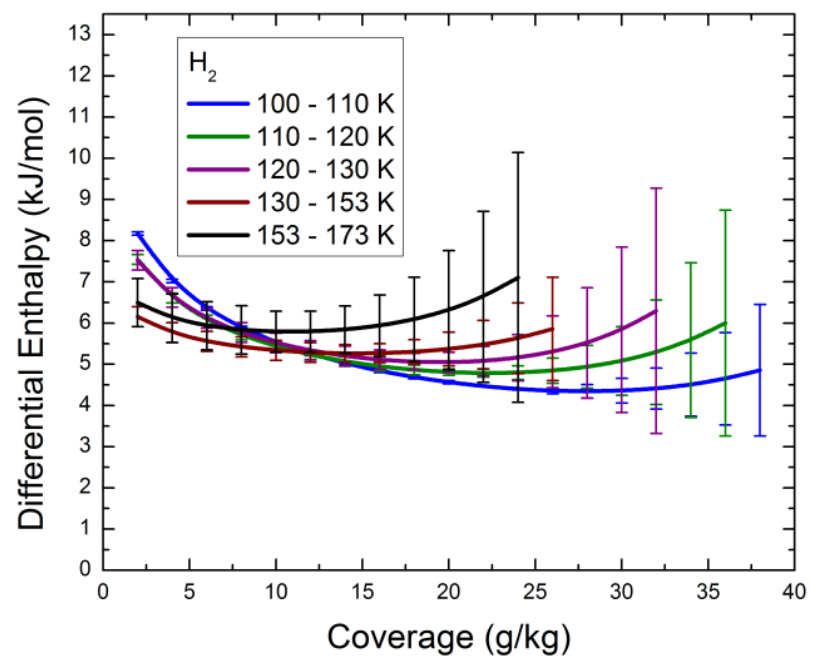

Figure 120. Resulting differential enthalpy of adsorption in the high pressure regime as a function of coverage and temperature for sample BR-0311. The error bars have been determined based on the high and low limits of the calculated isosteric heat. High and low limits of the isosteric heat were calculated by 
propagating the uncertainty of the adsorbed film volume through the conversion to absolute adsorption and the application of the Clausius-Clapeyron relation.

\subsection{Isosteric Heat from Henry's Law Analysis Near Zero-Coverage}

In the high gas density regime, the absolute adsorption values are sensitive to the choice of film volume. In the low gas density regime, the bulk gas density is much less than the density of the adsorbed film and the absolute adsorption values are approximately equivalent to the excess adsorption values. At sufficiently low pressures, the excess adsorption isotherm is expected to obey Henry's Law and exhibit linear behavior with increasing pressure.

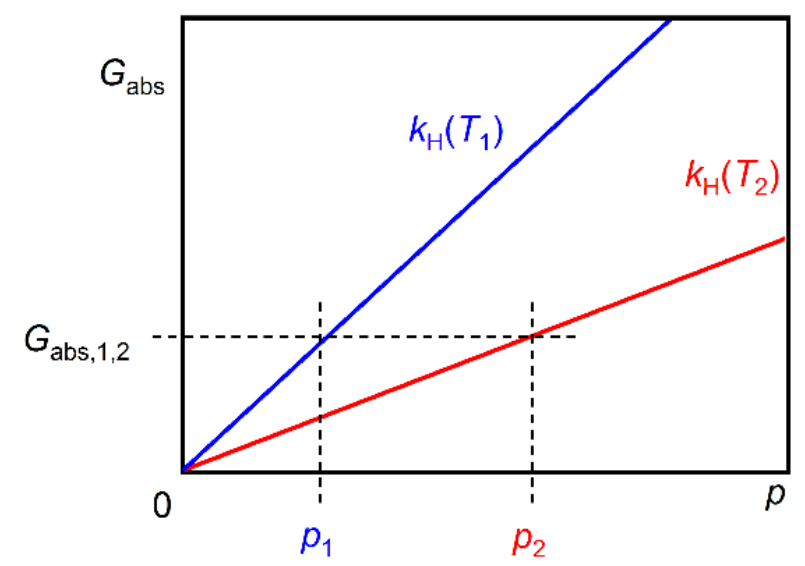

Figure 121. Absolute adsorption in the low coverage limit at $77 \mathrm{~K}$ and $87 \mathrm{~K}$. The Clausius-Clapeyron relation was applied to the $77 \mathrm{~K}$ and $87 \mathrm{~K}$ absolute adsorption isotherms for each sample. 
Table 19: Differential enthalpy of adsorption near zero coverage for various samples

\begin{tabular}{|l|r|r|r|}
\hline \multicolumn{1}{|c|}{ Sample Name } & \multicolumn{1}{|c|}{$\begin{array}{c}\sum_{\text {BET }} \\
\left(\mathrm{m}^{2} / \mathrm{g}\right)\end{array}$} & \multicolumn{1}{c|}{$\phi$} & \multicolumn{1}{c|}{$\begin{array}{l}\mathrm{H} \\
(\mathrm{kJ} / \mathrm{mol})\end{array}$} \\
\hline $3 \mathrm{~K}-0285$ & 2590 & 0.773 & 8.05 \\
\hline MWV-0260 & 2640 & 0.755 & 8.19 \\
\hline BR-0311 & 2320 & 0.744 & 8.40 \\
\hline BR-0134 & 1990 & 0.697 & 8.06 \\
\hline $2.3 \mathrm{~K}-0810$ & 2600 & 0.766 & 8.13 \\
\hline A-149 & 3080 & 0.796 & 7.82 \\
\hline xGnP-750 & 760 & 0.755 & 7.93 \\
\hline xGnP-500 & 500 & 0.736 & - \\
\hline Cabot EXP-14008 & 1090 & 0.535 & \\
\hline Cabot EXP-14009 & 1240 & 0.579 & \\
\hline PVDC-0400 & 780 & 0.489 & 9.02 \\
\hline HS;0B-20 & 940 & 0.464 & 9.62 \\
\hline
\end{tabular}


Table 20: Differential enthalpy of adsorption near zero coverage for chemically activated precursor samples

\begin{tabular}{|l|r|r|r|}
\hline \multicolumn{1}{|c|}{ Sample Name } & $\begin{array}{r}\sum_{\text {BET }} \\
\left(\mathrm{m}^{2} / \mathrm{g}\right)\end{array}$ & \multicolumn{1}{c|}{$\phi$} & $\begin{array}{c}\Delta \mathrm{H} \\
(\mathrm{kJ} / \mathrm{mol})\end{array}$ \\
\hline $1.85 \mathrm{~K}-0099$ & 2350 & 0.729 & 8.02 \\
\hline $2 \mathrm{~K}-0286$ & 1940 & 0.701 & - \\
\hline $2.5 \mathrm{~K}-0807$ & 2440 & 0.740 & 8.51 \\
\hline $3 \mathrm{~K}-0046$ & 2740 & 0.821 & - \\
\hline $3 \mathrm{~K}-0079$ & 2660 & 0.784 & 7.42 \\
\hline $4 \mathrm{~K}-0284$ & 2610 & 0.812 & - \\
\hline $4 \mathrm{~K}-0288$ & 2790 & 0.829 & - \\
\hline $5 \mathrm{~K}-0280$ & 2690 & 0.837 & - \\
\hline $6 \mathrm{~K}-0802$ & 2590 & 0.847 & 6.11 \\
\hline MSC-30 & 2760 & 0.806 & 6.94 \\
\hline
\end{tabular}

Table 21: Differential enthalpy of adsorption near zero coverage for deoxygenated precursor samples

\begin{tabular}{|l|r|r|r|}
\hline \multicolumn{1}{|c|}{ Sample Name } & $\begin{array}{c}\sum_{\text {BET }} \\
\left(\mathrm{m}^{2} / \mathrm{g}\right)\end{array}$ & \multicolumn{1}{c|}{$\phi$} & $\begin{array}{c}\Delta \mathrm{H} \\
(\mathrm{kJ} / \mathrm{mol})\end{array}$ \\
\hline 2K-0228-800C & 1760 & 0.684 & 6.10 \\
\hline $3 \mathrm{~K}-0218-1200 \mathrm{C}$ & 2140 & 0.740 & - \\
\hline 3K-0241-800C & 2550 & 0.771 & 7.32 \\
\hline 4K-0216-1200C & 2390 & 0.800 & - \\
\hline 4K-0239-800C & 2600 & 0.824 & 7.07 \\
\hline 5K-0214-1200C & 2560 & 0.832 & 8.39 \\
\hline 5K-0243-800C & 2600 & 0.827 & 6.57 \\
\hline PVDC-0735-800C & 850 & 0.580 & - \\
\hline
\end{tabular}


Table 22: Differential enthalpy of adsorption near zero coverage for boron doped materials

\begin{tabular}{|c|c|c|c|}
\hline Sample Name & $\begin{array}{c}\sum_{\text {BET }} \\
\left(\mathrm{m}^{2} / \mathrm{g}\right)\end{array}$ & $\phi$ & $\begin{array}{c}\Delta \mathrm{H} \\
(\mathrm{kJ} / \mathrm{mol})\end{array}$ \\
\hline $2.5 \mathrm{~K}-0754(4.4 * * \mathrm{wt} \% \mathrm{~B})$ & 2460 & 0.733 & 8.50 \\
\hline $2.5 \mathrm{~K}-0755(5.6 * * \mathrm{wt} \% \mathrm{~B})$ & 2030 & 0.717 & 9.58 \\
\hline $3 \mathrm{~K}-0201(8.0 \mathrm{wt} \% \mathrm{~B})$ & 2030 & 0.742 & 8.38 \\
\hline $3 \mathrm{~K}-0203(0.3 \mathrm{wt} \% \mathrm{~B})$ & 2650 & 0.784 & 7.65 \\
\hline $3 \mathrm{~K}-0205$ (9.7 wt\% B) & 2260 & 0.779 & 7.76 \\
\hline $3 \mathrm{~K}-0208(13.7 \mathrm{wt} \% \mathrm{~B})$ & 1950 & 0.739 & - \\
\hline $3 \mathrm{~K}-0211(6.2 \mathrm{wt} \% \mathrm{~B})$ & 2180 & 0.749 & 7.76 \\
\hline $3 \mathrm{~K}-1035(4.1 * \mathrm{wt} \% \mathrm{~B})$ & 2180 & 0.775 & 5.82 \\
\hline $3 \mathrm{~K}-1036(4.3 *$ wt $\%$ B $)$ & 2250 & 0.836 & 6.70 \\
\hline $3 \mathrm{~K}-1037(4.7 * w \mathrm{w} \% \mathrm{~B})$ & 2660 & 0.814 & 8.19 \\
\hline $3 \mathrm{~K}-1038(20.5 * \mathrm{wt} \% \mathrm{~B})$ & 1690 & 0.709 & 7.40 \\
\hline $3 \mathrm{~K}-0219(8.7 \mathrm{wt} \% \mathrm{~B})$ & 1980 & 0.737 & - \\
\hline $4 \mathrm{~K}-0240(1.5 \mathrm{wt} \% \mathrm{~B})$ & 2530 & 0.824 & 7.32 \\
\hline $4 \mathrm{~K}-0244(1.6 \mathrm{wt} \% \mathrm{~B})$ & 2460 & 0.817 & 7.61 \\
\hline $4 \mathrm{~K}-0245$ (3.9 wt\% B) & 2490 & 0.820 & 7.62 \\
\hline $4 \mathrm{~K}-0246(4.1 \mathrm{wt} \% \mathrm{~B})$ & 2370 & 0.810 & 7.38 \\
\hline $4 \mathrm{~K}-0747$ (3.6 wt\% B) & 2350 & 0.804 & 7.07 \\
\hline $4 \mathrm{~K}-0748(5.6 \mathrm{wt} \% \mathrm{~B})$ & 2390 & 0.805 & 8.27 \\
\hline $4 \mathrm{~K}-0749(5.9 \mathrm{wt} \% \mathrm{~B})$ & 2250 & 0.791 & 7.22 \\
\hline $4 \mathrm{~K}-0750(6.9 \mathrm{wt} \% \mathrm{~B})$ & 2190 & 0.788 & 8.09 \\
\hline $4 \mathrm{~K}-0751(5.9 \mathrm{wt} \% \mathrm{~B})$ & 2490 & 0.815 & 7.38 \\
\hline $4 \mathrm{~K}-0752(9.1 \mathrm{wt} \% \mathrm{~B})$ & 2060 & 0.779 & 7.24 \\
\hline $5 \mathrm{~K}-0215$ (8 wt \% B) & 1950 & 0.793 & 9.64 \\
\hline
\end{tabular}


Table 23: Differential enthalpy of adsorption near zero coverage for monolithic sorbent materials

\begin{tabular}{|l|r|r|r|}
\hline \multicolumn{1}{|c|}{ Sample Name } & $\begin{array}{c}\sum_{\text {BET }} \\
\left(\mathrm{m}^{2} / \mathrm{g}\right)\end{array}$ & \multicolumn{1}{c|}{$\phi$} & $\begin{array}{c}\Delta \mathrm{H} \\
(\mathrm{kJ} / \mathrm{mol})\end{array}$ \\
\hline BR-0122 & 1820 & 0.661 & - \\
\hline BR-0134 & 1980 & 0.697 & 8.40 \\
\hline BR-0311 & 2320 & 0.744 & 8.19 \\
\hline
\end{tabular}

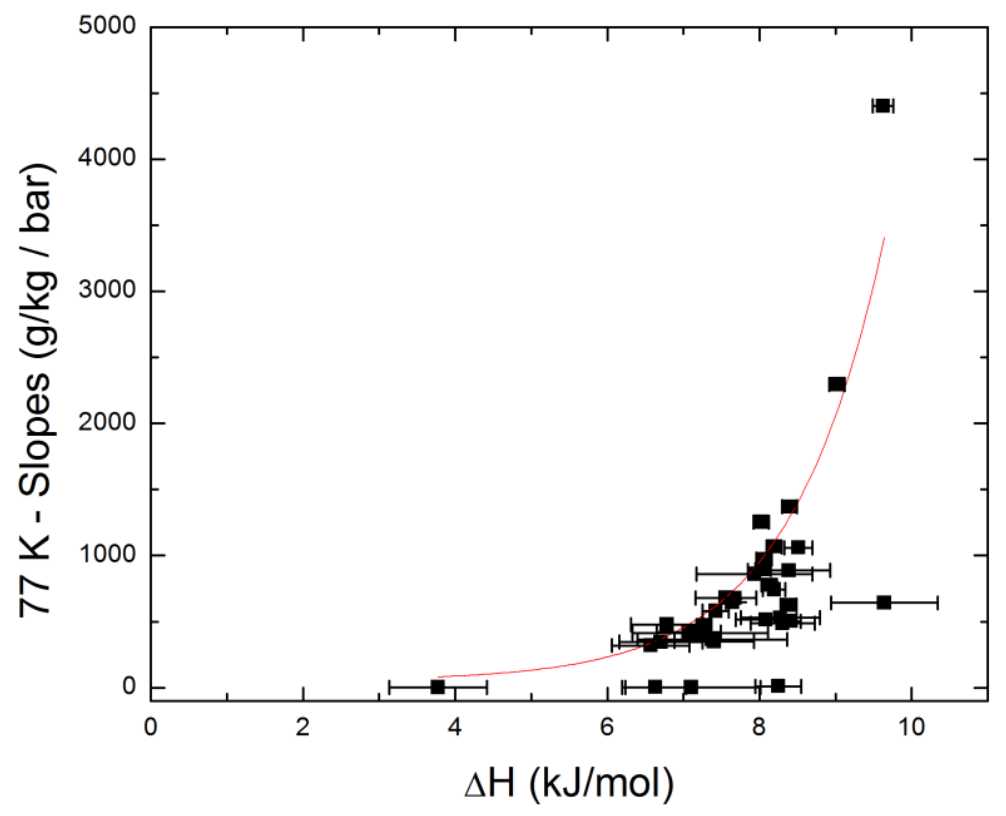

Figure 122. Slopes of the low density excess adsorption isotherms at $77 \mathrm{~K}$ versus the isosteric heat of adsorption. The slope of the $77 \mathrm{~K}$ excess adsorption isotherm should be directly related to the specific surface area and the isosteric heat.

According to the Ono-Kondo model of adsorption, the low density regime of the excess isotherm should be directly proportional to the specific surface area as well as the exponential of the binding energy. With a few exceptions, this correlation is observed within this dataset. Sample 5K-0215 is a considerable outlier in this comparison. This sample has an isosteric heat around $9.6 \mathrm{~kJ} / \mathrm{mol}$, but a surface area of $1900 \mathrm{~m}^{2} / \mathrm{g}$. 
Table 24: Binding energy and isosteric heat of various adsorbent solids

\begin{tabular}{|l|l|l|l|l|l|}
\hline Sample Name & Slope $(77 \mathrm{~K})$ & Slope $(87 \mathrm{~K})$ & $\begin{array}{l}\Delta \mathrm{H} \\
(\mathrm{kJ} / \mathrm{mol})\end{array}$ & $\begin{array}{l}E_{\mathrm{B}} \text { (Mobile) } \\
(\mathrm{kJ} / \mathrm{mol})\end{array}$ & $\begin{array}{l}\text { Uncertainty } \\
(\mathrm{kJ} / \mathrm{mol})\end{array}$ \\
\hline 3K-0285 & - & - & - & - & - \\
\hline MWV-0260 & 894 & 212 & 8.05 & 7.71 & 0.11 \\
\hline BR-0311 & 1066 & 246 & 8.19 & 7.85 & 0.1 \\
\hline BR-0134 & 1370 & 305 & 8.40 & 8.05 & 0.11 \\
\hline $2.3 \mathrm{~K}-0810$ & 972 & 230 & 8.06 & 7.72 & 0.1 \\
\hline A-149 & 776 & 182 & 8.13 & 7.78 & 0.11 \\
\hline xGnP-750 & 1757 & 434 & 7.82 & 7.47 & 1.27 \\
\hline xGnP-500 & 859 & 208 & 7.93 & 7.59 & 0.76 \\
\hline Cabot-EXP-14008 & - & - & - & - & - \\
\hline Cabot-EXP-14009 & - & - & - & - & - \\
\hline PVDC-0400 & 2295 & 458 & 9.02 & 8.68 & 0.1 \\
\hline HS;0B-20 & 4403 & 788 & 9.62 & 9.28 & 0.14 \\
\hline
\end{tabular}

The uncertainties associated with the differential enthalpy of adsorption primarily depend upon the accuracy of the pressure transducers and to what degree the experimental data is linear. In most cases, the experimental data exhibited very little deviation from linearity with $R^{2}>0.999$. However, if the experimental adsorption data deviates from linearity, then the calculated differential enthalpy will be heavily dependent upon the number of data points were used to generate the linear fit. This is because the excess adsorption curve will become non-linear at sufficiently high pressures $(\mathrm{P}>0.01 \mathrm{bar}, \mathrm{T}=77 \mathrm{~K})$ and the change in excess adsorption will decrease with increasing pressures. Therefore, it is necessary to establish some criteria prior to applying linear models and calculating differential enthalpy in the lowpressure limit. 
1) $\lim _{P \rightarrow 0}\left(\frac{m_{\mathrm{exc}}}{m_{\mathrm{s}}}\right)=0 \quad$ within the uncertainties of the measuring instrumentation

2) $R^{2}>0.999$ over the range of experimental data.

3) Both $77 \& 87 \mathrm{~K}$ isotherms must meet conditions $1 \& 2$ over an interval of constant coverage such that $G_{\text {abs }}(77 \mathrm{~K}) \approx G_{\text {abs }}(87 \mathrm{~K})$.

For a set of isotherms meeting these conditions, an upper and lower limit of differential enthalpy can be established. The upper limit may be determined by applying the Clausius-Clapeyron relation to the parameters obtained from the maximum slope of the $77 \mathrm{~K}$ isotherm and the minimum slope of the $87 \mathrm{~K}$ isotherm. This would result in the largest difference between $\mathrm{P}_{1}$ and $\mathrm{P}_{2}$ in Eq (28). The lower limit may be determined by applying the Clausius-Clapeyron relation to the parameters obtained from the minimum slope of the $77 \mathrm{~K}$ isotherm and the maximum slope of the $87 \mathrm{~K}$ isotherm. This would result in the smallest difference between $\mathrm{P}_{1}$ and $\mathrm{P}_{2}$ in Eq (28). The difference between the upper and lower limit represents the uncertainty in the calculated differential enthalpy of adsorption. A minimum uncertainty of $\pm 0.1 \mathrm{~kJ} / \mathrm{mol}$ was assigned to all calculated differential enthalpy values.
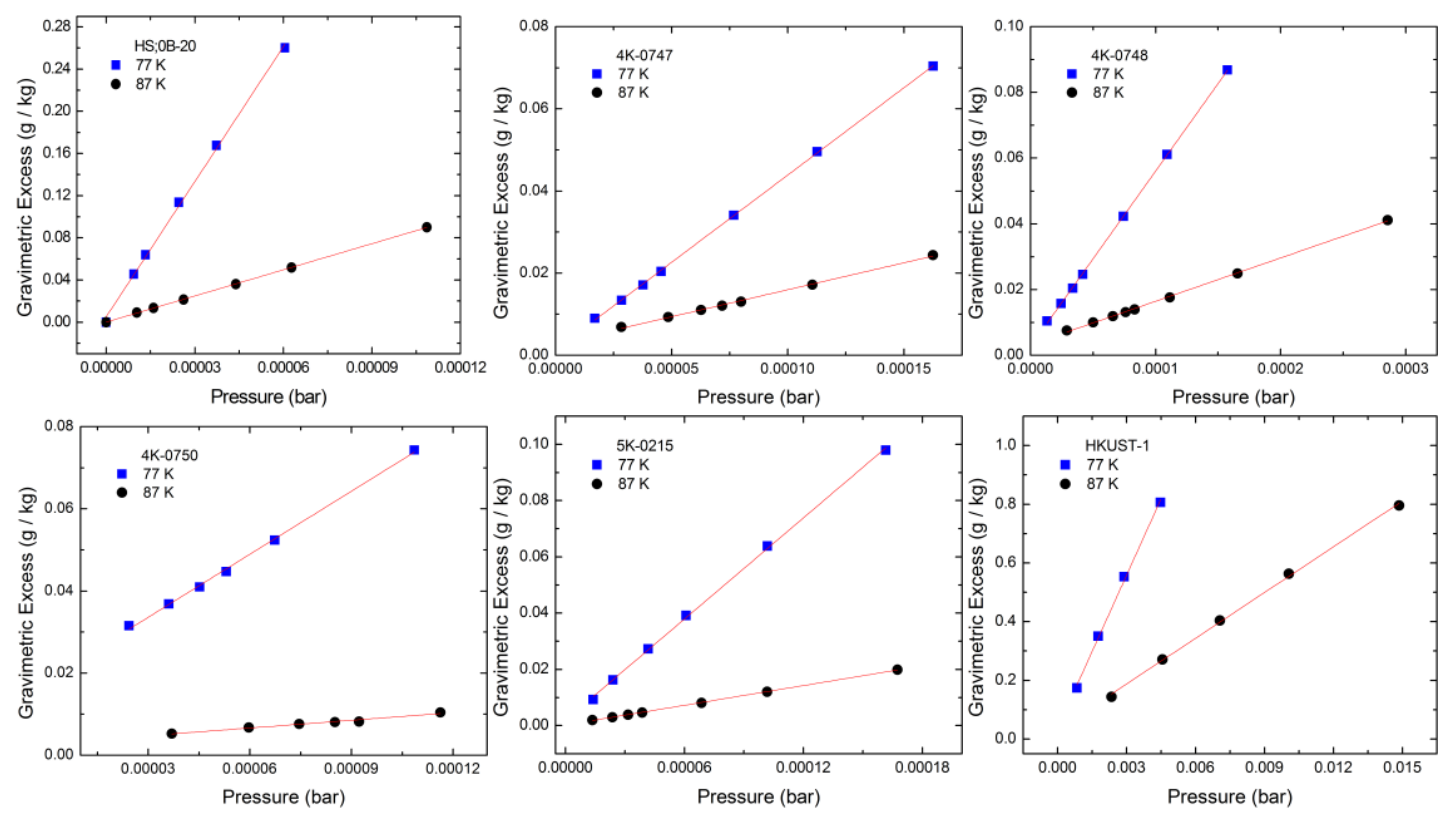

Figure 123. Low gas density linear regimes of hydrogen excess adsorption at $77 \mathrm{~K}$ and $87 \mathrm{~K}$. A linear fit was applied to all low pressure isothermal excess measurements to obtain the differential enthalpy of adsorption. 
Low pressure isotherms are displayed as a visual figure merit for the applicability of a linear isothermal model in the ultra-low pressure regime. Of the samples shown above, experimental data for samples HS;0B-20, 4K-0747, 4K-0748, 5K-0215, and HKUST-1 all meet the three listed criteria for obtaining isosteric heat from Henry's Law analysis. The experimental data for sample 4K-0750 does not meet the first and third criteria. The $77 \mathrm{~K}$ excess isotherm for sample $4 \mathrm{~K}-0750$ does not intersect zero excess in the low pressure limit and the linear regime of the $87 \mathrm{~K}$ adsorption data does not extend to a sufficient coverage such that $G_{\text {abs }}(77 \mathrm{~K}) \approx G_{\text {abs }}(87 \mathrm{~K})$.

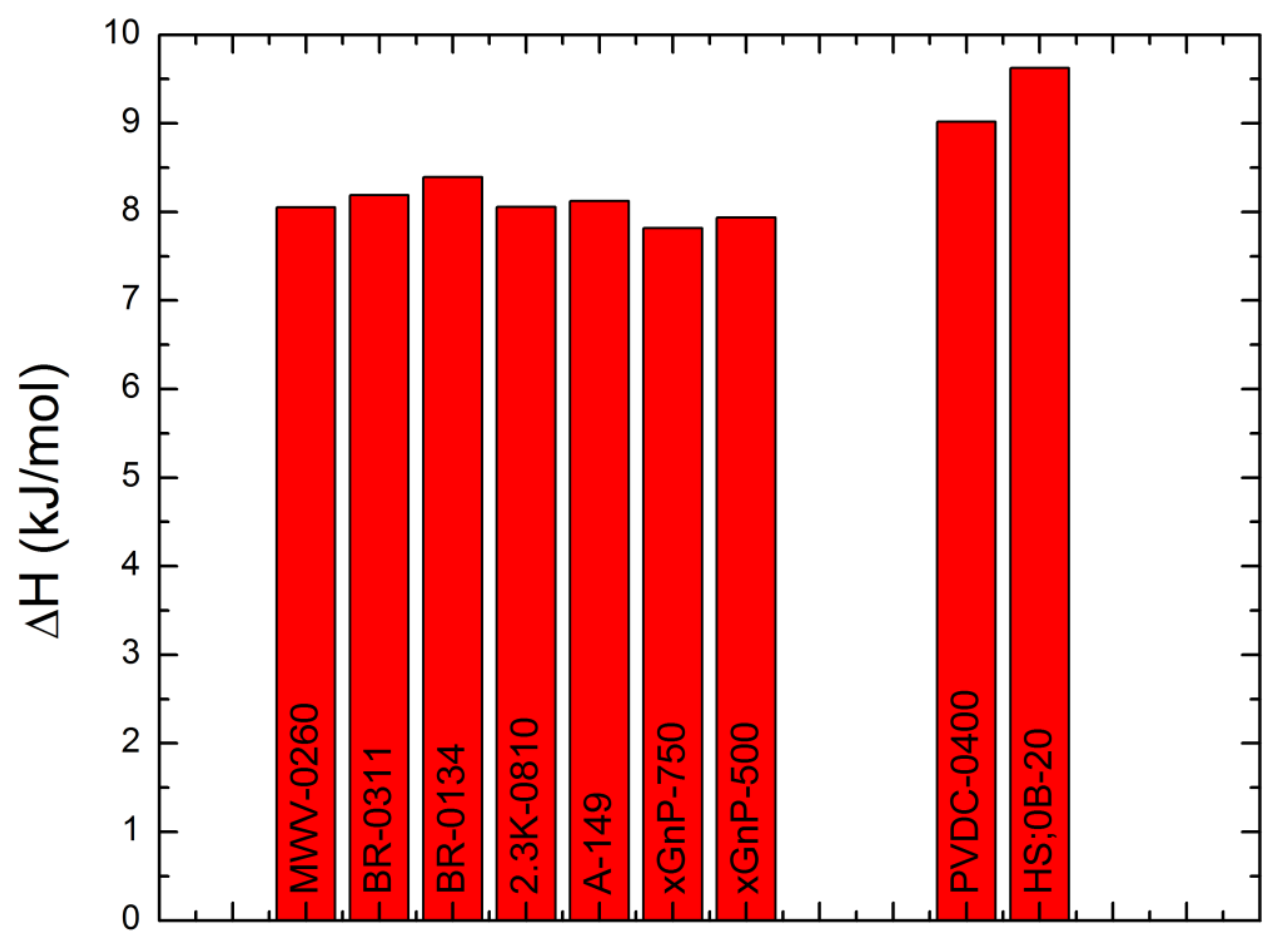

Figure 124. Bar graph of isosteric heats of adsorption for various material types. A linear fit was applied to all low pressure isothermal excess measurements

According to Eq (70), the differential enthalpy of adsorption can be determined in the low gas density limit by applying a linear model to a plot of excess adsorption versus pressure and analyzing the slopes. The slopes of these isotherms are primarily dependent upon the specific surface areas and binding energies. Assuming all other variables are constant, a sample with a higher specific surface area will adsorb more gas than one with a low specific surface area according to the Chahine Rule highlighted in fig 12. Assuming all other variables are constant, higher binding energies result in the adsorbed film reaching 143 
saturation at lower pressures compared to samples with lower binding energies. So the maximum excess adsorption occurs at lower pressures for such samples (reference introduction with Ono-Kondo Model "c" parameter). According to the Ono-Kondo model, excess adsorption should be directly proportional to the adsorbed film volume and, consequently, the specific surface area. In the low gas density limit, excess adsorption should be proportional to an exponential function of the binding energy.
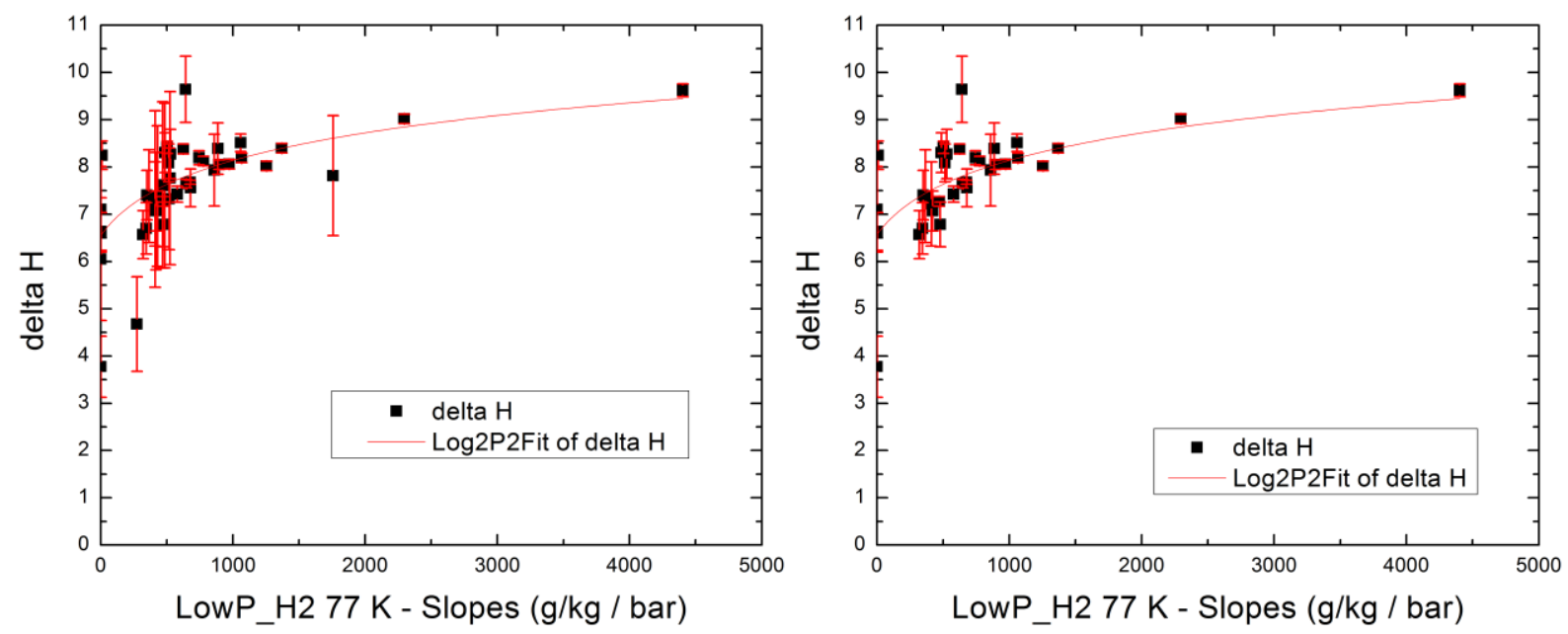

Figure 125. Differential enthalpy of adsorption versus the slope of the low pressure isotherms at $77 \mathrm{~K}$ for various adsorbents.

The differential enthalpy of adsorption describes the interaction of the gas to the adsorbent surface. If the differential enthalpy of adsorption is increased for any given sample then we expect to see an increase in the amount adsorbed. This would result in an increase in the slope of the low pressure isotherm. So the differential enthalpy should be correlated with the slope of the low pressure isotherm.

\subsection{Areal Excess Adsorption}

The performance of an adsorbent material is heavily influenced by the extent of its specific surface area. How do these samples perform when normalized to surface area? It is often conjectured that high areal excess adsorption should imply a high Isosteric heat of adsorption. If we can create samples with high $\Delta \mathrm{H}$ values that also retain their high surface areas, then we should be able to improve the performance of adsorbent materials. 


\section{Broad Range of Activated and Synthetic Carbonaceous Sorbent Materials:}

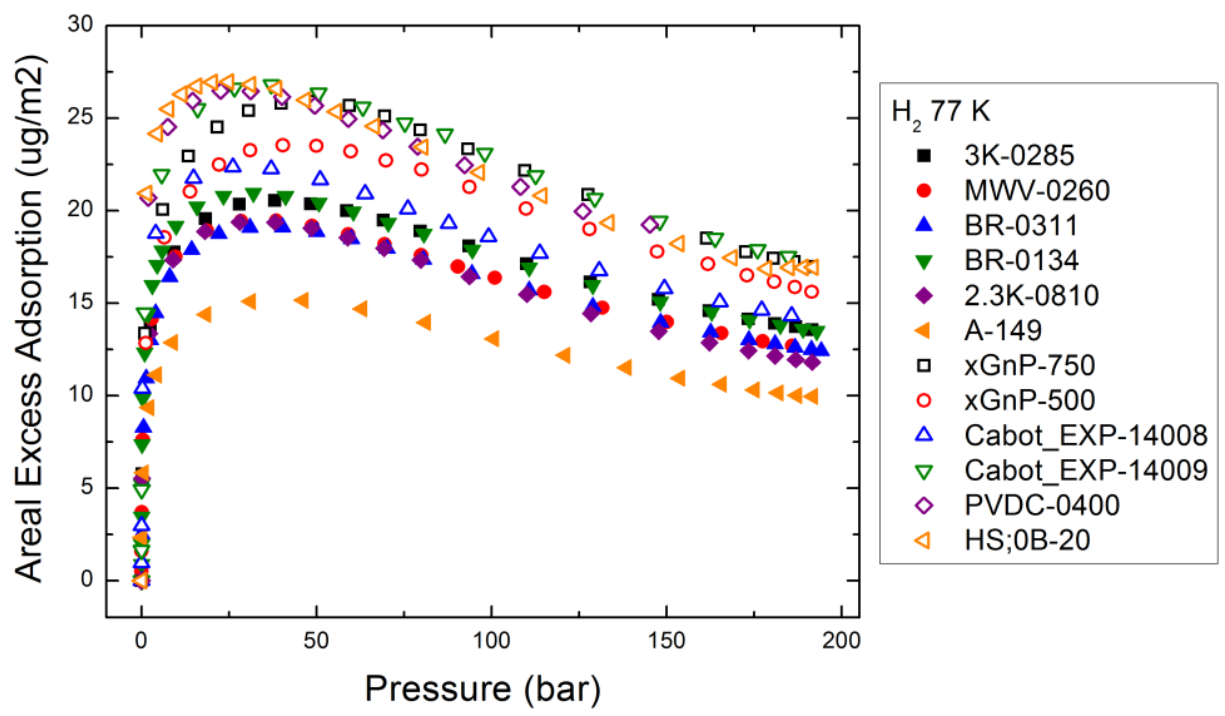

Figure 126. Areal excess adsorption isotherms for various samples measured at $77 \mathrm{~K}$. Areal excess adsorption is equal to the gravimetric excess adsorption normalized to the specific surface area.

Almost all typical chemically activated carbons have a maximum areal excess adsorption of $18-22 \mu \mathrm{g} / \mathrm{m}^{2}$. Both HS;0B-20 and PVDC -0400 have a maximum areal excess adsorption of approximately $27 \mu \mathrm{g} / \mathrm{m}^{2}$, which indicates that their performance was improved excluding effects of surface area.

\section{Chemically Activated Precursors and Deoxygenated Materials:}
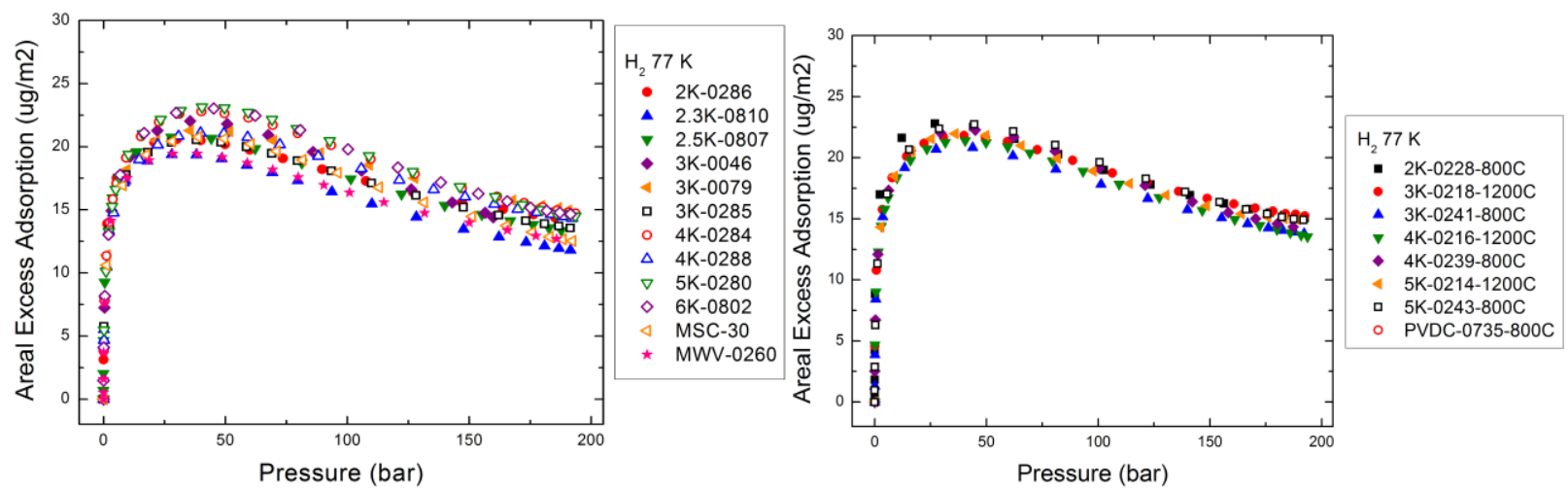

Figure 127. Areal excess adsorption isotherms for activated and deoxygenated sorbent materials measured at $77 \mathrm{~K}$. All precursor carbon materials have a maximum areal excess adsorption values ranging between $18-22 \mu \mathrm{g} / \mathrm{m}^{2}$. Most 3K-type carbons are similar to MSC-30 and have a maximum areal excess adsorption value of $20 \mu \mathrm{g} / \mathrm{m}^{2}$. After deoxygenation at $800{ }^{\circ} \mathrm{C}$, sample $5 \mathrm{~K}-0214$ still has a relatively high maximum areal excess adsorption value of $22 \mu \mathrm{g} / \mathrm{m}^{2}$, which should imply that this sample has a high binding energy to hydrogen compared to the other deoxygenated materials. 


\section{Boron-Doped Sorbent Materials (2.5K and 3K-type):}
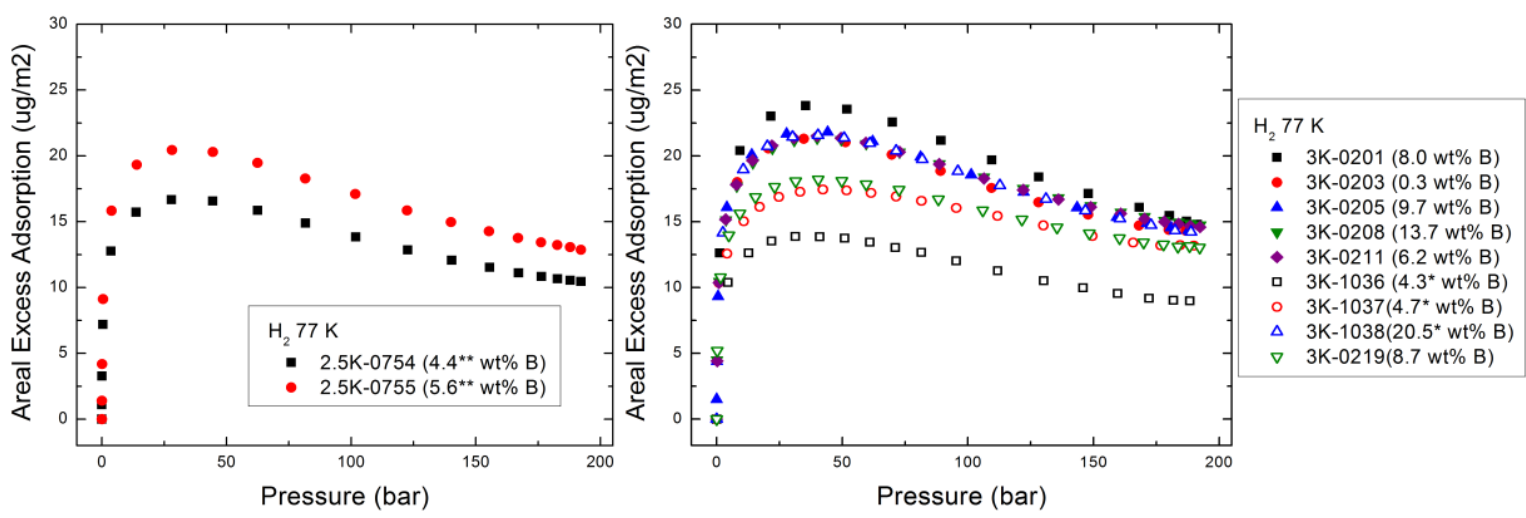

Figure 128. Areal excess adsorption isotherms for $2.5 \mathrm{~K}$ and $3 \mathrm{~K}$-type boron doped materials measured at 77 K. Samples have a larger variance in areal excess adsorption after doping. This serves as a qualitative figure of merit that the surface chemistry of the material is being modified in the doping process.

The maximum areal excess of sample $3 \mathrm{~K}-0201$ increased from 20 to $24 \mu \mathrm{g} / \mathrm{m}^{2}$ compared to its precursor, $3 \mathrm{~K}-0241$. This indicates that we have successfully modified the surface chemistry of the material after doping to achieve a higher binding energy to hydrogen in this sample. The maximum areal excess of sample $3 \mathrm{~K}-1036$ decreased from $20 \mu \mathrm{g} / \mathrm{m}^{2}$ to $14 \mu \mathrm{g} / \mathrm{m}^{2}$ compared to its precursor. This is most likely due to undesirable B-B bonds aggregating on the surface and blocking adsorption sites.

\section{Boron-Doped Sorbent Materials (4K and 5K-type):}
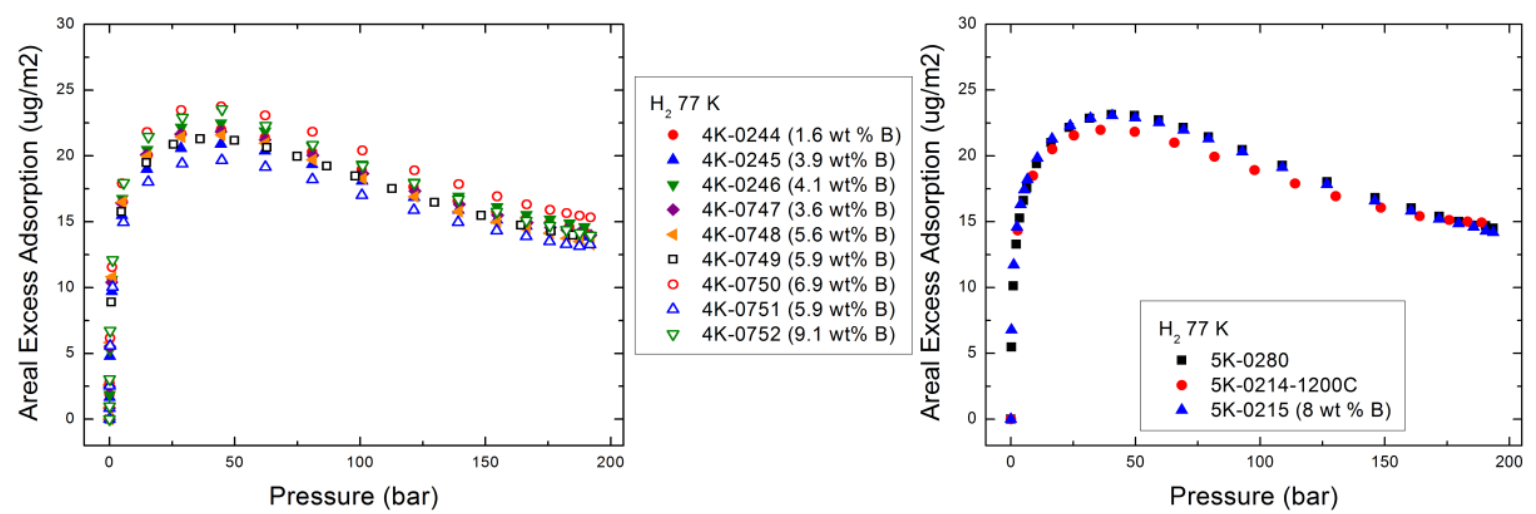

Figure 129. Areal excess adsorption isotherms for $4 \mathrm{~K}$ and 5K-type boron doped materials measured at $77 \mathrm{~K}$.

The maximum areal excess value for 4K-type samples has decreased compared to that of their precursor, 4K-0239. Very little change is observed in the maximum areal excess value for 5K-type samples. However, sample 5K-0280 has a large pore network, which may have graphitized slightly during high 
temperature treatment. This may be the reason that the areal excess of $5 \mathrm{~K}-0214$ was reduced slightly after deoxygenation. After doping, the areal excess adsorption increased back to approximately $23 \mu \mathrm{g} / \mathrm{m}^{2}$. Since there is little difference in the pore structures of $5 \mathrm{~K}-0214$ and $5 \mathrm{~K}-0215$, this increased areal excess adsorption suggests that the incorporation of boron has increased the binding of hydrogen to the sorbent surface.

\section{Carbonaceous Monolithic Sorbent Materials:}

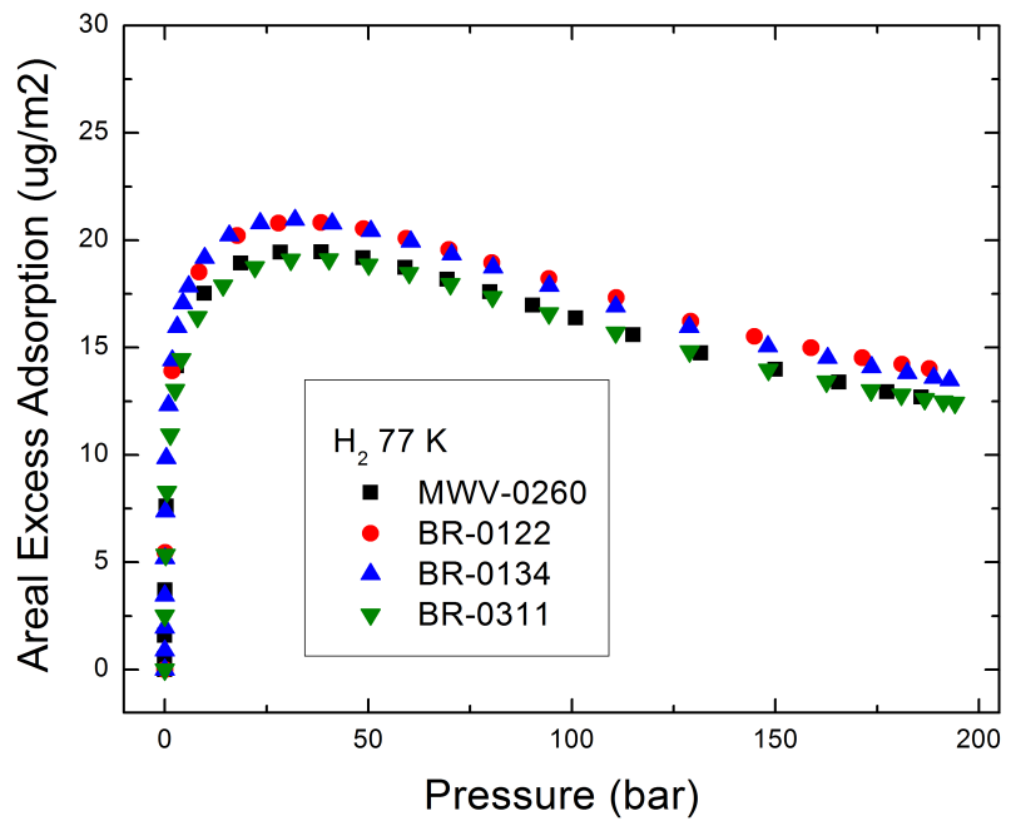

Figure 130. Areal excess adsorption isotherms for monolithic sorbent materials and their precursor measured at $77 \mathrm{~K}$.

With the a few exceptions, these boron doped materials performed similarly with a maximum areal excess adsorption around $21 \mu \mathrm{g} / \mathrm{m}^{2}$. After doping, the areal excess adsorption of samples $3 \mathrm{~K}-0201$, 4K0750, and $5 \mathrm{~K}-0215$ increase by $2-4 \mu \mathrm{g} / \mathrm{m}^{2}$ compared to their respective precursor materials. This loosely suggests that these materials should have similar isosteric heats of adsorption. Sample 3K-1037 exhibited a significantly lower areal excess adsorption at all pressures indicating that this sample has a lower isosteric heat of adsorption and that its differences in performance may be attributed to changes in its pore structure 
as well as interaction energies due to the presence of undesirable $\mathrm{B}-\mathrm{B}$ and $\mathrm{B}-\mathrm{O}$ bonded compounds that aggregated on its surface during the doping process.
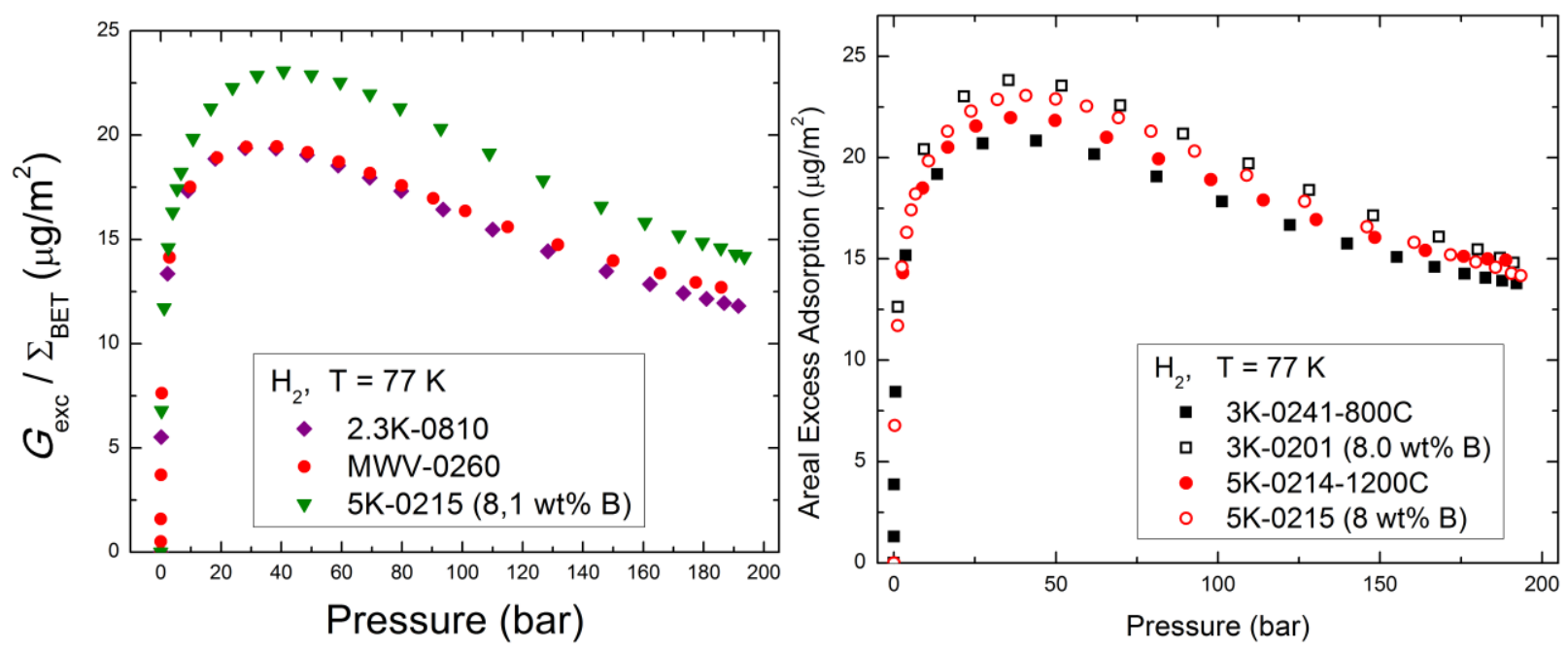

Figure 131. Areal excess adsorption isotherms for select precursor and boron doped samples.

A high areal excess adsorption should imply a high $\Delta \mathrm{H}$. If we can create samples with high $\Delta \mathrm{H}$ that also retain their high surface areas, then we can improve the performance of adsorbent materials. Almost all typical activated carbons have a maximum areal excess adsorption $18-22 \mathrm{ug} / \mathrm{m} 2$. Sample $5 \mathrm{~K}-0215 \mathrm{has}$ a maximum areal excess of $24 \mathrm{ug} / \mathrm{m} 2$, which indicates that its performance was improved excluding effects of a reduced surface area. This serves as a figure of merit that it is possible for the material performance to be improved through to surface functionalization (B-doping). 


\section{Parametric Case Studies for Improving Hydrogen Adsorption}

In this section, I compare the performance of briquette materials versus their precursor activated carbons; precursor carbons synthesized using varying $\mathrm{KOH}$ activation rations; deoxygenation and outgassing methods; optimal boron concentration of doped materials; the effect that boron incorporation has on the pore structure.

\subsection{Powdered Carbons and Briquettes}

Hydrogen adsorption isotherms for MWV-0260, BR-0134, and BR-0311 were analyzed in the low pressure regime to determine binding energies and isosteric heats of adsorption.

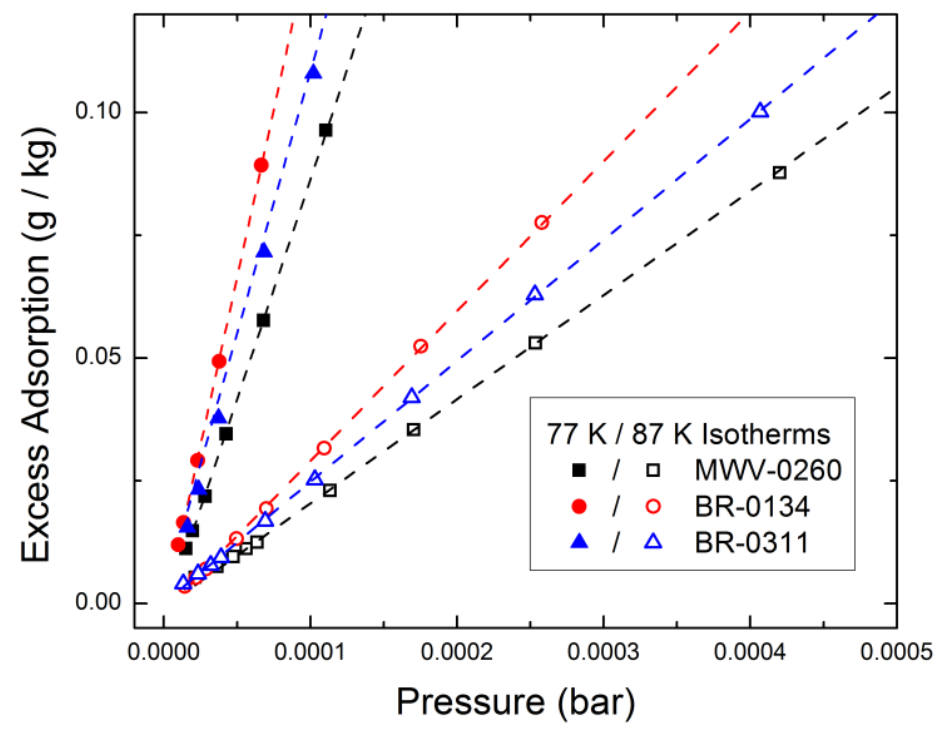

Figure 132. Low density linear regime of hydrogen excess adsorption isotherms at $77 \mathrm{~K}$ and $87 \mathrm{~K}$. A linear fit was applied to all low pressure isothermal data. Binding energies were calculated using the Langmuir model in its low pressure limit. Enthalpies of adsorption were calculated using the Clausius-Clapeyron relation.

Table 25: Slopes of the low pressure excess adsorption isotherms for briquettes and their precursors.

\begin{tabular}{|l|c|c|c|c|}
\hline Sample Name & Slope (77 K Isotherm) & Slope (87 K Isotherm) & $E_{\mathrm{B}}(\mathrm{kJ} / \mathrm{mol})$ & $\Delta H(\mathrm{~kJ} / \mathrm{mol})$ \\
\hline MWV-0260 & 894 & 212 & 7.70 & 8.05 \\
\hline BR-0134 & 1370 & 305 & 8.05 & 8.40 \\
\hline BR-0311 & 1066 & 246 & 7.85 & 8.19 \\
\hline
\end{tabular}


The hydrogen excess adsorption isotherms for these samples were also analyzed in the high density regime to determine the parameters of the adsorbed film.

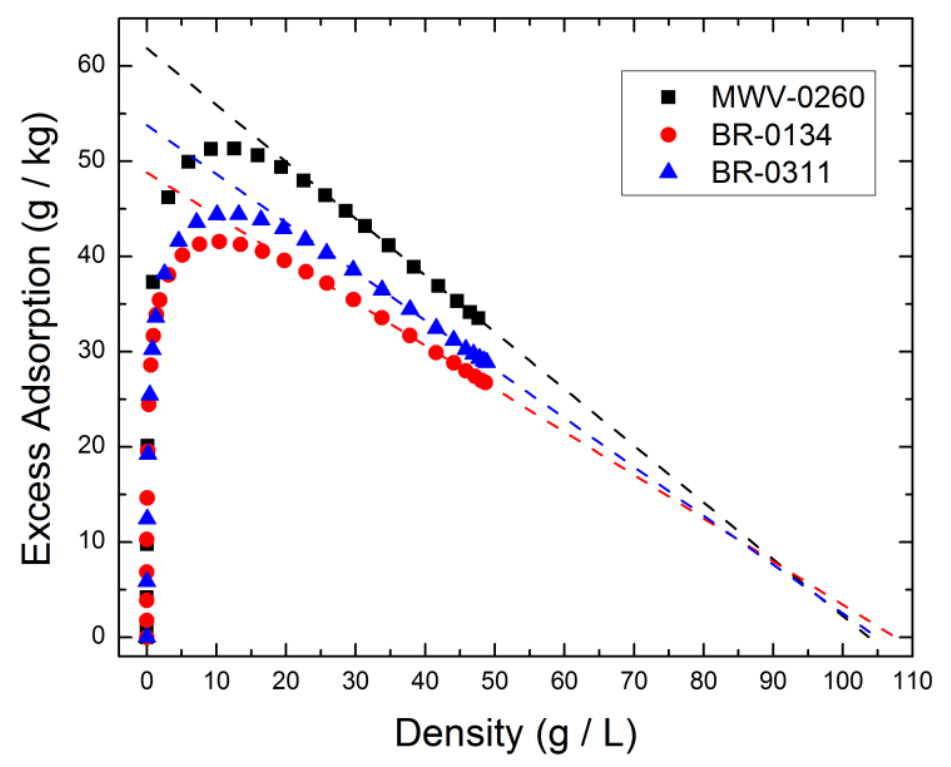

Figure 133. High density linear regimes of hydrogen excess adsorption isotherms at $77 \mathrm{~K}$. A linear fit was applied to all high pressure isothermal data. Adsorbed film volumes, densities, capacities, and thicknesses were calculated using the linear Eq (34).

Table 26: parameters of the adsorbed film obtained from a linear fit to the high gas density sorption data for monolithic sorbent materials and their precursor.

\begin{tabular}{|l|c|c|c|c|}
\hline $\begin{array}{c}\text { Sample } \\
\text { Name }\end{array}$ & $\begin{array}{c}V_{\text {film }} \\
(77 \mathrm{~K} \text { Isotherm })\end{array}$ & $\begin{array}{c}\rho_{\text {film }} \\
(77 \mathrm{~K} \text { Isotherm })\end{array}$ & $\begin{array}{c}m_{\text {film }} \\
(77 \mathrm{~K} \text { Isotherm })\end{array}$ & $\begin{array}{c}t_{\text {film }} \\
(77 \mathrm{~K} \text { Isotherm })\end{array}$ \\
\hline MWV-0260 & $0.596 \mathrm{~mL} / \mathrm{g}$ & $103 \mathrm{~g} / \mathrm{L}$ & $62 \mathrm{~g} / \mathrm{kg}$ & $3.18 \AA$ \\
\hline BR-0134 & $0.454 \mathrm{~mL} / \mathrm{g}$ & $108 \mathrm{~g} / \mathrm{L}$ & $49 \mathrm{~g} / \mathrm{kg}$ & $3.15 \AA$ \\
\hline BR-0311 & $0.513 \mathrm{~mL} / \mathrm{g}$ & $105 \mathrm{~g} / \mathrm{L}$ & $54 \mathrm{~g} / \mathrm{kg}$ & $3.17 \AA$ \\
\hline
\end{tabular}

Analyzing the linear regime of the $77 \mathrm{~K}$ isotherms of samples ranging in pore structure, surface areas, and surface chemistries results in saturated film densities of $105 \pm 5 \mathrm{~g} / \mathrm{L}$. Consequently, film thicknesses are all within the range of $3.1-3.2 \AA$, indicating that, on average, a monolayer of hydrogen is physisorbed on all carbonaceous materials at these high gas densities. It appears as though the saturated film density approaches a universal constant for all adsorbents at a given temperature. As long as there 
are no phase changes and the isothermal adsorption data exhibits a sufficient linear regime, one can obtain the parameters of the adsorbed film.

Due to the limitations on sorption instruments, we are unable to achieve similarly high bulk gas densities when performing measurements at higher temperatures. The flow controllers on the Hiden instrument limit our measurements to pressures of $\mathrm{P}<200$ bar. Therefore, the excess adsorption isotherm often does not exhibit a linear regime at temperatures exceeding $\mathrm{T}>110 \mathrm{~K}$. If we wish to obtain parameters of the adsorbed film, numeric methods and model-dependent methods must be employed.

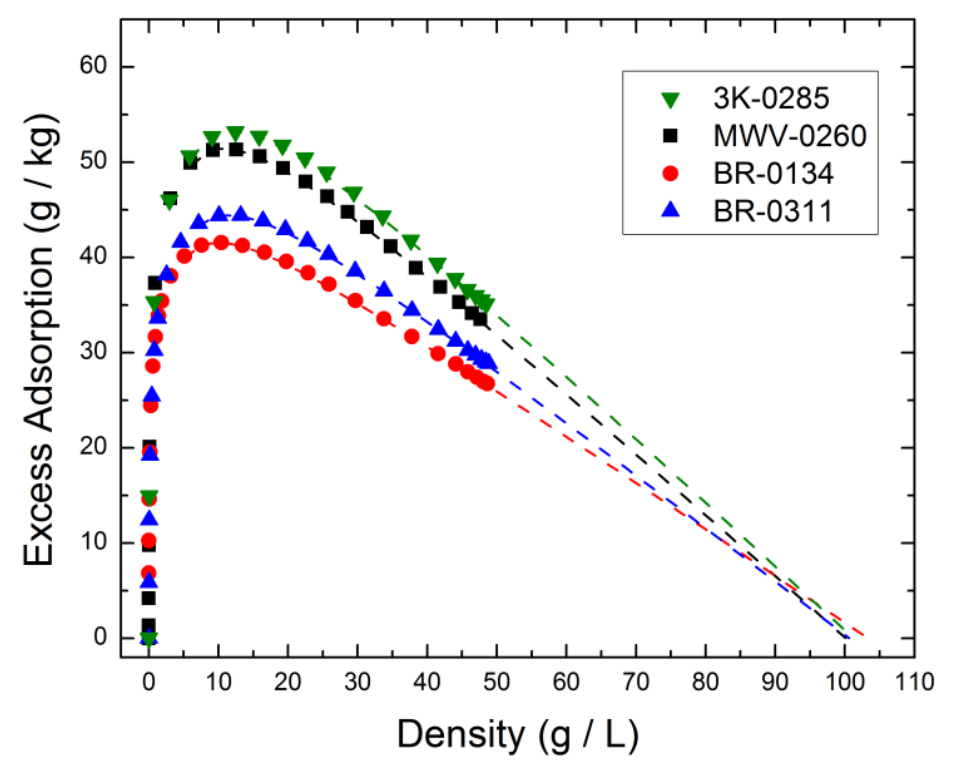

Figure 134. High gas density regimes of hydrogen excess adsorption isotherms at 77.35 K. An Ono-Kondo fit was applied to all high pressure isotherms for gas densities greater than $10 \mathrm{~g} / \mathrm{L}$.

Table 27: parameters of the adsorbed film obtained by applying the Ono-Kondo model to the high gas density sorption data for monolithic sorbent materials and their precursor.

\begin{tabular}{|c|c|c|c|c|c|}
\hline Sample & $\begin{array}{c}V_{\text {film }} \\
{[\mathrm{mL} / \mathrm{g}]}\end{array}$ & $\begin{array}{c}\rho_{\text {film }} \\
{[\mathrm{g} / \mathrm{L}]}\end{array}$ & $\begin{array}{c}m_{\text {film }} \\
{[\mathrm{g} / \mathrm{kg}]}\end{array}$ & $\begin{array}{c}V_{\text {pore }} \\
{[\mathrm{mL} / \mathrm{g}]}\end{array}$ & $\begin{array}{c}V_{\text {film }}, / V_{\text {pore }} \\
{[\%]}\end{array}$ \\
\hline MWV-0260 & 0.653 & 100.2 & 65.4 & 1.543 & 42.3 \\
\hline BR-0134 & 0.498 & 103.3 & 51.4 & 1.148 & 43.4 \\
\hline BR-0311 & 0.571 & 100.7 & 57.4 & 1.451 & 39.4 \\
\hline
\end{tabular}


The adsorbed film reaches an average density of $101 \pm 3 \mathrm{~g} / \mathrm{L}$ for all samples at $77 \mathrm{~K}$. The adsorbed film occupies less than $44 \%$ of the total pore volume at this temperature. There are slight differences between film parameters obtained from the linear model compared to those obtained using the OnoKondo Model. On average, adsorbed film volumes obtained from the Ono-Kondo Model are 10\% higher than those obtained from the linear model. On average, adsorbed film densities obtained from the OnoKondo Model are 4\% lower than those obtained from the linear model. On average, maximum capacity of the adsorbed film obtained from the Ono-Kondo Model are 5\% higher than those obtained from the linear model. Either model seems to provide a reasonable estimate of the saturated film density. However, the estimates for film volumes and maximum capacities vary significantly depending on the choice of model. When applying the Ono-Kondo adsorption model, volumes, densities, and capacities of the adsorbed film vary by less than $5 \%$ when using different numbers of experimental data points in the fit.

\subsection{Powdered Carbons and KOH Activation Ratios}

The effect of $\mathrm{KOH}: \mathrm{C}$ activation ratio was studied by analyzing excess adsorption isotherms at $77 \mathrm{~K}$, $273 \mathrm{~K}$, and $296 \mathrm{~K}$.
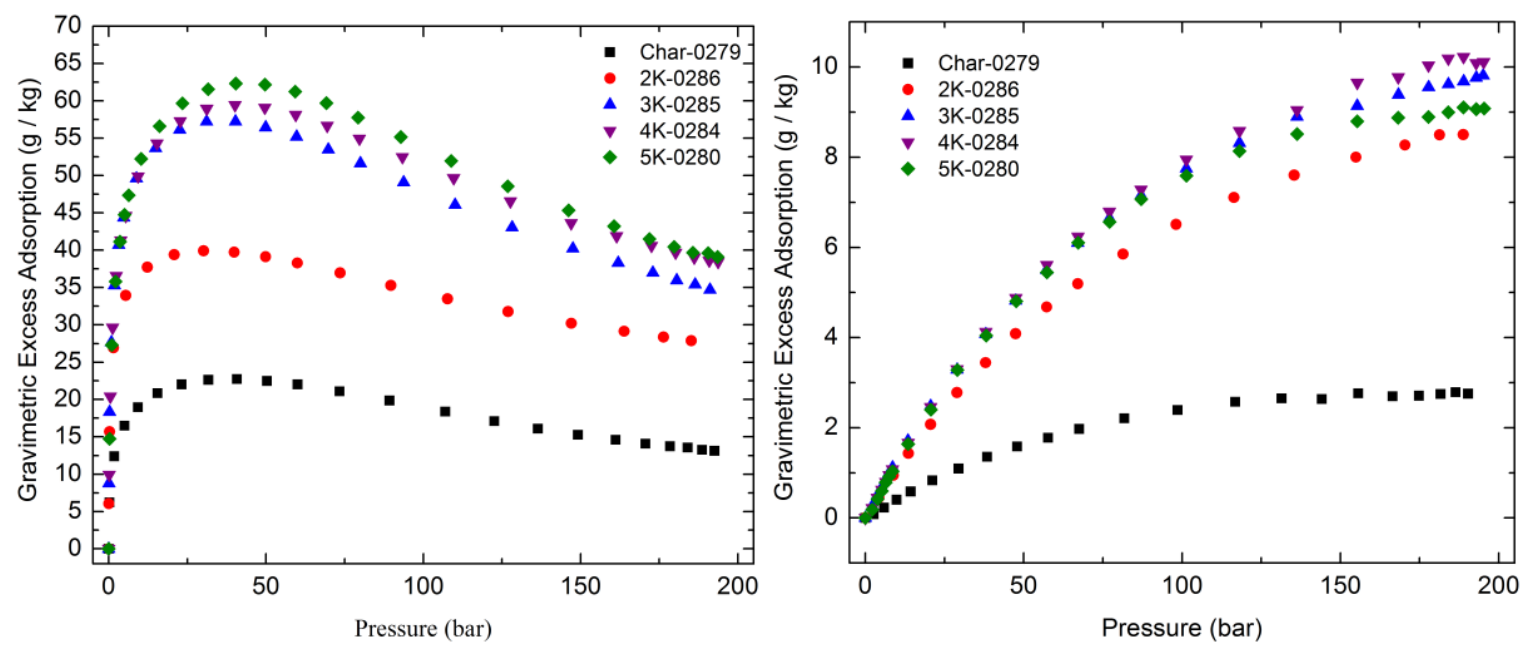

Figure 135. Gravimetric excess adsorption isotherms measured at $77 \mathrm{~K}$ and $296 \mathrm{~K}$ for precursor carbons used for boron doping. After converting to absolute adsorption and fitting with appropriate models, the isosteric heat of adsorption was calculated by the Clausius-Clapeyron relation. 

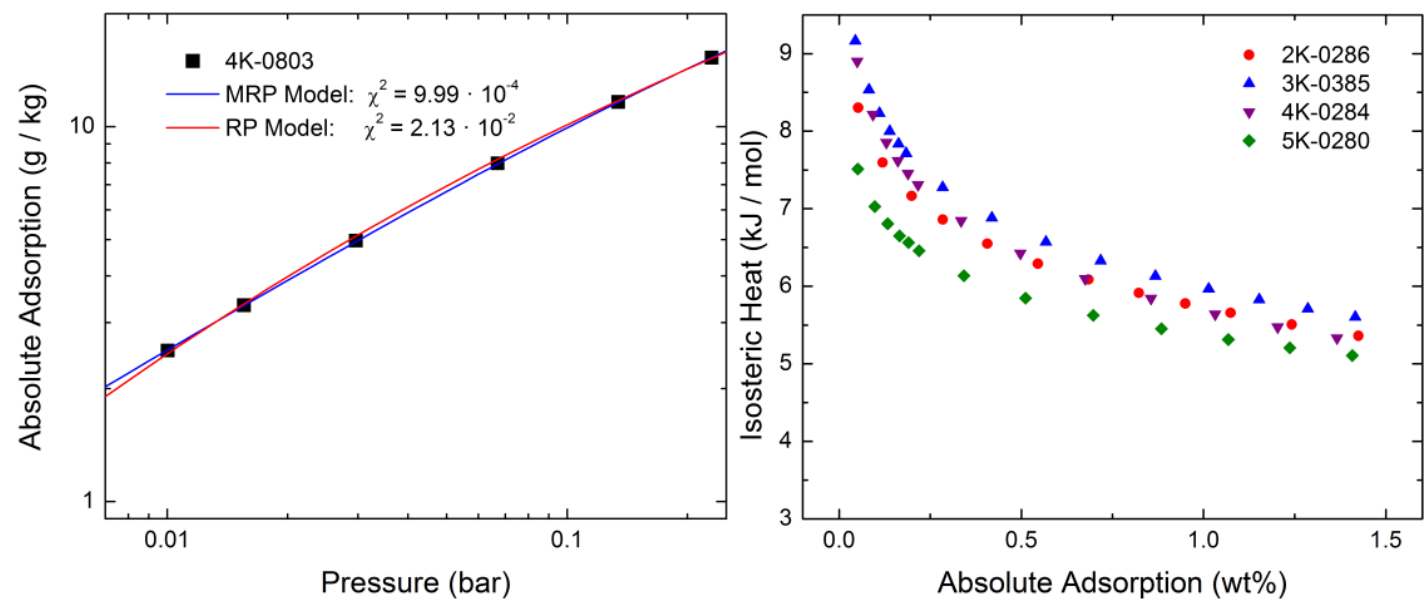

Figure 136. Absolute adsorption and isosteric heats for precursor carbons used for boron doping. Left: The Modified Redlich-Peterson Model tends to fit slightly more accurately than the Redlich-Peterson Model over the entire range of the adsorption isotherms taken at various temperatures. Right: resulting isosteric heats as a function of coverage.

A table of fitting parameters and chi-squared values have been included below as a figure of merit to demonstrate the accuracy of the model.

Table 28: Fitting parameters for the Modified Redlich-Peterson Model applied to undoped precursor activated carbons.

\begin{tabular}{lllll}
\hline Sample & $\mathrm{a}$ & $\mathrm{b}$ & $\mathrm{C}$ & $\chi^{2}$ \\
\hline Char-0279 $(296 \mathrm{~K})$ & 31.2055 & 0.00221 & 0.04404 & $1.17 \cdot 10^{-3}$ \\
Char-0279 $(273 \mathrm{~K})$ & 33.9829 & 0.00245 & 0.02617 & $7.38 \cdot 10^{-4}$ \\
Char-0279 $(77 \mathrm{~K})$ & 52.8062 & 0.03626 & 0.57059 & $1.26 \cdot 10^{-2}$ \\
2K-0286 $(296 \mathrm{~K})$ & 67.9242 & 0.00213 & 0.05522 & $1.69 \cdot 10^{-3}$ \\
2K-0286 $(273 \mathrm{~K})$ & 70.1622 & 0.00239 & 0.07374 & $3.20 \cdot 10^{-3}$ \\
2K-0286 $(77 \mathrm{~K})$ & 59.1703 & 0.43877 & 0.49001 & $8.21 \cdot 10^{-1}$ \\
3K-0285 $(296 \mathrm{~K})$ & 76.6333 & 0.00251 & 0.03606 & $1.10 \cdot 10^{-3}$ \\
3K-0285 $(273 \mathrm{~K})$ & 88.0599 & 0.00251 & 0.05804 & $3.28 \cdot 10^{-3}$ \\
3K-0285 $(77 \mathrm{~K})$ & 104.268 & 0.12472 & 0.53710 & $7.80 \cdot 10^{-1}$ \\
4K-0284 $(296 \mathrm{~K})$ & 86.1239 & 0.00221 & 0.03645 & $3.77 \cdot 10^{-3}$ \\
4K-0284 $(273 \mathrm{~K})$ & 87.3763 & 0.00263 & 0.03832 & $414.10^{-3}$ \\
4K-0284 $(77 \mathrm{~K})$ & 122.365 & 0.06088 & 0.54545 & $8.72 \cdot 10^{-1}$ \\
5K-0280 $(296 \mathrm{~K})$ & 66.9899 & 0.00318 & 0.00493 & $1.85 \cdot 10^{-3}$ \\
5K-0280 $(273 \mathrm{~K})$ & 81.5049 & 0.00305 & 0.02435 & $5.35 \cdot 10^{-3}$ \\
5K-0280 $(77 \mathrm{~K})$ & 127.895 & 0.05807 & 0.53735 & $6.31 \cdot 10^{-1}$ \\
\hline
\end{tabular}




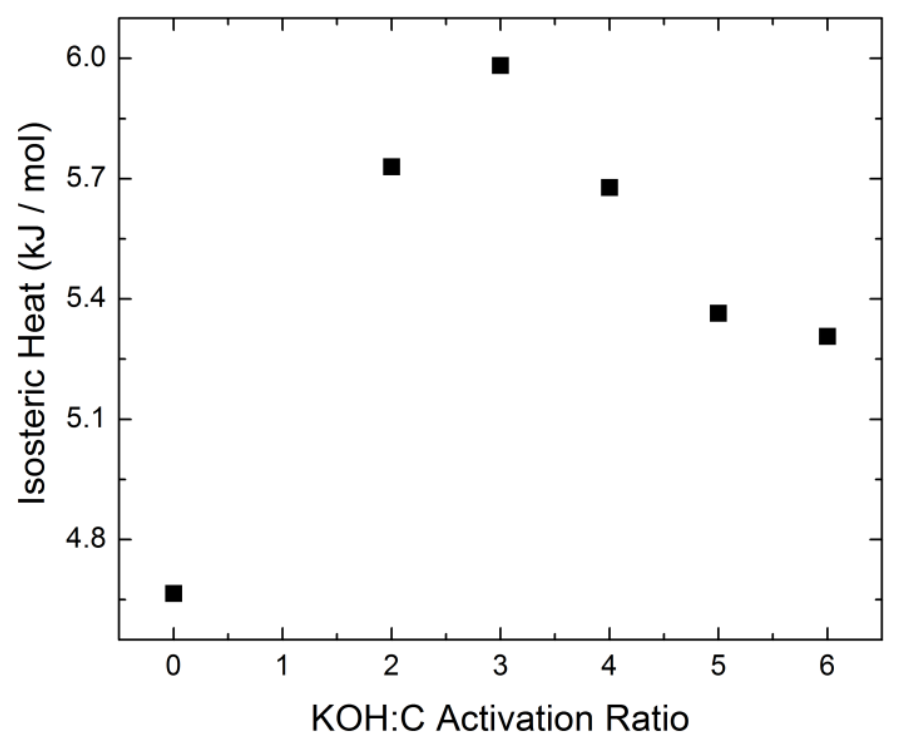

Figure 137. Isosteric heat of adsorption versus $\mathrm{KOH}: \mathrm{C}$ activation ratio.

Isosteric heats of adsorption were evaluated at a coverage of $1 \mathrm{wt} \%$. Changes in the isosteric heat are observed with increasing $\mathrm{KOH}: \mathrm{C}$ activation ratios. For physisorption, gas is adsorbed as a high density fluid by strong Van der Waals forces. GCMC simulations of hydrogen adsorbed in slit shaped pores support the conjecture that Van der Waals potentials overlap for pores with widths $w>1 \mathrm{~nm}$, which we will call sub nanometer pores. The binding energy is enhanced by the overlapping potentials from opposing sides of the pore and subsequently, the adsorption density is increased. Therefore, an increase in isosteric heat of adsorption should be observed for samples having larger fraction of sub nanometer pores. This nanopore volume is maximized for carbon samples that have been activated with $2-3 \mathrm{KOH}: \mathrm{C}$ mass ratio.

\section{Volumetric Storage}

At cryogenic temperatures, the volumetric storage capacities of these materials increases quickly with pressure, approaching that of compressed hydrogen at pressures exceeding 190bar. At ambient temperatures, these materials exhibit small deviations in volumetric storage capacity from that of compressed hydrogen. No significant variations in volumetric storage capacities of these materials are observed at high pressures. Within a given subclass of adsorbent materials having similar skeletal densities, the volumetric storage capacity should correlate with isosteric heat. These effects are most prevalent when the adsorbed storage capacity has its greatest difference from the storage capacity of compressed hydrogen. 


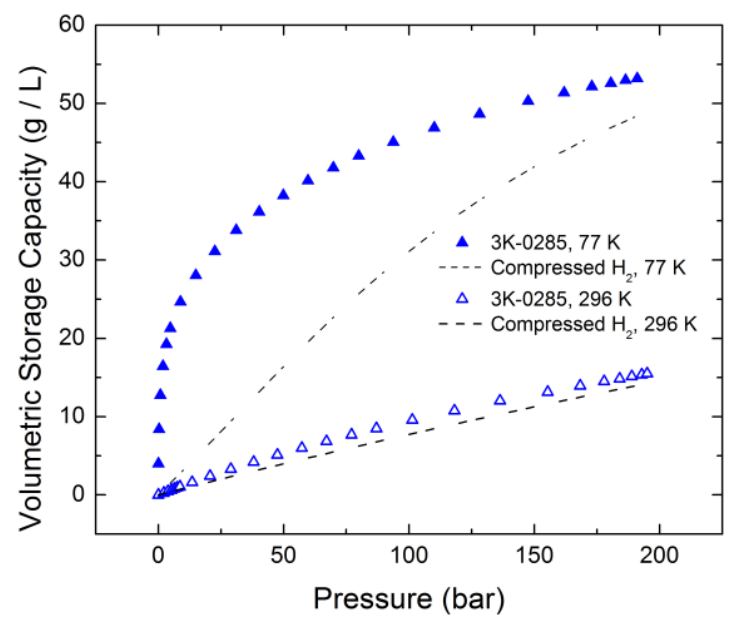

Figure 138. Volumetrc storage capacities of sample 3K-0285 compared to compressed hydrogen.

For most activated carbon materials, the greatest difference between the envelope storage capacity and the bulk gas density occurs in the pressure range of 10-60bar at $77 \mathrm{~K}$ and 50-150bar at $296 \mathrm{~K}$. In figure 139 , such correlations were presented using volumetric storage data measured at $25 \mathrm{bar}$ at $77 \mathrm{~K}$ and $100 \mathrm{bar}$ at $296 \mathrm{~K}$.

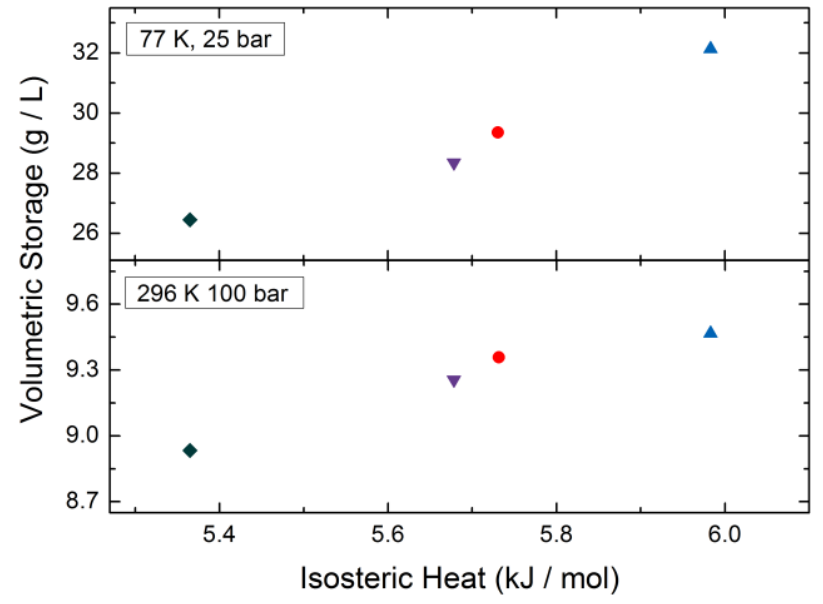

Figure 139. Volumetric storage capacity versus isosteric heat of adsorption.

An increase in volumetric storage capacity was observed with increasing isosteric heat of adsorption. This correlation provides additional evidence that overlapping Van der Waals potentials densify the gas more readily at lower pressures. 


\subsection{Deoxygenation Methods}

It is important to remove as much surface oxygen as possible from precursor carbons prior to boron doping. Three methods were employed in an effort to accomplish this task. Samples were outgassed under vacuum at high temperatures $\left(\mathrm{T}>600{ }^{\circ} \mathrm{C}\right)$, underwent microwave treatment, or chemically etched to remove surface oxygen. X-Ray Photoelectron Spectroscopy (XPS) was used to characterize the samples for oxygen content.

\section{How does Outgassing temperature affect boron incorporation \& sorption?}
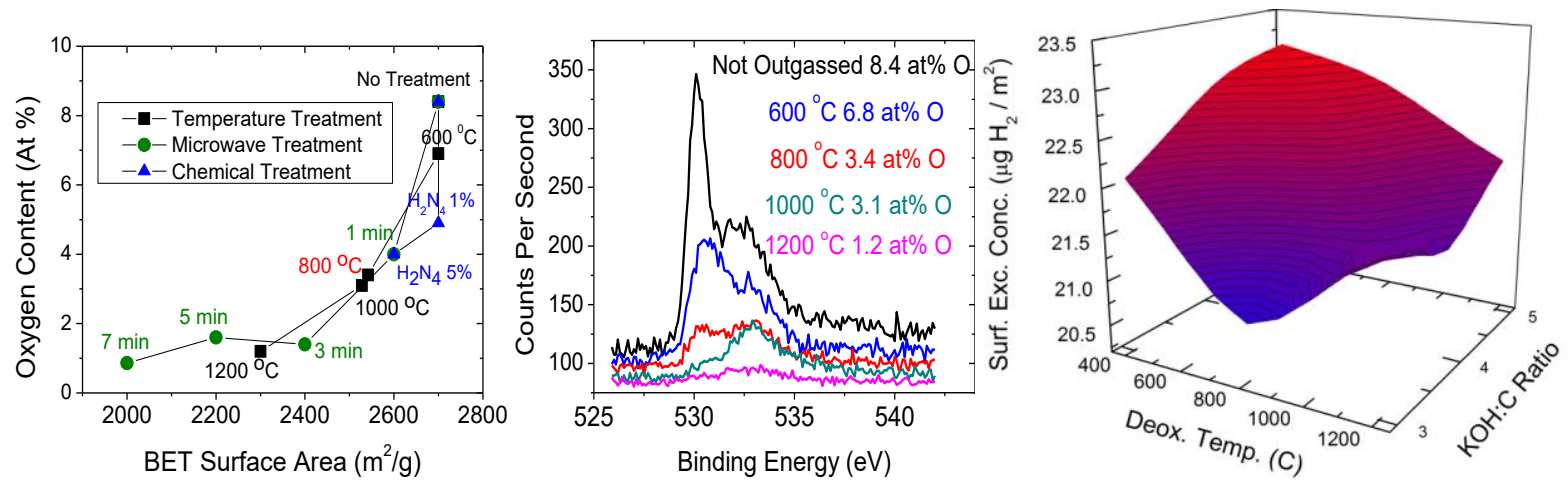

Figure 140. Performance of various activated carbon materials after deoxygenation. Left: Oxygen content versus specific surface area. Center: Outgassing temperature and XPS oxygen spectra. Right: Areal excess adsorption as a function of deoxygenation temperature and $\mathrm{KOH}: \mathrm{C}$ activation ratio.

High $\mathrm{KOH}: \mathrm{C}$ ratios create high binging energy sites. However, the activation process leaves 8-9\% oxygen on the surface of the precursor carbon. High temperature outgassing removes oxygen, but destroys high binding energy sites by partially graphitizing the sample. Lower deoxygenation temperatures maintain high binding energy sites. Deoxygenation temperatures of 800C was sufficient to decrease oxygen levels without a significant decrease in surface area.

\subsection{Optimal Boron Concentrations}

Binding energies were evaluated at zero coverage using Henry's Law analysis and isosteric heats were evaluated using the Clausius-Clapeyron relation at $1 \mathrm{wt} \%$ coverage. Boron contents were determined using PGNAA measurements taken at the University of Missouri Research Reactor. 

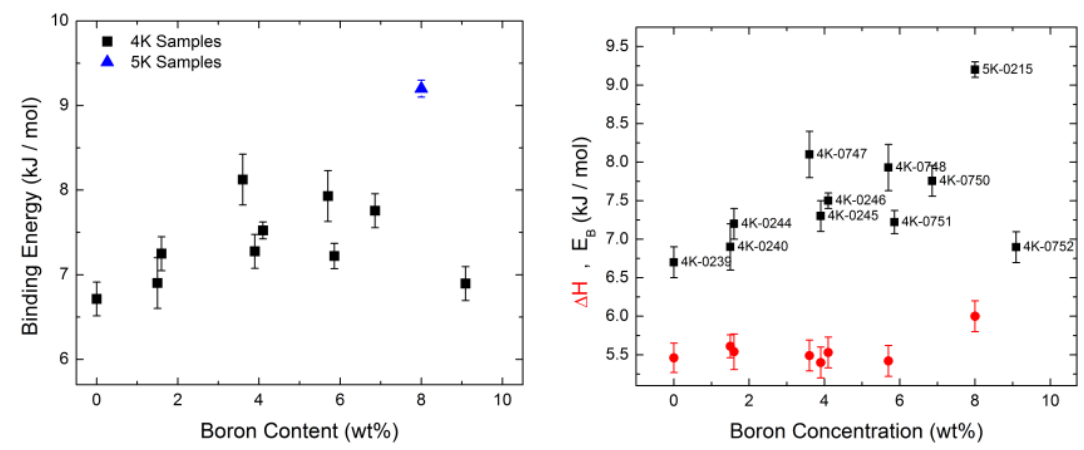

Figure 141. Binding energy versus boron concentration for various doped samples. Left: Binding energies from Henry's Law analysis of $4 \mathrm{~K}$ and $5 \mathrm{~K}$ samples. Right: Binding energy near zero coverage and isosteric heat evaluated at $1 \mathrm{wt} \%$ coverage.

For the $4 \mathrm{~K}$ samples, low coverage isosteric heat increases with boron concentration in the range of 0-4 wt\% until reaching a maximum. A similar analysis was performed for 5K-0215 (precursor outgassed at $1200 \mathrm{C}$, doped at $8.0 \mathrm{wt} \%$ Boron).

\subsection{Structural Changes of Boron Doped Powders}

Analysis of nitrogen isotherms measured on boron doped, 4K activated carbons.
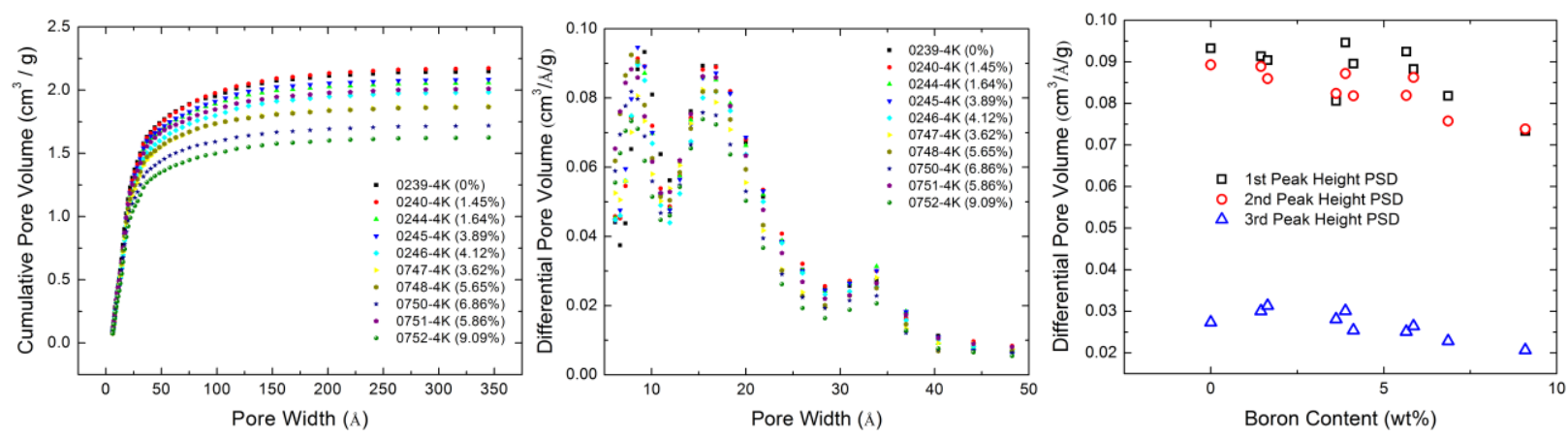

Figure 142. Pore size information for $4 \mathrm{~K}$ samples doped with varying boron concentrations. Left: Cumulative pore volume as a function of pore widths. Center: Differential pore volumes as a function of pore width. Right: Differential pore volumes as a function of boron concentrations.

Pore size information for these boron doped $4 \mathrm{~K}$ samples was calculated using QSDFT. The cumulative pore volume tends to decrease with increasing boron concentrations. There are three modes in the pore size distributions. In general, the first and second peak in the pore size distributions are most affected by increased boron contents, decreasing by $0.0017 \mathrm{~cm}^{3} / \AA ̊ g$ per wt $\%$ boron. The third peak in the 
PSD decreases negligibly with boron content in range of the 1-10 wt $\%$ boron. This indicates that the borane reactants are preferentially adsorbed into small pores compared to pores that have widths greater than $3 \mathrm{~nm}$.
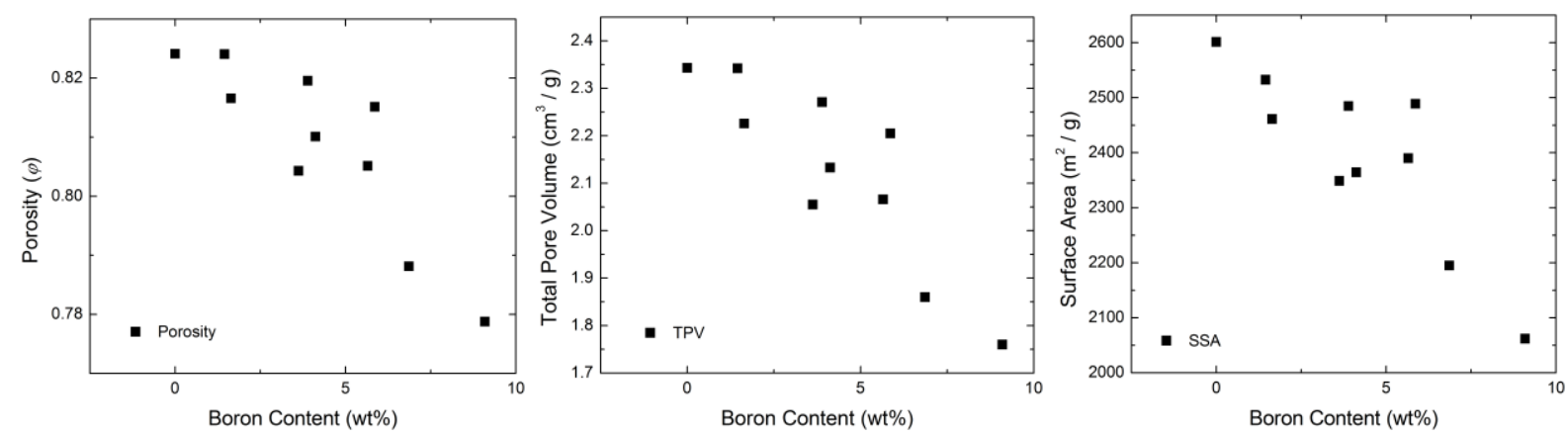

Figure 143. Porosity, total pore volume, and specific surface areas as a function of boron concentrations. Left: Porosity as a function of boron concentration. Center: Total pore volume as a function of boron concentration. Right: Specific surface area as a function of boron concentration.

Porosity, total pore volume, and specific surface area all tend to decrease with increased boron contents.

\subsection{Material Performance and $\mathrm{B}-\mathrm{C} \mathrm{sp}^{2}$ Bonding}

XPS results indicate that boron has been successfully doped into the carbon matrix and that $\mathrm{sp}^{2} \mathrm{~B}-\mathrm{C}$ comprises of up to $1.7 \mathrm{wt} \%$ boron to sample mass. If incorporating boron into the samples in the form of $\mathrm{sp}^{2} \mathrm{~B}-\mathrm{C}$ bonds does, in fact, increase the binding energy with hydrogen then we should be able to observe this trend in the isosteric heat data.
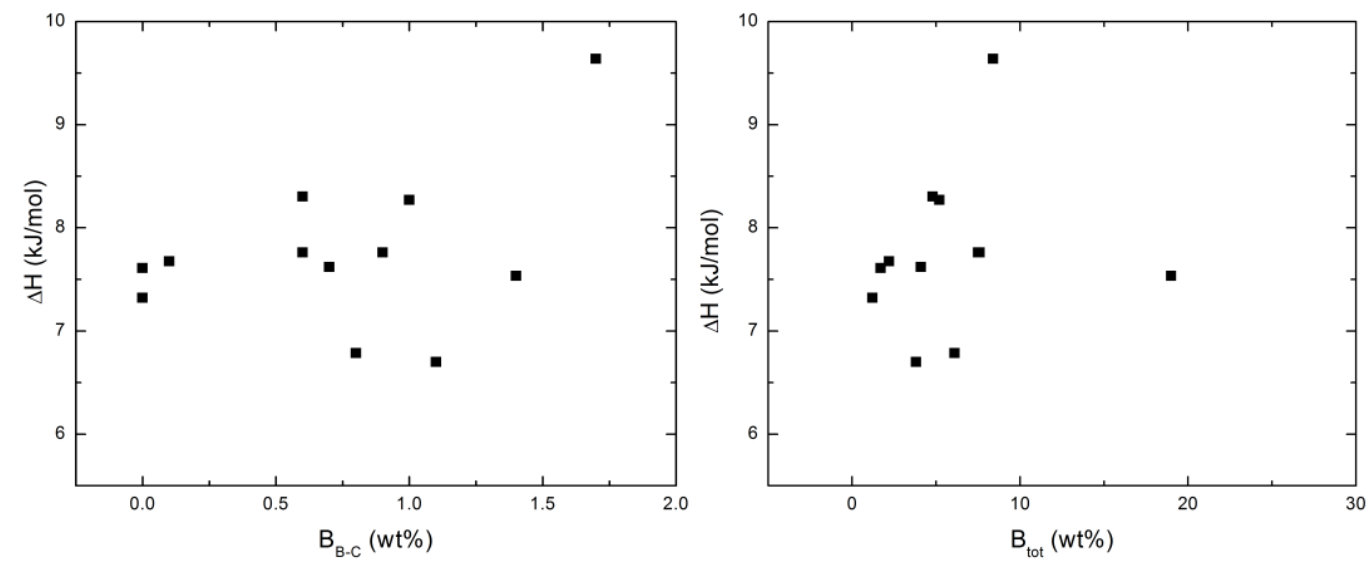

Figure 144. Isosteric heat of adsorption near zero coverage as a function of boron contents for all available samples. Left: Isosteric heat as a function of $\mathrm{sp}^{2} \mathrm{~B}-\mathrm{C}$ bonds. Right: Isosteric heat as a function of total boron content. 
However, no such general trend is observed in this set of experimental data. XPS data only exists for a sparse set of boron doped samples produced at MU. These samples were produced using various doping conditions for argon flow, temperatures, and pressures. So this lack of any correlation between $\mathrm{sp}^{2}$ B-C bonds and isosteric heat could be due to a number of parameters that were not well controlled across these experiments. Sample 5K-0215 did exhibit both a high isosteric heat with the highest $\mathrm{sp}^{2} \mathrm{~B}-\mathrm{C}$ ratio. The 4K-type doped materials were all synthesized using the same process and only varying the boron content. Comparing across those four samples might provide better insight regarding how $\mathrm{sp}^{2} \mathrm{~B}-\mathrm{C}$ bonds affect the isosteric heats of adsorption.
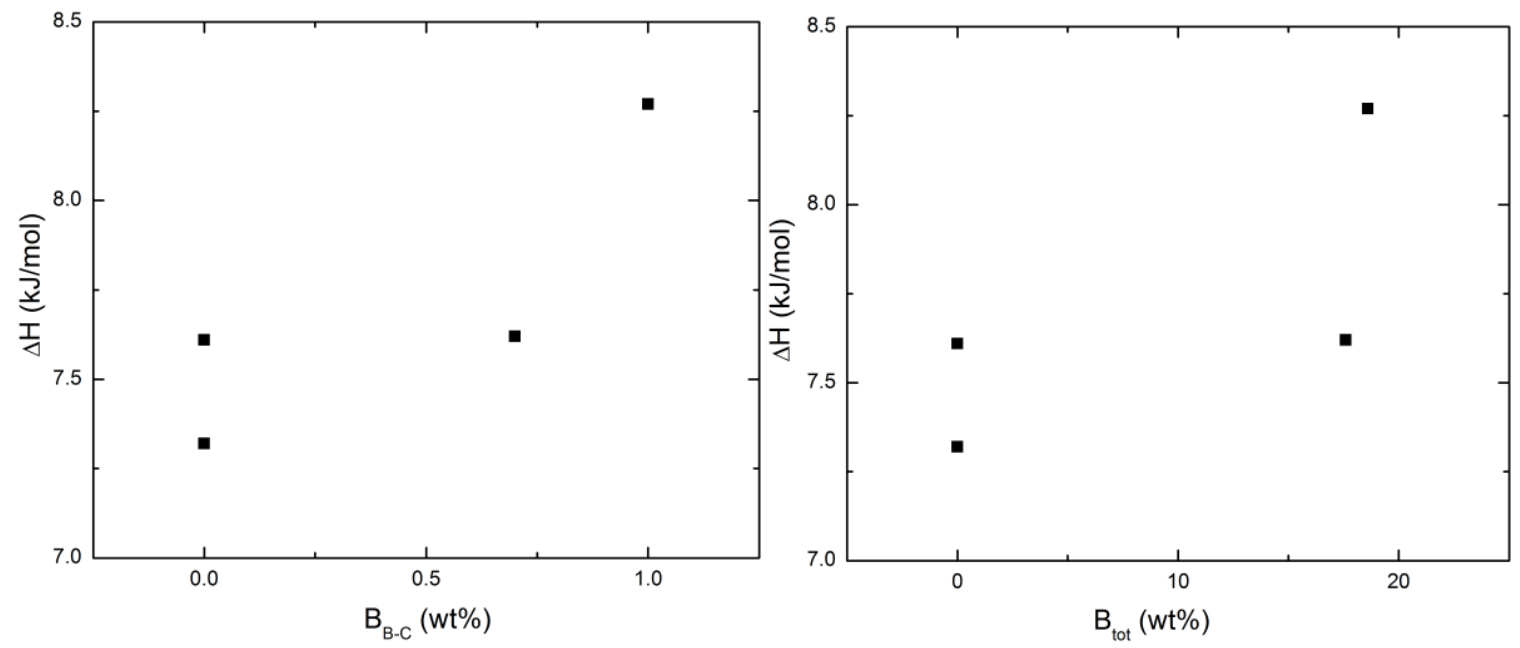

Figure 145. Isosteric heat of adsorption near zero coverage as a function of boron contents for 4K-type doped materials. Left: Isosteric heat as a function of $\mathrm{sp}^{2} \mathrm{~B}-\mathrm{C}$ bonds. Right: Isosteric heat as a function of total boron content.

When all synthesis parameters are well controlled and only the boron content is varied during the doping process, an increasing trend emerges between $\mathrm{sp}^{2} \mathrm{~B}-\mathrm{C}$ bonds and isosteric heats of adsorption. However, this is only a very loose correlation over a small number of samples. In order to establish that the existence of $\mathrm{sp}^{2} \mathrm{~B}-\mathrm{C}$ bonds facilitates increased binding to hydrogen, more extensive studies will need to be performed over a broader range of samples where the synthesis conditions are well-controlled. 


\section{Material Performance for Methane Adsorption}

It is also interesting to consider how the parameters of the adsorbed film might vary with temperature. When considering an ideal gas, one expects the gas density to decrease with increasing temperature. However, the saturated adsorbed film acts quite differently with increasing temperature.

\subsection{Properties of the Adsorbed Methane Film}
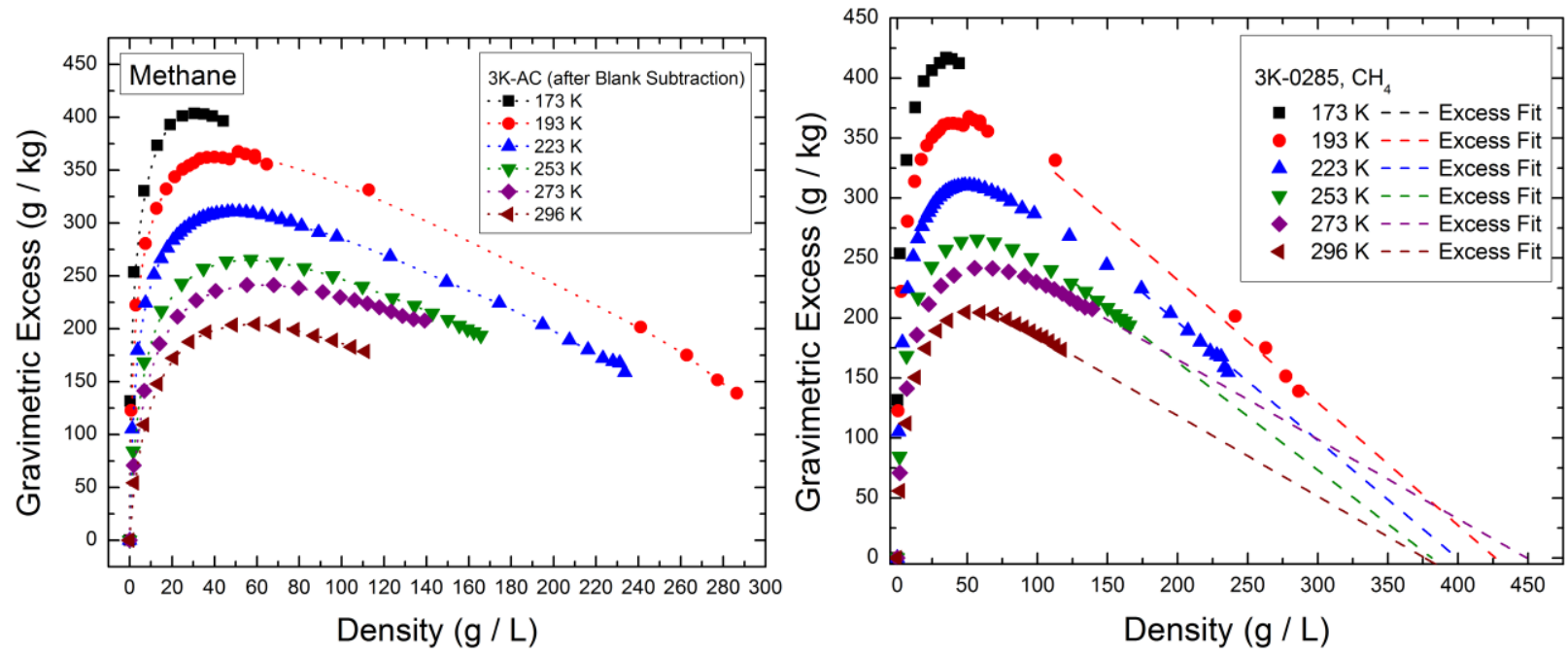

Figure 146. Methane gravimetric excess adsorption versus bulk gas density for sample 3K-0285 at various temperatures. Left: Excess adsorption versus gas density. Right: Excess adsorption versus gas density with Ono-Kondo model applied to each isotherm extrapolated to the horizontal axis.
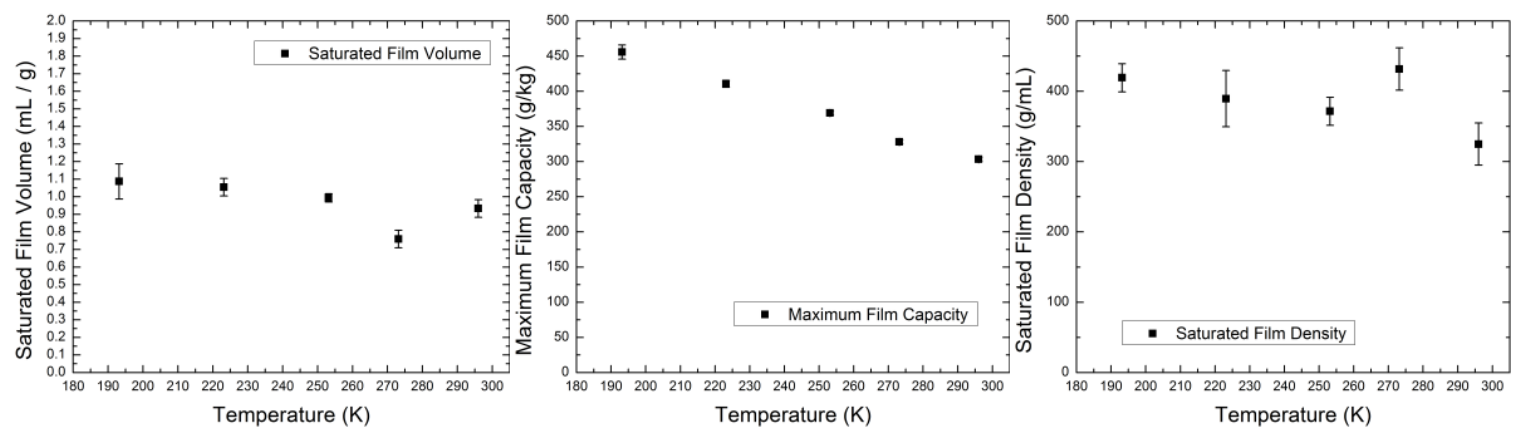

Figure 147. Parameters of the adsorbed methane film for sample $3 \mathrm{~K}-0285$ at various temperatures. Left: Saturated film volume versus temperature. Middle: Maximum film capacity versus temperature. Right: Saturated film density versus temperature.

The maximum capacity of the adsorbed film decreases with increasing temperature as predicted by the Ono-Kondo model. The adsorbed film volume exhibits a decreasing trend with increasing temperatures over this span of isothermal measurements, ranging from $1.1-0.8 \mathrm{~mL} / \mathrm{g}$. However, the saturated film 
density remains constant at all temperatures from $173-296 \mathrm{~K}$ within uncertainties. The saturated film density is approximately $400 \pm 50 \mathrm{~g} / \mathrm{L}$ over this temperature range, which is close to the liquid density of methane when near its normal boiling point at $112 \mathrm{~K}$.
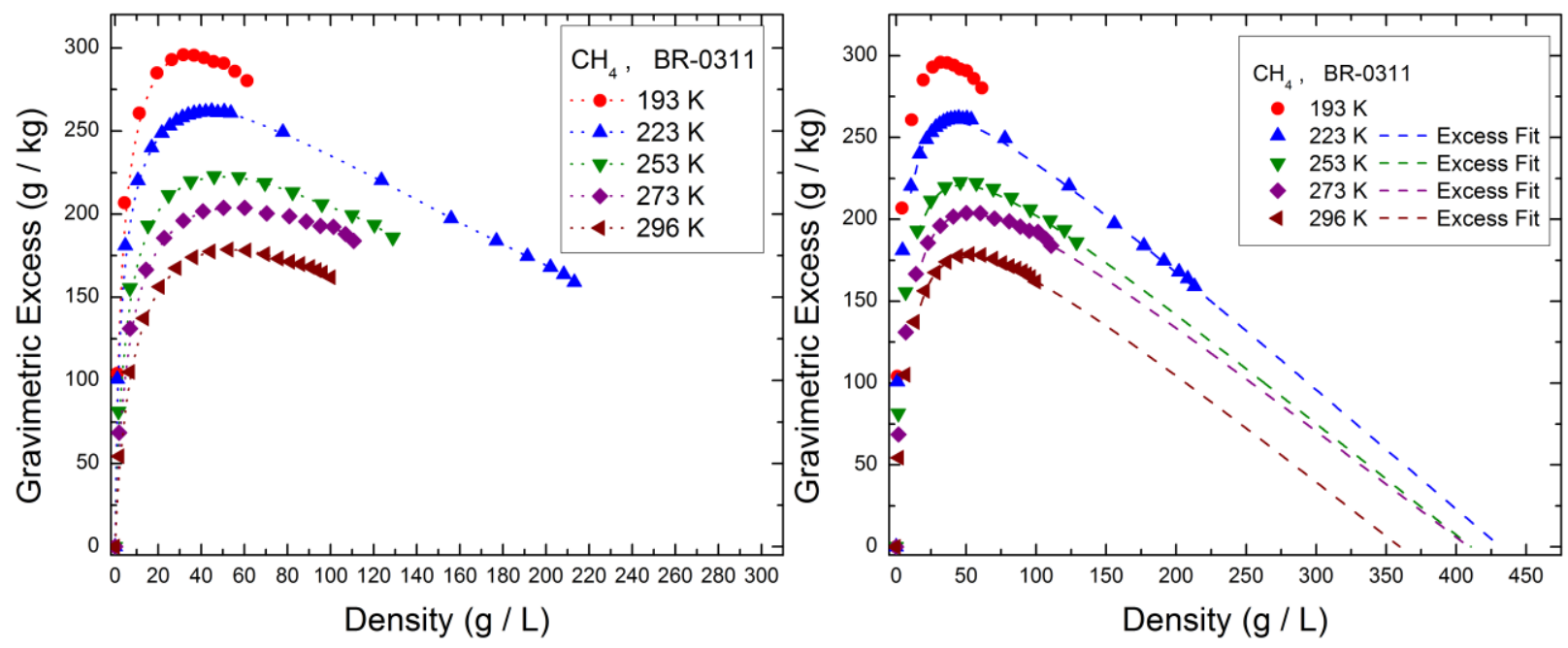

Figure 148. Methane gravimetric excess adsorption versus bulk gas density for sample BR-0311 at various temperatures. Left: Excess adsorption versus gas density. Right: Excess adsorption versus gas density with Ono-Kondo model applied to each isotherm extrapolated to the horizontal axis. The saturated film density reaches $400 \pm 50 \mathrm{~g} / \mathrm{L}$ over this temperature range. Insufficient data exists for the $193 \mathrm{~K}$ measurement. Therefore, no attempt was made to determine the parameters of the adsorbed film at this temperature.
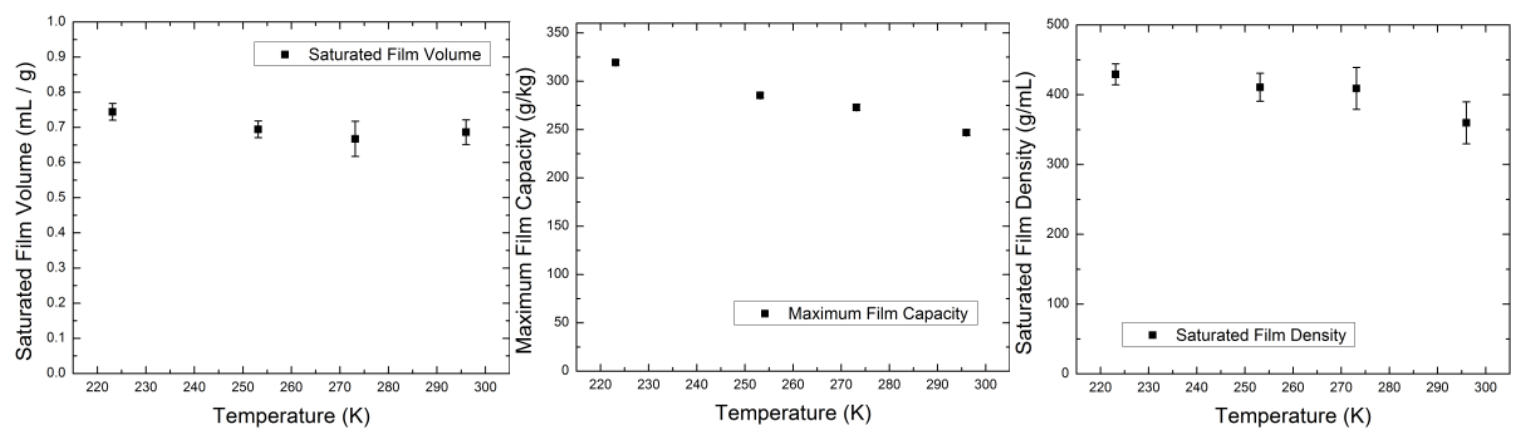

Figure 149. Parameters of the adsorbed methane film for sample BR-0311 at various temperatures. Left: Saturated film volume versus temperature. Middle: Maximum film capacity versus temperature. Right: Saturated film density versus temperature. Saturated film densities between $350-450 \mathrm{~g} / \mathrm{L}$ correspond to film thicknesses between $0.39-0.42 \mathrm{~nm}$.

For sample BR-0311, the maximum film capacity tends to decrease with increasing temperature as predicted by the Ono-Kondo model. However, any trends in the experimental saturated film volumes and densities are unclear due to the high uncertainty associated with the saturated film density. Within 
uncertainties, it appears that the saturated film volume is constant over this range of temperatures. If the volume remains constant and the maximum capacity decreases, then the saturated film density must also decrease with increasing temperature.

\subsection{Isosteric Heat of Methane Adsorption as a Function of Temperature and Coverage}

Two samples were measured for methane excess adsorption over a temperature range of 173-296 K. After determining the saturated adsorbed film volume, it was possible to convert excess adsorption into absolute adsorption isotherms and apply the Clausius-Clapeyron relation. This yielded isosteric heats of adsorption as a function of coverage as well as temperature.
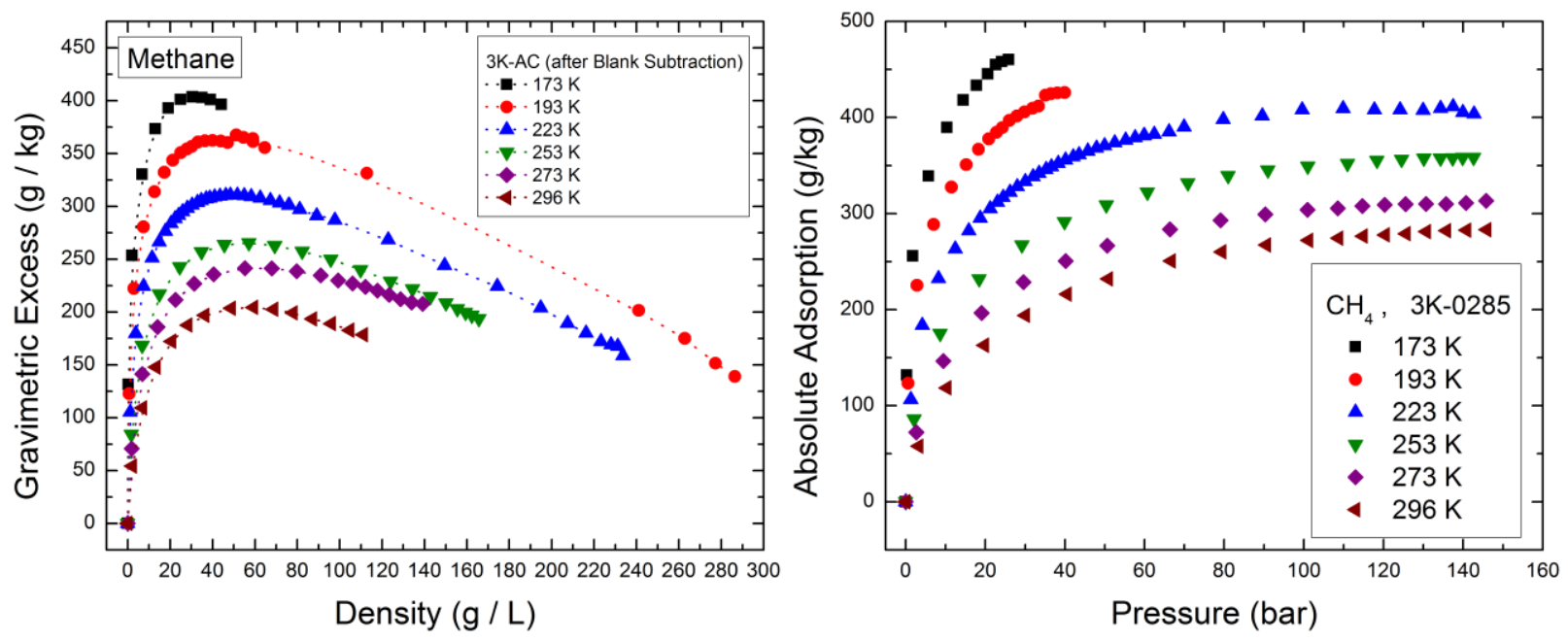

Figure 150. Methane excess and absolute adsorption isotherms measured between 173-296 K for sample 3K-0285. Left: Gravimetric excess adsorption isotherms measured between 173-296 K. Right: Absolute adsorption isotherms measured between 173-296 K. No experimental data exists below a coverage of 50 $\mathrm{g} / \mathrm{kg}$. Therefore, any calculated isosteric heat values for coverages below that value will entirely depend on the choice of model applied to the isothermal adsorption data. 

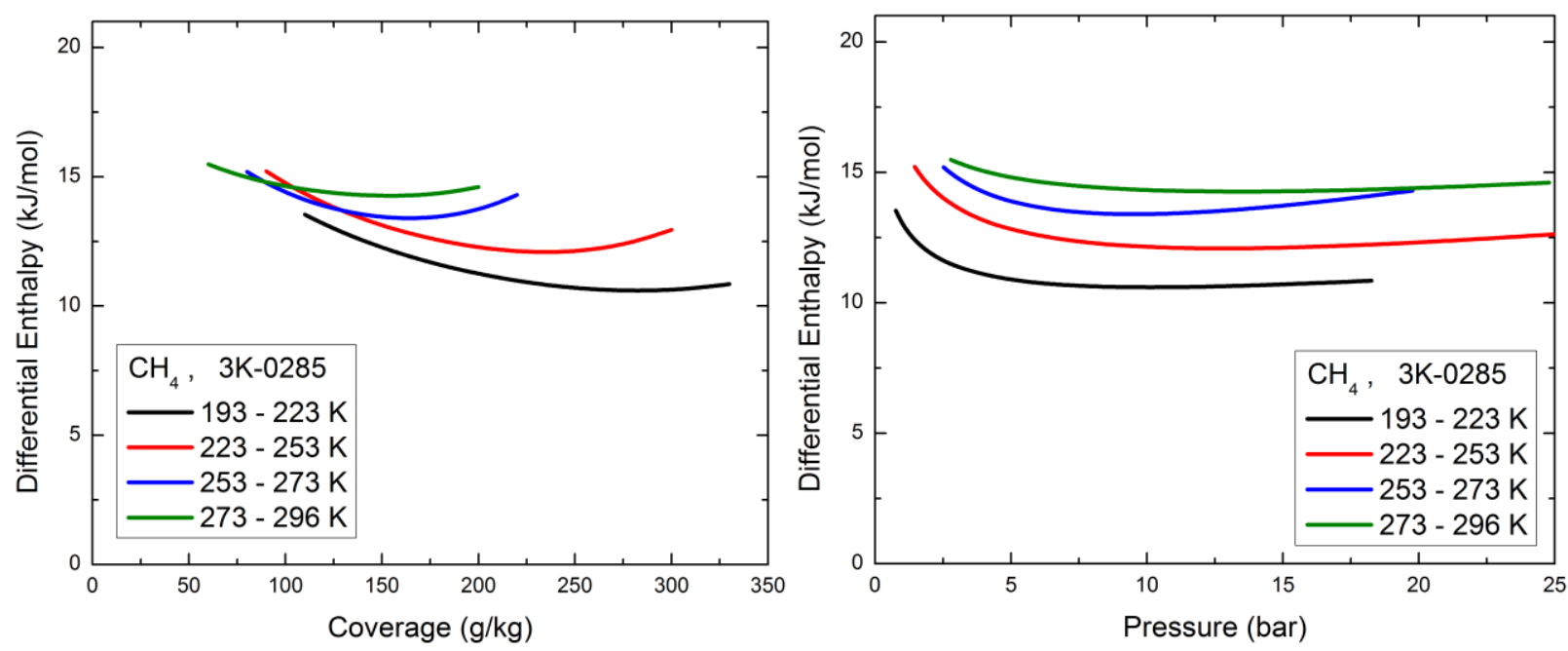

Figure 151. Resulting differential enthalpy of adsorption in the high pressure regime for sample 3K-0285. Left: Differential enthalpy of adsorption as a function of coverage and temperature. Right: Differential enthalpy of adsorption as a function of the geometric mean pressure and temperature.

Methane is more massive than hydrogen and also has a higher binding energy to the sorbent surface. Gravimetrically methane is adsorbed in large amounts, even at low pressures. For these reasons, it is often more practical to represent the calculated isosteric heats as a function of the geometric mean pressure.

All of these isosteric heats of adsorption have an unphysical rise in the high coverage regime. This is completely due to the choice of model used when interpolating between experimental absolute adsorption data. The Modified Redlich-Peterson Model tends to have greater residuals toward the extreme ends of the isotherm. The average isosteric heat of adsorption of methane on activated carbon is approximately $15 \mathrm{~kJ} / \mathrm{mol}$ at ambient temperatures and approximately $11 \mathrm{~kJ} / \mathrm{mol}$ at $200 \mathrm{~K}$. 

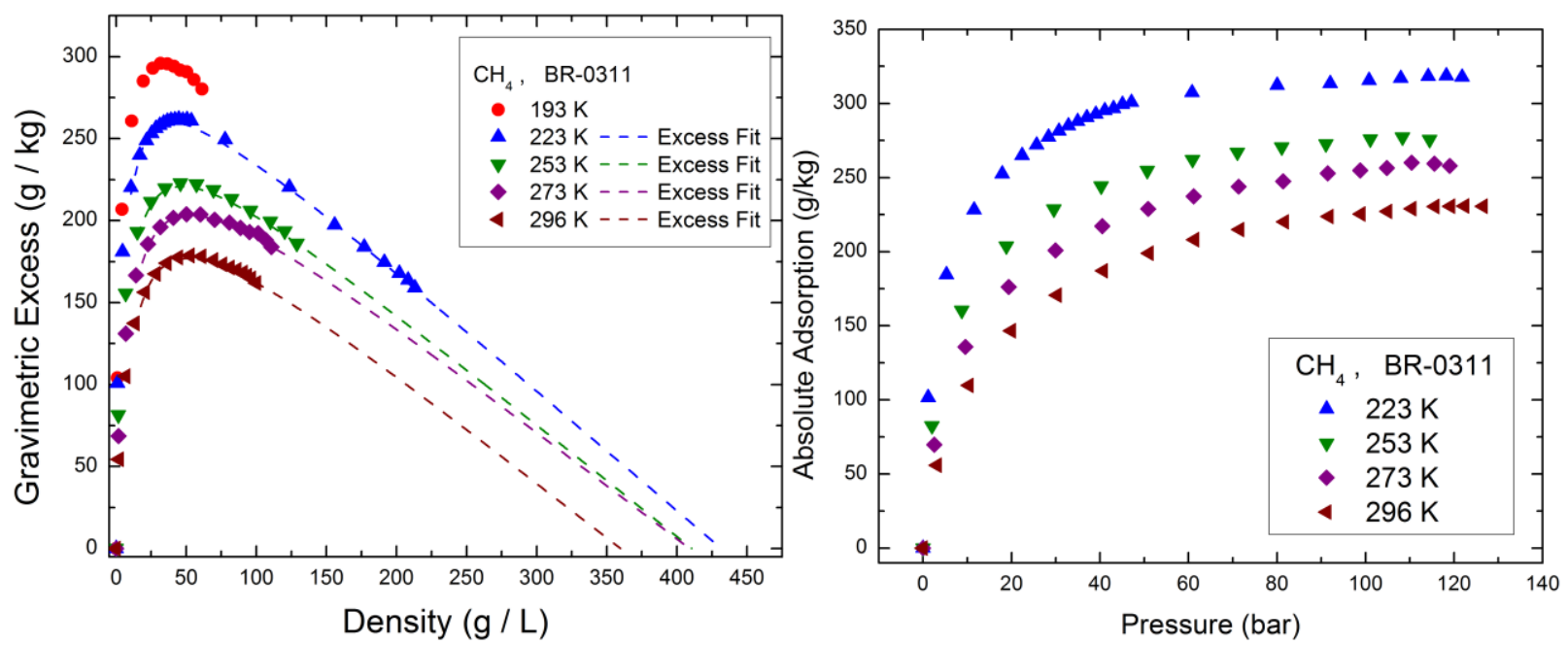

Figure 152. Excess and absolute adsorption measured between 193-296 K for sample BR-0311. Left: Gravimetric excess adsorption isotherms measured between 193-296 K. Right: Absolute adsorption isotherms measured between 223-296 K. Insufficient data exists for the isothermal measurement at $193 \mathrm{~K}$. Therefore, no attempt was made to determine the parameters of the adsorbed film at that temperature. No experimental data exists below a coverage of $50 \mathrm{~g} / \mathrm{kg}$. Therefore, any calculated isosteric heat values for coverages below that value will entirely depend on the choice of model applied to the isothermal adsorption data.
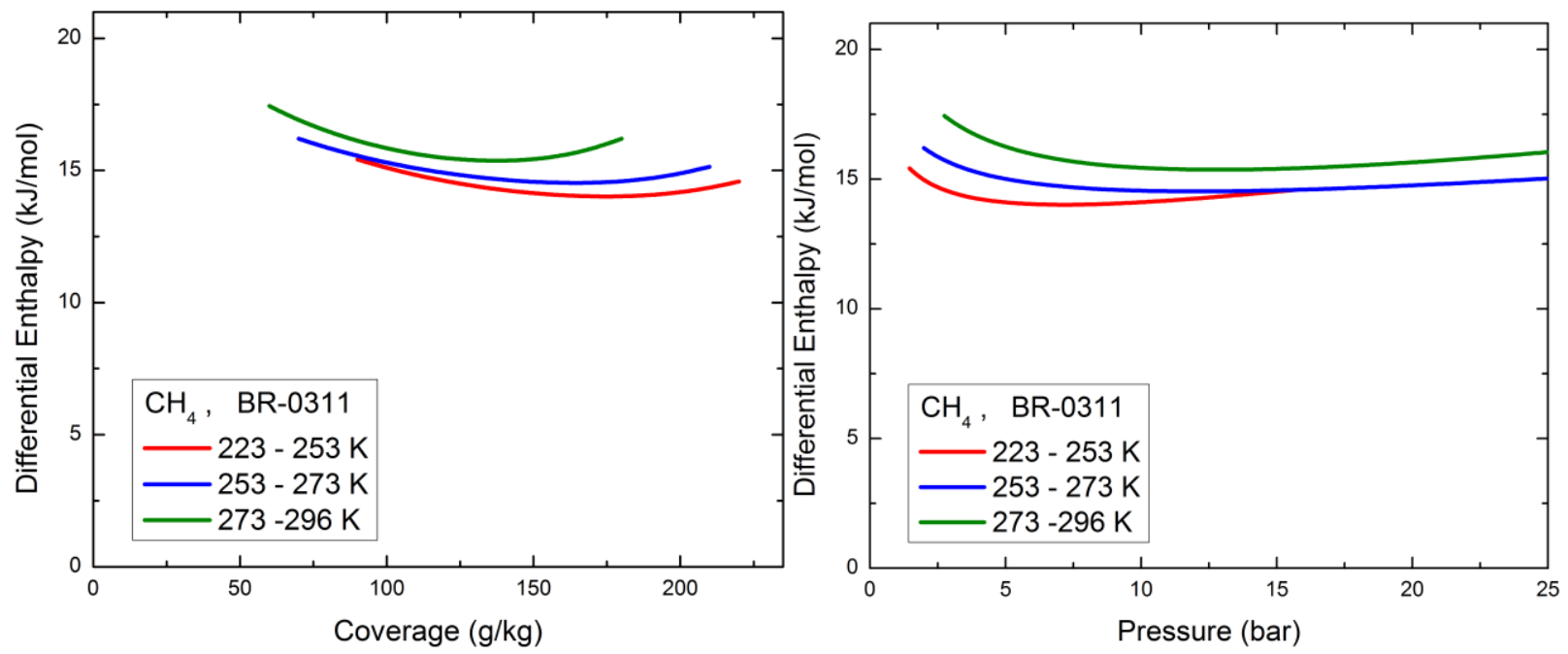

Figure 153. Resulting differential enthalpy of adsorption in the high pressure regime for sample BR-0311. Left: Differential enthalpy of adsorption as a function of coverage and temperature. Right: Differential enthalpy of adsorption as a function of the geometric mean pressure and temperature. Methane is more massive than hydrogen and also has a higher binding energy to the sorbent surface. Gravimetrically methane is adsorbed in large amounts, even at low pressures. For these reasons, it is often more practical to represent the calculated isosteric heats as a function of the geometric mean pressure.

All of these isosteric heats of adsorption have an unphysical rise in the high coverage regime. This is completely due to the choice of model used when interpolating between experimental absolute adsorption 
data. The Modified Redlich-Peterson Model tends to have greater residuals toward the extreme ends of the isotherm. The average isosteric heat of adsorption of methane on activated carbon is approximately $16 \mathrm{~kJ} / \mathrm{mol}$ at ambient temperatures and approximately $14 \mathrm{~kJ} / \mathrm{mol}$ at $240 \mathrm{~K}$. 


\section{Predicting Volumetric Storage Capacity from Surface Geometries}

\subsection{Theoretical Framework for a Continuous Two-Fluid Model}

Sorption-based storage is a three-phase equilibrium, and of the three phases the film is where all the action is. The primary metrics of interest are: absolute adsorption, $G_{\text {abs }}$ (mass of adsorbed film per mass of solid; also referred to as coverage or coverage by mass); film density, $\rho_{\text {film }}$ (mass of adsorbed film per volume of film); and intrapore density, $\rho_{\text {ip }}$ (total mass of hydrogen stored, i.e, mass of adsorbed film and non-adsorbed gas, per volume of pore space).

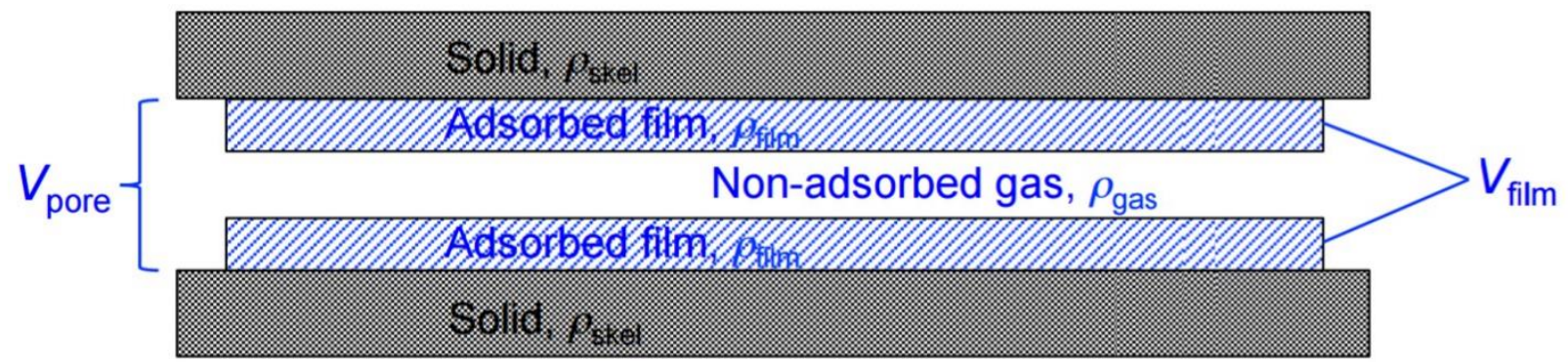

Figure 154. Two-fluid model in a pore of volume $V_{\text {pore }}$.

$$
\begin{aligned}
G_{\mathrm{abs}}(p, T)= & G_{\mathrm{exc}}(p, T)+\frac{\rho_{\mathrm{gas}}(p, T) V_{\mathrm{film}}(T)}{m_{\mathrm{s}}} \\
\rho_{\mathrm{film}}(p, T) & =G_{\mathrm{abs}}(p, T)+\frac{G_{\mathrm{abs}}(p, T) m_{\mathrm{s}}}{V_{\mathrm{film}}(T)} \\
= & \frac{G_{\mathrm{exc}}(p, T) m_{\mathrm{s}}}{V_{\mathrm{film}}(T)}+\rho_{\mathrm{gas}}(p, T) \\
\rho_{\mathrm{ip}}(p, T) & =\frac{V_{\mathrm{st}}(p, T)}{\phi} \\
& =\frac{G_{\mathrm{exc}}(p, T) \rho_{\mathrm{sk}}(1-\phi)}{\phi}+\rho_{\mathrm{gas}}(p, T)
\end{aligned}
$$

The relation Eq (92) between volumetric storage capacity and intrapore density follows from the observation that intrapore density assigns the hydrogen stored to the pore space only, while $V_{\text {st }}$ assigns the hydrogen stored to the solid plus pore space. Hence the intrapore density is larger than $V_{\text {st }}$ by a factor of 
$1 / \phi$. Chahine advocated a similar concept under the term average storage density in micropores: "The average storage density of hydrogen in micropores varies from 61 to $71 \mathrm{~kg} / \mathrm{m}^{3}$ which is the same as liquid hydrogen at $20 \mathrm{~K} "{ }^{[55]}$. The three metrics are relevant as follows:

(i) The absolute adsorption is the source for accurate isosteric heats of adsorption.

(ii) The film density is a quantitative measurement to investigate the "liquid hydrogen question," posed by the Department of Energy: Is it possible to store $71 \mathrm{~g} / \mathrm{L}$, the density of liquid $\mathrm{H} 2$ at its normal boiling point ( $\mathrm{p}=1 \mathrm{bar}, \mathrm{T}=20 \mathrm{~K}$ ), or higher, in a suitably engineered sorbent at $77 \mathrm{~K}$ ? The unexpected answer is yes: A wide variety of U. Missouri carbons were found to exhibit saturated film densities $\rho_{\text {film,sat }}=$ $100-120 \mathrm{~g} / \mathrm{L}$ at $77 \mathrm{~K}$, which is $50-70 \%$ higher than the density of liquid hydrogen at $20 \mathrm{~K}$, and $20-40 \%$ higher than the density of solid hydrogen, $86 \mathrm{~g} / \mathrm{L}$, at $14 \mathrm{~K}$. The finding is unexpected because the high film density occurs at a temperature more than twice the liquid-gas critical temperature of hydrogen, $\mathrm{T}_{\mathrm{c}}=33 \mathrm{~K}$, above which no bulk liquid exists at any pressure. The existence of a high-density hydrogen film above $\mathrm{T}_{\mathrm{c}}$, to which we refer as supercritical condensation (we leave undetermined whether the film is liquid-like or solid-like), is not in contradiction to the non-existence of bulk liquid: the film is not a bulk, 3D phase, but a monomolecular 2D phase. Adsorbent materials can be approximated slit-shaped pores with a distribution of widths, $w_{\text {pore }}$, and single wall widths, $w_{\text {wall. }}$. The decomposition of storage into high-density film and low-density non-adsorbed gas, coexisting in the pore space may be expressed as

$V_{\text {st }}(p, T)=\phi\left[\left\{\frac{1}{V_{\text {pore }}} \int_{0}^{\infty} \frac{2}{w} \frac{d V_{\text {pore }}}{d w} d w\right\} t_{\text {film }}(T)\left[\rho_{\text {film }}(p, T)-\rho_{\text {gas }}(p, T)\right]+\rho_{\text {gas }}(p, T)\right]$

where $d V_{\text {pore }} d w$ is the differential pore size distribution of the adsorbent (volume in pores of width between $w$ and $w+d w$, per pore width increment $d w$ ) and $V_{\text {pore }}$ is the total pore volume of the sample as before. The integral in Eq (94) has units of area and, through the product with the film thickness, divided by the total pore volume, counts the volume fraction occupied by the dense film. The factor $2 / w$ gives narrow pores a large weight, consistent with the fact that narrow/wide pores host a large/small 
fraction of their volume as dense film. Thus, the decomposition Eq (94) reduces the search for materials with "narrow pores, thick walls" to a search for materials in which the integral in Eq (94) is large.

(iii) Intrapore density is like the volumetric storage capacity, $V_{\mathrm{st}}$, but considers the volume of the pore space only, without skeletal volume of the sorbent. So the intrapore density is quantitative measure to investigate the "liquid hydrogen question." By including the film and gas, it is one step closer to $V_{\text {st }}$ in the progression to low density, from the inside out:

$$
\begin{aligned}
\operatorname{adsorbed} \text { film }\left(\rho_{\text {film }}\right) & \rightarrow \text { adsorbed film }+ \text { non-adsorbed gas }\left(\rho_{\text {ip }}\right) \\
& \rightarrow \text { adsorbed film }+ \text { non-adsorbed gas }+\operatorname{sorbent}\left(V_{\text {st }}\right)
\end{aligned}
$$

The virtue of the intrapore density is that it can be evaluated entirely from gravimetric excess adsorption and porosity, Eq. (93), without any additional information. This is important when the film volume needed to calculate the film density, Eq. (1.36), is not available, such as in hydrogen adsorption at room temperature. In this case, $\rho_{\text {ip }}$ is a lower bound for $\rho_{\text {film. }}$. In the case that $\rho_{\text {film }}$ can be determined from Eq (1.36), the inequality between $\rho_{\text {ip }}$ and $\rho_{\text {film }}$ provides a consistency test between the two independently determined quantities. The inequalities and relations between the different densities read, in ascending order:

$$
\begin{gathered}
\rho_{\text {gas }}(p, T) \leq \rho_{\text {ip }}(p, T) \leq \rho_{\text {film }}(p, T) \\
V_{\text {st }}(p, T) \leq \rho_{\text {ip }}(p, T) \\
\rho_{\text {ip }}(p, T)=\frac{V_{\text {film }}(T)}{V_{\text {pore }}} \rho_{\text {film }}(p, T)+\frac{V_{\text {pore }}-V_{\text {film }}(T)}{V_{\text {pore }}} \rho_{\text {gas }}(p, T) \\
=\frac{V_{\text {film }}(T)}{V_{\text {pore }}}\left[\rho_{\text {film }}(p, T)-\rho_{\text {gas }}(p, T)\right]+\rho_{\text {gas }}(p, T)
\end{gathered}
$$

valid and rigorous for any sorbent. [Eq (96) follows from Eq (92) and $\phi<1$.] For good sorbents, it is additionally true that $\rho_{\text {gas }}(\mathrm{p}, \mathrm{T})<V_{\mathrm{st}}(\mathrm{p}, \mathrm{T})$ 
Table 29: High observed film densities and intrapore densities in U. Missouri carbons and resulting pathways to $V_{\text {st }} \geq 71 \mathrm{~g} / \mathrm{L}$ at $77 \mathrm{~K}$ ("liquid hydrogen question"). In the samples studied, the film volume occupies only $\sim 25-50 \%$ of the total pore volume, and $\sim 35-70 \%$ of the local pore space. So one pathway is to create narrower pores, so as to eliminate the pore space holding non-adsorbed gas ("wasted pore space"). The other pathway is to make walls between pores thinner. In the formulas, $\mathrm{N}_{\mathrm{A}}$ is Avogadro's number, $M$ is the molar mass of hydrogen, and $\Sigma$ is the specific surface area.

\begin{tabular}{|c|c|c|}
\hline & Saturated film density, $\rho_{\text {film sta }}$ & Intrapore density, $\rho_{\mathrm{ip}}$ \\
\hline $\begin{array}{l}\text { High observed values } \\
\text { Source }\end{array}$ & $\begin{array}{c}100-120 \mathrm{~g} / \mathrm{L} \text { at } p \geq 35-75 \text { bar } \\
\text { Fig. } 1.8 \text {, Sect. } 8\end{array}$ & $\begin{array}{c}80 \mathrm{~g} / \mathrm{L} \text { at } p=120 \mathrm{bar} \\
\text { Sect. } 8\end{array}$ \\
\hline Samples & Most U. Missouri carbons, MSC-30 & U. Missouri carbon HS;0B-20 \\
\hline Pore structure & Sub-nm \& supra-nm pores & Monodisperse $0.7 \mathrm{~nm}$ pores \\
\hline $\begin{array}{l}\text { Does the film globally fill } \\
\text { pore space? }\end{array}$ & No: $V_{\text {film }} / V_{\text {pore }}=0.25-0.53$ & No: $V_{\text {film }} / V_{\text {pore }}=0.53$ \\
\hline $\begin{array}{l}\text { Film thickness, } \\
t_{\text {film }}=\left(\rho_{\text {film.sat }} \cdot N_{\mathrm{A}} / M\right)^{-1 / 3}\end{array}$ & $0.30-0.32 \mathrm{~nm}$ & $0.31 \mathrm{~nm}$ \\
\hline $\begin{array}{l}\text { Average pore width, } \\
w_{\text {pore.av }}=2 /\left(\Sigma \cdot \rho_{\text {skel }}\right)\left(\phi^{-1}-1\right)^{-1}\end{array}$ & $0.87-1.87 \mathrm{~nm}$ & $0.87 \mathrm{~nm}$ \\
\hline $\begin{array}{l}\text { Average wall width, } \\
w_{\text {wall av }}=2 /\left(\Sigma \cdot \rho_{\text {skel }}\right)\end{array}$ & $0.36-1.28 \mathrm{~nm}$ & $1.01 \mathrm{~nm}$ \\
\hline $\begin{array}{l}\text { Does the film locally fill } \\
\text { pore space (Fig. 1.2.c)? }\end{array}$ & No: $2 \cdot t_{\text {film }} / w_{\text {pore, av }}=0.34-0.71$ & No: $2 \cdot t_{\text {film }} / w_{\text {pore,av }}=0.71$ \\
\hline Pathway to $V_{\mathrm{st}} \geq 71 \mathrm{~g} / \mathrm{L}$ & $\begin{array}{l}\text { Given } \rho_{\text {film }} \text {, store film and gas in } \\
\text { narrow pores between narrow walls } \\
\text { (minimize } w_{\text {pore,av }} \text { and } w_{\text {wall,av }} \text { ) }\end{array}$ & $\begin{array}{l}\text { Given } \rho_{\text {ip }} \text { and } w_{\text {pore,av }} \text {, store film } \\
\text { and gas between narrow walls } \\
\text { (minimize } w_{\text {wall,av }} \text { without } \\
\text { raising } w_{\text {pore,av }} \text { ) }\end{array}$ \\
\hline
\end{tabular}


Table 30: Classification of materials into narrow vs. wide pores and thick vs. thin pore walls. Input: average pore width, $w_{\text {pore,av }}$, and average wall width, $w_{\text {wall,av }}$, from Table 29 . Classifier: ratio $\mathrm{r}:=w_{\text {pore,av }} / w_{\text {wall,av }}$. Samples with a small pore-width-to-wall-width ratio, $\mathrm{r}<1$ ("narrow pores, thick walls"), or equivalently with porosity $<0.5$, are carriers of high intrapore densities

\begin{tabular}{|l|c|c|}
\hline & Narrow pores, thick walls & Wide pores, thin walls \\
\hline Illustration & & \\
& & \\
\hline $\begin{array}{l}\text { Pore width to wall width, } \\
r:=w_{\text {pore,av }} / w_{\text {wall,av }}=\left(\phi^{-1}-1\right)^{-1}=V_{\text {pore }} / V_{\text {solid }}\end{array}$ & $r<1$ & $r>1$ \\
Observed values in U. Missouri samples & $r=0.86,0.96$ & $r=1.3-4.6$ \\
\hline $\begin{array}{l}\text { Characterization in terms of porosity, } \phi \\
\text { Observed values in U. Missouri samples }\end{array}$ & $0<\phi<0.5$ & $0.5<\phi<1$ \\
\hline $\begin{array}{l}\text { Characterization in terms of pore volume } \\
\text { to skeletal volume, } V_{\text {pore }} / V_{\text {solid }} \\
\text { Observed values in U. Missouri samples }\end{array}$ & $\phi=0.46,0.49$ & $\phi=0.56-0.82$ \\
\hline
\end{tabular}

Equation (96) states that $\rho_{\text {ip }}$ equals the weighted average of the density of the adsorbed film and the density of the non-adsorbed gas, with weights equal to the fraction of the pore volume that is occupied by the film and gas, respectively. Formulas (96) and (92) can be combined to express the volumetric storage capacity entirely in terms of film volume and density

$$
\begin{aligned}
\frac{V_{\text {st }}}{\phi}= & \left(1-\frac{V_{\text {film }}}{V_{\text {pore }}}\right) \rho_{\text {gas }}+\frac{V_{\text {film }}}{V_{\text {pore }}} \rho_{\text {film }} \\
= & (1-\lambda) \rho_{\text {gas }}+\lambda \rho_{\text {film }}
\end{aligned}
$$

which displays the linear dependence on the gas density and where $\lambda$ is the ratio of the film volume to pore volume. If the adsorbed film volume and density are known quantities, then one may also calculate a specific surface area from the two-fluid model $\left(\Sigma_{2 \mathrm{~F}}\right)$ by defining the film volume in terms of the specific surface area and the adsorbed film thickness.

$$
\begin{gathered}
\lambda=\frac{V_{\text {film }}}{V_{\text {pore }}}=\frac{\Sigma_{2 F}}{V_{\text {pore }}} t_{\text {film }} \\
\Sigma_{2 F}=\int_{0}^{\infty} \frac{2}{w} \frac{d V_{\text {pore }}}{d w} d w
\end{gathered}
$$


Results (99-12) bring a number of remarkable relations together. In Table 29, the ratio $\lambda$ was an experimental figure of merit, with $V_{\text {film }}$ determined from the slope of $G_{\text {ex }}$ vs. $\rho_{\text {gas }}$ at high pressure and $V_{\text {pore }}$ from nitrogen adsorption, to address the question, “does the film globally fill pore space?" Here, in Eq (100), the ratio $\lambda$ determines the slope of $V_{\text {st }} / \phi$ vs. $\rho_{\text {gas }}$ at high pressure when the film density approaches saturation and $V_{\text {st }} / \phi$ vs. $\rho_{\text {gas }}$ becomes a straight line

$$
\begin{gathered}
\frac{V_{\text {st }}}{\phi}=A \rho_{\text {gas }}+B \\
A=1-\lambda \\
B=\lambda \rho_{\text {film,sat }}
\end{gathered}
$$

Conversely, $\lambda$ and $\rho_{\text {film,sat }}$ can be determined from a linear fit, (103), to high-pressure volumetric storage capacity (Fig. 155). Finally, Eq (101) relate $\lambda$ to the surface area alluded to in Eq. (94) and film thicknesses tabulated in Table 29. In fact, Eq (101) follows from comparing the right-hand sides of Eq (100) and (94). The relation (101) decomposes $\lambda$ into a purely pore geometric factor, $\Sigma_{2 \mathrm{~F}} / V_{\text {pore, }}$, and a purely thermodynamic factor, $t_{\text {film}}$. We call the surface area (102) "two-fluid-weighted" surface area because it manifestly does not count area in narrow and wide pores equally, but counts area according to the fraction of pore volume the area supports, perpendicular to the surface (Fig. 154), in a pore of width $w$. The weight $2 / w$ gives area in narrow pores a large weight and discounts area in large pores. BET surface area, in contrast, counts surface area in narrow and wide pores equally.

If we take the weighted average, (97), as the conceptual definition of the intrapore density, the working formula (92) has the status of a "sum rule," which says that $\rho_{\text {ip }}$ can be determined without any knowledge of $V_{\text {film }}$ and $\rho_{\text {film. }}$. Similarly, the bounds of Eq (95) may be regarded as the result of evaluating Eq (97) with the lower bound $0 \leq V_{\text {film }}$ and upper bound $V_{\text {film }} \leq V_{\text {pore }}$ for the film volume 


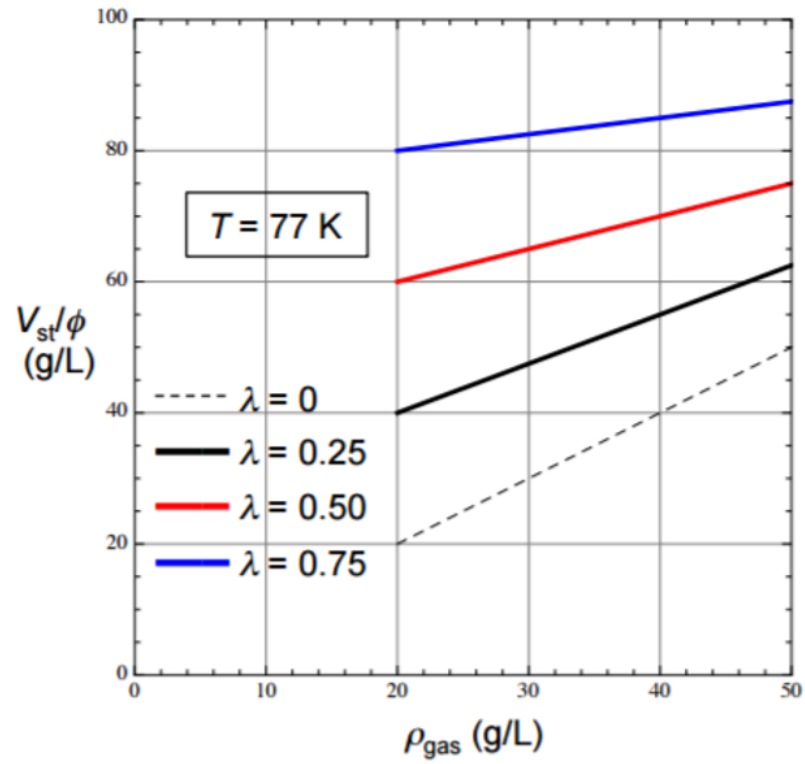

Figure 155. Asymptotic linear relation for volumetric storage capacity as a function of gas density at high pressure.

Increasing the ratio of film-to-pore volume yields higher $V_{\mathrm{st}} / \phi$ values. As pressure is increased, materials with low $\lambda$ start out low and fill rapidly with gas. Materials with high $\lambda$ start out high with a large fraction of the pore volume filled with saturated, adsorbed film. Such materials fill slowly with additional compressed gas.

The "Two-Fluid" model was applied to adsorption isotherms of sample MSC-30.

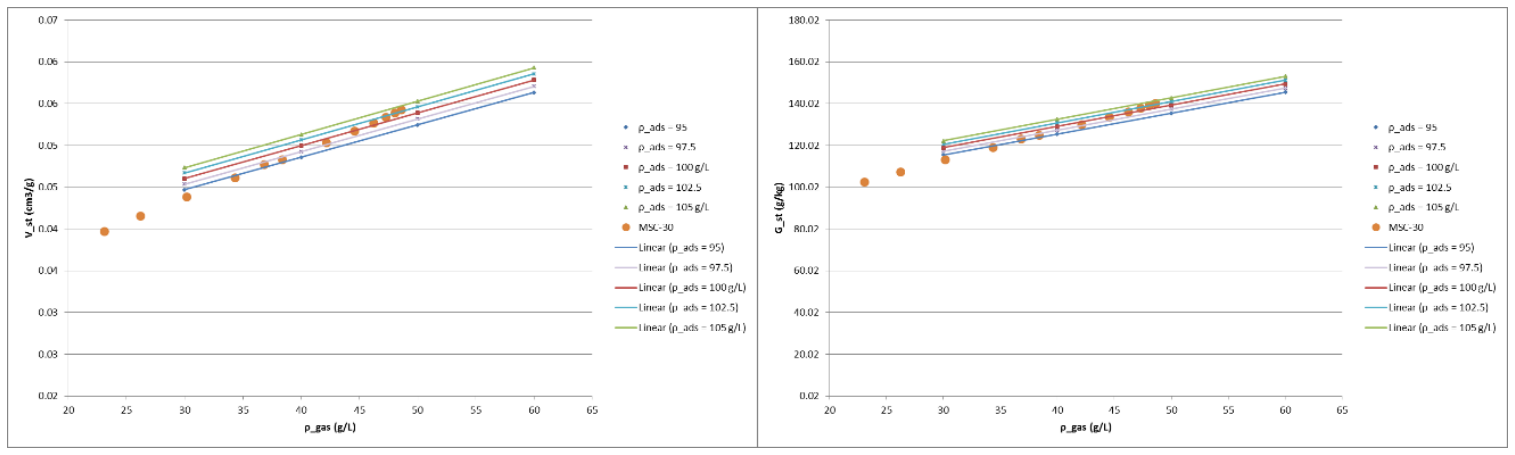

Figure 156. Predicted storage capacities of MSC-30 using the discrete two-fluid model. Assuming that the density of the adsorbed film is approximately $100 \pm 5 \mathrm{~g} / \mathrm{L}$, this model successfully predicts both the gravimetric and volumetric storage capacities of sample MSC-30 at $77 \mathrm{~K}$ and in high pressure regime. 
Experimentally, Eq (94) may be applied to cumulative pore size distributions in order to predict storage performance. Two discrete methods were developed to predict the storage capacities of activated carbon materials based on pore structure information from nitrogen sorption experiments and a two-fluid model of the adsorbed film. Empirical universalities (observed through hydrogen and methane adsorption experiments) were combined with structural information (obtained from nitrogen isotherms) in an attempt to discover correlations between excess adsorption, volumetric storage, and the surface geometry of the adsorbent material.

In the first method, observations were recorded regarding how the adsorbed film builds at a given temperature. Using this universal adsorbed film density along with the pore filling fractions, the volumetric storage capacity and gravimetric excess adsorption of various adsorbent materials was predicted. Interestingly, this method allows me to model gravimetric excess adsorption without using the specific surface area. This predicts gravimetric excess within $10 \%$ of experimental values at pressures less than 40 bar and within $5 \%$ at pressures greater than 70 bar. In the second method, I define a quantity called the "nanoporosity" of the material. This quantity correlates well with the volumetric storage capacity of hydrogen and methane at low pressures. These correlations can be used to predict volumetric storage capacity and gravimetric excess adsorption of materials. This method is admittedly circular, but can be used to predict gravimetric excess adsorption within $5 \%$ of the experimental values using only the nanoporosity of the material.

\subsection{Framework for the Discrete Two-Fluid Model}

\section{Predicting storage capacities using universal adsorbed film densities:}

The ultimate goal of developing a discrete two-fluid model is to predict the storage capacities of sorbent materials based on observations of how the adsorbed film density changes with pressure and temperature. First, it is necessary to develop relation between the adsorbed film density and pressure. The adsorbed film thickness may be calculated from the film density and is approximately the same for all 
samples at $77 \mathrm{~K}$. These universalities may be used in conjunction with geometric information from QSDFT analysis of nitrogen sorption to predict volumetric storage capacities and excess adsorption for any arbitrary sample.

\section{Adsorbed Film Densities and hydrogen:}

Excess adsorption may be defined as

$$
m_{\mathrm{exc}}=\int_{V_{\mathrm{ads}}}\left(\rho_{\mathrm{ads}}-\rho_{\mathrm{gas}}\right) d V
$$

As the adsorbed film saturates, it reaches a constant adsorbed film density. On several occasions, it has been shown that the adsorbed film density reaches a nearly universal value at a given temperature and sufficiently high pressures. At $77 \mathrm{~K}$, the adsorbed film density of hydrogen reaches approximately $100 \mathrm{~g} / \mathrm{L}$. If we know approximately how the adsorbed film density builds in pressure and we know the limits of integration over volume of the adsorbed state, then we should be able to model excess adsorption and volumetric storage capacity of any material.

Recall Fig 134. The excess adsorption isotherms for MWV-0260, BR-0134, and BR-0311 all intersect the horizontal axis at a common saturated film density. Let's assume that the adsorbed film volume is constant for any given sample. Using this along with the excess adsorption data, we can see how the adsorbed film density builds with pressure.

$$
\rho_{\mathrm{exc}}=m_{\mathrm{exc}} / V_{\mathrm{film}}
$$

Therefore,

$$
\rho_{\mathrm{ads}}=\rho_{\mathrm{exc}}+\rho_{\mathrm{gas}}
$$

Now we can create isotherms for the adsorbed film for any sample as a function of bulk gas density. 


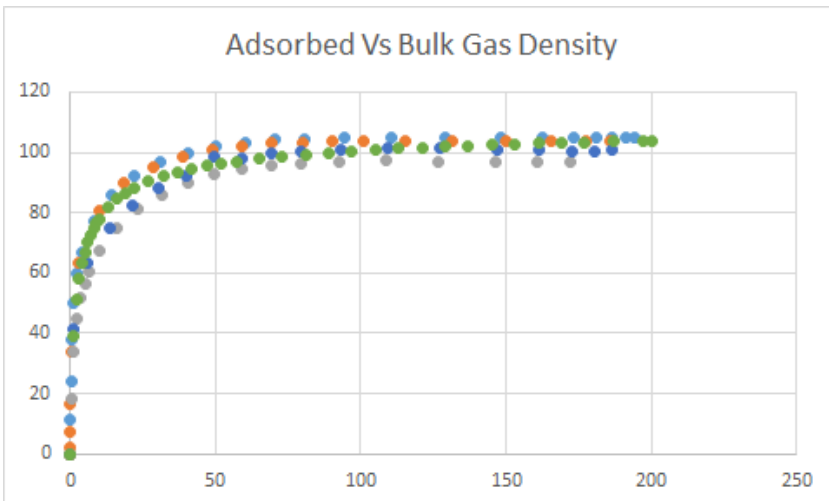

Figure 157. Adsorbed film density of hydrogen as a function of pressure at $77 \mathrm{~K}$. All adsorbed film densities increase exponentially, attaining an approximate adsorbed film density of $105 \mathrm{~g} / \mathrm{L}$.

Assume that the adsorbed film density of all adsorbent materials builds the same in pressure within a first-order approximation. Carbonaceous materials are typically composed of slit-shaped pores with varying pore widths. Consider any given cumulative pore size distribution from QSDFT. Let $\Delta V_{\mathrm{i}, \mathrm{j}}$ represent the fraction of the total pore space attributed to pores of widths between $i-j$ widths.

$$
\Delta V_{\mathrm{i}, \mathrm{j}}=V_{\mathrm{j}}-V_{\mathrm{i}}
$$

The total mass of gas contained within a crystal of a nanoporous sample may be defined in terms of these volume fractions and gas densities. This mass is defined as the mass of gas in the adsorbed state plus the gas that is in the compressed state and can be expressed as

$$
m_{\text {all gas }}=\sum_{\mathrm{i}<\mathrm{j}=\mathrm{i}+1}^{W(\max )}\left[\frac{\Delta V_{\mathrm{i}, \mathrm{j}}}{W_{\mathrm{i}-\mathrm{j}(\mathrm{avg})}}\left(\rho_{\text {gas }}\left(W_{\mathrm{i}-\mathrm{j}(\operatorname{avg})}-2 t_{\text {film }}\right)+\rho_{\text {ads }} 2 t_{\text {film }}\right)\right]
$$

The $\mathrm{i}^{\text {th }}$ summation represents the mass of gas contained within pores of a specified width. I define the mass of gas in the adsorbed state as the fraction of $\Delta V_{\mathrm{i}, \mathrm{j}}$ that it occupies. This is given by

$$
m_{\text {ads }}=\rho_{\text {ads }}\left[\frac{\Delta V_{\mathrm{i}, \mathrm{j}}}{W_{\mathrm{i}-\mathrm{j}(\mathrm{avg})}} 2 t_{\mathrm{film}}\right]
$$


where $W_{\mathrm{i}-\mathrm{j} \text { (avg) }}$ is the average pore with between the $\mathrm{i}-\mathrm{j}$ widths from QSDFT and $t_{\text {film }}$ is the adsorbed film thickness. Similarly, the mass of gas contained in the rest of the pore space is given by

$$
m_{\text {gas }}=\rho_{\text {gas }}\left[\frac{\Delta V_{\mathrm{i}, \mathrm{j}}}{W_{\mathrm{i}-\mathrm{j}(\mathrm{avg})}}\left(W_{\mathrm{i}-\mathrm{j}(\mathrm{avg})}-2 t_{\text {film }}\right)\right]
$$

One may use these assumptions and formulas and sum over all pore sizes to obtain a good estimate of the total mass of gas contained in a crystal of any sample.

Case 1: Assume that $t_{\text {film }}=3.1 \AA$ for all samples. This is the average film thickness for all samples solved through the cubed root of the adsorbed film volume. Though the adsorbed film volume is not the same for all samples, the film thickness is approximately the same.
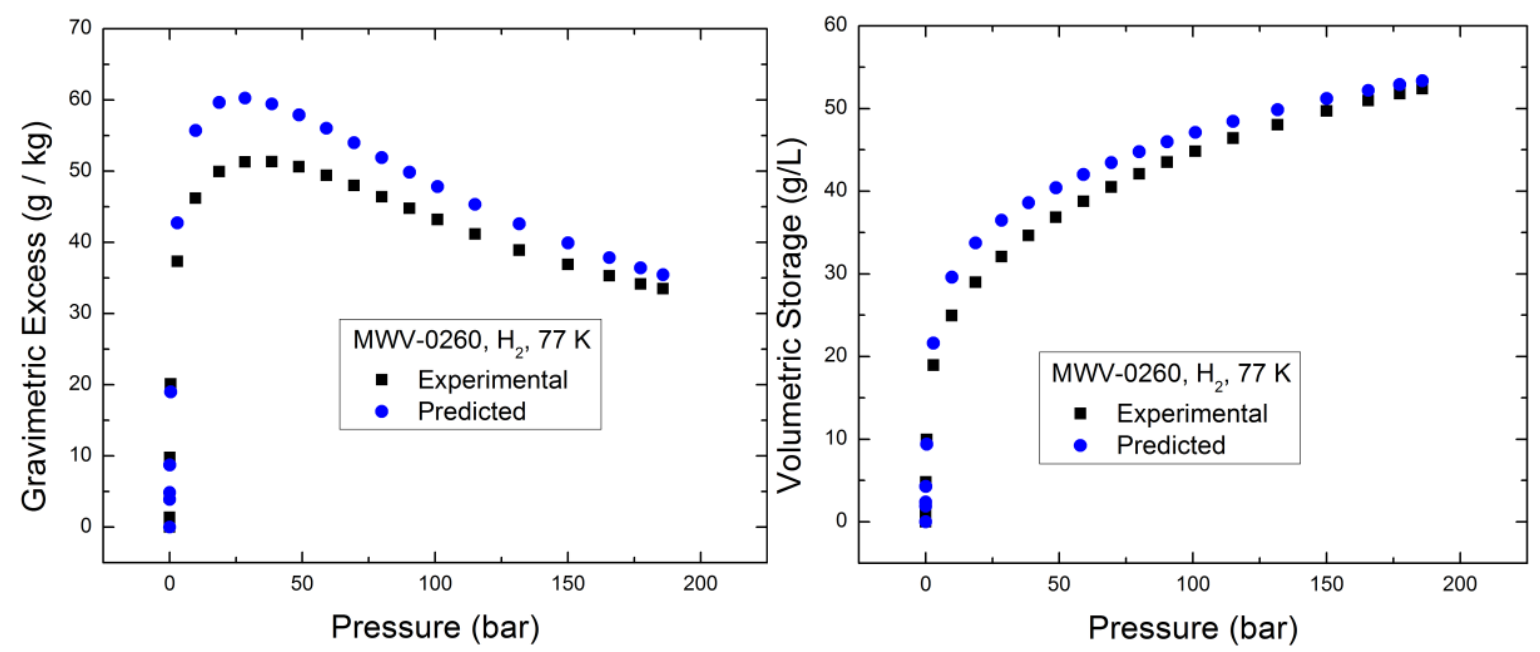

Figure 158. Experimental and predicted volumetric storage capacities and excess adsorption of hydrogen for sample MWV-0260. The predicted excess adsorption deviates by $\sim 10 \%$ difference on average along the entire isotherm. 

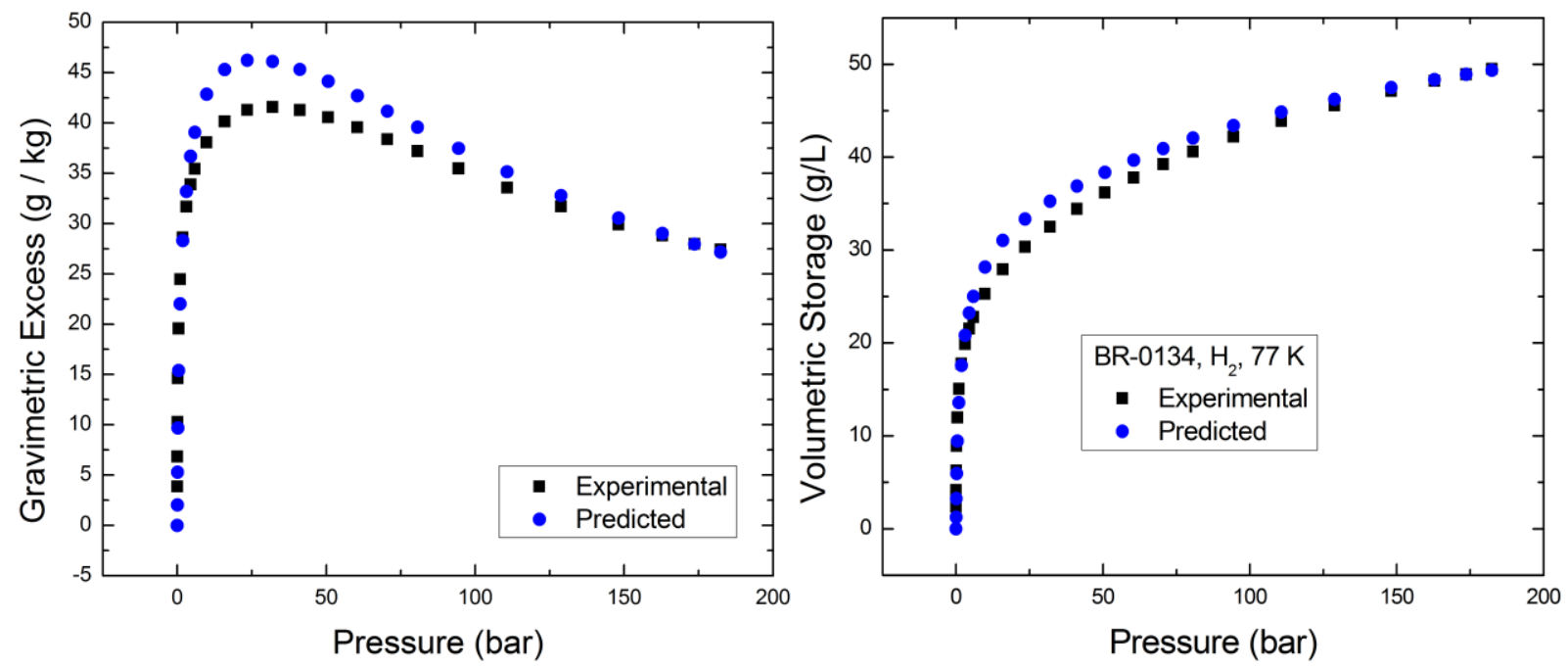

Figure 159. Experimental and predicted volumetric storage capacities and excess adsorption of hydrogen for sample BR-0134. The predicted excess adsorption deviates by $\sim 5 \%$ difference on average along the entire isotherm.
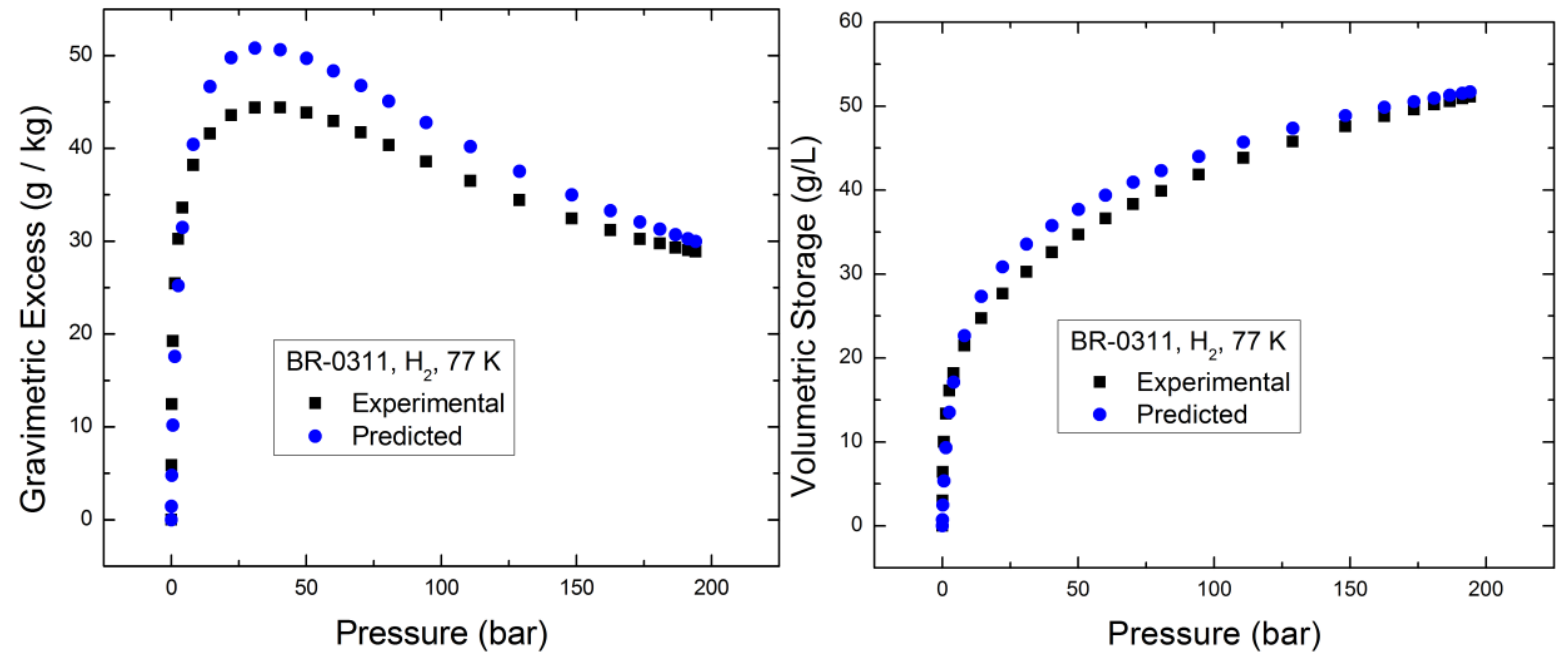

Figure 160. Experimental and predicted volumetric storage capacities and excess adsorption of hydrogen for sample BR-0311. The predicted excess adsorption deviates by $\sim 10 \%$ difference along the entire isotherm.

Overall, this method consistently overestimates the gravimetric excess adsorption by $\sim 10 \%$ at most pressures. This is insufficient to estimate the excess adsorption.

Case 2: Obtain the average $t_{\text {film }}$ by dividing the adsorbed film volume by the BET surface area. This $t_{\text {film }}$ has far more variance between samples as it is dependent upon the accuracy of the BET fit. When obtained through this method, the average $t_{\text {film }} \sim 2.9 \AA$. 

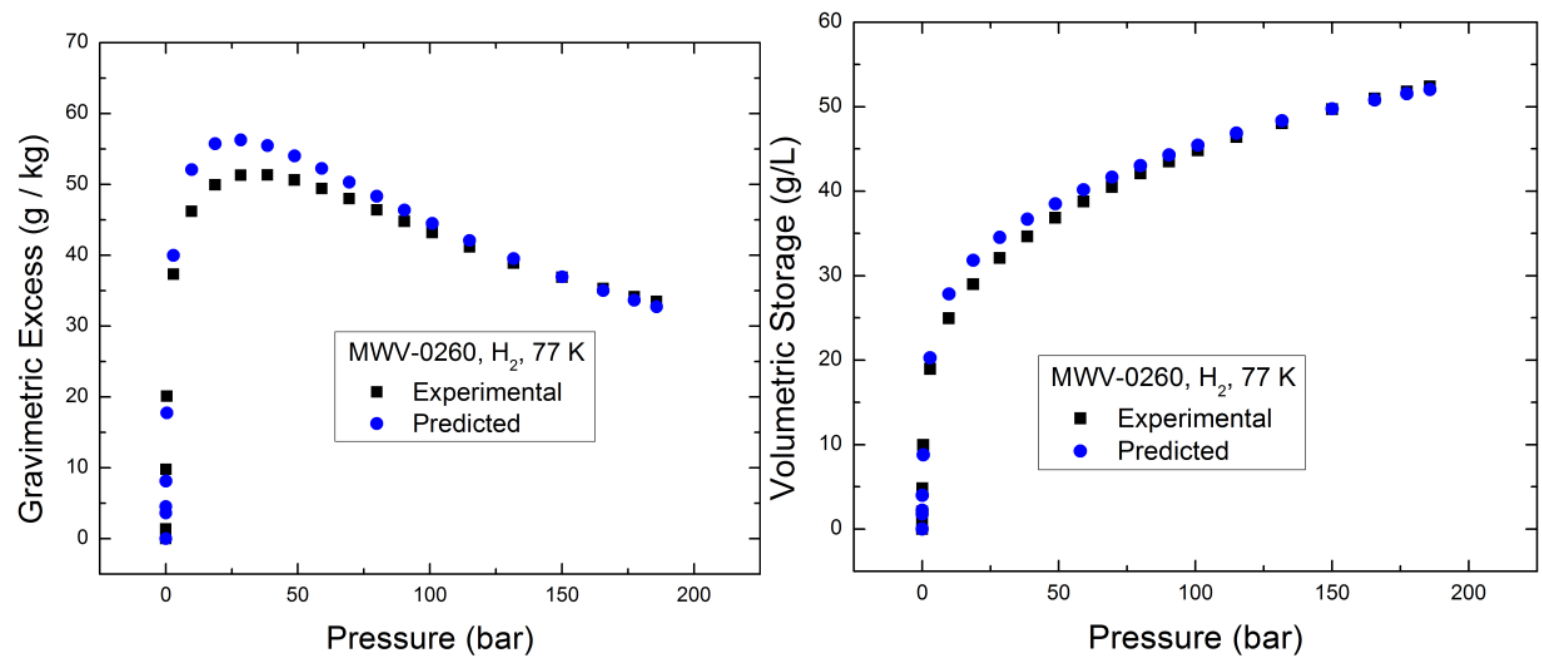

Figure 161. Experimental and predicted volumetric storage capacities and excess adsorption of hydrogen for sample MWV-0260. The predicted excess adsorption deviates by a maximum of $10 \%$ difference and deviates by an average of $\sim 4 \%$ difference along the entire isotherm.
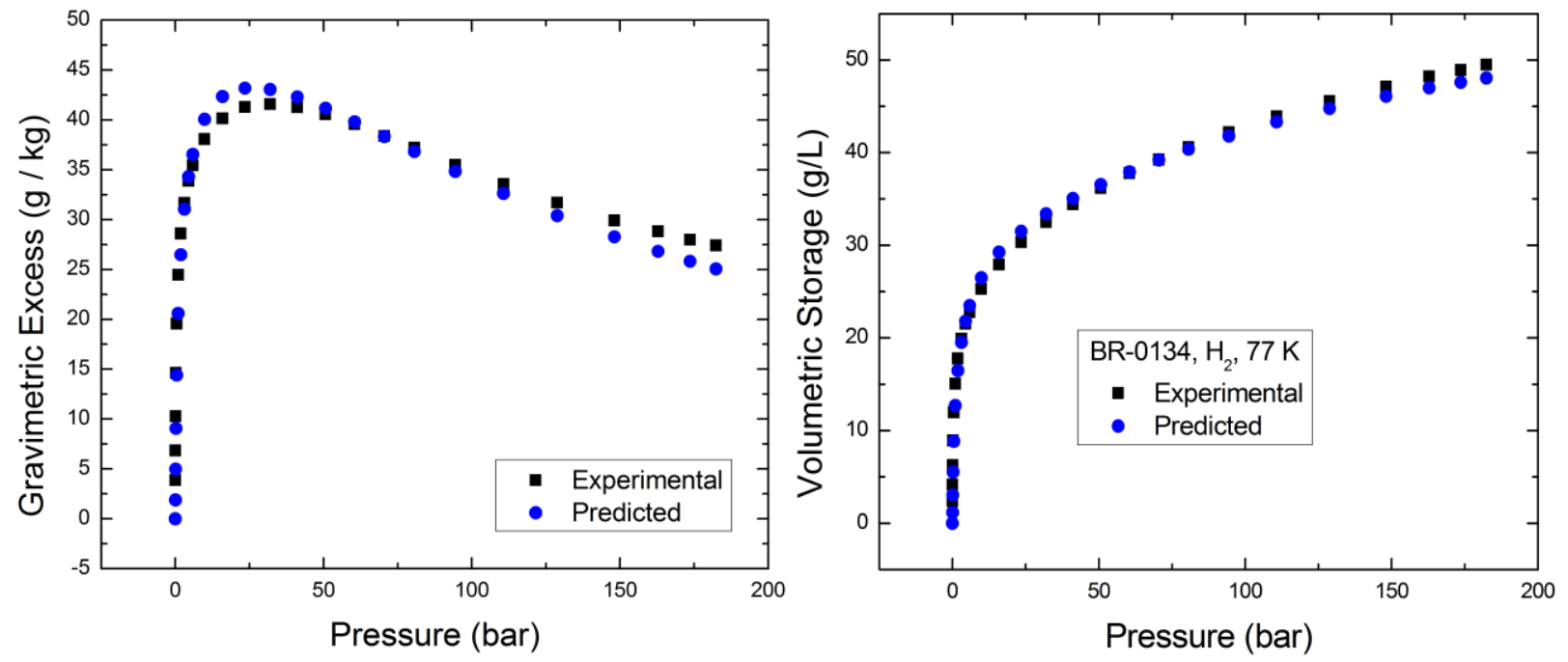

Figure 162. Experimental and predicted volumetric storage capacities and excess adsorption of hydrogen for sample BR-0134. The predicted excess adsorption deviates by a maximum of $5 \%$ difference and an average deviation of $3 \%$ along the entire isotherm. 

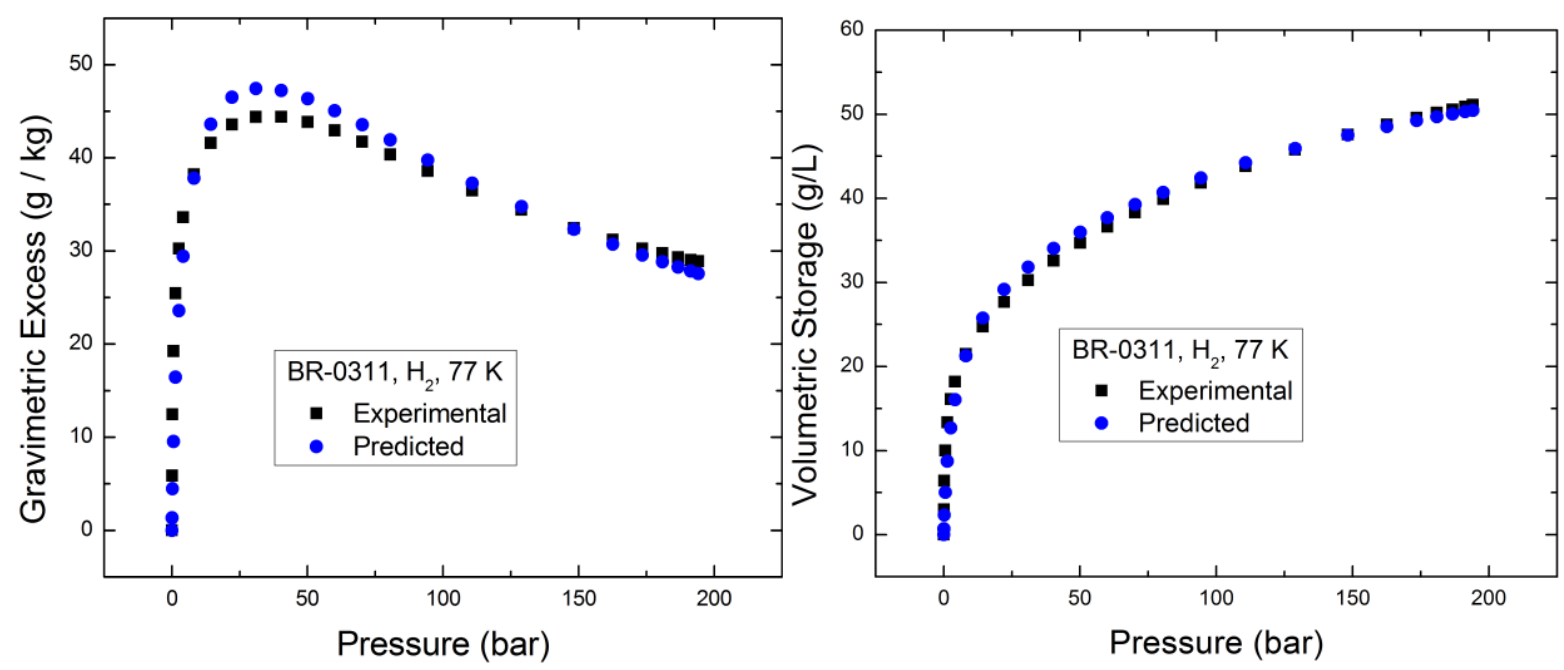

Figure 163. Experimental and predicted volumetric storage capacities and excess adsorption of hydrogen for sample BR-0311. The predicted excess adsorption deviates by a maximum of $7 \%$ difference and an average deviation of $3 \%$ along the entire isotherm.

Overall, this method tends to overestimate the excess adsorption and volumetric storage. Despite the many assumptions underlying these two methods, the predicted volumetric storage values were very close to experimental values with an average deviation that was always less than $\sim 5 \%$ over the entire isotherm. These methods could prove useful as a quick means to gauge the potential storage capacity of a carbonaceous sorbent material.

\section{3 "Nanoporosity" and the Discrete Two-Fluid Model}

The goal of this method is to make observations about the volumetric storage capacities across many samples. Correlations between storage capacities and pore geometries will be used to predict volumetric storage capacities and excess adsorption for any arbitrary sample. 

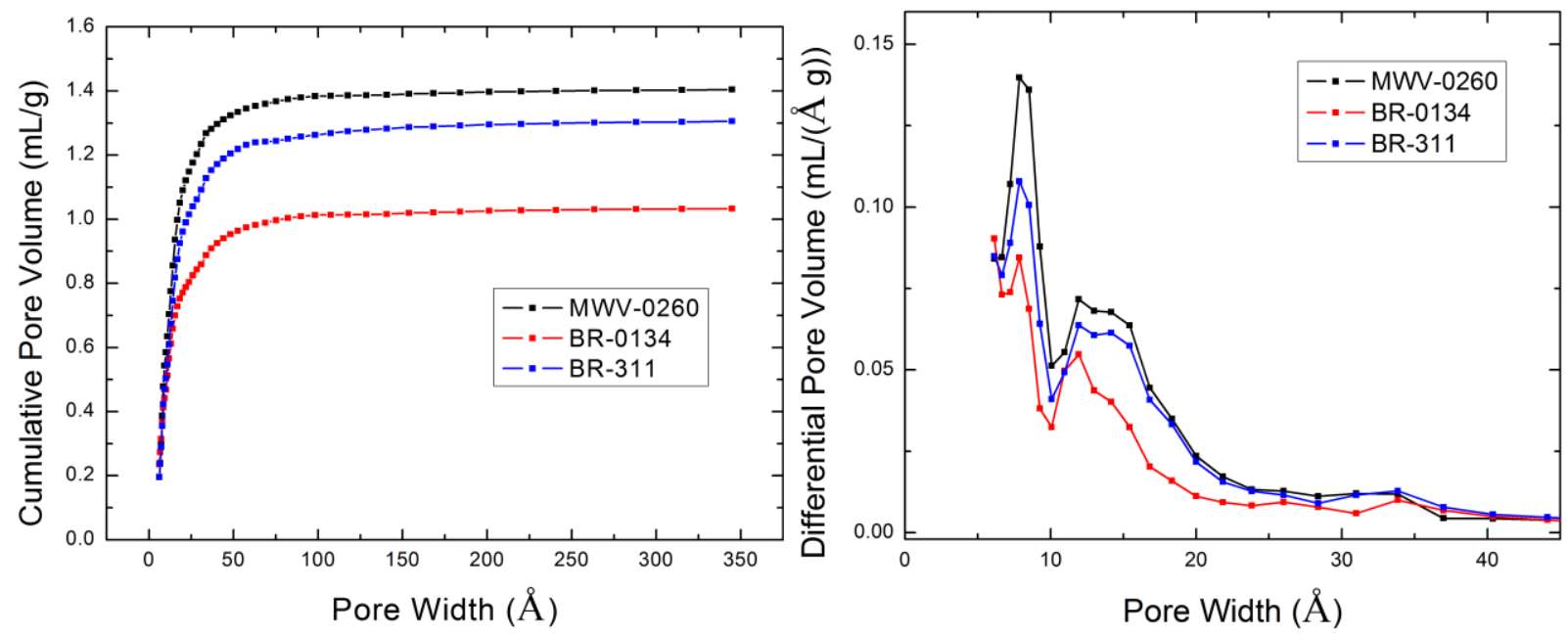

Figure 164. Cumulative pore volume and differential pore volume data obtained from QSDFT analysis of sub-critical nitrogen isotherms using an assumption of nearly slit-shaped pores. MWV-0260 is a powder sample representative of the precursors used to synthesize BR-0134 and BR-0311. All pore structures are similar in that they are bimodal about $8 \AA$ and $15 \AA$ slit-shaped pores. The monolithic samples lost pore volume because a PVDC-based binder was used during their synthesis, which tends to yield samples with lower pore volumes.

The plot of cumulative pore volume represents the amount of pore volume attributed to slit shaped pores up to a given width. For activated carbon samples, the majority of pore volume can be attributed to pores with widths less than $30 \AA$. From sub-critical nitrogen isotherms, it is easy to determine the total pore volume. Using pycnometry measurements, we can determine the skeletal volume. With these two measurements, the void fraction or "porosity" of the material may be determined.

The void fraction of an individual crystal of adsorbent material can be defined as:

$$
\phi_{\text {crystalline }}=\frac{V_{\text {pores }}}{V_{\text {pores }}+V_{\text {sk }}}=\frac{V_{\text {pores }}}{V_{\text {pores }}\left(1+\rho_{\mathrm{sk}}^{-1}\right)}
$$

This represents the fraction of the total crystalline system that is occupied by void space. Similarly, we can define any fraction of the void space:

$$
\phi_{(\mathrm{i}-\mathrm{j})}=\frac{V_{(\mathrm{i}-\mathrm{j})}}{V_{\text {system }}}=\frac{V_{(\mathrm{i}-\mathrm{j})}}{V_{\text {pores }}+V_{\text {sk }}}=\rho_{\text {system }} \frac{V_{(\mathrm{i}-\mathrm{j})}}{m_{\text {system }}}
$$

The definition of the system density is expressed

$$
\rho_{\text {system }}=\frac{m_{\text {system }}}{V_{\text {system }}}=\rho_{\text {sk }}\left(1-\phi_{\text {crystalline }}\right)
$$


Substituting Eq (115) into Eq (114) allows one to describe any fraction of the void space in terms of the crystalline porosity and skeletal density as

$$
\phi_{(\mathrm{i}-\mathrm{j})}=\frac{V_{(\mathrm{i}-\mathrm{j})}}{m_{\text {system }}}\left(1-\phi_{\text {crystalline }}\right) \rho_{\text {sk }}
$$

Let this quantity be defined as the "nanoporosity" of a material. It represents the fraction of the total void space attributed to pores with a select range of pore widths. For example, sample MWV-0260 has a nanoporosity of approximately 0.38 for pores with widths between $0-13 \AA$. This means that $38 \%$ of its total system volume $\left(V_{\mathrm{sk}}+V_{\text {pore }}\right)$ is attributed to pores that are less than $13 \AA$ in width. Up until this point, $\phi_{\text {nano }}(0-13 \AA)$ has been referred to as the "sub-nanometer volume fraction" of the material. This quantity may be used to examine which pore widths foster high volumetric storage capacities.

\subsection{Discrete Two-Fluid Model: Comparisons with Experimental Storage Capacities Nanoporosity and Storage Capacities for Hydrogen:}

Assuming slit-shaped pores and interpretation of the cumulative pore volume allows one to determine the fraction of the total pore volume that is comprised of sub-nanometer pores. A higher fraction of sub-nanometer pores should translate into higher storage capacities due to overlapping Van der Waals potentials. In an irreverent manner, one can plot all available performance data against nanoporosities and observe this relationship. Samples with lower porosities tend to have lower surface areas, which should translate into lower excess adsorption. However, samples with a high fraction of sub-nanometer pores should perform better with respect to volumetric storage capacity. 


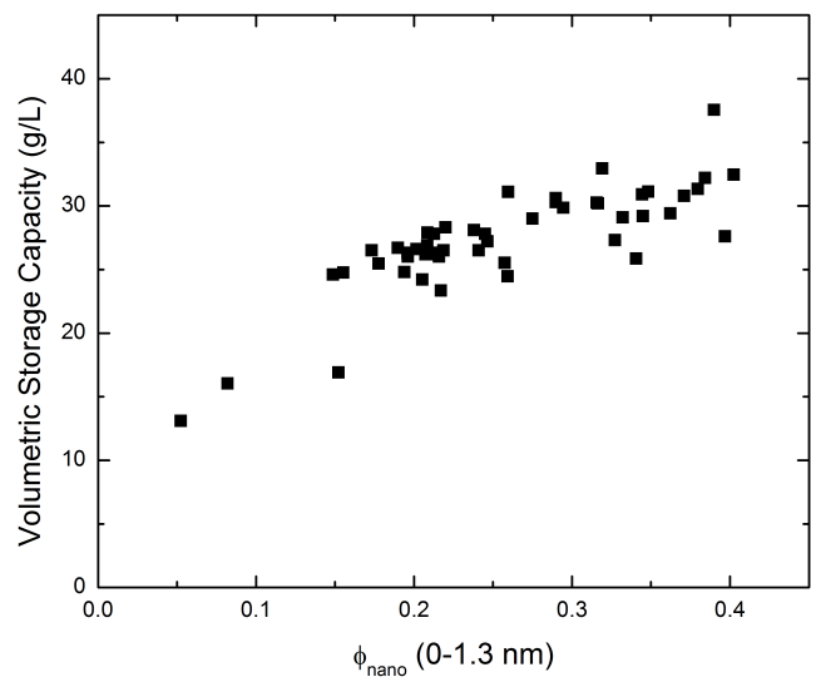

Figure 165 . Volumetric storage capacity at $\mathrm{P}=25$ bar and $\mathrm{T}=77 \mathrm{~K}$ versus $\phi_{\text {nano }}(0-13 \AA)$.

Samples with low sub-nanometer volume fractions tend to perform worse with respect to volumetric storage capacities because there is less volume occupied by the high binding energy sites provided from overlapping Van der Waals potentials. Samples with large sub-nanometer volume fractions are able to store a larger quantity of high density, adsorbed gas.

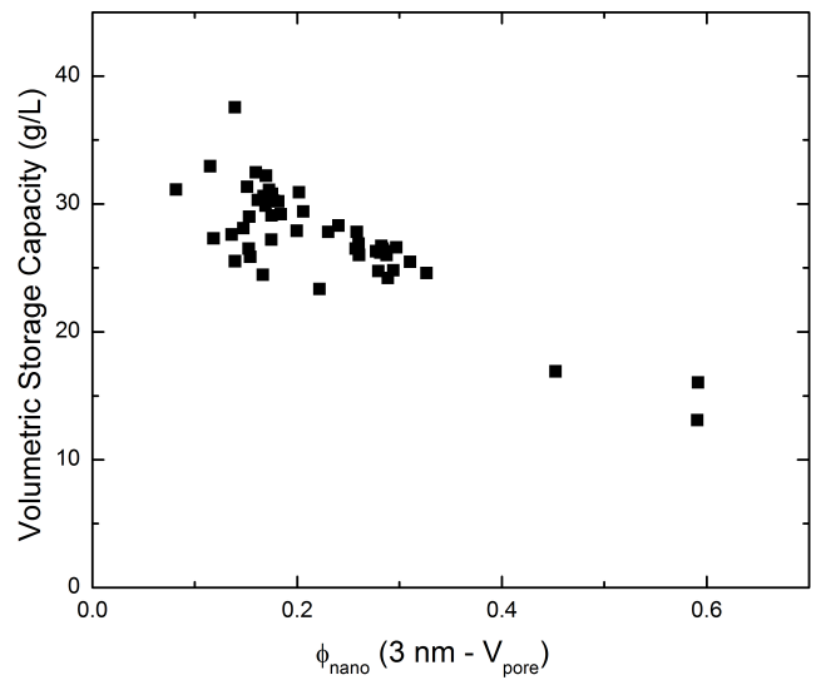

Figure 166 . Volumetric storage capacity at $\mathrm{P}=25$ bar and $\mathrm{T}=77 \mathrm{~K}$ versus $\phi_{\text {nano }}\left(30 \AA-V_{\text {pore }}\right)$.

Samples comprised of large average pore widths tend to perform worse with respect to volumetric storage capacities because more of their volume is occupied by low density compressed gas and less volume is occupied by the high binding energy sites provided from overlapping Van der Waals potentials. The two 
figures above serve as direct evidence that small pores facilitate high density gas storage across a wide range of samples. This trend is present regardless of differences in synthesis conditions, boron contents, and surface areas.

Table 31: Tabular data for nanoporosity and volumetric storage capacity of hydrogen at $77 \mathrm{~K}$ at various pressure increments.

\begin{tabular}{|l|r|r|r|r|r|r|r|}
\hline $\begin{array}{l}\text { Sample } \\
\text { Name }\end{array}$ & \multicolumn{1}{c|}{$\begin{array}{c}\phi_{\text {nano }} \\
(0-13 \AA)\end{array}$} & $\begin{array}{c}\phi_{\text {nano }} \\
\left(30 \AA-V_{\text {pore }}\right)\end{array}$ & $\begin{array}{c}V_{\text {st }} \\
(\mathrm{P}=5 \text { bar })\end{array}$ & $\begin{array}{c}V_{\text {st }} \\
(\mathrm{P}=10 \text { bar })\end{array}$ & $\begin{array}{c}V_{\text {st }} \\
(\mathrm{P}=25 \text { bar })\end{array}$ & $\begin{array}{c}V_{\text {st }} \\
(\mathrm{P}=35 \text { bar })\end{array}$ & $\begin{array}{c}V_{\text {st }} \\
(\mathrm{P}=50 \text { bar })\end{array}$ \\
\hline MWV-0260 & .380 & .151 & 20.9 & 25.1 & 31.0 & 33.8 & 37.1 \\
\hline BR-0134 & .371 & .176 & 22.0 & 25.4 & 30.7 & 33.1 & 36.1 \\
\hline BR-0311 & .345 & .184 & 19.2 & 22.8 & 28.8 & 31.5 & 35.0 \\
\hline $6 \mathrm{~K}-0802$ & .149 & .327 & 14.3 & 17.9 & 24.6 & 27.7 & 32.0 \\
\hline 5K-0280 & .173 & .283 & 15.9 & 19.6 & 26.5 & 29.9 & 34.0 \\
\hline 4K-0284 & .220 & .241 & 17.7 & 21.7 & 28.3 & 31.7 & 35.6 \\
\hline 3K-0285 & .316 & .177 & 21.5 & 25.6 & 32.1 & 34.9 & 38.4 \\
\hline 2K-0286 & .362 & .206 & 21.3 & 24.5 & 29.4 & 32.0 & 34.9 \\
\hline
\end{tabular}
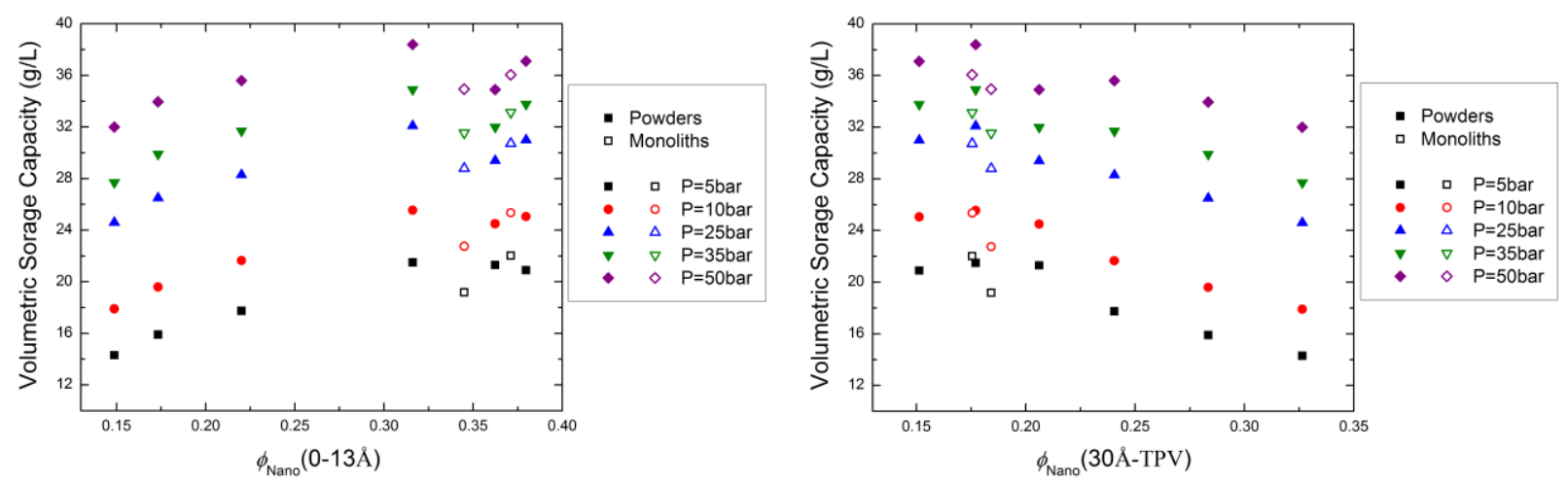

Figure 167. Volumetric storage capacity of hydrogen at $77 \mathrm{~K}$ versus nanoporosity. Volumetric storage capacity is observed to increase with increasing nanoporosity for pores less than $13 \AA$ in width and decrease with increasing porosity for pores with widths greater than $30 \AA$.

At sufficiently low pressures, volumetric storage increases with increasing $\phi_{\text {nano }}(0-13 \AA)$ and decreasing $\phi_{\text {nano }}(30 \AA$-TPV). At pressures above 40 bar, the adsorbed film begins to saturate. As bulk gas 183 
densifies, the volumetric storage capacity no longer correlates well with $\phi_{\text {nano. }}$ Consider a single crystal of adsorbent carbonaceous material.
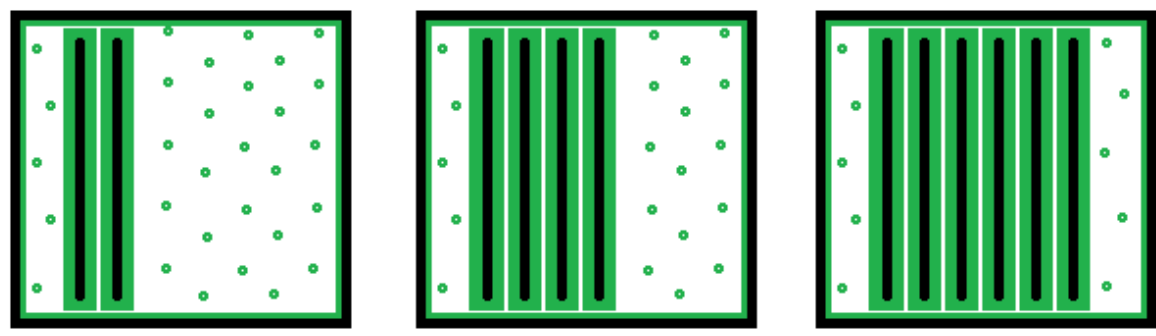

Figure 168. A single crystal of carbonaceous adsorbent material with increasing $\phi_{\text {nano }}(0-13 \AA)$ and decreasing $\phi_{\text {nano }}(30 \AA$-TPV).

Gas will condense such that the adsorbed film is close to the adsorbent surface. The smallest pores will contain mostly adsorbed gas occupying the smallest pores will condense into the adsorbed state where there exist overlapping Van der Waals potentials. The larger pores will consist of mostly compressed gas and little gas in the adsorbed state. A higher fraction of the void space that can be attributed to nanopores should indicate a larger volume occupied by the adsorbed state, which should correlate to a higher volumetric storage capacity. 


\section{Nanoporosity \& Storage Capacities for Methane}

Table 32: Tabular Data for volumetric storage capacity of methane at $296 \mathrm{~K}$ and nanoporosity.

\begin{tabular}{|l|r|r|r|}
\hline $\begin{array}{l}\text { Sample } \\
\text { Name }\end{array}$ & $\begin{array}{c}\phi_{\text {nano }} \\
(0-13 \AA)\end{array}$ & $\begin{array}{c}\phi_{\text {nano }} \\
\left(30 \AA-V_{\text {pore }}\right)\end{array}$ & $\begin{array}{c}V_{\text {st }} \\
(\mathrm{P}=35 \text { bar })\end{array}$ \\
\hline MWV-0260 & 0.380 & 0.151 & 105 \\
\hline BR-0134 & 0.371 & 0.175 & 108 \\
\hline BR-0311 & 0.345 & 0.184 & 113 \\
\hline 5K-0280 & 0.173 & 0.283 & 86 \\
\hline 4K-0284 & 0.220 & 0.241 & 92 \\
\hline 3K-0285 & 0.316 & 0.177 & 103 \\
\hline 2K-0286 & 0.362 & 0.206 & 102 \\
\hline 1.85-099 & 0.397 & 0.178 & 111 \\
\hline BR-0353 & 0.327 & 0.178 & 109 \\
\hline BR-0343 & 0.331 & 0.171 & 105 \\
\hline BR-0311 & 0.345 & 0.184 & 113 \\
\hline BR-0323 & 0.346 & 0.167 & 110 \\
\hline BR-0132 & 0.387 & 0.148 & 106 \\
\hline BR-0152 & 0.267 & 0.195 & 93 \\
\hline BR-0134 & 0.371 & 0.176 & 103 \\
\hline BR-0117 & 0.374 & 0.148 & \\
\hline BR-0122 & 0.390 & 0.139 & 0.227 \\
\hline BR-0162 & 0.309 & 0.192 & \\
\hline BR-0130 & 0.286 & 03 & \\
\hline
\end{tabular}



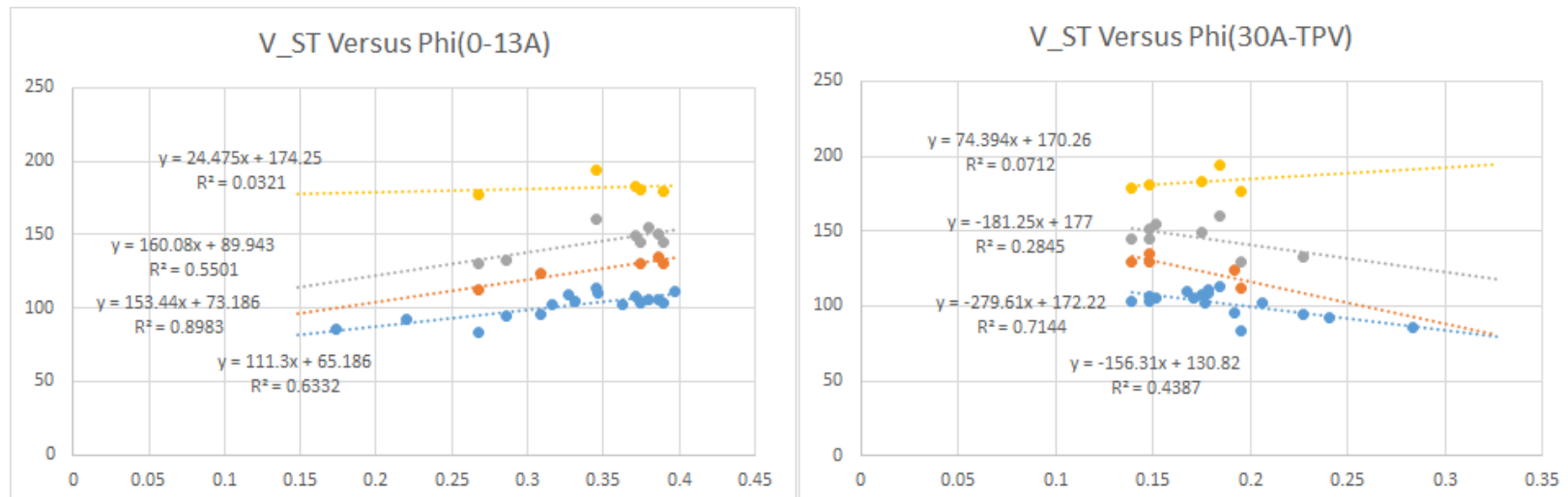

Figure 169. Volumetric storage capacity of methane at $296 \mathrm{~K}$ versus nanoporosity. As with hydrogen, the methane volumetric storage capacity is observed to increase with increasing nanoporosity for pores less than $13 \AA$ in width and decrease with increasing porosity for pores with widths greater than $30 \AA$.

Focusing only on methane data at $296 \mathrm{~K}$ and $35 \mathrm{bar}$, two rough linear functions relate volumetric storage and nanoporosity. The first relation is an increasing linear function is given by:

$$
V_{\text {st }}=111.3(\mathrm{~g} / \mathrm{L}) \phi_{\text {nano }}(0-13 \AA)+65.186(\mathrm{~g} / \mathrm{L})
$$

The second is a decreasing linear function given by:

$$
V_{\text {st }}=-156.31(\mathrm{~g} / \mathrm{L}) \phi_{\text {nano }}(30 \AA-T P V)+130.82(\mathrm{~g} / \mathrm{L})
$$

These two correlations were applied to pore size data from various samples in an attempt to predict adsorbed amounts for other materials. Six additional arbitrary materials spanning a wide range of nanoporosities have been analyzed. The two linear models were employed in attempt to predict the storage performance of the six arbitrary materials. 
Table 33: Tabular Data for modeled and experimental volumetric storage capacities of methane at $296 \mathrm{~K}$.

\begin{tabular}{|c|c|c|c|c|c|c|c|}
\hline $\begin{array}{l}\text { Sample } \\
\text { Name }\end{array}$ & $\begin{array}{c}\phi_{\text {nano }} \\
(0-13 \AA)\end{array}$ & $\begin{array}{c}\phi_{\text {nano }} \\
\left(30 \AA-V_{\text {pore }}\right)\end{array}$ & $\begin{array}{c}V_{\mathrm{st}}-\operatorname{Exp} \\
(\mathrm{P}=35 \text { bar })\end{array}$ & $\begin{array}{c}V_{\mathrm{st}} \\
\text { from inc. } \\
\text { model } \\
(\mathrm{P}=35 \mathrm{bar})\end{array}$ & $\begin{array}{c}V_{\mathrm{st}} \\
\text { from dec. } \\
\text { model } \\
(\mathrm{P}=35 \mathrm{bar})\end{array}$ & $\begin{array}{c}\% \text { diff. } \\
\text { between } \\
\text { models }\end{array}$ & $\begin{array}{c}\% \text { diff. } \\
\text { between } \\
\text { Avg - Exp } \\
\text { Values }\end{array}$ \\
\hline MWV-0260 & 0.380 & 0.151 & 105 & 107.4 & 107.2 & 0.1 & 2.2 \\
\hline BR-0134 & 0.371 & 0.175 & 108 & 106.5 & 103.4 & 1.5 & 2.9 \\
\hline BR-0311 & 0.345 & 0.184 & 113 & 103.6 & 102.0 & 0.8 & 9.5 \\
\hline $5 \mathrm{~K}-0280$ & 0.173 & 0.283 & 86 & 84.5 & 86.5 & 1.2 & 0.6 \\
\hline $4 \mathrm{~K}-0284$ & 0.220 & 0.241 & 92 & 89.7 & 93.2 & 1.9 & 0.6 \\
\hline $3 \mathrm{~K}-0285$ & 0.316 & 0.177 & 103 & 100.4 & 103.1 & 1.3 & 1.2 \\
\hline $2 \mathrm{~K}-0286$ & 0.362 & 0.206 & 102 & 105.5 & 98.6 & 3.4 & 0.0 \\
\hline $1.85-099$ & 0.397 & 0.178 & 111 & 109.4 & 103.0 & 3.1 & 4.4 \\
\hline BR-0353 & 0.327 & 0.178 & 109 & 101.5 & 102.9 & 0.7 & 6.4 \\
\hline BR-0343 & 0.331 & 0.171 & 105 & 102.0 & 104.1 & 1.0 & 1.9 \\
\hline BR-0323 & 0.346 & 0.167 & 110 & 103.7 & 104.7 & 0.5 & 5.4 \\
\hline BR-0132 & 0.387 & 0.148 & 106 & 108.3 & 107.7 & 0.3 & 1.9 \\
\hline BR-0152 & 0.267 & 0.195 & 83 & 94.9 & 100.3 & 2.7 & 16.2 \\
\hline BR-0117 & 0.374 & 0.148 & 103 & 106.8 & 107.6 & 0.4 & 4.0 \\
\hline BR-0122 & 0.390 & 0.139 & 103 & 108.6 & 109.0 & 0.2 & 5.5 \\
\hline BR-0162 & 0.309 & 0.192 & 96 & 99.6 & 100.8 & 0.6 & 4.3 \\
\hline BR-0130 & 0.286 & 0.227 & 94 & 97.0 & 95.3 & 0.9 & 2.3 \\
\hline $1.85 \mathrm{~K}-0257$ & 0.415 & 0.166 & 111.4 & 111.4 & 105.0 & 3.0 & 2.9 \\
\hline $1.6 \mathrm{~K}-0277$ & 0.388 & 0.201 & 108.8 & 108.4 & 99.3 & 4.5 & 4.7 \\
\hline $2.5 \mathrm{~K}-0086$ & 0.413 & 0.137 & 115.2 & 111.2 & 109.4 & 0.8 & 4.3 \\
\hline $2.67 \mathrm{~K}-0278$ & 0.341 & 0.157 & 106.2 & 103.1 & 106.3 & 1.5 & 1.4 \\
\hline $3 \mathrm{~K}-0046$ & 0.209 & 0.200 & 93.1 & 88.4 & 99.6 & 5.8 & 1.0 \\
\hline $\begin{array}{l}\text { MWV-0302 - } \\
\text { Sawdust }\end{array}$ & 0.439 & 0.136 & - & 114.1 & 109.6 & 2.0 & - \\
\hline
\end{tabular}


With exception to sample BR-0152, the predicted values for volumetric storage capacity agree well with experimentally determined values. These predictions for volumetric storage capacities may be converted in order to predict gravimetric excess adsorption values. Recall that the volumetric storage capacity is expressed as

$$
V_{\mathrm{st}}=\frac{m_{\mathrm{st}}}{m_{\mathrm{s}}} \rho_{\text {system }}=\frac{m_{\mathrm{exc}}}{m_{\mathrm{s}}} \rho_{\mathrm{sk}}(1-\phi)+\rho_{\mathrm{H}_{2}} \phi
$$

One may rearrange this this relation for gravimetric excess adsorption. In terms of volumetric storage capacity and skeletal density, gravimetric excess adsorption may be expressed as

$$
\frac{m_{\mathrm{exc}}}{m_{\mathrm{s}}}=\left(V_{\mathrm{st}}-\rho_{\mathrm{H}_{2}} \phi\right) /\left(\rho_{\mathrm{sk}}(1-\phi)\right)
$$


Table 34: Tabular Data for modeled and experimental gravimetric excess adsorption of methane at $296 \mathrm{~K}$.

\begin{tabular}{|c|c|c|c|c|c|c|c|}
\hline Sample Name & $\begin{array}{c}\phi_{\text {nano }} \\
(0-13 \AA)\end{array}$ & $\begin{array}{c}\phi_{\text {nano }} \\
\left(30 \AA-V_{\text {pore }}\right)\end{array}$ & $\begin{array}{l}G_{\text {exc }}-\text { Exp } \\
(\mathrm{P}=35 \mathrm{bar})\end{array}$ & $\begin{array}{c}G_{\text {exc }} \\
\text { from inc. } \\
\text { model } \\
(\mathrm{P}=35 \mathrm{bar})\end{array}$ & $\begin{array}{c}G_{\text {exc }} \\
\text { from dec. } \\
\text { model } \\
(\mathrm{P}=35 \mathrm{bar})\end{array}$ & $\begin{array}{c}\% \text { diff. } \\
\text { between } \\
\text { models }\end{array}$ & $\begin{array}{c}\% \text { diff. } \\
\text { between } \\
\text { Avg - Exp } \\
\text { Values }\end{array}$ \\
\hline MWV-0260 & 0.380 & 0.151 & 177.6 & 182.0 & 181.5 & 0.2 & 2.3 \\
\hline BR-0134 & 0.371 & 0.175 & 142.1 & 147.6 & 142.5 & 1.8 & 2.0 \\
\hline BR-0311 & 0.345 & 0.184 & 165.5 & 166.8 & 163.8 & 0.9 & 0.1 \\
\hline $5 \mathrm{~K}-0280$ & 0.173 & 0.283 & 197.5 & 196.8 & 203.0 & 1.6 & 1.2 \\
\hline $4 \mathrm{~K}-0284$ & 0.220 & 0.241 & 193.7 & 186.1 & 195.5 & 2.4 & 1.5 \\
\hline $3 \mathrm{~K}-0285$ & 0.316 & 0.177 & 182.9 & 179.7 & 185.8 & 1.7 & 0.0 \\
\hline $2 \mathrm{~K}-0286$ & 0.362 & 0.206 & 142.1 & 148.0 & 136.4 & 4.1 & 0.1 \\
\hline $1.85-099$ & 0.397 & 0.178 & 174.1 & 168.9 & 157.1 & 3.7 & 6.6 \\
\hline BR-0353 & 0.327 & 0.178 & - & 161.1 & 163.8 & 0.8 & - \\
\hline BR-0343 & 0.331 & 0.171 & - & 163.9 & 167.9 & 1.2 & - \\
\hline BR-0323 & 0.346 & 0.167 & - & 156.8 & 158.5 & 0.5 & - \\
\hline BR-0132 & 0.387 & 0.148 & 156.7 & 151.0 & 150.1 & 0.3 & 4.0 \\
\hline BR-0152 & 0.267 & 0.195 & - & 156.0 & 166.9 & 3.3 & - \\
\hline BR-0117 & 0.374 & 0.148 & 138.5 & 142.8 & 144.1 & 0.4 & 3.5 \\
\hline BR-0122 & 0.390 & 0.139 & 144.6 & 136.4 & 137.1 & 0.2 & 5.5 \\
\hline BR-0162 & 0.309 & 0.192 & 131.1 & 142.6 & 144.8 & 0.8 & 9.2 \\
\hline BR-0130 & 0.286 & 0.227 & 117.9 & 122.1 & 119.5 & 1.1 & 2.4 \\
\hline $1.85 \mathrm{~K}-0257$ & 0.415 & 0.166 & 162.7 & 161.3 & 150.3 & 3.6 & 4.3 \\
\hline $1.6 \mathrm{~K}-0277$ & 0.388 & 0.201 & 163.5 & 160.4 & 144.4 & 5.4 & 7.0 \\
\hline $2.5 \mathrm{~K}-0086$ & 0.413 & 0.137 & 174.8 & 167.5 & 164.3 & 0.9 & 5.2 \\
\hline $2.5 \mathrm{~K}-0278$ & 0.341 & 0.157 & 190.6 & 181.0 & 187.9 & 1.8 & 3.3 \\
\hline $3 \mathrm{~K}-0046$ & 0.209 & 0.200 & 200.4 & 191.2 & 222.4 & 7.3 & 3.1 \\
\hline $\begin{array}{l}\text { MWV-0302 - } \\
\text { Sawdust }\end{array}$ & 0.439 & 0.136 & 175.6 & 170.4 & 162.6 & 2.4 & 5.3 \\
\hline
\end{tabular}


With exception to two of these samples, values predicted from the nanoporosity agree with experimental values within $5 \%$ difference.
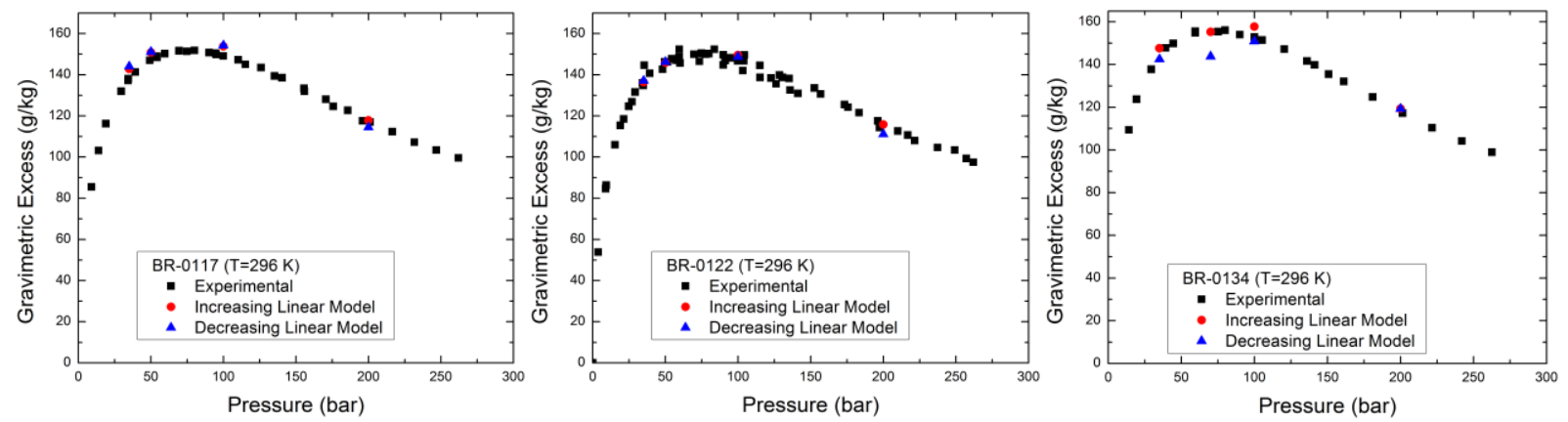

Figure 170. Experimental and predicted methane gravimetric excess adsorption values for BR-0117, BR0122, and BR-0134 at $296 \mathrm{~K}$. For these particular samples, the nanoporosity correlations were used to predict the gravimetric excess adsorption with reasonable accuracy at higher pressures as well.

By using universalities of the adsorbed film along with information about the nanostructure of the pores, it is possible to predict the volumetric storage capacities and gravimetric excess adsorption of materials with a high degree of accuracy. It was possible to predict gravimetric excess adsorption of methane on select materials over pressures ranging up to 200 bar. 


\section{Conclusions}

Pore geometries may be tuned by varying the amount of $\mathrm{KOH}$ used during activation. The best $\mathrm{KOH}: \mathrm{C}$ activation ratio for high volumetric storage capacities and isosteric heats of adsorption is between 2-3. Pore geometries and interaction energies may be tuned by incorporating boron into the carbon lattice. Specific surface areas tend to increase with increasing activation ratios as more potassium intercalation causes a higher defect concentration.

Sample 5K-0215 was boron doped with $8.1 \mathrm{wt} \%$ (PGNAA). XPS measurements revealed that this sample was well-doped and achieved $1.7 \mathrm{wt} \% \mathrm{sp}^{2} \mathrm{~B}-\mathrm{C}$ bonds. This sample also exhibited an increase in zero-coverage isosteric heat compared to its precursor materials. However, it had a lower excess adsorption due to the decrease in surface area. This sample had an increased areal excess adsorption, which also indicates that the binding energy of hydrogen to the surface was increased excluding any affect due to surface area. The isosteric heat near zero coverage may be obtained by applying Henry's Law to the low pressure regime of the excess adsorption isotherm. In this regime, the isosteric heat is less sensitive to the choice of adsorbed film volume. Boron doped samples show promise with isosteric heats of adsorption up to $9.6 \mathrm{~kJ} / \mathrm{mol}$. However, it will be necessary to incorporate a higher weight percent of $\mathrm{sp}^{2} \mathrm{~B}-\mathrm{C}$ bonds while maintaining high surface areas in order to significantly alter the storage performance.

All saturated, adsorbed film densities of hydrogen at $77 \mathrm{~K}$ converge upon the same value of approximately $100 \mathrm{~g} / \mathrm{L}$, which is much higher than its liquid density at $20 \mathrm{~K}(71 \mathrm{~g} / \mathrm{L})$. Further, two samples were investigated at temperatures ranging from $77-180 \mathrm{~K}$. The saturated, adsorbed film density did not appear to change significantly with increasing temperatures for these two samples. If $100 \mathrm{~g} / \mathrm{L}$ is a "universal" density of adsorbed hydrogen films, then this serves as an incredibly useful tool for predicting the excess adsorption, storage capacities, isosteric heat, and properties of the adsorbed film as a function of temperature for any arbitrary sample. The adsorbed hydrogen film thickness is approximately $3.1-3.2 \AA$ for all samples measured at temperatures between $77-180 \mathrm{~K}$. All saturated, adsorbed film densities of methane appear to converge upon an approximate value of $400 \pm 50 \mathrm{~g} / \mathrm{L}$ within a temperature range of 191 
193-296 K. Measuring the properties of the adsorbed film at high gas densities allows one to determine the saturated adsorbed film volume. An appropriate estimate of the adsorbed film volume is necessary to convert excess adsorption into absolute adsorption, which allows one to apply the Clausius-Clapeyron relation to determine isosteric heats of adsorption with reasonable accuracy. When determining the isosteric heat of adsorption, researchers typically assume that the adsorbed film volume is equal to the total pore volume, which may result in isosteric heats that are underestimated by over $3 \mathrm{~kJ} / \mathrm{mol}$ for hydrogen and over $5 \mathrm{~kJ} / \mathrm{mol}$ for methane.

The two-fluid models of adsorption utilizing "universal" adsorbed gas densities were successful in predicting hydrogen volumetric storage capacities of various materials. The discrete two-fluid model only requires one to analyze the low-pressure nitrogen adsorption isotherms and is independent of specific surface area. These methods tend to overestimate storage capacity and excess adsorption of hydrogen by approximately 5\%. This model is highly dependent upon the accuracy of the cumulative pore volumes obtained from QSDFT. If the model significantly overestimates these metrics, this indicates that the adsorbent surface has a lower binding energy to hydrogen. 


\section{Appendix}

\subsection{Redlich-Peterson and Modified Redlich-Peterson Models}

As the name suggests, the Modified Redlich-Peterson Model is an altered version of the RedlichPeterson Model. The Redlich-Peterson Model is expressed

$$
\frac{m_{\mathrm{abs}}(p, T)}{m_{\mathrm{s}}}=\frac{a p}{1+b p^{c}}
$$

where $a, b$, and $c$ are empirical constants and $c$ lies between 0 and 1 . This model is in accordance with the low-pressure limit of the Langmuir Model and satisfies Henry's Law. The model usually fits experimental data to a high degree (typical $\mathrm{R}^{2}$ values exceeding 0.999), but is inconvenient for the purpose of interpolating between experimental data points. This model is not directly solvable for the pressure for a given adsorbed amount. Thus, numeric methods are required to determine the pressure at which a constant number of particles exist in the adsorbed phase. I present a modified version of the Redlich-Peterson Model that is directly solvable for pressure without numeric methods. An additional benefit is that this model typically fits high pressure experimental data with a higher degree of accuracy. The Modified RedlichPeterson Model is expressed

$$
\frac{m_{\mathrm{abs}}(p, T)}{m_{\mathrm{s}}}=\frac{a(b p)^{1-c}}{1+(b p)^{1-c}}
$$

where $a, b$, and $c$ are empirical constants. Though model is appropriate for interpolating between high pressure isothermal data, it is important to note that it is not in accordance with the low pressure limit of the Langmuir Model and holds no physical significance. Therefore, it should only be applied to high pressure data.

\subsection{Hiden Calibrations}

The Hiden instrument is nearly calibrated to take measurements at $77 \mathrm{~K}, 87 \mathrm{~K}, 100 \mathrm{~K}, 110 \mathrm{~K} 120 \mathrm{~K}$, $130 \mathrm{~K}, 153 \mathrm{~K}, 173 \mathrm{~K}, 193 \mathrm{~K}, 223 \mathrm{~K}, 253 \mathrm{~K}, 273 \mathrm{~K}$, \& $296 \mathrm{~K}$. We are in the process of taking blank isotherms at $77-153 \mathrm{~K}$. 


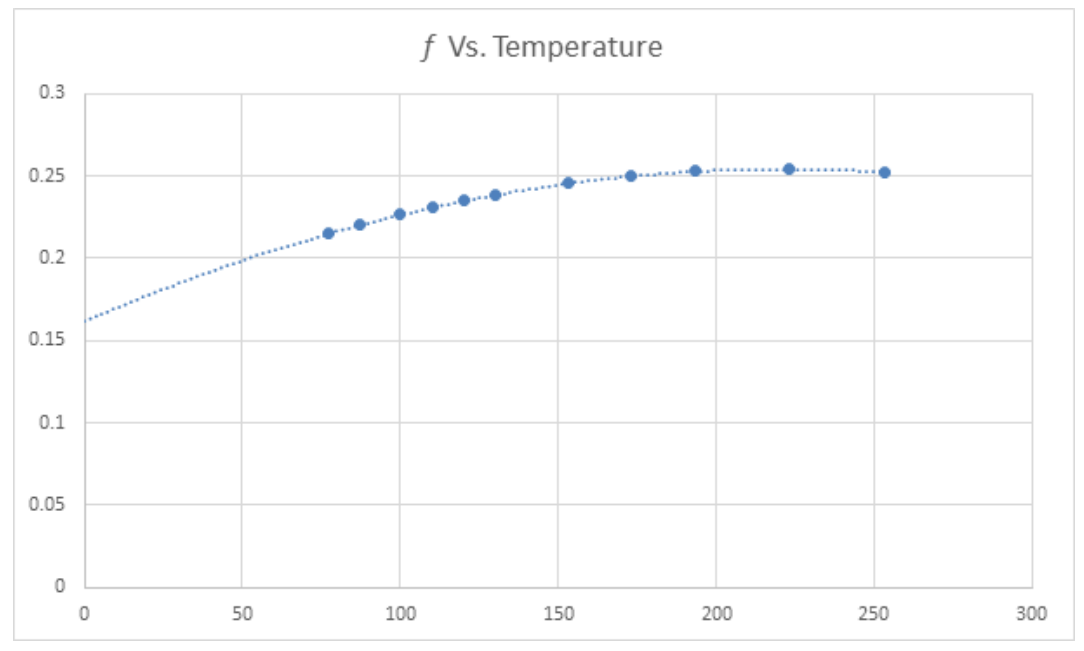

Figure 171. Fractional volumes at temperatures ranging from 77-273 K. The volume represents the percentage of the reactor volume that is kept at a given temperature during an isothermal measurement. It is used to approximate the thermal gradient.

\subsection{Error Calculation and Instrument Validation}

Excess adsorption measurements were validated internally and externally. Internal validation was performed by comparing measurements from the HTP-1 with a custom built sorption instrument named the MU-7K instrument. Select samples were sent to the National Renewable Energy Laboratory (NREL) for measurement validation.

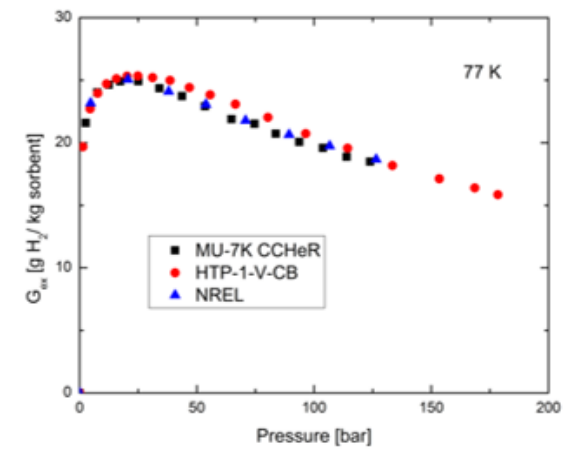

$800 \mathrm{~m}^{2} / \mathrm{g}$ material

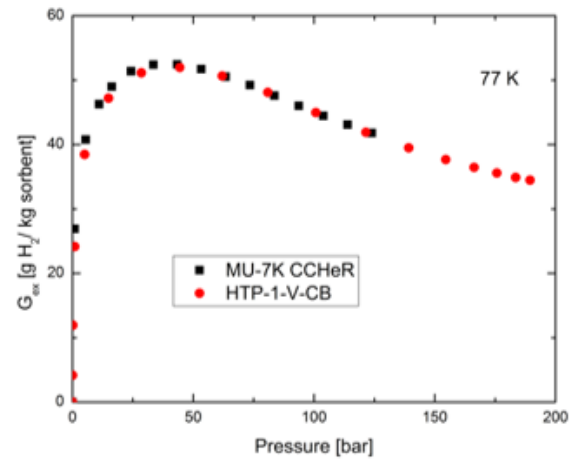

$2300 \mathrm{~m}^{2} / \mathrm{g}$ material

Agreement within 2\%

Figure 172. Excess adsorption measurements for samples HS;0B-20 and 4K-0245 measured on the HTP-1, MU-7K, and NREL instrumentation. 
Equations used to calculate excess adsorption and error estimation:

$$
\frac{m_{\mathrm{exc}}}{m_{\mathrm{s}}}=\frac{1}{m_{\mathrm{s}}}\left[\sum_{i=1}^{k}\left(\rho_{1 i}-\rho_{3(i-1)}\right) V_{\mathrm{d}}-\left[\rho_{2 \mathrm{i}}\left(V_{\mathrm{d}}+V_{\mathrm{R}}\left(1-f_{\mathrm{o}}\right)\right)+\rho^{\prime}{ }_{2 \mathrm{i}} V_{\mathrm{R}} f_{\mathrm{o}}(1-f)+\rho^{\prime \prime}{ }_{2 \mathrm{i}}\left(V_{\mathrm{R}} f_{\mathrm{o}} f-V_{\text {sample }}\right)\right]\right]
$$

Excess adsorption calculations depend on a variety of variables such as temperatures, volumes of the dosing respectively reactor site, pressures and sample volume. Each of them contains an uncertainty which affects the calculation, and their effect can be calculated by the method of propagation of uncertainty. This requires calculating partial derivatives of Gex with respect to all variables and the cumulative uncertainty is obtained via linearized partial derivate approximation according to

$$
\Delta G_{\mathrm{exc}}=\sqrt{\begin{array}{c}
\left(\frac{\partial G_{\mathrm{exc}}}{\partial m_{\mathrm{s}}}\right)^{2} \Delta m_{\mathrm{s}}{ }^{2}+\left(\frac{\partial G_{\mathrm{exc}}}{\partial \rho_{1 i}}\right)^{2} \Delta \rho_{1 i}{ }^{2}+\left(\frac{\partial G_{\mathrm{exc}}}{\partial \rho_{3(i-1)}}\right)^{2} \Delta \rho_{3(i-1)}{ }^{2}+\left(\frac{\partial G_{\mathrm{exc}}}{\partial V_{\mathrm{d}}}\right)^{2} \Delta V_{\mathrm{d}}{ }^{2} \\
+\left(\frac{\partial G_{\mathrm{exc}}}{\partial \rho_{2 \mathrm{i}}}\right)^{2} \Delta \rho_{2 \mathrm{i}}{ }^{2}+\left(\frac{\partial G_{\mathrm{exc}}}{\partial V_{\mathrm{R}}}\right)^{2} \Delta{V_{\mathrm{R}}}^{2}+\left(\frac{\partial G_{\mathrm{exc}}}{\partial f_{\mathrm{o}}}\right)^{2} \Delta{f_{\mathrm{o}}}^{2}+\left(\frac{\partial G_{\mathrm{exc}}}{\partial \rho^{\prime}{ }_{2 \mathrm{i}}}\right)^{2} \Delta \rho_{2 \mathrm{i}}^{\prime}{ }^{2} \\
+\left(\frac{\partial G_{\mathrm{exc}}}{\partial f}\right)^{2} \Delta f^{2}+\left(\frac{\partial G_{\mathrm{exc}}}{\partial \rho^{\prime \prime}{ }_{2 \mathrm{i}}}\right)^{2} \Delta \rho_{2 \mathrm{i}}^{\prime \prime}{ }^{2}+\left(\frac{\partial G_{\mathrm{exc}}}{\partial V_{\text {sample }}}\right)^{2} \Delta V_{\text {sample }}{ }^{2}
\end{array}}
$$

Typical sample masses were $m=200 \pm 1 \mathrm{mg}$. Uncertainties in gas densities are dependent upon the instrumentation in that different equipment is able to maintain pressures and temperatures to a higher degree of accuracy. The Hiden Isochema HTP-1 instrument was able to maintain temperatures within $0.1 \mathrm{C}$

The uncertainties in system and sample volumes $V_{\mathrm{d}}, V_{\mathrm{R}}$, and $V_{\mathrm{s}}$ were estimated from the standard deviation governed from multiple volume calibrations using helium pycnometry. A precision balance from Mettler (PB503-s/Fact) with an error of $0.001 \mathrm{~g}$ was used to determine the adsorbent's dry mass. Typical sample masses were $m=200 \pm 1 \mathrm{mg}$. Uncertainties in gas densities are dependent upon the accuracy of the pressures and temperatures. The error in pressure is proportional to the accuracy of the pressure transducer picked for the experiment. Both the Hiden HTP-1 and MU-7K instruments were equipped with similar pressure transducers; A high pressure transducer with an operating range from 0 to 200 bar and a low pressure transducer working from 0 to 2 bar, resulting in different uncertainties depending which one is used. The full-scale accuracy of the high pressure transducer is $0.04 \%$, including non-linearity, hysteresis 
and repeatability and the low pressure one is rated to $0.05 \%$, respectively. Another source of error in the gas density comes from the temperature of the dosing and reactor volumes. The gas in the dosing volume is monitored with a high precision platinum resistance temperature detector which has an accuracy of $0.04 \mathrm{~K}$. Uncertainties in the fractional volumes were taken to be equal to the standard deviation over multiple calibration measurements.

$$
\begin{aligned}
& \frac{\partial G_{\mathrm{exc}}}{\partial m_{\mathrm{s}}}=-\frac{1}{m_{\mathrm{s}}^{2}}\left[\sum_{i=1}^{k}\left(\rho_{1 i}-\rho_{3(i-1)}\right) V_{\mathrm{d}}\right. \\
& \left.-\left[\rho_{2 \mathrm{i}}\left(V_{\mathrm{d}}+V_{\mathrm{R}}\left(1-f_{\mathrm{o}}\right)\right)+\rho^{\prime}{ }_{2 \mathrm{i}} V_{\mathrm{R}} f_{\mathrm{o}}(1-f)+\rho^{\prime \prime}{ }_{2 \mathrm{i}}\left(V_{\mathrm{R}} f_{\mathrm{o}} f-V_{\text {sample }}\right)\right]\right] \\
& \frac{\partial G_{\mathrm{exc}}}{\partial \rho_{1 i}}=\frac{V_{\mathrm{d}}}{m_{\mathrm{s}}} \\
& \frac{\partial G_{\mathrm{exc}}}{\partial \rho_{3(i-1)}}=-\frac{V_{\mathrm{d}}}{m_{\mathrm{s}}} \\
& \frac{\partial G_{\mathrm{exc}}}{\partial V_{\mathrm{d}}}=\frac{1}{m_{\mathrm{s}}}\left[\sum_{i=1}^{k}\left(\rho_{1 i}-\rho_{3(i-1)}\right)-\left[\rho_{2 \mathrm{i}}\right]\right] \\
& \frac{\partial G_{\mathrm{exc}}}{\partial \rho_{2 \mathrm{i}}}=-\frac{1}{m_{\mathrm{s}}}\left(V_{\mathrm{d}}+V_{\mathrm{R}}\left(1-f_{\mathrm{o}}\right)\right) \\
& \frac{\partial G_{\mathrm{exc}}}{\partial V_{\mathrm{R}}}=-\frac{1}{m_{\mathrm{s}}}\left[\rho_{2 \mathrm{i}}\left(1-f_{\mathrm{o}}\right)+\rho^{\prime}{ }_{2 \mathrm{i}} f_{\mathrm{o}}(1-f)+\rho^{\prime \prime}{ }_{2 \mathrm{i}} f_{\mathrm{o}} f\right] \\
& \frac{\partial G_{\mathrm{exc}}}{\partial f_{\mathrm{o}}}=\frac{1}{m_{\mathrm{s}}}\left[\rho_{2 \mathrm{i}} V_{\mathrm{R}}-\rho^{\prime}{ }_{2 \mathrm{i}} V_{\mathrm{R}}(1-f)-\rho^{\prime \prime}{ }_{2 \mathrm{i}} V_{\mathrm{R}} f\right] \\
& \frac{\partial G_{\mathrm{exc}}}{\partial \rho_{2 \mathrm{i}}^{\prime}}=-\frac{1}{m_{\mathrm{s}}}\left[V_{\mathrm{R}} f_{\mathrm{o}}(1-f)\right] \\
& \frac{\partial G_{\text {exc }}}{\partial f}=\frac{1}{m_{\mathrm{s}}}\left[\rho^{\prime}{ }_{2 \mathrm{i}} V_{\mathrm{R}} f_{\mathrm{o}}-\rho^{\prime \prime}{ }_{2 \mathrm{i}} V_{\mathrm{R}} f_{\mathrm{o}}\right] \\
& \frac{\partial G_{\text {exc }}}{\partial \rho^{\prime \prime}{ }_{2 \mathrm{i}}}=-\frac{1}{m_{\mathrm{s}}}\left(V_{\mathrm{R}} f_{\mathrm{o}} f-V_{\text {sample }}\right) \\
& \frac{\partial G_{\text {exc }}}{\partial V_{\text {sample }}}=\frac{1}{m_{\mathrm{s}}}\left[\rho_{2 \mathrm{i}}^{\prime \prime}\right]
\end{aligned}
$$




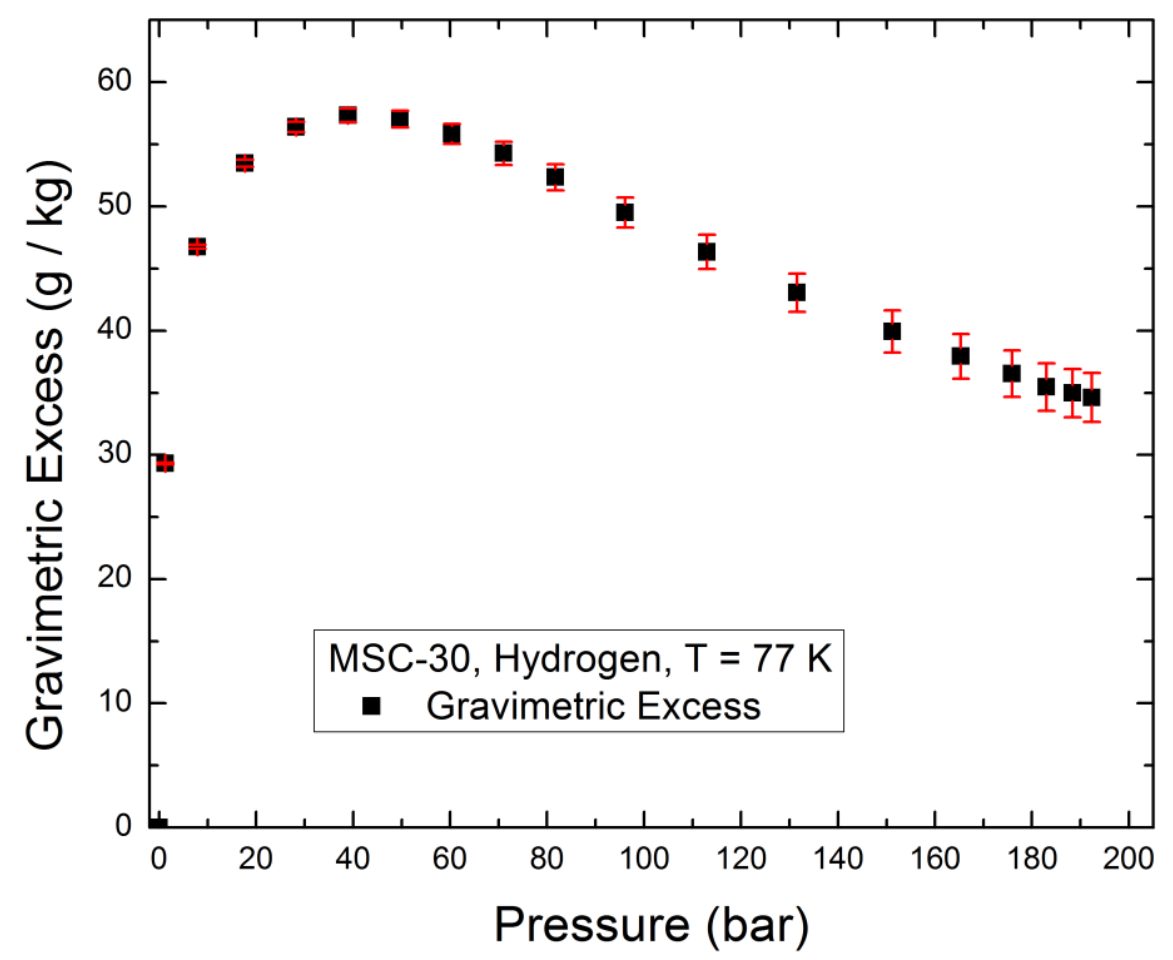

Figure 173. Excess adsorption measurements and calculated error for sample MSC-30. 


\subsection{Samples \& Available Measurements}

* indicates projected boron content.- Q is calculated from adsorption data between 1-200 bar and $77 \mathrm{~K}, 87 \mathrm{~K}, 273 \mathrm{~K}$, \& $296 \mathrm{~K}$ Isotherms. All isosteric heats of adsorption listed here were determined at a coverage of $1 \mathrm{wt} \%$.

Table 35: Precursor Carbon Samples:

\begin{tabular}{|c|c|c|c|c|c|c|c|c|}
\hline Sample & $\begin{array}{l}\text { Boron } \\
\text { Content } \\
(\mathrm{wt} \%)\end{array}$ & Porosity & $\begin{array}{c}\mathrm{SSA} \\
\left(\mathrm{m}^{2} / \mathrm{g}\right)\end{array}$ & $\begin{array}{c}\mathrm{G}_{\text {exc }} \mathrm{H}_{2} \\
(77 \mathrm{~K} \max ) \\
(\mathrm{wt} \%)\end{array}$ & $\begin{array}{c}\mathrm{G}_{\text {exc } \mathrm{H}_{2}} \\
(296 \mathrm{~K}, 200 \mathrm{bar}) \\
(\mathrm{wt} \%)\end{array}$ & $\begin{array}{c}\mathrm{V}_{\text {stored }} \\
(77 \mathrm{~K}, 200 \mathrm{bar}) \\
(\mathrm{g} / \mathrm{L})\end{array}$ & $\begin{array}{c}\rho_{\text {stored }} \\
(77 \mathrm{~K}, 200 \text { bar }) \\
(\mathrm{g} / \mathrm{L})\end{array}$ & $\begin{array}{c}\mathrm{Q} \\
\mathrm{kJ} / \mathrm{mol}\end{array}$ \\
\hline 0279-Char & 0 & .72 & 1100 & 2.22 & 0.27 & 42.4 & 58.8 & 4.7 \\
\hline $0286-2 \mathrm{~K}$ & 0 & .70 & 1900 & 3.84 & 0.84 & 50.5 & 71.3 & 5.7 \\
\hline $0807-2.5 \mathrm{~K}$ & 0 & .74 & 2400 & 4.83 & 1.02 & 52.8 & 71.4 & 4.7 \\
\hline $0285-3 \mathrm{~K}$ & 0 & .77 & 2600 & 5.41 & 0.97 & 53.2 & 68.8 & 5.1 \\
\hline $0284-4 \mathrm{~K}$ & 0 & .81 & 2600 & 5.61 & 1.00 & 54.1 & 66.6 & 5.7 \\
\hline $0280-5 \mathrm{~K}$ & 0 & .84 & 2700 & 5.95 & 0.90 & 53.5 & 64.0 & 5.9 \\
\hline $3 \mathrm{~K}-3 / 3 / 10-\mathrm{A}$ & 0 & .78 & 2700 & 5.50 & 0.95 & 57.2 & 73.3 & - \\
\hline $3 \mathrm{~K}-0079-600 \mathrm{C}$ & 0 & .79 & 2700 & 5.40 & 1.14 & 55.7 & 72.3 & 5.5 \\
\hline $0214-5 \mathrm{~K}-1200 \mathrm{C}$ & 0 & .83 & 2600 & 5.32 & 0.98 & 52.9 & 63.8 & 5.0 \\
\hline $0216-4 \mathrm{~K}-1200 \mathrm{C}$ & 0 & .80 & 2400 & 4.86 & 0.88 & 51.9 & 65.0 & - \\
\hline $0218-3 \mathrm{~K}-1200 \mathrm{C}$ & 0 & .74 & 2100 & 4.45 & 0.92 & 52.9 & 71.5 & 5.0 \\
\hline $0228-2 \mathrm{~K}-800 \mathrm{C}$ & 0 & .68 & 1800 & 3.86 & 0.90 & 50.0 & 73.1 & - \\
\hline 0239-4K-800C & 0 & .82 & 2600 & 5.47 & 1.03 & 52.6 & 63.8 & 5.5 \\
\hline 0241-3K-800C & 0 & .77 & 2550 & 5.05 & 1.00 & 53.6 & 69.5 & 5.7 \\
\hline $0243-5 K-800 C$ & 0 & .83 & 2600 & 5.58 & 1.09 & 53.5 & 64.7 & - \\
\hline 0735-PVDC-800C & 0 & .58 & 850 & - & - & - & - & - \\
\hline $0753-2.5 \mathrm{~K}-800 \mathrm{C}$ & 0 & .73 & 2283 & 4.61 & 0.98 & 52.4 & 72.1 & 5.3 \\
\hline
\end{tabular}


Table 36: Precursor Carbon Sample Descriptions:

Sample Descriptions \& Synthesis Conditions

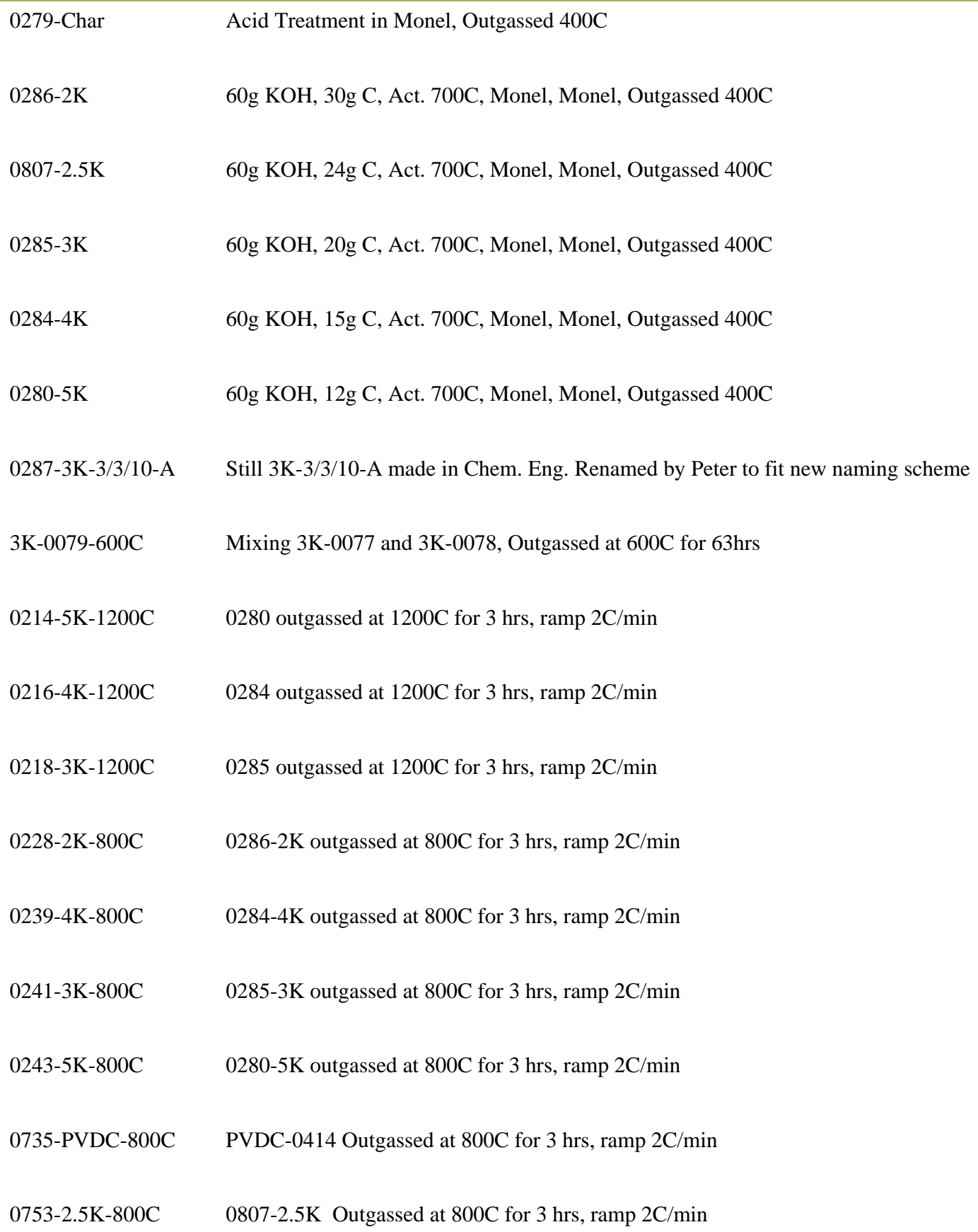


Table 37: Boron-doped sample list and available measurements:

\begin{tabular}{|c|c|c|c|c|c|c|c|c|}
\hline Sample & $\begin{array}{l}\text { Boron } \\
\text { Content } \\
(\mathrm{wt} \%)\end{array}$ & Porosity & $\begin{array}{c}\text { SSA } \\
\left(\mathrm{m}^{2} / \mathrm{g}\right)\end{array}$ & $\begin{array}{c}\mathrm{G}_{\text {exc }} \mathrm{H}_{2} \\
(77 \mathrm{~K} \max ) \\
(\mathrm{wt} \%)\end{array}$ & $\begin{array}{c}\mathrm{G}_{\mathrm{exc}} \mathrm{H}_{2} \\
(296 \mathrm{~K}, 200 \mathrm{bar}) \\
(\mathrm{wt} \%)\end{array}$ & $\begin{array}{c}\mathrm{V}_{\text {stored }} \\
(77 \mathrm{~K}, 200 \mathrm{bar}) \\
(\mathrm{g} / \mathrm{L})\end{array}$ & $\begin{array}{c}\rho_{\text {stored }} \\
(77 \mathrm{~K}, 200 \mathrm{bar}) \\
(\mathrm{g} / \mathrm{L})\end{array}$ & $\begin{array}{c}-\mathrm{Q} \\
\mathrm{kJ} / \mathrm{mol}\end{array}$ \\
\hline $0201-3 \mathrm{~K}-\mathrm{DB} 1(\mathrm{I}, \mathrm{A})$ & 8.0 & .74 & 2000 & 4.55 & 0.90 & 51.4 & 70.4 & - \\
\hline $0202-3 \mathrm{~K}-\mathrm{DB} 1(\mathrm{I}, \mathrm{B})$ & 5.8 & .77 & 2300 & - & - & - & - & - \\
\hline 0203 - 3K-DB2(III,A) & 0.3 & .78 & 2600 & 5.34 & 1.04 & 54.5 & 69.9 & - \\
\hline $0205-3 \mathrm{~K}-\mathrm{DB} 3(\mathrm{I}, \mathrm{A})$ & 9.7 & .78 & 2300 & 4.70 & 1.17 & 51.7 & 66.4 & 5.5 \\
\hline 0207 - 3K-DB4-SS(I,A) & 12.4 & .75 & 2000 & - & - & - & - & - \\
\hline $0208-3 \mathrm{~K}-\mathrm{DB} 5(\mathrm{I}, \mathrm{A})$ & 13.7 & .74 & 1900 & 3.99 & 0.79 & 50.9 & 68.9 & 5.3 \\
\hline $0209-3 \mathrm{~K}-\mathrm{DB} 5(\mathrm{I}, \mathrm{C})$ & 14.8 & .75 & 1700 & - & - & - & - & - \\
\hline $0211-3 \mathrm{~K}-\mathrm{DB} 6(\mathrm{I}, \mathrm{A})$ & 6.2 & .75 & 2200 & 4.47 & 0.87 & 52.3 & 69.9 & 5.6 \\
\hline $0212-3 \mathrm{~K}-\mathrm{DB} 7(\mathrm{I}, \mathrm{A})$ & 7.4 & .76 & 2100 & - & - & - & - & - \\
\hline $0215-5 \mathrm{~K}-\mathrm{DB} 1(\mathrm{I}, \mathrm{C})$ & 8.0 & .79 & 1900 & 4.30 & 0.71 & 50.1 & 63.4 & 6.2 \\
\hline 0219-3K-DB1(I,C) & 8.7 & .74 & 2000 & 3.48 & 0.73 & 49.4 & 67.0 & 4.5 \\
\hline 0221-3K-DB8(I,0) & 29.0 & .73 & 1600 & 2.15 & 0.29 & - & - & - \\
\hline 0226-3K-DB9(I,0) & 3.4 & .78 & 2300 & 4.72 & 0.94 & 52.8 & 67.6 & - \\
\hline 0227-3K-DB9(I,0) & 4.0 & .78 & 2400 & 4.62 & 0.91 & 52.0 & 67.1 & - \\
\hline
\end{tabular}


Table 38: Boron Doped Sample Descriptions:

Sample

$0201-3 \mathrm{~K}-\mathrm{DB} 1(\mathrm{I}, \mathrm{A})$

$0202-3 \mathrm{~K}-\mathrm{DB} 1(\mathrm{I}, \mathrm{B})$

0203 - 3K-DB2(III,A)

$0205-3 \mathrm{~K}-\mathrm{DB} 3(\mathrm{I}, \mathrm{A})$

0207 - 3K-DB4-SS(I,A)

$0208-3 \mathrm{~K}-\mathrm{DB} 5(\mathrm{I}, \mathrm{A})$

0209 - 3K-DB5(I,C)

0211 - 3K-DB6(I,A)

$0212-3 \mathrm{~K}-\mathrm{DB} 7(\mathrm{I}, \mathrm{A})$

$0215-5 \mathrm{~K}-\mathrm{DB} 1(\mathrm{I}, \mathrm{C})$

0219-3K-DB1(I,C)

0221-3K-DB8(I,0)

0226-3K-DB9(I,0)

0227-3K-DB9(I,0)
Descriptions \& Synthesis Conditions

3K-0079-600C Prec., 600C Anneal

3K-0079-600C Prec., 1000C Anneal

3K-0079-600C Prec., 600C Anneal

3K-0079-600C Prec., 600C Anneal

3K-0079-600C Prec., Doped in Stainless Steel rather than schlenk flask, 600C Anneal

3K-0079-600C Prec., 600C Anneal

3K-0079-600C Prec., 1200C Anneal

3K-0079-600C Prec., 600C Anneal

3K-0079-600C Prec., 600C Anneal

0214-5K-1200C Prec, 1200C Anneal

0218-3K-1200C Prec, 1200C Anneal

3K-0079-600C Prec., mod. temp. profile, 600C Anneal with 400C OG

3K-0079-600C Prec., mod. temp. profile, 600C Anneal with 400C OG

3K-0079-600C Prec., mod. temp. profile, 600C Anneal with 400C OG 
Table 39: Boron-doped sample list and available measurements:

\begin{tabular}{|c|c|c|c|c|c|c|c|c|}
\hline Sample & $\begin{array}{l}\text { Boron } \\
\text { Content } \\
(\mathrm{wt} \%)\end{array}$ & Porosity & $\begin{array}{c}\mathrm{SSA} \\
\left(\mathrm{m}^{2} / \mathrm{g}\right)\end{array}$ & $\begin{array}{c}\mathrm{G}_{\mathrm{exc}} \mathrm{H}_{2} \\
(77 \mathrm{~K} \max ) \\
(\mathrm{wt} \%)\end{array}$ & $\begin{array}{c}\mathrm{G}_{\mathrm{exc}} \mathrm{H}_{2} \\
(296 \mathrm{~K}, 200 \mathrm{bar})(77 \\
(\mathrm{wt} \%)\end{array}$ & $\begin{array}{l}\mathrm{V}_{\text {stored }} \\
7 \mathrm{~K}, 200 \mathrm{bar}) \\
(\mathrm{g} / \mathrm{L})\end{array}$ & $\begin{array}{c}\rho_{\text {stored }} \\
(77 \mathrm{~K}, 200 \text { bar }) \\
(\mathrm{g} / \mathrm{L})\end{array}$ & $\begin{array}{c}\mathrm{Q} \\
\mathrm{kJ} / \mathrm{mol}\end{array}$ \\
\hline 0236-2K-DB1(I,E) & $31.0 *$ & - & - & - & - & - & - & - \\
\hline 0240-4K-DB1(I,E) & 1.5 & .82 & 2500 & - & - & - & - & 5.5 \\
\hline 0244-4K-DB2(I,E) & 1.6 & .82 & 2460 & 5.14 & 0.95 & 52.3 & 64.0 & 5.4 \\
\hline 0245-4K-DB2(I,E) & 3.9 & .82 & 2480 & 4.94 & 0.92 & 51.9 & 63.4 & 5.2 \\
\hline 0246-4K-DB2(I,E) & 4.1 & .81 & 2360 & 5.05 & 0.89 & 52.2 & 64.4 & 5.4 \\
\hline 0248-2K-DB1(I,E) & 1.7 & .66 & 1700 & - & - & - & - & - \\
\hline 0249-2K-DB1(I,E) & 2.5 & - & - & - & - & - & - & - \\
\hline 0250-2K-DB1(I,E) & 2.6 & - & - & - & - & - & - & - \\
\hline 0734-3K-DB1(I,E) & 3.1 & - & - & - & - & - & - & - \\
\hline 0736-PVDC-DB1(I,E) & 0.8 & .494 & 813 & - & - & - & - & - \\
\hline 0738-PVDC-DB1(I,E) & 1.2 & - & - & - & - & - & - & - \\
\hline 0742-5K-DB1(I,E) & 3.9 & .813 & 2350 & - & - & - & - & - \\
\hline 0745-6K-DB1(I,E) & 3.4 & - & - & - & - & - & - & - \\
\hline 0747-4K-DB1(I,E) & 3.6 & .80 & 2350 & 4.88 & 0.99 & 51.9 & 64.5 & 5.5 \\
\hline 0748-4K-DB1(I,E) & 5.6 & .805 & 2390 & 4.90 & 0.96 & 51.5 & 63.9 & 5.4 \\
\hline 0749-4K-DB3(I,E) & 5.9 & .791 & 2248 & 4.57 & 0.93 & 50.7 & 64.1 & 5.4 \\
\hline 0750-4K-DB3(I,E) & 6.9 & .79 & 2200 & 4.95 & 1.01 & 52.5 & 66.6 & 5.5 \\
\hline 0751-4K-DB3(I,E) & 5.9 & .82 & 2490 & 4.67 & 0.95 & 51.7 & 63.5 & 5.3 \\
\hline 0752-4K-DB3(I,E) & 9.1 & .78 & 2060 & 4.63 & 0.81 & 50.5 & 64.9 & 5.5 \\
\hline 0754-2.5K-DB1(I,E) & $4.4^{*}$ & .73 & 2460 & 3.94 & 0.79 & 49.3 & 67.3 & 6.0 \\
\hline 0755-2.5K-DB1(I,E) & $5.6^{*}$ & .72 & 2033 & 3.99 & 0.85 & 49.6 & 69.3 & 5.8 \\
\hline
\end{tabular}


Table 40: Boron Doped Sample Descriptions:

Sample Descriptions \& Synthesis Conditions

\begin{tabular}{|c|c|}
\hline 0236-2K-DB1(I,E) & 0228-2K-800C Prec., 800C Anneal \\
\hline 0240-4K-DB1(I,E) & 0239-4K-800C Prec., 800C Anneal \\
\hline 0244-4K-DB2(I,E) & 0239-4K-800C Prec., 800C Anneal \\
\hline 0245-4K-DB2(I,E) & 0239-4K-800C Prec., 800C Anneal \\
\hline 0246-4K-DB2(I,E) & 0239-4K-800C Prec., 800C Anneal \\
\hline 0248-2K-DB1(I,E) & 0228-2K-800C Prec., 800C Anneal \\
\hline 0249-2K-DB1(I,E) & 0228-2K-800C Prec., 800C Anneal \\
\hline 0250-2K-DB1(I,E) & 0228-2K-800C Prec., 800C Anneal \\
\hline 0734-3K-DB1(I,E) & 0241-3K-800C Prec., 800C Anneal \\
\hline 0736-PVDC-DB1(I,E) & 0735-PVDC-800C Prec., 800C Anneal \\
\hline 0738-PVDC-DB1(I,E) & 0735-PVDC-800C Prec., 800C Anneal \\
\hline 0742-5K-DB1(I,E) & 0243-5K-800C Prec., 800C Anneal \\
\hline 0745-6K-DB1(I,E) & 0744-6K-800C Prec., 800C Anneal \\
\hline 0747-4K-DB1(I,E) & 0239-4K-800C Prec., 800C Anneal \\
\hline 0748-4K-DB1(I,E) & 0239-4K-800C Prec., 800C Anneal \\
\hline 0750-4K-DB3(I,E) & 0239-4K-800C Prec., 800C Anneal \\
\hline 0751-4K-DB3(I,E) & 0239-4K-800C Prec., 800C Anneal \\
\hline 0752-4K-DB3(I,E) & 0239-4K-800C Prec., 800C Anneal \\
\hline
\end{tabular}


Table 41: Other High Binding Energy Materials: GCN and carbon derived from ionic liquids

\begin{tabular}{|c|c|c|c|c|c|c|c|c|}
\hline Sample & $\begin{array}{l}V_{\text {pore }} \\
\left(\mathrm{cm}^{3} / \mathrm{g}\right)\end{array}$ & Porosity & $\begin{array}{c}\text { SSA } \\
\left(\mathrm{m}^{2} / \mathrm{g}\right)\end{array}$ & $\begin{array}{c}\rho_{\mathrm{sk}} \\
\left(\mathrm{g} / \mathrm{cm}^{3}\right)\end{array}$ & $\begin{array}{c}\mathrm{G}_{\mathrm{exc}} \mathrm{H}_{2} \\
(77 \mathrm{~K} \max ) \\
(\mathrm{wt} \%)\end{array}$ & $\begin{array}{c}\mathrm{V}_{\text {stored }} \\
(77 \mathrm{~K}, 200 \mathrm{bar}) \\
(\mathrm{g} / \mathrm{L})\end{array}$ & $\begin{array}{c}\rho_{\text {stored }} \\
(77 \mathrm{~K}, 200 \text { bar }) \\
(\mathrm{g} / \mathrm{L})\end{array}$ & $\begin{array}{c}\text { AEA } \\
(77 \mathrm{~K} \mathrm{max}) \\
\left(\mu \mathrm{g} / \mathrm{m}^{2}\right)\end{array}$ \\
\hline GCN-1001 & .151 & .223 & 13.3 & 1.90 & 0.3 & 10.5 & 46.7 & 21.8 \\
\hline GCN-1002 & .084 & .137 & 7.8 & $1.90 *$ & - & - & - & - \\
\hline GCN-1003 & .48 & .476 & 36.4 & $1.90^{*}$ & 1.5 & 23.4 & 49.1 & 40.5 \\
\hline GCN-1004 & .148 & .219 & 13.2 & $1.90^{*}$ & - & - & - & - \\
\hline SR-1A-1005 & - & & & $2^{*}$ & - & - & - & - \\
\hline SR-11B-1006 & .312 & .384 & 544 & $2^{*}$ & - & - & - & - \\
\hline SR-11A-1007 & .365 & .422 & 434 & $2^{*}$ & - & - & - & - \\
\hline SR-11C & .331 & .398 & 229 & $2^{*}$ & & & & \\
\hline SR-11D & .275 & .355 & 478 & $2 *$ & & & & \\
\hline SR-11E & .013 & .025 & 4.4 & $2^{*}$ & & & & \\
\hline GCN-1008 & .467 & .471 & 31.5 & 1.91 & 0.6 & 21.3 & 45.3 & 19.3 \\
\hline GCN-1009 & - & - & - & $1.90^{*}$ & - & - & - & - \\
\hline GCN-1010 & .128 & .192 & 12.0 & 1.86 & 0.3 & $\mathrm{n} / \mathrm{a}$ & $\mathrm{n} / \mathrm{a}$ & 23.7 \\
\hline GCN-1011 & - & - & - & $1.86^{*}$ & - & - & - & - \\
\hline
\end{tabular}


Table 42: Sample Descriptions.

Sample

Descriptions \& Synthesis Conditions

GCN-1001

Carbon Nitride material synthesized from pyrolysis of melamine

GCN-1002

Carbon Nitride material synthesized from pyrolysis of melamine

GCN-1003

GCN-1001 that has undergone exfoliation: sonicated, centrifuged, freeze dried. This material was still in the supernate after centrifugation.

GCN-1004

GCN-1001 that has undergone exfoliation: sonicated, centrifuged, freeze dried. This material was in the sediment after centrifugation.

SR-1A-1005

SR-1B-1006

SR-11A-1007

GCN-1008

GCN-1001 that has undergone exfoliation: sonicated, centrifuged, freeze dried. This material was still in the supernate after centrifugation.

GCN-1009

GCN-1001 that has undergone exfoliation: sonicated, centrifuged, freeze dried. This material was in the sediment after centrifugation.

GCN-1010

Carbon Nitride material synthesized from pyrolysis of melamine

GCN-1011

Carbon Nitride material synthesized from pyrolysis of melamine

Samples synthesized after 2013 have been labelled with a short, four digit naming scheme for the purpose of ease of reference. The four lot numbers correspond to this short naming system, whereas additional letters, numbers, and symbols are indicative of synthesis conditions. 


\section{Bibliography}

1. F. C. T. Office, (www1.eere.energy.gov/hydrogenandfuelcells.mypp/, 2005), Vol. 2012.

2. S. Satyapal, J. Petrovic, C. Read, G. Thomas and G. Ordaz, Catal. Today 120 (3-4), 246-256 (2007).

3 T. LLC, Full Fuel Cycle Assessment Well to Tank Energy Inputs, Emissions, and Water Impacts, Cupertino California, 2007.

4. J. E. Sinor, Comparison of CNG and LNG Technologies for Transportation Applications, MRIGlobal, NREL, National Renewable Energy Laboratory, 1991.

5. P. Bénard, and R. Chahine. Int J Hydrogen Energy, 26 (2001) 849-855.

6. R. Olsen. University of Missouri Comprehensive Examination (2010).

7. R. Ahluwalia; T. Hua; J. Peng; D. Papadias; R. Kumar. System Level Analysis of Hydrogen Storage Options. 2011 DOE Hydrogen Peer Review.

8. T. Hill. An Introduction to Statistical Thermodynamics. Mineola, NY: Dover Pubs, 1960. Print.

9. A. M. J. F. Michels, P. G. Menon, C. A. Ten Seldam. Trav Chim Pays-Bas, 80 (1961) 483.

10. F. Rouquerol, J. Rouquerol, and K. Sing. Adsorption by Powders \& Porous Solids: Principles, Methodology and Applications. San Diego: Academic Press, 1999. 94-96, 171. Print.

11. V. Golub, "Mechanisms of High-Pressure Hydrogen Gas Self-Ignition in Tubes," Journal of Loss Prevention in the Process Industries, 21.2(185-198) 2008.

12. A. Sieverts. Zeitschrift für Metallkunde, 21, 37 (1929).

13. M. Beckner. University of Missouri Doctoral Thesis (2012).

14. BS EN 1936:2006, "Natural stone test methods. Determination of real density and apparent density, and of total and open porosity," British Standards Institute, London, UK, 2006.

15. J. Burress, M. Kraus, M. Beckner, R. Cepel, G. Suppes, C. Wexler and P. Pfeifer, Nanot 20 (20), 204026 (2009).

16. S. K. Bhatia and A. L. Myers. 2006 Langmuir 22 1688-700.

17. T. Rash. University of Missouri Doctoral Thesis (2014).

18. O. Redlich and D. L. Peterson. J Phys Chem, 63 (1959) 1024.

19. E. Pourier "Investigation of the Hydrogen State in IRMOF-1 from Measurements and Modeling of Adsorption Isotherms at High Gas Densities," J Phys Chem C. (112) 2008.

20. F. Rouquerol, J. Rouquerol, and K. Sing. Adsorption by Powders \& Porous Solids: Principles, Methodology and Applications. San Diego: Academic Press, 1999. (166). Print

21. A. L. McClellan and H. F. Harnsberger. (1967) J. Colloid Interface Sci. 23, 577.

22. S. Brunauer and P. H. Emmett. (1937) J. Am. Chem. Soc. 59, 2682.

23. W. D. Harkins. (1952) In: The Physical Chemistry of Surface Films, Reinhold Publishing, Division, New York.

24. E. Dohnke. University of Missouri Doctoral Thesis (2015).

25. Z.B. Alfassi, (1990). Activation Analysis, Volumes I and II. CRC Press: Boca Raton, FL.

26. J. Harder, 2009, 'Material analysis for process control in cement plants', ZKG INTERNATIONAL, 6/7 - 2009, Volume 62, p. 64.

27. P. Kruger, (1971). Principles of Activation Analysis. Wiley Interscience: New York, NY.

28. D. Robertson, S. Caddell, (2014, June 13) Email Interview. University of Missouri Research Reactor.

29. “C. D. Wagner, Empirical atomic sensitivity factors for quantitative analysis by electron spectroscopy for chemical analysis, Volume 3, Issue 5, Version of Record online: 15 SEP 2004."

30. P. Pfeifer, "Multiply Surface-Functionalized Nanoporous Carbon for Vehicular Hydrogen Storage" DOE Final Report (2014).

31. S. Jacques, et al. "LPCVD and characterization of boron-containing pyrocarbon materials." Carbon 34.9 (1996): 1135-1143.

32. D.P. Hashim, et al. "Covalently bonded three-dimensional carbon nanotube solids via boron induced nanojunctions." Scientific reports 2 (2012). 
33. J.B.Bult, et al. "Manipulation of Hydrogen Binding Energy and Desorption Kinetics by Boron Doping of High Surface Area Carbon." The J Phys Chem C 116.50 (2012): 26138-26143.

34. F. Wang, (2017, February 22) Email Interview.

35. R.E. Franklin, "The interpretation of diffuse x-ray diagrams of carbon.” Acta Cryst.3, 107- 121 (1950).

36. R.E. Franklin, "Crystallite growth in graphitizing and nongraphitizing carbon.” Proc. Roy. Soc. Lond. A 209, 196-218 (1951).

37. J.J. Kipling and R.B. Wilson, "Adsorptive properties of polymer carbons. Part I- Comparative data.” Trans. Faraday Soc. 56, 557-561 (1960).

38. J.J. Kipling and R.B. Wilson, "Adsorptive properties of polymer carbons. Part II- Determination of pore sizes." Trans. Faraday Soc. 56, 562-569 (1960).

39. T. Otowa, R. Tanibata, M. Itoh, Production and adsorption characteristics of MAXSORB: highsurface-area active carbon, Gas Sep. Purif., 7 (4) (1993), pp. 241-245

40. J. Liu, N. Sun, C. Sun, H. Liu, C. Snape, K. Li, et al., Spherical potassium intercalated activated carbon beads for pulverised fuel CO2 post-combustion capture, Carbon 94 (2015) 243-255.

41. L. Firlej, S. Roszak, B. Kuchta P. Pfeifer, C. Wexler. J Chem Phys 131, 164702 (2009).

42. Y. Ferro, F. Marinelli, A. Allouche, C. Brosset. J Chem Phys 118, 12 (2003).

43. T. C. Chung, Y. Jeong, Q. Chen, A. Kleinhammes, Y. Wu. J Am Chem Soc 130 (2008).

44. P. Pfeifer, "Multiply Surface Functionalized Nanoporous Carbon for Vehicular Hydrogen Storage" DOE Annual Merit Review, ST-019 2014. Oral Presentation.

45. C. Wexler, M. Connolly, M. Beckner, P. Pfeifer. "Boron Doping Carbon Structures Using Decaborane? A Theoretical Study.” Bull. Am. Phys. Soc. 57, W33.00001 (2012)

46. G. T. Furukawa and R. P. Park. J Res Natl Bur Std, 55, 255 (1955)

47. G. A. Miller. J Phys Chem, 67, 6 (1963) 1363-1364

48. R. Lewis, Hawley's Condensed Chemical Dictionary. 15. Hoboken, NJ: Wiley, 2007

49. M. Beckner, "Analysis of hydrogen sorption characteristics of boron-doped activated carbons." APS March Meeting 2011. Dallas Convention Center, Dallas, TX. 22 March 2011. Oral Presentation.

50. M.A. Kraus, Fundamental Building Block of Nanoporous Network from Ultra-Small-Angle Xray Scattering (USAXS) and Small-Angle X-Ray Scattering (SAXS) Diss. University of Missouri, 2010. Columbia, MO: University of Missouri, 2010

51. T. Rash, "Microporous Carbon Monolith Synthesis and Production for Methane Storage" Fuel, 200 (2017), pp. 371-379.

52. Gillespie, Andrew. "Application of Henry's Law for Binding Energies of Adsorbed Hydrogen" Bull. Am. Phys. Soc. 60, T34.00011 (2016)

53. A. Gillespie, "Direct Measurement of the Adsorbed Film Volume for Estimating Heats of Adsorption" Bull. Am. Phys. Soc. 61, X53.00011 (2016)

54. M. Connolly, "Boron Doping of Activated Carbon." 2013 Annual Fall Meeting of the APS Prairie Section. Memorial Union, Columbia, MO. 8 November 2013. Poster Presentation.

55. R. Chahine, DOE Hydrogen Storage Principal Investigator. Contractor Meeting, Washington, DC, November 27-28, 2012 


\section{VITA}

Andrew Karl Gillespie was born on July 11, 1988 in Freeport, Illinois. He received a BS in Physics and Physics Education from Illinois State University in 2011. In 2014, he received a MS in Physics from the University of Missouri. He received a PhD in Physics from the University of Missouri in 2017 with an emphasis in condensed matter physics and hydrogen adsorption. 